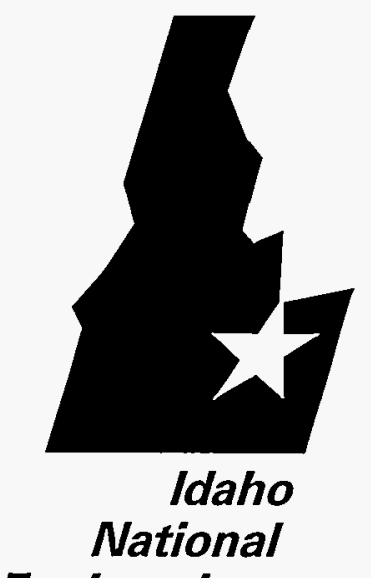

Engineering Laboratory

\title{
Development of Environmentally Advanced Hydropower Turbine System Design Concepts
}

\author{
RECEVED \\ WOV 031997 \\ OSTI
}

Gary F. Franke

Donald R. Webb

Richard K. Fisher, Jr.

Dilip Mathur

Paul N. Hopping

Patrick A. March

Michael R. Headrick

Istvan T. Laczo

Yiannis Ventikos

Fotis Sotiropoulos 


\section{DISCLAIMER}

This report was prepared by Voith Hydro, Normandeau Associates, TVA, Harza Engineering Company and the School of Civil and Environmental Engineering of Georgia Institute of Technology for the purpose of documenting work undertaken in connection with the Advanced Hydropower Turbine System Program sponsored by the U.S. Department of Energy (DOE). The information contained in this report represents our opinion about the issues it addresses within the context of its intended purpose. However, the DOE, any co-sponsor of this program, Voith Hydro, Normandeau Associates, TVA, Harza Engineering Company and the School of Civil and Environmental Engineering of Georgia Institute of Technology, and any of their representatives make no warranty or representation of any kind (whether express or implied) as to the accuracy, completeness, or use of such information, and expressly disclaim any and all liability for the use of, or reliance on, such information beyond its stated purpose. 
INEEL/EXT-97-00639

Voith Report No. 2677-0141

\title{
Development of Environmentally Advanced Hydropower Turbine System Design Concepts
}

\author{
Gary F. Franke, Senior Engineer \\ Donald R. Webb, Manager, Applied Hydraulic Engineering \\ Richard K. Fisher, Jr., Vice President, Technology \\ Voith Hydro, Inc. \\ Dilip Mathur, Ph.D., Vice President \\ Normandeau Associates \\ Paul N. Hopping, Ph.D., Civil Engineer \\ Patrick A. March, Senior Manager, TVA Engineering Laboratory \\ Tennessee Valley Authority \\ Michael R. Headrick, Ph.D., Senior Environmental Scientist \\ Istvan T. Laczo, Vice President and Chief Mechanical Engineer \\ Harza Engineering Company \\ Yiannis Ventikos, Ph.D., Postdoctoral Associate \\ Fotis Sotiropoulos, Ph.D., Assistant Professor \\ Georgia Institute of Technology
}

Published August 1997

Idaho National Engineering and Environmental Laboratory

Renewable Energy Products Department

Lockheed Martin Idaho Technologies Company

Idaho Falls, Idaho 83415

Prepared for the

U.S. Department of Energy

Energy Efficiency and Renewable Energy and

Hydropower Research Foundation, Inc.

Under DOE Idaho Operations Office

Contract DE-AC07-94ID13223

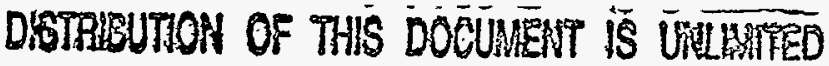

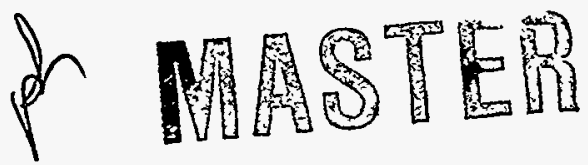




\section{DISCLAMIER}

Portions of this doecoment mey be illegible in electronic image products. Images are produced from the best available origion dosomentert 


\title{
ACKNOWLEDGEMENTS
}

The Advanced Hydropower Turbine System Program Phase 1 - Develop Conceptual Engineering Designs, . was initiated by an agreement between the U.S. Department of Energy and the Hydropower Research Foundation, Inc. This foundation is a non-profit organization representing the participants of the industry who are providing funds for Phase $I$. The participants include:

\author{
Chelan County PUD \\ Electric Power Research Institute \\ Georgia Power Company \\ Grant County PUD \\ Idaho Power Company \\ New England Power \\ Niagara Mohawk Power Corporation \\ Pacific Gas \& Electric \\ Tennessee Valley Authority \\ Washington Water Power Company \\ National Hydropower Association (NHA)
}

The Technical Review Committee consisted of representatives of these participants and representatives from:
U.S. Department of Energy
U.S. Army Corps of Engineers
Bonneville Power Administration
National Marine Fisheries Service
Department of Interior
Bureau of Reclamation
Northwest Power Planning Council
Native American Tribes
Oak Ridge National Laboratory
Idaho National Engineering Laboratory
Other utilities and private companies

The Technical Review Committee provided valuable input toward development of Advanced Hydropower Turbine System Design Concepts and to this report. 


\section{TABLE OF CONTENTS}

\subsection{EXECUTIVE SUMMARY}

\subsection{INTRODUCTION}

2.1 Goals and Objectives

2.2 Approach To The Project

Task 1: Categorization of Environmental Issues and Selection of Concepts for Further Detailed Conceptual Design

Task 2: Fish Physiology and Hydropower Physics

Task 3: In-Depth Investigation of Selected Design Elements

Task 4: Development of Conceptual Designs

\subsection{Team Structure}

2.4 Organization of the Report

\subsection{TASK 1 REPORT - REVIEW OF THE ISSUES}

3.1 Introduction

3.2 Discussion

3.3 Summary Of Task 1 Findings

3.4 References

\subsection{TASK 2 REPORT - BIOLOGICAL ISSUES \& TURBINE DESIGN AND OPERATIONAL CONSIDERATIONS}

4.1 Introduction

4.2 General Review

4.2.1 Compilation of Survival Data

4.2.2 Components Of Mortality

4.2.3 Potential Sources Of Injury/Mortality

4.2.3.1 Effect of Intake Modifications

4.2.4 Quantification Of Probable Causes Of Injury/Mortality

4.2.4.1 Mechanical Related Injuries

4.2.4.2 Pressure Related Injuries

4.2.4.3 Shear Related Injuries

4.2.5 Screening Criteria For Selecting Survival Tests

4.3 Fish Survival Prediction Methods

4.3.1 Mechanisms For Fish Injury

4.3.1.1 Background

Overview of Prediction Methods

Operation Limits and Hill Curves

\subsubsection{Nomenclature}

4.3.2 Mechanical Mechanisms Leading to Fish Injury

4.3.2.1 Development of New Leading Edge Strike Equation

Review of Existing Method

Derivation of New Equation

An Improved Form of the New Leading Edge Strike Equation

4.3.2.2 Gap Grinding 
4.3.2.3 Abrasion

4.3.2.4 Wall Strike

4.3.3 Fluid Mechanisms Leading to Fish Injury

4.3.3.1 Overview

4.3.3.2 Evaluation of Avoidable Loss

4.3.3.3 Evaluation of Fluid Shear

Definition of Shear

Estimation of Critical Value of Shear

Evaluation of Shear by One-Dimensional Method

Development of Shear Mortality Equations

Application of Shear Concept to Non-Damaging Velocity and

Explanation of the Minor Role of Tip Speed

Outlook for Shear Based Mortality Prediction

\subsubsection{Cavitation}

4.3.3.5 Draft Tube Backroll

4.3.4 Pressure Mechanisms Leading to Fish Injury

4.3.5 Implications of Survival Prediction for Turbine Design and Operation

4.3.5.1 Evaluation of Francis Turbine Number of Blades

4.3.5.2 Evaluation of Francis Turbine Specific Speed

4.3.5.3 Evaluation of Adjustable Speed Turbines

4.3.5.4 Critical Velocity Implications for Specific Turbine Components

4.3.6 Zonal Dependence of Injury/Mortality Mechanisms

4.4 Insights to Injury Mechanisms and Survival Prediction Methods Obtained from Evaluation of Fish Survival Test Results

4.4.1 Introduction

4.4.2 Effect of Location of Fish within the Water Column

4.4.3 Evaluation of N L / D

4.4.4 Investigation of Peripheral Speed, Turbine Head, Indirect Effects, and Species

4.4.5 Clues to Gap Related Injury

4.4.6 Insight from the Tests at Wanapum Dam

4.4.7 Kaplan Turbine Operation for Maximum Fish Survival

4.4.8 Effect of Fish Screens and Flow Disturbances on Fish Paths

4.4.9 Propeller Turbines

4.4.10 Francis Turbine Evaluation of Prediction Methods

4.4.11 Efficiency and Fish Survival at Francis Sites

4.5 Survival through Sluices/Spillways

4.5.1 Specific Data

4.6 Perspective on Improvements of Fish Passage Survival

4.7 Summary and Conclusions

4.8 References

\subsection{TASK 3 REPORT - INVESTIGATION OF INDIVIDUAL DESIGN ELEMENTS}

5.1 Introduction

5.2 Discussion

5.3 Three-Dimensional CFD Studies

5.3.1 Kaplan Intake

5.3.2 Kaplan Intake with Fish Screen

5.3.3 Stay Vanes and Wicket Gates

Kaplan and Francis Turbines 
5.3.4 Kaplan Turbine Runner

5.3.5 Francis Turbine Runner

Operating Condition Evaluation with a Thick Entrance Edge Shape

Blade Thickness Evaluation

5.3.6 Kaplan Turbine Draft Tube

5.3.7 Francis Turbine Draft Tube

5.3.8 Summary and Conclusions of Three-Dimensional CFD Studies

5.3.9 References

5.4 Advanced CFD Modeling for Fish-Friendly Hydroturbines

5.4.1 Introduction

5.4.2 Advanced Turbulence Models for Hydroturbine Flows

5.4.2.1 Flow Through a Strongly Curved Rectangular Duct

5.4.2.2 Flow Through a Francis Turbine Draft Tube

5.4.3 Unsteady Vortex Phenomena in Francis Turbine Draft Tubes

5.4.4 Numerical Simulation of Fish Passage: Can Fish be Modeled as a Fluid Particle

5.4.5 Summary and Conclusions

5.4.6 References

5.5 Dissolved Oxygen Enhancement Using Turbine Aeration

5.5.1 State-of-the-Art Practice and Advanced Technology

5.5.1.1 Existing Turbines

Hub Baffles

Bypass Conduits

Experience

Advanced Technology

5.5.1.2 New Turbines

Background

Design and Applicability

Advanced Technology

5.5.2 Analysis of Aerating Turbines

5.5.2.1 Environmental Performance

Mass Transfer Scaling

Aeration Scaling Relationship of Thompson and Gulliver

An Aeration Scaling Relationship Incorporating Draft Tube Losses

Analysis of Turbine Aeration Data

5.5.2.2 Hydraulic Performance

Energy Loss Mechanisms

Predicting Efficiency Loss

5.5.2.3 Economic Considerations

5.5.3 Testing of Aerating Turbines

5.5.3.1 Specification Requirements

5.5.3.2 Test Parameters

5.5.3.3 Test Code Recommendations

5.5.4 Operation of Aerating Turbines

5.5.4.1 Water Quality Requirements

5.5.4.2 Monitoring and Control

5.5.4.3 Biological Impact

5.5.5 Summary and Conclusions

5.5.6 References 


\subsection{TASK 4 REPORT - PRESENTATION OF DESIGN CONCEPTS}

6.1 Introduction

6.2 Environmentally Advanced Kaplan Design for Improved Fish Survivability

6.2.1 Primary Issues

6.2.1.1 Runner Gaps

6.2.1.2 Wicket Gate Overhang

6.2.1.3 Optimized Hydraulic Design

6.2.1.4 Lubrication

6.2.1.5 Surface Roughness

6.2.1.6 Fixed vs Adjustable Rotational Speed (RPM)

6.2.1.7 Advanced Control System

6.2.2 Secondary Issues

6.2.2.1 Interaction of Wicket Gates and Stay Vanes

6.2.2.2 Rotational Speed (RPM)

6.2.2.3 Draft Tube Piers

6.2.2.4 Runner Cones

6.2.2.5 Inlet Valves

6.2.2.6 Sharp Corners

6.2.2.7 Gate Slots

6.3 Environmentally Advanced Francis Design for Improved Fish Survivability

6.3.1 Primary Issues

6.3.1.1 Number of Runner Blades

6.3.1.2 Inlet Edge Thickness

6.3.1.3 Interaction of Runner Blades, Wicket Gates, and Stay Vanes

6.3.1.4 Optimized Hydraulic Design

6.3.1.5 Lubrication

6.3.1.6 Surface Roughness

6.3.1.7 Fixed vs Adjustable Rotational Speed (RPM)

6.3.1.8 Advanced Control System

6.3.1.9 Pressure Change

6.3.2 Secondary Issues

6.3.2.1 Rotational Speed (RPM)

6.3.2.2 Draft Tube Piers

6.3.2.3 Runner Cones

6.3.2.4 Inlet Valves

6.3.2.5 Sharp Comers

6.3.2.6 Gate Slots

6.4 Aerating Francis Design for Increasing Dissolved Oxygen Content

6.5 Summary and Conclusions

7.0 OVERALL CONCLUSIONS

8.0 RECOMMENDATIONS FOR FUTURE TESTING AND INVESTIGATION

9.0 SUPPLEMENTAL REPORT 


\subsection{APPENDICES}

10.1 Compilation of Survival Data

10.2 Types of Turbines

10.3 Derivation of Shear Probability Equation

10.4 Evaluation of Accuracy of Flow Angle Calculations

10.5 Advanced Turbulence Modelling Publications 10.6 Performance Testing of Aerating Hydroturbines

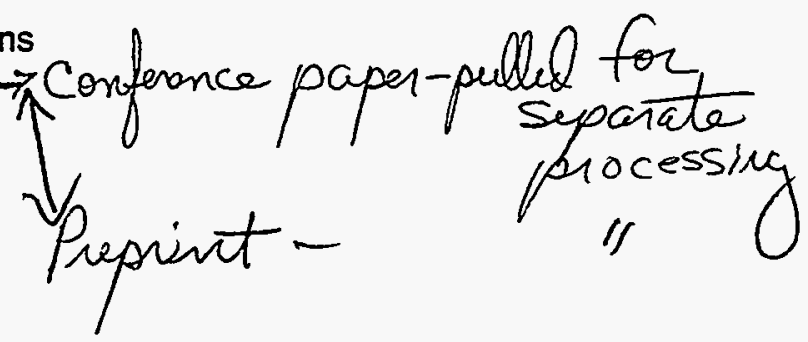




\subsection{EXECUTIVE SUMMARY}




\subsection{EXECUTIVE SUMMARY}

The team consisting of Voith Hydro, Normandeau Associates, TVA, Harza Engineering Company and the School of Civil and Environmental Engineering of Georgia Institute of Technology worked together on the Development of Environmentally Advanced Hydro Turbine Design Concepts to reduce hydropower's impact on the environment, and to improve the understanding of the technical and environmental issues involved, in particular, with fish survival as a result of their passage through hydro power sites. Through a combination of advanced technology and engineering analyses, innovative design concepts for this Phase I project were developed. In line with the request of the DOE, the solutions explored are adaptable to both new and existing hydro facilities.

The approach teamed a turbine design and manufacturing company, biologists, a utility, a consulting engineering firm and a university research facility in order to benefit from the synergy of diverse disciplines. One of the primary objectives of the project was to advance the understanding of the issues involved to effectively improve the environmental compatibility of hydro plant equipment designs.

The approach was divided into four tasks. Task 1 investigated a broad range of environmental issues and how the issues differ throughout the country. From this overview, the team looked for common elements which characterize the problems and chose three families of design concepts addressing the groups of most significant problem elements for further investigation. The concept families address environmentally advanced Kaplan turbines designed for improved fish survivability; environmentally advanced Francis turbines designed for improved fish survivability; and aerating Francis turbines designed for increasing dissolved oxygen content in turbine discharges. Of the families chosen, Kaplan units are the most important for considerations of fish passage. However, low head Francis units are also important for fish passage at older projects in the eastern states and in the upper mid west. Designs to enhance dissolved oxygen in turbine discharges require consideration of medium-head Francis units in addition to low-head Francis, propeller and Kaplan turbines.

Task 2 addressed fish physiology and turbine physics. In this task, the team studied the state of available information, the mechanisms for injury and methods to predict injury and defined which design elements to address to improve fish survival at hydro sites. Characteristics of turbine types are defined. The importance of a turbine's geometry and operation on fish passage survival is presented. Misconceptions present in the literature derived from interpreting past experiments are pointed out. The concept of the zonal effectiveness of fish passage survival in turbines is introduced. The need for additional controlled experiments to further clarify the effects of turbine geometry and the associated flow conditions on injury mechanisms is discussed.

Task 3 investigated individual design elements needed for the refinement of the three families of design concepts defined in Task 1. Advanced computational fluid dynamic (CFD) tools for numerical flow simulation in turbines were used to quantify characteristics of flow and pressure fields within turbine water passageways. Improvements of the simulation tools are discussed and evaluated in light of their utility in improving the environmental design of hydraulic turbines. The issues associated with dissolved oxygen enhancement using turbine aeration are defined. The state of the art and recent advancements of this technology are reviewed. Key elements for applying turbine aeration to projects to improve aquatic habitat are discussed. A review of the procedures for testing of aerating turbines is presented.

Tasks 2 and 3 activities brought forth several conclusions. Turbine operation has a significant effect on fish survival during turbine passage. Controlled field test experiments and CFD calculations demonstrate that different zones of the turbine have significantly different effects on fish during passage. Zonal geometry and associated flow conditions are important. In planning tests to evaluate fish passage, zonal 
effect determination must be considered to adequately develop a survival estimate for the turbine. Advanced turbulence models in CFD investigations were demonstrated to more accurately correlate with measured flow fields. In the absence of cavitation, pressure effects on fish during turbine passage are not significant. Effects related to the state of pressure acclimation are significant. These effects relate more to project planning than to turbine design or operation. Incorporating capabilities for aeration into the turbine design can alleviate water quality problems stemming from low dissolved oxygen in hydropower releases. Depending on design conditions aerating turbines can increase the level of dissolved oxygen by over $5 \mathrm{mg} / \mathrm{L}$.

Multiple areas for additional investigation were identified. Fish paths within intakes and turbines are not well understood. Additional testing is required to develop accurate indices of forces, pressure differentials, or other deterministic quantities that can be related to fish damage mechanisms in more detail. Calculation of flow fields can be performed. However, a means of calculating the resulting forces on the fish and the effect of the loads on fish survival is needed to advance the state of the art.

Task 4 assembled the results of Task 2 and Task 3 into three families of design concepts to address the most sigr::"cant issues defined in Task 1 . Significantly, the team pointed out that improvements in fish passage survival are achievable. The team provided design concepts which can be, and in some instances are being, implemented at today's existing hydro projects.

Finally, the team developed a set of recommendations for future work needed to improve the knowledge of the processes involved in inflicting injury to fish and pointed out the need for additional testing in controlled laboratory experiments and at existing hydro plants and at those currently being rehabilitated. They pointed out that none of the passage routes is $100 \%$ safe for fish and that recent experimental data and reanalysis of historical data do not support certain historical hypotheses. Instead, they show that (1) survival is not necessarily maximized at peak turbine operating efficiency, (2) survival is not necessarily higher for fish entrained near the hub, and (3) survival is not necessarily lower for unguided fish at turbines equipped with fish guidance screens. The report demonstrates that complex interacting mechanisms occur within the turbine and that fish passage survival depends on the turbine geometry, its operation and the location of the fish in the water column. In addition, they concluded that the effectiveness of turbine designs should be evaluated against "best of class" benchmarks. This would help in setting realistic, achievable goals in fish survival improvement for each turbine type. Effects of turbine modifications on fish survival can be evaluated using consistent test protocols and "comparative" benchmarking.

While the fundamental focus of the solutions developed is in the environmental arena, many of the issues addressed to improve the environmental compatibility also can improve plant efficiency thereby improving project economics and reducing the need for replacement energy generation from non-renewable sources. In addition, improvements reducing cavitation and vibration will result in lowered maintenance requirements for operators implementing the designs. 


\subsection{INTRODUCTION}




\subsection{INTRODUCTION}

\subsection{GOALS AND OBJECTIVES}

In the spirit of the DOE's mission for the Advanced Hydro Turbine System Program, Voith Hydro, Normandeau Associates, TVA, Harza Engineering Company and the School of Civil and Environmental Engineering of Georgia Institute of Technology worked together on a goal to define a family of environmentally advanced hydro turbine design concepts to meet the objective of improving hydropower's impact on the environment. Another goal of the project was to separate fact from fiction in understanding the issues involved to effectively improve the environmental compatibility of hydro plant equipment. To meet this goal a project objective to improve the understanding of the technical and environmental issues involved was established, in particular relating to fish survival as a result of their passage through hydro power sites. In addition, an objective to point out reeds and provide recommendations for further research was defined.

While the fundamental objectives of the solutions sought were in the environmental arena, it was envisioned that many of the issues addressed to improve the environmental compatibility could also improve plant efficiency thereby improving project economics and reduce the need for replacement energy generation from non-renewable sources. In addition, improvements sought were expected to reduce cavitation and vibration which would result in lowered maintenance requirements for operating utilities implementing the designs.

In developing the design concepts, the team remained cognizant of the following:

1. Design features of existing turbines can be modified to make significant improvements in their environmental compatibility. Hydro turbine plants contain more than $92,000 \mathrm{MW}$ of installed capacity at over 2300 sites in the US alone. This large installed base creates an opportunity to significantly address the environmental improvement issues through upgrade and rehabilitation of existing units.

2. Design features of new turbines can be chosen to make them more environmentally compatible. However, few new hydro installations are currently envisioned.

3. Conventional thinking, with respect to turbine design economics, was not used as a limitation. While turbine performance is still a very important factor in evaluating the benefits of different designs, the focus for design concept development was on environmental enhancement. When environmental cost/benefit values are used in the economic evaluation of the project, unconventional environmentally enhanced design solutions will be seen as cost effective.

4. Understanding of the behavior of fish in turbine flow fields and of the fluid and mechanical mechanisms involved in injuring fish in their passage through turbines is key to the development of design concepts for producing environmentally enhanced designs. This understanding will come from investigations using advanced technology for simulation of flow fields within turbines and from analysis of carefully designed field and laboratory testing. 


\subsection{APPROACH TO THE PROJECT}

The approach teamed a turbine design and manufacturing company, biologists, a utility, a consulting engineering firm and a university research facility, in order to benefit from the synergy of diverse disciplines. The knowledge of the contributors based on work done on related projects funded elsewhere (previous and concurrent activities) was combined with that developed from work done on this project to formulate the background, interpret experiments and conduct specific analyses. The design concepts presented are a combination of concepts developed on related projects funded elsewhere (both previous and concurrent) and those developed as a result of the work done on this contract. Some of the design concepts which were derived based on non DOE funding are covered by patents or are the subject of pending patent applications.

The approach was divided into four tasks. Task 1 investigated a broad range of environmental issues and how the issues differ throughout the country. From this overview, the team looked for common elements which characterize the problems and chose three families of design concepts addressing the groups of most significant problem elements for further investigation. Task 2 addressed fish physiology and turbine physics. During this task, the team studied the state of available information, the mechanisms for injury, injury prediction methods and defined what design elements to address to improve fish survival at hydro sites. Task 3 investigated individual design elements needed for the refinement of the three concepts defined in Task 1 . Task 4 then assembled the results of Task 2 and Task 3 into three design concept families to address the most significant issues defined in Task 1. Details of the four tasks were as follows:

\section{Task 1: Categorization of Environmental Issues and Selection of Concepts for Further Detailed Conceptual Design}

Biological issues related to environmental compatibility (EC) improvements are geographically dependent. In the Pacific Northwest, the EC issues are dominated by migratory fish and their survival in passing through turbines. In the Southeast, the EC issues are driven by resident fish and dissolved gas content. In the Northeast, migratory fish and resident fish survivability when passing through turbines are the principal factors. In all regions, maintaining minimum stream flows and reducing oil and grease pollution play a role.

In Task 1 , a broad summary of the principal issues addressing the environmental compatibility of turbines and power plants in all regions of the United States was made. The principal issues were related to fish passage survival through hydropower sites and the effect of hydropower sites on aquatic habitat. In the Northwest region of the country, Kaplan turbines and fish passage survival predominated. In the upper mid west region and the northern Atlantic coast region, Francis turbines and fish passage survival issues were dominant. In the Southeast region, issues associated with low levels of dissolved oxygen in turbine releases were dominant. In all areas, issues with respect to minimum stream flows existed.

The above, as well as additional concepts developed from the Task 1 activities, were evaluated with the help of the DOE AHT's project review committee. From those considered, three families of design concepts best addressing the hydropower industry's needs were selected for further design element development in Task 3. They were an advanced Kaplan turbine focused on fish passage survival improvements; an advanced Francis turbine focused on fish passage survival improvements; and an advanced Francis turbine stressing improvements in the levels of dissolved oxygen in the discharge water. 


\section{Task 2: Fish Physiology and Hydropower Physics}

The team reviewed the data available in the literature and screened selected data from the data set for detailed investigation. Injury mechanisms related to fish passage through hydro sites were quantified. Fish passage survival models were developed based on simplified models of the turbine geometry and performance characteristics and further evaluated with the help of sophisticated flow analysis tools. The mechanisms and models were then evaluated in light of the screened data.

In the process of the above, the opportunity to gather some additional data in conjunction with a planned site test at Wanapum dam was used and the test plan was expanded to gather additional data. Analysis of the test results provided further insight into importance of the zonal characteristics of the turbine geometry and associated flow fields.

Data associated with fish passage survival in turbine bypasses were also reviewed to benchmark these alternative routes.

A key facet in developing an environmentally compatible design relating to fish survivability involves the development of a clear understanding of the physiology of the fish and how the fish behave as they enter a hydro project. More specifically, the following questions, among others, were addressed:

1. What pressure, velocity and acoustic gradients influence fish behavior?

2. What physiological stresses and turbine features are responsible for injuring and killing fish?

$\begin{array}{ll}\text { - } & \text { Decompression } \\ \text { - } & \text { Strike } \\ \text { - } & \text { Gas supersaturation (bends) } \\ \text { - } & \text { Cavitation }\end{array}$

3. How are different species and size of fish affected?

4. How do plant civil design, head and flow impact fish behavior and mortality?

A survey of available data and discussions between team members to share insights were used to discover features and operations that have proven to be relatively fish friendly. Additional laboratory and field tests were identified that will enable the designer to formalize features that will produce a hydraulic environment compatible with high fish survival.

\section{Task 3: In-depth Investigation of Selected Design Elements}

Based on the results of Task 1 and Task 2, selected design studies were conducted to gain a technical understanding of the issues required to achieve the design objectives of the three selected families of design concepts.

Advanced methods of Computational Fluid Dynamics (CFD) were used by Voith Hydro to analyze and evaluate elements of existing designs to provide insight leading to the conceptual designs. The methods were used to calculate velocity and pressure fields to: i) calculate the pressure gradients experienced by fish passing through the turbine; ii) identify regions where cavitation would occur; iii) identify the 
presence of vortices, regions of flow reversal, and regions of large velocity gradients; iv) identify loss zones; and v) illustrate flow streamlines, among others. Investigations of limitations of existing CFD turbulence modeling were conducted by Georgia Tech. Improved methods were tested numerically to evaluate their impact.

A definition of critical issues relating to turbine aeration was developed by TVA. The issues associated with dissolved oxygen enhancement using turbine aeration are defined. The state of the art and recent advancements of this technology are reviewed. Key elements for applying turbine aeration to projects to improve aquatic habitat are discussed. A review of the procedures for testing of aerating turbines is presented.

\section{Task 4: Development of Conceptual Designs}

Because each hydro plant is custom designed to adapt to its unique site and operational requirements, a single design for each of the three topics selected in Task 1 was not addressed. Instead, based on the results of Tasks 1,2 and 3, three sets of design concepts were developed which can be implemented in the context of the unique requirements of each hydropower plant. The sets of concepts address:

Advanced environmentally friendly Kaplan turbines.

Advanced environmentally friendly Francis turbines.

Advanced environmentally friendly aerating Francis turbines. 
Development Of Environmentally Advanced Hydropower Turbine System Design Concepts Section 2.0

\subsection{TEAM STRUCTURE}

To accomplish the proposed tasks, a multi-disciplinary team was formed to address the issues. The team consisted of the following organizations:

1. Voith Hydro, Inc.

2. Tennessee Valley Authority (TVA)

3. Harza Engineering Company

4. Normandeau Associates

5. The School of Environmental and Civil Engineering of Georgia Institute of Technology

The team brought to the project tremendous synergy benefits from the diverse background of each. It is important to note that the team consisted of a manufacturer, utility, consulting engineers, an environmental service group and a university. Voith Hydro served as the prime contractor and team leader. The other organizations served as subcontractors. 


\subsection{ORGANIZATION OF THE REPORT}

This report is organized following the Tasks of the Project. Section 3.0 discusses Task 1 activities. Section 4.0 discusses Task 2 activities. Section 5.0 presents the results of Task 3 studies including those associated with CFD investigations of turbine components, those associated with development of advanced CFD capabilities, and those associated with the enhancement of dissolved oxygen levels in water passing through turbines. Section 6 presents design concept families. Section 6.4 reporting on a third concept family related to aerating Francis turbines will be supplied as a report supplement. Section 7 presents a summary of conclusions derived from the work of all Sections. Section 8 presents recommendations for future work. Section 9 is reserved for a future supplement which will report on the use of advanced CFD and a "virtual fish" to evaluate the 4 conditions tested experimentally by fish injection at Wanapum dam (described in Section 4.4.6). An appendix (Section 10) contains background material from all sections. 
. 


\subsection{TASK 1 REPORT- REVIEW OF THE ISSUES}

\subsection{INTRODUCTION}

The objective of Task 1 was to review environmental issues and select concepts having the greatest impact on improving the environmental compatibility of turbines for further detalied conceptual design. Issues identified as addressable through turbine design included fish passage through turbines, dissolved gasses in turbine discharge, and minimum flow downstream of hydroelectric stations. Experience of the Voith team was used to define the geographic distribution of concerns about these issues. The cumulative experience of the Technical Committee was solicited by mail. Design characteristics of turbines associated with identified issues and regions were established by queries of an extensive database. Initial results were presented at the Design Review Meeting on March 6-7, 1996. Additional queries followed receipt of comments from the Technical Committee.

Harza Engineering Company compiled a database from the National Inventory of Dams of the U.S. Army Corps of Engineers and the Federal Energy Regulatory Commission database of licensed hydroelectric projects. The database includes information on 2555 dams associated with hydroelectric projects. The dam database includes:

$\begin{array}{lllll}\text { Name } & \text { Owner } & \text { Latitude } & \text { Longitude } & \text { River } \\ \text { Nearest City } & \text { State } & \text { Purpose } & \text { Age } & \text { Length } \\ \text { Height } & \text { Max. Discharge } & \text { Max. Storage } & \text { Normal Storage } & \end{array}$

Harza also has a series of manufacturers' turbine databases that includes more than 6,000 entries, including some overseas. The Voith-Allis Chalmers dataset is the largest, with more than 850 entries in the U.S. Turbine data were also provided by Neyrpic, GE Canada, Mitsubishi, Fuji, Hitachi, Toshiba, Kvaerner, Sulzer and Voest Alpine. Turbines were designated by the following parameters:

Hydraulic Type

Axial (Kaplan, propeller)

Diagonal (Deriaz)

Radial (Francis)

Impulse (Pelton)

Cross-Flow (Ossberger, Banzi)
Hydromachine Control

Axial (Kaplan, propeller runner blades only)

Dual control

No control
Hydromachine

Turbine

Pump Turbine

$\begin{array}{ll}\text { No. of Jets } & \begin{array}{l}\text { Runner } \\ \text { (Pelton only) }\end{array} \\ \begin{array}{l}\text { Single } \\ \text { Tandem } \\ \text { Multistage }\end{array} & \cdot \frac{\text { No. of Stages }}{\text { (or no. of Pelton runners) }}\end{array}$

\begin{tabular}{llll} 
Arrangement & Drive & Orientation & Spiral Case \\
\cline { 3 - 5 } Bulb & Direct & Horizontal & Concrete, semispiral \\
Pit & Spur gear & Vertical & Steel \\
S-type & Bevel gear & Inclined & Flume \\
Straflo (Harza) & Chain & & \\
Tube & Belt & & \\
Conventional & Plenetary gear & &
\end{tabular}


Each project was identified by name and units were specified by:

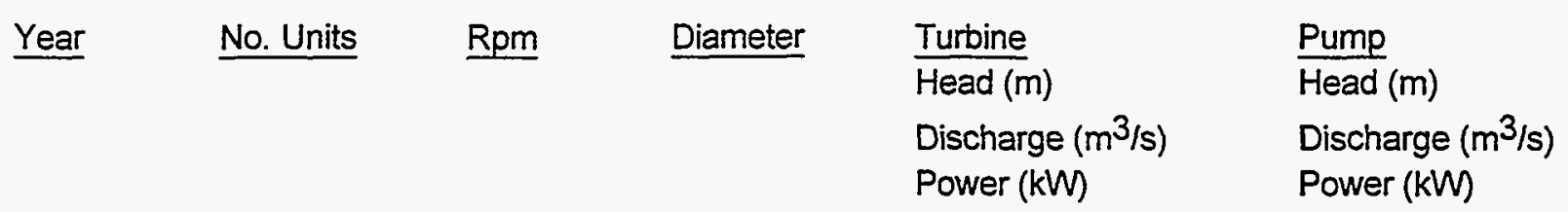

Original goals of the project team were to develop turbine design concepts to address questions of fish passage, dissolved gases and minimum flow. Filters and sorting on various fields were applied to the database to screen for key issues. The filters were used to associate turbine and plant parameters with fish related problems such as fish passage, dissolved gases, and minimum streamflow. The turbine and plant parameters that were identified as related to these problems and could be obtained from the database were: location (state and region) of the plants, turbine type, head, turbine and plant discharges, turbine output, turbine size, plant output, and plant factor. Filters were developed in the form of specifying staies composing regions that defined the geographic extent of a question or the regionally specific manner in which a question was addressed. After presentation of the results of filtering the database at the first Design Review Meeting, the team was directed to drop the minimum flow objective and develop design concepts for a fishfriendly Francis turbine. Additional queries were made of the turbine database to determine the size distribution of Francis turbines by region. In most cases, turbine diameter was missing from the database, but rated discharge was nearly always listed. From the cases where both parameters were quantified, the equation

$$
\begin{aligned}
D=(Q / 6.5)^{0.5} & \\
\text { where } D & =\text { runner diameter }(\mathrm{m}) \text { and } \\
Q & =\text { discharge }\left(\mathrm{m}^{3} / \mathrm{s}\right)
\end{aligned}
$$

was fit and applied to the cases where diameter was missing for a conventional Francis turbine.

The dissolved oxygen issue was researched by the Tennessee Valley Authority. Depending on sitespecific conditions, one or more of the factors listed in Table 3.1 (Ruane and Hauser 1991) may affect DO in turbine discharges.

\begin{tabular}{|l|l|}
\hline Category & Items \\
\hline \hline Fhysical Design & $\begin{array}{l}\text { Reservoir volume } \\
\text { Reservoir surface area } \\
\text { Reservoir depth } \\
\text { Discharge capacity of turbines } \\
\text { Location and depth of outlets }\end{array}$ \\
\hline Environmental Factors & $\begin{array}{l}\text { Meteorology (e.g. air temperature and rainfall), } \\
\text { Hydrology (e.g., mean annual flow rate) } \\
\text { Inflow water temperature }\end{array}$ \\
\hline Watershed Factors & $\begin{array}{l}\text { Size } \\
\text { Type of land use } \\
\text { Point and nonpoint wastewater discharges } \\
\text { Natural loadings of organic substances and } \\
\text { nutrients }\end{array}$ \\
\hline Operational Factors & $\begin{array}{l}\text { Schedule for hydropower releases } \\
\text { Schedule of releases for upstream projects }\end{array}$ \\
\hline
\end{tabular}

Table 3.1 Factors Affecting Tailrace Dissolved Oxygen Concentrations 
To determine the dominant factors, correlation studies are required using data from a large sample of projects. The data requirements include tailwater $D O$ as well as the items given in Table 3.1. The results for one such study were presented by EPRI (1990). Reservoirs were identified as more than likely to encounter periods when the discharge contains less than $5 \mathrm{mg} / \mathrm{L}$ DO if they had the following characteristics:

$$
\begin{aligned}
& \text { Depth at dam } \quad>50 \text { feet, } \\
& \text { Power capacity }>10 \mathrm{MW} \text {, } \\
& \text { Reservoir volume } \quad>50,000 \text { acre-feet, } \\
& \text { Densimetric Froude Number } F_{d}<7 \text {, and } \\
& \text { Retention Time } V_{A} Q \quad>10 \text { days, } \\
& \text { where } F_{d}=\frac{1.952 L Q\left(V_{1}-V_{A}\right)}{V_{A}^{2}} \text { and } \\
& L=\text { Reservoir length (miles) } \\
& Q=\text { Average annual inflow (CFS), } \\
& V_{A}=\text { Average annual volume (1000 CFS-days), and } \\
& V_{1}=1 \text {-foot above average storage ( } 1000 \text { CFS-days). }
\end{aligned}
$$

and $1 \mathrm{ft}=0.305 \mathrm{~m}, 1$ acre- $\mathrm{ft}=1,233 \mathrm{~m}^{3}$, and $1 \mathrm{cfs}=2.830 \times 10^{-2} \mathrm{~m}^{3} / \mathrm{s}$. At this time, these conditions represent the only filter for identifying projects that are likely to encounter low DO. It should be emphasized that EPRI (1990) does not provide a reference from which these conditions are recommended. Hence, the "accuracy" of this filter for identifying projects with low DO is unknown.

A measure of the extent of low DO throughout the country can currently be obtained from two sources of information: statistical analyses by others who have obtained DO data for many US hydro projects, and water quality summaries for dams managed by the US Army Corps of Engineers (USACE), Tennessee Valley Authority (TVA), and US Bureau of Reclamation (USBR). 


\subsection{DISCUSSION}

The Harza dataset included 64 GW of capacity among 1600 projects identified by head, discharge and turbine type. FERC (1992) reported a total of $92 \mathrm{GW}$ capacity in the private and public utilities of the U.S. Known projects that were not included in the database because of incomplete data were less than $1 \mathrm{MW}$ capacity. Examination of the entire data set showed that most generating capacity was installed in Francis turbines at medium and low head (Tables 3.2 and 3.3). However, most flow passed through axial turbines at low and very low head.

\begin{tabular}{|l|l|l|l|l|}
\hline & Axial & Francis & Pelton & Ossberger \\
\hline \hline Capacity (MW) & 20,561 & 43,859 & 2,959 & 124 \\
Design discharge (ms) & 123,998 & 95,829 & 962 & 886 \\
\hline
\end{tabular}

Table 3.2 Distribution of Capacity and Design Flow by Turbine Type

\begin{tabular}{|l|l|l|c|c|}
\hline & $\begin{array}{l}\text { very low } \\
<10 \mathrm{~m}\end{array}$ & $\begin{array}{c}\text { low } \\
10-50 \mathrm{~m}\end{array}$ & $\begin{array}{c}\text { medium } \\
50-150 \mathrm{~m}\end{array}$ & $\begin{array}{c}\text { high } \\
>150 \mathrm{~m}\end{array}$ \\
\hline \hline Axial units & 24,475 & 99,277 & 247 & 0 \\
Francis units & 5,523 & 50,995 & 35,721 & 3,590 \\
\hline
\end{tabular}

Table 3.3 Total Design Discharge $\left(\mathrm{m}^{3} / \mathrm{s}\right)$ as a Function of Head $(\mathrm{m})$

The fish passage issue has been the impetus for studies dealing with anadromous salmon species on the West Coast, anadromous Atlantic salmon and American shad on the East Coast, and freshwater resident species in the Upper Midwest and other inland sites (Eicher and Associates 1987, Stone \& Webster 1992). Concerns about the effects of dams on anadromous fishes date back to the Industrial Revolution, but most studies on resident species have been conducted since 1990. Low head Axial units typify turbines associated with Pacific salmon in California, Oregon, Washington and Idaho (Tables 3.4 and 3.5). Francis units at low and medium head were also important on the East Coast states from Maine to Georgia and in the New York and the Upper Midwest (Michigan, Wisconsin and Minnesota). 
Development Of Environmentally Advanced Hydropower Turbine System Design Concepts Section 3.0

\begin{tabular}{|c|c|c|c|c|}
\hline & \multicolumn{4}{|c|}{ Turbine Type } \\
\hline & Axial & Francis & Pelton & Ossberger \\
\hline West Coast & & & & \\
\hline Total MW & 11,333 & 22,581 & 2,624 & 7 \\
\hline Total $\mathrm{m}^{3} / \mathrm{s}$ & 52,234 & 38,827 & 842 & 53 \\
\hline East Coast & & & & \\
\hline Total MW & 1,950 & 5,619 & 33 & 30 \\
\hline Total $\mathrm{m}^{3} / \mathrm{s}$ & 11,908 & 19,975 & 12 & 199 \\
\hline Upper Midwest & & & & \\
\hline Total MW & 1,386 & 3,229 & 0 & 29 \\
\hline Total $\mathrm{m}^{3} / \mathrm{s}$ & 10,307 & 9,888 & 0 & 395 \\
\hline
\end{tabular}

Table 3.4 Total Turbine Capacity (MW) and Design Discharges $\left(\mathrm{m}^{3} / \mathrm{s}\right)$ at Hydroelectric Projects in Regions with Notable Fish Passage Issues

\begin{tabular}{|l|l|c|c|c|c|}
\hline & & $\begin{array}{c}\text { very low } \\
<10 \mathrm{~m}\end{array}$ & $\begin{array}{c}\text { low } \\
10-50 \mathrm{~m}\end{array}$ & $\begin{array}{c}\text { medium } \\
50-150 \mathrm{~m}\end{array}$ & $\begin{array}{c}\text { high } \\
>150 \mathrm{~m}\end{array}$ \\
\hline \hline West Coast & Axial units & 1,950 & 50,046 & 237 & 0 \\
& Francis units & 27 & 16,527 & 20,522 & 1,750 \\
\hline East Coast & Axial units & 3,046 & 8,859 & 3 & 0 \\
& Francis units & 2,556 & 13,891 & 3,394 & 124 \\
\hline NY \& Upper & Axial units & 4,149 & 6,151 & 7 & 0 \\
Midwest & Francis units & 2,338 & 4,877 & 2,657 & 17 \\
\hline
\end{tabular}

Table 3.5 Total Design Discharge $\left(\mathrm{m}^{3} / \mathrm{s}\right)$ as a Function of Head $(\mathrm{m})$ at Hydroelectric Projects in Regions with Notable Fish Passage Issues

Axial turbines accounted for 31 percent of the total hydro generation capacity and $57 \%$ of the design discharge for the West Coast. Ninety-six percent of the West Coast Axial design discharge was through low (10-50 m (33-164 ft.)) head units. Low head Axial units accounted for 28 percent and 30 percent of the design discharge on the East Coast and in New York and the Upper Midwest, respectively. The hydro generation capacity for the East Coast and Upper Midwest was mostly (74 and 70 percent, respectively) by Francis turbines. Low head Francis units were 43 percent of the design discharge database for the East Coast and 24 percent for the Upper Midwest.

Francis turbine size data were sorted for Pacific Northwest and New York and Upper Midwest States to address the fish passage issue (Table 3.6). There was a nearly even distribution of turbines across size categories in the Pacific Northwest. Size categories of less than $2 \mathrm{~m}$ (6.6 ft.), $2 \mathrm{~m}$ to $4 \mathrm{~m}$ (13.1 ft.), and greater than $6 \mathrm{~m}$ (19.7 ft.) each accounted for 27 to 29 percent of the number of turbines. Turbines tended to be smaller in the Upper Midwest. Most (55 percent) of those turbines had diameters of 2 to $4 \mathrm{~m}$, and 23 percent were smaller than $2 \mathrm{~m}$. 


\begin{tabular}{|c|c|c|}
\hline Diameter $(\mathrm{m})$ & Pacific Northwest States & $\begin{array}{c}\text { New York and Upper } \\
\text { Midwest States }\end{array}$ \\
\hline \hline 2 & 91 & 73 \\
$2-4$ & 97 & 174 \\
$4-6$ & 51 & 43 \\
$>6$ & 93 & 27 \\
no data & 3 & 1 \\
\hline
\end{tabular}

Table 3.6 Size Distribution of Francis Turbines in Pacific Northwest and Upper Midwest States

Statistical analyses of the water quality of hydro releases were summarized by Cada et al. $(1981,1983)$ and EPA (1989). Cada et al. (1981, 1983) compiled information for water quality downstream of hydro projects from two databases, the USACE National Hydropower Study (NHS), and the National Water Data Storage and Retrieval System (WATSTORE). At the time of the study, NHS contained descriptive information for about 15,300 dams. WATSTORE contained water quality measurements for about 220,000 stations. Searches of the databases paired hydro projects with water quality stations that were iocated within three miles downstream of the dam. All projects in the NHS database having more than two DO measurements from a tailrace station in the WATSTORE database were evaluated statistically to determine the probability of noncompliance (PNC). The PNC was defined as the probability that concentration of dissolved oxygen downstream of the project will be less than $5 \mathrm{mg} / \mathrm{L}$.

The data were evaluated based on a regional division of the 48 contiguous states (Table 3.7). The analyses included two groups of hydro projects and two seasons, those with capacity less than 30 MW and those with capacity greater than $30 \mathrm{MW}$, for summer (July-October) and winter (other months). The frequency of occurrence of low DO, and hence the mean PNC, is generally greater for the summer. This is due to warmer temperatures, which cause thermal stratification in the reservoirs. This process inhibits reservoir mixing and causes hypolimnetic oxygen depletion. Since these are the conditions that usually create the need for low DO improvements, the results summarized herein will focus only on the summer. For these months, the mean PNC for each group of hydro projects is given in Tables 3.8 and 3.9, respectively. 
Development Of Environmentally Advanced Hydropower Turbine System Design Concepts Section 3.0

\begin{tabular}{|l|l|}
\hline Region & States \\
\hline \hline Great Basin States & Arizona, Nevada, New Mexico, Utah \\
\hline Great Plains States & lowa, Kansas, Nebraska, North Dakota, Oklahoma, South Dakota, Texas \\
\hline Lake States & Michigan, Minnesota, Wisconsin \\
\hline Northeast States & $\begin{array}{l}\text { Connecticut, Maine, Massachusetts, New Hampshire, New Jersey, New } \\
\text { York, Pennsylvania, Rhode Island, Vermont }\end{array}$ \\
\hline Ohio Valley States & $\begin{array}{l}\text { Delaware, Illinois, Indiana, Kentucky, Maryland, Missouri, Ohio, } \\
\text { Tennessee, Virginia, West Virginia }\end{array}$ \\
\hline Pacific Coast States & California, Oregon, Washington \\
\hline Rocky Mountain States & Colorado, Idaho, Moniana, Wyoming \\
\hline Southeast States & $\begin{array}{l}\text { Alabama, Arkansas, Florida, Georgia, Louisiana, Mississippi, North } \\
\text { Carolina, South Carolina }\end{array}$ \\
\hline
\end{tabular}

Table 3.7 Regional Division of US for Analysis of Low DO

EPA (1989) repeated the study of Cada et al. $(1981,1983)$ using available data from a sample of 40 hydro projects randomly selected from the USACE National Inventory of Dams Database. At the time of the study this database included 68,155 dams. In the EPA work, the 40 projects were selected from a subset of the USACE database defined as those sites with over 100 kilowatts of installed power and over $12,340,000 \mathrm{~m}^{3}(10,000$ acre-feet) of reservoir volume. This subset included 424 hydro projects. Dissolved Oxygen data for each of the 40 sites, if any, were obtained from EPA's STORET data repository. Results of the EPA study, again for the summer months, are also shown in Tables 3.8 and 3.9.

\begin{tabular}{|l|c|l|l|l|l|}
\hline \multirow{2}{*}{ Region } & \multicolumn{2}{|c|}{$\begin{array}{l}\text { Cada et al. (1981, } \\
\text { 1983) }\end{array}$} & \multicolumn{2}{|c|}{ EPA (1989) } & Observed \\
\cline { 2 - 6 } & $\begin{array}{l}\text { No. } \\
\text { Sites }\end{array}$ & $\begin{array}{l}\text { Mean PNC } \\
(\%)\end{array}$ & $\begin{array}{l}\text { No. } \\
\text { Sites }\end{array}$ & $\begin{array}{l}\text { Mean } \\
\text { PNC } \\
(\%)\end{array}$ & $\begin{array}{l}\text { Range } \\
(\%)\end{array}$ \\
\hline \hline Great Basin & 3 & 37.3 & no data & - & $\begin{array}{l}\text { no data } \\
37.3\end{array}$ \\
\hline Great Plains & 1 & 0.0 & 1 & 0.0 & $0.0-?$ \\
\hline Lake & 5 & 4.3 & 4 & 12.3 & $4.3-12.3$ \\
\hline Northeast & 15 & 6.6 & no data & - & no data - 6.6 \\
\hline Ohio Valley & 3 & 11.1 & 3 & 22.0 & $11.1-22.0$ \\
\hline Pacific Coast & 7 & 0.3 & no data & - & no data - 0.3 \\
\hline $\begin{array}{l}\text { Rocky } \\
\text { Mountain }\end{array}$ & 9 & 2.7 & no data & - & no data - 2.7 \\
\hline Southeast & 17 & 13.1 & 2 & 19.0 & $13.1-19.0$ \\
\hline
\end{tabular}

Table 3.8 Mean Summer PNC for Projects $<30 \mathrm{MW}$ 


\begin{tabular}{|c|c|c|c|c|c|}
\hline \multirow[b]{2}{*}{ Region } & \multicolumn{2}{|c|}{$\begin{array}{c}\text { Cada et al. (1981, } \\
\text { 1983) }\end{array}$} & \multicolumn{2}{|c|}{ EPA (1989) } & \multirow{2}{*}{$\begin{array}{l}\text { Observed } \\
\text { Range } \\
(\%)\end{array}$} \\
\hline & $\begin{array}{l}\text { No. } \\
\text { Sites }\end{array}$ & $\begin{array}{l}\text { Mean PNC } \\
(\%)\end{array}$ & $\begin{array}{l}\text { No. } \\
\text { Sites }\end{array}$ & $\begin{array}{l}\text { Mean } \\
\text { PNC } \\
(\%)\end{array}$ & \\
\hline Great Basin & 3 & 0.4 & no data & - & no data -0.4 \\
\hline Great Plains & 6 & 18.2 & no data & - & $\begin{array}{l}\text { no data - } \\
18.2\end{array}$ \\
\hline Lake & no data & - & no data & - & no data \\
\hline Northeast & 3 & 14.4 & no data & - & $\begin{array}{l}\text { no data - } \\
14.4\end{array}$ \\
\hline Ohio Valley & 16 & 40.4 & 5 & 56.0 & $40.4-56.0$ \\
\hline Pacific Coast & 19 & 3.9 & 4 & 5.3 & $3.9-5.3$ \\
\hline $\begin{array}{l}\text { Rocky } \\
\text { Mountain }\end{array}$ & 6 & 5.2 & 2 & 0.0 & $0.0-5.2$ \\
\hline Southeast & 18 & 30.8 & 2 & 17.0 & $17.0-30.8$ \\
\hline
\end{tabular}

Table 3.9 Mean Summer PNC for Projects $>30 \mathrm{MW}$

No region is free of low DO episodes. PNC had some value above zero in all regions among large or small projects. Mean summer PNC's tend to be higher for large scale facilities (> $30 \mathrm{MW}$ ), indicating that low DO occurs more frequently for these sites. The mean summer PNC tends to be higher for the Southeast and Ohio Valley, indicating that low DO occurs more frequently in these areas. For small scale facilities (<30 MW), the same was true for the Great Basin, but it was represented by only three projects. High PNC occurs in these regions because summers are longer and hotter, and therefore the magnitude and duration of thermal stratification in reservoirs are higher. For large scale facilities $(>30 \mathrm{MW})$, the mean summer PNC's for the Great Plains and Northeast are less than half of that for the Ohio Valley and Southeast, respectively, but are still considered significant.

Cada et al. $(1981,1983)$ urged caution in reviewing the results summarized in Tables 3.8 and 3.9. For some regions, not enough hydro projects have data for taihwater $D O$ to obtain reliable statistics. At some sites the measurements are infrequent. Watershed and meteorological data that affect DO are very limited. Improved predictions of low DO may result by including not only power capacity but also retention time, reservoir depth, oLtlet location, inflow temperature, and size and character of watershes in the analyses.

Kennedy and Gaugush (1987) summarized the results of an analysis of USACE hydropower projects in an exhibit that showed sites in the Southeast, Ohio Valley, Great Plains, Rocky Mountain, and Pacific Coast regions (Table 3.10). Their data generaliy supported the previous indication that low DO occurs more frequently in the Ohio Valley and Southeast, and less frequently in the Great Plains, Pacific Coast, and Rocky Mountains. This exhibit was also presented by EPA (1989) and EPRI (1990). For the Ohio Valley, the overall fraction of sites with DO problems was slightly higher than that suggested by the mean summer PNC in Table 3.9. For the Southeast, the overall fraction of sites with DO problems is more than twice that suggested by the mean summer PNC in Table 3.9. However, data by Kennedy and Gaugush (1987) were not selected at random and may contain bias towards USACE projects with DO problems. 
Detailed DO measurements for TVA hydro projects were reported by TVA (1990). Nineteen out of 29 projects located in the Ohio Valley and Southeast were reported as having tailwater $D O<5 \mathrm{mg} / \mathrm{L}$ on the average of at least 3 weeks per year. Table 3.11 gives the percent of low DO projects based on the total number of TVA hydropower sites in each of these regions. For both regions, the overall fraction of sites with low DO is higher than that suggested by the mean summer PNC's in Table 3.9. The data in Table 3.11 obviously is biased towards TVA projects, and probably toward larger projects and reservoirs as well, but again supports the previous indication that low DO occurs more frequently in the Ohio Valley and Southeast.

\begin{tabular}{|l|c|c|l|}
\hline Region & \multirow{2}{*}{$\begin{array}{l}\text { No. Of } \\
\text { Sites }\end{array}$} & \multicolumn{2}{|l|}{ Sites With Low DO } \\
\cline { 2 - 4 } & No. & Percent \\
\hline \hline Great Plains & 5 & 0 & 0.0 \\
\hline Ohio Vailey & 14 & 9 & 64.3 \\
\hline Pacific Coast & 18 & 0 & 0.0 \\
\hline Rocky Mountain & 4 & 0 & 0.0 \\
\hline Southeast & 20 & 15 & 75.0 \\
\hline \hline Total & 61 & 24 & 39.3 \\
\hline
\end{tabular}

Table 3.10 USACE Hydropower Projects Having at Least Minor DO Problems

\begin{tabular}{|l|c|c|l|}
\hline Region & Total No. & \multicolumn{2}{|l|}{ Sites With Low DO } \\
\cline { 3 - 4 } & Sites & No. & Percent \\
\hline \hline Ohio Valley & 23 & 16 & 69.6 \\
\hline Southeast & 6 & 3 & 50.0 \\
\hline \hline Total & 29 & 19 & 55.2 \\
\hline
\end{tabular}

Table 3.11 TVA Hydropower Projects with

DO $<5 \mathrm{mg} / \mathrm{L}$ at Least 3 Weeks Per Year on Average

EPA (1989) presented the results of a water quality survey for 250 of 349 USBR power and nonpower water resources projects. These include sites in the Great Plains, Rocky Mountains, Great Basin, and Pacific Coast states. About $54 \%$ of the surveys reported that no data were available to assess low DO problems (i.e., 134 of 250 projects). Assuming there are no DO problems at the "no data" sites (i.e., data are collected only when a problem exists), only about $4 \%$ of the reported USBR projects would contain low tailwater DO as at least an intermittent problem. At this time, $4 \%$ is the best estimate available for the fraction of USBR hydropower projects that contain low tailwater DO. This is based on the unsubstantiated assumption that sites with low DO are uniformly distributed among all the different project types. These results, however, support the general indication in Tables 3.8 and 3.9 that low DO is not as frequently observed in the western regions of the US, especially the Pacific Coast and Rocky Mountain states.

The Harza database was sorted by the same regions used in the dissolved oxygen analyses and queried to determine the turbine types that have been most commonly associated with low DO. Low head Axial units pass most of the flow in Southeast and Ohio Valley states where DO problems are well documented (Tables 3.12 and 3.13$)$. 


\begin{tabular}{|l|r|r|r|r|}
\hline & Axial & Francis & Pelton & Ossberger \\
\hline \hline Southeast & & & & \\
Total MW & 4,984 & 6,206 & 23 & 98 \\
Total $\mathrm{m}^{3} / \mathrm{s}$ & 37,618 & 18,554 & 7 & 545 \\
\hline Ohio Valley & & & & \\
Total MW & 794 & 2,066 & 10 & 0 \\
Total ms & 7,926 & 6,942 & 5 & 0 \\
\hline Entire Data Set & & & & \\
Total MW & 20,561 & 43,859 & 2,959 & 124 \\
Total $\mathrm{m}^{3} / \mathrm{s}$ & 123,998 & 95,829 & 962 & 886 \\
\hline
\end{tabular}

Table 3.12 Total Turbine Capacity (MW) and Design Discharge $\left(\mathrm{m}^{3} / \mathrm{s}\right)$ at Hydroelectric Projects in Regions with Notable Dissolved Oxygen issues

\begin{tabular}{|c|c|c|c|c|}
\hline & $\begin{array}{l}\text { Very Low } \\
<10 \mathrm{~m}\end{array}$ & $\begin{array}{l}\text { Low } \\
10-50 \mathrm{~m}\end{array}$ & $\begin{array}{l}\text { Medium } \\
50-150 \mathrm{~m}\end{array}$ & $\begin{array}{c}\text { High } \\
>150 \mathrm{~m}\end{array}$ \\
\hline $\begin{array}{l}\text { Southeast } \\
\text { Axial units } \\
\text { Francis units }\end{array}$ & $\begin{array}{r}10,639 \\
1,187\end{array}$ & $\begin{array}{l}26,972 \\
12,689\end{array}$ & $\begin{array}{r}7 \\
4,555\end{array}$ & $\begin{array}{r}0 \\
124\end{array}$ \\
\hline $\begin{array}{l}\text { Ohio Valley } \\
\text { Axial units } \\
\text { Francis units }\end{array}$ & $\begin{array}{r}3,376 \\
257\end{array}$ & $\begin{array}{l}4,550 \\
4,727\end{array}$ & $\begin{array}{c}0 \\
1,958\end{array}$ & $\begin{array}{l}0 \\
0\end{array}$ \\
\hline $\begin{array}{l}\text { Entire Data Set } \\
\text { Axial units } \\
\text { Francis units }\end{array}$ & $\begin{array}{r}24,475 \\
5,523\end{array}$ & $\begin{array}{l}99,277 \\
50,995\end{array}$ & $\begin{array}{r}247 \\
35,721\end{array}$ & $\begin{array}{r}0 \\
3,590\end{array}$ \\
\hline
\end{tabular}

Table 3.13 Total Design Discharge $\left(\mathrm{m}^{3} / \mathrm{s}\right)$ as a Function of Head at Hydroelectric Projects in Regions with Notable Dissolved Oxygen Issues

Low head Axial units accounted for 48 percent of the installed design discharge in the Southeast very low head Axials, 19 percent; and low head Francis units 22 percent. In the Ohio Valley, low head Axials accounted for 31 percent of the installed design discharge; very low head Axials, 23 percent; and low head Francis units 32 percent.

Storage projects are more likely than run-of-river projects to suffer DO problems. Storage reservoirs are more likely to stratify in the summer and have low DO in their deeper layers because storage reservoirs tend to be larger and deeper and have much longer hydraulic residence times than run-of-river facilities. Data for the Southeast and Ohio Valley regions were also sorted by plant factor, where

$$
\text { plant factor }=\frac{\text { yearly } k W h \text { produced }}{\text { plant capacity } \times \text { hours per year }}
$$

Plant factor may have values from 0 , representing no generation, to slightly greater than 1 , representing continuous operation of all units with actual output slightly above nameplate capacity. Run-of-river projects tend to have high plant factors. At these facilities, dissolved oxygen problems, when they occur, tend to be due to causes unrelated to hydro operation. Storage projects tend to have lower plant factors because discharge and generation vary over daily or seasonal scales. Dissolved oxygen problems at 
these sites may be due to thermal stratification of the reservoir and oxygen consumption by the deep (hypolimnetic) aquatic community as well as the internal factors affecting run-of-river projects.

Most of the flow at projects with low plant factors (where there is some idle capacity most of the time) passes through Francis units. Nationally, the distribution of plant factors was:

$\begin{array}{lll}\text { Total MW } & \frac{<0.33}{13,580} & \frac{0.33-0.66}{43,30610,707} \geq 0.66 \\ \text { Total } \mathrm{m}^{3} / \mathrm{s} & 37,041 & 137,32347,311\end{array}$

Most of the generating capacity and design flow through plants with plant factors less than 0.33 was through Francis units:

$\begin{array}{lcccc} & \text { Axial } & \text { Francis } & \text { Pelton } & \text { Ossberger } \\ \text { Total MW } & 2,852 & 10,150 & \frac{564}{15} & 106 \\ \text { Total } \mathrm{m}^{3} / \mathrm{s} & 15,394 & 21,353 & 188 & 106\end{array}$

In the Southeast and Ohio Valley states, low plant factors were associated with a tendency toward larger turbines (Table 3.15). In the Southeast, 53\% of the turbines with low plant factors were larger than $6 \mathrm{~m}$ in diameter, in the Ohio Valley, $68 \%$. This is consistent with a peaking mode of operation that would discharge large volumes of water in a short period of time. Most turbines with plant factors of 0.33 to 0.66 were 2 to $6 \mathrm{~m}$ in diameter.

\begin{tabular}{|c|c|c|c|c|}
\hline \multirow{3}{*}{$\begin{array}{c}\text { Diameter } \\
(\mathrm{m})\end{array}$} & \multicolumn{2}{|c|}{ Number of Turbines in Southeast } & \multicolumn{2}{c|}{ Number of Turbines in Ohio Valley States } \\
\cline { 2 - 5 } & \multicolumn{2}{|c|}{ Plant Factor (kWh produced /(plant capacity $\times$ hours per year)) } \\
\cline { 2 - 6 } & $0-0.33$ & $0.34-0.66$ & $0-0.33$ & $0.34-0.66$ \\
\hline $2-4$ & 8 & 28 & 2 & 2 \\
$4-6$ & 18 & 69 & 4 & 18 \\
$>6$ & 38 & 62 & 4 & 13 \\
\hline
\end{tabular}

Table 3.15 Turbines in Southeast and Ohio Valley States Sorted by Diameter and Plant Factor 


\subsection{SUMMARY OF TASK 1 FINDINGS}

Most hydroelectric generating capacity in the United States is in low and medium head Francis units, but most flow (and therefore possibly fish) passes through low head Axial units. Low head Francis accounted for 23 percent of the installed design discharge. Because most early hydropower development was in the East, there are more low head Francis units in the eastern and central states than there are in western states.

The fish passage issue has been the impetus for studies dealing with anadromous salmon species on the West Coast, anadromous Atlantic salmon and American shad on the East Coast, and freshwater resident species in the Upper Midwest and other inland sites. Low head Axial units typify turbines associated with Pacific salmon in California, Oregon, Washington and Idaho. Francis units at low and medium head are also important on the East Coast and Upper Midwest. There is a nearly even size distribution of turbines in the Pacific Northwest. Size categories of less than $2 \mathrm{~m}, 2$ to $4 \mathrm{~m}$ and greater than $6 \mathrm{~m}$ each account for 27 to 29 percent of the number of turbines. Turbines tend to be smaller in the Upper Midwest. Most (55 percent) of those turbines have diameters of 2 to $4 \mathrm{~m}$, and 23 percent are smaller than $2 \mathrm{~m}$.

Low levels of dissolved oxygen in hydropower discharges are most common the Southeast and Ohio Valley states. Probabilities of low DO episodes for the Great Plains and Northeast are less than half of that for the Ohio Valley and Southeast, but are still considered significant. Low DO occurs less frequently in the Great Plains, Pacific Coast, and Rocky Mountains. Low head Axial units accounted for 48 percent of the installed design discharge in the Southeast: very low head Axials, 19 percent; and low head Francis units 22 percent. In the Ohio Valley, low head Axials accounted for 31 percent of the installed design discharge; very low head Axials, 23 percent; and low head Francis units 32 percent.

TVA demonstrated that minimum flow and dissolved oxygen problems are most common at projects with plant factors below 0.35 . About 80 percent of the capacity and $2 / 3$ of the flow through projects with low plant factor is through Francis units. In the Southeast, $53 \%$ of the turbines with low plant factors were larger than $6 \mathrm{~m}$ in diameter, in the Ohio Valley, $68 \%$. This is consistent with a peaking mode of operation that would discharge large volumes of water in a short period of time. Most turbines with plant factors of 0.33 to 0.66 were 2 to $6 \mathrm{~m}$ in diameter.

Based on interaction with the Technical Committee, these issues were selected for further study and for development of design concepts for environmental compatibility enhancement. The three concepts were:

1. Large Axial turbines characteristic of those on the Columbia River in the Pacific Northwest where fish passage survival is the dominant issue.

2. Medium size Francis turbines characteristic of the Upper Midwest and Atlantic coast where fish passage survival is of dominant interest.

3. Medium to large size Francis turbines in Southeast and Ohio when low D.O. in turbine discharges in summer months is of dominant interest. 


\subsection{REFERENCES}

Cada, Glenn F., K.D. Kumar, Jean A: Solomon, and Stephen G. Hildebrand. 1983. An Analysis of Dissolved Oxygen Concentrations in Tail Waters of Hydroelectric Dams and the Implications for Small-Scale Hydropower Development. Water Resources Research, Vol. 19, No. 4, pp. 10431048, August

Cada, Glenn F., K.D. Kumar, Jean A. Solomon, and Stephen G. Hildebrand. 1981. An Analysis of Environmental Issues Related to Small-Scale Hydroelectric Development, VI, Dissolved Oxygen Concentrations Below Operating Dams. Report ORNLTM-7.887, Oak Ridge National Laboratory, Oak Ridge, Tennessee,

Eicher and Associates. 1987. Turbine-related Fish Mortality: Review and Evaluation of Studies. Research Project 2694-4. Prepared for the Electric Power Research Institute, Palo Alto, California.

Environmental Protection Agency (EPA). 1989. Dam Water Quality Study. EPA Report to Congress, EPA 506/2-89/002, Office of Water Regulations and Standards, Washington, D.C.

Electric Power Research Institute (EPRI). 1990. Assessment and Guide for Meeting Dissolved Oxygen Water Quality Standards for Hydroelectric Plant Discharges," EPRI GS-7001, Final Report, Project 2694-8, Palo Alto, California.

Federal Energy Regulatory Commission (FERC). 1992. Hydroelectric power resources of the United States, developed and undeveloped. page XI. Federal Energy Regulatory Commission, Washington, DC

Kennedy, R.H., and R.F. Gauges, 1987. Assessment of Water Quality Enhancement Needs for Corps of Engineers Reservoirs. North American Lake and Reservoir Management, Vol. 4, No. 2, pp. 253260,

Rune, J.R., and GE Hawser. 1991. "Factors Affecting Dissolved Oxygen in Hydropower Reservoirs," Proceedings, Waterpower '91, ASCE, pp. 226-235.

Stone \& Webster Environmental Services. 1992. Fish Entrainment and Turbine Mortality Review and Guidelines. Prepared for the Electric Power Research Institute, Palo Alto, California.

Tennessee Valley Authority (TVA). 1990. Tennessee River and Reservoir system Operation and Planning Review. Report TVA/RDG/EQS-91/1. Norris, Tennessee. 


\subsection{TASK 2 REPORT -- BIOLOGICAL ISSUES \& TURBINE DESIGN AND OPERATIONAL CONSIDERATIONS}




\subsection{TASK 2 REPORT -- BIOLOGICAL ISSUES \& TURBINE DESIGN AND OPERATIONAL CONSIDERATIONS}

\subsection{INTRODUCTION}

Fish traveling downstream encounter three major exit routes at hydro dams: turbines, spillways/sluices, or bypasses. A successful passage through any of these routes is of importance, particularly for emigrating juveniles of migratory fish, for maintenance and enhancement of adult populations. Fish passage through sluices, spillways, and bypasses generally has been considered a benign process; survival rates have been assumed to be $98 \%$ in the Pacific Northwest (EPRI 1992). A survival rate of 85 to $89 \%$ in passage through Kaplan type turbines has been generally assumed for juvenile salmonids in the Pacific Northwest (EPRI 1992). However, turbine passage survival rates have been reported to be as low as $18 \%$ for young clupeids in passage through Kaplan type turbines (Taylor and Kynard 1985). It is not clear, however, whether the reported survival rates represent immediate (direct) effects of turbine passage or include the indirect effects as well. Thus, it is imperative that results of studies that may be useable for developing biological criteria for turbine design modifications be separated for identification of important biological issues. Where information is lacking from field studies laboratory data may be gleaned to increase our understanding of threshold values of factors that affect injury/mortality rates. Mathur et al. (1996a) have suggested that quantification of direct effects of passage has practical importance in improving turbine design, as they-reflect the effects embodied in turbine geometries and hydraulics. As an example, the turbine replacement program (design, model testing, and installation of structural modifications) undertaken by the Public Utility District No. 1 of Chelan County at Rocky Reach Dam on the Columbia River to improve fish passage survival through the new turbines, utilized the data on direct effects (RMC 1994a; RMC and Skalski 1994a,b). These data guided a design effort to improve fish passage survival for a turbine rehabilitation project. The modified design included elimination of the gaps between the hub and leading edge of the runner blades, an area which was believed to inflict higher rate of injury/mortality to entrained fish.

This section provides (1) a brief review of historical literature with some statistical analysis of those data, detailed reviews have been provided elsewhere (Bell 1981; Monten 1985; Eicher Associates 1987; EPRI 1992); (2) a summary of some of the most recent data on fish survival as a function of physical and hydraulic characteristics of turbines, operating efficiency, and fish size; (3) a review of sources of injury/mortality in passage through Kaplan, propeller (fixed blade tilt), and Francis turbines; (4) the development of new leading blade edge strike prediction method; (5) a description of mechanisms of fish injury due to mechanical, fluid induced, and pressure reduction; and (6) in-depth analysis of controlled experiments conducted recentiy at large turbine in the Pacific northwest. Most of our emphasis is placed on the above types of turbines (Figures 10.2-1 through 10.2-6) because some recent studies provide reliable estimates of direct effects of turbine passage and also these turbines are dominant in the United States (see Section 3.0). However, to provide a benchmark for survival through turbines, available data from sluices, bypasses, or spillways are also presented. The latter structures, though devoid of moving parts, may expose fish to similar type of fluid-induced risks, thus provide some idea on quantification of their effects on fish survivability.

The ultimate objectives of summarizing the available data are to (1) identify turbine characteristics that enhance survival so that biological criteria can be incorporated into a new turbine design; (2) evaluate the importance of factors that affect survival; (3) provide fish survivability in passage through other exit routes without moving parts such as spillways and sluices; (4) provide some perspective on the magnitude of improvement in survival that can be achieved given the observed survival rates; (5) discern avenues wherein the turbine environment improvements should or could be made, and (6) point out significant data deficiencies and need for conducting controlled experiments with the objective of enhancing the application of the Advanced Hydropower Turbine System Program. 


\subsection{GENERAL REVIEW}

\section{Summary}

Historical studies primarily focused on juvenile salmonids of limited size range. However, in recent years turbine passage survivability of other species has also been reported allowing for examination of species differences. Most studies did not provide turbine operating data and where exactly within the turbine test fish were released. Many prevailing hypotheses and "rules of thumb" relative to turbine fish passage were developed based on system configuration and operating conditions that are vastly different from those of the present and thus may not be applicable at many sites. There is a need to test some of the hypotheses over a range of operating conditions with fish introductions at multiple locations in a turbine to improve the knowledge on injury mechanisms and their relationship to biological factors so that it can be incorporated into the advanced turbine design.

\section{Discussion}

Several reviews of turbine passage survival (Ruggles 1980; Bell 1981; Turbak et al. 1981; Monten 1985; Eicher Associates 1987; Ruggles and Paimeter 1989; Cada 1990; Ruggles et ai. 1990; EPRI 1992) indicated that most efforts on estimating turbine passage survival were initially focused on Pacific salmonids (e.g., steelhead trout, coho salmon, chinook salmon). However, in recent years survival rates of other species (e.g., resident fish, clupeids such as American shad, river herrings, and Atlantic saimon) have also appeared, primarily as a result of relicensing of hydro dams and interest in restoration and enhancement of migratory fish on the East Coast. These data provide a perspective on fish species/sizerelated interaction with a turbine type. This perspective is important from the standpoint of developing design features for an advanced hydro turbine to protect the greatest number of species encompassing wide size ranges.

Eicher Associates (1987) concluded that despite decades of research on salmonids, much uncertainty remained in estimating turbine passage survival. A variety of factors may cause this uncertainty; namely, the variability and lack of details relating to the design of turbine, wicket gate setting, head, species, size of fish, trajectory of entrained fish, rotational speed of runner blades, runner blade angle, number of blades, discharge, etc. These factors in combination with uncertainties associated with the prevailing tagrecapture methodologies used to estimate survival have made results of some early studies difficult to interpret. Eicher Associates (1987) also concluded that there was no turbine operating mode or design that can result in fish survival of greater than $90 \%$. Some recent studies, however, have reported survival higher than 95\% (Heisey et al. 1992, 1995, 1996; RMC 1994c,d; Mathur et al. 1994; Normandeau Associates 1996a,b).

In general, survival of fish was and still is deemed higher in passage through Kaplan type turbines than through Francis type turbines (Eicher Associates 1987; EPRI 1992). The survival was also hypothesized to be higher when turbines operate at maximum efficiency (Bell 1981). As a consequence, many large Kaplan turbines on the Columbia River Basin are operated within $1 \%$ of maximum efficiency for the head. However, a statistical analysis of the data presented in Bell (1981) was recently performed by Dr. John R. Skalski, Professor of Biostatistics at University of Washington, to evaluate the effects of turbine efficiency, wicket gate openings, fish length, specific speed, and head on passage survival. His analysis showed that the survival was more a function of percent wicket gate opening, fish length, and runner blade speed. How.zver, the latter three variables explained only about $40 \%$ of the variation in survival. No single variable was significantly correlated to fish survival. While the effects of peak turbine efficiency on survival were not statistically correlated in this analysis, subsequent analysis of recent data from Wanapum Dam on the Columbia River show that the point of turbine operation can have significant 
influence on fish survival (Fisher et al. 1997). Higher survival coincided with turbine discharges greater than the discharges in the range of $1 \%$ efficiency below peak efficiency.

These reviews indicated the same factors that were considered as the underlying sources of variability are also deemed critical factors in affecting fish survival. These include: turbine type, fish size, trajectory of entrained fish relative to flow streams, clearance between structural components (i.e., spacing between runner blades or buckets, wicket gates, and turbine housing), number of runner blades or buckets, runner blade speed, flow, and angle of water flow through turbines (Bell 1981; Eicher Associates 1987). A mathematical equation, attributed to Von Raben (Bell 1981; Ruggles and Palmeter 1989; Cada 1990), has been developed for axial flow turbines incorporating some of the above variables to predict the probability of contact with runner blades or buckets. However, the equation tends to underestimate turbine passage survival when compared to site test estimates (Bell 1981; Ruggles and Palmeter 1989; RMC 1994b). It should be noted, however, that fish mortality depending upon the site may occur from other sources as well. The equation predicts only the strike probability, which has been used to estimate potential fish mortality in some investigations. In one study, the mathematical equation predicted fish survival rates that were 3.7 to $13.9 \%$ lower than through testing (RMC 1994b). All observed fish mortality at this low head project ( $6 \mathrm{~m}$ or $21 \mathrm{ft}$ ) was attributed to blade strikes. The existing equation has been modified by our team to improve predictability (see Section 4.3 ).

It should be emphasized that many earlier hypotheses have not been widely tested over a range of operating conditions with spatially distributed fish introduction locations within turbines, particularly using newer mark-recapture techniques (balloon tag, Passive Integrated Transponder (PIT) tag, radio tags, etc.). Also, most of the earlier survival estimates, particularly in the Pacific northwest, were derived under system configurations and operational conditions that were significantly different from those presently used. For example, estimates of survival of fish entering different intake bays and depths at differing turbine operating efficiencies had been largely lacking. Similarly, the effects of turbine intake screens on unguided entrained fish were not well defined. Most of the earlier studies had involved fish releases at a single depth within an intake bay when the turbine was operating over a narrow range of operating conditions or in the absence of intake screens. Even now, many experiments are limited to tests over a narrow range of operating conditions and only to obtain estimates of survival within pre-specified variation. Experiments to determine the actual path an entrained fish traverses for quantification of the mechanisms of injury/mortality are lacking. Thus, there are large gaps in our knowledge of which factors affect fish survival in passage through turbines. It may be further compounded at many sites by the observed high survival rates, leaving little room for significant improvements.

The discussion presented in this Task 2 will address the information gaps and attempt to shed more light on the causes of fish mortality. Only through recognition of the causes can design and operational methods be changed to improve fish passage survival at hydro plants. 


\subsubsection{COMPILATION OF SURVIVAL. DATA}

\section{Summary}

Available fish survival and injury data were assembled and sorted by turbine type [axia: flow-(Kaplan and propeller) and Francis], head, turbine operating status, depth of entrainment, fish size, tag-recapture methodology, recapture rates, etc. for examining trends and evaluation of variables in affecting survival. Although many of the literature data were collected to obtain only point estimates of passage survival, available information provided some general trends which can be utilized for turbine enhancement. These were: species per se is not important, larger sized fish $(>200 \mathrm{~mm})$ suffer greater mortality in passage through smaller turbines (as indexed by runner diameter ( $<2.5 \mathrm{~m}$ or $100 \mathrm{in})$, runner speed (>100 rpm), lower discharge $(<71 \mathrm{cms}$ or $2,500 \mathrm{cfs}$ ), and when wicket gate settings are narrow. The survival of smaller sized fish $(<200 \mathrm{~mm})$ are affected less by the above parameters. However, detailed experiments, conducted specifically to modify turbine design, showed that the survival of small sized fish ( $<200 \mathrm{~mm}$ ) varied between sites having similar type turbines, entrainment depth, turbine operating status, and presence or absence of fish guidance screens or protective devices. The assembled data provided a basis for further analysis and data needs for turbine design modifications.

\section{Discussion}

The available data were separated by turbine types because earlier reviews had indicated that differences in survival may be due to whether the tested turbine was Francis or axial flow type (Kaplan and propeller). Additional information extracted from each study included the following: site name and location; turbine characteristics; head; species/size; estimation of direct effects (use of full discharge netting, radio telemetry, balloon tags) versus total effects (PIT tags, coded wire tags, branding, etc.); tag-recapture methodology; sample size employed; turbine operating conditions; recapture rate; control survival rate; statement of assumptions and tests for their validity; and precision of survival estimates. All data listings and projects at which survival was estimated are provided in Appendix Section 10.1.

Studied axial flow turbines had 3 to 7 runner blades, runner blade speeds of 75 to $241 \mathrm{rpm}$, runner diameters of 1.8 to $7.9 \mathrm{~m}$ ( 69 to 312 inches), heads ranging from 5 to $30 \mathrm{~m}$ ( 16 to $98 \mathrm{ft}$ ), discharges of 6 to $600 \mathrm{cms}$ (200 to $21,000 \mathrm{cfs}$ ), and operated in efficient or inefficient mode. The latter designation is that of the dam operator at the time each study was conducted.

The Francis turbines had 12 to 19 buckets; single, double, or quad runners with runner blade speed of 72 to $510 \mathrm{rpm}$; head 4 to $120 \mathrm{~m}$ ( 13 to $387 \mathrm{ft}$ ); and discharge of 8 to $200 \mathrm{cms}$ ( 275 to $7,000 \mathrm{cfs}$ ). Relative to the axial flow turbines, Francis turbines were generally smaller, with lower discharges and higher runner speeds.

Species tested include some of the most sensitive ones such as the juvenile clupeids (e.g., American shad, slueback herring) to the more hardier ones like the salmon, sunfish, and catfish. However, most emphasis has been on juvenile salmonid survival.

The dataset includes three basic fish body forms: generally cylindrical (e.g., salmon, most clupeids, cattish, sucker), compressed (e.g., bluegill), and ribbon-like (eels). Fish size ranged from about 55 to 881 $\mathrm{mm}$; most data is for fish less than $200 \mathrm{~mm}$ because they are more likely to be entrained (EPRI 1992). Consequently, perhaps, data on survival of larger sized adult fish are limited. The results reviewed by Eicher Associates (1987) pertain mostly to salmonids while those given in EPRI (1992) show a greater diversity of species/size. 


\subsubsection{COMPONENTS OF MORTALITY}

\section{Summary}

Definitions of the two primary components of fish passage mortality are given so that relevant information for turbine design modifications can be extracted from the available data or from any future planned experiments. In most cases the literature data do not provide a clear separation between the direct and indirect effects. Quantification of direct effects is deemed important from the standpoint of turbine design modifications.

\section{Discussion}

There are two primary components of total mortality of fish entrained in hydro turbines or other passage routes: direct and indirect effects. The direct effects (e.g., mechanically-induced, pressure, cavitation, or shear-related) are manifested immediately after passage as instantaneous mortality, injury, and loss of equilibrium; the indirect effects (e.g., predation, disease, physiological stress, etc.) may occur over an extended period and distance individually or synergistically. The direct effects are easier to quantify and isolate than those due to indirect sources. Tables $4.2-1,4.2-2$, and $4.2-4$ provide fish survival data based on estimating direct effects while Table 4.2-3 shows data depicting effects of both direct and indirect sources. The latter studies cover exclusively large hydro dams in the Pacific Northwest. 


\subsubsection{POTENTIAL SOURCES OF INJURYIMORTALITY}

\section{Summary}

The risks encountered by turbine entrained fish are defined (e.g., mechanical, shear-turbulence, pressure, and cavitation) and the difficulty of quantifying each risk is explained, particularly in light of intake modifications (installation of fish guidance screens, surface bypass collection system, etc.) at several hydro plants. These modifications alter the turbine hydraulics resulting in deflection of unguided fish to areas through which fish may not have been transported if modifications had not been made. This points out the need for considering turbine design modifications separately for turbines equipped with intake fish guidance screens and those without them.

\section{Discussion}

Entrained fish face three primary risks associated with turbine environment:

\section{Mechanical mechanisms:}

Fluid mechanisms:

Pressure: forces on fish body resulting from direct contact with turbine structural components such as rotating runner blades, wicket gates, stay vanes, discharge ring, draft tube, passage through gaps between the blades and the hub or at the distal end of blades, and other structures inserted into the water passageway (e.g., trash racks, intake fish guidance screens, etc.). The probability of mechanical contact depends on the distances between blades, number of blades, and fish length;

Shear-turbulence - the effect on fish of encountering hydraulic forces due to rapidly changing water velocities; forces on fish body resulting from strong velocity gradients relative to fish length are significant.

Cavitation - injury resulting from forces on fish body due to vapor pockets imploding near fish tissue. Under certain hydraulic conditions implosions can cause formation of velocity jets, high levels of turbulence, and high pressure shock waves. It has been assumed that if these implosions can erode metal they could damage fish tissue as well.

The probability of a fish encountering these fluid mechanisms also depends to a large extent on the distances between blades, number of blades, and fish length.

injuries resulting from the inability of fish to adjust from the regions of high pressure immediately upstream of the turbine to regions of $\mathrm{cW}$ pressure downstream of the turbine; the pressure change in the turbine environment itself may not be of sufficient magnitude and duration to be significant.

The above risks are related to details of the turbine, plant design, and operation as well as to the location of fish in the water column. These risks, however, are not universally applicable to all species and their life stages at all turbines; only a small proportion of the entrained fish population may be exposed to any of these risks at a site (Heisey et al. 1992; RMC 1994b,c,d,e; RMC and Skalski 1994a,b; RMC et al. 1994). Unless an individual fish is physically retrieved immediately after passage and/or somehow visually observed during its passage through a turbine, it is difficult to quantify these risks when evaluating at the level of fish size relative to the magnitude of the above forces. Thus, only probable causal sources of injury, mortality can be attributed. Also, if a fish suffers multiple injuries it may be difficult to pinpoint the 
causative factor. Although fish recaptured after exiting turbines have shown manifestations of injury/mortality suspected to be due to mechanical, pressure, or shear forces such categorizations were not based on direct observations (Eicher Associates 1987).

\subsubsection{Effect of Intake Modifications}

\section{Summary}

Turbine intake modifications such as installation of fish guidance screens can alter hydraulic conditions such that entrained fish may encounter areas of higher mortality. The survival of unguided fish could vary with the magnitude of alteration in the intake hydraulics. The redistribution, deflection, and acceleration of intake flows toward the bottom may transport unguided fish near the blade tips potentially resulting in lower survival. The Advanced Hydropower Turbine System design needs to account for the presence of intake structural modifications.

\section{Discussion}

Turbine passage survival can be influenced by turbine geometries and the point of operation, but can also be significantly altered by installation of new structures in the waterway. As an example, extended length fish guidance screens (Figure 4.2-1) installed at intakes to exclude fish from entering turbines may drastically alter hydraulic conditions such that entrained fish may encounter areas of higher mortality (Turner et al. 1993). The screening devices may also result in non-uniform distribution of intake flow, formation of eddies, and turbulence in some areas (Turner et al. 1993). Figure 4.2-2 shows a schematic of modeled velocity distribution within a turbine intake with and without an extended length screen. Intake screens cause acceleration of velocities downward. The redistribution and acceleration of flow may increase the level, incidence, and effect shear has on unguided fish passing through the turbine. Thus, the potential effect on survival of unguided fish could vary by the magnitude of alteration in the intake hydraulics. An effect of installing intake screens is a head loss which in turn can alter the hydraulics of hydro turbines.

The redistribution, deflection, and acceleration of intake flows toward the bottom of the intake may also transport unguided fish near the blade tips. Although the actual effects are not yet fully understood it has been hypothesized that fish may suffer different mechanically-induced mortality in passage near the blade tips or hub than at the mid region of the blade (Ferguson 1993, Fisher et al. 1997). Survival of fish entering different depths within a turbine operating at various efficiencies is largely unknown. However, a few recent studies shed more light on this issue, specifically, studies at Wanapum and Rocky Reach Dams on the Columbia River have provided impetus for turbine design improvements (RMC 1994b; RMC and Skalski 1994a,b, 1996; Ledgenwood et al. 1990; Normandeau Associates et al. 1995, 1996a; Fisher et al. 1997). 


\subsubsection{QUANTIFICATION OF PROBABLE CAUSES OF INJURY/MORTALITY}

\section{Summary}

Quantification of exact sources of injury/mortality on fish transported through turbines is difficult in the field due to a lack of controlled experiments and that the observed symptoms could be manifested by two different sources. However, some mechanically-related injuries, as evident by sliced bodies and pinched bodies, may be quantified with greater certainty. Results from most studies indicate that mechanically related injuries are a dominant source of mortality, particularly for fish transported near the hub where gaps exist (Kaplan adjustable blades). Pressure-related injuries appear to be more a function of acclimation history of fish upstream of turbine than passage through turbines per se. At dams (>30 $\mathrm{m}$ or $100 \mathrm{ft}$ head), without hydro turbines, fish transported through bottom sluices or openings suffer decompression trauma (as evident by rupture of air bladder and other internal organs) when rapidly exposed to shallow tailrace conditions. Though evidence of injuries due to fluid shear forces exist, relative to other sources, it is not a dominant source of fish injury/mortality in passage through turbines.

\section{Discussion}

A lack of controlled experiments to replicate and correlate each injury type/characteristic to a specific causative mechanism (in combination with the meager knowledge of the actual path fish traverse within a turbine) precludes definitive classification of observed injuries in the field. Literature suggests that observed injury symptoms could be manifested by two different sources and accurate delineation of a cause and effect relationship may be difficult (Eicher Associates 1987). Consequently, only probable causal mechanisms of injury can be assigned. However, some mechanically related injuries (e.g., sliced or pinched bodies) may be assigned with greater certainty (Figure 4.2-3). Injuries likely associated with direct contact with turbine runner blades or impacting structural components are classified as mechanical and include: bruises/hemorrhaging, lacerations, and severed/sliced body (Dadswell et al. 1986; Eicher Associates 1987; RMC and Skalski 1994a,b). Injuries likely attributed to fluid shear forces are decapitation (with the isthmus attached to the body and a slanted wound), torn or flared opercula, and inverted or broken gill arches (Dadswell et al. 1986). The effects of pressure changes are manifested as bloody eyes, popped eyes, air bladder rupture, and embolism (Figure 4.2-4).

In general, turbine-passage experiments conducted in the Pacific Northwest have provided most of the empirical field evidence (Oligher and Donaldson 1966; RMC 1994a; RMC and Skalski 1994a,b; RMC et al. 1994; Normandeau Associates et al. 1995; 1996a; Normandeau Associates and Skalski 1996) of probable sources of injury while laboratory experiments (Muir 1959; Lucas 1962; Harvey 1963; Groves 1972; Feathers and Knable 1983; Turnpenny et al. 1992) have provided data on effects of individual factors such as pressure changes, cavitation, velocity, shear, turbulence, etc. Some of the former experiments were conducted over a narrow range of turbine operation efficiencies, entrainment depths, head, fish size, etc. and could only speculate where in the turbine environment the observed injuries may have been inflicted.

\subsubsection{Mechanical Related Injuries}

\section{Summary}

Direct contact with the turbine runner blades and passage through the gaps between the blades and hub are prime suspect areas of mechanical fish damage. Injury rates increase with fish size. However, the rate of mechanical related injury can also vary with the fish entrainment depth, turbine operating status, and whether the intakes are equipped with fish guidance screens. Mechanical related causes have been reported as dominant cause of fish mortality at low head ( $<30 \mathrm{~m}$ or $100 \mathrm{ft}$ ) projects. 


\section{Discussion}

Mechanically related injuries have been posited as a major source of fish mortality in field investigations. Oligher and Donaldson (1966) conducted a series of relatively controlled experiments to evaluate the effects of turbine operating efficiency, head, and runner blade angles on fish survival at Big Cliff Dam and provided some early empirical evidence of probable sources of injury/mortality. Data presented by these authors for the 1966 experiments showed that about 70 to $93 \%$ of the injuries (based on number of recaptured injured fish) were due to probable mechanical causes and less than $2 \%$ due to probable pressure related causes. In the 1964 experiments by Oligher and Donaldson (1996) probable pressurerelated injuries accounted for 9 to $16 \%$ while mechanically related causes accounted for 77 to $84 \%$. The relative importance of pressure related injuries as a function of head ( 22 to $28 \mathrm{~m}$ or 71 to $91 \mathrm{ft}$ ) or blade angles could not be observed.

Turbine configuration can influence the rate of mechanically related injuries. RMC (1994a) noted a predominance of probable mechanically related injuries $(4.4 \%$ as indicated by severed body, bruises/hemorrhaging) on chinook salmon smolts in passage through Unit 7 (adjustable blade Kaplan) of Rocky Reach Dam. In contrast, only 1.3\%, though nonsignificant, of fish showed similar injury types in passage through Unit 8 (fixed blade). At Unit 3 (adjustable blade Kaplan), mechanically induced injuries were observed on $5.7 \%$ of recaptured fish after passage at $3 \mathrm{~m}$ (10 fit) depth; at $9 \mathrm{~m}(30 \mathrm{ft})$ depth injury rate was estimated at $4.1 \%$ (RMC 1994a). It was concluded that the higher injury rate, though nonsignificant, on fish entrained at $3 \mathrm{~m}$ (10 ft) depth of Units 3 and 7 was most likely due to passage through the gaps between the runner blades and the hub; Unit 8 is a fixed blade turbine and gaps are absent. At Wilder Dam on the Connecticut River, RMC (1994c) reported that 3.2\% of recaptured Atlantic salmon smolts had severed bodies and on additional $1.6 \%$ showed external bruises/hemorrhaging and internal hemorrhaging.

Injury types and rates can differ between entrainment depth, turbine operating status, and whether the intake is equipped with fish guidance screens. At Lower Granite Dam turbine Unit 4 injuries on recaptured/injured chinook salmon smolts introduced at the depth of standard length screens, with the turbine operating at normal efficiency, were attributed to probable sources as follows: $67 \%$ mechanical (Figure 4.2-3), 21\% shear and pressure (Figure 4.2-4), and the remainder to multiple causes (RMC et al. 1994). In a 1995 study at the same turbine the overall injury distribution for chinook smolts introduced about $3 \mathrm{~m}$ deeper (at the depth of extended length screens) than in 1994 was as follows: $50 \%$ mechanical, $18.8 \%$ pressure, $14.1 \%$ to shear, and remainder to multiple causes. Fish introduced at upper elevation (about $3 \mathrm{~m}$ below the intake ceiling) appeared to suffer greater rate of mechanical injuries $(70.6 \%)$ than at greater depths $(<45 \%)$; the difference in mechanically-related injury rate was attributed to the presence of gaps between the runner blades and the hub through which the upper released fish were transported (Normandeau Associates et al. 1995). Gap related injuries were characterized by pinching types (Figure 4.2-3). At Wanapum Dam, probable mechanically related injuries were also common (43\%) on injured coho salmon smolts; pressure related injuries accounted for $23 \%$, and shear $10 \%$; the remainder to multiple causes (Normandeau Associates et al. 1996c). Only 30 of the 1,202 turbine passed, recaptured fish were injured and a shift of one or two fish into any injury category can make substantial changes in the indicated percentages. As mentioned earlier, a lack of controlled experiments precludes definitive assignments of exact source of injury mechanism.

\subsubsection{Pressure Related Injuries}

\section{Summary}

Fish are more sensitive to exposure to sudden pressure reduction than an increase in pressure. However, the magnitude of pressure change and fish acclimation history are important factors. Fish with a pneumatic duct (physostomes) attached to air bladders are able to adjust to pressure changes quicker than those without the duct (physoclist). Physostomes can vent excess gas quicker, but if access to free 
air is not available, they will not be able to adjust to increasing pressures except through the gas gland. Laboratory studies have shown variable effects of pressure reduction and most studies did not simulate pressure regimes that fish encounter in the field. Thus, a blanket application of these results to the design of a turbine may be risky; the effects of pressure reduction are related to the difference in pressure between the acclimation depth (a function of head) and duration of time and the pressure at the exposure depth. A true acclimation history of fish and the time it takes to become fully acclimated to a depth are unknown. Recent studies at low head projects ( $<30 \mathrm{~m}$ or $100 \mathrm{ft}$ ) have shown only a secondary importance of pressure-related damage. However, at higher head dams whether equipped with hydro turbines or not, exposure to pressure reduction is a significant source of fish mortality; at projects with head less than 18 $\mathrm{m}(60 \mathrm{ft})$ probable pressure-related injuries have not been observed. Also, even relatively shallow intakes ( $<9 \mathrm{~m}$ or $30 \mathrm{ft}$ ) leading into long pipes or penstocks ( $>303 \mathrm{~m}$ or $1,000 \mathrm{ft}$ ) at high head projects (generally discharge $<23 \mathrm{cms}$ or $800 \mathrm{cfs}$ ) pose significant risk of fish mortality because of low relative velocities allowing time for entrained fish to become acclimated to deeper depth prior to passage through the turbines. The proportional contribution of pressure-related injuries to the total fish mortality may increase at large turbine intakes equipped with fish guidance screens compared to those without them (Normandeau Associates et al. 1995).

\section{Discussion}

Fish are more tolerant of increases in pressure than sudden reduction in pressure. The latter is of more relevance to fish passage at hydro dams. Fish are more tolerant of gradual reduction in pressure than to sudden exposures. In this section pressure is expressed as pound per inch (psi) in the English system and as pascal $(\mathrm{Pa})$ in the International (SI) System.(Cada et al. 1997). One pascal equals one $\mathrm{N} / \mathrm{m}^{2}$; water pressure at one atmosphere equals 101.3 (kilo pascal or $\mathrm{kPa}$ ) or $14.7 \mathrm{psi}$.

The laboratory-derived relationship between fish acclimation pressure and subsequent rapid exposure to pressure reductions may not adequately simulate fish responses within the turbine environment of concern (e.g., exposure to limited or small area of low pressure on the lower side of runner blades). The results from laboratory-derived data need to be carefully applied to the turbine rehabilitation program. In addition, some field tests may prove more instructive in determining the tolerance of fish to pressure regime experienced in lakes or reservoirs; these studies are described below. Little guidance exists to estimate the time needed to acclimate fish to a given pressure. In addition, Cada et al. (1997) have pointed out several shortcomings of some of the past laboratory experiments including poor documentation, inadequate or no controls, use of small numbers of fish, and measurement of fish responses to reduction in pressure only from atmospheric levels (101 kPa or $14.7 \mathrm{psi}$ ) to sub-atmosphere levels. The latter factor is, perhaps, of most relevance to hydroelectric turbines because fish are subjected to pressures higher than atmospheric levels prior to entering the turbine environment and then rapidly traversing a low pressure region on the downstream side of the runner blade and then finally becoming exposed tc near atmospheric levels in exiting the turbine draft tube. Thus, the eventual fate of entrained fish would be dictated by its previous acclimation history (depth and time) prior to entering the turbine and its end pressure in the tailrace rather than a split second passage through a zone of pressure differential at the runner blades. It is unlikely that this turbine passage time is sufficient for acclimation to changing pressures. At many sites surface-oriented fish have to sound to greater depths $(12$ to $20 \mathrm{~m}$ or 40 to $65 \mathrm{ft}$ ) to exit, such as bottom opening tainter gates at spillways in the Pacific Northwest, and are undoubtedly subjected to rapid pressure reductions presumably with little adverse effect; spill is routinely used to minimize fish passage through turbines. Also, fish intercepted by extended length screens from deeper depths and collected in gatewells or surface bypass structures have not shown adverse effects of pressure reductions.

The tolerance to pressure reduction appears to be dependent on whether a species is physostome or physoclist and their acclimation history (depth and time). Physostomous species (those having pneumatic 
duct, connecting air bladder to the esophagus, for venting air bladder gas) are more tolerant than physoclists (those without pneumatic duct). The presence of pneumatic duct allows the physostomous species (e.g., salmon, minnows, catfish, etc.) to rapidly take in or vent gases from the swim bladder (within seconds) through the mouth so that adjustment to changing water pressures can be made quickly. However, the time to reach full acclimation to a given depth is uncertain. In physoclists (e.g., basses, sunfish, perch, walleye, etc.) contents and pressures within the swim bladder must be adjusted by diffusion into the blood, a process taking hours (Cada et al. 1997).

Laboratory experiments by Harvey (1963) and Turnpenny et al. (1992) suggest that physostomes (primarily salmonids) can tolerate reductions in absolute pressures. When he rapidly exposed sockeye smolts presumably. acclimated at $2,064 \mathrm{kPa}$ (20.4 atmosphere or $300 \mathrm{psi}$ ) to atmospheric pressure, Harvey (1963) observed mortalities of less than $1 \%$ per week. Mortalities among the treatment groups were indistinguishable from those among the controls. Smolts acclimated to $350 \mathrm{kPa}$ (50 psi) for $24 \mathrm{~h}$ then rapidly returned to atmospheric conditions exhibited less than $0.5 \%$ mortality per week. Similarly, Tsvetkov et al. (1972), cited by Cada et al. (1997), reported resistance of two species of sturgeon to reduction in absolute pressure. These fish presumably acclimated to $608 \mathrm{kPa}$ (88 psi) and then rapidly exposed to decompression did not exhibit lethality. However, physoclists (primarily largemouth bass) when acclimated at 280 to $369 \mathrm{kPa}$ and rapidly exposed to $101 \mathrm{kPa}$ suffered significant mortalities (Feathers and Knable 1983). Muir (1959) rapidly decompressed (from 22 psi to vapor pressure) 20 coho salmon fingerlings ( $66 \mathrm{~mm}$ ) for $0.4 \mathrm{sec}$. A $60 \%$ mortality was observed which was attributed to the rapid high pressure shock waves associated with the collapse of the cavitation bubble. In another experiment 10 coho fingerlings were exposed for $1.6 \mathrm{sec}$. to similar decompression (from 22 psi to vapor pressure) no mortality was observed. Laboratory experiments by Turnpenny et al. (1992) indicated low mortality (0 to $10 \%$ ) with sudden pressure reductions of up to $90 \%$ exposure (from a pressure of $343 \mathrm{kPa}$ to $30 \mathrm{kPa}$ ); these low mortalities were supported by mathematical equations developed to predict pressure-related fish damage in a reference turbine. No external damage (e.g., popped eyes, hemorrhaging) was observed; a small proportion of fish (10\%), however, showed air bladder rupture. They attributed the high tolerance of tested species to the ability to rapidly vent gases from their swim bladders under decompression conditions. In contrast, physoclists (e.g., seabass) suffered a higher rate of air bladder rupture and mortality. Under sustained decompression conditions swim bladder rupture of physoclists occurred at about doubling of the swim bladder volume.

Field studies provide important perspective on fish tolerance to pressure reduction (differences in absolute pressure values from high to low) manifested through intake configuration and depth, acclimation depth/time, and transit time through penstocks. Studies at Bond Falls Station, Ml (head $64 \mathrm{~m}$ or $210 \mathrm{ft}$, discharge $11 \mathrm{cms}$ or $385 \mathrm{cfs}$ ) and McClure, MI (head $129 \mathrm{~m}$ or $425 \mathrm{ft}$, discharge $9 \mathrm{cms}$ or $309 \mathrm{cfs}$ ), each equipped with a 2 to $4 \mathrm{~km}$ ( 1.3 to $2.5 \mathrm{mi}$ ) long penstock showed that most fish suffered decompression trauma (as evidenced by ruptured or extruded air bladder, ruptured heart and kidney, and broken bones) upon exiting the turbines. The intakes for these plants are located in the upper water level (about 3 to $9 \mathrm{~m}$ or 10 to $30 \mathrm{ft}$, below reservoir surface) and lead into long sloping $3 \mathrm{~m}$ diameter pipes (penstocks) which may allow fish to gradually acclimate to deeper depths (absolute pressures exceeding 9 atmospheres or $142 \mathrm{psi}$ ); the estimated velocity through the pipes (penstocks) were less than $0.5 \mathrm{~m} / \mathrm{s}$ (1.5 ft/s), probably insufficient to move fish rapidly through the system (RMC 1993b, 1996).

At Berlin Lake in Ohio, walleye passing through bottom sluice gates (depth approximately $35 \mathrm{~m}$ or $115 \mathrm{ft}$ ) died of decompression trauma (air bladder rupture) while those passing over the tainter gates survived (Smith and Anderson 1984). Fish acclimated to higher pressure at greater depths suffered decompression trauma when discharged into shallow tailrace depths. Decompressed fish were more common during the winter months, perhaps walleyes moving to deeper waters to over-winter. Similar high levels of decompression-related fish mortalities (74\%) were observed in Allegheny Reservoir in the winter months. 
Fish migrating through bottom opening sluices (depth about $30 \mathrm{~m}$ or $100 \mathrm{ft}$ ) at Tygart Dam, West Virginia exhibited symptoms of decompression trauma when discharged into a stilling basin (depth $9 \mathrm{~m}$ or $30 \mathrm{ft}$; Jernezcic 1986). RMC (1992a) reported that a rapid exposure of fish acclimated to pressures of about $376.3 \mathrm{kPa}$ (54.6 psi) or in a long tunnel to pressures of $12.3 \mathrm{kPa}(1.8 \mathrm{psi})$ or in the tailrace, proved lethal in passage through wheel gates (without hydroelectric plant) at the Youghiogheny Dam, PA (operating head of about $36 \mathrm{~m}$ or $120 \mathrm{ft}$ ). The estimated mortality due to decompression trauma exceeded $90 \%$ for small fish ( $<100 \mathrm{~mm}$ ) and about $49 \%$ for large fish $(221-531 \mathrm{~mm})$. Most common fish depicting symptoms of decompression were physoclists such as walleye, alewife, crappies, and yellow perch. These fish had entered the long intake tunnel and became acclimated to deeper depth prior to being suddenly discharged into the shallow tailrace. Decompression trauma was most common in winter, presumably most fish moved deeper in the water column to over-winter or to follow the forage fish.

\subsubsection{Shear Related Injuries}

\section{Summary}

Effects of shear induced forces have been studied primarily under laboratory conditions which are not representative of internal hydraulic conditions of a turbine. However, these studies indicate that shear effects may be species and size specific and are related to the orientation of fish in the shear zone. Larger sized fish and those facing a water jet appear to suffer less injuries; water jet experiments involved velocities of 9 to $36 \mathrm{~m} / \mathrm{s}$ ( 30 to $120 \mathrm{ft} / \mathrm{s}$ ) with a velocity of $18 \mathrm{~m} / \mathrm{s}$ (58 ft/s) having little effect on fish.

\section{Discussion}

Effects of shear induced forces have been primarily studied under laboratory conditions (Groves 1972; Johnson 1972; Turnpenny et al. 1992) where fish were exposed to high velocity discharge in a static water tank rather than interaction between moving flows as encountered in a turbine. These studies indicate that shear effects may be dependent on species and size and related to the manner of contact rather than to a particular velocity difference. Johnson (1972) observed no mortality of juvenile coho salmon, chinook salmon, and steelhead when these fish were transported through a 102 to $152 \mathrm{~mm}$ (4 to 6 inches) submerged nozzle at velocity of about $18 \mathrm{~m} / \mathrm{s}$ (58 ft/s; Figure 4.2-5). The location of fish in the jet, orientation of fish as they exited the nozzle, and location where they exited the jet into the static water could not be controlled (Cada et al. 1997). Groves (1972) flushed juvenile coho, chinook, and steelhead into the water tank through an angled tube so that they would strike the jet within $76 \mathrm{~mm}$ ( 3 inches) of its emergence from the nozzle. Jet velocities ranged from 9 to $36 \mathrm{~m} / \mathrm{s}$ ( 30 to $120 \mathrm{ft} / \mathrm{s}$ ), however, actual shear forces and velocities experienced by fish relative to its length were not measured. He concluded that fish could be injured in any high energy flow situation that creates momentary localized points of sharp velocity change. Smaller salmon ( $<30 \mathrm{~mm}$ long) suffered greater injury and mortality rates than larger salmon (135 $\mathrm{mm}$ long), probably because of lesser tissue strength and exposure of a greater proportion of the body to initial contact with the water jet (Groves 1972). Greatest injuries occurred when the water jet contacted the head region and it was moving from the rear toward the head of the fish (Figure 4.2-6). Less injurious was when the fish faced into the jet. Turnpenny et al. (1992) noted that water velocities of up to $15 \mathrm{~m} / \mathrm{s}(50 \mathrm{ft} / \mathrm{s})$ and associated shear stresses caused little mortality in young clupeids and American eel while the salmonids suffered no mortality at velocities up to $9 \mathrm{~m} / \mathrm{s}$ ( $30 \mathrm{ft} / \mathrm{s}$ ); velocities of 15 $\mathrm{m} / \mathrm{s}(50 \mathrm{ft} / \mathrm{s})$ inflicted variable mortality rates. None of the studies considered the interrelationships of force, inertia, and shear relative to the fish size. Section 4.3 provides a detailed background of effects of shear forces for greater understanding so that better experiments can be run. 


\subsubsection{SCREENING CRITERIA FOR SELECTING SURVIVAL TESTS}

\section{Summary}

Although literature reviews and recent studies provide estimates of fish survivability, not all estimates are useful from the standpoint of understanding the mechanisms leading to the observed mortality so that the knowle:ge can be used for potential turbine design modifications; mechanistic types of studies are generally lacking. Most studies were not conducted with the objective of developing information for turbine modifications However, a careful review of the studies from the existing database was considered necessary to select those which may contribute to our understanding of fish reactions within turbines. Therefore, screening criteria which when applied in aggregate rather than only one parameter were developed to select studies to provide some insight into the mechanisms of turbine related mortality. These included: high recapture rates, low control mortality, acceptable tag-recapture methodology, description of injury types, direct or indirect effects, turbine operating status, turbine characteristics, and adequate sample size. Also, because reporting of survival estimates vary $(1 \mathrm{~h}, 24 \mathrm{~h}, 48 \mathrm{~h}, 72 \mathrm{~h}, 120 \mathrm{~h}$, etc.) only $1 \mathrm{~h}$ estimates were extracted to delineate the direct effects of turbine passage. This selection criteria is similar to that recommended recently by EPRI (1992) for conducting survival studies.

\section{Discussion}

Major obstacles to obtaining reliable survival estimates of fish in transport through a hydro turbine, particularly those with higher discharges ( $>60 \mathrm{cms}$ or $2,000 \mathrm{cfs}$ ), have been the inability of investigators to recapture a high proportion of released fish and to maximize control group survival (Heisey et al. 1992). Burnham et al. (1987) and Ruggles et al. (1990) indicated that the reliability of a survival estimate is enhanced when investigators can recapture a high proportion of fish after turbine passage, recapture rates of treatment and control fish are similar, and survival of control fish is high. Mathur et al. (1994) noted that reliability of survival estimates (direct passage effects) generally increases when fish recapture rates exceed $70 \%$. The superiority of high recapture of fish in release-recapture survival experiments in simplifying assumptions is well known (Burnham et al. 1987).

Although literature reviews contain numerous field estimates of fish survivability not all estimates can be considered useful from the standpoint of potential turbine design modifications. Most of the studies, particularly related to relicensing of hydroelectric projects in the 1990's, were not conducted with a specific objective of obtaining information usable for advanced turbine design development; in many cases the objective was simply to provide an estimate of fish survivability. Additionally, many studies suffered from a lack of standardized experimental protocols, lack of replication for estimating between turbine variability, poor documentation of results, low precision, lack of adequate controls or high control mortality $(>30 \%)$, limited turbine operating data, accurate species/size identification, and sampling gear deemed suitable for survival estimation (e.g., tailrace netting for estimating survival of herring like fish is not deemed suitable by EPRI $(1992,1997)$. Therefore, a set of criteria was developed, to be used in aggregate rather than based on a single parameter, to select data that may yield useful information for turbine designers and narrow down the list of important candidate variables which may be amenable for possible modifications. Undoubtedly, the selection process requires some professional judgment. Although the database in this report contains almost all the studies reported in the literature reviews (Bell 1981; Eicher Associates 1987; EPRI 1992) usable information was extracted from studies which also provided the following: estimation of direct effects; acceptable sample size ( $\geq 100)$; high control survival rate (preferably $\geq 90 \%$ ); high recapture rates (generally $\geq 70 \%$ ); description and quantification of injury types; turbine chäacteristics (e.g., discharge, number of blades or buckets, runner diameter, head, etc.); turbine operating data; and species and size. Tables 4.2-1 to $4.2-4$ show the data used in further analysis. 
Recently, EPRI (1997) has provided detailed guidelines for obtaining acceptable survival estimates emphasizing many of the criteria components cited above: need for detailed turbine physical and hydraulic characteristics; detailed information on species origin (hatchery-reared or river run), condition, number used, and size; accurate location of fish introduction within a turbine; turbine operating status; minimal control mortality (preferably less than $20 \%$ ); number of fish recaptured; replication of tests; survival estimates ( $1 \mathrm{~h}, 48 \mathrm{~h}$, or $120 \mathrm{~h}$, etc.) accompanied with confidence limits (precision); and assumptions used to derive estimates.

The following Section 4.3 presents background and quantitative characteristics of flow through turbines so that a better understanding of the processes occurring in turbine leading to fish mortality can be obtained. As a result, better turbine design features can be planned and implemented to achieve lower turbine passage mortality. 
Physical and hydraulic characteristics of all hydroelectric dams equipped with Kaplan type turbines for which survival data were deemed usable (direct effects data used in statistical analyses).

\begin{tabular}{|c|c|c|c|c|c|c|c|c|c|c|}
\hline Station & Sampling Mothod & Specles Tested & $\begin{array}{l}\text { Avg. Fish } \\
\text { Length } \\
\text { (mm) }\end{array}$ & $\begin{array}{l}\text { Turblne } \\
\text { Discharge } \\
\text { (cms) }\end{array}$ & $\begin{array}{l}\text { No. } \\
\text { of } \\
\text { Blades }\end{array}$ & $\begin{array}{l}\text { Runner } \\
\text { Spoed } \\
\text { (rpm) }\end{array}$ & $\begin{array}{l}\text { Head } \\
\text { (m) }\end{array}$ & $\begin{array}{l}\text { Runner } \\
\text { Dla. } \\
\text { (m) } \\
\end{array}$ & $\begin{array}{l}\text { Perlpheral } \\
\text { Velocity } \\
(\mathrm{m} / \mathrm{s})\end{array}$ & $\begin{array}{l}\text { Percent } \\
\text { Survlval } \\
1 \mathrm{Hr} \text {. }\end{array}$ \\
\hline Big Clill, OR (1964) & Full discharge nelting & Chinook Salmon & 100 & 52.5 & 6 & 163.6 & 27.7 & 3.76 & 32.2 & 91.1 \\
\hline Big Cliit, OR (1964) & Full discharge nelling & Chinook Salmon & 100 & 71.1 & 6 & 163.6 & 24.7 & 3.76 & 32.2 & 94.5 \\
\hline Big Cliff, OR (1964) & Full discharge nelling & Chinook Salmon & 100 & 71.1 & 6 & 163.6 & 21.6 & 3.76 & 32.2 & 89.7 \\
\hline Big Clilf, OR (1966) & Full discharge nelling & Chinook Salmon & 100 & 52.5 & 6 & 163.6 & 27.7 & 3.76 & 32.2 & 92.2 \\
\hline Big Clitf, OR (1966) & Full discharge nelling & Chinook Salmon & 100 & 71.1 & 6 & 163.6 & 24.7 & 3.76 & 32.2 & 89.8 \\
\hline Blg Clilt, OR (1966) & Full discharge nelling & Chinook Salmon & 100 & 71.1 & 6 & 163.6 & 21.6 & 3.76 & 32.2 & 90.6 \\
\hline Big Cliil, OR (1967) & Full discharge netling & Sleelhead & 152 & 71.1 & 6 & 163.6 & 21.6 & 3.76 & 32.2 & 90.4 \\
\hline Chalk Hill, MI-WI & HI-Z Turb'N Tag & Bluegill & 103 & 37.7 & 4 & 150 & 8.8 & 2.59 & 20.3 & 97.0 \\
\hline Chalk Hill, MI-WI & HI-Z Turb'N Tag & Bluegill & 153 & 37.7 & 4 & 150 & 8.8 & 2.59 & 20.3 & 98.0 \\
\hline Chalk Hill, MI-WI & Hl-Z Turb'N Tag & W. Sucker/R. Trout & 119 & 37.7 & 4 & 150 & 8.8 & 2.59 & 20.3 & 91.0 \\
\hline Chalk Hill, MI-WI & HI-Z Turb'N Tag & W. Sucker/R. Trout & 261 & 37.7 & 4 & 150 & 8.8 & 2.59 & 20.3 & 97.0 \\
\hline Conowingo, MD & HI-Z Turb'N Tag & American Shad & 125 & 226.6 & 6 & 120 & 27.4 & 5.72 & 35.9 & 94.9 \\
\hline Craggy Dam, NC & HI-Z Turb'N Tag & Channel Callish & 180 & 17.0 & 4 & 229 & 6.4 & 1.75 & 21.0 & 93.0 \\
\hline Craggy Dam, NC & HI-Z Turb'N Tag & Channel Caltish & 180 & 5.7 & 4 & 229 & 6.4 & 1.75 & 21.0 & 90.0 \\
\hline Craggy Dam, NC & HI-Z Turb'N Tag & Channel Cattish & 277 & 5.7 & 4 & 229 & 6.4 & 1.75 & 21.0 & 81.0 \\
\hline Craggy Dam, NC & HI-Z Turb'N Tag & Bluegill & 100 & 5.7 & 4 & 229 & 6.4 & 1.75 & 21.0 & 96.0 \\
\hline Craggy Dam, NC & HI-Z Turb'N Tag & Channel Cattish & 277 & 17.0 & 4 & 229 & 6.4 & 1.75 & 21.0 & 93.0 \\
\hline Craggy Dam, NC & HI-Z Turb'N Tag & Bluegill & 155 & 5.7 & 4 & 229 & 6.4 & 1.75 & 21.0 & 86.0 \\
\hline Crescent, NY & HI-Z Turb'N Tag & Blueback Herring & 91 & 43.0 & 5 & 144 & 8.2 & 2.74 & 20.7 & 96.0 \\
\hline Essex, MA (bulb turbine) & Radlo lelemelry & Allantic Salmon & 288 & 124.6 & 3 & 128.6 & 8.8 & 4.00 & 26.9 & 98.0 \\
\hline Fosler, OR (lests combined") & Full discharge nelling & Chinook Salmon & 120 & 22.7 & 6 & 257 & 26.2 & 2.54 & 34.2 & 82.1 \\
\hline Fosler, OR (lests combined; & Fyke netting & Chinook Salmon & 130 & 22.7 & 6 & 257 & 30.8 & 2.54 & 34.2 & 92.7 \\
\hline Fosler, OR (lests combined; & Full discharge nelling & Chinook Salmon & 120 & 22.7 & 6 & 257 & 33.5 & 2.54 & 34.2 & 91.2 \\
\hline Feeder Dam, NY & Full dlscharge nelting & Bluegill & 92 & 29.5 & 6 & 120 & 4.7 & 2.92 & 18.3 & 97.3 \\
\hline Feeder Dam, NY & Full discharge nelting & Bluegill & 129 & 29.5 & 6 & 120 & 5.2 & 2.92 & 18.3 & 92.3 \\
\hline Feoder Dam, NY & Full discharge nelting & Largemouth bass & 88 & 29.5 & 6 & 120 & 5.5 & 2.92 & 18.3 & 98.0 \\
\hline Feeder Dam, NY & Full discharge nelting & Largemouth bass & 190 & 29.5 & 6 & 120 & 5.8 & 2.92 & 18.3 & 90.0 \\
\hline Feeder Dam, NY & Full discharge nelting & Largemouth bass & 292 & 29.5 & 6 & 120 & 6.1 & 2.92 & 18.3 & 86.8 \\
\hline Feeder Dam, NY & Fuil discharge nelling & Brown trout & 206 & 29.5 & 6 & 120 & 6.4 & 2.92 & 18.3 & 86.4 \\
\hline Feeder Dam, NY & Full discharge nelling & Golden shiner & 88 & 29.5 & 6 & 120 & 6.7 & 2.92 & 18.3 & 96.8 \\
\hline Greenup Dam, OH (Vanceburg) & Radio telemetry & Sauger & 231 & 336.1 & 5 & 90 & 9.1 & 6.10 & 28.7 & B5.4 \\
\hline Hadley Falls, MA & Radio telemetry & American Shad & 560 & 118.9 & 5 & 128 & 15.8 & 4.32 & 28.9 & 78.2 \\
\hline Hadley Falls, MA & HI-Z Turb'N Tag & American Shad & 82 & 118.9 & 5 & 128 & 15.8 & 4.32 & 28.9 & 97.3 \\
\hline Hadley Falls, MA & Radio telemetry & Atlantic Salmon & 285 & 118.9 & 5 & 128 & 15.8 & 4.32 & 28.9 & 93.7 \\
\hline Hadley Falls, MA & HI-Z Turb'N Tag & American Shad & 82 & 43.9 & 5 & 128 & 15.8 & 4.32 & 28.9 & 100.0 \\
\hline
\end{tabular}


Table 4.2-1

Physical and hydraulle characteristics of all hydroelectrle dams equlpped with Kaplan type turbines for whlch survlval data were deemod usable (direct effects data used in stalislical analyses).

\begin{tabular}{|c|c|c|c|c|c|c|c|c|c|c|}
\hline Station & Samplling Mothod & Spocles Tested & $\begin{array}{l}\text { Avg. Fish } \\
\text { Length } \\
\text { (mm) }\end{array}$ & $\begin{array}{l}\text { Turbine } \\
\text { Dlscharge } \\
\text { (cms) }\end{array}$ & $\begin{array}{l}\text { No. } \\
\text { of } \\
\text { Blades }\end{array}$ & $\begin{array}{l}\text { Runner } \\
\text { Spoed } \\
\text { (rom) }\end{array}$ & $\begin{array}{l}\text { Head } \\
\text { (m) }\end{array}$ & $\begin{array}{l}\text { Runner } \\
\text { Dia. } \\
\text { (m) }\end{array}$ & $\begin{array}{l}\text { Poripheral } \\
\text { Veloclty } \\
(\mathrm{m} / \mathrm{s})\end{array}$ & $\begin{array}{l}\text { Percent } \\
\text { Survlval } \\
1 \mathrm{Hr} \text {. } \\
\end{array}$ \\
\hline Herrings, NY & Full discharge nelting & Centrarchild & 100 & 34.0 & 4 & 138 & 5.8 & 2.87 & 20.7 & 98.3 \\
\hline Herrings, NY & Full discharge nelling & Centrarchid & 175 & 34.0 & 4 & 138 & 5.8 & 2.87 & 20.7 & 97.3 \\
\hline Herrings, NY & Full discharge nelling & Centrarchid & 250 & 34.0 & 4 & 138 & 5.8 & 2.87 & 20.7 & 93.2 \\
\hline Herrings, NY & Full discharge nelting & Percid & 100 & 34.0 & 4 & 138 & 5.8 & 2.87 & 20.7 & 91.1 \\
\hline Herrings, NY & Full discharge nelting & Salmonids & 100 & 34.0 & 4 & 138 & 5.8 & 2.87 & 20.7 & 90.0 \\
\hline Herrings, NY & Full discharge nelling & Salmonids & 175 & 34.0 & 4 & 138 & 5.8 & 2.87 & 20.7 & 87.5 \\
\hline Herrings, NY & Full discharge nelting & Salmonids & 250 & 34.0 & 4 & 138 & 5.8 & 2.87 & 20.7 & 96.2 \\
\hline Herrings, NY & Full discharge nelting & Centrarchid & 100 & 34.0 & 4 & 138 & 5.8 & 2.87 & 20.7 & 95.0 \\
\hline Herrings, NY & Full discharge nelting & Centrarchid & 175 & 34.0 & 4 & 138 & 5.8 & 2.87 & 20.7 & 96.4 \\
\hline Herrings, NY & Full discharge nelting & Centrarchid & 250 & 34.0 & 4 & 138 & 5.8 & 2.87 & 20.7 & 92.5 \\
\hline Herrings, NY & Full discharge nelting & Percid & 100 & 34.0 & 4 & 138 & 5.8 & 2.87 & 20.7 & 94.9 \\
\hline Herrings, NY & Full discharge netting & Percld & 175 & 34.0 & 4 & 138 & 5.8 & 2.87 & 20.7 & 98.2 \\
\hline Herrings, NY & Full discharge nelting & Percid & 250 & 34.0 & 4 & 138 & 5.8 & 2.87 & 20.7 & 96.2 \\
\hline Herrings, NY & Full discharge netting & Salmonids & 100 & 34.0 & 4 & 138 & 5.8 & 2.87 & 20.7 & 95.5 \\
\hline Herrings, NY & Full discharge netting & Salmonids & 175 & 34.0 & 4 & 138 & 5.8 & 2.87 & 20.7 & 98.7 \\
\hline Herrings, NY & Full discharge nelting & Salmonids & 250 & 34.0 & 4 & 138 & 5.8 & 2.87 & 20.7 & 98.6 \\
\hline Herrings, NY & Full discharge netting & Solt ray & 100 & 34.0 & 4 & 138 & 5.8 & 2.87 & 20.7 & 97.5 \\
\hline Herrings, NY & Full discharge nelting & Soft ray & 175 & 34.0 & 4 & 138 & 5.8 & 2.87 & 20.7 & 91.7 \\
\hline Herrings, NY & Full discharge nelting & Soll ray & 250 & 34.0 & 4 & 138 & 5.8 & 2.87 & 20.7 & 85.1 \\
\hline Herrings, NY & Full discharge netting & Clupeids & 100 & 34.0 & 4 & 138 & 5.8 & 2.87 & 20.7 & 92.8 \\
\hline la centrale de Beauharnois, & Float tag & American eel & 881 & 262.7 & 6 & 94.7 & 24.1 & 6.32 & 31.3 & 76.1 \\
\hline Lowell, MA & Radio telemetry & Atlantlc Salmon & 265 & 127.4 & 5 & 120 & 11.9 & 3.86 & 24.2 & 88.5 \\
\hline Lower Granite, WA & HI-Z Turb'N Tag & Chinook Salmon & 134 & 594.7 & 6 & 90 & 29.9 & 7.92 & 37.3 & 94.6 \\
\hline Lower Granite, WA & Hl-Z Turb'N Tag & Chinook Salmon & 151 & 509.8 & 6 & 90 & 29.9 & 7.92 & 37.3 & 94.9 \\
\hline Lower Granite, WA & HI-Z Turb'N Tag & Chinook Salmon & 150 & 509.8 & 6 & 90 & 29.9 & 7.92 & 37.3 & 95.3 \\
\hline Lower Granile, WA & HI-Z Turb'N Tag & Chinook Salmon & 148 & 382.3 & 6 & 90 & 29.9 & 7.92 & 37.3 & 97.2 \\
\hline Lower Granite, WA & HI-Z Turb'N Tag & Chinook Salmon & 148 & 538.1 & 6 & 90 & 29.9 & 7.92 & 37.3 & 94.6 \\
\hline Lower Granite, WA & HI-Z Turb'N Tag & Chinook Salmon & 151 & 509.8 & 6 & 90 & 29.9 & 7.92 & 37.3 & 97.5 \\
\hline Lower Granite, WA & HI-Z Turb'N Tag & Chinook Salmon & 150 & 509.8 & 6 & 90 & 29.9 & 7.92 & 37.3 & 97.5 \\
\hline Raymondville, NY & Full discharge netting & Eel & 625 & 46.4 & 6 & 120 & 6.4 & 3.33 & 20.9 & 63.0 \\
\hline Rock Island, WA (bulb lurbine) & HI-Z Turb'N Tag & Chinook Salmon & 179 & 481.5 & 4 & 85.7 & 12.2 & 7.01 & 30.5 & 96.1 \\
\hline Rock Island, WA (PH 1, U 4) & HI-Z Turb'N Tag & Chinook Salmon & 179 & 481.5 & 6 & 100 & 13.7 & 5.74 & 30.5 & 95.0 \\
\hline Rock Island, WA (PH 1, U 5) & HI-Z Turb'N Tag & Chinook Salmon & 179 & 481.5 & 6 & 100 & 13.7 & 5.74 & 30.5 & 96.1 \\
\hline Rocky Reach, WA $\left(30^{\prime}\right.$, U. 3) & Hl-Z Turb'N Tag & Chinook Salmon & 161 & 453.1 & 6 & 90 & 28.0 & 7.11 & 33.5 & 94.7 \\
\hline Rocky Reach, WA $\left(10^{\prime}, \mathrm{U} .3\right)$ & HI-Z Turb'N Tag & Chinook Salmon & 161 & 453.1 & 6 & 90 & 28.0 & 7.11 & 33.5 & 93.9 \\
\hline Rocky Reach, WA (10',U. 5) & HI-Z Turb'N Tag & Chinook Salmon & 184 & 396.5 & 6 & 90 & 28.0 & 7.11 & 33.5 & 97.3 \\
\hline
\end{tabular}


Table 4.2-1

Physical and hydraulic characteristles of all hydroelectric dams equipped with Kaplan type turbines for which survival data were doemed usable (direct effects data used in statistical analyses).

\begin{tabular}{|c|c|c|c|c|c|c|c|c|c|c|}
\hline Station & Sampling Melhod & Specles Tested & $\begin{array}{l}\text { Avg. Fish } \\
\text { Length } \\
\text { (mm) }\end{array}$ & $\begin{array}{l}\text { Turblne } \\
\text { Dlscharge } \\
\text { (cms) } \\
\end{array}$ & $\begin{array}{l}\text { No. } \\
\text { of } \\
\text { Blades }\end{array}$ & $\begin{array}{l}\text { Runner } \\
\text { Spoed } \\
\text { (rpm) } \\
\end{array}$ & $\begin{array}{l}\text { Head } \\
\text { (m) }\end{array}$ & $\begin{array}{l}\text { Runner } \\
\text { Dla. } \\
\text { (m) }\end{array}$ & $\begin{array}{l}\text { Porlphoral } \\
\text { Volocity } \\
(\mathrm{m} / \mathrm{s})\end{array}$ & $\begin{array}{l}\text { Percent } \\
\text { Survival } \\
1 \mathrm{Hr} .\end{array}$ \\
\hline $\begin{array}{l}\text { Rocky Reach, WA }\left(30^{\prime}, \text { U. 5) }\right. \\
\text { Rocky Reach, WA }\left(10^{\prime}, \text { U. 6) }\right. \\
\text { Rocky Reach, WA }\left(30^{\prime}, \text { U. 6) }\right.\end{array}$ & $\begin{array}{l}\text { Hl-Z Turb'N Tag } \\
\text { Hl-Z Turb'N Tag } \\
\text { HI-Z Turb'N Tag }\end{array}$ & $\begin{array}{l}\text { Chinook Salmon } \\
\text { Chinook Salmon } \\
\text { Chinook Salmon }\end{array}$ & $\begin{array}{l}184 \\
184 \\
184\end{array}$ & $\begin{array}{l}396.5 \\
396.5 \\
396.5\end{array}$ & $\begin{array}{l}6 \\
6 \\
6\end{array}$ & $\begin{array}{l}90 \\
90 \\
90\end{array}$ & $\begin{array}{l}28.0 \\
28.0 \\
28.0\end{array}$ & $\begin{array}{l}7.11 \\
7.11 \\
7.11\end{array}$ & $\begin{array}{l}33.5 \\
33.5 \\
33.5\end{array}$ & $\begin{array}{l}94.4 \\
94.2 \\
95.8\end{array}$ \\
\hline Safe Harbor, PA (Unit 7) & HI-Z Turb'N Tag & American Shad & 118 & 235.1 & 5 & 109 & 16.8 & 5.64 & 32.2 & 98.0 \\
\hline $\begin{array}{l}\text { Townsend Dam, PA (bulb lurbine) } \\
\text { Townsend Dam, PA (bulb furbine) } \\
\text { Townsend Dam, PA (bulb turbine) } \\
\text { Townsend Dam, PA (bulb lurbine) } \\
\text { Townsend Dain, PA (bulb lurbine) } \\
\text { Townsend Dam, PA (bulb lurbine) }\end{array}$ & $\begin{array}{l}\text { HI-Z Turb'N Tag } \\
\text { HI-Z Turb'N Tag } \\
\text { Hl-Z Turb'N Tag } \\
\text { HI-Z Turb'N Tag } \\
\text { Hl-Z Turb'N Tag } \\
\text { HI-Z Turb'N Tag }\end{array}$ & $\begin{array}{l}\text { Largemouth Bass } \\
\text { Rainbow Trout } \\
\text { Rainbow Trout } \\
\text { Largemouth Bass } \\
\text { Largemoulh Bass } \\
\text { Rainbow Trout }\end{array}$ & $\begin{array}{l}217 \\
139 \\
344 \\
102 \\
217 \\
139\end{array}$ & $\begin{array}{l}42.5 \\
22.7 \\
22.7 \\
22.7 \\
22.7 \\
42.5\end{array}$ & $\begin{array}{l}3 \\
3 \\
3 \\
3 \\
3 \\
3\end{array}$ & $\begin{array}{l}152 \\
152 \\
152 \\
152 \\
152 \\
152\end{array}$ & $\begin{array}{l}4.9 \\
4.9 \\
4.9 \\
4.9 \\
4.9 \\
4.9\end{array}$ & $\begin{array}{l}2.87 \\
2.87 \\
2.87 \\
2.87 \\
2.87 \\
2.87\end{array}$ & $\begin{array}{l}22.8 \\
22.8 \\
22.8 \\
22.8 \\
22.8 \\
22.8\end{array}$ & $\begin{array}{l}96.8 \\
94.4 \\
86.5 \\
100.0 \\
86.0 \\
100.0\end{array}$ \\
\hline $\begin{array}{l}\text { Wanapum, WA (1011, Unit 9) } \\
\text { Wanapum, WA (1011, Unil 9) } \\
\text { Wanapum, WA (101t, Unil 9) } \\
\text { Wanapum, WA (1011, Unil 9) } \\
\text { Wanapum, WA (3011, Unil 9) } \\
\text { Wanapum, WA (3011, Unil 9) } \\
\text { Wanapum, WA (3011, Unil 9) } \\
\text { Wanapum, WA (3011, Unil 9) }\end{array}$ & $\begin{array}{l}\text { Hl-Z Turb'N Tag } \\
\text { Hl-Z Turb'N Tag } \\
\text { HI-Z Turb'N Tag } \\
\text { HI-Z Turb'N Tag } \\
\text { Hl-Z Turb'N Tag } \\
\text { Hl-Z Turb'N Tag } \\
\text { HI-Z Turb'N Tag } \\
\text { HI-Z Turb'N Tag }\end{array}$ & $\begin{array}{l}\text { Coho Salmon } \\
\text { Coho Salmon } \\
\text { Coho Salmon } \\
\text { Coho Salmon } \\
\text { Coho Salmon } \\
\text { Coho Salmon } \\
\text { Coho Salmon } \\
\text { Coho Salmon }\end{array}$ & $\begin{array}{l}154 \\
154 \\
154 \\
154 \\
154 \\
154 \\
154 \\
154\end{array}$ & $\begin{array}{l}254.9 \\
311.5 \\
424.8 \\
481.5 \\
254.9 \\
311.5 \\
424.8 \\
481.5\end{array}$ & $\begin{array}{l}\mathbf{5} \\
5 \\
\mathbf{5} \\
\mathbf{5} \\
5 \\
5 \\
\mathbf{5} \\
5\end{array}$ & $\begin{array}{l}85.7 \\
85.7 \\
85.7 \\
85.7 \\
85.7 \\
85.7 \\
85.7 \\
85.7\end{array}$ & $\begin{array}{l}22.9 \\
22.9 \\
22.9 \\
22.9 \\
22.9 \\
22.9 \\
22.9 \\
22.9\end{array}$ & $\begin{array}{l}7.24 \\
7.24 \\
7.24 \\
7.24 \\
7.24 \\
7.24 \\
7.24 \\
7.24\end{array}$ & $\begin{array}{l}32.5 \\
32.5 \\
32.5 \\
32.5 \\
32.5 \\
32.5 \\
32.5 \\
32.5\end{array}$ & $\begin{array}{l}89.7 \\
92.4 \\
94.8 \\
88.5 \\
94.9 \\
96.8 \\
100.0 \\
96.8\end{array}$ \\
\hline West Enfield, ME & Radio telemelry & Allantic Salmon & 212 & 150.1 & 3 & 89 & 6.4 & 4.88 & 22.7 & 96.0 \\
\hline Wilder, VT-NH & HI-Z Turb'N Tag & Allantic Salmon & 191 & 127.4 & 5 & 112.5 & 15.5 & 4.57 & 26.9 & 96.0 \\
\hline
\end{tabular}


Table 4.2-2

Physical and hydraulic characteristles of all hydroelectrle dams equipped with propeller type turbines for which survival data were deemed usable (direct effects data used In statistlcal analyses).

\begin{tabular}{|c|c|c|c|c|c|c|c|c|c|c|}
\hline Station & Sampllng Method & Species Tested & $\begin{array}{l}\text { Avg. Fish } \\
\text { Length } \\
\text { (mm) }\end{array}$ & $\begin{array}{l}\text { Turbine } \\
\text { Dlscharge } \\
\text { (cms) }\end{array}$ & $\begin{array}{l}\text { No. } \\
\text { of } \\
\text { Blades }\end{array}$ & $\begin{array}{l}\text { Runner } \\
\text { Spoed } \\
\text { (rpm) } \\
\end{array}$ & $\begin{array}{l}\text { Head } \\
(\mathrm{m})\end{array}$ & $\begin{array}{l}\text { Runner } \\
\text { Dla. } \\
\text { (m) }\end{array}$ & $\begin{array}{l}\text { Peripheral } \\
\text { Velocity } \\
(\mathrm{m} / \mathrm{s})\end{array}$ & $\begin{array}{l}\text { Percent } \\
\text { Survival } \\
1 \mathrm{Hr} \text {. }\end{array}$ \\
\hline Hadley Falls, MA & HI-Z Turb'N Tag & American Shad & 82 & 118.9 & 5 & 150 & 15.8 & 3.96 & 31.1 & 89.1 \\
\hline Rocky Reach, WA (10',U. 8) & HI-Z Turb'N Tag & Chinook Salmon & 114 & 566.4 & 5 & 85.7 & 26.4 & 7.90 & 35.4 & 96.9 \\
\hline $\begin{array}{l}\text { Safe Harbor, PA (Unit 8) } \\
\text { Safe Harbor, PA (Unit 8) }\end{array}$ & $\begin{array}{l}\text { HI-Z Turb'N Tag } \\
\text { HI-Z Turb'N Tag }\end{array}$ & $\begin{array}{l}\text { American Shad } \\
\text { American Shad }\end{array}$ & $\begin{array}{l}118 \\
118\end{array}$ & $\begin{array}{l}260.5 \\
260.5\end{array}$ & $\begin{array}{l}7 \\
7\end{array}$ & $\begin{array}{l}75 \\
75\end{array}$ & $\begin{array}{l}16.8 \\
16.8\end{array}$ & $\begin{array}{l}6.15 \\
6.15\end{array}$ & $\begin{array}{l}24.1 \\
24.1\end{array}$ & $\begin{array}{l}97.8 \\
98.9\end{array}$ \\
\hline
\end{tabular}




\section{Table 4.2-3}

Survival estimates (containing both direct and indirect effects) in passage through Kaplan type turbines.

\begin{tabular}{|c|c|c|c|c|c|c|c|c|c|}
\hline Station & Sampling Method & Species Tested & $\begin{array}{l}\text { Runner } \\
\text { Dia. } \\
\text { (m) }\end{array}$ & $\begin{array}{l}\text { Turbine } \\
\text { Discharge } \\
\text { (cms) }\end{array}$ & $\begin{array}{l}\text { No. } \\
\text { of } \\
\text { Blades } \\
\end{array}$ & $\begin{array}{l}\text { Runner } \\
\text { Speed } \\
\text { (rpm) }\end{array}$ & $\begin{array}{l}\text { Head } \\
\text { (m) }\end{array}$ & $\begin{array}{l}\text { Peripheral } \\
\text { Velocity } \\
(\mathrm{m} / \mathrm{s})\end{array}$ & $\begin{array}{l}\text { Percent } \\
\text { Survival } \\
1 \mathrm{Hr} \text {. }\end{array}$ \\
\hline Bonneville, OR/WA & Branding/CWT & Chinook salmon & 7.62 & 498.4 & 5 & 69.2 & 18.3 & 27.6 & 97.5 \\
\hline Little Goose, WA & PIT tag & Chinook salmon & 7.92 & 509.8 & 6 & 90.0 & 28.3 & 37.3 & 92.0 \\
\hline Lower Granite, WA & PIT tag & Chinook salmon & 7.92 & 509.8 & 6 & 90.0 & 29.9 & 37.3 & 92.7 \\
\hline Rock Island, WA & Brand/partial netting & Coho salmon & 7.01 & 509.8 & 4 & 85.7 & 12.2 & 31.4 & 93.0 \\
\hline Rock Island, WA & Brand/partial netting & Steelhead & 7.01 & 509.8 & 4 & 85.7 & 12.2 & 31.4 & 96.9 \\
\hline Wells, WA & Brand/partial netting & Steelhead & 7.43 & 566.4 & 6 & 85.7 & 19.8 & 33.3 & 84.0 \\
\hline Lower Monumental, WA & PIT tag & Chinook salmon & 7.92 & 509.8 & 6 & 90.0 & 28.7 & 37.3 & 86.5 \\
\hline McNary, WA & Brand/partial netting & Chinook salmon & 7.11 & 348.3 & 6 & 87.5 & 24.4 & 32.6 & 89.0 \\
\hline
\end{tabular}


Physical and hydraulic characteristics of hydroelectric dams equipped with Francls type turbines for which survival dala were deemed usable tor direct effects (analysis uttlized these data).

\begin{tabular}{|c|c|c|c|c|c|c|c|c|c|c|c|c|}
\hline Station & $\begin{array}{l}\text { Sampling } \\
\text { Molhod }\end{array}$ & Species Tested & $\begin{array}{l}\text { Test } \\
\text { sample } \\
\text { size } \\
\end{array}$ & $\begin{array}{l}\text { Control } \\
\text { sample } \\
\text { size } \\
\end{array}$ & $\begin{array}{l}\text { Avg. Flsh } \\
\text { Length } \\
\text { (mm) }\end{array}$ & $\begin{array}{l}\text { Turblne } \\
\text { Dlscharge } \\
\text { (cms) } \\
\end{array}$ & $\begin{array}{l}\text { No. } \\
\text { of } \\
\text { Buckets }\end{array}$ & $\begin{array}{l}\text { Aunner } \\
\text { Speed } \\
\text { (rpm) } \\
\end{array}$ & $\begin{array}{l}\text { Head } \\
\text { (m) }\end{array}$ & $\begin{array}{l}\text { Runner } \\
\text { Dla. } \\
\text { (m) } \\
\end{array}$ & $\begin{array}{l}\text { Peripheral } \\
\text { Volocily } \\
(\mathrm{m} / \mathrm{s}) \\
\end{array}$ & $\begin{array}{l}\% \\
\text { Survlval } \\
1 \mathrm{hr}\end{array}$ \\
\hline Alcona, MI & Full dschrg neltling & Bluegill & 97 & - & 118 & 46.9 & 16 & 90 & 13.1 & 2.54 & 12.0 & 90.2 \\
\hline Alcona, MI & Full dschrg nelling & BluegllI & 102 & - & 170 & 47.0 & 16 & 90 & 13.1 & 2.54 & 12.0 & 84.1 \\
\hline Alcona, MI & Full dschrg nelling & Gold./Common Shiner & 51 & - & 114 & 47.0 & 16 & 90 & 13.1 & 2.54 & 12.0 & 80.9 \\
\hline Alcona, MI & Full dschrg netling & Gold./Common Shlner & 58 & - & 154 & 47.0 & 16 & 90 & 13.1 & 2.54 & 12.0 & 84.7 \\
\hline Alcona, MI & Full dschrg nelling & Northem Plke & 44 & - & 352 & 47.1 & 16 & 90 & 13.1 & 2.54 & 12.0 & 51.2 \\
\hline Alcona, MI & Full dschrg nelting & Aalnbow Trout & 40 & - & 108 & 47.1 & 16 & 90 & 13.1 & 2.54 & 12.0 & 100 \\
\hline Alcona, MI & Full dschrg nelling & Rainbow Trout & 10 & - & 317 & 47.1 & 16 & 90 & 13.1 & 2.54 & 12.0 & 89.4 \\
\hline Alcona, MI & Full dschrg nelling & Walleye & 45 & - & 385 & 47.2 & 16 & 90 & 13.1 & 2.54 & 12.0 & 38.7 \\
\hline Alcona, MI & Full dschrg nelling & Whlle Sucker & 60 & - & 180 & 47.2 & 16 & 90 & 13.1 & 2.54 & 12.0 & 94.4 \\
\hline Alcona, MI & Full dschrg nelting & While Sucker & 54 & $\cdot$ & 290 & 47.3 & 16 & 90 & 13.1 & 2.54 & 12.0 & 90.4 \\
\hline Buchanan, MI & Full dschrg nelling & Chinook salmon & 600 & 400 & 420 & 2.8 & - & - & - & - & - & 79.6 \\
\hline Buchanan, MI & Full dschrg nelling & Sleelhead trout & 600 & 400 & 420 & 6.2 & - & $\cdot$ & $\cdot$ & $\cdot$ & - & 79.4 \\
\hline Bond Falls, MI & Full dschrg nelling & Ralnbow Trout & 350 & 225 & 210 & 12.7 & - & 300 & 64.0 & - & - & 83.8 \\
\hline Bond Falls, MI & Full dschrg netting & Yellow Perch & 360 & 225 & 102 & 12.7 & - & 300 & 64.0 & - & - & 79.5 \\
\hline Bond Falls, MI & Full dschrg netting & Golden Shlner & 405 & 225 & 70 & 12.7 & - & 300 & 64.0 & - & - & 77.9 \\
\hline Bond Falls, MI & Full dschrg netting & Blueglll & 660 & 450 & $\$ 15$ & 12.7 & $\cdot$ & 300 & 64.0 & $\cdot$ & • & 81.7 \\
\hline Caldron Falls, WI ( Unit 1) & Full dschrg netling & Centrarchiloms & 144 & 94 & 76 & 18.4 & 15 & 226 & 24.4 & 1.83 & 21.6 & 100.0 \\
\hline Caidron Falls, WI ( Unit 1) & Full dschrg nelling & Centrarchliorms & 141 & 90 & 127 & 18.4 & 15 & 226 & 24.4 & 1.83 & 21.6 & 98.2 \\
\hline Caldron Falls, WI ( Unit 1) & Full dschrg netting & Centrarchiforms & 76 & 35 & 178 & 18.4 & 15 & 226 & 24.4 & 1.83 & 21.6 & 86.8 \\
\hline Caldron Falls, WI ( Unif 1) & Full dschrg nelling & Fuslioms & 145 & 86 & 76 & 18.4 & 15 & 226 & 24.4 & 1.83 & 21.6 & 80.3 \\
\hline Caldron Falls, WI ( Unil 1) & Full dschrg nelting & Fusliorms & 139 & 92 & 127 & 18.4 & 15 & 226 & 24.4 & 1.83 & 21.6 & 84.8 \\
\hline Caldron Falls, Wi (Unil 1) & Full dschrg netting & Fusiloms & 125 & 58 & 178 & 18.4 & 15 & 226 & 24.4 & 1.83 & 21.6 & 70.3 \\
\hline Caldron Falls, WI ( Unit 1) & Full dschrg nelting & Fusilorms & 136 & 63 & 229 & 18.4 & 15 & 226 & 24.4 & 1.83 & 21.6 & 64.3 \\
\hline Caldron Falls, WI ( Unit 1) & Full dschrg netling & Fusilorms & 146 & 94 & 292 & 18.4 & 15 & 226 & 24.4 & 1.83 & 21.6 & 59.5 \\
\hline Caldron Falls, WI ( Unit 1) & Full dschrg nelling & Fusiloms & 153 & 76 & $>292$ & 18.4 & 15 & 226 & 24.4 & 1.83 & 21.6 & 35.5 \\
\hline Centralla, WI (Unlt 2) & Full dschrg netting & White Sucker & - & - & 125 & 14.4 & 15 & 90 & 6.1 & 0.71 & 3.3 & 97.9 \\
\hline Centralla, WI (Unit 1) & Full dschrg netting & Blueglil & - & - & 125 & 14.4 & 15 & 90 & 6.1 & 0.71 & 3.3 & 98.2 \\
\hline Centralla, WI (Unit 1) & Full dschrg netting & Blueglll & $\cdot$ & - & 175 & 14.4 & 15 & 90 & 6.1 & 0.71 & 3.3 & 86.8 \\
\hline Crown Zellerback, OR (Unit 20) & Full dschrg nelling & Steolhead trout & 1,777 & 500 & - & 11.6 & - & 277 & 11.9 & - & - & 69.4 \\
\hline Crown Zellerback, OR (Unit 20) & Full dschrg nelling & Chinook salmon & 1,800 & 500 & - & 11.6 & - & 277 & 11.9 & - & - & 71.6 \\
\hline Crown Zellerback, OR (Unit 21) & Full dschrg netling & Steelhead trout & 17,999 & 500 & - & 14.7 & - & 255 & 13.0 & - & - & 80.0 \\
\hline Crown Zellerback, OR (Unlt 21) & Full dschrg netling & Chinook salmon & 1.798 & 500 & - & 14.7 & $\cdot$ & 255 & 13.0 & $\cdot$ & $\cdot$ & 81.2 \\
\hline Cushman Plant 2 (1960) & Full dschrg netting & Salmonids & 25,108 & - & 58 & 22.6 & 17 & 300 & 137.2 & 2.11 & 33.1 & 61.0 \\
\hline Cushman Plant 2 (1960) & Full dschrg nettling & Salmonids & 25.108 & - & 58 & $40 \%$ wickel & & & & & - & 59.0 \\
\hline Cushman Plant 2 (1960) & Fult dschrg nettling & Salmonids & 25,108 & - & 58 & $40 \%$ wicket & & & & & - & 44.6 \\
\hline Cushman Plant 2 (1960) & Full dschrg nelling & Salmonids & 25,108 & - & 58 & $40 \%$ wickel & & & & & - & 52.2 \\
\hline Cushman Plant 2 (1960) & Full dschrg nelling & Salmonlds & 25,108 & - & 58 & $65 \%$ wlckel & & & & & - & 77.3 \\
\hline Cushman Plant 2 (1960) & Full dschrg nettlng & Salmonids & 25,108 & - & 58 & $65 \%$ wickel & & & & & - & 70.9 \\
\hline
\end{tabular}


Physical and hydraullc characterlstics of hydroelectric dams equipped with Francls type turbines for whlch survival data were deemed usable for direct ettects (analysis uflized these data).

\begin{tabular}{|c|c|c|c|c|c|c|c|c|c|c|c|c|}
\hline Statlon & $\begin{array}{l}\text { Sampling } \\
\text { Mothod }\end{array}$ & Specles Tested & $\begin{array}{l}\text { Test } \\
\text { sample } \\
\text { size } \\
\end{array}$ & $\begin{array}{l}\text { Control } \\
\text { sample } \\
\text { slze } \\
\end{array}$ & $\begin{array}{l}\text { Avg. Fish } \\
\text { Lenglh } \\
\text { (mm) }\end{array}$ & $\begin{array}{l}\text { Turblne } \\
\text { Dlscharge } \\
\text { (cms) }\end{array}$ & $\begin{array}{l}\text { No. } \\
\text { of } \\
\text { Buckets } \\
\end{array}$ & $\begin{array}{l}\text { Runner } \\
\text { Speed } \\
\text { (rpm) }\end{array}$ & $\begin{array}{l}\text { Head } \\
\text { (m) }\end{array}$ & $\begin{array}{l}\text { Funner } \\
\text { Dla. } \\
\text { (m) }\end{array}$ & $\begin{array}{l}\text { Peripheral } \\
\text { Velocity } \\
(\mathrm{m} / \mathrm{s})\end{array}$ & $\begin{array}{l}\% \\
\text { Survival } \\
1 \text { hr }\end{array}$ \\
\hline Cushman Plant 2 (1960) & Full dschrg nelling & Salmonids & 25,108 & - & 58 & $65 \%$ wickel & & & & & - & 65.5 \\
\hline Cushman Plant 2 (1960) & Full dschrg nelling & Salmonids & 25,108 & - & 58 & $80 \%$ wicket & & & & & - & 75.0 \\
\hline Cushman Plant 2 (1960) & Full dschrg nelling & Salmonids & 25,108 & - & 58 & $80 \%$ wlcket & & & & & - & 73.7 \\
\hline Cushman Plant 2 (1960) & Full dschrg nelling & Salmonids & 25,108 & - & 58 & $80 \%$ wicket & & & & & - & 55.1 \\
\hline Cushman Plant 2 (1960) & Full dschrg nelling & Salmonids & 25,108 & - & 58 & $100 \%$ wicket & & & & & - & 73.5 \\
\hline Cushman Plant 2 (1960) & Full dschrg nelling & Salmonids & 25,108 & - & 58 & $100 \%$ wicket & & & & & - & 69.1 \\
\hline Cushman Plant 2 (1960) & Full dschrg nelling & Salmonids & 25,108 & - & 58 & $100 \%$ wlcket & & & & - & - & 63.8 \\
\hline Cushman Plant 2 (1961) & Full dschrg nelting & Sllver Salmon & 7,923 & 4,000 & 89 & 22.6 & 17 & 300 & 137.2 & 2.11 & 33.1 & 53.3 \\
\hline Cushman Plant 2 (1961) & Full dschrg nelling & Steelhead & 1,590 & 800 & 127 & 22.6 & 17 & 300 & 137.2 & 2.11 & 33.1 & 42.9 \\
\hline Cushman Plant 2 (1961) & Full dschrg netting & Silver Salmon & 7,923 & 4,000 & 89 & $40 \%$ wicket & & & & & - & 34.5 \\
\hline Cushman Plant 2 (1961) & Full dschrg nelling & Sliver Salmon & 7,923 & 4,000 & 89 & $50 \%$ wlcket & & & & & - & 50.9 \\
\hline Cushman Plant 2 (1961) & Full dschrg nelling & Steelhead & 1,590 & 800 & 127 & $50 \%$ wlckel & & & & & - & 51.9 \\
\hline Cushman Plant 2 (1961) & Full dschrg nelling & Sliver Salmon & 7,923 & 4,000 & 89 & $60 \%$ wickel & & & & & - & 59.9 \\
\hline Cushman Plant 2 (1961) & Full dschrg nelling & Steelhead & 1,590 & 800 & 127 & $60 \%$ wickel & & & & & - & 38.6 \\
\hline Cushman Plant 2 (1961) & Full dschrg nelling & Silver Salmon & 7,923 & 4,000 & 89 & $68 \%$ wlckel & & & & & - & 60.5 \\
\hline Cushman Plant 2 (1961) & Full dschrg nelting & Steelhead & 1,590 & 800 & 127 & $68 \%$ wlckel & & & & & - & 42.3 \\
\hline Cushman Plant 2 (1961) & Full dschrg nelting & Silver Salmon & 7,923 & 4,000 & 89 & $76 \%$ wlckel & & & & & - & 72.0 \\
\hline Cushman Plant 2 (1961) & Full dschrg nelling & Steelhead & 1,590 & 800 & 127 & $76 \%$ wlckel & & & & & - & 50.0 \\
\hline Cushman Plant 2 (1961) & Full dschrg nelting & Silver Salmon & 7,923 & 4,000 & 89 & $84 \%$ wicket & & & & & - & 68.4 \\
\hline Cushman Plant 2 (1961) & Full dschrg nelling & Sleolhead & 1,590 & 800 & 127 & $84 \%$ wickel & & & & & - & 33.8 \\
\hline Cushman Plant 2 (1961) & Full dschrg netting & Silver Salmon & 7,923 & 4,000 & 89 & $90 \%$ wlckel & & & & & - & 77.7 \\
\hline Cushman Plant 2 (1961) & Full dschrg nelting & Sllver Salmon & 7,923 & 4,000 & 89 & $100 \%$ wlckel & & & & & - & 64.9 \\
\hline E. J. West, NY & Full dschrg nelling & Centrarchld & 320 & 320 & $<100$ & 76.3 & 15 & 113 & 19.2 & 3.33 & 19.7 & 71.7 \\
\hline E. J. West, NY & Full dschrg netting & Centrarchld & 159 & 160 & 175 & 76.3 & 15 & 113 & 19.2 & 3.33 & 19.7 & 85.5 \\
\hline E. J. West, NY & Full dschrg nettlng & Centrarchld & 128 & 128 & $>250$ & 76.3 & 15 & 113 & 19.2 & 3.33 & 19.7 & 59.8 \\
\hline E.J. West, NY & Full dschrg nelting & Percid & 240 & 240 & $<100$ & 76.3 & 15 & 113 & 19.2 & 3.33 & 19.7 & 56.1 \\
\hline E. J. West, NY & Full dschrg netting & Solt Ray & 157 & 159 & $<100$ & 76.3 & 15 & 113 & 19.2 & $\mathbf{3 . 3 3}$ & 19.7 & 32.3 \\
\hline E. J. Wesi, NY & Full dschrg netting & Solt Ray & 160 & 159 & 175 & 76.3 & 15 & 113 & 19.2 & 3.33 & 19.7 & 71.3 \\
\hline E. J. West, NY & Full dschrg nettlng & Soll Ray & 160 & 160 & $>250$ & 76.3 & 15 & 113 & 19.2 & 3.33 & 19.7 & 67.5 \\
\hline E. J. West, NY & Full dschrg nettlng & Salmonid & 280 & 280 & $<100$ & 76.3 & 15 & 113 & 19.2 & 3.33 & 19.7 & 65.2 \\
\hline E. J. Wesl, NY & Full dschrg netting & Salmonld & 160 & 160 & 175 & 76.3 & 15 & 113 & 19.2 & 3.33 & 19.7 & 90.6 \\
\hline E. J. Wesi, NY & Full dschrg nettlng & Salmonid & 160 & 160 & $>250$ & 76.3 & 15 & 113 & 19.2 & 3.33 & 19.7 & 95.6 \\
\hline Elwha, WA & Parllal netting & Chinook salmon & 42,168 & 20,030 & $\cdot$ & 14.1 & - & 300 & 31.7 & 1.49 & 23.4 & 100.0 \\
\hline Finch Pruyn, NY (Unlt 4) & Balloon tag & Smallmouth Bass & 61 & 44 & 191 & 20.0 & 15 & 225 & 14.0 & 0.91 & 10.8 & 95.0 \\
\hline Finch Pruyn, NY (Unit 4) & Balloon tag & Smallmouth Bass & 49 & 37 & 210 & 20.0 & 15 & 225 & 14.0 & 0.91 & 10.8 & 91.0 \\
\hline Finch Pruyn, NY (Untt 5) & Balloon tag & Smallmouth Bass & 32 & 37 & 210 & 23.6 & 15 & 225 & 14.0 & 0.91 & 10.8 & 91.0 \\
\hline Finch Pruyn, NY (Unit 5) & Balloon tag & Smallmouth Bass & 43 & 44 & 271 & 23.6 & 15 & 225 & 14.0 & 0.91 & 10.8 & 71.0 \\
\hline
\end{tabular}


Table 4.2-4

Physical and hydraulic characteristics of hydroelectric dams equipped wilh Francls type turbines for which survival data were deemed usable for direct effects (analysis utilized these data).

\begin{tabular}{|c|c|c|c|c|c|c|c|c|c|c|c|c|}
\hline Station & $\begin{array}{l}\text { Sampling } \\
\text { Mothod }\end{array}$ & Species Tested & $\begin{array}{l}\text { Test } \\
\text { sample } \\
\text { slzo } \\
\end{array}$ & $\begin{array}{l}\text { Control } \\
\text { sample } \\
\text { size } \\
\end{array}$ & $\begin{array}{l}\text { Avg. Fish } \\
\text { Length } \\
\text { (mm) }\end{array}$ & $\begin{array}{l}\text { Turblne } \\
\text { Discharge } \\
\text { (cms) }\end{array}$ & $\begin{array}{l}\text { No. } \\
\text { of } \\
\text { Buckets }\end{array}$ & $\begin{array}{l}\text { Runner } \\
\text { Spoed } \\
\text { (rpm) }\end{array}$ & $\begin{array}{l}\text { Head } \\
(m)\end{array}$ & $\begin{array}{l}\text { Runner } \\
\text { Dla. } \\
\text { (m) }\end{array}$ & $\begin{array}{l}\text { Perlpheral } \\
\text { Velocity } \\
\text { (m/s) }\end{array}$ & $\begin{array}{l}\% \\
\text { Survival } \\
1 \mathrm{hr}\end{array}$ \\
\hline Five Channels, Ml & Full dschrg nelling & Bluegill & 95 & - & 118 & 33.0 & 16 & 150 & 11.0 & 1.40 & 11.0 & 93.6 \\
\hline Flve Channels, MI & Full dschrg netling & Blueglll & 91 & - & 170 & 33.0 & 16 & 150 & 11.0 & 1.40 & 11.0 & 89.2 \\
\hline Five Channels, Ml & Full dschrg netting & Gold./Common ShIner & 59 & - & 114 & 33.0 & 16 & 150 & $\$ 1.0$ & 1.40 & 11.0 & 81.8 \\
\hline Five Channels, MI & Full dschrg netting & Gold./Cominon ShIner & 60 & - & 154 & 33.0 & 16 & 150 & 11.0 & 1.40 & 11.0 & 85.5 \\
\hline Five Channels, MI & Full dschrg netling & Northem PIke & 31 & - & 352 & 33.0 & 16 & 150 & 11.0 & 1.40 & 11.0 & 91.3 \\
\hline Flve Channels, MI & Full dschrg netling & Ralnbow Trout & 40 & - & 108 & 33.0 & 16 & 150 & 11.0 & 1.40 & 11.0 & 95.8 \\
\hline Flve Channels, MI & Full dschrg netting & Ralnbow Trout & 46 & - & 317 & 33.0 & 16 & 150 & 11.0 & 1.40 & 11.0 & 70.0 \\
\hline Five Channels, MI & Full dschrg netting & Walleye & 55 & - & 162 & 33.0 & 16 & 150 & 11.0 & 1.40 & 11.0 & 71.2 \\
\hline Five Channels, MI & Full dschrg nettlng & Walleye & 60 & - & 385 & 33.0 & 16 & 150 & 11.0 & 1.40 & 11.0 & 76.7 \\
\hline Flve Channels, MI & Full dschrg nettling & White Sucker & 56 & - & 180 & 33.0 & 16 & 150 & 11.0 & 1.40 & 11.0 & 88.6 \\
\hline Five Channels, Ml & Full dschrg neltling & White Sucker & 60 & - & 290 & 33.0 & 16 & 150 & 11.0 & 1.40 & 11.0 & 71.4 \\
\hline Five Channels, MI & Full dschrg netling & Yellow Perch & 30 & - & 186 & 33.0 & 16 & 150 & 11.0 & 1.40 & 11.0 & 77.1 \\
\hline Gilnes, WA & Partlal netling & Silver salmon & 31,256 & 23,442 & - & 42.4 & $\cdot$ & 225 & 59.1 & 2.35 & 27.6 & 69.6 \\
\hline Grand Raplds, WI (U 1,2,4 comb) & Full dschrg netllng & Blueglil & - & - & 76 & 18.2 & 15 & 90 & 8.5 & 1.47 & 6.9 & 96.7 \\
\hline Grand Raplds, WI (U 1,2,4 comb) & Full dschrg netting & BluegllI & - & - & 127 & 18.2 & 15 & 90 & 8.5 & 1.47 & 6.9 & 100.0 \\
\hline Grand Raplds, WI (U 1,2,4 comb) & Full dschrg nettlng & BluegllI & - & - & 178 & 18.2 & 15 & 90 & 8.5 & 1.47 & 6.9 & 94.9 \\
\hline Grand Rapids. WI (U 1,2,4 comb) & Full dschrg nelling & White Sucker & - & - & 76 & 18.2 & 15 & 90 & 8.5 & 1.47 & 6.9 & 100.0 \\
\hline Grand Raplds, WI (U 1,2,4 comb) & Full dschrg netling & While Sucker & - & - & 127 & 18.2 & 15 & 90 & 8.5 & 1.47 & 6.9 & 100.0 \\
\hline Grand Rapids, WI (U 1,2,4 comb) & Full dschrg netling & While Sucker & - & - & 178 & 18.2 & 15 & 90 & 8.5 & 1.47 & 6.9 & 94.9 \\
\hline Grand Raplds, WI (U 1,2,4 comb) & Full dschrg netling & While Sucker & - & - & 229 & 18.2 & 15 & 90 & 8.5 & 1.47 & 6.9 & 93.7 \\
\hline Grand Raplds, WI (U 1,2,4 comb) & Full dschrg netling & Whille Sucker & - & - & 292 & 18.2 & 15 & 90 & 8.5 & 1.47 & 6.9 & 90.4 \\
\hline Grand Rapids, WI (U 1,2,4 comb) & Full dschrg nelling & While Sucker & - & $\cdot$ & $>292$ & 18.2 & 15 & 90 & 8.5 & 1.47 & 6.9 & 80.5 \\
\hline Hardy, MI (UnIl 2) & Full dschrg netling & Blueglll & 63 & - & 118 & 14.4 & 16 & 163.6 & 30.5 & 2.13 & 18.2 & 89.5 \\
\hline Hardy, MI (Unil 2) & Full dschrg netllng & BluegllI & 30 & - & 170 & 14.4 & 16 & 163.6 & 30.5 & 2.13 & 18.2 & 91.5 \\
\hline Hardy, MI (Unil 2) & Full dschrg nelling & Gold./Common Shiner & 30 & - & 114 & 14.4 & 16 & 163.6 & 30.5 & 2.13 & 18.2 & 85.5 \\
\hline Hardy, MI (Unll 2) & Full dschrg netling & Gold./Common Shiner & 59 & - & 154 & 14.4 & 16 & 163.6 & 30.5 & 2.13 & 18.2 & 88.7 \\
\hline Hardy, MI (Unlt 2) & Full dschrg netling & Largemoulh Bass & 60 & - & 118 & 14.4 & 16 & 163.6 & 30.5 & 2.13 & 18.2 & 76.2 \\
\hline Hardy, MI (Unit 2) & Full dschrg netling & Northem Pike & 58 & - & 352 & 14.4 & 16 & 163.6 & 30.5 & 2.13 & 18.2 & 76.0 \\
\hline Hardy, MI (Unll 2) & Full dschrg netling & Rainbow Trout & 59 & - & 108 & 14.4 & 16 & 163.6 & 30.5 & 2.13 & 18.2 & 71.4 \\
\hline Hardy, MI (Unil 2) & Full dschrg nelling & Ralnbow Trout & 60 & - & 317 & 14.4 & 16 & 163.6 & 30.5 & 2.13 & 18.2 & 68.6 \\
\hline Hardy, Ml (Unit 2) & Full dschrg netting & Walleye & 60 & - & 385 & 14.4 & 16 & 163.6 & 30.5 & 2.13 & 18.2 & 77.3 \\
\hline Hardy, MI (Unil 2) & Full dschrg nelling & While Sucker & 59 & - & 180 & 14.4 & 16 & 163.6 & 30.5 & 2.13 & 18.2 & 76.9 \\
\hline Hardy, MI (Unit 2) & Full dschrg nelling & While Sucker & 60 & - & 290 & 14.4 & 16 & 163.6 & 30.5 & 2.13 & 18.2 & 64.5 \\
\hline Hardy, MI (Unil 2) & Full dschrg nelling & Yellow Perch & 60 & - & 107 & 14.4 & 16 & 163.6 & 30.5 & 2.13 & 18.2 & 83.1 \\
\hline Hardy, MI (UnIl 2) & Full dschrg netling & Yellow Perch & $\cdot$ & - & 186 & 14.4 & 16 & 163.6 & 30.5 & 2.13 & 18.2 & 95.5 \\
\hline
\end{tabular}


Table 4.2-4

Physical and hydraulle characteristlcs of hydroelectric dams equipped with Francis type turbines for which survival data were deemed usable for direct eftects (analysis utlilzed these data).

\begin{tabular}{|c|c|c|c|c|c|c|c|c|c|c|c|c|}
\hline Station & $\begin{array}{l}\text { Sampling } \\
\text { Method }\end{array}$ & Specles Tested & $\begin{array}{l}\text { Test } \\
\text { sample } \\
\text { slze } \\
\end{array}$ & $\begin{array}{l}\text { Control } \\
\text { samplo } \\
\text { slze } \\
\end{array}$ & $\begin{array}{l}\text { Avg. Fish } \\
\text { Longth } \\
\text { (mm) }\end{array}$ & $\begin{array}{l}\text { Turblne } \\
\text { Dlscharge } \\
\text { (cms) }\end{array}$ & $\begin{array}{l}\text { No. } \\
\text { of } \\
\text { Buckets } \\
\end{array}$ & $\begin{array}{l}\text { Funner } \\
\text { Speed } \\
\text { (rpm) } \\
\end{array}$ & $\begin{array}{l}\text { Head } \\
(\mathrm{m})\end{array}$ & $\begin{array}{l}\text { Runner } \\
\text { Dla. } \\
\text { (m) } \\
\end{array}$ & $\begin{array}{l}\text { Perlpheral } \\
\text { Veloclty } \\
\text { (m/s) } \\
\end{array}$ & $\begin{array}{l} \\
\text { Survlval } \\
1 \mathrm{hr}\end{array}$ \\
\hline Hlgh Falls (Unlt 5) & Full dschrg nelling & Centrarchllorms & 154 & 88 & 76 & 7.8 & 12 & 358 & 25.3 & 0.99 & 18.6 & 85.5 \\
\hline Hlgh Falls (Unil 5) & Full dschrg netling & Centrarchlforms & 90 & 48 & 127 & 7.8 & 12 & 358 & 25.3 & 0.99 & 18.6 & 78.1 \\
\hline HIgh Falls (Unit 5) & Full dschrg netling & Centrarchiforms & 111 & 70 & 178 & 7.8 & 12 & 358 & 25.3 & 0.99 & 18.6 & 58.9 \\
\hline Hlgh Falls (Unit 5) & Full dschrg netling & Fusilorms & 146 & 95 & 76 & 7.8 & 12 & 358 & 25.3 & 0.99 & 18.6 & 87.8 \\
\hline HIgh Falls (Unil 5) & Full dschrg nelling & Fusllorms & 81 & 49 & 127 & 7.8 & 12 & 358 & 25.3 & 0.99 & 18.6 & 67.9 \\
\hline Hlgh Falls (Unit 5) & Full dschrg nelling & Fusiforms & 184 & 79 & 178 & 7.8 & 12 & 358 & 25.3 & 0.99 & 18.6 & 48.4 \\
\hline High Falls (Unit 5) & Full dschrg netling & Fusllorms & 96 & 66 & 229 & 7.8 & 12 & 358 & 25.3 & 0.99 & 18.6 & 46.2 \\
\hline High Falls (Unit 5) & Full dschrg netllng & Fusllorms & 160 & 58 & 292 & 7.8 & 12 & 358 & 25.3 & 0.99 & 18.6 & 20.1 \\
\hline High Falls (Unit 5) & Full dschrg netling & Fusiloms & 71 & 41 & $>292$ & 7.8 & 12 & 358 & 25.3 & 0.99 & 18.6 & 2.7 \\
\hline Holst, MI & Full dschrg netling & Brown Trout & 150 & 150 & 85 & 8.5 & - & 360 & 43.3 & - & - & 45.1 \\
\hline Holst, MI & Full dschrg netling & Brook Trout & 150 & 150 & 135 & 8.5 & $\cdot$ & 360 & 43.3 & $\cdot$ & $\cdot$ & 43.0 \\
\hline Holst, MI & Full dschrg nelling & Brown Trout & 150 & 150 & 220 & 8.5 & - & 360 & 43.3 & - & - & 22.8 \\
\hline Holst, MI & Full dschrg netting & Bluegill & 150 & 150 & 65 & 8.5 & - & 360 & 43.3 & - & - & 19.7 \\
\hline Holst, MI & Full dschrg nelting & Bluegill & 150 & 150 & 115 & 8.5 & - & 360 & 43.3 & - & - & 75.0 \\
\hline Holtwood, $\mathrm{PA}(\mathrm{U} 10 /$ single runner) & Balloon tag & American Shad & 100 & 100 & 125 & 99.0 & 16 & 94.7 & 18.9 & 3.80 & 18.8 & 69.4 \\
\hline Hollwood, PA (U3/double runner) & Balloon tag & Amerlcan Shad & 100 & 80 & 125 & 99.0 & 17 & 102.8 & 18.9 & 2.84 & 15.3 & 83.5 \\
\hline la cenlrale Beaurharnols, QE & Float lag & American eel & 100 & $\cdot$ & 888 & 197.9 & 13 & 75 & 24.1 & 5.38 & 21.1 & 84.2 \\
\hline Leaburg, OR & Full dschrg netling & Ralnbow trout & 1,249 & 624 & - & 31.1 & - & 225 & 27.1 & 2.29 & 26.9 & 95.2 \\
\hline Lequille, NS & Full dschrg nelling & Allantle salmon & $\cdot$ & $\cdot$ & $\cdot$ & 9.9 & 13 & 519 & 118.0 & 1.37 & 37.3 & 52.0 \\
\hline Luray, VA & Full dschrg nelting & Amerlcan Eel & 393 & $\cdot$ & 853 & 10.4 & 12 & 164 & 4.9 & 1.59 & 13.7 & 99.0 \\
\hline Minello, NY & Full dschrg nelling & Centrarchid & 164 & 104 & $<100$ & 42.4 & 16 & 72 & 5.2 & 3.53 & 13.3 & 62.0 \\
\hline Minello, NY & Full dschrg nelling & Centrarchid & 236 & 110 & 175 & 42.4 & 16 & 72 & 5.2 & 3.53 & 13.3 & 83.0 \\
\hline Minello, NY & Full dschrg nelting & Centrarchid & 165 & 120 & $>250$ & 42.4 & 16 & 72 & 5.2 & 3.53 & 13.3 & 84.0 \\
\hline Minello. NY & Full dschrg neltting & Percld & 133 & 117 & $<100$ & 42.4 & 16 & 72 & 5.2 & 3.53 & 13.3 & 80.0 \\
\hline Minello, NY & Full dschrg netting & Percld & 243 & 142 & 175 & 42.4 & 16 & 72 & 5.2 & 3.53 & 13.3 & 86.0 \\
\hline Minetlo, NY & Full dschrg nelting & Solt Ray & 348 & 220 & $<100$ & 42.4 & 16 & 72 & 5.2 & 3.53 & 13.3 & 82.0 \\
\hline Minello, NY & Full dschrg nelting & Solt Ray & 214 & 133 & 175 & 42.4 & 16 & 72 & 5.2 & 3.53 & 13.3 & 94.0 \\
\hline Minetlo, NY & Full dschrg netting & Solt Ray & 177 & 160 & $>250$ & 42.4 & 16 & 72 & 5.2 & 3.53 & 13.3 & 84.0 \\
\hline Mlnetlo, NY & Full dschrg netting & Salmonids & 237 & 160 & $<100$ & 42.4 & 16 & 72 & 5.2 & 3.53 & 13.3 & 92.0 \\
\hline Minetlo, NY & Full dschrg netting & Salmonlds & 184 & 107 & 175 & 42.4 & 16 & 72 & 5.2 & 3.53 & 13.3 & 91.0 \\
\hline Mlnetlo, NY & Full dschrg netting & Salmonlds & 178 & 159 & $>\mathbf{2 5 0}$ & 42.4 & 16 & 72 & 5.2 & 3.53 & 13.3 & 92.0 \\
\hline Minetlo, NY & Full dschrg nelting & Amerlcan Eel & 107 & 92 & 625 & 42.4 & 16 & 72 & 5.2 & 3.53 & 13.3 & 94.0 \\
\hline Minello, NY & Full dschrg nelling & Alewile & 189 & 140 & $<100$ & - & $\cdot$ & - & $\cdot$ & $\cdot$ & - & 80.0 \\
\hline North Fork, OR & Partlal netling & Coho salmon & 4,076 & 5,158 & - & 70.7 & - & 139 & 41.5 & 2.95 & 21.4 & 74.0 \\
\hline
\end{tabular}


Table 4.2-4

Physical and hydraulic characterlstics of hydroelectric dams equlpped with Francls type lurblnes for whlch survival data were deemed usable for direct effects (analysis utllized these data).

\begin{tabular}{|c|c|c|c|c|c|c|c|c|c|c|c|c|}
\hline Station & $\begin{array}{l}\text { Sampling } \\
\text { Mothod }\end{array}$ & Species Tested & $\begin{array}{l}\text { Test } \\
\text { sample } \\
\text { size } \\
\end{array}$ & $\begin{array}{l}\text { Control } \\
\text { sample } \\
\text { slze }\end{array}$ & $\begin{array}{l}\text { Avg. FIsh } \\
\text { Length } \\
\text { (mm) }\end{array}$ & $\begin{array}{l}\text { Turbine } \\
\text { Dlscharge } \\
\text { (cms) }\end{array}$ & $\begin{array}{l}\text { No. } \\
\text { of } \\
\text { Buckets }\end{array}$ & $\begin{array}{l}\text { Runner } \\
\text { Speed } \\
\text { (rpm) } \\
\end{array}$ & $\begin{array}{l}\text { Head } \\
\text { (m) }\end{array}$ & $\begin{array}{l}\text { Runner } \\
\text { Dia. } \\
\text { (m) } \\
\end{array}$ & $\begin{array}{l}\text { Peripheral } \\
\text { Veloclty } \\
\text { (m/s) } \\
\end{array}$ & $\begin{array}{l}\% \\
\text { Survival } \\
1 \mathrm{hr}\end{array}$ \\
\hline Peshtigo, WI (Unil 4) & Full dschrg nelling & Centrarchilorns & 146 & 84 & 76 & 13.0 & 15 & 100 & 4.0 & 2.03 & 10.6 & 100.0 \\
\hline Peshtlgo, WI (UnII A) & Full dschrg netling & Contrarchllorms & 140 & 77 & 127 & 13.0 & 15 & 100 & 4.0 & 2.03 & 10.6 & 98.9 \\
\hline Peshillgo, WI (Unit d) & Full dschrg nelling & Centrarchilorms & 121 & 75 & 178 & 13.0 & 15 & 100 & 4.0 & 2.03 & 10.6 & 100.0 \\
\hline Peshtlgo, WI (Unll 4) & Full dschrg nelling & Fusilorms & 158 & 103 & 76 & 13.0 & 15 & 100 & 4.0 & 2.03 & 10.6 & 94.0 \\
\hline Peshtlgo, WI (Unil 4) & Full dschrg nelling & Fusiloms & 141 & 90 & 127 & 13.0 & 15 & 100 & 4.0 & 2.03 & 10.6 & 93.7 \\
\hline Peshtlgo, WI (Unll 4) & Full dschrg nelling & Fusiloms & 166 & 109 & 178 & 13.0 & 15 & 100 & 4.0 & 2.03 & 10.6 & 96.6 \\
\hline Peshtlgo. WI (Unil 4) & Full dschrg netling & Fusliorms & 158 & 93 & 229 & 13.0 & 15 & 100 & 4.0 & 2.03 & 10.6 & 95.4 \\
\hline Peshitlgo, WI (Unll 4) & Full dschrg netling & Fusiforms & 166 & 105 & 292 & 13.0 & 15 & 100 & 4.0 & 2.03 & 10.6 & 85.5 \\
\hline Peshilgo, WI (Unil 4) & Full dschrg netling & Fuslioms & 128 & 79 & $>292$ & 13.0 & 15 & 100 & 4.0 & 2.03 & 10.6 & 82.8 \\
\hline Potato Raplds, WI (Unit 1) & Full dschrg netling & Centrarchilorms & 134 & 94 & 76 & 14.1 & 15 & 123 & 5.2 & 2.13 & 13.7 & 100.0 \\
\hline Potato Raplds, WI (Unlt 1) & Full dschrg nelling & Centrarchilorms & 154 & 93 & 127 & 14.1 & 15 & 123 & 5.2 & 2.13 & 13.7 & 84.7 \\
\hline Potato Rapids, WI (Unlt 1) & Full dschrg netling & Centrarchiforms & 111 & 70 & 178 & 14.1 & 15 & 123 & 5.2 & 2.13 & 13.7 & 83.0 \\
\hline Potato Rapids, WI (Unlt 1) & Full dschrg netting & Fuslforms & 168 & 104 & 76 & 14.1 & 15 & 123 & 5.2 & 2.13 & 13.7 & 89.2 \\
\hline Potato Rapids, WI (Unit 1) & Full dschrg netling & Fusilorms & 104 & 69 & 127 & 14.1 & 15 & 123 & 5.2 & 2.13 & 13.7 & 76.5 \\
\hline Potato Raplds, WI (Unlt 1) & Full dschrg netling & Fuslions & 150 & 91 & 178 & 14.1 & 15 & 123 & 5.2 & 2.13 & 13.7 & 68.4 \\
\hline Potato Raplds, WI (Unil 1) & Full dschrg netling & Fuslionms & 160 & 96 & 229 & 14.1 & 15 & 123 & 5.2 & 2.13 & 13.7 & 61.1 \\
\hline Potato Rapids, WI (Unit 1) & Full dschrg netting & Fusitoms & 136 & 83 & 292 & 14.1 & 15 & 123 & 5.2 & 2.13 & 13.7 & 53.3 \\
\hline Potato Rapids, WI (Unit 1) & Full dschrg netling & Fusliorms & 145 & 112 & $>292$ & 14.1 & 15 & 123 & 5.2 & 2.13 & 13.7 & 34.5 \\
\hline Potato Raplds, WI (Unit 2) & Full dschrg netling & Centrarchiloms & 166 & 105 & 76 & 14.1 & 15 & 123 & 5.2 & 2.13 & 13.7 & 93.4 \\
\hline Potato Rapids, WI (Unit 2) & Full dschrg netting & Centrarchilorms & 137 & 104 & 127 & 12.4 & 15 & 135 & 5.2 & 2.03 & 14.4 & 83.7 \\
\hline Potato Raplds, WI (Unit 2) & Full dschrg netling & Centrarchilorms & 58 & 28 & 178 & 12.4 & 15 & 135 & 5.2 & 2.03 & 14.4 & 91.4 \\
\hline Potato Rapids, WI (Unit 2) & Full dschrg netling & Fuslioms & 179 & 123 & 76 & 12.4 & 15 & 135 & 5.2 & 2.03 & 14.4 & 84.5 \\
\hline Potato Raplds, WI (Unit 2) & Full dschrg netling & Fuslioms & 134 & 93 & 127 & 12.4 & 15 & 135 & 5.2 & 2.03 & 14.4 & 61.7 \\
\hline Potato Rapids, WI (Unit 2) & Full dschrg netling & Fusllorms & 138 & 92 & 178 & 12.4 & 15 & 135 & 5.2 & 2.03 & 14.4 & 75.1 \\
\hline Potato Rapids, WI (Unit 2) & Full dschrg netling & Fuslioms & 158 & 98 & 229 & 12.4 & 15 & 135 & 5.2 & 2.03 & 14.4 & 61.0 \\
\hline Potato Raplds, WI (Unlt 2) & Full dschrg nettlng & Fusiforms & 156 & 91 & 292 & 12.4 & 15 & 135 & 5.2 & 2.03 & 14.4 & 57.8 \\
\hline Potato Raplds, WI (Unlt 2) & Full dschrg netling & Fuslfoms & 149 & 85 & $>292$ & 12.4 & 15 & 135 & 5.2 & 2.03 & 14.4 & 48.2 \\
\hline Pricket, MI & Full dschrg nelling & BluegllI & 256 & 150 & 52 & 9.2 & 15 & 257 & 16.5 & 1.36 & 18.3 & 97.7 \\
\hline Pricket, MI & Full dschrg nelling & Golden Shiner & 182 & 120 & $<100$ & 9.2 & 15 & 257 & 16.5 & 1.30 & 18.3 & 93.9 \\
\hline Pricket, MI & Full dschrg nelling & BluegllI & 131 & 90 & 102 & 9.2 & 15 & 257 & 16.5 & 1.36 & 18.3 & 92.5 \\
\hline Prickel, MI & Full dschrg netling & Bluegill & 21 & 21 & $>127$ & 9.2 & 15 & 257 & 16.5 & 1.36 & 18.3 & 85.7 \\
\hline Prickel, MI & Full dschrg nelling & Whille Sucker & 201 & 119 & 165 & 9.2 & 15 & 257 & 16.5 & 1.36 & 18.3 & 70.8 \\
\hline Publlshers, OR (1960) & Full dschrg nelling & Steelhead troul & 1,768 & 500 & - & 7.8 & - & 255 & 12.2 & $\cdot$ & - & 87.9 \\
\hline Publlshers, OR (1960) & Full dschrg nelling & Chinook saimon & 1,798 & 503 & - & 7.8 & - & 255 & 12.2 & - & - & 87.4 \\
\hline Publlshers, OR (1961) & Full dschrg netling & Steelhead trout & 1,800 & 500 & - & 7.8 & - & 255 & 12.2 & - & - & 84.5 \\
\hline Publishers, OR (1961) & Full dschrg nelling & Chinook saimon & 1,800 & 500 & - & 7.8 & $\cdot$ & 255 & 12.2 & - & - & 87.1 \\
\hline Punlledge, BC & Floating nel & Steolhead trout & 1,500 & - & 124 & $\cdot$ & - & 277 & 103.6 & 2.16 & 31.4 & 58.1 \\
\hline Punlledge, BC & Floating nel & Kamploops & 1,500 & - & 69 & - & - & 277 & 103.6 & 2.16 & 31.4 & 72.5 \\
\hline Puntledge, BC & Floating nel & Kamploops & 1,500 & - & 46 & - & - & 277 & 103.6 & 2.16 & 31.4 & 71.2 \\
\hline Punlledge, BC & Floating nel & Salmon & 1,500 & - & 36 & - & - & 277 & 103.6 & 2.16 & 31.4 & 67.4 \\
\hline
\end{tabular}


Physlcal and hydraulic characteristics of hydroelectric dams equipped with Francis type turbines for which survival dala were deemed usable for direcl effects (analysis utlized these data).

\begin{tabular}{|c|c|c|c|c|c|c|c|c|c|c|c|c|}
\hline Slation & $\begin{array}{l}\text { Sampling } \\
\text { Mothod }\end{array}$ & Specles Tested & $\begin{array}{l}\text { Test } \\
\text { sample } \\
\text { size } \\
\end{array}$ & $\begin{array}{l}\text { Control } \\
\text { sample } \\
\text { size } \\
\end{array}$ & $\begin{array}{l}\text { Avg. Fish } \\
\text { Length } \\
\text { (mm) }\end{array}$ & $\begin{array}{l}\text { Turblne } \\
\text { Discharge } \\
\text { (cms) }\end{array}$ & $\begin{array}{l}\text { No. } \\
\text { of } \\
\text { Buckets } \\
\end{array}$ & $\begin{array}{l}\text { Runner } \\
\text { Speed } \\
\text { (rpm) } \\
\end{array}$ & $\begin{array}{l}\text { Head } \\
\text { (m) }\end{array}$ & $\begin{array}{l}\text { Runner } \\
\text { Dia. } \\
\text { (m) }\end{array}$ & $\begin{array}{l}\text { Perlpheral } \\
\text { Velocity } \\
\text { (m/s) }\end{array}$ & $\begin{array}{l}\% \\
\text { Survlval } \\
1 \mathrm{hr} \\
\end{array}$ \\
\hline Rogers, MI (Unlls 1 \& 2) & Full dschrg netling & Bluegill & 90 & - & 118 & 10.8 & 15 & 150 & 11.9 & 1.52 & 12.0 & 96.0 \\
\hline Rogers, MI (Unils 1 \& 2) & Full dschrg nettlng & Bluegill & 92 & $\cdot$ & 170 & 10.8 & 15 & 150 & 11.9 & 1.52 & 12.0 & 85.2 \\
\hline Rogers, MI (Unlls 1 \& 2) & Fuil dschrg nettling & Gold./Common Shiner & 60 & - & 114 & 10.8 & 15 & 150 & 11.9 & 1.52 & 12.0 & \\
\hline Rogers, MI (Unils 1 \& 2) & Full dschrg nettling & Gold./Common Shlner & 34 & - & 154 & 10.8 & 15 & 150 & 11.9 & 1.52 & 12.0 & 92.5 \\
\hline Rogers, Ml (Unlls 1 \& 2) & Full dschrg nettling & Largemouth Bass & 60 & - & 118 & 10.8 & 15 & 150 & 11.9 & 1.52 & 12.0 & 77.4 \\
\hline Rogers, MI (Unils 1 \& 2) & Full dschrg netllng & Northem Pike & 47 & - & 352 & 10.8 & 15 & 150 & 11.9 & 1.52 & 12.0 & 83.4 \\
\hline Rogers, Ml (Unlls 1 \& 2) & Full dschrg netling & Spollall Shiner & 31 & $\cdot$ & 116 & 10.8 & 15 & 150 & 11.9 & 1.52 & 12.0 & 73.5 \\
\hline Rogers, MI (Unils 1 \& 2) & Full dschrg netling & Walleye & 40 & - & 385 & 10.8 & 15 & 150 & 11.9 & 1.52 & 12.0 & 86.2 \\
\hline Rogers, MI (Unils 1 \& 2) & Full dschrg nelllng & Whlle Sucker & 55 & - & 180 & 10.8 & 15 & 150 & 11.9 & 1.52 & 12.0 & 91.2 \\
\hline Rogers, MI (Unlls 1 \& 2) & Full dschrg nelling & While Sucker & 57 & - & 290 & 10.8 & 15 & 150 & 11.9 & 1.52 & 12.0 & 88.1 \\
\hline Rogers, Ml (Unlls 1 \& 2) & Full dschrg nelling & Yellow Perch & 78 & - & 107 & 10.8 & 15 & 150 & 11.9 & 1.52 & 12.0 & 91.8 \\
\hline Ruskin, BC & Fyke netting dwnstm & Sockeye Salmon & 12,125 & 12,159 & 86 & 113.1 & $\cdot$ & 120 & 39.6 & 3.78 & 23.8 & 89.5 \\
\hline Sandstone Raplds,WI & Full dschrg nelling & Centrarchliforms & 165 & 99 & 76 & 18.4 & 15 & 150 & 12.8 & 2.21 & 17.3 & 97.0 \\
\hline Sandstone Raplds,WI & Full dschrg nelling & Centrarchilorms & 141 & 90 & 127 & 18.4 & 15 & 150 & 12.8 & 2.21 & 17.3 & 80.7 \\
\hline Sandstone Raplds,WI & Full dschrg nelling & Centrarchilorms & 61 & 53 & 178 & 18.4 & 15 & 150 & 12.8 & 2.21 & 17.3 & 79.9 \\
\hline Sandstone Raplds,WI & Full dschrg nelling & Fusllonns & 169 & 100 & 76 & 18.4 & 15 & 150 & 12.8 & 2.21 & 17.3 & 64.9 \\
\hline Sandstone Raplds,WI & Full dschrg nelling & Fuslioms & 132 & 96 & 127 & 18.4 & 15 & 150 & 12.8 & 2.21 & 17.3 & 75.0 \\
\hline Sandstone Raplds,WI & Full dschrg nelling & Fusliorms & 145 & 97 & 178 & 18.4 & 15 & 150 & 12.8 & 2.21 & 17.3 & 76.0 \\
\hline Sandstone Raplds,WI & Full dschrg nelling & Fuslioms & 127 & 78 & 229 & 18.4 & 15 & 150 & 12.8 & 2.21 & 17.3 & 69.8 \\
\hline Sandstone Raplds,WI & Full dschrg nelling & Fusilorms & 119 & 71 & 292 & 18.4 & 15 & 150 & 12.8 & 2.21 & 17.3 & 58.4 \\
\hline Sandstone Raplds, WI & Full dschrg netlling & Fusilorms & 144 & 92 & $>292$ & 18.4 & 15 & 150 & 12.8 & 2.21 & $\begin{array}{l}17.3 \\
-\end{array}$ & 47.1 \\
\hline Schaghillicoke, NY & Full dschrg nelling & Centrarchid & 160 & 160 & 175 & 11.6 & 17 & 300 & 43.6 & 2.03 & 31.9 & 59.0 \\
\hline Schaghillicoke, NY & Full dschrg nelting & Percld & 239 & 237 & $<100$ & 11.6 & 17 & 300 & 43.6 & 2.03 & 31.9 & 68.0 \\
\hline Schaghllicoke. NY & Full dschrg neltting & Soft ray & 160 & 160 & $<100$ & 11.6 & 17 & 300 & 43.6 & 2.03 & 31.9 & 60.0 \\
\hline Schaghllicoke, NY & Full dschrg nelting & Soft ray & 149 & 150 & $>250$ & 11.6 & 17 & 300 & 43.8 & 2.03 & 31.9 & 22.0 \\
\hline Schaghillcoko, NY & Full dschrg nelling & Salmonld & 159 & 160 & $<100$ & 11.6 & 17 & 300 & 43.6 & 2.03 & 31.9 & 56.0 \\
\hline Selon Creek, BC & Fyke nel In talirace & Sockeye Salmon & - & $\cdot$ & 86 & 127.2 & $\cdot$ & 120 & 43.3 & 3.66 & 23.0 & 90.8 \\
\hline Shasla, CA (January) & Full dschrg nettlng & Chlnook Salmon & 4,800 & - & 102 & $41 \%$ wicket & 15 & 138.5 & 115.8 & 4.67 & 33.9 & 57.6 \\
\hline Shasla, CA (January) & Full dschrg netling & Ralnbow Trout & 1,000 & - & 254 & $41 \%$ wicket & 15 & 138.5 & 115.8 & 4.67 & 33.9 & 58.6 \\
\hline Shasla, CA (January) & Full dschrg netling & Steelhead & 3,200 & - & 152 & $41 \%$ wlcket & 15 & 138.5 & 115.8 & 4.67 & 33.9 & 79.0 \\
\hline Shasta, CA (January) & Full dschrg netling & Chinook Salmon & 4,800 & - & 102 & $50 \%$ wlcket & 15 & 138.5 & 115.8 & 4.67 & 33.9 & 60.4 \\
\hline Shasta, CA (January) & Full dschrg nelling & Ralnbow Trout & 1,000 & - & 254 & $50 \%$ wlcket & 15 & 138.5 & 115.8 & 4.67 & 33.9 & 53.1 \\
\hline Shasla, CA (January) & Full dschrg nelling & Steelhead & 3,200 & - & 152 & $50 \%$ wicket & 15 & 138.5 & 115.8 & 4.67 & 33.9 & 75.4 \\
\hline Shasta, CA (January) & Full dschrg nelling & Ralnbow Troul & 1,000 & - & 254 & $55 \%$ wicket & 15 & 138.5 & 115.8 & 4.67 & 33.9 & 58.8 \\
\hline Shasta, CA (January) & Full dschrg netllng & Steelhead & 3,200 & - & 152 & $55 \%$ wlcket & 15 & 138.5 & 115.8 & 4.67 & 33.9 & 81.6 \\
\hline Shasta, CA (January) & Full dschrg netllng & Chinook Salmon & 4,800 & - & 102 & $60 \%$ wlcket & 15 & 138.5 & 115.8 & 4.67 & 33.9 & 72.1 \\
\hline Shasta, CA (January) & Full dschrg netllng & Rainbow Trout & 1,000 & - & 254 & $60 \%$ wickel & 15 & 138.5 & 115.8 & 4.67 & 33.9 & 66.2 \\
\hline
\end{tabular}


Physical and hydraulic characteristics of hydroelectrle dams equipped with Francis lype turbines for which survival data were deemed usable for direct effects (analysis utlized these data).

\begin{tabular}{|c|c|c|c|c|c|c|c|c|c|c|c|c|}
\hline Station & $\begin{array}{l}\text { Sampling } \\
\text { Method }\end{array}$ & Species Tested & $\begin{array}{l}\text { Test } \\
\text { sample } \\
\text { slze } \\
\end{array}$ & $\begin{array}{l}\text { Control } \\
\text { sample } \\
\text { slze } \\
\end{array}$ & $\begin{array}{l}\text { Avg. Fish } \\
\text { Length } \\
\text { (mm) }\end{array}$ & $\begin{array}{l}\text { Turbine } \\
\text { Discharge } \\
\text { (cms) }\end{array}$ & $\begin{array}{l}\text { No. } \\
\text { of } \\
\text { Buckats } \\
\end{array}$ & $\begin{array}{l}\text { Runner } \\
\text { Speed } \\
\text { (rpm) }\end{array}$ & $\begin{array}{l}\text { Head } \\
(\mathrm{m})\end{array}$ & $\begin{array}{l}\text { Runner } \\
\text { Dla. } \\
\text { (m) } \\
\end{array}$ & $\begin{array}{l}\text { Perlpheral } \\
\text { Velocity } \\
(\mathrm{m} / \mathrm{s}) \\
\end{array}$ & $\begin{array}{l}\% \\
\text { Survival } \\
1 \mathrm{hr} \\
\end{array}$ \\
\hline Shasta, CA (January) & Full dschrg nelting & Steelhead & 3,200 & $\cdot$ & 152 & $60 \%$ wickel & 15 & 138.5 & 115.8 & 4.67 & 33.9 & 78.6 \\
\hline Shasta, CA (January) & Full dschrg netting & Chinook Salmon & 4,800 & - & 102 & $65 \%$ wlckel & 15 & 138.5 & 115.8 & 4.67 & 33.9 & 54.8 \\
\hline Shasta, CA (January) & Full dschrg nelling & Ralnbow Troul & 1,000 & - & 254 & $65 \%$ wlckel & 15 & 138.5 & 115.8 & 4.67 & 33.9 & 71.2 \\
\hline Shasta, CA (January) & Full dschrg nelling & Steelhead & 3,200 & - & 152 & $65 \%$ wickol & 15 & 138.5 & 115.8 & 4.67 & 33.9 & 89.3 \\
\hline Shasta, CA (November) & Full dschrg nelling & Chlnook Salmon & 11,500 & - & 102 & $40 \%$ wlckel & 15 & 138.5 & 115.8 & 4.67 & 33.9 & 61.7 \\
\hline Shasta, CA (November) & Full dschrg nelling & Steelhead & 4,400 & - & 152 & $40 \%$ wickel & 15 & 138.5 & 115.8 & 4.67 & 33.9 & 39.6 \\
\hline Shasta, CA (November) & Full dschrg nelting & Ralnbow Trout & 1,025 & . & 254 & $40 \%$ wlckel & 15 & 138.5 & 115.8 & 4.67 & 33.9 & 50.5 \\
\hline Shasta, CA (November) & Full dschrg nelling & Chinóok Salmon & 11,500 & - & 102 & $50 \%$ wlckel & 15 & 138.5 & 115.8 & 4.67 & 33.9 & 69.7 \\
\hline Shasta, CA (November) & Full dschrg nelting & Sleelhead & 4,400 & - & 152 & $50 \%$ wickel & 15 & 138.5 & 115.8 & 4.67 & 33.9 & 72.3 \\
\hline Shasta, CA (November) & Full dschrg nelting & Ralnbow Trout & 1,025 & - & 254 & $50 \%$ wlcket & 15 & 138.5 & 115.8 & 4.67 & 33.9 & 59.8 \\
\hline Shasta, CA (November) & Full dschrg nelting & Chinook Salmon & 11,500 & * & 102 & $55 \%$ wlckel & 15 & 138.5 & 115.8 & 4.67 & 33.9 & 77.9 \\
\hline Shasta, CA (November) & Full dschrg nelling & Sleelhoad & 4,400 & - & 152 & $55 \%$ wlckel & 15 & 138.5 & 115.8 & 4.67 & 33.9 & 90.5 \\
\hline Shasta, CA (November) & Full dschrg nelling & Ralnbow Trout & 1,025 & - & 254 & $55 \%$ wlckel & 15 & 138.5 & 115.8 & 4.67 & 33.9 & 69.2 \\
\hline Shasta, CA (November) & Full dschrg nelling & Chinook Saimon & 11,500 & - & 102 & $61 \%$ wickel & 15 & 138.5 & 115.8 & 4.67 & 33.9 & 84.5 \\
\hline Shasta, CA (November) & Full dschrg nelling & Sleelhead & 4,400 & - & 152 & $61 \%$ wlckel & 15 & 138.5 & 115.8 & 4.67 & 33.9 & 59.8 \\
\hline Shasta, CA (November) & Full dschrg nelling & Rainbow Trout & 1,025 & • & 254 & $61 \%$ wicket & 15 & 138.5 & 115.8 & 4.67 & 33.9 & 68.1 \\
\hline Stevens Creek, SC & Balloon lag & Bluegill & 110 & 110 & 122 & 28.3 & 14 & 75 & 8.5 & 3.43 & 13.5 & 95.4 \\
\hline Stevens Creek, SC & Balloon lag & Blueback Herring & 131 & 120 & 203 & 28.3 & 14 & 75 & 8.5 & 3.43 & 13.5 & 95.3 \\
\hline Stevens Creek, SC & Balloon lag & Spolted SuckerN. Perch & 120 & 120 & 165 & 28.3 & 14 & 75 & 8.5 & 3.43 & 13.5 & 98.3 \\
\hline T. W. Sullivan, OR & Dlscharge nelting & Steelhead trout & - & - & - & - & - & 242 & 12.5 & - & . & 74.1 \\
\hline T. W. Sullivan, OR & Discharge nelting & Chinook salmon & - & - & - & 7.4 & - & 242 & 12.5 & - & - & 85.7 \\
\hline Vernon, VT/NH & Balloon tag & American Shad & 153 & 150 & 95 & 51.9 & 15 & 74 & 10.4 & 3.96 & 15.3 & 94.7 \\
\hline Whlle Raplds, WI & Balloon tag & While Sucker & 42 & 36 & 204 & 25.4 & 14 & 100 & 8.8 & 3.40 & 17.8 & 93.0 \\
\hline White Raplds, WI & Balloon tag & While Sucker & 58 & 64 & 112 & 25.4 & 14 & 100 & 8.8 & 3.40 & 17.8 & 100.0 \\
\hline Whilte Raplds, WI & Balloon tag & Blueglll & 56 & 62 & 90 & 25.4 & 14 & 100 & 8.8 & 3.40 & 17.8 & 95.0 \\
\hline Whlte Raplds, WI & Balloon tag & Bluegill & 44 & 38 & 155 & 25.4 & 14 & 100 & 8.8 & 3.40 & 17.8 & 100.0 \\
\hline Youghlogheny, PA & Full dschrg netling & Alewile & \multicolumn{3}{|c|}{ Naluralty entrained 51} & 21.2 & - & - & 36.6 & - & - & 0.1 \\
\hline Youghlogheny, PA & Full dschrg netling & Walleye & \multicolumn{3}{|c|}{ Naturally entrained 376} & 21.2 & - & - & 36.6 & - & - & 39.5 \\
\hline Youghlogheny, PA & Full dschrg netling & Pock bass & \multirow{2}{*}{\multicolumn{2}{|c|}{$\begin{array}{l}\text { Nalurally entralned } \\
\text { Nalurally entralned }\end{array}$}} & $\cdot$ & 21.2 & - & - & 36.6 & - & - & 4 \\
\hline Youghlogheny. PA & Full dschrg netling & Yellow perch & & & - & 21.2 & - & - & 36.6 & - & - & 7 \\
\hline Youghlogheny.PA & Full dschrg netlling & Crapples & \multicolumn{2}{|c|}{ Naturally entrained } & & 21.2 & - & - & 36.6 & - & - & 0.2 \\
\hline Youghlogheny. PA & Full dschrg netling & While sucker & \multicolumn{2}{|c|}{ Nalurally entralned } & - & 21.2 & - & - & 36.6 & - & - & 9.5 \\
\hline
\end{tabular}

- Composite number of tish Introduced and their recapture rates; November tests - test $=91.0 \%$ and control $=73.8 \%$, January lests - 1 est $=72 \%$ and control=66\%. 

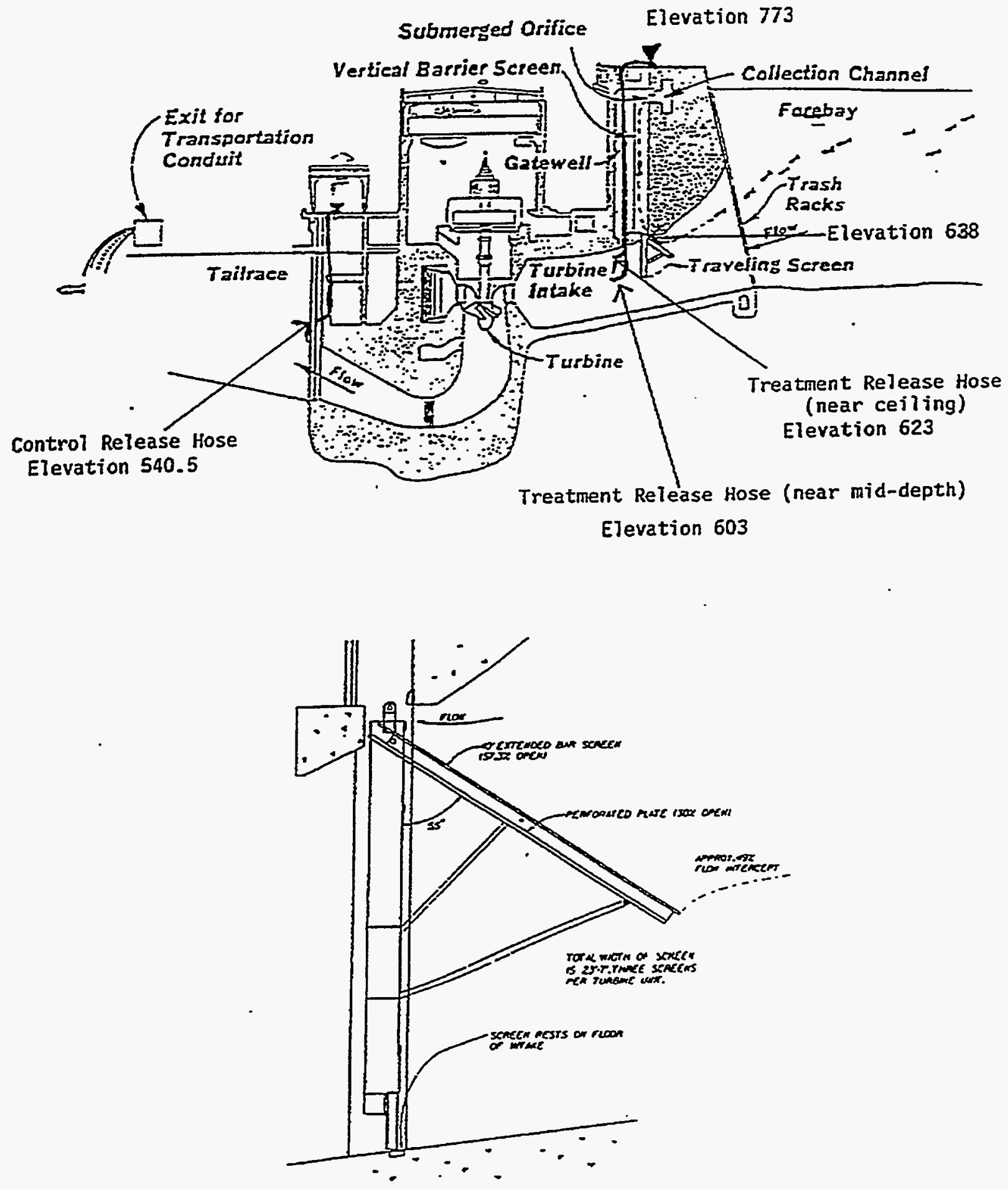

Figure 4.2-1

Turbine intake equipped with fish guidance extended length screens at Lower Granite Dam. From Normandeau Associates et al. (1995). 

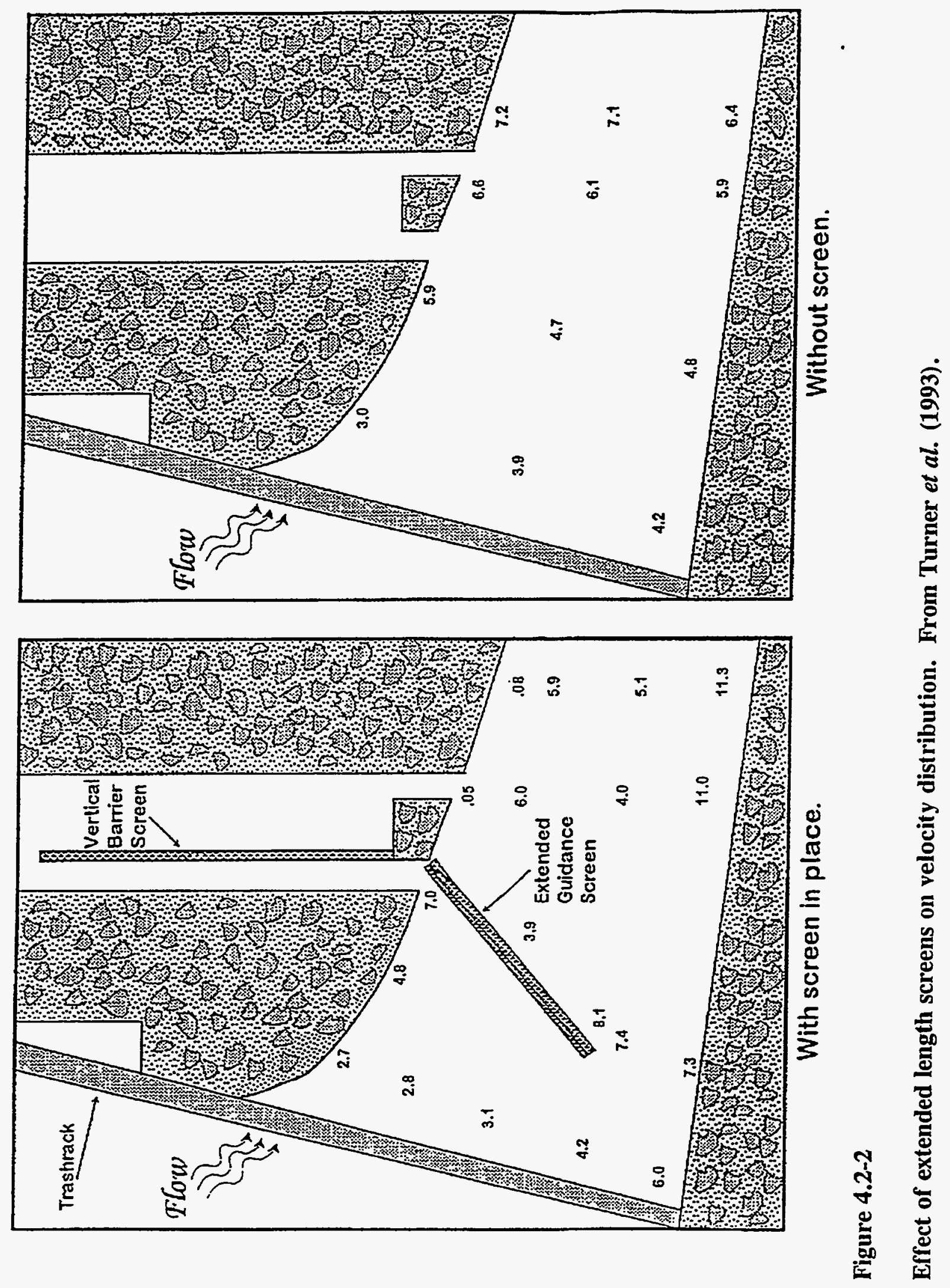


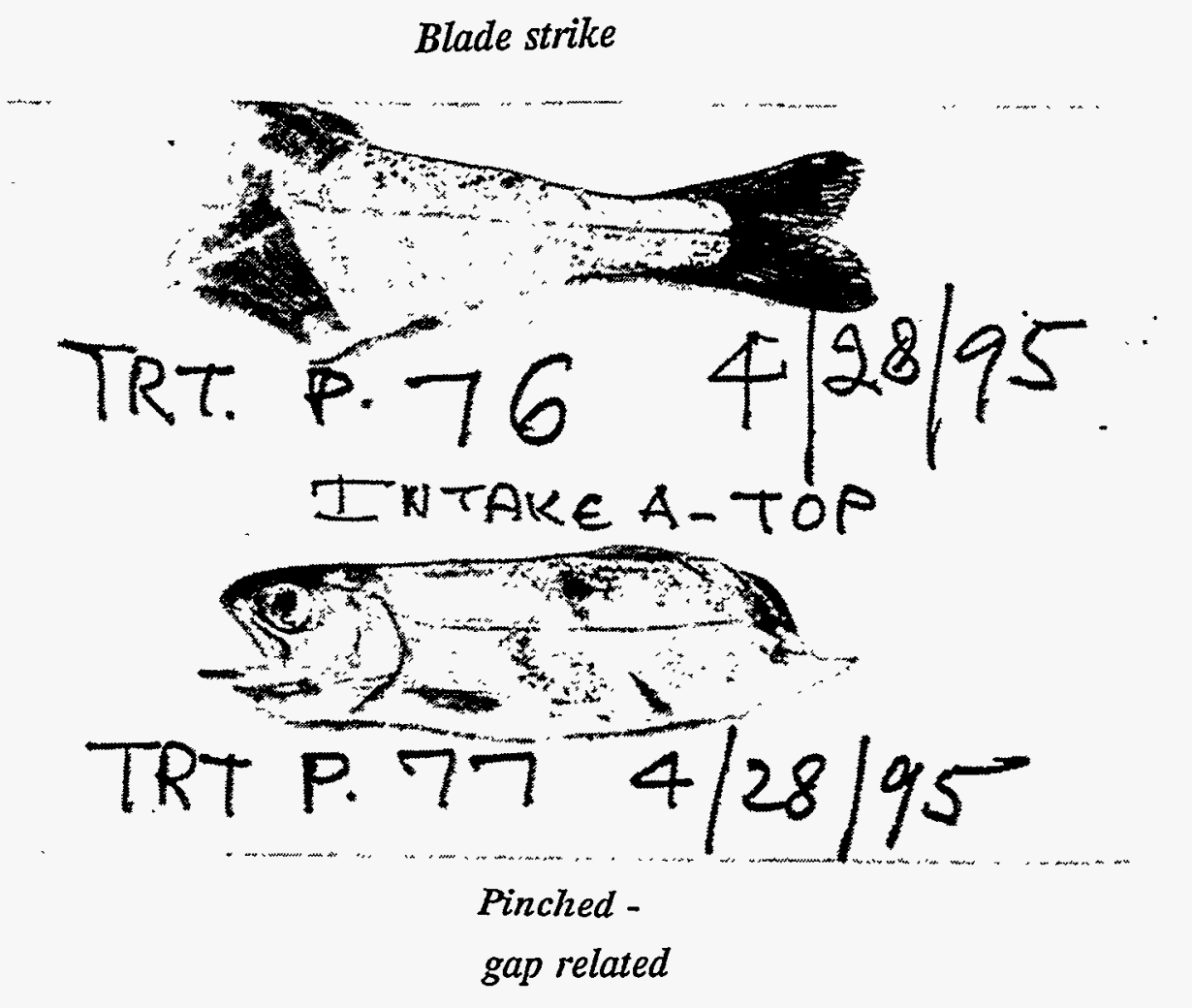

Figure 4.2-3

Example of mechanical injuries, blade and gap related. From Normandeau Associates et al. (1995). 


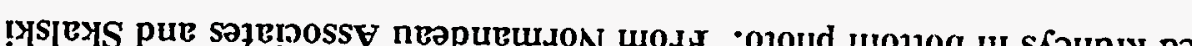

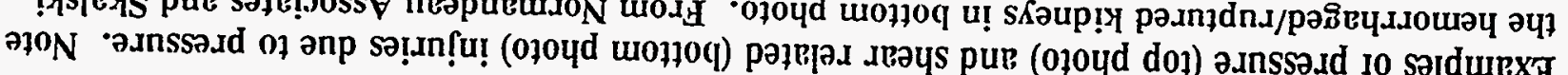
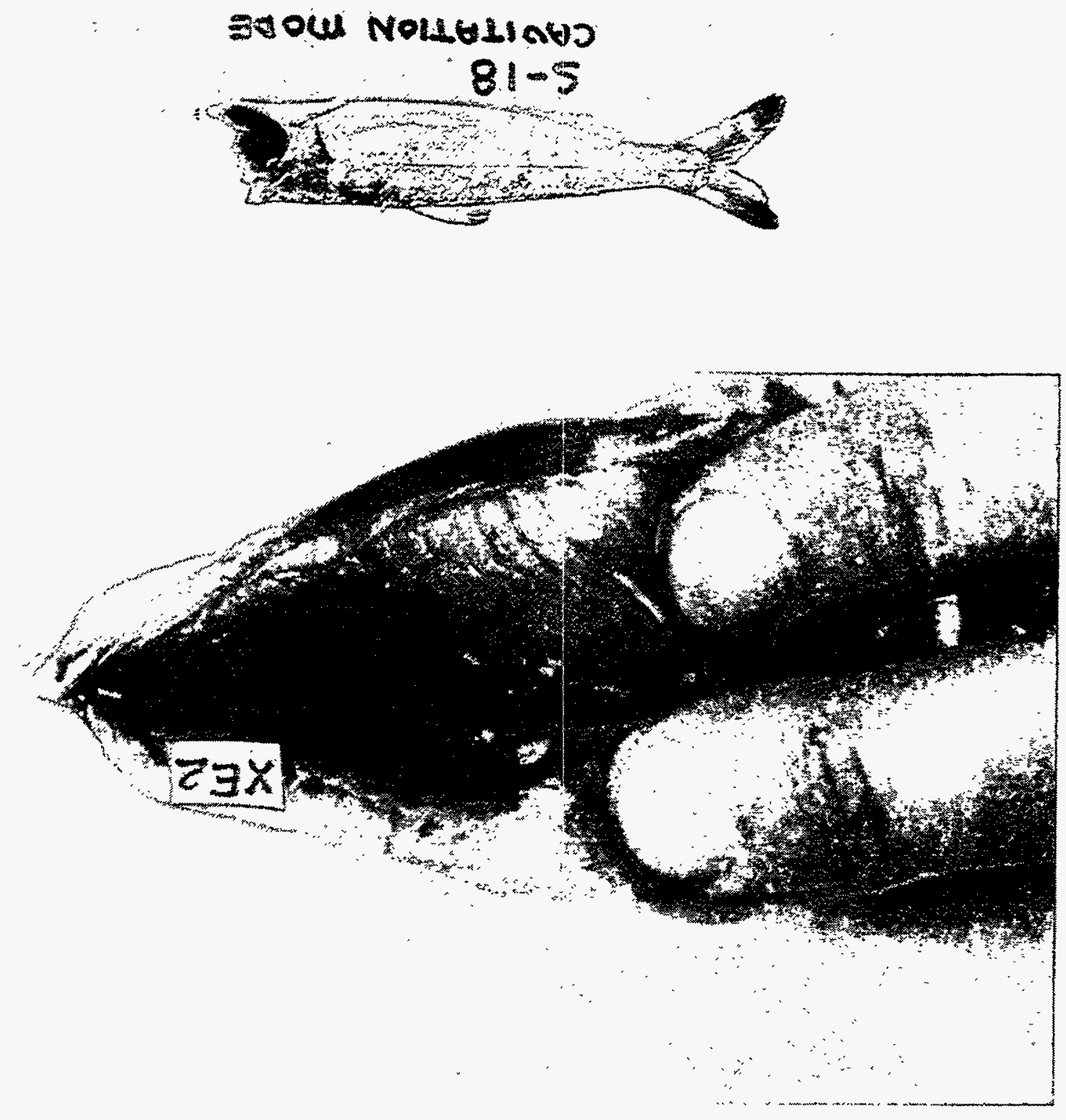


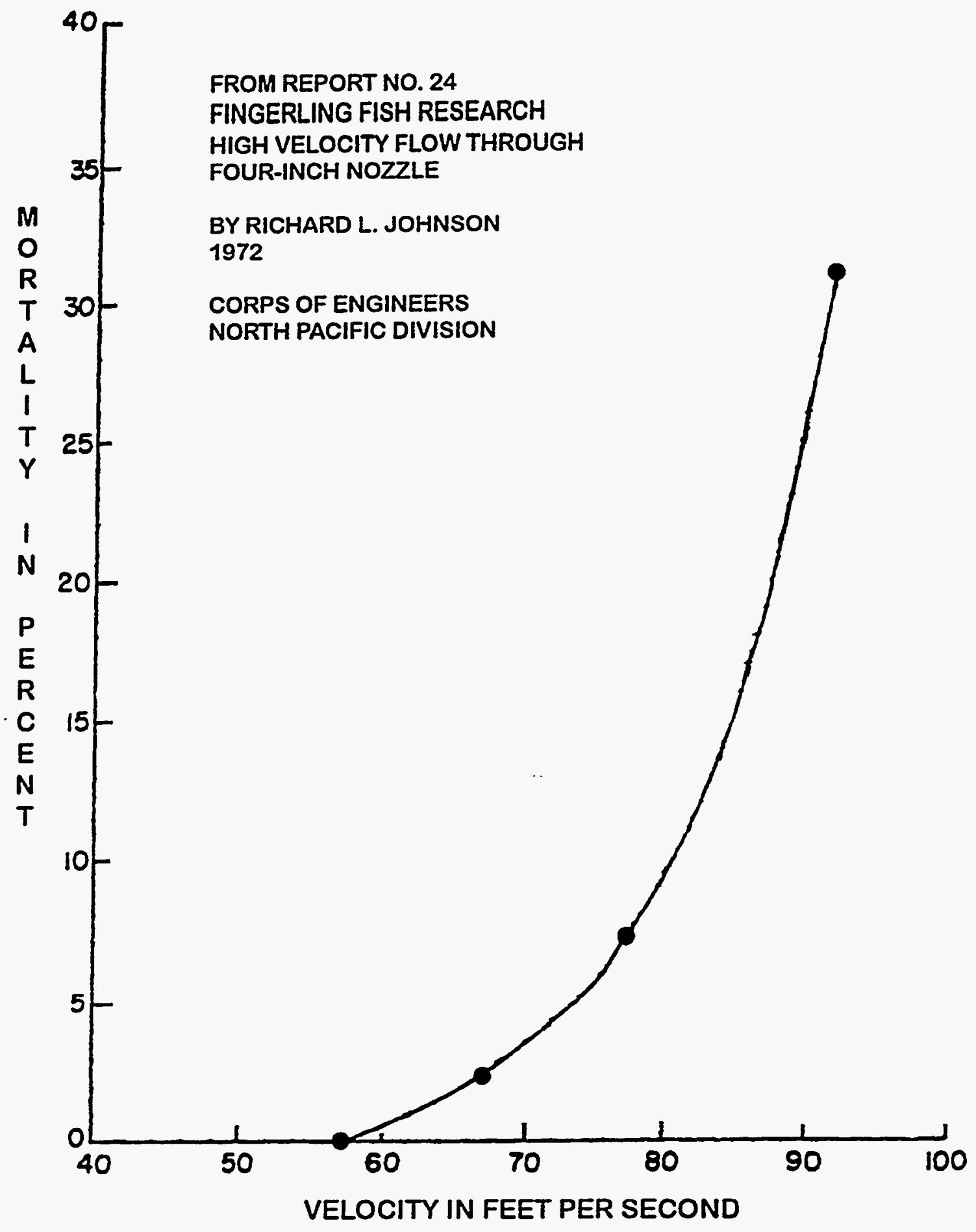

Figure 4.2-5

Effect of shear velocity on fingerling salmonid mortality. From Bell (1984). 


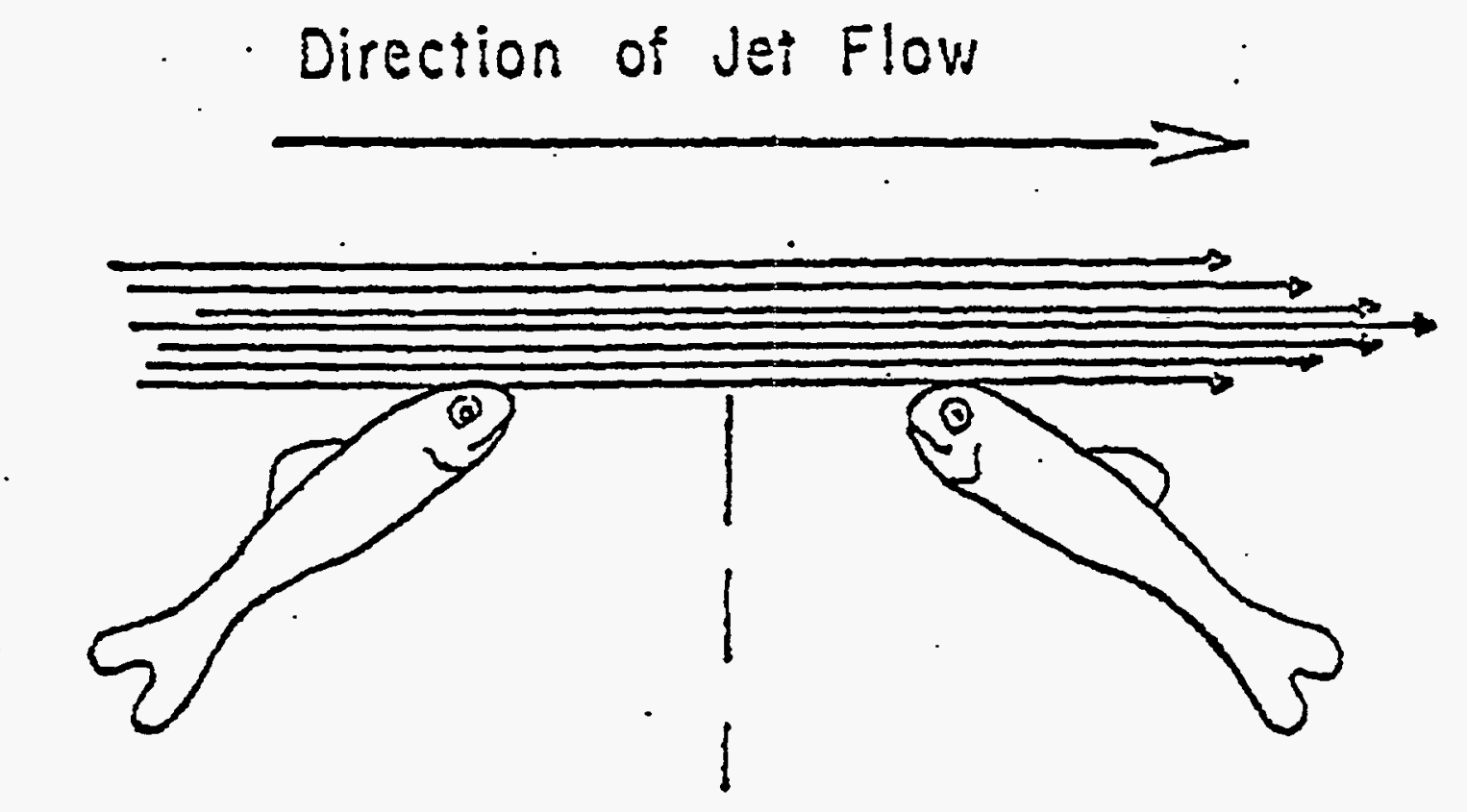

FISH POSITION "A" I FISH POSITION "B"

$$
\text { I }
$$

Figure 4.2-6

Effects of shear on the orientation of fish. From Groves (1972). 


\subsection{FISH SURVIVAL PREDICTION METHODS}

\subsubsection{MECHANISMS FOR FISH INJURY}

\subsubsection{Background}

\section{Overview of Prediction Methods}

Fish survival prediction methods developed here are primarily oriented toward direct effects that may be verified by field studies of fish passage through turbines. Other effects that could cause indirect mortality such as stress induced effects leading to mortality after a longer period of time or abrasion related infection, disorientation, visual or other sensory impairment resulting in predation and so forth have not been explicitly considered. Predation, an indirect effect, resulting from turbine powerhouse design and its impact on the backroll in the tairace is discussed in Section 4.3.3.5. The types of analyses performed here may be extended to other effects such as disorientation (leading to an increased probability of predation), if biological data become available showing the effects of quantified disorienting phenomena.

Several mechanisms inducing fish injury may be amenable to numerical prediction. These include mechanical, fluid and pressure mechanisms. Mechanical mechanisms inducing damage to the fish body may be classified as being related to:

- leading edge strike The effect of a fish impact on a turbine blade leading edge, possibly a gap between a blade and adjacent structure, a stay vane leading edge, a wicket gate leading edge, or the leading edge of a support pier in an intake or draft tube.

- gap grinding The effect of a fish caught in a narrow region formed between a blade and an adjacent component

- abrasion The effect of a fish sliding against a turbine structure

- wall strike The effect of a fish impact on a relatively flat turbine structure

- mechanical chop The effect of a fish cut by a rotating blade against a stationary wicket gate trailing edge

Fluid mechanisms inducing damage to the fish body may be classified as being related to:

- excess energy dissipation (Theoretically Avoidable Loss) The effect of a fish passing near or through a region where the flow is experiencing turbulence, velocity gradients, vortices, or related phenomena that dissipate more energy (cause more losses) than the most benign flow field that could exist in an idealized turbine flow field. These phenomena, when sufficiently intense, can create a force on a fish body of high enough level to cause damage or mortality. A variety of mechanisms will induce such damage, such as:

* non-optimum incidence on blades, vanes, gates, etc.

* flow through and downstream of gaps (blade or wicket gate overhang) and clearances which produce vortices and shear zones

* vortices that form at a blade leading edge, or as a result of complex flow phenomena

* non-optimum flow entering the draft tube or developing in the draft tube as a result of flow separation or flow interaction with pier structures.

- cavitation The effect of water vapor bubble collapse. The bubble which forms in a region of low pressure, moves to a region of higher pressure and collapses due to the increase in pressure above the vapor pressure. Depending on the shape of the vaporized region and the pressure and velocity gradients involved, the collapse may create intense local pressure waves, jets of high velocity fluid and regions of strong flow turbulence. 
Pressure related mechanisms inducing damage to the fish body may be related to

- pressure reduction injury resulting from the inability of fish to adjust from the regions of high pressure immediately upstream of the turbine to regions of low pressure downstream of the turbine. This includes both bladder rupture and gas embolism effects. The pressure change in the turbine environment itself may not be of sufficient magnitude and duration to be significant;

Two types of predictions have been considered: 1) global one-dimensional methods that are based on overall turbine characteristics, and 2) detailed three-dimensional methods that are based on precise details of the flow field that are calculated for all internal components for all operating conditions. Sections 4.3.2 through 4.3.4 discuss these methods in the application to survival prediction. For additional insight, Section 5.3 presents results of three-dimensional Computational Fluid Dynamics (CFD) flow field analysis methods applied to typical turbine geometry to quantify characteristics of turbine flow fields.

Several types of predictive approaches have been considered. In the study of mechanically induced damage, particularly leading edge strike, one dimensional methods with some guidance from 3-D methods have shown some success and are examined further. For fluid-induced damage mechanisms, another approach was developed. Here, the mortality caused by the dissipation of energy in the turbine was evaluated in a novel way. This evaluation does not explicitly calculate the individual effects of turbulence and strong velocity gradients, nor the effects of grinding, scraping or wall strike. Instead, the mortality is implicitly addressed based on empirical data through knowledge of the flow field. Based on the analysis of measured survival data, new insights into turbine operation to maximize fish survival were obtained. For shear, using the results of turbulence modeled two-dimensional calculations and correlation with previous experiments utilizing fish, a basis for prediction of a critical shear zone was developed

To assist in the quantification of pressure and time scales which are characteristic of the turbine environment so that the data can be used for further biological evaluation, pressure versus time determination was done for flow through typical turbine components and the results are presented in Section 5.3. The design of the power plant, and in particular, the turbine intake structure and its location in the dam, its length, the time of passage and so forth are important as the plant civil design may allow fish to become acclimated to a high pressure so that when fish are discharged into a low pressure in the tailrace, decompression trauma may occur. For this effect, no formal predictions have been made as they lay outside the scope of this study.

With better biological basis it may be possible to derive mortality predictions associated with fish body forces determined from the computation of some of these fluid and mechanically based effects arising from fish swimming through actual turbine environments. Sections 5.3 and 5.4 demonstrate some of the flow field features that can be calculated with modern three-dimensional turbulence modeled calculation methods.

\section{Operation Limits and Hill Curves}

The performance of a turbine is typically displayed on a hill curve as shown in Figure 4.3.1-1. On the abscissa( $x$ axis) the head $(H)$ or head coefficient $\left(E_{\omega d}\right)$ is presented. On the ordinate $(y$ axis) the discharge rate $(Q)$ or discharge coefficient $\left(Q_{\omega d}\right)$ is presented. The head coefficient is based on the net head, the acceleration of gravity, as well as the rotational speed and the turbine diameter. The discharge 
is the volume of water discharged through the turbine per unit time. The discharge coefficient is based on the discharge as well as the rotational speed and the turbine diameter. The definitions of these coefficients are given below.

The use of coefficients rather than dimensional data for a particular size and speed turbine is a common practice. In this way the performance data of a turbine is known for any choice of turbine size, head, rpm, etc. If a turbine is constructed to be geometrically similar to another turbine (such as to a scale size laboratory model), then the turbine performance characteristics shown in coefficient form are also similar.

The turbine efficiency is presented in the form of iso-efficiency contours. Each of the contour curves represents a constant efficiency level. The center point of these contour curves is the best efficiency point of the machine. There are several reasons that the operation of a turbine is not always made at this best efficiency point. As conditions change the location of the operating point can move to different regions on the hill curve. As head varies, the point of operation moves to the left or right of the peak. As the demand for power varies, more or less water is required to be discharged and the operation moves'above or below this optimum point. There are also operational limitations associated with power (generator limitations), cavitation, gate opening capability, and/or pressure pulsations. Operation of a Kaplan turbine anywhere on this performance curve requires operation of the machine at the "on-cam" combination of wicket gate opening and blade tilt. On-cam operation means that the wicket gate opening and the blade tilt vary with head and output in order to maximize the efficiency of the machine at the given head and discharge of the point of operation. If not operated on cam, efficiency values will be less and undesirable fluid and vibratory conditions can exist. For a more in depth presentation of operating characteristics of turbines, the reader is referred to ASME Hydro Power Technical Committee (1996).

\subsubsection{Nomenclature}

The reader is referred to Figures 4.3.2-1 through 4.3.2-3 to help understand the variables defined here.

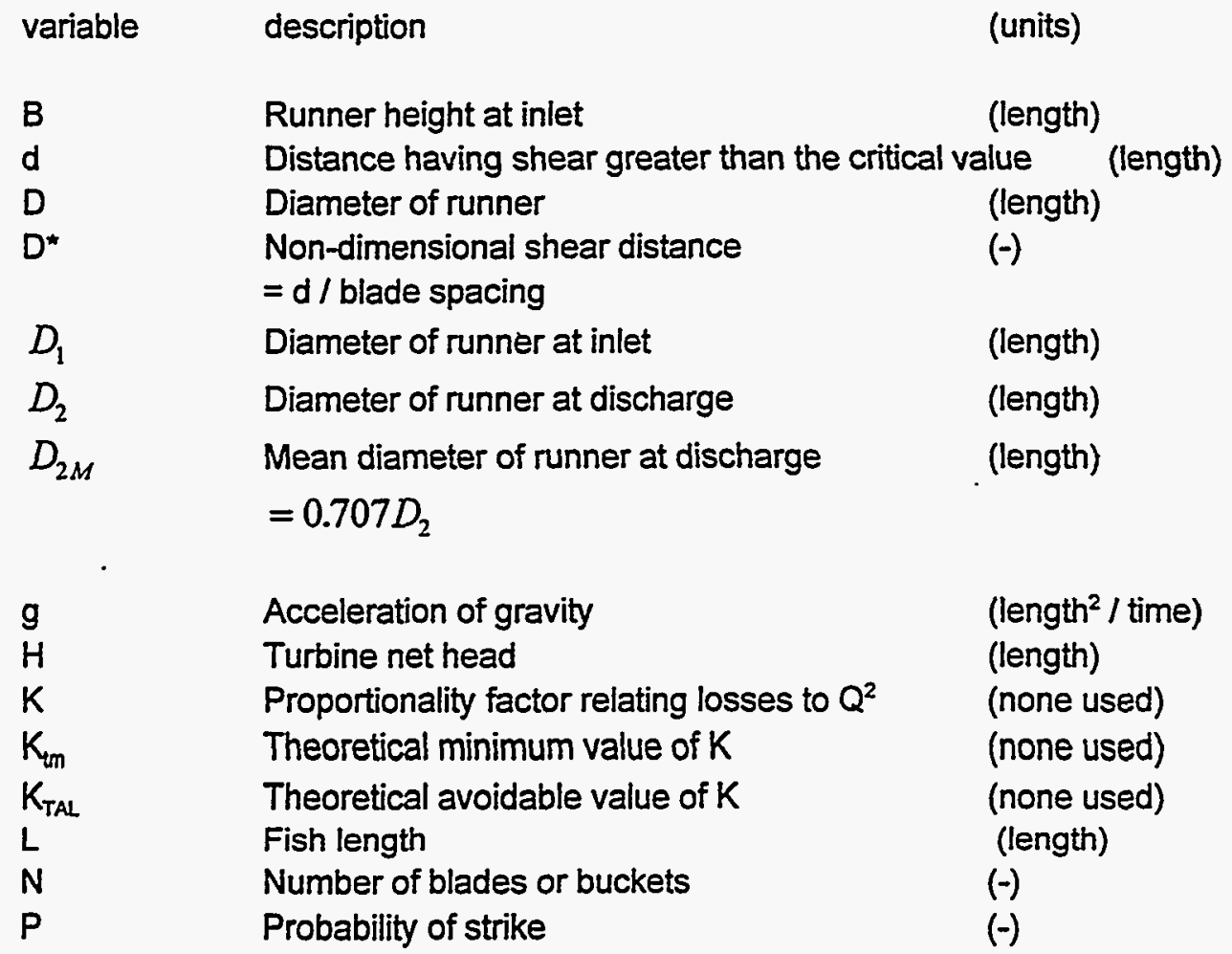




\begin{tabular}{|c|c|c|}
\hline Q & Turbine discharge & (length ${ }^{3} /$ time $)$ \\
\hline$Q_{\text {opt }}$ & Turbine discharge at best efficiency & (length ${ }^{3} /$ time) \\
\hline$r$ & Radius & (length) \\
\hline $\mathrm{R}$ & Maximum radius & (length) \\
\hline RPM & Revolutions per minute & \\
\hline$t$ & Time for passage of fish or runner blade & (time) \\
\hline$V_{a}$ & Axiai velocity & (length / time) \\
\hline$V_{r}$ & Radial velocity & (length / time) \\
\hline Vref & Reference velocity & (length / time) \\
\hline$V_{\theta 1}$ & Absolute tangential velocity at runner inlet & (length / time) \\
\hline$V_{\theta 2}$ & Absolute tangential velocity at runner exit & (length / time) \\
\hline$\alpha_{t}$ & \multicolumn{2}{|c|}{$\begin{array}{l}\text { angle to tangential of absolute flow upstream of runner }(-) \\
\text { (for Francis turbines) }\end{array}$} \\
\hline$\alpha_{a}$ & \multicolumn{2}{|l|}{$\begin{array}{l}\text { angle to axial of absolute flow upstream of runner } \\
\text { (for Axial flow turbines) }\end{array}$} \\
\hline$\beta$ & Relative flow angle at runner discharge & $(-)$ \\
\hline$\xi$ & Ratio between $Q$ with no exit swirl and $Q$ opt & $(-)$ \\
\hline$\lambda$ & Strike mortality correlation factor ( lambda) & $(-)$ \\
\hline$\eta$ & Turbine efficiency & $(-)$ \\
\hline$\omega$ & $\begin{array}{l}\text { Rotational speed } \\
=R P M \cdot \frac{2 \pi}{60}\end{array}$ & (1/ time) \\
\hline$E_{o d d}$ & $\begin{array}{l}\text { Energy coefficient } \\
=\frac{g H}{(\omega D)^{2}}\end{array}$ & $(-)$ \\
\hline$Q_{a d}$ & $\begin{array}{l}\text { Discharge coefficient } \\
=\frac{Q}{\omega D^{3}}\end{array}$ & $(-)$ \\
\hline
\end{tabular}




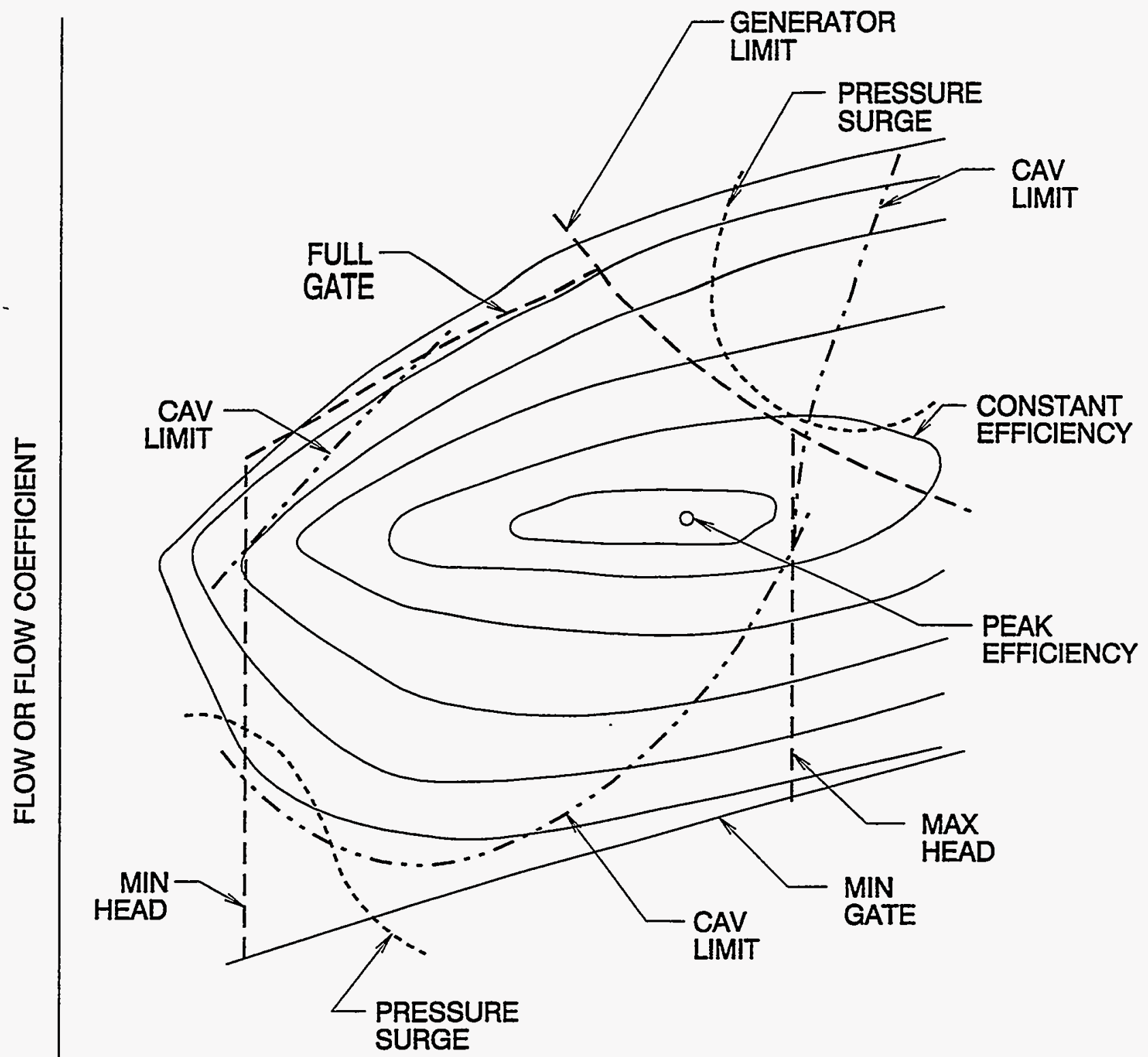

\section{HEAD OR HEAD COEFFICIENT}

Figure 4.3.1-1 Turbine Operation is Quantified on a Hill Curve 


\subsubsection{MECHANICAL MECHANISMS LEADING TO FISH INJURY}

\subsubsection{Development of New Leading Edge Strike Equation}

\section{Summary}

The existing strike equations are reviewed, an improved set of equations are developed and better methods are developed to apply the equations. The improvement to the equations is based on adding consideration for the tangential projection of the fish length. Better methods to apply the equations are based upon calculating the flow angles based on overall operating head and discharge parameters. New insights are obtained by analysis of a non-dimensional form of the equations. While their development is similar in concept, the equations for Kaplan, Propeller and Francis turbines are presented separately.

\section{Discussion}

\section{Review of Existing Method}

An existing method for strike prediction was examined (Von Raben 1957, cited by Bell 1991). This method considers the fish length, turbine runner size and number of buckets, turbine rpm, and assumes the fish is aligned with the local flow. The basis of the derivation is that the strike probability is the ratio of time for the meridional length of the fish to pass the leading edge of a runner blade divided by the time between passage of successive runner blades. The analysis assumes that the fish remains in a twodimensional plane of revolution of a point at a given radius on the blade. Essentially, the fish is modeled as a meridional line segment and the blade is modeled as a point. It was also initially assumed that any impact by the blade along any portion of the fish length would be fatal. A factor to correlate experimental data was included. The phenomena that small fish (relative to blade size) may be transported around the blade leading edge was not considered.

Note that the terms mortality and survival are related. This section discusses the probability of strike, and with a correlation factor, strike could be considered to be related to mortality. Most of the presentation of experimental turbine passage data is presented in terms of survival. Survival can be determined from mortality, for example, using percentages, as:

\section{Survival $=100 \%-$ Mortality}

The physics of strike are the same for Francis turbines and for axial flow turbines (both Kaplan, Propeller and Bulb turbines), but the equations have slightly different form because of the different geometries of these turbines. Figure 4.3.2-1 and 4.3.2-2 illustrates the terminology used for the flow field variables and Figure 4.3.2-3 shows the geometry variables for Francis turbines. For example, for a Francis turbine, the times of passage are:

$$
\begin{aligned}
& t_{\text {numer }}=\frac{\frac{\pi D_{1}}{N}}{\frac{\omega D_{1}}{2}} \\
& t_{\text {fish }}=\frac{L \cdot \sin \alpha_{1}}{V_{r}}
\end{aligned}
$$

The resulting Von Raben strike probability equations are: 
Francis

$P_{\text {VonRuhen }}=\frac{L \cdot \sin \alpha_{1}}{V_{r}} \cdot \frac{N \cdot \frac{\omega D_{1}}{2}}{\pi D_{1}}$

Axial Flow

$P_{\text {VonRaben }}=\frac{L \cdot \cos \alpha_{a}}{V_{a}} \cdot \frac{N \cdot \frac{\omega D}{2}}{\pi D}$

\section{Derivation of New Equation}

Since the existing method has demonstrated some promise in correlating fish survival, the basic physics used to derive these equations was reexamined. It was observed that the meridional component of the fish length was considered, but the tangential component of length was not considered. The Von Raben equation gave results that could be physically unrealistic in some circumstances. As an example, in a situation where the tangential projection of the fish length is greater than the blade to blade spacing, it is not possible for a fish to pass through the ei:arance edge region of a runner without touching a runner blade, Figure 4.3.2-4. In this case, the actual strike probability is $100 \%$. The strike probability calculated by the above equations gives a false value less than $100 \%$.

By considering the tangential projection of fish length, a more accurate strike prediction is obtained. This contribution to strike probability is the ratio of the tangential projection of fish length to distance between successive runner blades, Figure 4.3.2-5. The additional contribution to strike probability is:

Francis

$P_{\text {tan gential }}=\frac{L \cdot \cos \alpha_{t}}{\frac{\pi D}{N}}$

Axial Flow

$$
P_{\text {tan gential }}=\frac{L \cdot \sin \alpha_{a}}{\frac{2 \pi \cdot r}{N}}
$$

With some rearrangement, both contributions can be expressed as:

\section{Francis}

$$
P=\frac{N \cdot L}{D} \cdot\left[\frac{\omega D_{1} \cdot \sin \alpha_{1}}{2 \pi \cdot V_{r}}+\frac{\cos \alpha_{1}}{\pi}\right]
$$




\section{$\underline{\text { Kaplan and Propeller }}$}

$$
P=\frac{N \cdot L}{D} \cdot\left[\frac{\cos \alpha_{a} \cdot \omega}{2 \pi \cdot V_{a}}+\frac{\sin \alpha_{a}}{\pi \frac{r}{R}}\right]
$$

Although the terms N L I D have been grouped to clarify their importance, this form of the strike equations has several drawbacks. Key relationships between variables are not clear and their application to a specific turbine operating condition, i.e. calculation of the flow angle, requires a number of assumptions. Note that if the orientation of the fish were not equal to the local flow angle, and if this angle were available from other means, then the orientation could be used directly. The following section presents an alternative form of the new leading edge strike equations.

\section{An Improved Form of the New Leading Edge Strike Equation Summary}

The use of the strike equations can be improved by replacing some of the ad hoc estimates of flow angle that had been used by previous investigators. The use of non-dimensional head and discharge parameters clarifies important relationships between variables. Additional generalizations were added to provide a correlation factor that may be based on experimental fish survival data.

\section{Discussion}

By using more accurate assumptions regarding the internal flow field in a turbine and expressing the result in a non-dimensional form, the usefulness and accuracy of the strike equations is greatly enhanced. Two main concepts have been used. The first is the use of Euler's equation to evaluate the flow angle based on known values of key operating parameters, such as head and discharge. The second concept is the use of non-dimensional parameters. Euler's equation states the reaction torque on the runner is equal to the change in angular momentum of the flow through the runner. As was done by other investigators, the discharge and cross sectional area are used to calculate an average through-flow velocity.

An additional correlation function, lambda $(\lambda)$, is added to the equations to account for several factors. One is that the fish may not lie entirely in a plane of revolution. This could be caused by the forces that act on a three-dimensional body in a flow or fish free will. Another is, as has been suggested by other investigators, a length related fraction could be applied because an impact on a sensitive portion of the fish body, particulariy the head region may be more damaging than an impact to a different region, such as near the tail. Yet another factor is the phenomena that the local details of the flow at the leading edge of a blade will transport a fish in a manner that can carry it around the leading edge. While readily observed in physical tests, this factor has not been quantified numerically at this time.

In addition to strike phenomena, the use of lambda extends the applicability of these equations to all injury mechanisms that are related to the variable $N$ L / D. Such mechanisms could include mechanical mechanisms of leading edge strike and gap grinding as well as fluid induced mechanisms related to flow through gaps or other flow phenomena associated with blades. Subsequent discussion will conclude that these "strike" equations may be generalized and could be termed "Blade Zone Encounter" (BZE) equations. The lambda factor is further discussed in Sections 4.4.3 and 4.4.6. 
Axial Flow Turbines

For axial turbines, the average axial velocity is assumed to be

$V_{a}=\frac{Q}{\frac{\pi}{4} D^{2}}$

and $a$ useful form of Euler's equation is

$g H \eta=\omega \cdot r\left(V_{\theta 1}-V_{\theta 2}\right)$ with

$\tan \alpha_{a}=\frac{V_{\theta 1}}{V_{a}}$

A Kaplan turbine is double regulated with both wicket gates and runner blades being adjustable in position. When operated "on - cam", the blade and gate positions are coordinated to achieve the highest possible efficiency. As a result, the flow discharging the blades, entering the draft tube, has a small and reasonably constant amount of swirl (tangential velocity) at all operating conditions. A good assumption is to use $V_{\theta 2}$ equal to zero. Figure 4.3.2-6 illustrates the difference between the exit swirl characteristics of an adjustable blade machine, i.e., a Kaplan, versus a fixed blade machine such as a propeller turbine or Francis turbine. The complete strike equation including the lambda function can be expressed as:

\section{Kaplan Turbine Leading Edge Strike Equation}

$P=\lambda \frac{N \cdot L}{D} \cdot\left[\frac{\cos \alpha_{a}}{8 Q_{a d}}+\frac{\sin \alpha_{a}}{\pi \frac{r}{R}}\right]$ with the value of $\alpha_{a}$ most conveniently obtained from

$\tan \alpha_{a}=\frac{\pi E_{\omega d} \cdot \eta}{2 Q_{\omega d} \frac{r}{R}}$

Several important relationships can be deduced from this form of the equation. A primary variable is the non-dimensional grouping of $N L / D$. This is the ratio of fish length to blade spacing. The individual values of $L, N$, or $D$ are not important, only their ratio is important. Fish strike probability is linearly proportional to this ratio. The use of non-dimensional head and flow variables shows that factors such as head, discharge, rpm, or tip speed do not appear individually. Therefore, they do not affect the strike probability. The variables head, discharge and rpm occur only in the terms $E_{\text {odd }}$ (the head coefficient) and $Q_{\omega d}$ (the discharge coefficient). For a given design of Kaplan turbine, the variables $E_{\omega d d}$ and $Q_{\omega d}$ uniquely specify the operating point. A given design of Kaplan turbine with the same number of blades $\mathrm{N}$ can be built in different sizes, rpm, and for different heads to suit specific site requirements. Therefore, machines of varying size, head, etc. (such as a model in a laboratory or an extremely large unit) will have identical fish strike characteristics, and will be a function only of the non-dimensional grouping of $L / D$. 
Figure 4.3.2-7 shows a strike probability calculation at the blade mid span non-dimensional radius $r / R=$ 0.75 for all operating conditions for a particular Kapian design. Since the values of the correlation factors are not yet determined, the strike probability is normalized by-the value that occurs at the best efficiency point. The primary trend which can be observed is that strike probability decreases significantly as the discharge increases, and that the strike probability increases somewhat when operating at heads less than the optimum head. This leads to the proposition that higher discharges are beneficial for fish survival influenced by blade leading edge strike. This proposition is further evaluated in Section 4.4. Also, operation at heads lower than the optimum head will have higher strike probability and presumably higher mortality than operation at the optimum head.

The probability of strike varies with the radius along the blade entrance edge. Figures 4.3.2-8 and 4.3.2-9 show the calculated effect for two discharges as a function of radius. The currently developed formula as well as the previous formula are used to demonstrate that the previously accepted belief that strike probability is lower at the hub is valid for low discharges, but not at high discharges. Figure 4.3.2-10 presents the result of the calculated ratio of strike probability at the hub to strike probability at the periphery as a function of discharge.

The contribution of the additional term in the strike equation due to the tangential length of a fish was examined by calculating the strike probability for a number of Kaplan units. This calculation included the full range of specific speed for axial flow turbines, from three bladed Bulb units to seven bladed Kaplan's. Figure 4.3.2-11 shows that the additional term, although generally small compared to the overall strike probability, is growing in magnitude as specific speed decreases. For reference, a discussion of specific speed in contained in Appendix 10.2.

\section{Propeller Turbine}

A propeller machine is similar to a Kaplan, but has runner blades that are fixed to the hub. They can not be adjusted. The discharge swirl of such a machine varies continuously with the machine discharge. Under the assumption that at the propeller turbine's best efficiency point, its operation is similar to a Kaplan turbine, the exit swirl velocity, $V_{\theta 2}$ is assumed to be zero at the best efficiency point. Using this known relationship, $V_{\theta 2}$ is calculated for any other operating condition. The strike equation is the same as for a Kaplan, but the relationship for the flow angle can be expressed as:

Propeller Turbine Leading Edge Strike Equation

$$
\tan \alpha_{a}=\frac{\frac{\pi}{2} E_{\alpha d} \cdot \eta}{Q_{\omega d} \frac{r}{R}}+\frac{\frac{\pi}{8} \frac{r}{R}}{Q_{\omega d}}-\tan \beta \quad \text { where }
$$

$$
\tan \beta=\frac{\frac{\pi}{8} \frac{r}{R}}{Q_{o d} o p t}
$$


Francis Turbines

A similar procedure may be followed for Francis turbines. The average radial speed is calculated from the discharge and the area at the runner inlet.

$$
V_{r}=\frac{Q}{\pi D_{1} B}
$$

This assumption is most applicable to turbines of low specific speed. For turbines of high specific speed, the meridional curvature of the water passage causes a variation in the flow velocity. The velocity near the band is higher than the average value and the velocity near the crown is lower than the average, Figure 4.3.2-12. The strike probability : will vary along the inlet edge, from crown to band. The equations presented below are based on a constant inflow velocity from band to crown, therefore, it is likely that these equations will suffer reduced accuracy for higher specific speed Francis turbines. An attempt was made to approximate the velocity profile based on a simple radius of curvature method, however, the low accuracy of this approximate method does not seem to justify its additional complexity. Higher accuracy velocity profiles may be obtained through application of CFD analysis tools.

A useful form of Euler's equation is:

$g H \eta=\omega\left(\frac{D_{1} V_{\theta 1}}{2}-\frac{D_{2 M} V_{\theta 2}}{2}\right)$ with

$\tan \alpha_{i}=\frac{V_{r}}{V_{\theta 1}}$

In a similar manner to a propeller turbine, the discharge swirl from the runner changes continuously with discharge. It is assumed that a zero swirl discharge flow occurs at a user specified multiple of the discharge at the best efficiency point $(\xi \cdot Q o p t)$. At this value of flow, the discharge conditions are known, in particular, the relative flow angle $\beta$. Using this known flow angle, $V_{\theta 2}$ is calculated for any other operating condition. Note that a mean radius is used at the runner discharge. The complete equation can be expressed as:

\section{Francis Turbine Leading Edge Strike Equation}

$$
\begin{aligned}
& P=\lambda \frac{N \cdot L}{D} \cdot\left[\frac{\sin \alpha_{t} \cdot \frac{B}{D_{1}}}{2 Q_{\omega d}}+\frac{\cos \alpha_{t}}{\pi}\right] \text { with the value of } \alpha_{t} \text { most convenientiy obtained from } \\
& \tan \left(90-\alpha_{t}\right)=\frac{2 \pi E_{\alpha d} \cdot \eta}{Q_{\alpha d}} \cdot \frac{B}{D_{1}}+\frac{\pi \cdot 0.707^{2}}{2 Q_{\alpha d}} \frac{B}{D_{1}}\left(\frac{D_{2}}{D_{1}}\right)^{2}-4 \cdot 0.707 \cdot \tan \beta \frac{B}{D_{1} D_{1}} \text { and }
\end{aligned}
$$




$$
\tan \beta=\frac{0.707 \cdot \frac{\pi}{8}}{\xi \cdot Q_{\omega x} \text { opt }\left(\frac{D_{1}}{D_{2}}\right)^{3}}
$$

A value of $\xi=1.1$ is suggested as a typical value for a zero swirl discharge. The resulting leading edge strike probability is shown in Figure 4.3.2-13. The strike probability is normalized by the value at the best efficiency point. Since the flow mechanisms are different than a Kaplan turbine, the resulting strike probability is different. Generally, the strike probability increase at lower heads (similar to the Kaplan) but the strike probability can increase with increasing discharge. This strike probability increase is caused by the change in the flow angle compared to the change in discharge and occurs differently than in a Kaplan turbine. The implications for fish passage are that increased discharge may not contribute to lower mortality in the same manner as is expected for Kaplan turbines.

The accuracy of the improved method for calculating values of flow angle, $\alpha_{t}$ and $\alpha_{a}$ is evaluated in Appendix 10.4

\subsubsection{Gap Grinding}

\section{Summary}

The presence of a gap as defined below creates a source of both mechanical and fluid mechanisms which may injure fish. The prediction of mortality due to gap induced velocity fields and mechanical gap grinding requires an advancement of technology from today's basis. Estimations of the gap related effect on fish injury are developed based on two experimental observations discussed in Section 4.4.5.

\section{Discussion}

Kaplan blades rotate with a hub around the shaft axis of rotation and also in the hub about a blade axis of rotation and change position as the turbine operates. To accommodate the rotation on the unit in the stationary discharge ring and the blades within the hub assembly between high blade tilts and low blade titts, traditional Kaplan blades have clearances and gaps. Before discussing gaps, it is important to differentiate between clearances and gaps. Clearance describes the minimal distance required between two surfaces for relative movement of those two surfaces. In order for the individual blades to change tilt within the runner, there must be a minimal clearance between the inner radius of the blades and the hub (approximately 0.00035 times the runner diameter). In order for the runner assembly to rotate within the stationary discharge ring there must be a minimal clearance between the outer radius of the blades and the discharge ring (approximately 0.0007 times the runner diameter). These minimal clearances are unavoidable; they must exist for the unit to function. Typically, these clearances are much smaller than a typical fish, and are presumed to have minimal impact on fish mortality. The terminology "gap" as used here describes a distance that is significantly greater than a clearance. The causes of gaps are described below.

In a conventional Kaplan design the hub and discharge ring surfaces are combinations of spherical, cylindrical and conical sections in the areas where they are in close proximity to the blades. The hub and discharge ring surface shapes are designed to accommodate mechanical needs such as disassembly, or to provide space for conventional blade servomotor and linkage mechanisms to operate. Figure 6.2.1-2 shows a Kaplan blade at minimum and maximum tilts and the gaps typically created by cylindrical and conical sections on the hub and periphery. With the blade set at its maximum tilt, the inner radius surface 
of the blade is machined to fit any adjacent non-spherical surface of the hub. At maximum tilt there is no gap between the blade and hub. At minimum tilt a significant gap is created between the blade and hub. Some turbines have had special considerations whereby gaps between the blades and the hub have been minimized in certain regions between the blade and the hub. Because of the ease of assembly and disassembly, most Kaplan turbines are provided with discharge rings having a cylindrical surface upstream of the blade centerline and with a partially spherical surface downstream of the blade centerline. With the blade set at its minimum tilt, the outer radius surface of the blade is machined to fit any adjacent non-spherical surface of the discharge ring. At minimum tilt there is no gap between the blade and discharge ring. At maximum tilt there is a significant gap between the blade and discharge ring, particularly upstream and occasionally at the lower region of the discharge ring as the blade extends beyond the often provided partially spherical segment. Gaps can exist in other locations in the turbine. For example, some wicket gate and discharge ring designs are such that the wicket gate overhangs the top of the discharge ring at high gate openings creating a gap. Thus, gap geometries vary significantly depending on the turbine design and the point of operation of the turbine.

Gaps between the blade and hub may cause significant mortality (from approximately $2 \%$ to more than $5 \%$ ) for the fish entering the turbine near the roof of the intake and passing through the runner at it's inner radius (Section 4.4.5). Similar gap related mortality may exist for the fish entering the turbine blades near the outer blade diameter. Fish in this outer diameter region could come from those near the floor elevation of the intake which pass through the runner at it's outer radius (Section 4.4.6) or come from fish which entered the turbine intake at other elevations but were then transported to the region of the blade tip gaps because of cross flow currents caused by fish diversion devices, or by large separation regions or secondary flows in the intake, stay vanes, wicket gates or the runner inlet. Gap related mortality includes not only the effect of mechanical gap grinding (a fish caught in the narrow gap), but mortality arising from fluid related effects such as excess energy dissipation effects (Section 4.3.3).

The prediction of gap grinding is not amenable to a one-dimensional analysis other than to account for the presence or absence of a gap. A preliminary CFD analysis is presented in Section 5.3.4 that verifies some of the expectations of the flow through a gap. A prediction of the loads applied to a fish being caught in this region would require a CFD calculation including the presence of a "virtual fish". Gap effects are related to the number of blades.

Observations of carefully planned and executed experiments do give some indications of mortality that has occurred in these regions. Section 4.4 .5 reviews the results of a fish passage survival determination at the Rocky Reach Dam and concludes that a gap at the trailing edge of a blade caused approximately $4.4 \%$ additional mortality for a particular operating condition. Section 4.4 .6 reviews the results of a fish passage survival determination at Wanapum Dam and concludes that fish injected at a location expected to transport the fish near the runner inner radius experienced approximately $3 \%$ additional mortality in comparison to fish passing through the middle section of the blades. This mortality is attributed to fluid and mechanical effects related to the blade leading edge gap and other geometries in the vicinity of the runner hub.

\subsubsection{Abrasion}

\section{Summary}

Use of 3-D advanced CFD methods is probably necessary for abrasion prediction. However, a new insight into the role of cross sectional area is presented here. The probability of occurrence of scrape due to the space between blades is unknown. 


\section{Discussion}

While abrasion is a mechanical effect arising from a fish scraping a mechanical surface, it can also be related to the degree of excess fiuid energy dissipation in a design, and therefore the point of operation of a turbine and to the overall quality of the hydraulic design. As an example, fish in a swirling draft tube flow may have a higher chance for wall scrape. A fish having a large size in relationship to the minimum space between turbine blades (the vent dimension) could lead to scrape. The scrape effect related to vent depends on turbine type. The blades of Francis and Propeller turbines are fixed in position and have a fixed value of vent. Kaplan turbine blades change their position as a function of operating point. At low blade tilts (openings), the space between blades is smaller, while at high blade tilts, which correspond to high discharge, the space is larger. Also the smaller number of blades in Kaplan and Propeller turbines will give larger values of vent.

The prediction of scrape generally requires the use of advanced CFD analysis tools for any quantitative assessment. It is expected that scrape could occur due to both primary and secondary flows, centrifugal and buoyancy effects, or fish volitional movement. The flow field effects leading to abrasion will be discussed in Section 4.3.3, Fluid Mechanisms Leading to Fish Injury.

One aspect of scrape, however, that can be clarified is the role of cross sectional area. Several references have presumed that a turbine design goal should be to maximize the cross sectional area through the turbine. Figure 4.3.2-14 illustrates the concept of "vent" of a turbine. The vent of a turbine is the minimum distance between adjacent blades. It occurs near the blade trailing edge. In general, a fish passing through the turbine runner would experience a continuous decrease in cross sectional area. If the body of the fish were not flow aligned, and if the fish length were larger than the vent dimension, then it seems possible that the decreasing cross sectional area could cause the fish to scrape against a runner blade.

The value of vent for a particular turbine design is determined by the number of blades and the local geometry of the blade outlet edge, particularly the blade angle. A smaller number of blades will have a larger vent. For a given design condition, (number of blades, head, discharge, rpm, etc.) the blade angle is essentially fixed, therefore, the vent is fixed and can not be arbitrarily adjusted.

The frequency of scrape type injuries and factors that influence scrape are uncertain. The fish survival studies that have attributed sources of injury to possible causes are limited.

\subsubsection{Wall Strike}

\section{Summary}

Use of 3-D advanced CFD methods is probably necessary for wall strike prediction

\section{Discussion}

While wall strike could be thought of as similar to abrasion, we differentiate it here as a mechanical injury caused by a fish body impact with a wall with enough energy to cause mechanical injury. For this to occur a relatively high rate of change of velocity over a distance related to fish length is necessary. While it is basically a mechanically induced injury, wall strike is assumed to be induced by vortices and high turbulence levels related to the fish length. It is related to the point of operation and the quality of the hydraulic design. Section 5 addresses fluid conditions that could lead to wall strike. 


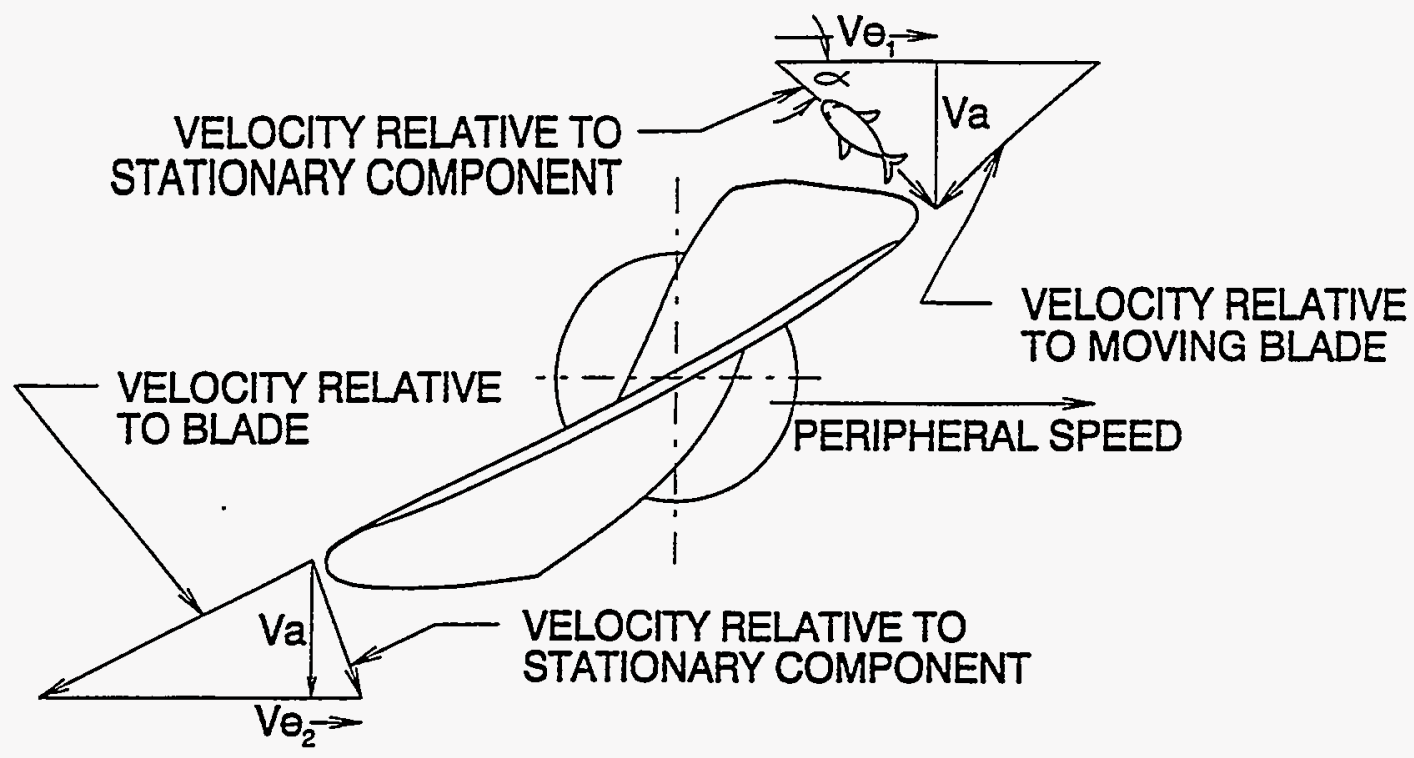

Figure 4.3.2-2 Illustration of Axial Flow Turbine Flow Inlet and Outlet Velocities and Angles

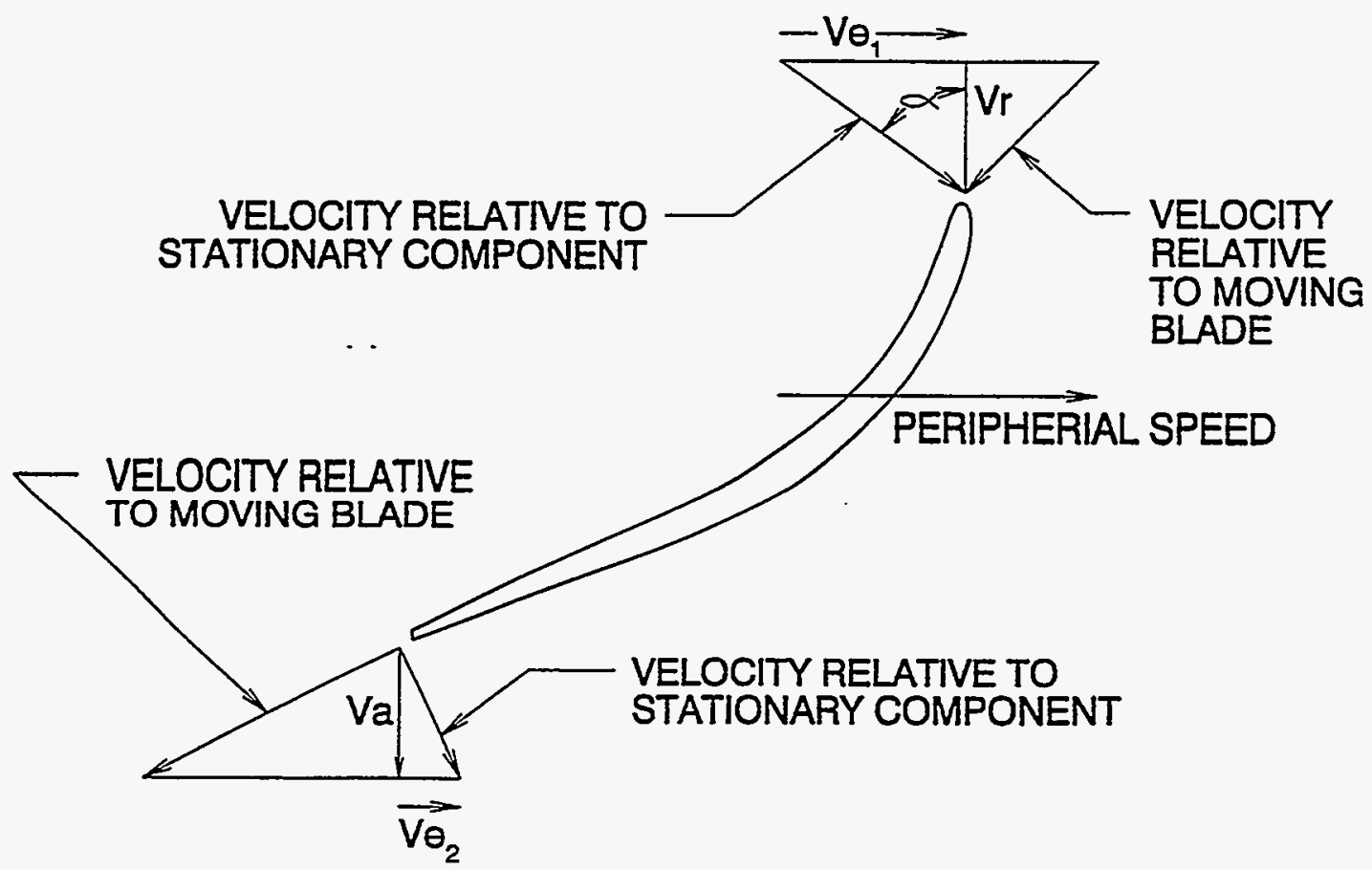

Figure 4.3.2-1 Illustration of Francis Turbine Flow Inlet and Outlet Velocities and Angles 


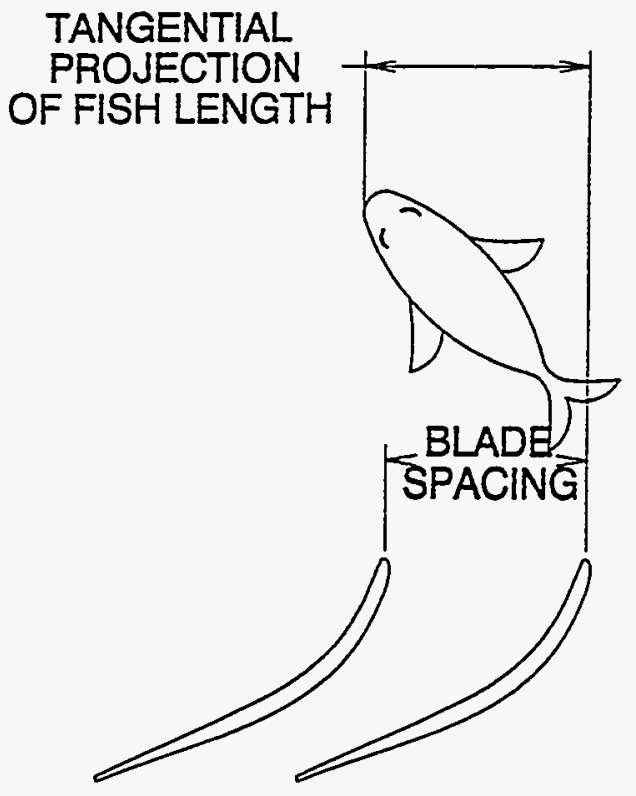

Figure 4.3.2-4 Illustration of Tangential Fish Length that Exceeds Blade Spacing

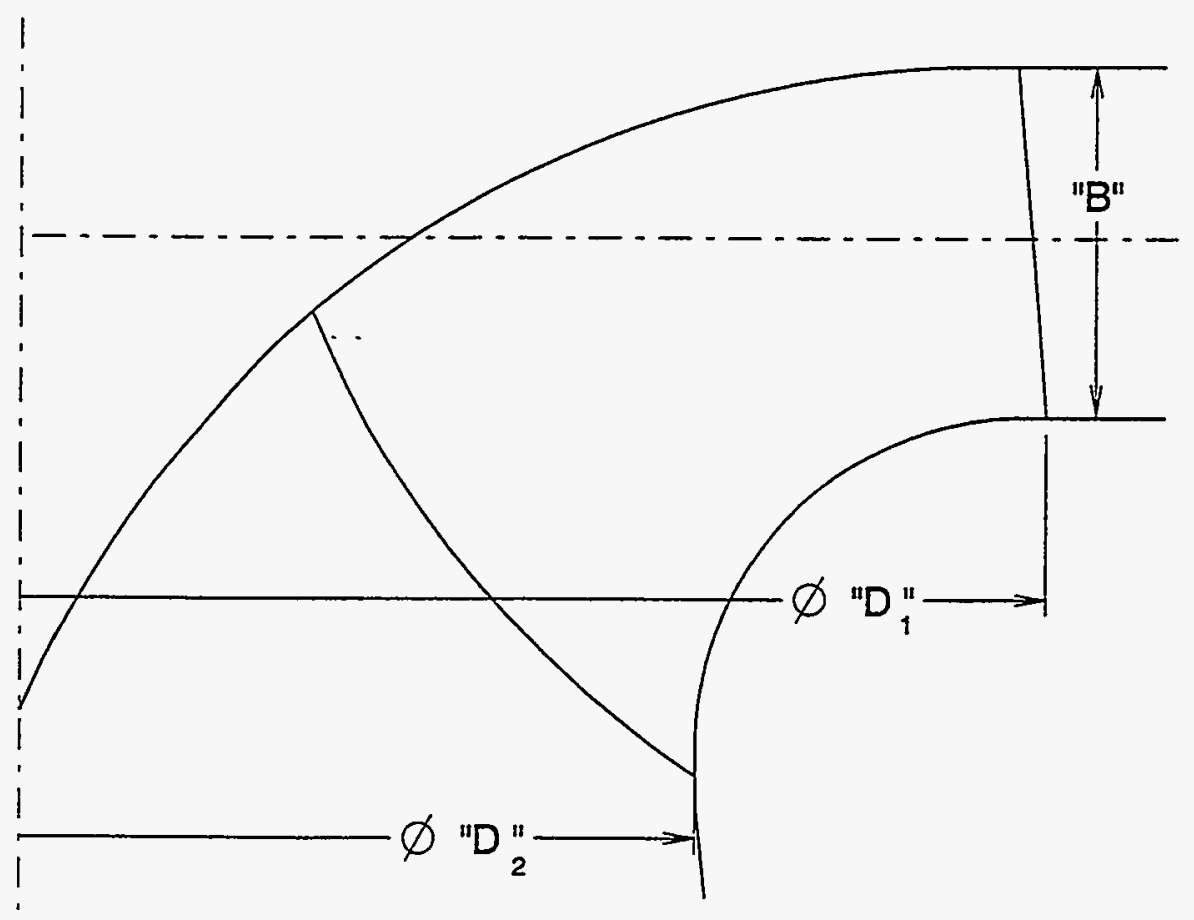

Figure 4.3.2-3 Geometry Notation for Francis Turbines 


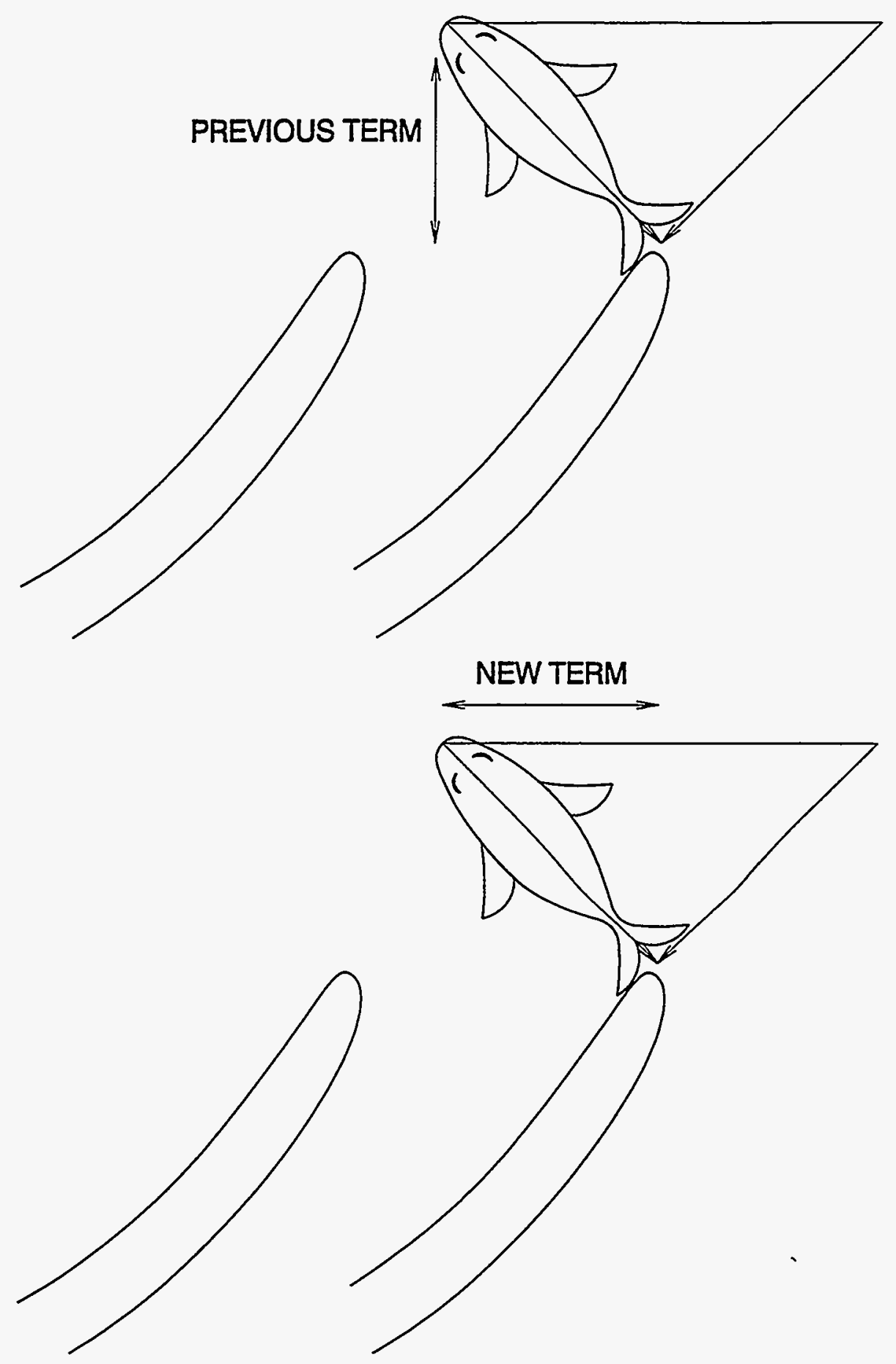

Figure 4.3.2-5 Illustration of Additional Term in Leading Edge Strike Equation 


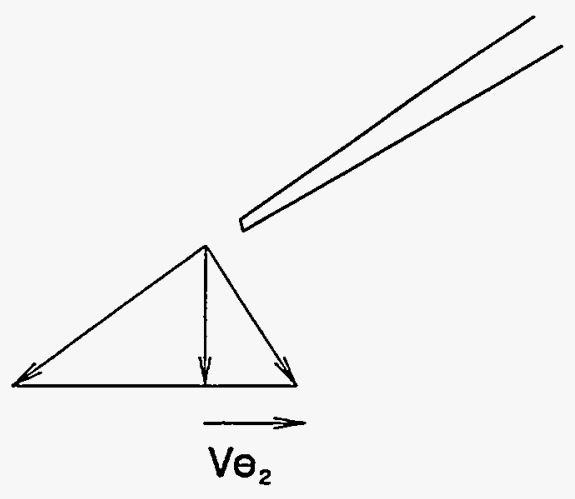

HIGH Q

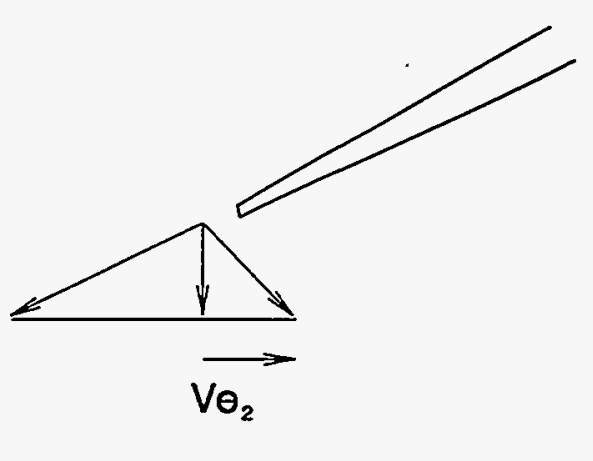

LOW Q

\section{KAPLAN (ADJUSTABLE BLADES)}

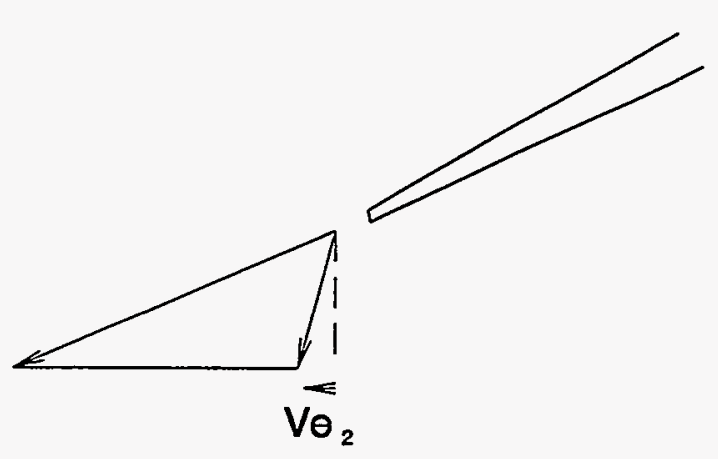

HIGH Q

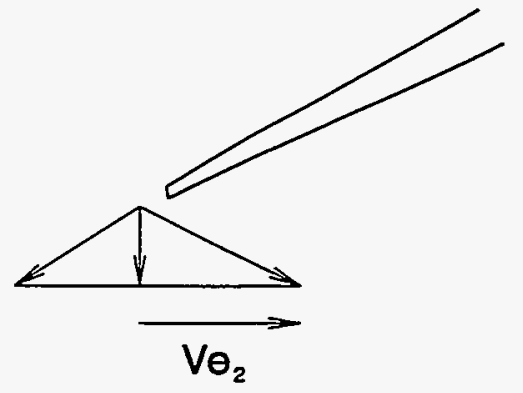

LOW Q

FRANCIS (FIXED BLADES)

Figure 4.3.2-6 Exit Swirl Characteristics of Francis and Adjustable Blade Turbines 


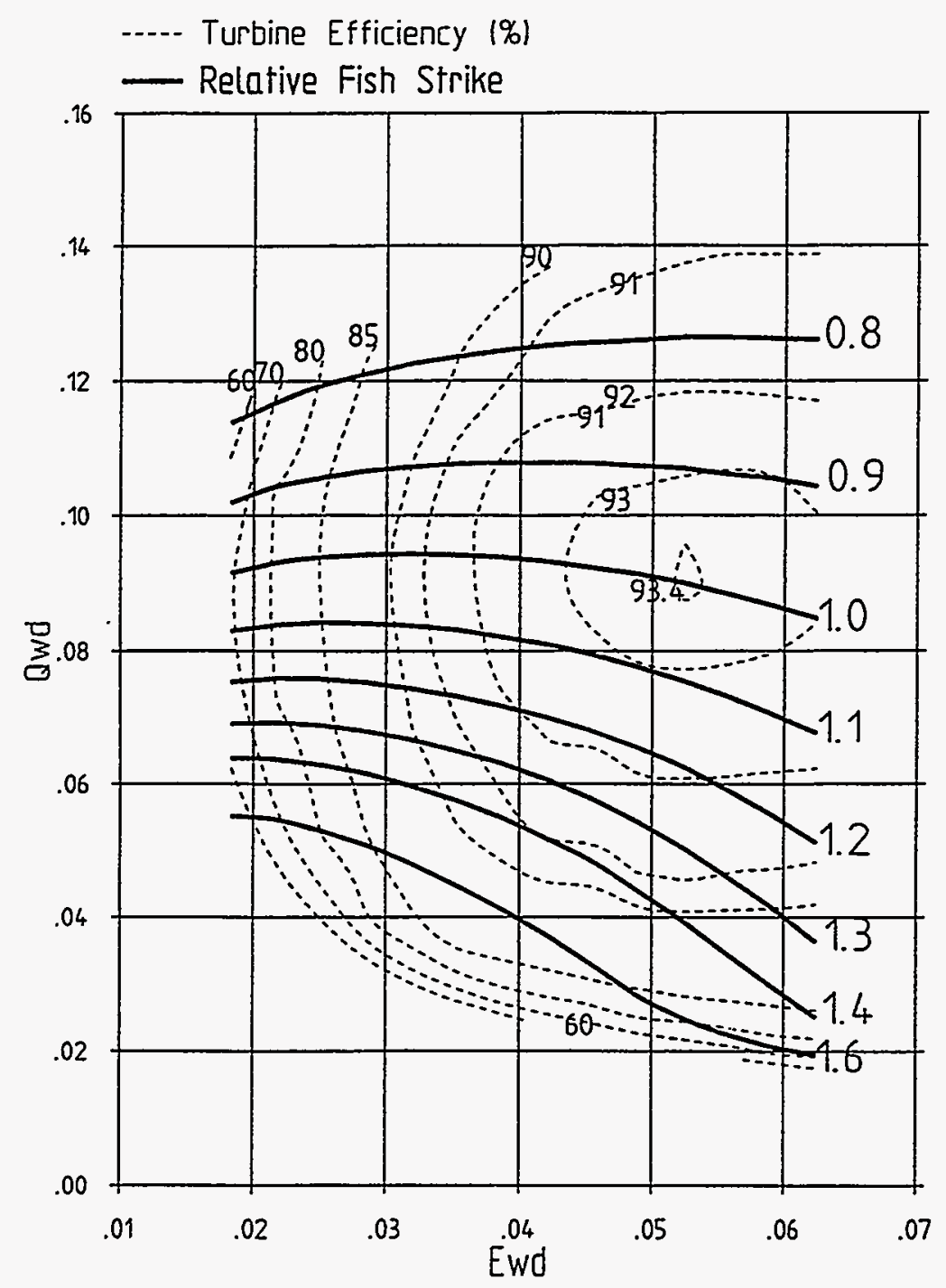

Figure 4.3.2-7 Relative Strike Probability for Kaplan Turbines (at blade tip) 
Kaplan fish strike probability

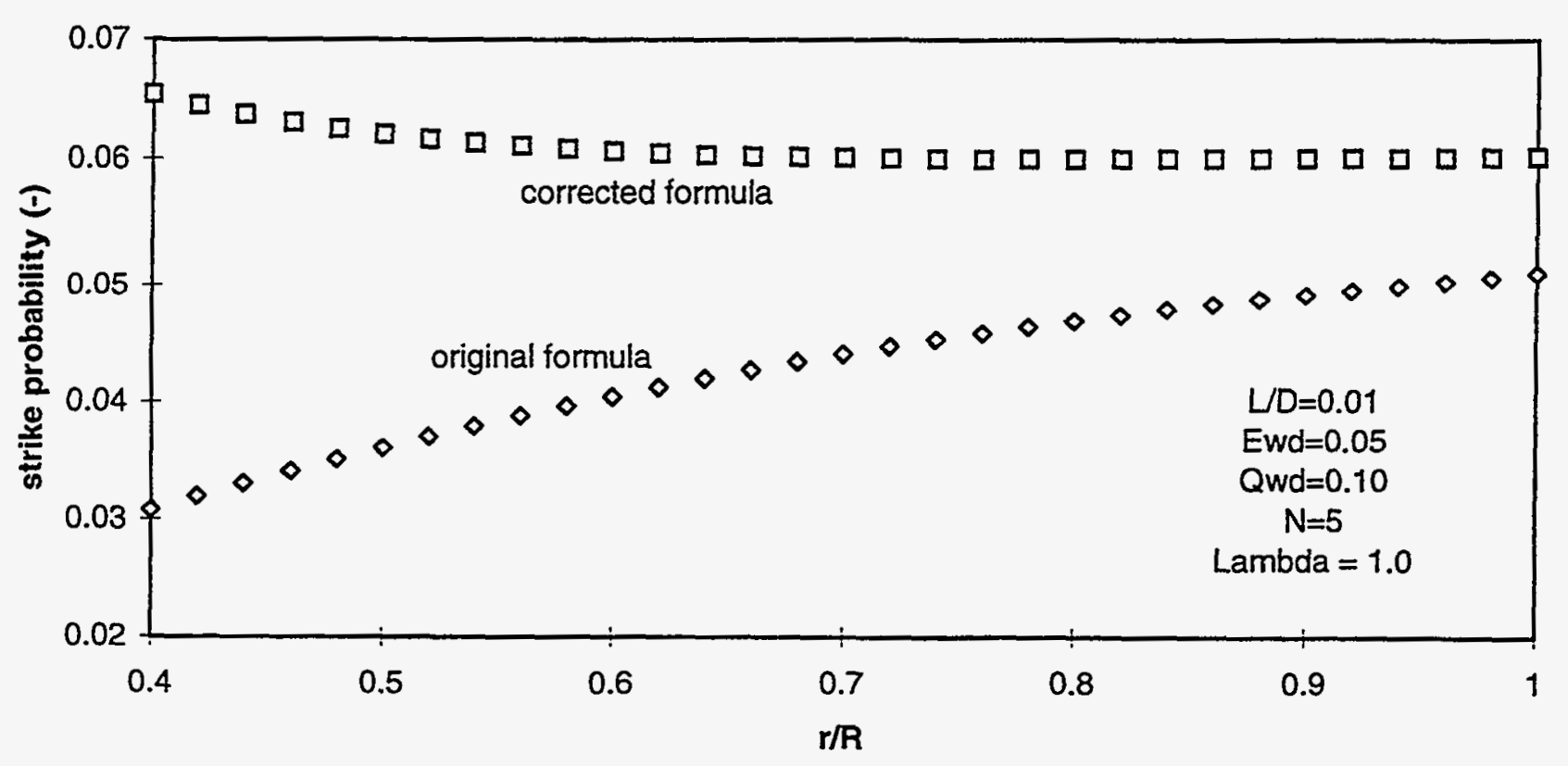

Figure 4.3.2-9 Comparison of Original and New Leading Edge Strike Equation at Higher Flow

\section{Kaplan fish strike probability}

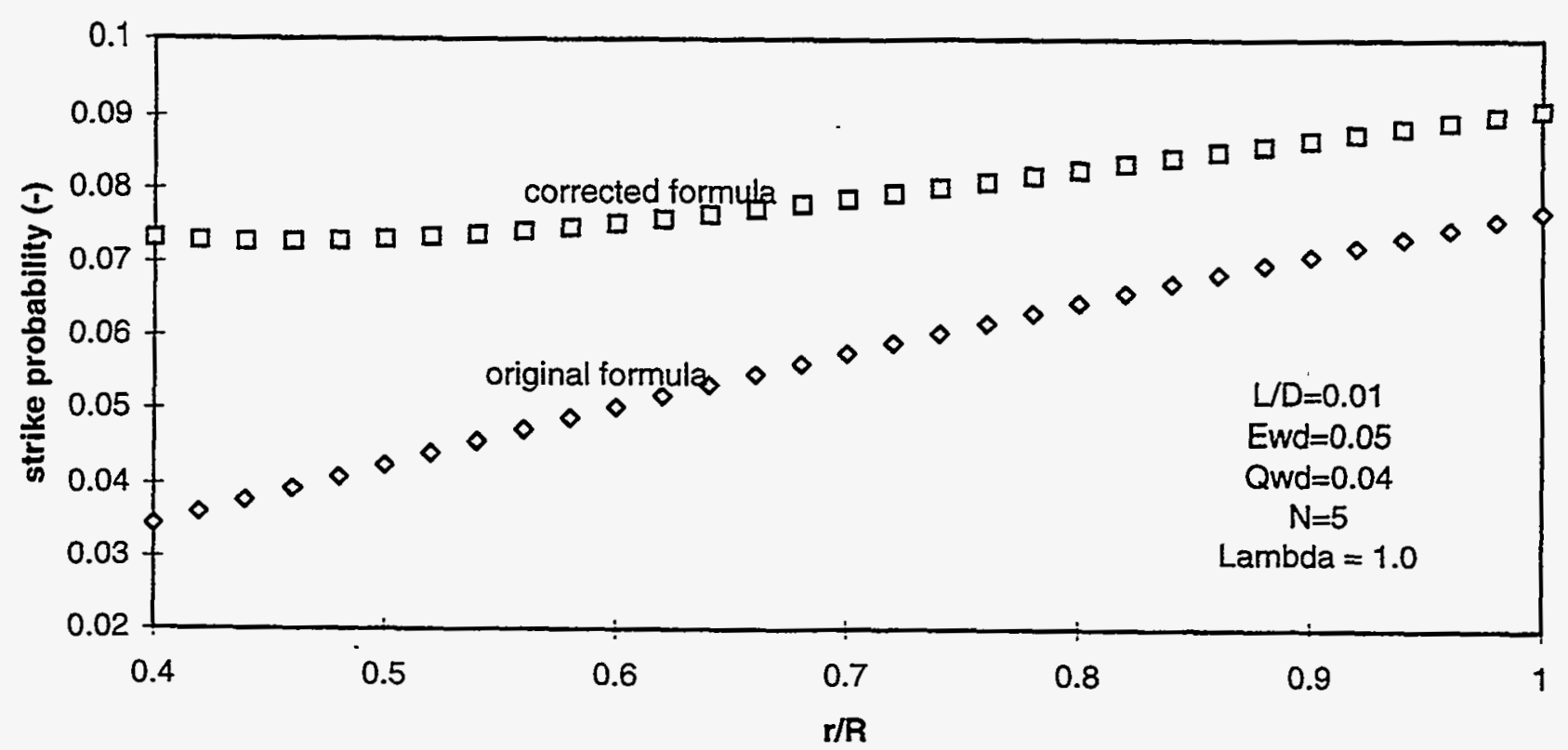

Figure 4.3.2-8 Comparison of Original and New Leading Edge Strike Equation at Low Flow 


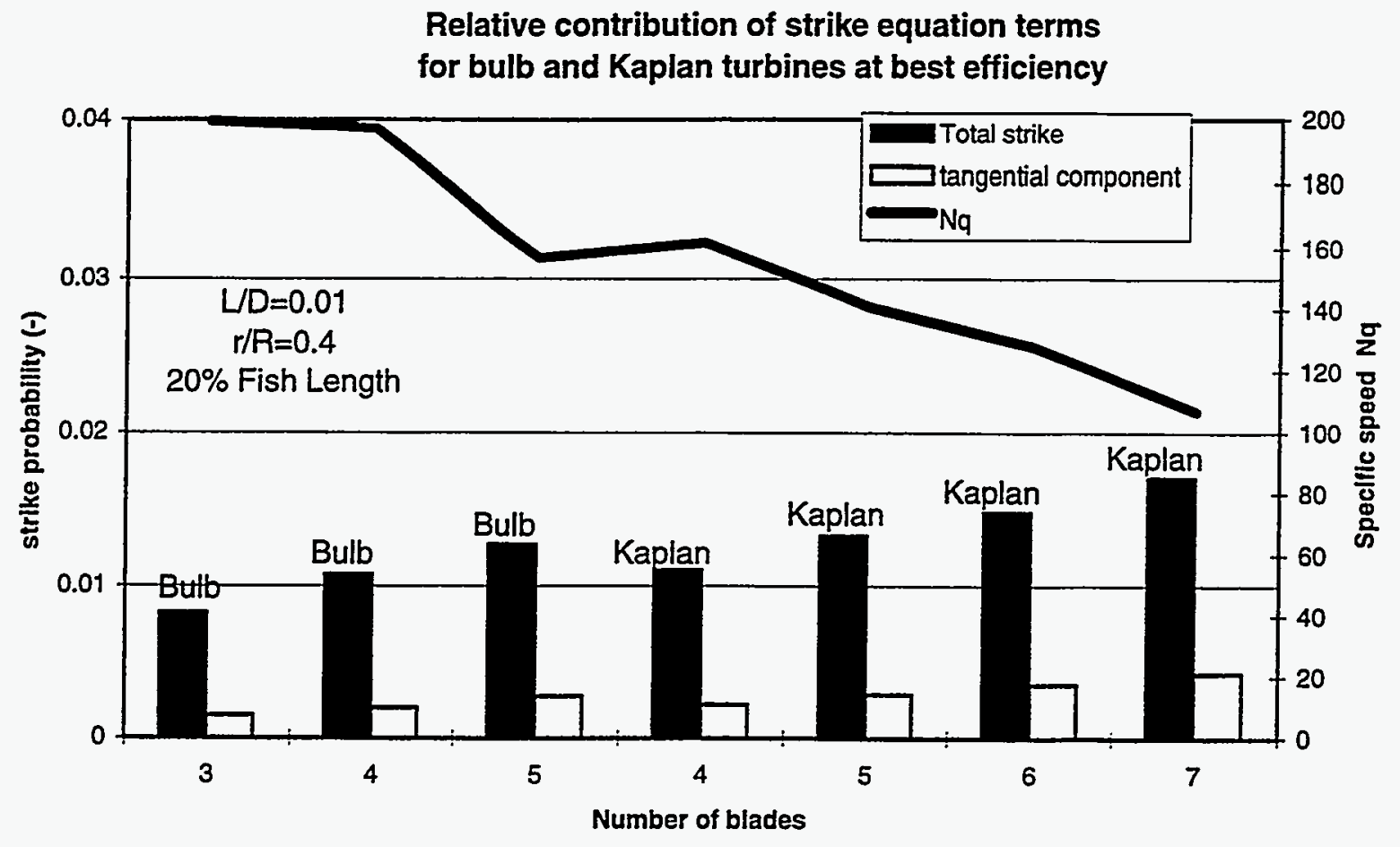

Figure 4.3.2-11 Illustration of Contribution of the Tangential Fish Length to Total Strike Probability

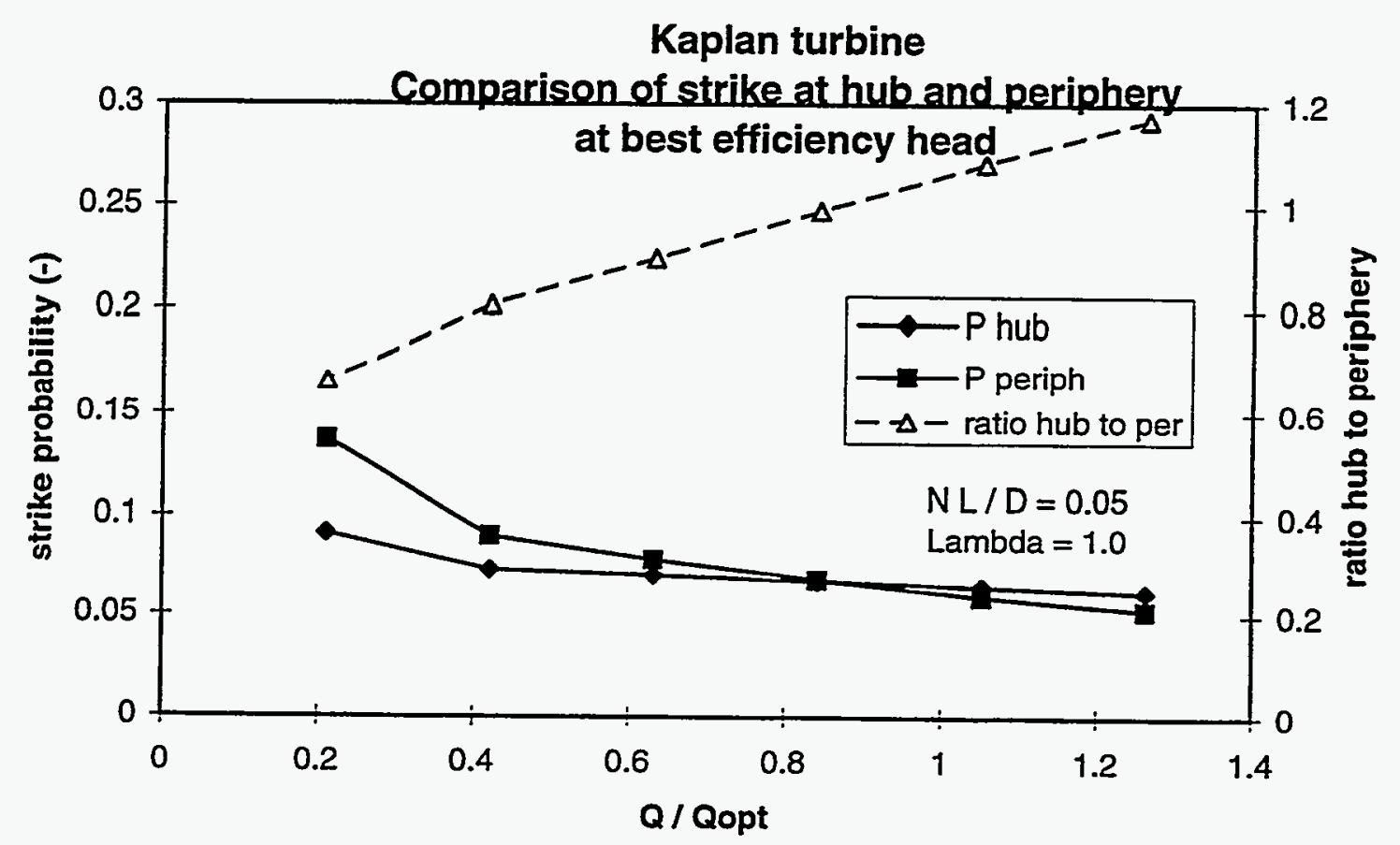

Figure 4.3.2-10 Comparison of Strike Probability at Hub and Periphery vs Flow Rate 


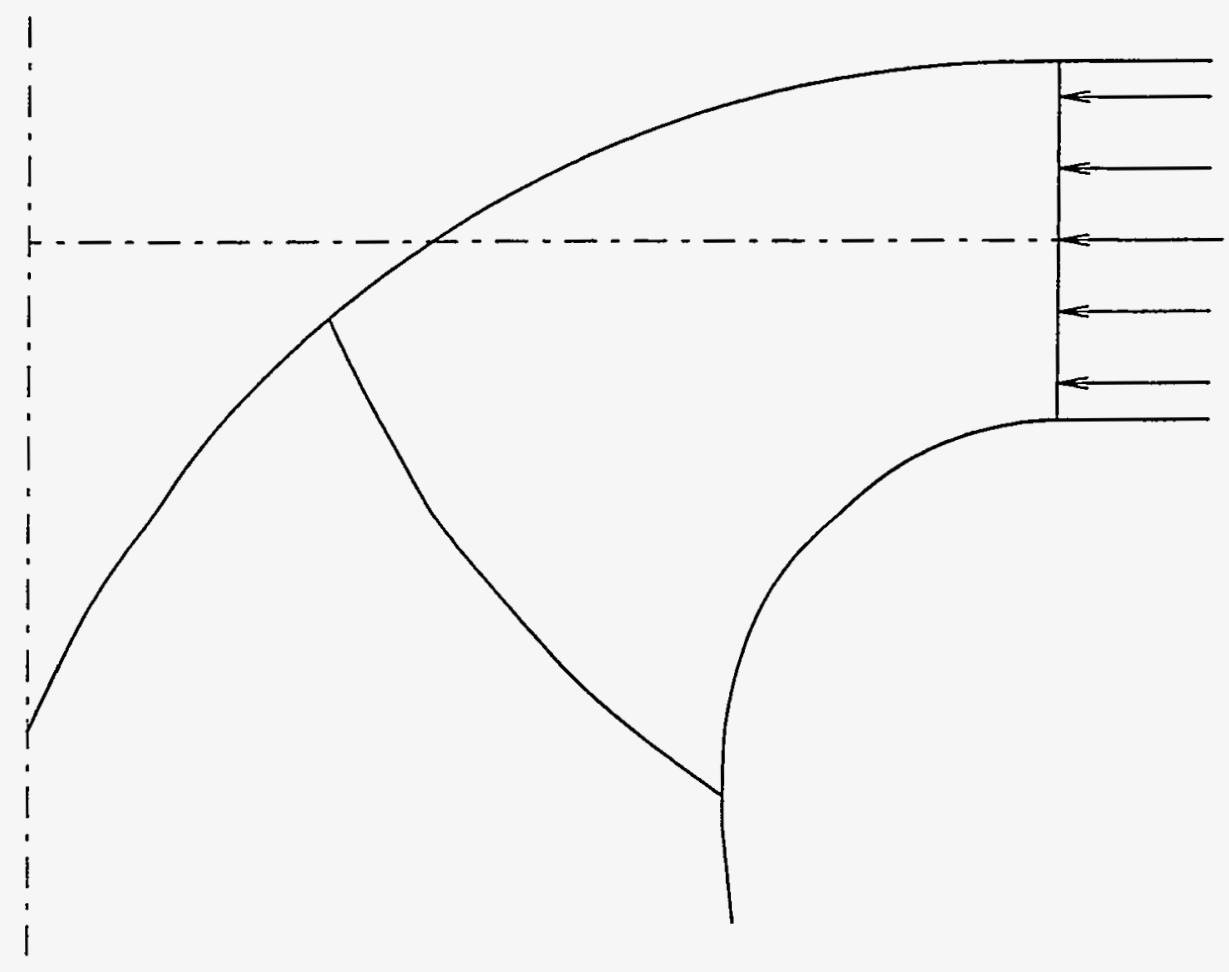

LOW SPECIFIC SPEED

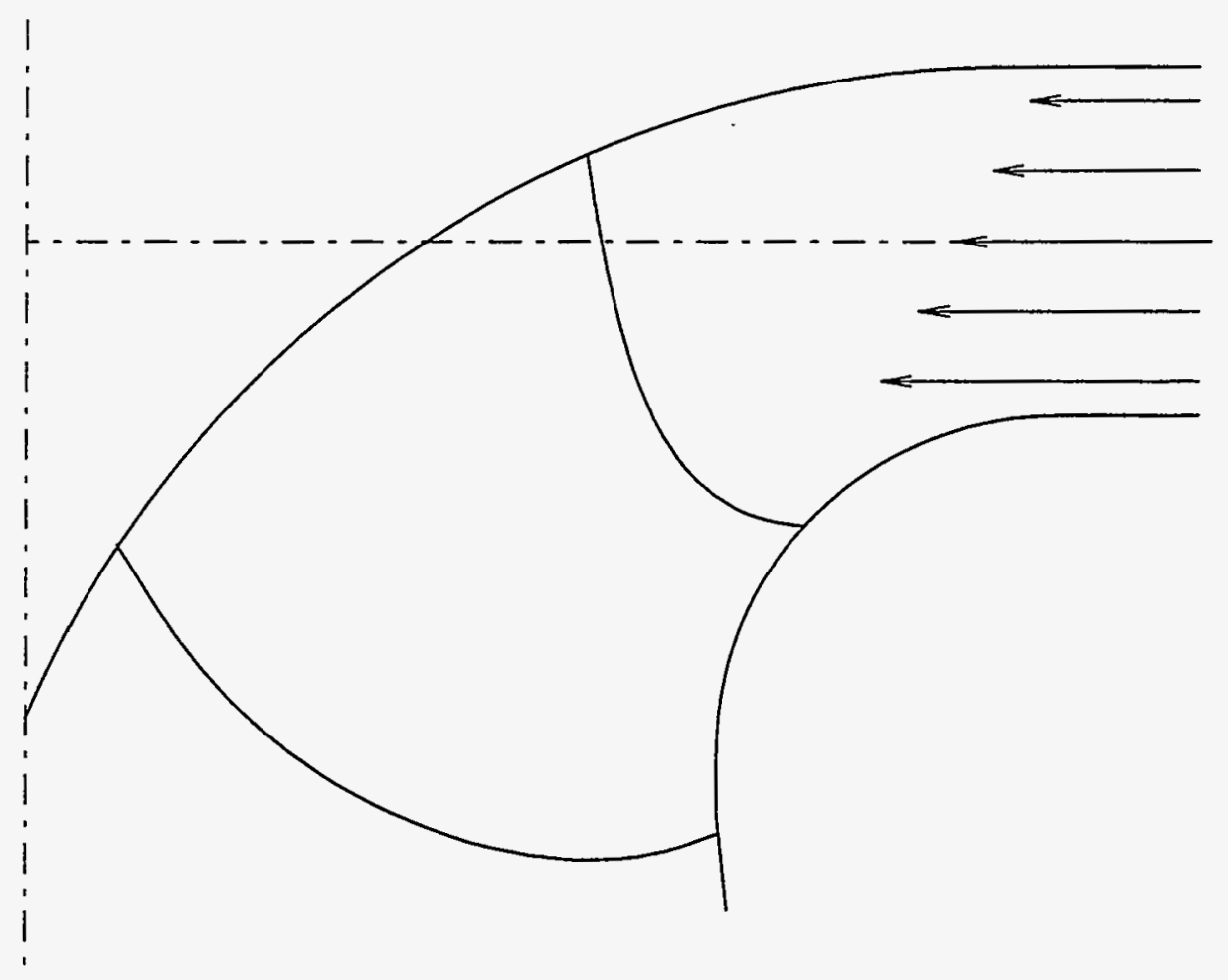

HIGH SPECIFIC SPEED

Figure 4.3.2-12 Francis Turbine Runner Inlet Velocity Profile Varies with Specific Speed 


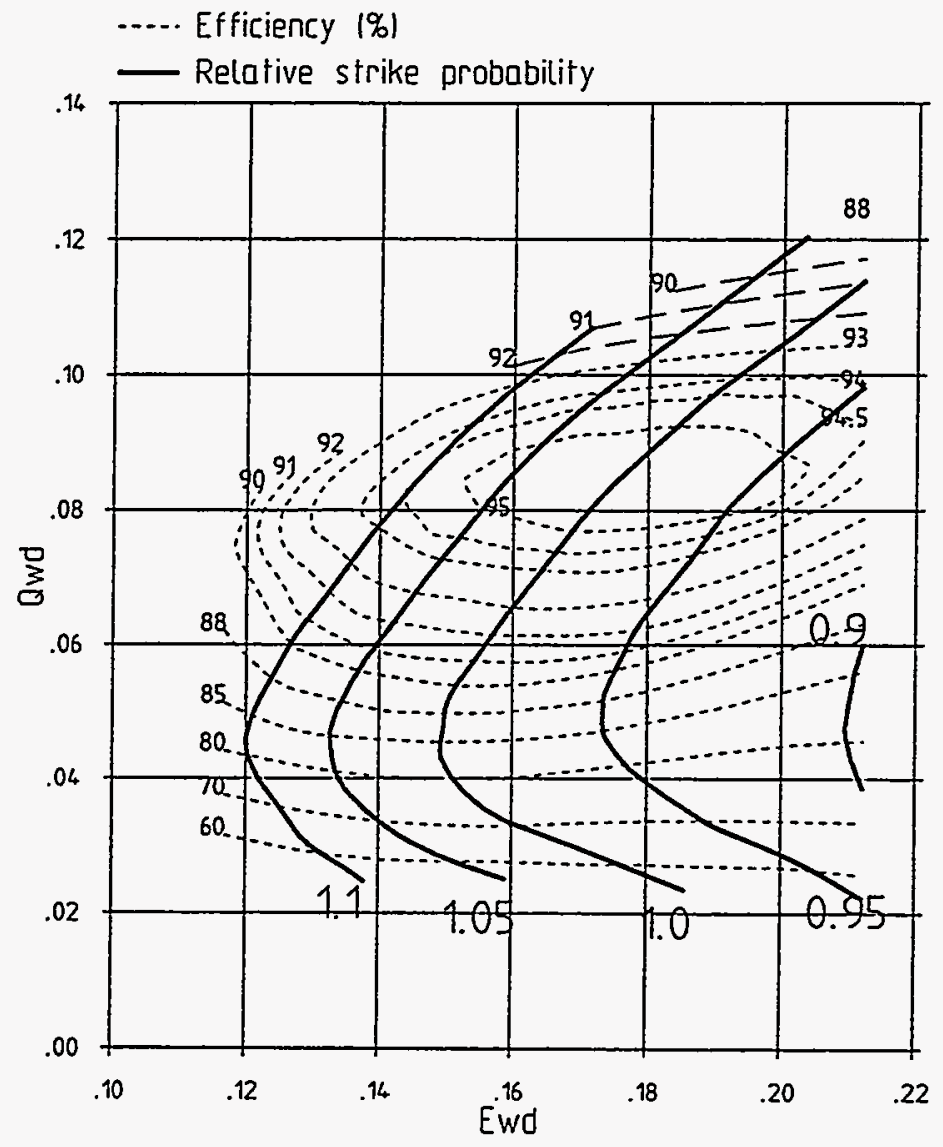

Figure 4.3.2-13 Relative Strike Probability for Francis Turbines 


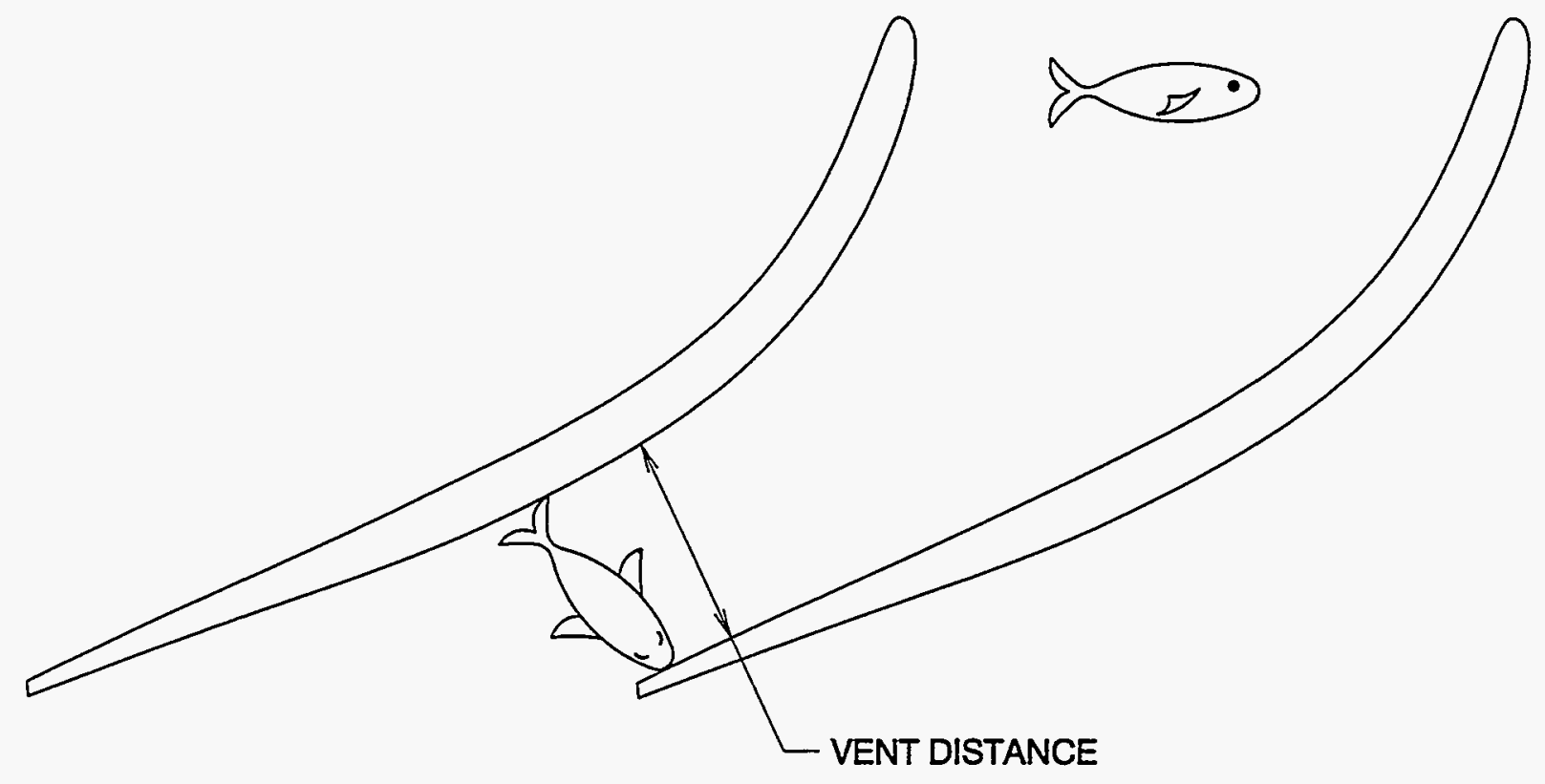

Figure 4.3.2-14 Runner Vent Could Lead to Scrape Injuries 


\subsubsection{FLUID MECHANISMS LEADING TO FISH INJURY}

\subsubsection{Overview}

The concept of excess energy dissipation is an attempt to quantify the injurious effects that a non-ideal flow field can cause. Excess energy dissipation can be equated to Theoretical Avoidable Loss (TAL), a concept which has been observed to correlate with measured fish survival: The concept of critical shear is developed and shows some promise of being a credible prediction method. A one-dimensional prediction method based on critical shear is not adequate to predict observed fish survival.

The general assumption regarding fish survival and turbine operating condition is that inefficient turbine operation causes adverse flow field conditions leading to fish mortality. This assumption agrees with the fact that inefficiency is a measure of losses caused by the dissipation of energy (head loss) in the flow. Some of this energy is presumably available to harm fish. It is also known that energy losses are a direct result of flow that is not smoothly aligned with hydraulic surfaces. Two paths have been taken in this study to quantify this phenomenon.

The first method, the overall energy dissipated in the flow, is analyzed without consideration of the precise flow field details. It considers that some energy dissipation is inevitable and causes no harm to fish, while other energy dissipation exceeds a theoretical minimum and this excess energy dissipation is available to cause mortality. The second methr'd, the analysis of shear, is an atter: $p t$ to directly quantify the details of the flow field. A quantity defined as shear is postulated as a quality of the flow that can be linked to fish mortality. A critical value of shear was estimated from experiments in the literature. Based on a simplified flow field analysis, a general method for estimating shear for any turbine operating condition was developed. The foundation was established for subsequent, more detailed, analyses by CFD methods.

It should be pointed out that both TAL and fluid shear are related to the geometry of the turbine. The number of turbine blades, stay vanes, and wicket gates as well as the presence or absence of blade gaps and the overall quality of the hydraulic design influence the fluid mechanisms which can damage fish. Mortality correlations with the number of turbine blades can relate to the physical strike by a blade structure as well as to the fluid mechanisms associated with the number of blades. 


\subsubsection{Evaluation of Avoidable Loss}

\section{Summary}

Some loss of energy in a turbine can not be avoided. Other sources of energy loss are dependent on the turbine operating condition. The losses that are in excess of a theoretical minimum possible were correlated to measured fish survival. When losses are greater than the minimum amount, fish survival is adversely affected. The point of minimum theoretically avoidable loss usually occurs at a discharge greater than the best efficiency point discharge.

\section{Discussion}

Two explicit methods have been applied to predict and evaluate mortality:

- Theoretically Avoidable Loss (TAL) An explicit calculation of the portion of the overall energy that has been dissipated in the turbine and that is available to damage fish.

- Shear The effect of a fish passing near or through a region where the flow is experiencing a velocity gradient that is sufficiently intense to cause damage. This effect is listed separately from excess energy dissipation because of a different prediction methodology that is used.

The concept of a theoretically avoidable loss has been found to be a useful parameter to correlate a turbine operating condition to internal flow mechanisms capable of causing damage to fish. The flow of water over any surface results in friction that causes a reduction in the useful energy of the flow. This frictional energy loss (actually a transfer of energy into heat) attains a minimum value when the flow is smooth and the velocity is a minimum. For example, the flow of water through a pipe causes losses, but unless the fish comes in near proximity to the pipe wall, in fact so close that it would touch the wall, this energy exchange as a result of the discharge (therefore deemed unavoidable) does not cause damage to the fish. In the turbine, energy losses occur due to several mechanisms. Flow through the spiral case can have losses associated with vortices and secondary flows, but mostly contains losses related to friction on the spiral case walls. Flow over stay vanes, wicket gates, and runner blades may encounter the structure with an angle of attack (depending on the particular operating condition) and the resulting velocity patterns and associated losses are higher than could be achieved under optimum conditions. The flow in a draft tube is typically swirling, with a flow pattern that can cause flow separation from the wetted surfaces. This generates increased turbulence and flow mixing, resulting in energy losses. Flow through various clearance spaces and over thick trailing edges also induce losses. Some of these losses are related to the requirement of moving flow through the machine, and cannot be avoided. Other losses are related to non-optimum flow patterns and could theoretically be eliminated (at a particular operating condition) by redesign of the non-optimum components. Therefore, a method has been developed to separate the theoretically avoidable losses from the losses that cannot be eliminated.

In a turbine the sum of all losses is quantified by the turbine efficiency. Efficiency can be related to losses with the relationship:

efficiency $=1-($ losses $/$ Head $)$

where the losses are taken as the sum of all losses in the turbine. Since some of the losses are proportional to the velocity squared, this offers a means to examine the distribution of losses as a function of operating condition. A procedure was developed to assess the magnitude of frictional losses that are proportional to the velocity squared, and are thus unavoidable, and the magnitude of losses caused by other mechanisms that are considered to be theoretically avoidable. The discharge is used as an indicator of the local velocity. Defining a proportionality between losses and discharge gives: 
losses $=K \cdot Q^{2}$

and to be able to separate avoidable and unavoidable losses, $K$ is further separated

$K=K_{T A L}+K_{t m}$

$K_{\mathrm{lm}}$, where tm means theoretical minimum, accounts for the unavoidable frictional losses. $K_{T A L}$ accounts for the theoretically avoidable losses. The value of $K$ is dimensional, having units of $\left(\right.$ length $\left.{ }^{5} / t^{2} e^{2}\right)$. The use of this concept is to compare the value of the losses at various operating points. Therefore only relative values of $K$ at various operating points are most useful. The value of $K_{m}$ corresponds to the most favorable flow pattern possible for a particular turbine. After a value of $K_{t m}$ is selected, $K_{T A L}$ may be calculated. The value of $K_{T A L}$ is used to calculate the avoidable losses and can be deemed to be Theoretically Avoidable Losses (TAL). They are called "theoretically" avoidable because the turbine design to avoid them would need to have a geometry which can be adjusted to be "theoretically ideal" at every operating condition. TAL then, are an overall measure of the energy available to drive high velocity gradients, swirling flows, vortices and turbulence. These fluid effects, when of high enough energy can cause forces on fish bodies which can result in injury and direct mortality. They can also drive fish into mechanical structures with sufficient energy to create mechanical injury.

In Section 4.4.6, experimental fish survival data from the Wanapum project are analyzed with this approach to provide a quantitative measure of the impact of TAL on the overall measured fish mortality. 


\subsubsection{Evaluation of Fluid Shear}

\section{Summary}

Shear may be a quantifiable indicator of a flow field condition that causes fish injury. Based on the evaluation of a single study, an injury threshold value of shear $(450 / \mathrm{s})$ has been tentatively selected. A simplified design study has verified the adverse effects of off-design turbine operation on shear, i.e. operation with the turbine blades for a range of values of angle of attack. However, the simplified design study seems inadequate to explain observable mortality effects. Probability equations are developed to predict mortality based on the size of a critical shear zone. The shear concept is applied to confirm the existence of a non-lethal velocity and, for the first time, to explain the minor role that tip speed is observed to have in turbine fish passage survival studies.

\section{Discussion}

\section{Definition of Shear}

A flow field that causes forces on a fish body that are high enough to do damage are a cause of mortality. Velocity fields within a turbine that change significantly over a distance characteristic of a fish dimension could cause these types of forces. The concept of using this definition of shear to predict fish mortality has been evaluated.

Shear is defined as a change in velocity divided by a change in length. This definition of shear is an indicator of force on a finite three-dimensional body such as a fish. The velocity change causing the shear may be induced by viscous forces as in a boundary layer, in a separated flow region or in the wake downstream of a blade or vane trailing edge. Velocity changes can also be caused in a non-viscous manner and do not necessarily imply energy losses, viscosity, vorticity (rotational flow), or an unfavorable flow field. Note that this definition yields a dimension for shear of $(1 / \mathrm{s})$ as the length dimension in velocity cancels the length in the denominator. An evaluation of shear in Alden, 1997 used a dimension of ( $f / \mathrm{s} /$ inch), since these authors chose not to cancel the length units.

The definition of shear as a stress, related to laminar or turbulent viscous forces has been used in the literature. This definition was not chosen here because it excludes certain types of velocity gradients. $A$ flow field having velocity gradients will exert forces on a finite size body, such as a fish. Figure 4.3.3-1 shows velocities and hence velocity gradients, in a runner that are the result of a non-viscous calculation. A definition of shear that was based on viscous forces would incorrectly imply that no fluid induced forces would exist for this flow field.

Shear can be considered as an influence of a mechanical structure that exists some distance away from the structure. Intuitively, this effect is related to the energy contained in the speed between the fluid and the structure. The energy of a moving body is it's kinetic energy, which is proportional to velocity squared. Therefore, as an initial evaluation of the energy in a given flow field that may be available to cause injury to fish, a calculation of the kinetic energy of the flow relative to the blades was made.

As background information, the variation of blade impact energy for different operating conditions is provided. In contrast to initial expectations, this information did not lead to new insights. The fish approaches the blade at a relative velocity. This velocity difference defines the kinetic energy of a possible collision. Figure 4.3.3-2 shows the square of the ratio of relative flow velocity to tip velocity. This calculation was made for the same 5 bladed Kaplan turbine as was used for the sample strike calculation. These results may be used as a general indication of some trends for all turbines. A different view of the strike energy is accomplished by the following shear analysis. The magnitude of the effects caused by strike energy is evaluated and testable predictions are made. 


\section{Estimation of the Critical Value of Shear}

An important challenge in using the shear concept to evaluate fish survival is to determine if a threshold value exists. Shear above such a value would be described as a critical shear and would be sufficient to cause injury or mortality to a fish, while lower values would cause no injury or mortality. Of course this critical value may be species dependent and also dependent on the size of the region exhibiting this characteristic relative to the fish. If additional biological data become available and a value of shear that can cause disorientation or minor injury is known, then additional types of prediction could be made.

A series of experiments having a nozzle discharging into a quiet pond was used as a benchmark to look for a threshold value (Johnson, 1970a, 1970b, and 1972). A first test with a $150 \mathrm{~mm}$ (6 in) nozzle operated at $17.5 \mathrm{~m} / \mathrm{s}$ ( 57.5 feet / s). The species used were 120 to $180 \mathrm{~mm}$ (5 to 7 in) chinook salmon, and 180 to $200 \mathrm{~mm}$ ( 7 to 8 in) coho salmon. The results were recorded with a high speed movie camera, and it was noted that the fish came out in random positions (head first, tail first or broadside) and location in the jet (left, right, above, or in the center). Some fish broke out of the jet within one foot of the nozzle, while others remained in the jet throughout the picture. Many fish were subjected to violent distortions, both in and breaking out of the jet, with no apparent physical harm. No fish were killed.

A second test with a $100 \mathrm{~mm}$ (4 in) nozzle was operated at $20.4 \mathrm{~m} / \mathrm{s}$ (67 feet / s). The results were as follows:

$\begin{array}{llllll}\begin{array}{l}\text { length of fish } \\ \text { inches }\end{array} & \text { coho } & \text { chinook } & \text { steelhead } & \begin{array}{l}\text { Number } \\ \text { killed }\end{array} & \begin{array}{l}\text { percent } \\ \text { killed }\end{array} \\ 8 \text { to } 9 & & 350 & & 19 & 5.4 \\ 8 \text { to } 9 & 150 & & & 3 & 2.0 \\ 2.5 \text { to } 3.5 & 150 & & & 0 & 0.0 \\ 3 \text { to } 4 & & & 150 & 1 * * & 0.7\end{array}$

** In addition to the one mortality, three fish had popped eyeballs.

Apparently the critical factor governing mortality was their precise location when they were ejected from the jet. To further investigate the shear phenomenon, 100 each of the 8 to 9 inch chinook and coho were anesthetized and were allowed to be entrained into the jet. Approximately 30 percent were seen to enter the jet within one or two feet of the nozzle; none were ki:' $2 d$.

A detailed CFD analysis of this experiment was performed as an axisymmetric calculation. Figures 4.3.33 and 4.3.3-4 show the grid and velocity vectors. A four inch nozzle protruded into a large tank. The inflow boundary was the small pipe, the discharge boundary was far downstream. The large tank basically provides a large, low velocity area for a gentle recirculation region. Intense mixing occurs at the boundary of the discharge jet. Grids were concentrated in this region.

The shear was evaluated at all locations in the flow, Figure 4.3.3-5. Shear values change rapidly in the near vicinity of the nozzle exit. Considering the 57.5 feet / s experiment, ( where fish were ejected from the jet within one foot downstream from the nozzle exit), shear values in the one half to one foot distance ranged from about 400 to 600 (1/s), Figure 4.3.3-6. Considering the 67 feet / s experiment, ( where anesthetized fish entered from the jet one or two feet downstream from the nozzle exit, shear values ranged from about 300 to $450(1 / \mathrm{s})$ in this region Figure 4.3.3-7. Based on these two ranges of shear that caused no mortality, a value of 450 was selected as a tentative critical value. It is also noted that in a different experiment, a lower value of shear ( $360(1 / \mathrm{s})$ was found to cause no harm to alewives, a very fragile species that is highly susceptible to injury, (Alden, 1997). 
This critical value of shear was evaluated at a point in the flow field. Although the size of a shear zone with respect to fish size, and the direction of the velocity with respect to a fish are important, (Groves, 1972) these effects were not considered in this study. No information is available regarding the orientation of fish during turbine passage. This lack of information regarding fish orientation is a limitation in the application of mortality prediction.

\section{Evaluation of Shear by a One-dimensional Method}

The prediction of mortality based on the shear concept, mathematically developed in the next section, is based on the spatial extent of the region having shear values greater than the previously defined threshold value. During CFD evaluations of shear for certain turbine geometries, discussed in Section 5 , it was observed that the highest values of shear occurred near the entrance edge of blades, vanes, and gates. Two types of analyses may be useful in the determination of the size of a shear-affected region. A detailed three-dimensional CFD analysis of the exact turbine geometry and operating condition would provide the most accurate information. A second possibility is to approximate a precise analysis with a simplified blade shape and approximate the details of the three-dimensional flow by a two-dimensional calculation with an a priori estimate for the local inflow condition. For the simplified type of analysis, a series of calculations might be performed one time that could then be applied for a wide range of turbine geometries and operating conditions to provide guidance on the shear values that might exist. Based on these approximate calculations, it was hoped that the results could be distilled into a method that could be based only on readily known turbine operating parameters. In order to determine whether an approximate approach could give reasonable results, a series of two-dimensional analyses were performed.

An evaluation of flow over airfoils was performed for a range of conditions. An uncambered NACA airfoil (Abbott and Von Doenhoff 1959) in a two-dimensional linear cascade was used. A variation of angle of attack, blade thickness, and blade spacing was performed. Calculations were done with a $1 \mathrm{~m}$ long blade in a $10 \mathrm{~m} / \mathrm{s}$ inlet velocity flow field. An important part of this procedure was to non-dimensionalize the geometry and flow field to be able to relate these results to any turbine operating condition. Distances were non-dimensionalized by dividing by the blade spacing. Velocity and velocity related quantities were non-dimensionalized by dividing by a reference velocity (Vref). In this two-dimensional study the inlet velocity was used as Vref. For subsequent use, the non-dimensionalized values can be applied to particular situation by multiplying the non-dimensional distance by appropriate blade spacing and nondimensional velocity by a reference velocity.

A typical grid is shown in Figure 4.3.3-8. This grid also shows Cartesian coordinate axes, the blade is in the $x-y$ plane, with the $z$ axis normal to the paper. The label of the $z$ axis is more clearly visible in subsequent figures that show more detail of the blade leading edge. In these figures the $z$ is rather large, and since it is shown rotated, it has the appearance of a large capital $\mathrm{N}$. For small angles of attack, the velocity field is smooth with high shear values occurring near the leading edge stagnation point, in the boundary layer, and in the trailing edge wake, Figures 4.3.3-9 and 4.3.3-10. For higher angles of attack, the velocity field shows flow separating near the leading edge. This leads to high shear values that occur some distance away from the blade, Figures 4.3.3-11 and 4.3.3-12. Plots of the shear were made and a visual judgment was made as to the location having the greatest distance from the blade to the critical shear location.

The distance, $d$, from the airfoil to the critical value of shear $(450 / s)$ was determined and was nondimensionalized by the blade spacing, i.e.

$D^{*}=d /$ spacing 
and the shear was non-dimensionalized by the blade spacing and Vref, i.e.

$S^{*}=$ shear / (Vref / spacing)

Figure 4.3.3-13 summarizes the results of the parametric study. The non-dimensional distance, $D^{*}$, is presented as a function of angle of attack, since the angle of attack was found to have the strongest effect. Generally, the thin blades (having a maximum thickness of $2 \%$ of the blade length) have lower shear when operated at small angles of attack, while thick blades ( $4 \%$ thick) have lower shear when operated at larger angles of attack. This result confirms general expectations.

In order to use these data to predict mortality in a turbine, several steps are required. The value of the critical shear, i.e., the value that causes mortality, must be known. One must evaluate the angle of attack on the turbine entrance edge, and using the runner inlet velocity and the blade spacing, the distance where the critical shear value occurs can be calculated. This distance could be used to calculate the probability that a fish would pass through the critical shear zone. The development of this calculation is addressed in the next section.

\section{Development of Shear Mortality Equations}

Equations describing the probability that a fish will encounter a critical shear zone were developed in a manner similar to the leading edge strike equations. The dimension of a zone in the flow field that contains a critical value of shear can be subtracted from the blade spacing. The magnitude of the mortality due to shear calculated using general estimates seerns too low to account for observed fish survival effects. It may be possible to use CFD results, possibly with a virtual fish, to find accurate critical shear distances and correlation functions for use in these equations. The details of the derivation are included in Appendix 10.3.

\section{Application of Shear Concept to Non Damaging Velocity and Explanation of the Minor Role of Tip Speed}

\section{Summary}

Through a consistent application of the shear principles, a velocity of $5 \mathrm{~m} / \mathrm{s}$ adjacent to a structure will not generate a shear zone of sufficient strength to cause fish mortality. Velocities of this magnitude can exist in several locations in a typical turbine. Also, the mechanism causing blade tip speed to play such a minor role in fish mortality is explained.

\section{Discussion}

A further use of this shear analysis is the evaluation of the existence of a velocity that is low enough to avoid shear damage to fish. A typical calculation was examined to represent a flow over a blade, vane, or any other type of obstruction that is not ideally hydraulically streamlined. A $2 \%$ thick vane at 20 degree incidence was chosen because, due to the vane's sharpness at this incidence; a region of flow separation exists. This separation causes high shear values that can be studied. The non-dimensional shear values from this calculation were used to calculate the shear values that would exist for a range of velocities. A $1 \mathrm{~m}$ long vane was chosen with a $1 \mathrm{~m}$ vane spacing. The shear was calculated from the non-dimensional shear, $S^{*}$ by multiplying different values of (Vref / spacing). Figure 4.3.3-14 shows these shear values as a function of the distance from the vane. In general, lower values of velocity cause lower shear values, as expected. When the velocity decreases sufficiently, the highest value of shear attained does not reach the presumed critical value of $450(1 / \mathrm{s})$. This occurs at approximately $5 \mathrm{~m} / \mathrm{s}$. A strict interpretation of the $5 \mathrm{~m} / \mathrm{s}$ data would conclude that the shear does not reach the threshold value, however, recognizing some numerical inaccuracy easily leads to a judgment that the shear is quite close to the threshold and occurs 
at a distance of about $3.3 \%$ of the spacing. An exact value for a non-lethal velocity cannot be determined precisely, but at or slightly below $5 \mathrm{~m} / \mathrm{s}$ it appears that no mortality is expected based on this shear analysis. The results may be summarized in Table 4.3.3-1.

$\begin{array}{ll}\text { Vref }(\mathrm{m} / \mathrm{s}) & \frac{D^{*}}{\text { distance from vane / spacing }} \\ 20 & .044 \\ 10 & .039 \\ 5 & .033 \text { or } 0 \\ 2 & 0\end{array}$

Table 4.3.3 -1 Distance from vane to location of critical shear.

Although the injury mechanism of impact with a solid object seems likely to be different than a shear induced injury, results from two impact experiments are mentioned. First, an impact velocity of $5.2 \mathrm{~m} / \mathrm{s}$ was found to cause little damage and no mortality (Turnpenny, 1992), based on an experimental study using airfoil shapes mechanically propelled in a test tank. A second test showed that a velocity of $4.9 \mathrm{~m} / \mathrm{s}$ (16.1 $\mathrm{ft} / \mathrm{s}$ ) was required to cause mortality based on impact of fish by solid objects, (Bell, 1991). It is noted that the results of this experiment were presented without information regarding test protocols or test details. The magnitude of velocity required to cause mortality in a direct impact is quite similar to the velocity required to cause a critical shear zone adjacent to a solid object.

A second aspect of this study illuminates the manner in which strike energy, represented by higher head turbines with higher tip speeds, has not been observed to play an observable role in fish mortality. The distance from the vane to the location of the critical shear value varies with velocity, as is noted in Table 4.3.3-1. At $20 \mathrm{~m} / \mathrm{s}$, the distance from the vane to the location of the critical shear has increased by a mere $1 \%$ compared to the distance when the velocity is $5 \mathrm{~m} / \mathrm{s}$. The shear equation predicts that a $1 \%$ change in the non-dimensional shear distance leads to a $1 \%$ change in the probability that a fish will enter the critical shear region. Therefore, once the velocity is high enough to cause injury, a significant increase in velocity above this value will give a small increase in the extent of the critical shear zone and hence a small increase in the shear mortality probability.

\section{Outlook for Shear Based Mortality Prediction}

The previous sections have defined shear, estimated a threshold value of injuring shear, established general characteristics of probable shear distances, developed a one-dimensional shear mortality prediction equation, and used the shear concept to find a velocity that is low enough to avoid fluid induced damage. While these concepts are a necessary prerequisite to a useful mortality prediction method, several steps remain as a subject for further evaluation. These include

- evaluate threshold shear values and direction with respect to finite sized fish

- evaluate estimated shear zones compared with more accurate CFD results

- determine local angles of attack for any operating condition, both for axial flow and for Francis turbines and find a more accurate method for predicting high specific speed Francis turbine inlet velocities 


\subsubsection{Cavitation}

\section{Summary}

It is perceived that fish passing through cavitating flow fields can be damaged by fluid effects arising because of cavitation and subsequent vapor bubble collapse. The turbine operating condition that coincides with the onset of cavitation can be determined by CFD analysis. Designs for existing turbines can be developed to eliminate cavitation while increasing power production. Operational guidelines to minimize operation in cavitation regimes will reduce maintenance costs and reduce fish mortality associated with fluid induced loading on fish bodies related to cavitation.

\section{Discussion}

The phenomena of a water vapor bubble formation is referred to as cavitation. When the value of static pressure in a fluid reaches vapor pressure, cavitation is presumed to begin. CFD methods can reasonably determine when this condition occurs. However, damaging effects of the phenomena are associated with vapor bubble collapse. A bubble that forms in a region of low pressure is transported to a region of higher pressure and the increase in pressure above the vapor pressure causes the bubble to collapse: Depending on the shape of the vaporized region and the pressure and velocity gradients involved, the collapse may create intense local pressure waves, jets of high velocity fluid and regions of strong flow turbulence. These fluid effects can cause injury to fish and may be associated with mortality.

Numerical modeling of the growth and collapse of cavitation bubbles and the quantification of the velocities and forces created by the collapse are beyond the scope of current CFD methods. However, benefits are still obtained from the use of CFD. Utilizing today's technology, replacement runner designs can be developed to improve cavitating characteristics of existing turbines and in many cases eliminate cavitation while improving power output. Figure 4.3.3-15 shows a comparison of the cavitation performance improvement (expressed as a coefficient signifying the beginning of detrimental cavitation) that was obtained for the Bay D'Espoir Francis turbines. For this project, a turbine design which was normally operated in the cavitation region was replaced with a higher efficiency runner design which eliminated the cavitation while enabling operation at higher outputs than previously achievable.

The work conducted for this contract cannot directly add to the current state of knowledge regarding cavitation induced fish mortality. However, carefully designed fish survival experiments can be used to place fish into turbine cavitating flow fields. From these experiments, correlation between observed mortality and the state of the cavitating flow field estimated from scale model testing of turbine components may be able to be made. Section 4.4 .6 discusses fish passage survival testing at Wanapum Dam. For one of the operating conditions fish were injected into the turbine intake leading some of the fish to a region where cavitation was observed during model testing. An estimate of the effect of cavitation was derived from these turbine passage tests. More data are required to be able to develop a quantified prediction method.

\subsubsection{Draft Tube Backroll}

\section{Summary}

The flow leaving the draft tube and entering the tailrace can cause a complex flow field that may trap and possibly disorient fish. CFD methods may be applied, but would challenge current hardware and software.

\section{Discussion}

The flow leaving the draft tube and entering the tailrace is quite complex. A backroll is defined as a region of the flow that recirculates. This occurs due to the interaction of the velocity field inside the draft tube and the tailrace. The draft tube exit flow is commonly believed to behave like a fluid jet entering a 
quiescent pool. Such a jet has separated or recirculating flow on all sides. The draft tube exit jet typically has a solid boundary on the bottom and an atmospheric boundary at the tailrace pool surface. Adjacent turbines may or may not cause an interaction. Both civil structure and internal flow fields may interact to have significant effects. Figure 4.3.3-16 shows alternate arrangements that were used for the draft tube designs at the old and new sites ai Bonneville Dam. The draft tube with greater upsweep, had a more visible disturbance to the tailrace surface, compared to the more horizontally oriented discharge. The internal draft tube flow field is believed to have an appreciable influence. Figure 4.3.3-17 shows a tailrace surface that is more disturbed subsequent to a turbine runner replacement. Despite good turbine performance, it is postulated that the draft tube discharge has become more nonuniform.

Overall, the backroll phenomena seems to be relatively unexplored. CFD methods may be applied, but the analysis of a single operating point would require calculation of both the draft tube (with a suitable link to a runner calculation) and the tailrace. The tailrace would require that the location of the surface be determined as a result of the calculation. Calculations of this complexity may be possible or are becoming possible as computing hardware and software advances, but are not normally performed by turbine manufacturers. 


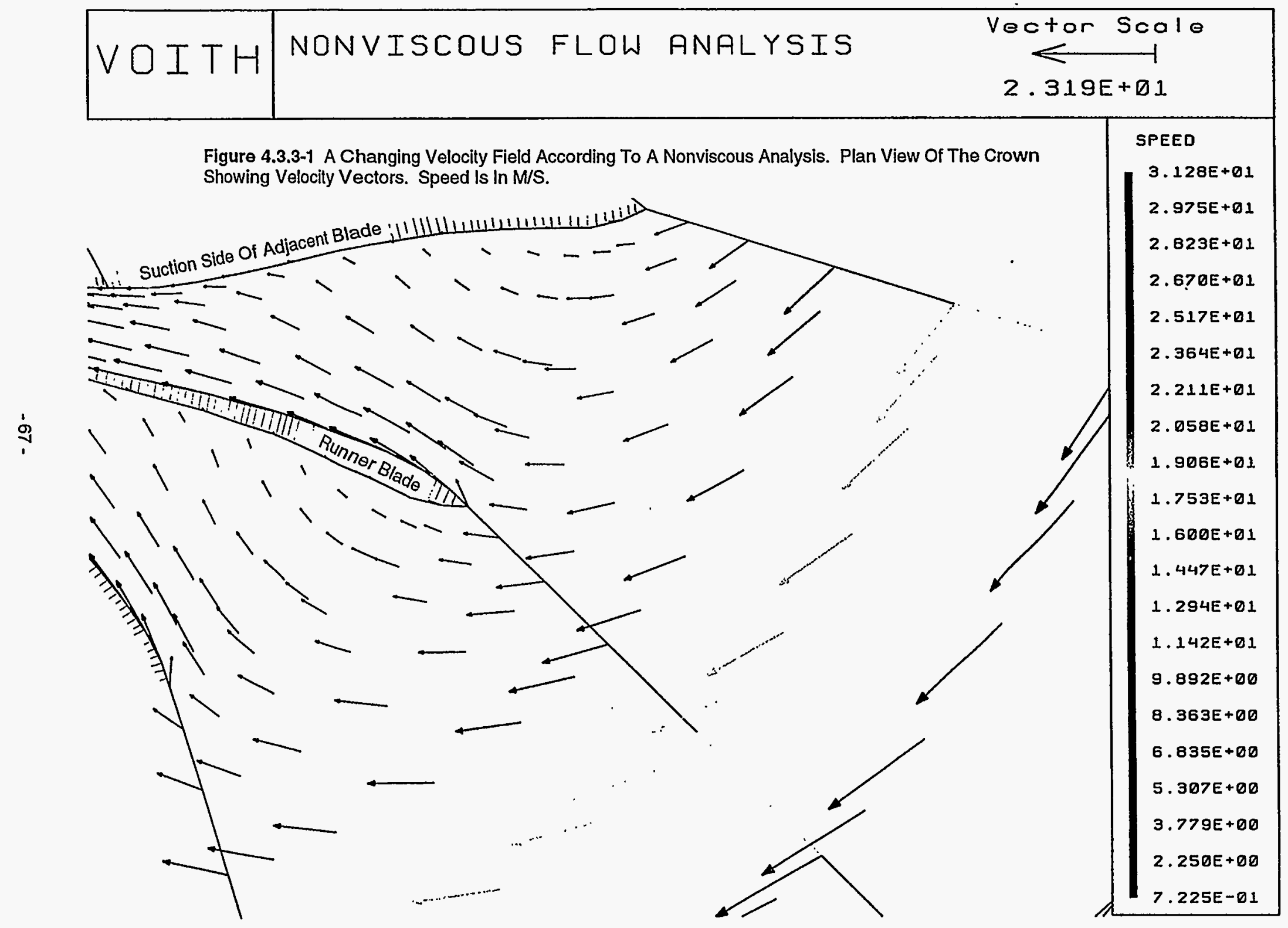




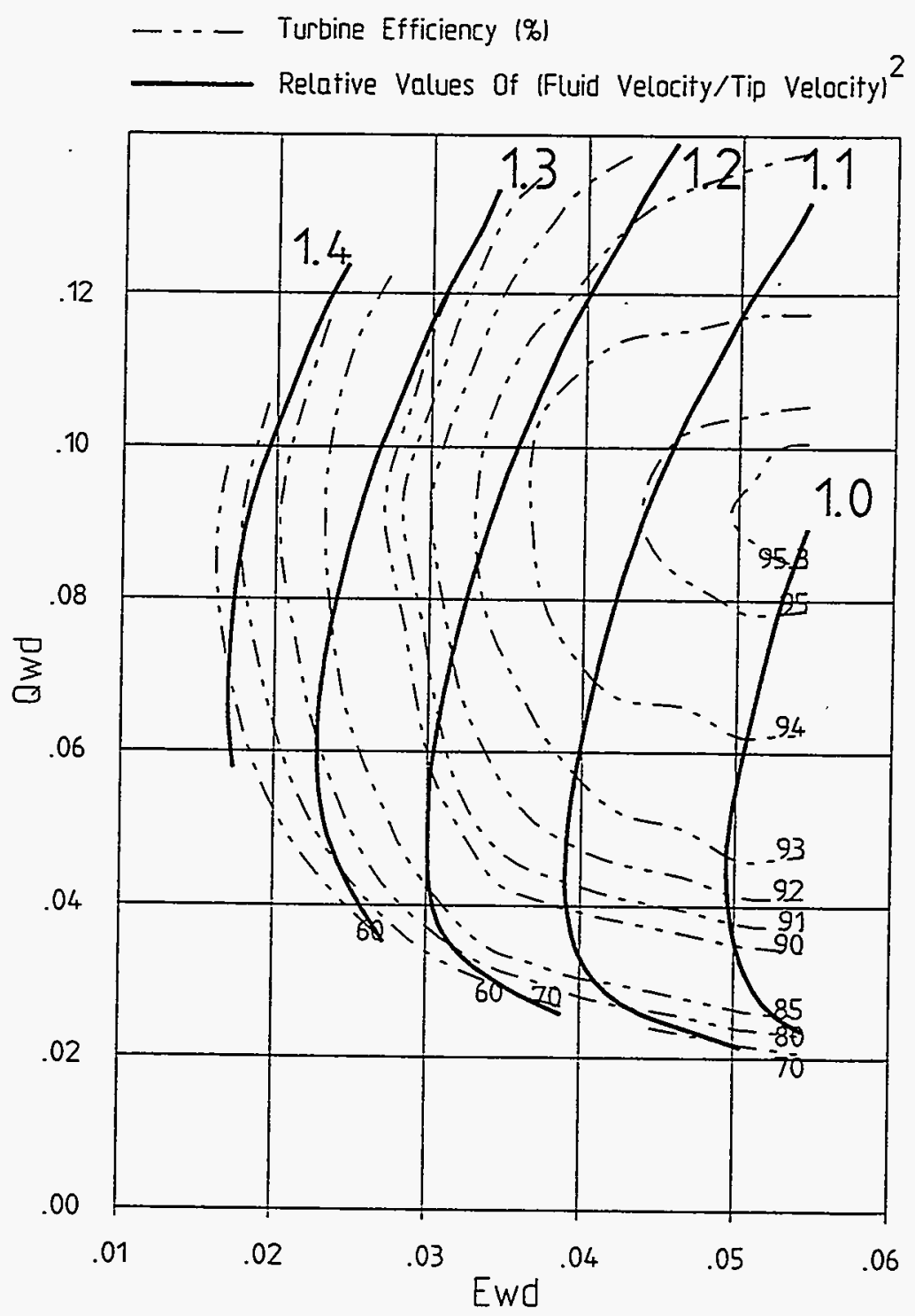

Figure 4.3.3-2 Square of the Ratio of Relative Flow Velocity to Tip Velocity for 5-Bladed Kaplan. 


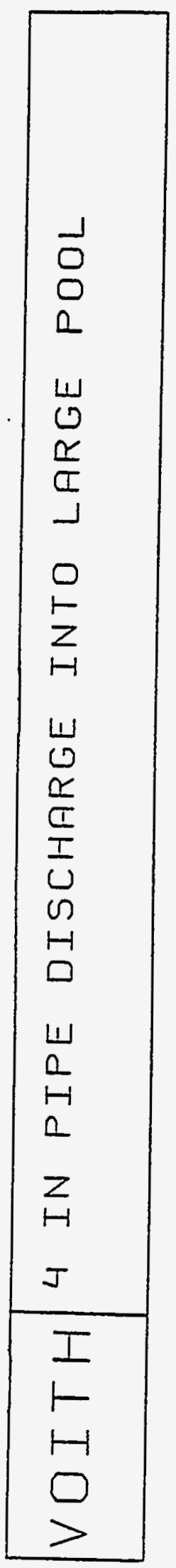

蒿

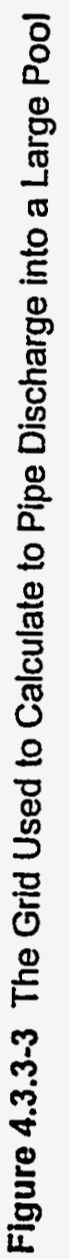




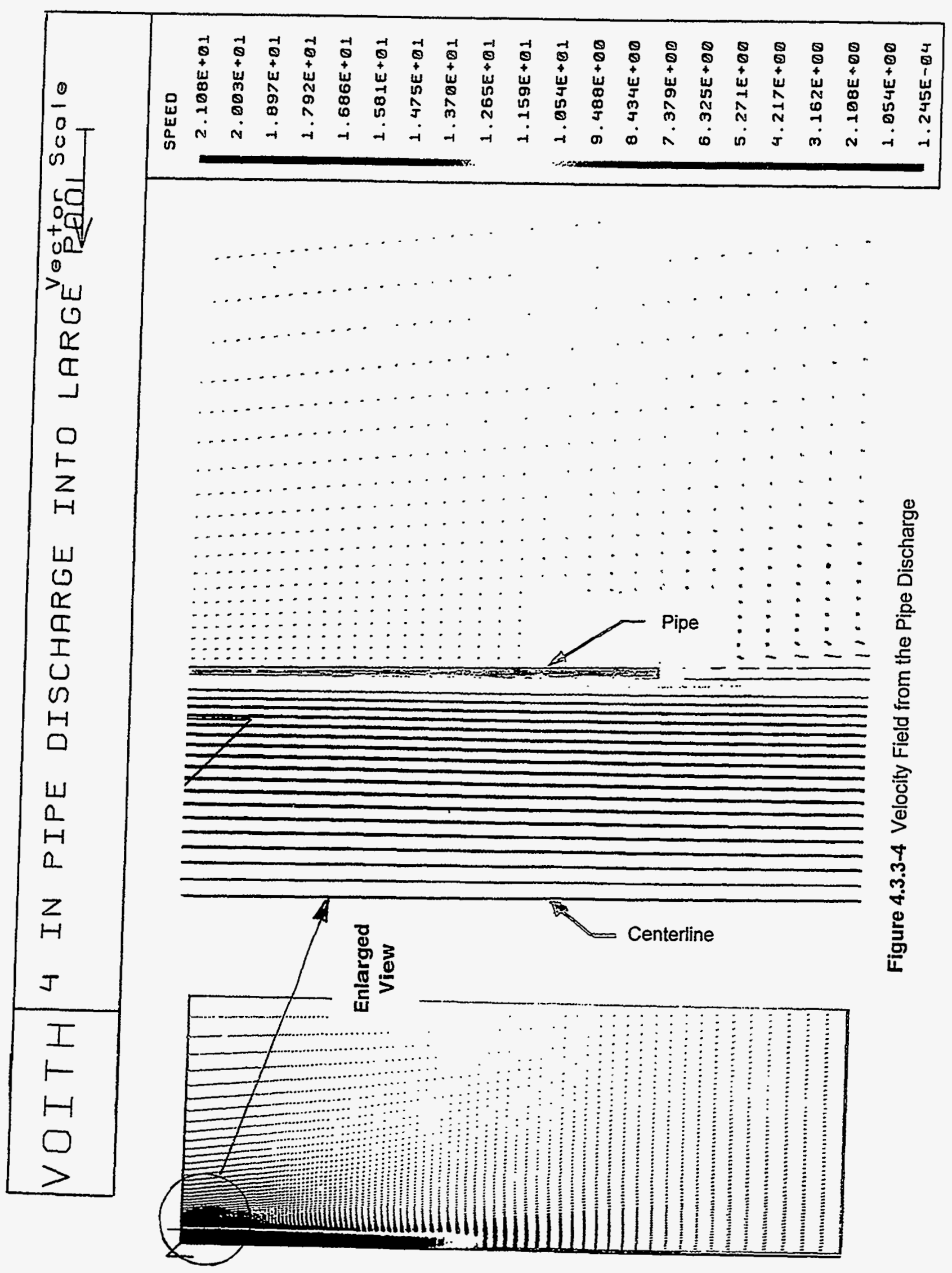




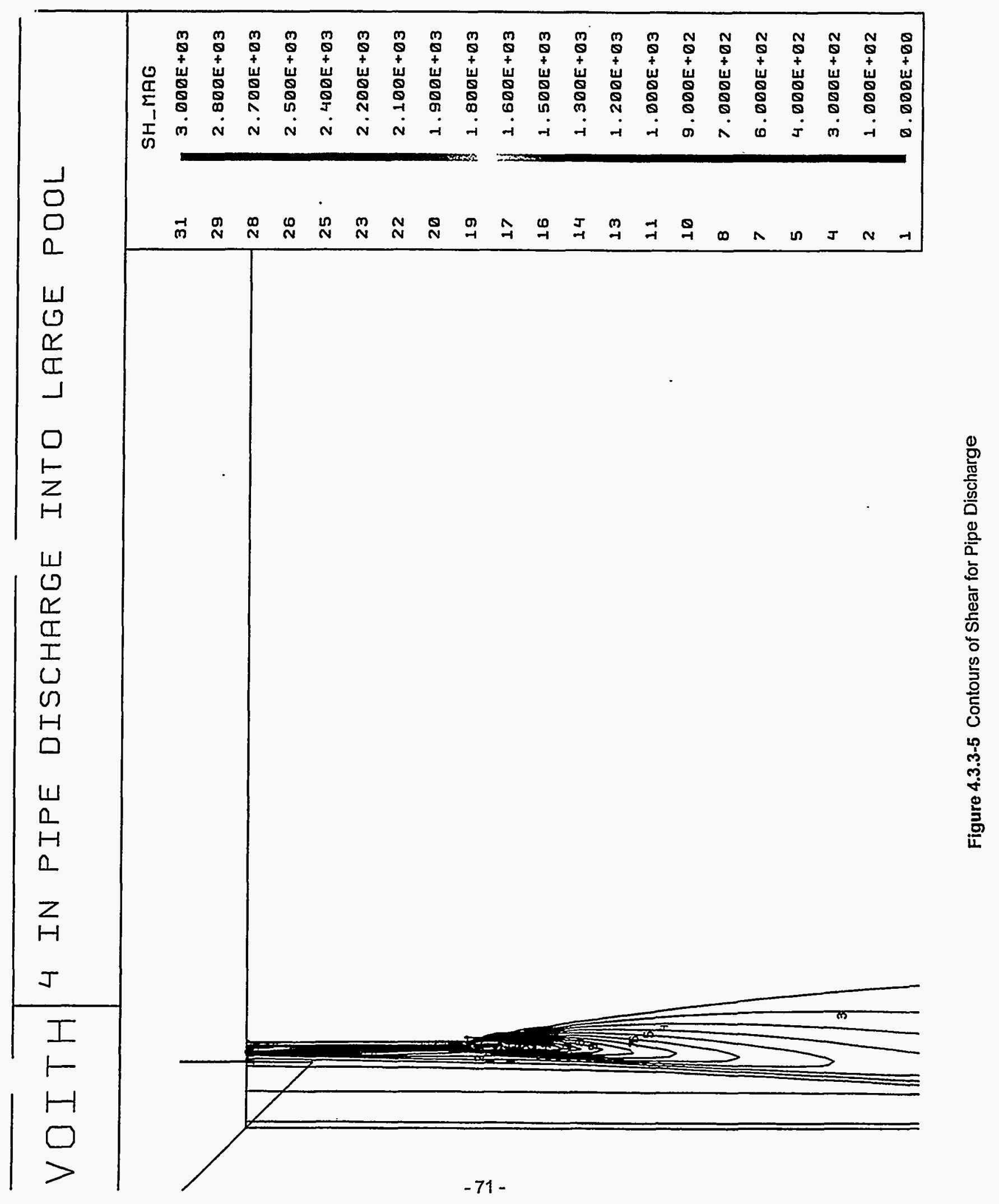




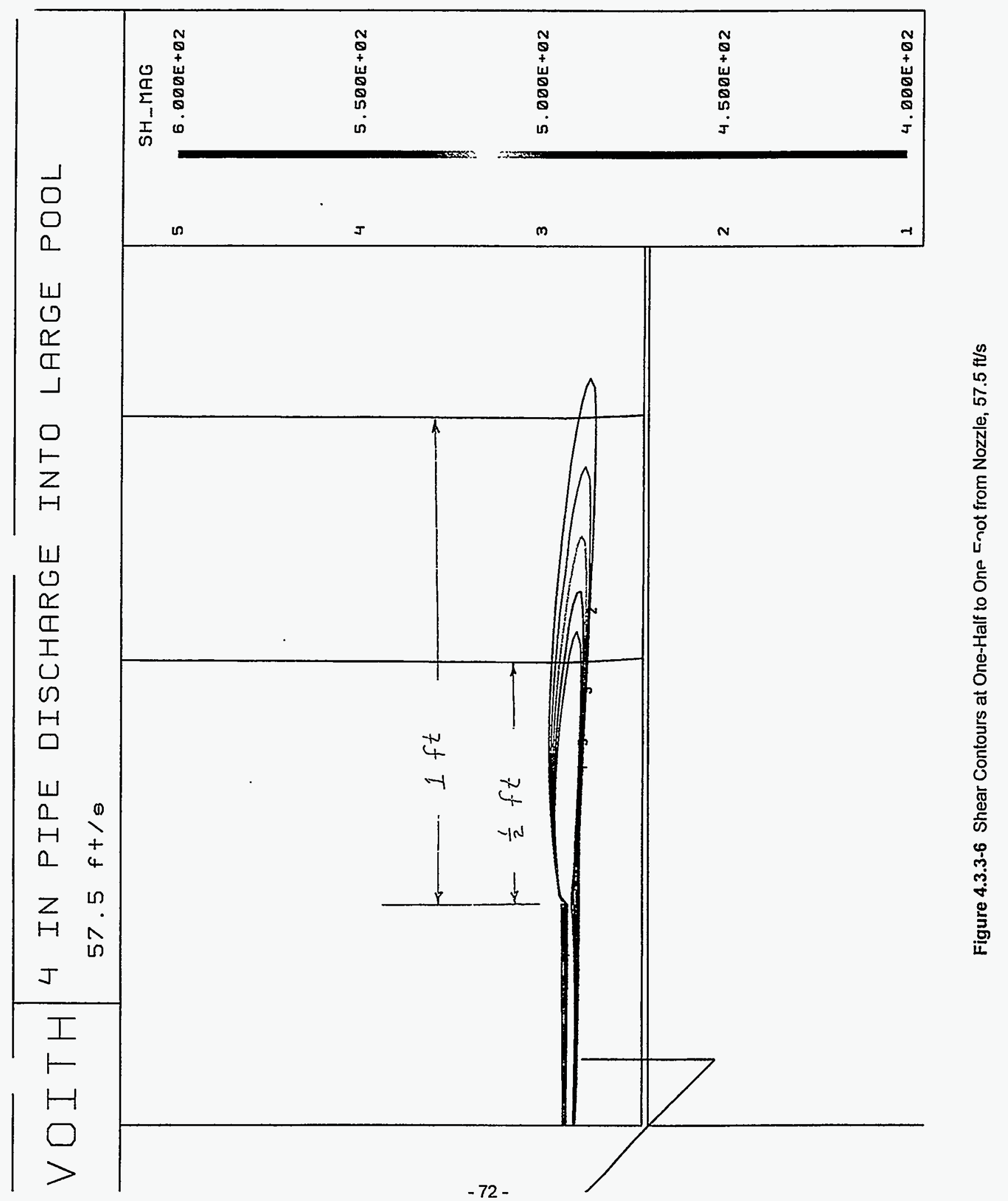




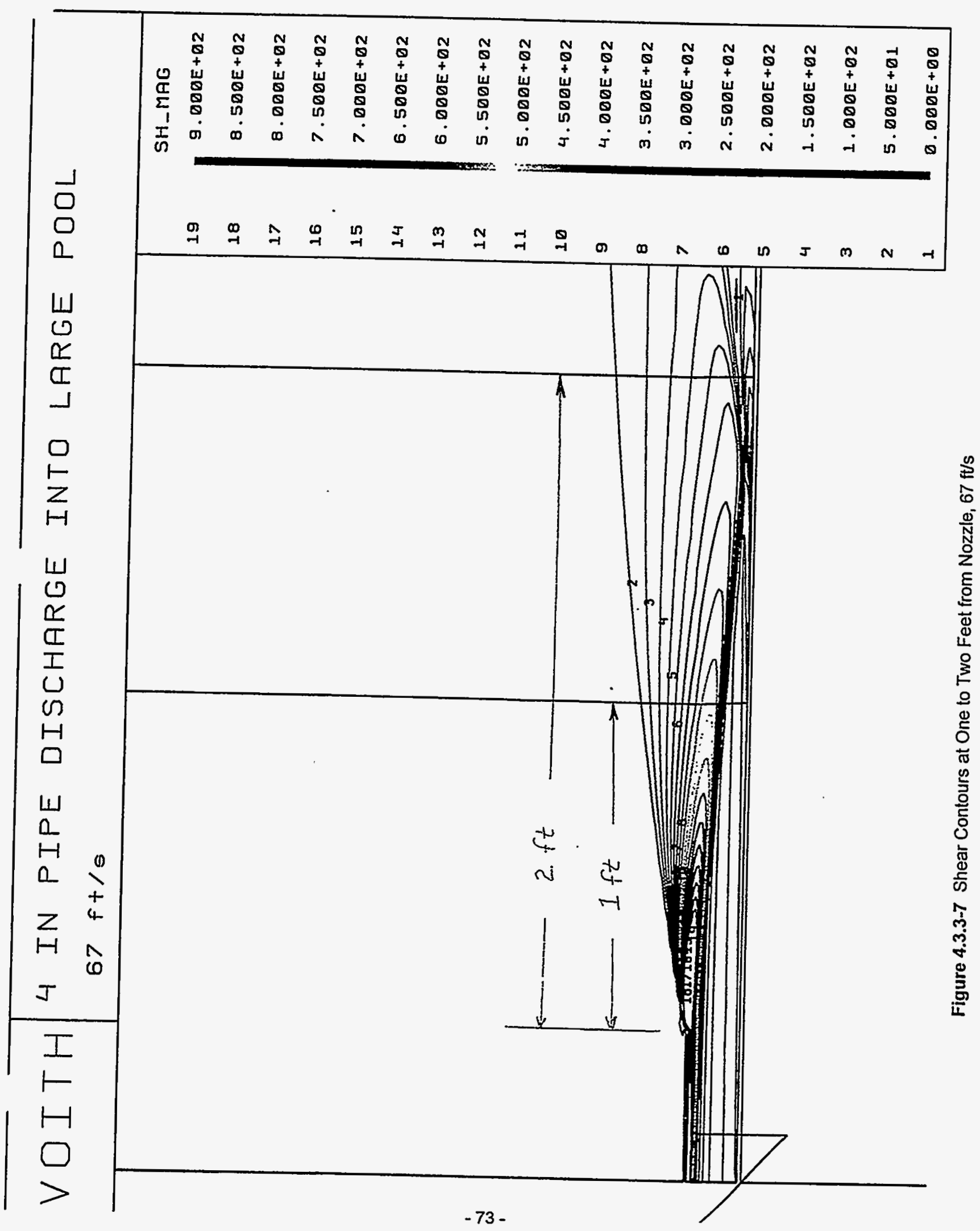




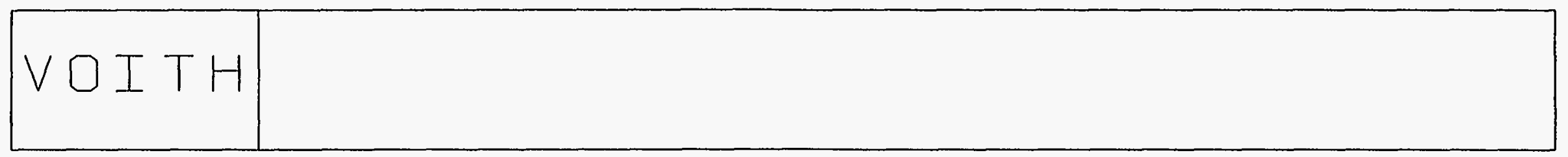

Figure 4.3.3-8 Grid For Two-Dimensional Airfoil Study. Blade Is $2 \%$ Thick, Spacing To Adjacent Blade Is One Blade Length.

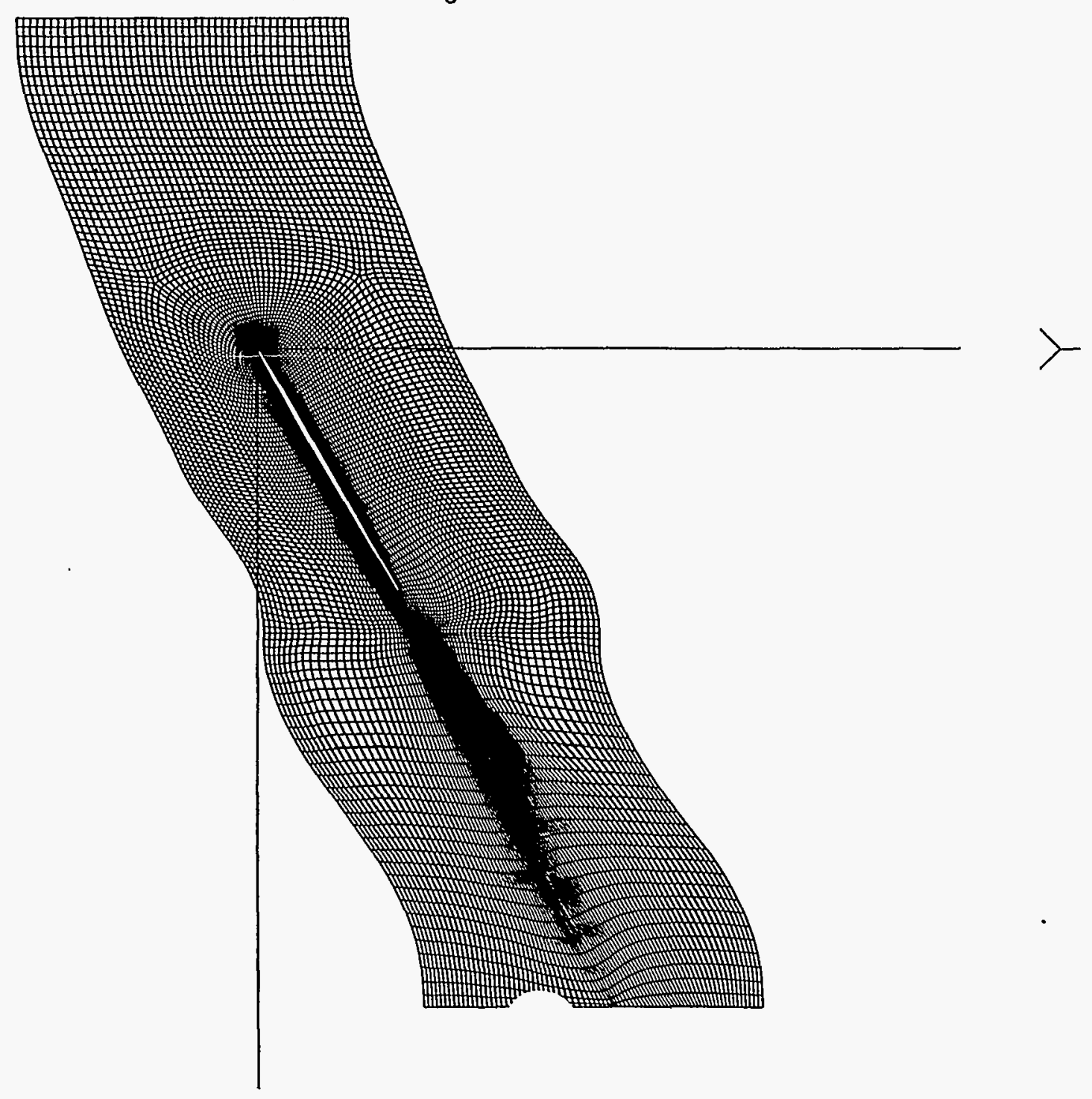




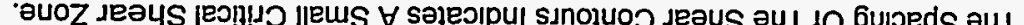

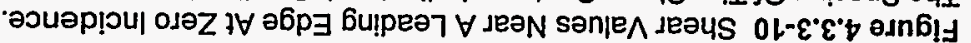

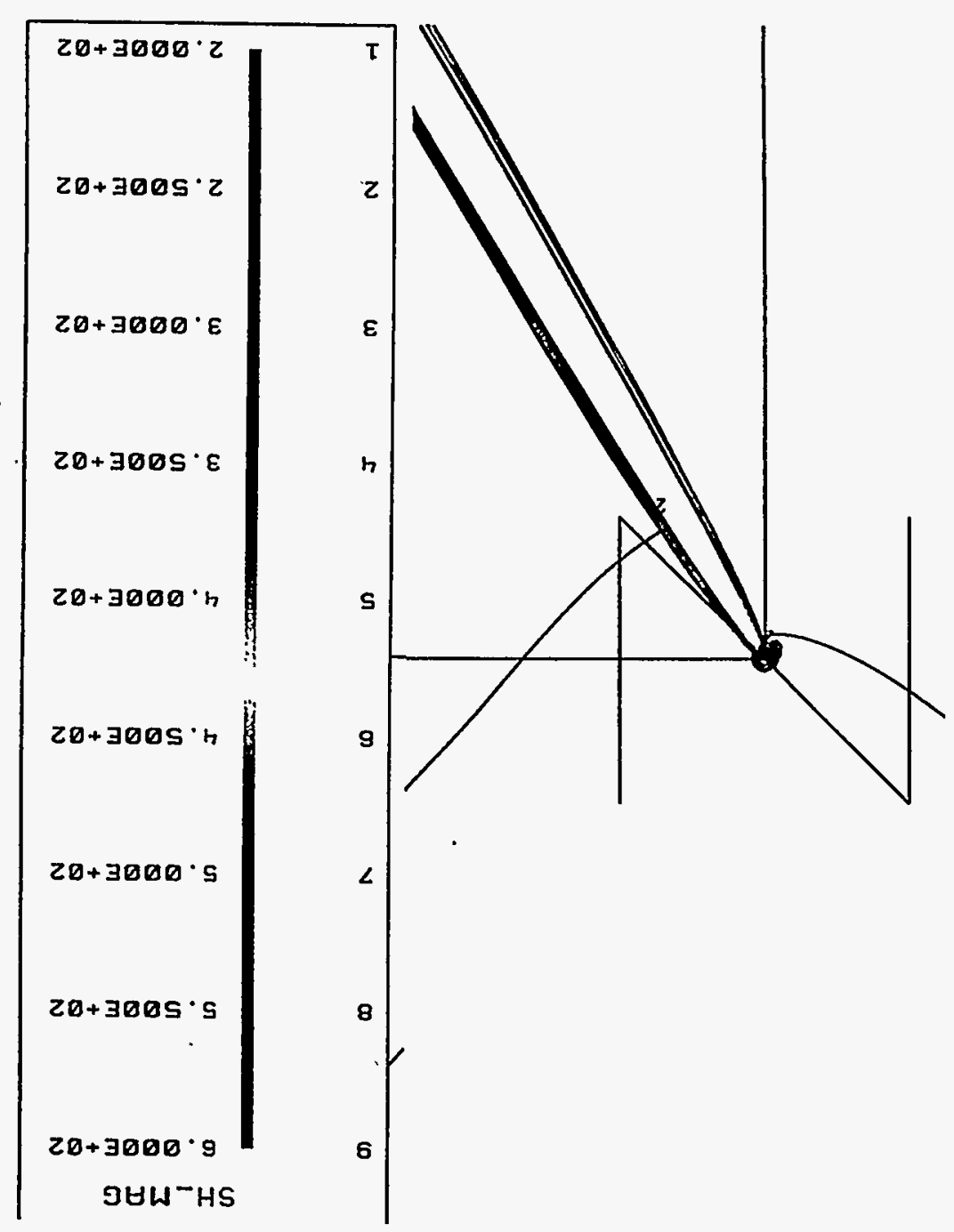

's/u uा s! paads 'aouəpเou

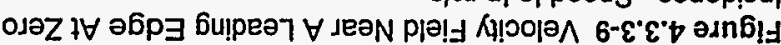

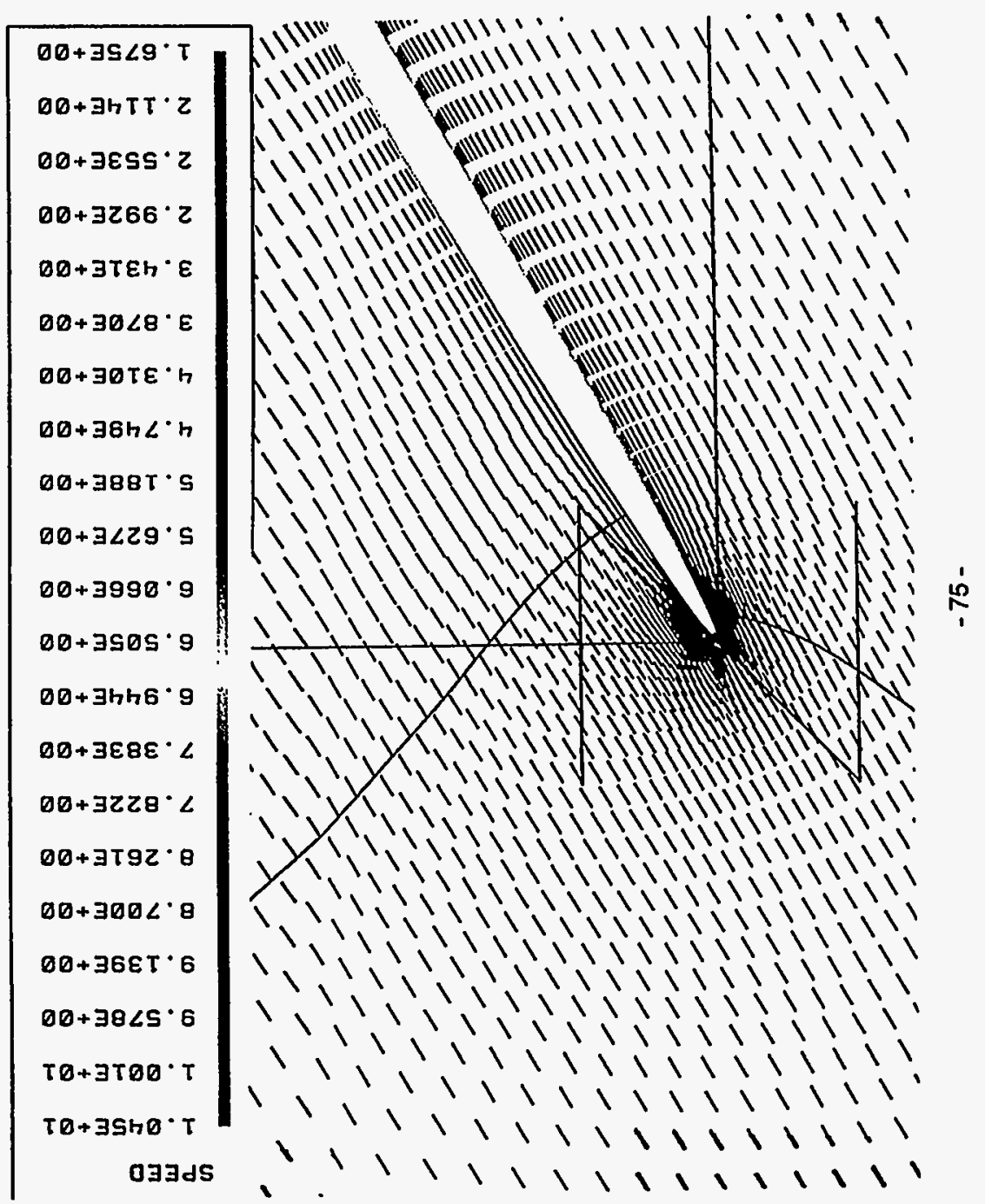




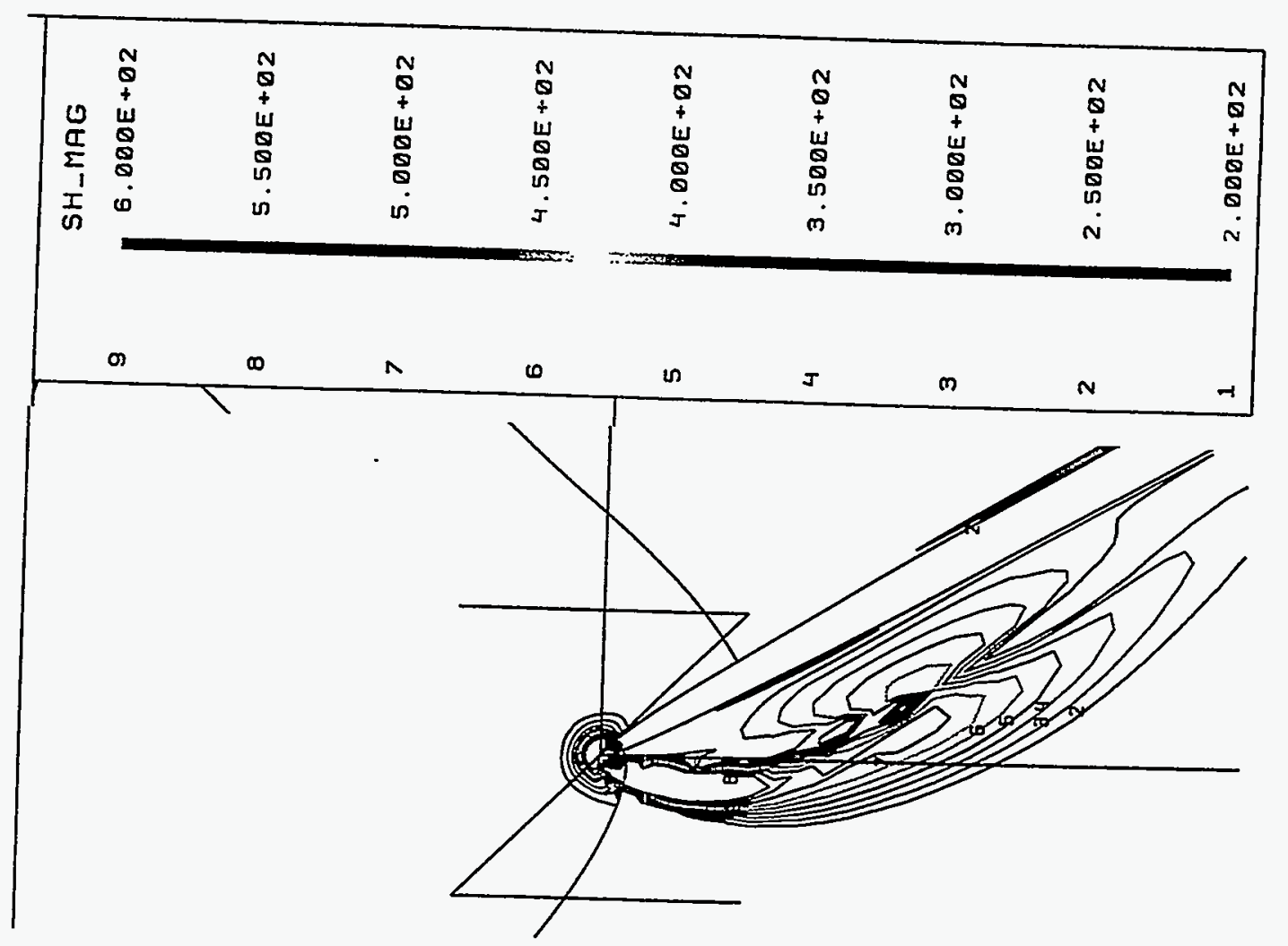

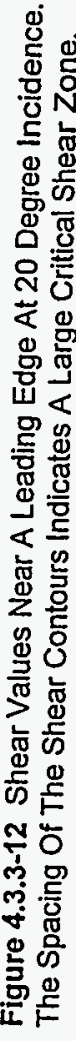

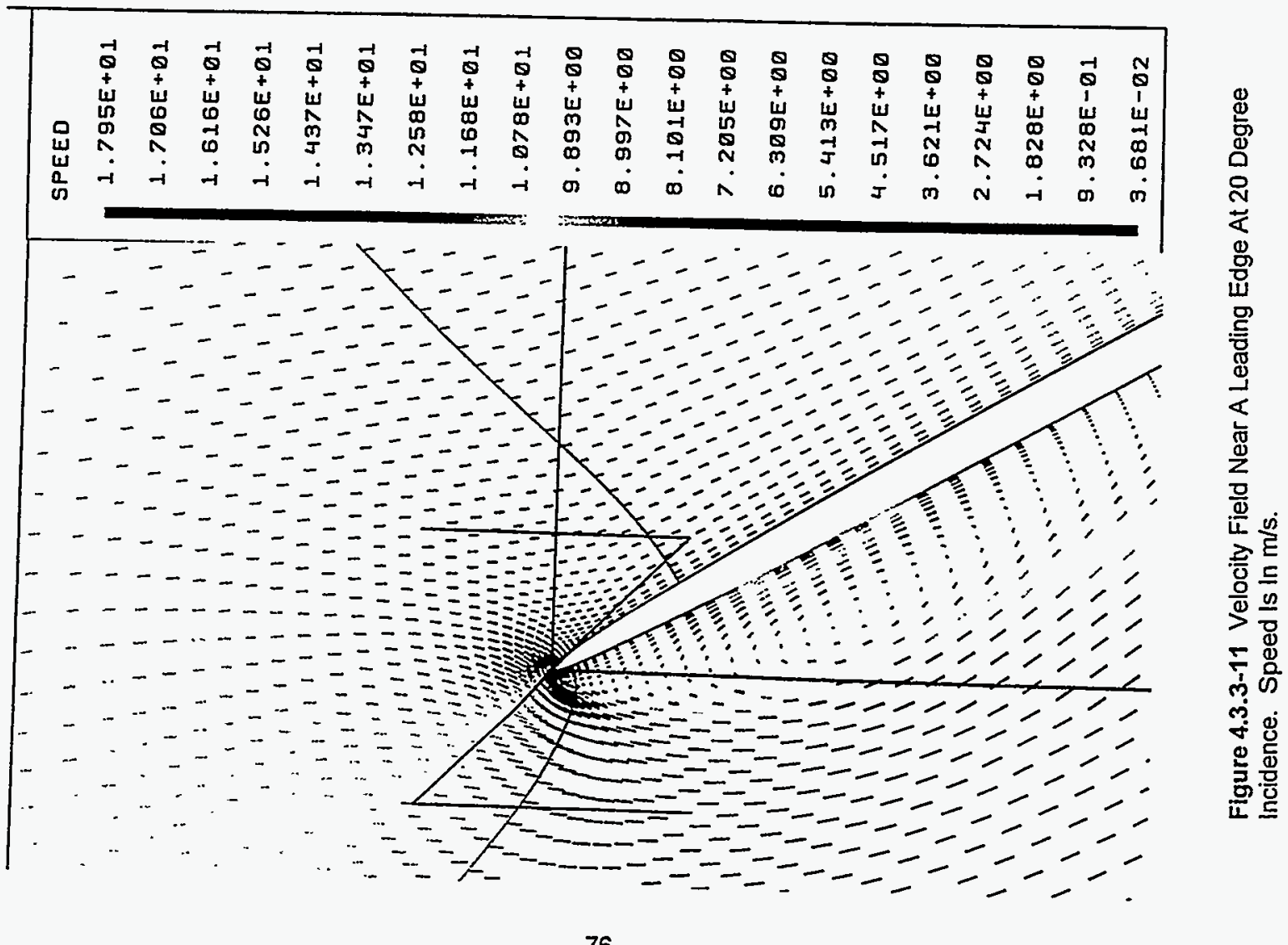




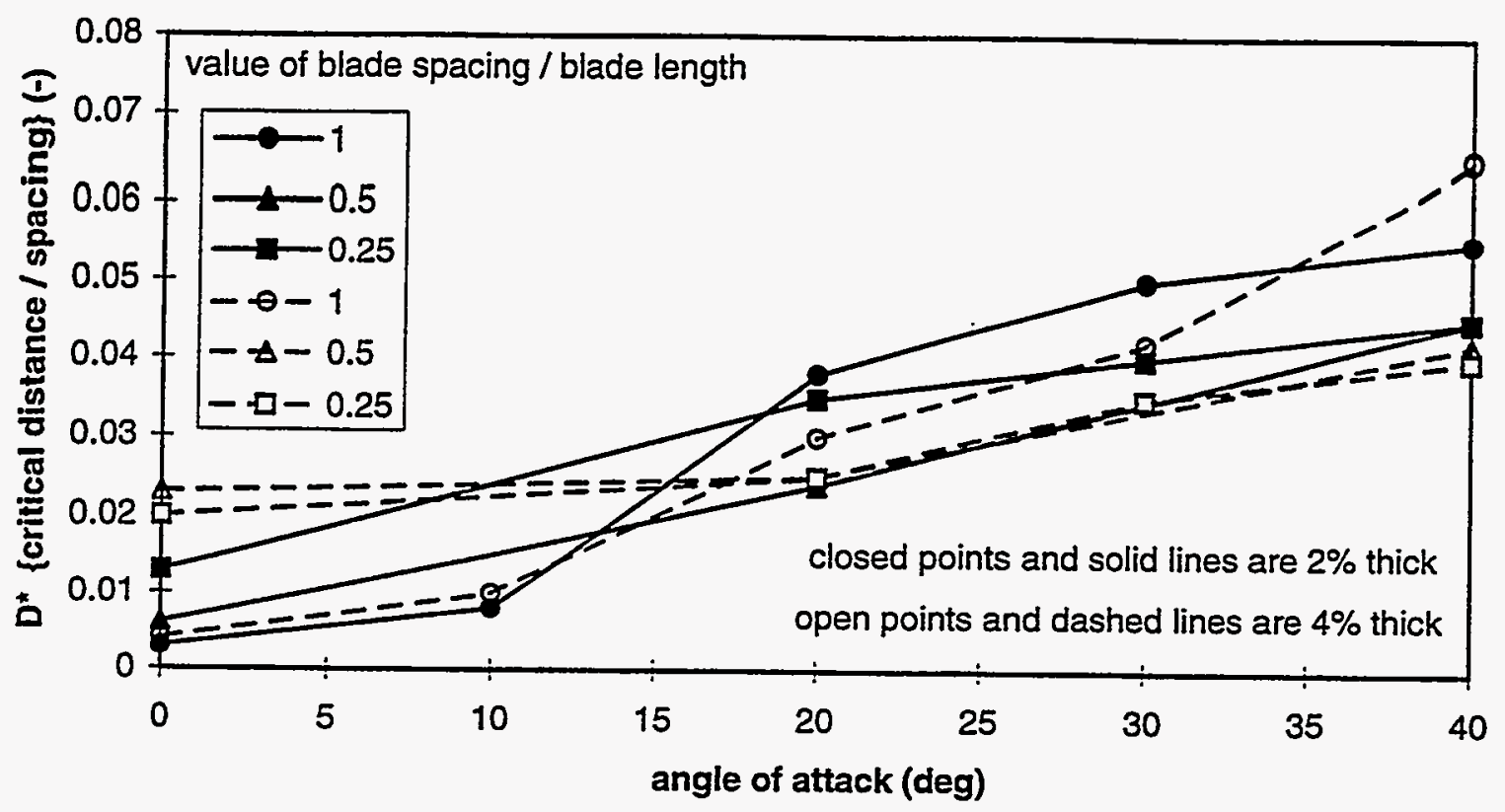

Figure 4.3.3-13 Summary of Critical Shear Distance 

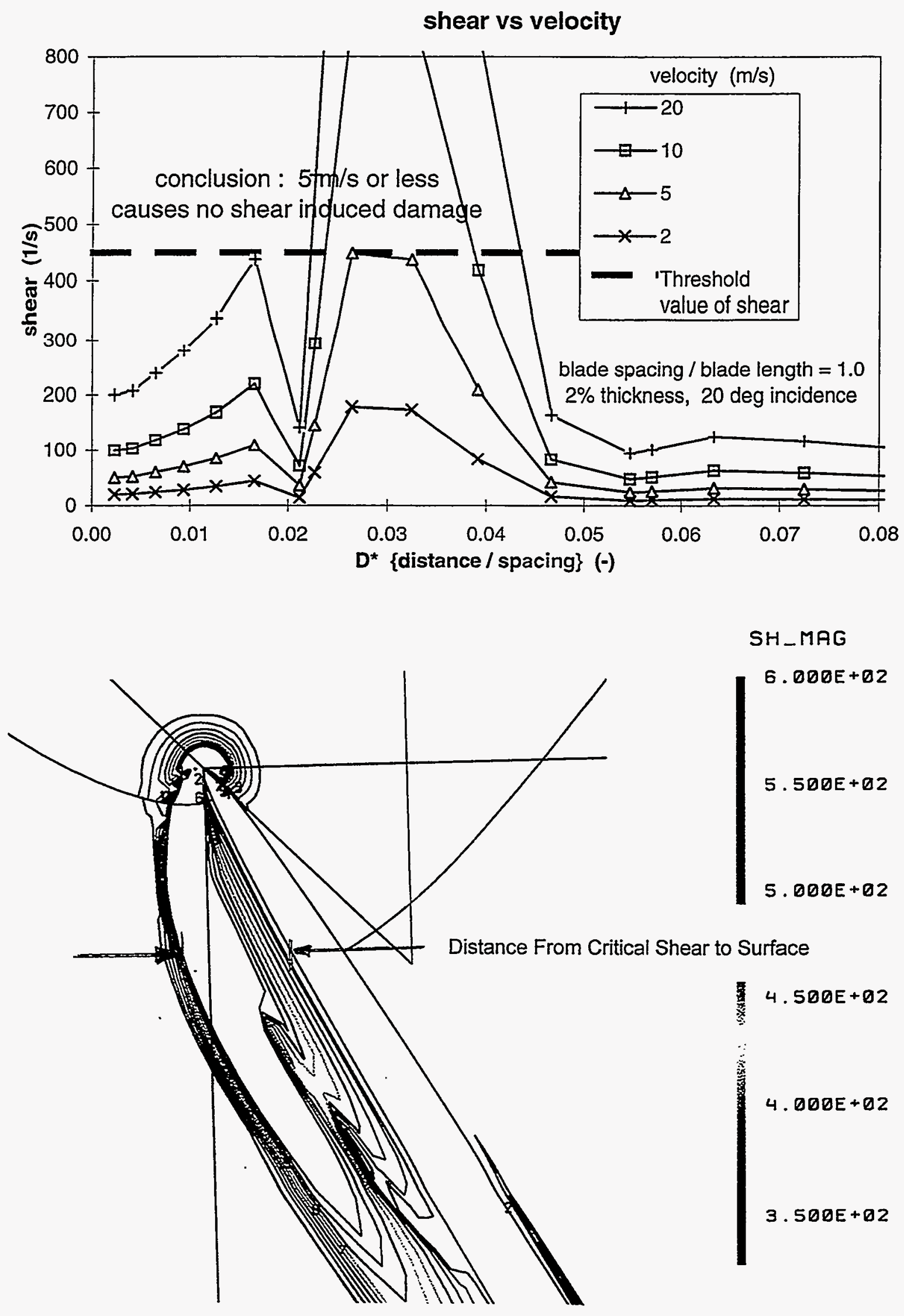

Figure 4.3.3-14 Illustration of Shear Magnitude and Critical Distance for Different Velocities 


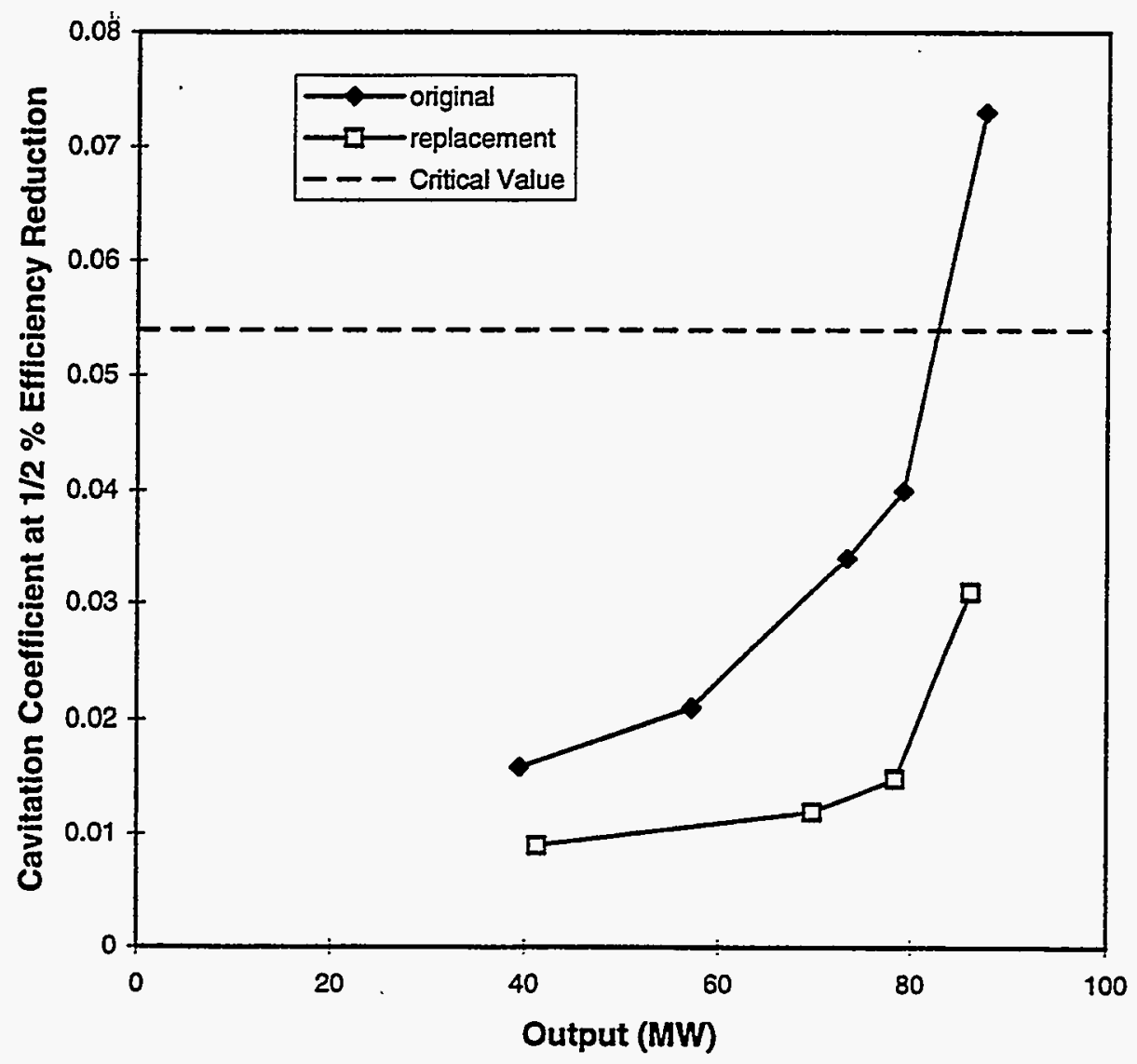

Figure 4.3.3-15 Rehabilitation Can Improve Cavitation Performance 


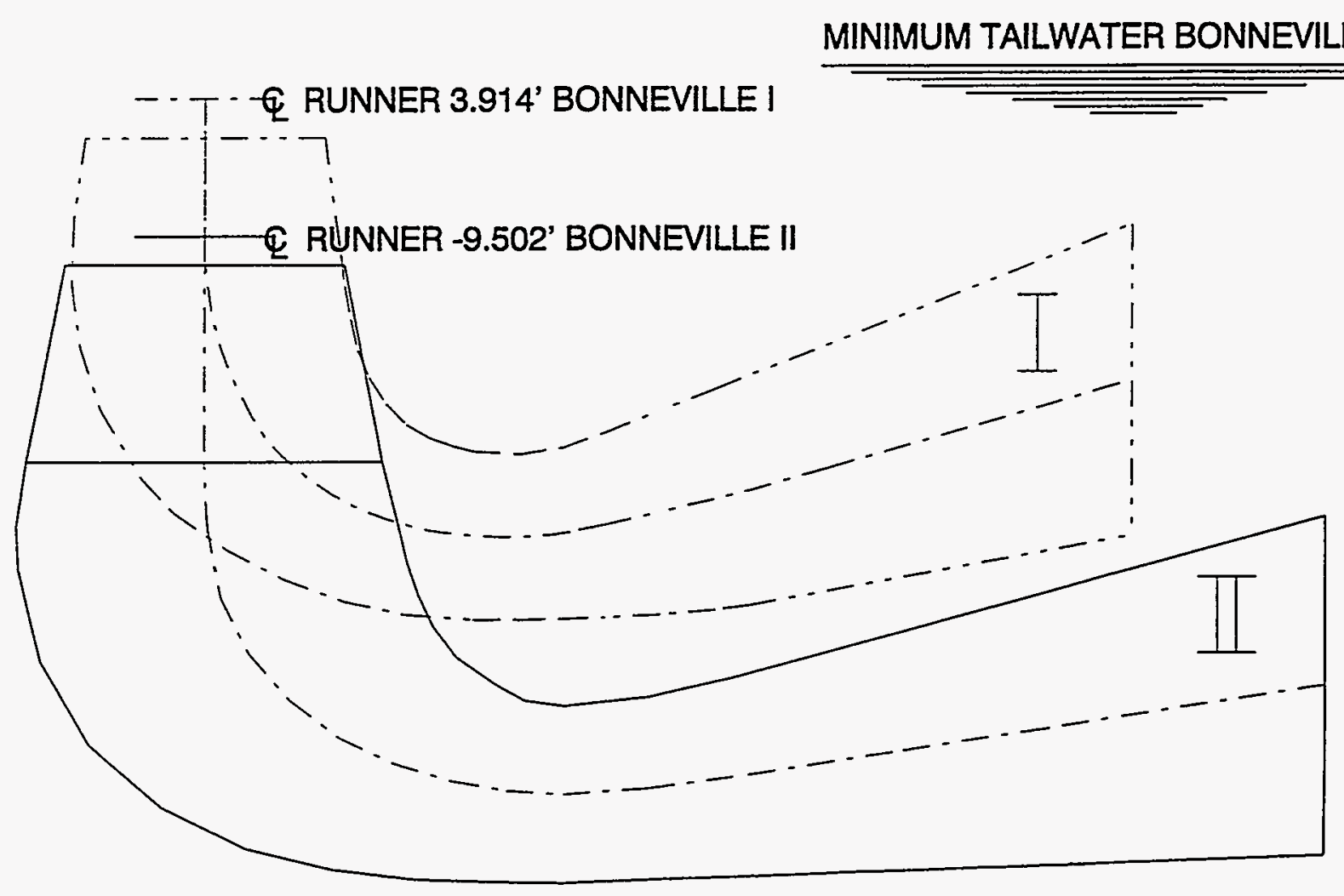

Figure 4.3.3-16 Bonneville Draft Tubes with Different Discharge Orientation 


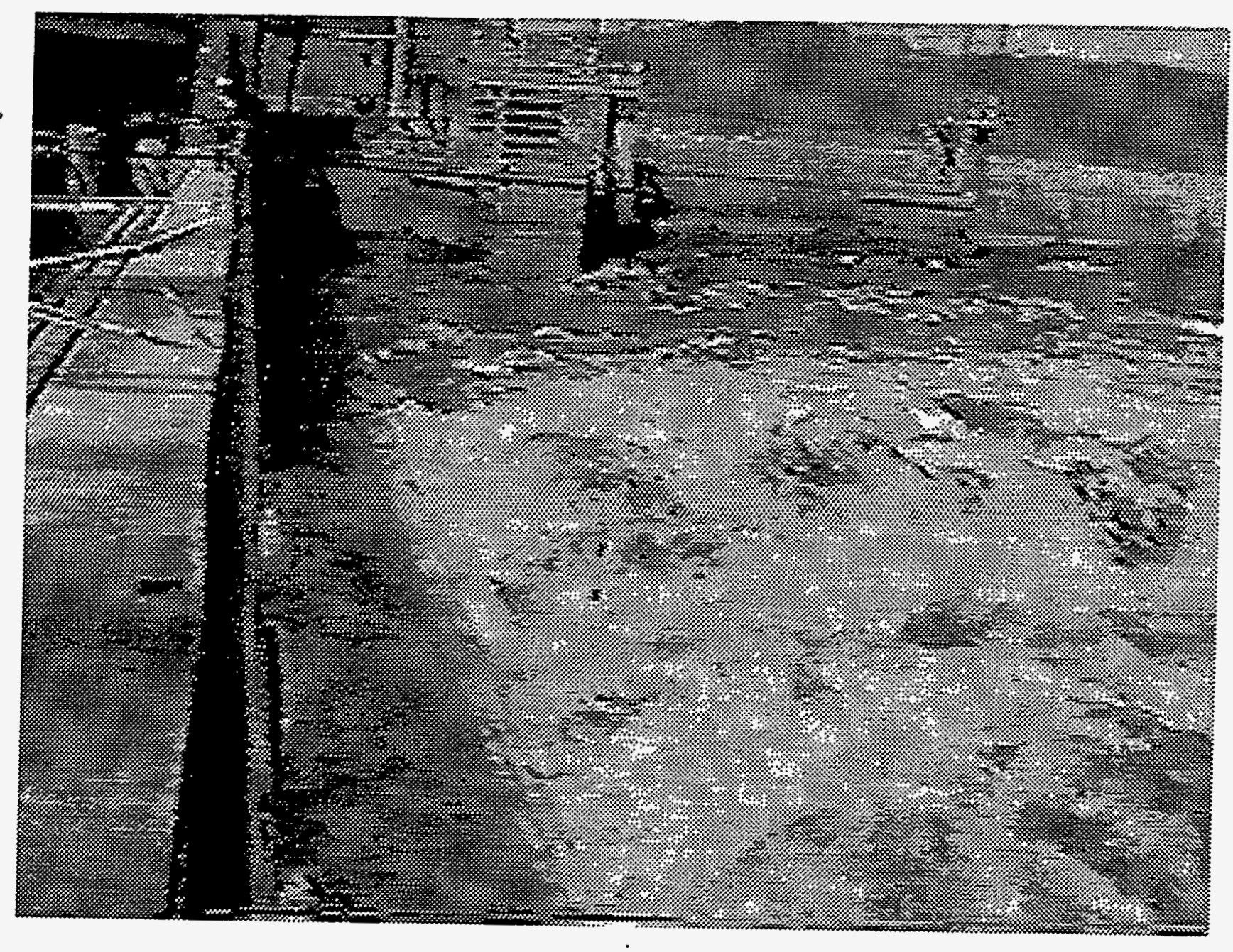

Figure 4.3.3-17 A Disturbed Tailrace Surface 


\subsubsection{PRESSURE MECHANISMS LEADING TO FISH INJURY}

\section{Summary}

Inside of turbines, the pressure distribution and the rate of change of pressure with time can be determined accurately by CFD analysis. Transit times from the high pressure region at the turbine spiral case inlet to the exit of the draft tube are relatively short, even for big turbines. Transit times through low pressure regions in the runner blade region are quite short. The rapid transit through this low pressure region in the blades is felt to cause no significant mortality. More important is the change in pressure from that to which the fish has become acclimated to a lower value at the draft tube exit. Controlled experiments on fish at low head projects ( $<30 \mathrm{~m}$ or $100 \mathrm{ft}$ ) indicate that pressure related injuries/mortality is low. However, pressure related mortality can be significant at higher head dams, whether equipped with hydroelectric turbines or not, if sufficient time is given to fish to acclimate to greater depths (high pressure) and subsequent rapid exposure to low pressures. Such environments can be associated with fish passage as fish move from the bottom of an upstream deep reservoir or long penstocks to a downstream reservoir. To minimize the adverse pressure effects, the turbine plant design may be more critical to fish passage survival than turbine machine design. For new advanced turbines, plant designs should be developed to minimize long times associated with penstock passage, and therefore the acclimation to deeper depths associated with them

\section{Discussion}

The absolute levels of pressure and their rate of change over time (between intake and the draft tube exit) are the result of complex interactions of factors associated with the environment and turbine design. For a particular turbine design, the head and discharge cause a unique flow pattern that can be calculated by advanced CFD methods. Subtle changes to the turbine runner geometry or the turbine operating condition can cause significant changes to the resulting pressure. However, in the absence of cavitation, pressure changes that fish experience for exceedingly short time cause no significant mortality (RMC 1994a,b,c,d; RMC and Skalski 1994a,b; RMC et al. 1994; Normandeau Associates et al. 1995, 1996a). Time to acclimation is probably too short to cause significant pressure related fish damage. However, as mentioned earlier acclimation history and the time to reach full acclimation are not precisely known.

On the other hand, time to acclimation may be sufficient to cause significant damage in plants where the civil design draws fish from lower regions of the reservoir, or allows fish to transit the penstock in a manner wherein the fish can become acclimated to the higher pressures by the time they reach the turbine spiral intake. Figure 4.3.4-1 shows schematics of two alternative turbine plant configurations, and the pressure history for fish passage. For all sites, the transit times for fish passing the turbine is relatively small in comparison to the transit times for fish passing from the dam to the turbine. For typical Kaplan projects the heads range from 6 to $26 \mathrm{~m}$ (20 to $120 \mathrm{ft}$ ) and the pressure changes associated with the difference in pressure from the headwater to the tailwater are not sufficient to create serious decompression trauma. For Francis turbines, however, heads are higher ( 15 to over $350 \mathrm{~m}$ or 40 to over $1,200 \mathrm{ft}$ ), the time of passage is longer (particularly at sites with long penstocks or tunnels leading to the turbine) and the possibility for decompression trauma is real.

Testing has been done to help understand the effects. The information derived from laboratory tests is quite variable and is based mostly on subjecting fish to pressure regimes that may not mimic those encountered by fish in passage at dams with greater than $14 \mathrm{~m}$ (45 ft) of head. Therefore, the development of criteria for maintenance of safe pressure differential at the turbine runners may be risky if based on currently available laboratory data. This is especially true if the fish tolerance to pressure differential (expressed as a ratio or proportion of fish exposure pressure to acclimation pressure) observed in a laboratory is applied to designing an advanced turbine. A numerical example may help clarify the importance of considering the site specific depth characteristics. A pressure reduction of $60 \%$, 
that is a ratio of final pressure to acclimation pressure of 0.4 , can be observed in two different situations with significantly different consequences. For example, fish acclimated at $30 \mathrm{~m}$ or $100 \mathrm{ft}$ depth (about 4 atm) and suddenly exposed to $6 \mathrm{~m}(20 \mathrm{ft})$ deep tailwater (about $1.6 \mathrm{~atm})$ and fish acclimated to $18 \mathrm{~m}$ (60 ft) depth (about $2.9 \mathrm{~atm}$ ) and rapidly exposed to $2 \mathrm{~m}(5 \mathrm{ft}$ ) deep tailwater (about $1.16 \mathrm{~atm}$ ), each experience a $60 \%$ reduction in pressure. The latter pressure condition is frequently encountered by surface oriented fish intercepted by extended length screens at large hydroelectric dams (e.g., Pacific Northwest) and collected in gatewells or surface bypass structures. Recent studies at hydro dams with less than $15 \mathrm{~m}$ ( $50 \mathrm{ft}$ ) of head have not shown pressure related injuries/mortality (see Section 4.2.3). Section 4.2.4.2 provides other specific examples of the effects of intake configuration, location, and depth on fish injuries/mortalities caused by changes in pressure. 

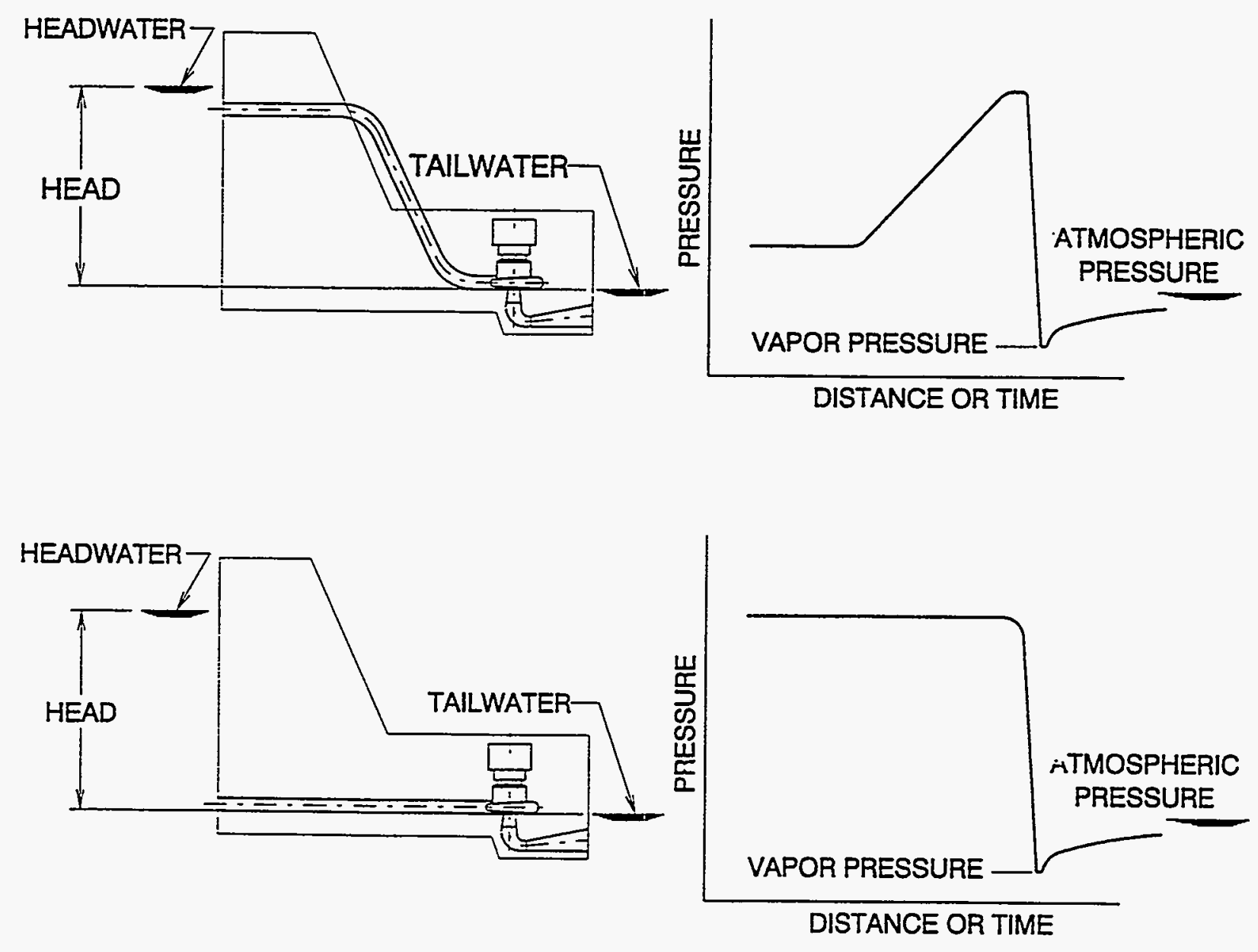

Figure 4.3.4-1 Alternative Plant Configurations Having Different Pressure Acclimation 


\subsubsection{IMPLICATIONS OF SURVIVAL PREDICTION FOR TURBINE DESIGN AND OPERATION}

\section{4:3.5.1 Evaluation of Francis Turbine Number of Blades}

\section{Summary}

Fewer blades appear to be a feasible design concept. For large turbines passing small fish, high survival can be achieved. For small Francis turbines with large fish, the best solution for fish survival may be to keep the fish out of the turbines. This section presents the results of a design study where a series of different turbine runner designs were developed and verified to operate cavitation free at the desired design point. Geometrical differences in the designs are shown along with estimates of fish passage strike survival.

\section{Discussion}

A detailed hydraulic design was made for a series of Francis turbine runners. Each design had a different number of blades. Precise contours were developed for the shape of the crown, band, and runner blades. Each runner was designed to have identical performance characteristics, i.e. had identical specific speed, discharge, power output, and cavitation characteristics. To achieve identical cavitation performance, designs with fewer blades required that each blade be longer. The determination of the complete characteristics of each design (efficiency, pressure pulsations, runaway speed, etc.) is beyond the scope of this study. A preliminary conclusion from the study is that a reduction in number of blades seems to be a modest extension to current design methods and seems likely to produce good turbine characteristics. Some performance and cost tradeoffs may need to be accommodated for designs having fewer than the traditional number of blades.

The designs were developed for a specific design condition: a diameter of $5.41 \mathrm{~m}$, a head of $91.4 \mathrm{~m}$, a discharge of $215 \mathrm{~m}^{3} / \mathrm{s}$, and a power of $180 \mathrm{MW}$. Survival prediction was based on the strike equation. The fish length used was $150 \mathrm{~mm}$ and the lambda correlation value was arbitrarily chosen as 0.2 . The value of lambda that would be most appropriate for Francis turbines is unknown, but values in the range of 0.1 to 0.2 were determined from Kaplan survival tests. Runner designs having $25,18,15,13$, and 11 buckets were developed. Figure 4.3.5-1 compares the water passage shapes of the designs. Table 4.3.5-1 shows the impact of bucket number on calculated survival, as well as the survival for a smaller turbine with the same operating point (head coefficient and discharge coefficient).

\section{using $D=1.0 \mathrm{~m}$ \\ Design Number of Blades \\ Survival Probability (\%)}

$\begin{array}{ll}\text { New } & 25 \\ \text { Original } & 18 \\ \text { New } & 15 \\ \text { New } & 13 \\ \text { New } & 11\end{array}$

using $D=5.41 \mathrm{~m}$

Survival Probability (\%)

$\begin{array}{rrr}25 & 89.7 & 98.1 \\ 18 & 92.6 & 98.6 \\ 15 & 93.8 & 98.9 \\ 13 & 94.6 & 99.0 \\ 11 & 95.5 & 99.2\end{array}$

Table 4.3.5-1 Predicted Survival for Various Number of Blades 


\subsubsection{Evaluation of Francis Turbine Specific Speed}

\section{Summary}

Through the use of a simplified sizing exercise for a turbine at a new hydro site, the role of specific speed is demonstrated. The principal effect of choosing a high specific speed for the head at the site is to reduce the turbine size, thus increasing the strike probability. The new term in the strike formula was found to have a significant contribution to the calculated strike probability.

\section{Discussion}

The strike equation was used to conduct an evaluation of design tradeoffs that might occur for the analysis of a new hydro site. The characteristics of turbines vary as a function of specific speed. As the selected specific speed increases, the turbine becomes smaller, operates at higher speed, and has increased susceptibility to cavitation for a given centerline elevation. The following scenario was used to evaluate calculated fish strike for different turbine designs operating at their best operating point.

$\begin{array}{ll}\text { Number of units } & 1 \\ \text { Discharge } & 28.3 \mathrm{cms} \text { (1000 cfs) } \\ \text { Head } & 25.91 \mathrm{~m} \text { (85 feet) } \\ \text { Number of blades } & 13 \\ \text { fish length } & 152 \mathrm{~mm} \quad \text { (6 inch) }\end{array}$

A number of considerations were ignored, such as unit submergence required to avoid cavitation, operational flexibility, energy production during a yearly flow duration cycle, etc. The result shown in Figure 4.3.5-2 is that fish survival due to strike is enhanced by selection of lower specific speed units for the head at the site. Further study for a specific plant would be required to evaluate other operating conditions to permit an overall judgment.

Since the strike equations used here are new, the contribution of the additional term in the strike equation due to the tangential length of a fish was examined. The strike probability was calculated separately for each term in the strike equations for these same Francis units. Figure 4.3.5-3 shows that the additional term is significant compared to the overall strike probability, and becomes relatively larger as specific speed decreases.

\subsubsection{Evaluation of Adjustable Speed Turbines}

\section{Summary}

Adjustable speed offers the possibility of improved fish survival. Adjusting the speed to compensate for head changes will allow the head coefficient characterizing the turbine performance location on the turbine performance hill curve to be kept at a more favorable operating point than a design having constant speed.

\section{Discussion}

When a turbine is operating at head and discharge coefficients that are not optimum for fish survival, alteration of the rotational speed offers the opportunity to move the operating point to a more favorable location on the hill curve. Consideration of the Kaplan turbine leading edge strike probability, Figure 4.3.27 indicates that higher discharge coefficients are always better, and higher head coefficients are typically better. Consideration of the Francis Turbine leading edge strike probability, Figure 4.3.2-13 indicates a different variation with discharge coefficient but, higher head coefficients are always better. The excess energy dissipation mechanisms relating to fish mortality, based primarily on the results of the Wanapum 
fish survival tests, indicates that the optimum fish survival occurs at the minimum TAL, which occurs at a head coefficient near best efficiency heads and a discharge coefficient greater than the best efficiency discharge, but less than the maximum possible discharge. Combining both of these considerations leads to the presumption that the overall minimum fish mortality location on the hill curve occurs near the best efficiency head coefficient and at a discharge coefficient that is greater than the best efficiency discharge, but less than the maximum possible discharge.

Operational considerations will have an effect on mortality. In the case of operation at a low head, a lower rpm will change the head coefficient to a higher value. If it is desired to discharge the same discharge at the lower rpm, the discharge coefficient must increase. This would be accomplished by opening the wicket gates. If this desired operating point is greater than the maximum gate opening, then this condition can not be realized. Also, it may be that this operating point is in a region of higher TAL, or possibly cavitation. A precise analysis of some of these effects could be evaluated for a particular design but is beyond the scope of this work.

\subsubsection{Critical Velocity Implications for Specific Turbine Components}

\section{Summary}

A survey type of analysis was performed to evaluate average values of velocity in several regions of a turbine to permit a rough assessment of potential mortality. For structural piers, in turbine intakes, typical velocities are significantly less than $5 \mathrm{~m} / \mathrm{s}$. Therefore, strike on these bodies seems to be of no concern.

For stay vane entrance edges and for runner blade tips, typical velocities are shown on Figure 4.3.5-4, as well as mortality results for fish impacting solid objects and entering water adapted from Bell (1991). It is noted that that Bell provided this data without information on test design, uncertainty estimates or protocols used. Although Tumpenny (1992) found that an impact with an airfoil shape at $5.2 \mathrm{~m} / \mathrm{s}$ caused little damage and no mortality, little supporting data is available to evaluate these mortality results.

The velocity on stay vane entrance edges is a function of the head. Velocities of $5 \mathrm{~m} / \mathrm{s}$ at the stay vanes of Kaplan turbines are expected when the head exceeds approximately $17 \mathrm{~m}$ (56 feet). Therefore, stay vanes should not be ignored except for very low head turbines. The tip speed of runners essentially always exceeds $5 \mathrm{~m} / \mathrm{s}$ and all blade strikes may be lethal. Also, the lowest speed portion of a Kaplan blade, (near the hub), will experience relative velocities between the blade and the water exceeding $5 \mathrm{~m} / \mathrm{s}$ when the head exceeds $3 \mathrm{~m}$. 


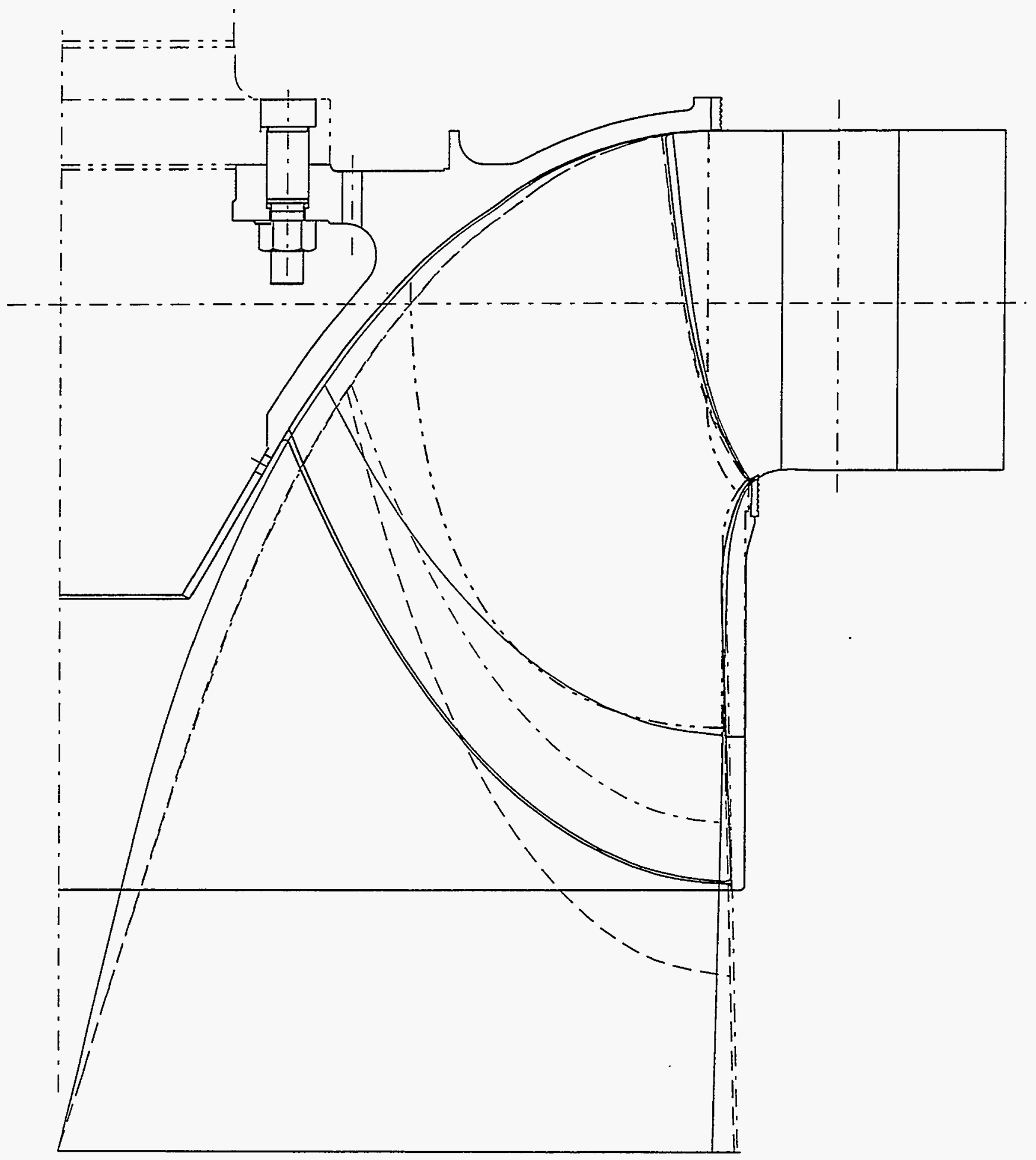

- - - 11 BUCKETS

13 BUCKETS

- - - 15 BUCKETS

-.. - 18 BUCKETS 25 BUCKETS

Figure 4.3.5-1 Francis Turbine Design Study: Comparison of Water Passage Shapes as a Function of Number of Blades 
Francis turbine fish survival

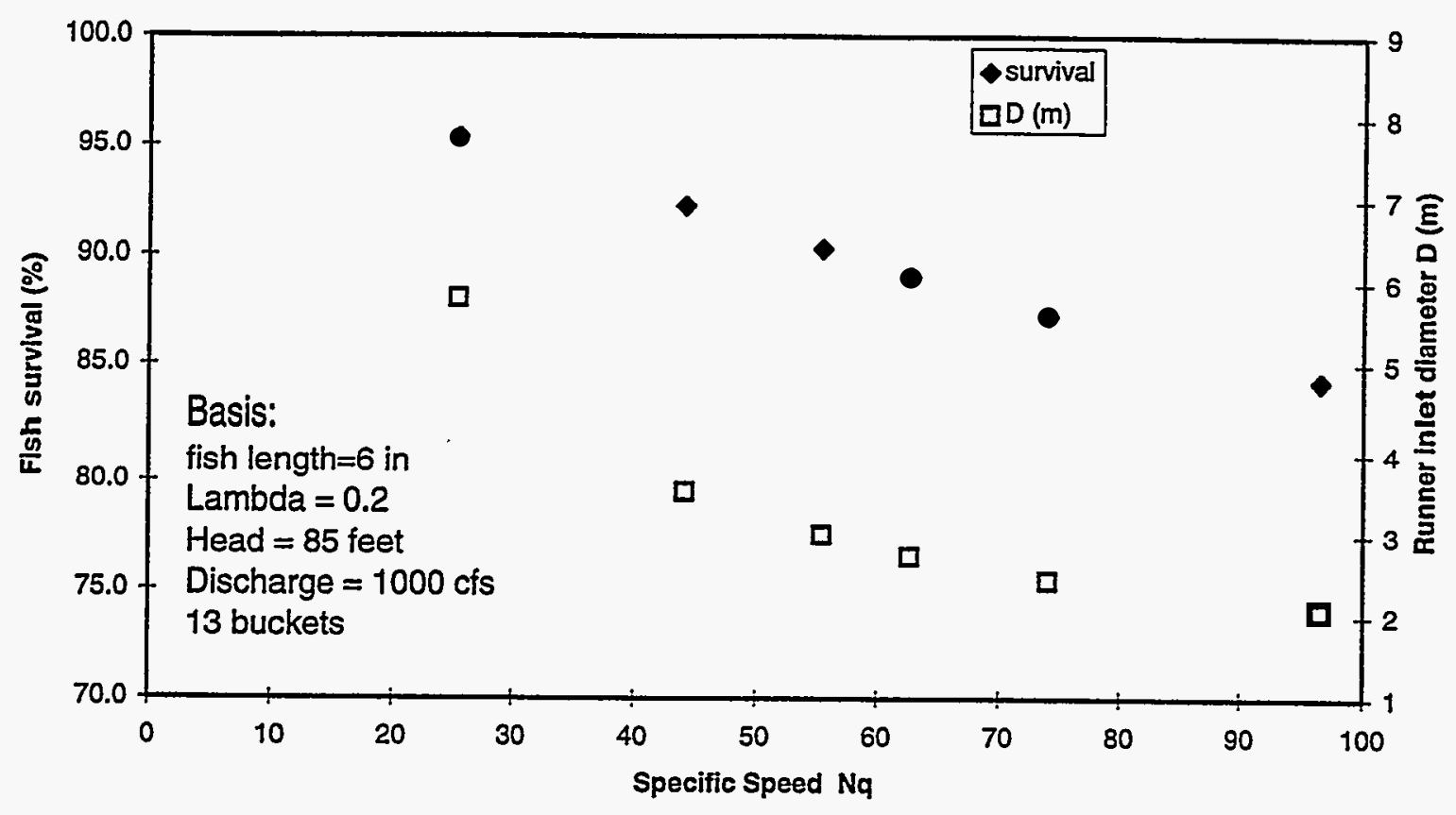

Figure 4.3.5-2 Francis Turbine Design Study: Comparison of Leading Edge Strike Probability and Turbine Size for Several Values of Specific Speed 
Relative contribution of strike equation terms

for Francis Turbines

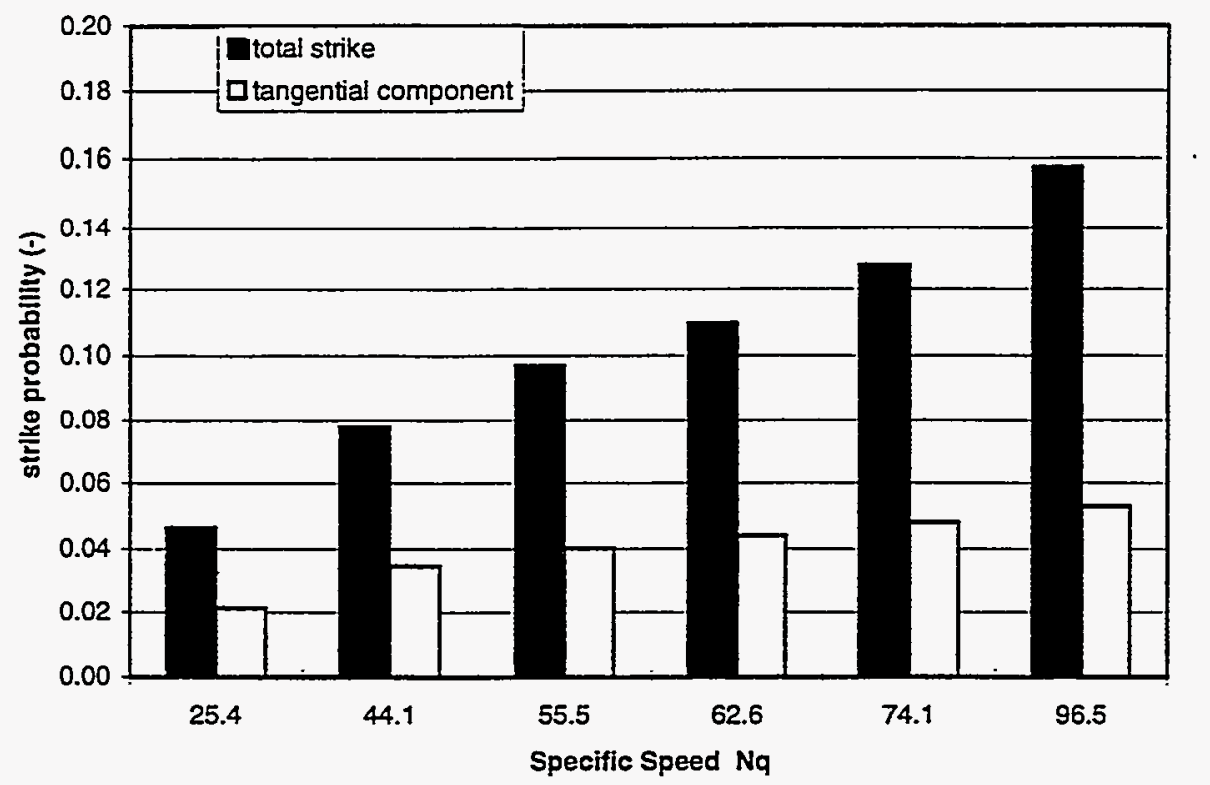

Figure 4.3.5-3 Illustration of Contribution of the Tangential Fish Length to Total Strike Probability

Fish Mortality and Typical Velocities

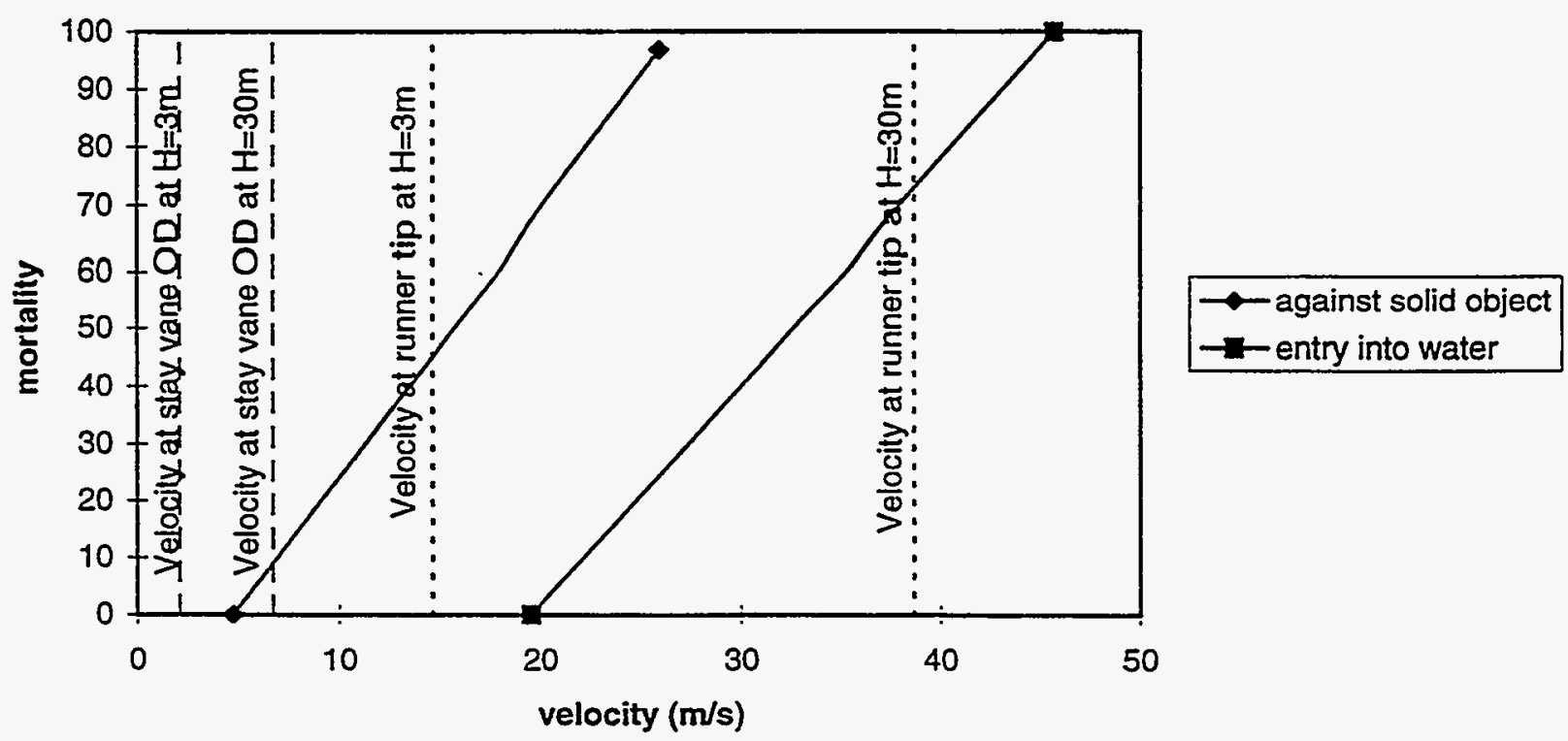

Figure 4.3.5-4 Comparison of Typical Turbine Velocities with Mortality Results. Mortalities Adapted from Bell. 1991 


\subsubsection{ZONAL DEPENDENCE OF INJURY/MORTALITY MECHANISMS}

\section{Summary}

Injury mechanisms are associated with specific zones of turbine geometry. This section introduces the concept.

\section{Discussion}

A turbine should not be treated as a black box into which fish are carried and out of which some injured fish and some uninjured fish emerge. The survival of the fish is highly dependent on the zones of the turoine traversed by the fish path.

For the purpose of evaluating the fish injury potential of a turbine, the turbine should be considered to be comprised of a number of separate zones and sub zones. Each zone's geometry and fluid characteristics will have a unique effect on the fish. Some zones are fish friendly, while others cause damage. As an example, the turbine can be divided into zones associated with the principal structures. Zones associated with the intake upstream of the turbine (penstock or other civil structure with trash racks), the near inlet (spiral case or semi spiral case), the stay vanes and wicket gates, the runner and the draft tube could be considered. In the vicinity of the runner, the zones could be further subdivided (Figure 4.3.6-1). Here, the annular regions of the water passage could be designated as the hub zone, the mid zone and the tip zone for Kaplan turbines, and other zones for Francis or propeller turbines. The annular regions could be further subdivided into rear blade zones and between blade zones. Within the hub zone, there would be a separate zone per blade, each of which may contain gaps with sharp edges and associated fluid injury mechanism sources such as cavitating vortices, regions of high shear and so forth. Experimentally measured mortality correlated with the number of turbine blades, for example, would contain the effects of both mechanical strike and fluid induced mortality. Experiments to determine the effect of certain mechanisms on fish mortality will need to recognize the zonal nature of damage mechanisms and be desig: :d to carry fish into appropriate zones.

In the discussions that follow, the concepts of the zonal nature of the turbine and the zonal effects on injury/mortality mechanisms will be used. 

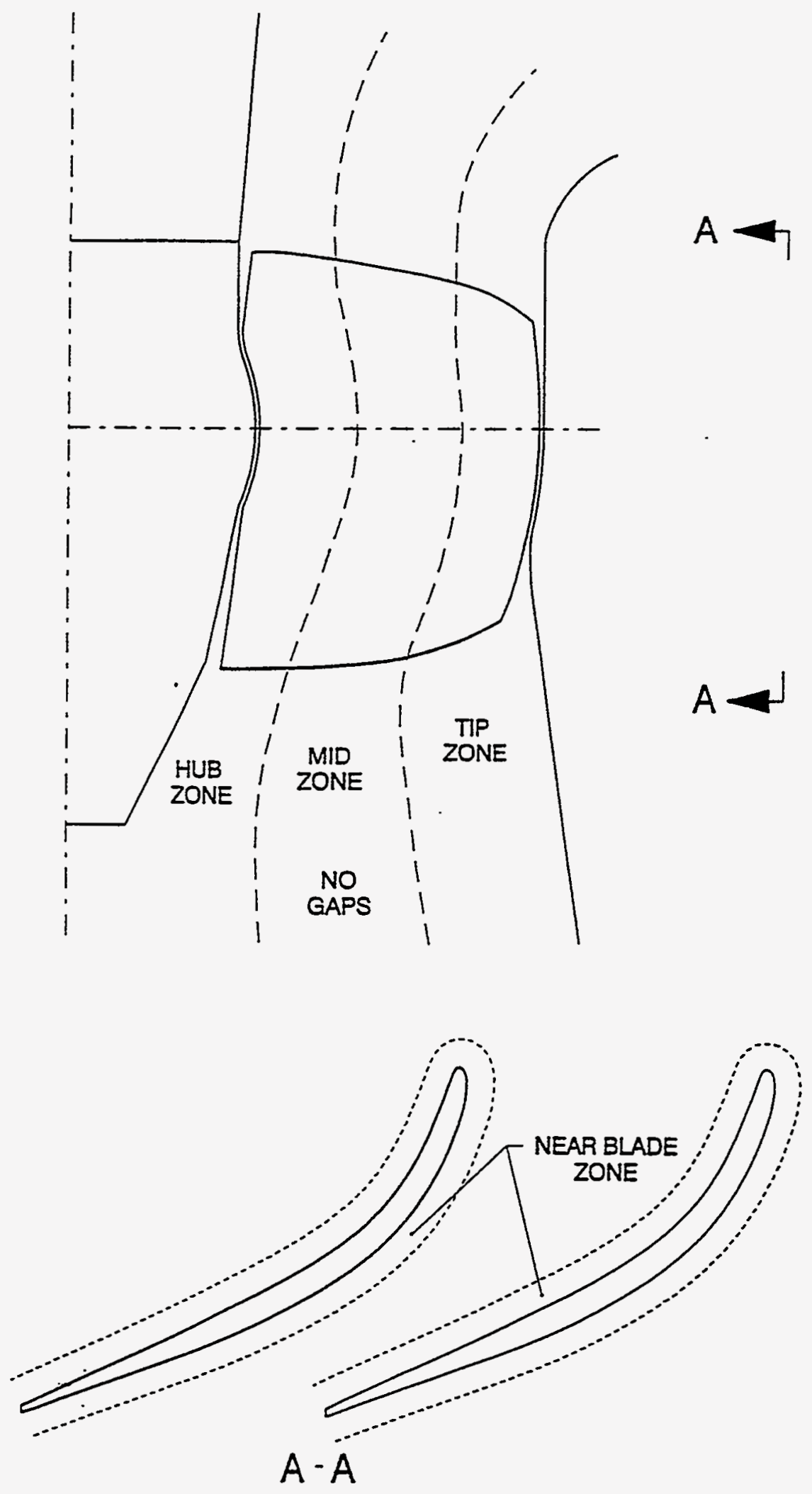

Figure 4.3.6-1 Fish Survival is Strongly Affected by Transit Through Different Zones of the Runner 


\subsection{INSIGHTS TO INJURY MECHANISMS AND SURVIVAL PREDICTION METHODS OBTAINED FROM EVALUATION OF FISH SURVIVAL TEST RESULTS}

\subsubsection{INTRODUCTION}

Data selected in Section 4.2 are evaluated herein to look for trends supporting concepts presented in Section 4.3. Kaplan, Propeller and Francis data are used, but treated separately in the evaluation. Note that statistics have not been relied upon for our evaluations. Instead, each evaluation outcome was examined for its merits in integration of biological significance with turbine fiow physics. This is to avoid confusion between statistical significance and practical significance

Fish injury during turbine passage and therefore survival is dependent on a number of factors. These have been outlined in Section 4.3. No single mechanism can be correlated with observed injury or mortality in fish passage survival testing. Instead, a combination of effects come into play which are dependent on the type of turbine, the turbine geometry, how the turbine and the turbine plant is operated, as well as the species and size of fish, the fish's location in the water column and the fish's behavior in approaching and passing through the turbine. The mechanisms of injury can be characterized into zones within the turbine. Fish passing through different zones can encounter different mechanisms and therefore experience different survivability.

Because of some unique characteristics of the hydroelectric dams on the Columbia River Basin, and the intensity of effort in improving fish passage survival there, significant fish passage testing has been conducted on Kaplan turbines providing a relatively good availability of comparable data, under relatively controlled conditions. The testing investigated the effect of intake modifications, turbine operating conditions, and turbine geometry with the specific objectives of improving turbine passage conditions. Insights gained from these tests are discussed separately below. The tests include those at Rocky Reach Dam and Wanapum Dam on the Columbia River and Lower Granite Dam on the Snake River. At Rocky Reach Dam the experiments were conducted to identify potential sources of fish injuries so that turbine design and structural modifications could be incorporated into a new replacement turbine. At Wanapum Dam, the investigation was done to determine the effects of turbine operating performance on the survival of fish entrained at two depths. Studies at Lower Granite Dam were conducted to provide baseline survival and sources of fish injury for comparison with turbine operation during the proposed reservoir drawdown and to evaluate the potential effects of extended length screens on unguided fish in passage through turbines, (Figure 4.4.1-1). For all tests, data were specifically obtained to evaluate the effects of turbine operating efficiency, fish entrainment depth, differences between turbine intake bays, and presence or absence of intake screens on fish survival and injury rates. With some minor exceptions, these types of data are generally not available from other regions of the country. However, even in this database a wide range of operating conditions, configurations, and fish behavioral reactions have not been tested to draw a predictive statistical relationship. The above data and others from previous testing are discussed below. 


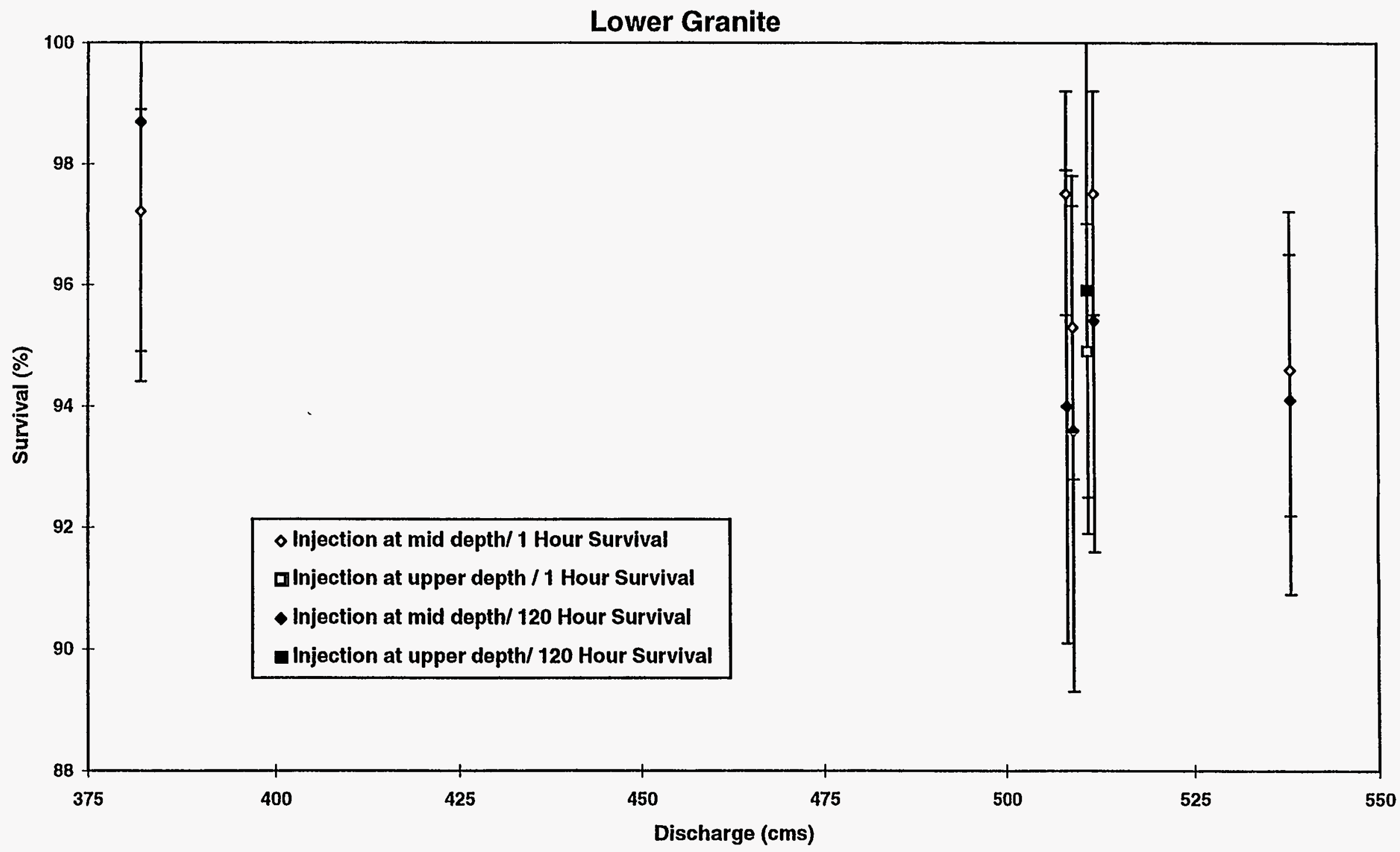

Figure 4.4.1-1 Survival Results At Lower Granite, Effect Of Injection Location And Operating Point 


\subsubsection{EFFECT OF LOCATION OF FISH WITHIN THE WATER COLUMN}

\section{Summary}

The geometry of the turbine intake influences the distribution of fish as they pass through the turbine internal geometries. For Kaplan turbines with large well designed intakes and low inflow distortions (such distortions may be induced by upstream flow nonuniformities, inserted structures, trash on the trashrack or the state of operation of the neighboring units), the location of fish relative to the height in the intakes reasonably predicts the relative height of their path through the stay vanes, wicket gates and within the runner. For Francis turbines this is often not the case. If the fish position is known as it passes through the turbine, observation of fish injuries incurred can be related to the local geometry and to the resulting injury mechanism.

\section{Discussion}

Based on the background developed in Section 4.3, the mechanisms associated with fish injury are related to the turbine geometry and its operation. In general, the mechanisms are localized and do not occur at the same time and in the same manner throughout the turbine water passageway. Thus, the probability of fish injury and the type of injury are related to the location of the fish relative to the turbine geometry or to the zone through which the fish pass. The location of the fish within the turbine geometry zones are related to their starting position in the intake, the flow characteristics of the turbine and their own free will response to fluid stimuli.

The geometry of a Kaplan intake frequently takes the form of a semispiral intake where the initial cross sectional geometry is a box like structure that has a significant distance from the upper portion of the water column to the bottom portion. Section 5.3 presents the results of CFD analysis of such a.Kaplan turbine intake showing flow paths of neutrally buoyant particles injected into the flow. Fish without the effect of fish volitional movement (FVM) would pass like neutrally buoyant particles. For Kaplan turbines, in the absence of FVM and significant disturbances within the turbine flow field, the flow will transport fish through the turbine in such a manner that fish in the upper water column pass by the top of the wicket gates and stay vanes and enter the runner near the hub. Fish near the lower portion of the water column will be transported past the stay vanes and wicket gates near the lower portions of these structures and into the blades near the runner tips. Fish entering the intake in the mid elevation will be transported to the zone in the center of the blades. Some Kaplan turbines have full spiral intakes connected to the upper reservoir by a penstock. In this case, the characteristics of the intake flow distribution will be as described below.

The geometry of a Francis intake is significantly different from that of a semispiral Kaplan. Typically, Francis turbines draw water into either the bottom or upper portion of the dam or intake structure and lead the water into a penstock (pipe) which carries the water to the full spiral intake. Section 5.3 presents the results of CFD analysis of a Francis full spiral turbine intake showing predicted flow paths of neutrally buoyant particles.injected into the flow. In contrast with Kaplan turbines, neutrally buoyant particles seeded into the flow at the full spiral intake for Francis turbines enter the stay vanes and runner at different locations dependent on their starting radius. Particles near the top on the spiral inlet can pass the stay vanes at the top, mid region or bottom of the vanes and then in similar positions of the wicket gates and into the runner entrance edge. The effect of the geometry of the penstock, which leads water into the spiral case, 'on particle distribution is also significant. Bends in the penstock can set up swirling flow patterns, redistributing the neutrally buoyant particles. Some Francis turbines have semispiral intakes much like the classic Kaplan and in that case have similar intake flow distributions as a Kaplan described above. 
Based on the above, it can be seen that the location of the fish in the intake of the turbine can be related to flow characteristics and geometry of each zone through which the fish pass. This has been observed in prior studies. For Kaplan turbines, it has been hypothesized that survival may be lower for fish entrained at greater depth because fish are likely to enter turbines nearer the blade tip (Eicher Associates 1987; Ferguson 1993; Turner et al. 1993). However, this hypothesis did not take other factors into consideration such as the detailed geometry of the turbine, the quality of the hydraulic design, the change in geometry as the point of operation changes, the impact of flow obstructions within the water passages such as fish screens and so forth. At Lower Granite Dam on the Snake River, the estimated survival (93.6 to 95.4\%) of chinook salmon smolts entrained at mid-depth elevations was similar to that at the upper elevation (94.9\%) with the turbine operation held constant at (Normandeau Associates et al. 1995). At Rocky Reach Dam Unit 3 on the Columbia River the point estimate (93\%) of survival of chinook salmon smolts released at upper elevation was slightly lower (though not significantly) than for the mid-elevation releases, $94.7 \%$ (Mathur et al. 1996a). The turbine operated over a wide range of normal power outputs and discharges during the test. However, as discussed earlier, survival at Unit 5 varied with power output and was higher at $9 \mathrm{~m}$ (30 ft) depth than at $3 \mathrm{~m}(10 \mathrm{ft})$ depth. At Wanapum Dam, coho salmon smolts were introduced at two depths within a turbine that presumably swept them either near the hub or near the middle of the blade at four different operating efficiencies (Normandeau Associates et al. 1996a). The two release depths were selected on the basis of CFD model predictions which assumed that fish was incapable of changing its path while entrained in these flow streams. Fish released $3 \mathrm{~m}(10 \mathrm{ft})$ below the turbine intake ceiling were expected to pass near the hub and those released at $9 \mathrm{~m}(30 \mathrm{ft})$ below the intake ceiling were expected to end up at the mid blade region. The survival was consistently lower for coho salmon introduced at $3 \mathrm{~m}$ depth than at $9 \mathrm{~m}$ depth; depth-related differences in survival increased with increased discharge; the largest difference $(9.3 \%)$ occurred at $184 \mathrm{cms}(17,000 \mathrm{cfs})$. At other discharges survival at $3 \mathrm{~m}$ depth was $4.4 \%$ to $5.2 \%$ lower that at $9 \mathrm{~m}$ depth.

The interrelationships between the mechanisms for injury and the flow characteristics that occur in different zones and how they vary with discharge will be explored in more detail below. 


\subsubsection{EVALUATION OF (NL/D)}

\section{Summary}

While fish passage survival is influenced by $N L / D$, the effect of other parameters such as turbine geometry, turbine performance (efficiency, cavitation), the point of operation, and the quality of the experiment lead to enough data scatter that it is difficult to define the effect of a fish passage experiment without a carefully designed and executed test. For Kaplan turbine data (from 3 to 6 blades) the newly developed leading edge strike (or blade zone encounter) equations verify that $N$ L / D correlates measured data well. An estimate for the strike mortality correlation factor, lambda, derived in Section 4.3 is developed for Kaplan turbines.

\section{Background Information for a New Data Analysis Technique}

A new data analysis technique is used. Previous analysis techniques have presented survival as a function of individual variables, such as peripheral speed. These previous presentations mask several effects that are known to occur simultaneously. For example, at a particular value of peripheral speed, various data points could exist for different fish length, or even different turbines having different number of blades. A useful data analysis technique would account for known correlations of certain variables and therefore, clarify whether other variables play a role. This is accomplished by combining measured survival with predicted survival as a ratio. This single quantity then contains information regarding the correlation of survival by the prediction method. In this case, the prediction uses the variable $N L / D$, as well as the correlation factor, lambda. Note that the predictive method used here does not include the variables head, peripheral speed, acclimation pressure, etc. Future use of this technique could employ more sophisticated prediction methods, when they become available. The success of this method requires that the prediction have reasonable success. A plot of this ratio versus a variable of interest, permits conclusions to be drawn regarding the isolated effects of that variable. If this variable had observable influence, with other effects occurring in a random manner, the ratio values would form a definite trend. If this variable had no observable influence, the ratio values would vary about unity with data points scattered above and below unity in a random manner.

Note that although the "strike" equation is used as the prediction method, this does not imply that strike is the only phenomena occurring. As an example, fluid mechanisms such as those associated with Kaplan blade gaps and entrance edge shear are related to the flow in the zone near the blades and are therefore, related to the number of blades. In the analysis of the data, several mechanisms of injury may contribute to the correlation, as long as they are strongly related to the geometrical variable $N L / D$, and are contained within the lambda value. Because of the zonal nature of the mechanical and fluid mortality mechanisms associated with the blade zone, the term "blade zone encounter" (BZE) might be a better choice of words replacing "leading edge strike" in the sections that follow.

\section{Discussion}

Fish Length: Fish length has long been known to directly influence fish survival. Evaluation of limited data selected in Section 4.2 where significant changes in length were evaluated confirms the effect. To evaluate whether the strike (BZE) equation correctly accounts for the fish length, the ratio of measured fish survival to fish survival predicted by the strike equation is used. Overall, this ratio will approximately equal unity due to the choice of lambda equal 0.2. If the strike (BZE) equation captures the essential influence of fish length on mortality, these ratio data points will occur at values both higher and lower than unity without any significant deviations at large or small values of fish length. For example, if less severe mortality effects would occur for large fish, their higher survival would cause the ratio value to increase. This would cause a cluster of data points at higher ratio values for large fish. 
For a Kaplan turbine at Hadley Falls, where significantly different length fish were used, the ratio of survival data shown in Figure 4.4.3-1 shows no clustering. The data point for the largest fish length, for example exceeds unity by a similar amount that the data points at the smallest fish length differ from unity. A similar analysis for all data from Table 4.2-1 (Figure 4.4.3-2a and b) shows greater scatter (presumably due to various uncontrolled aspects of the experiments), but shows no obvious data clustering. Since the fish trajectories are unknown, calculations are presented for two values of the radius where fish are assumed to enter the runner, $r / R=0.4$, and $r / R=0.75$.

For reference, Figure 4.4.3-3 presents survival data directly. For fish of approximately $300 \mathrm{~mm}$, the measured survival varies from 70 to $97 \%$. This large scatter is due to the effect caused by the simultaneous variation of other important variables. With this type of data analysis, even sophisticated statistics have not been successful in identifying fundamental physical relationships.

Number of Blades: Another physical effect considered by the one-dimensional leading edge blade strike (BZE) model is based on the physical size of the turbine, the fish and the number of blades. For large Kaplan turbines, this aspect of fish survival was examined for turbines having the most common number of blades ( 5 and 6 ) where fish of nearly the same size were tested. Figure 4.4.3-4 shows that within the scatter associated with operating conditions, fish location, turbine geometry and so forth, the effect of the number of blades was not significant. However, when data from 3 and 4 bladed turbines were considered, the N L / D parameter of the strike equation did correlate the data, Figure 4.4.3-5. The measured mortality (calculated as $100 \%$ - survival) includes both effects related to strike (BZE) and to other effects. These other effects include stay vane or gate strike, wicket gate overhang gaps, TAL (theoretical avoidable loss) related to the inlet, stay vanes, gates and draft tube flows, as.well as cavitation etc.

Plotting the ratio of measured mortality divided by predicted mortality, Figure 4.4.3-6, yields a ratio of approximately 0.2 which may be used to place an upper bound on lambda derived in Section 4.3.2, at least for Kaplans. It is also noted that the overall correlation achieved with the strike (BZE) equation indicates the substantial role of the variable $N L / D$.

To more precisely estimate the lambda factor, more accurately designed survival tests which lead fish into zones dominated by leading edge strike (BZE) need to be conducted. Such a test is discussed in Section 4.4.6. Based on those test results, lambda was estimated as having a value of 0.1 . 


\section{Hadley Falls Kaplan Turbine \\ Evaluation of Possible Effect Fish Length}

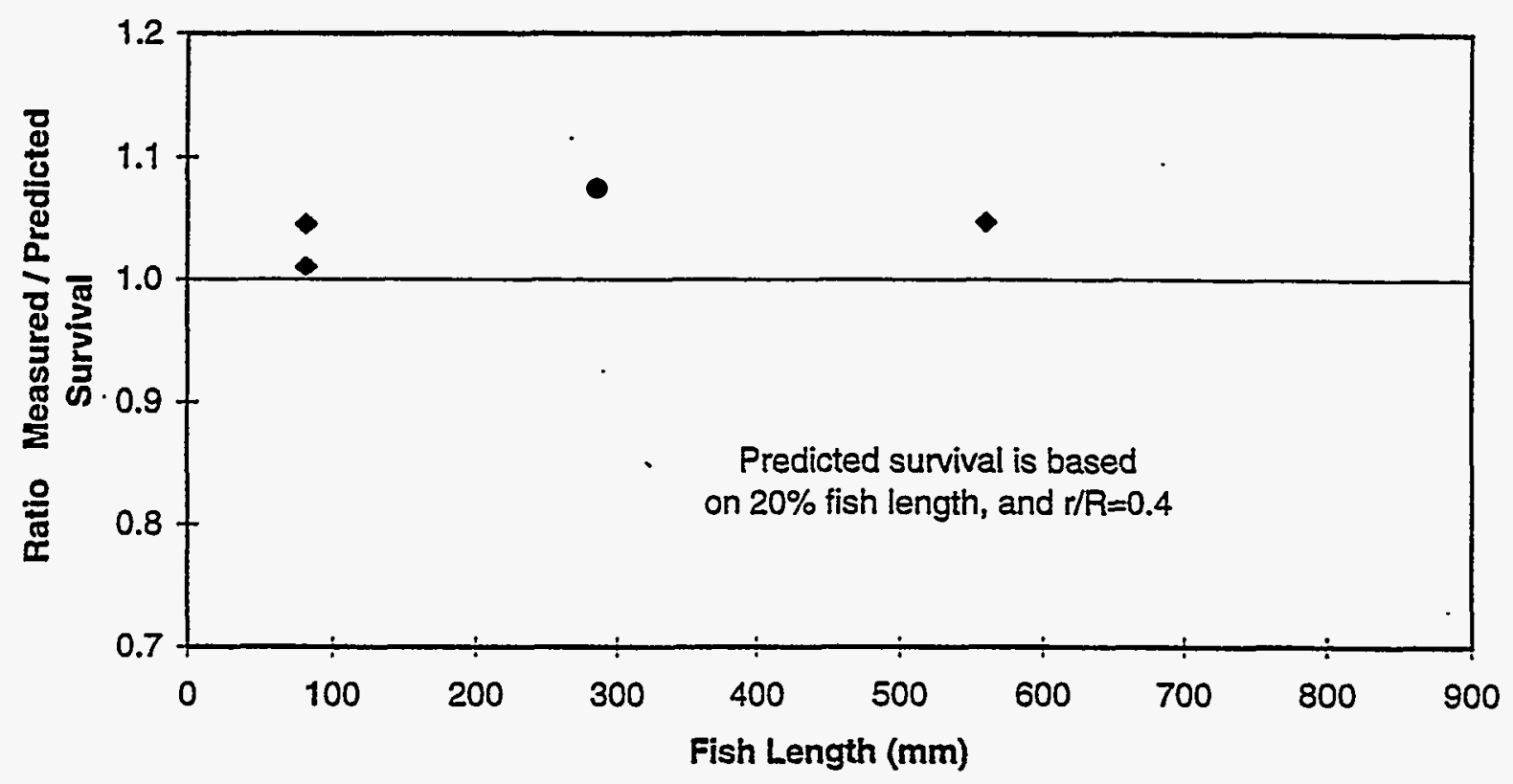

Figure 4.4.3-1 The Leading Edge Strike Equation Correctly Accounts For Fish Length 


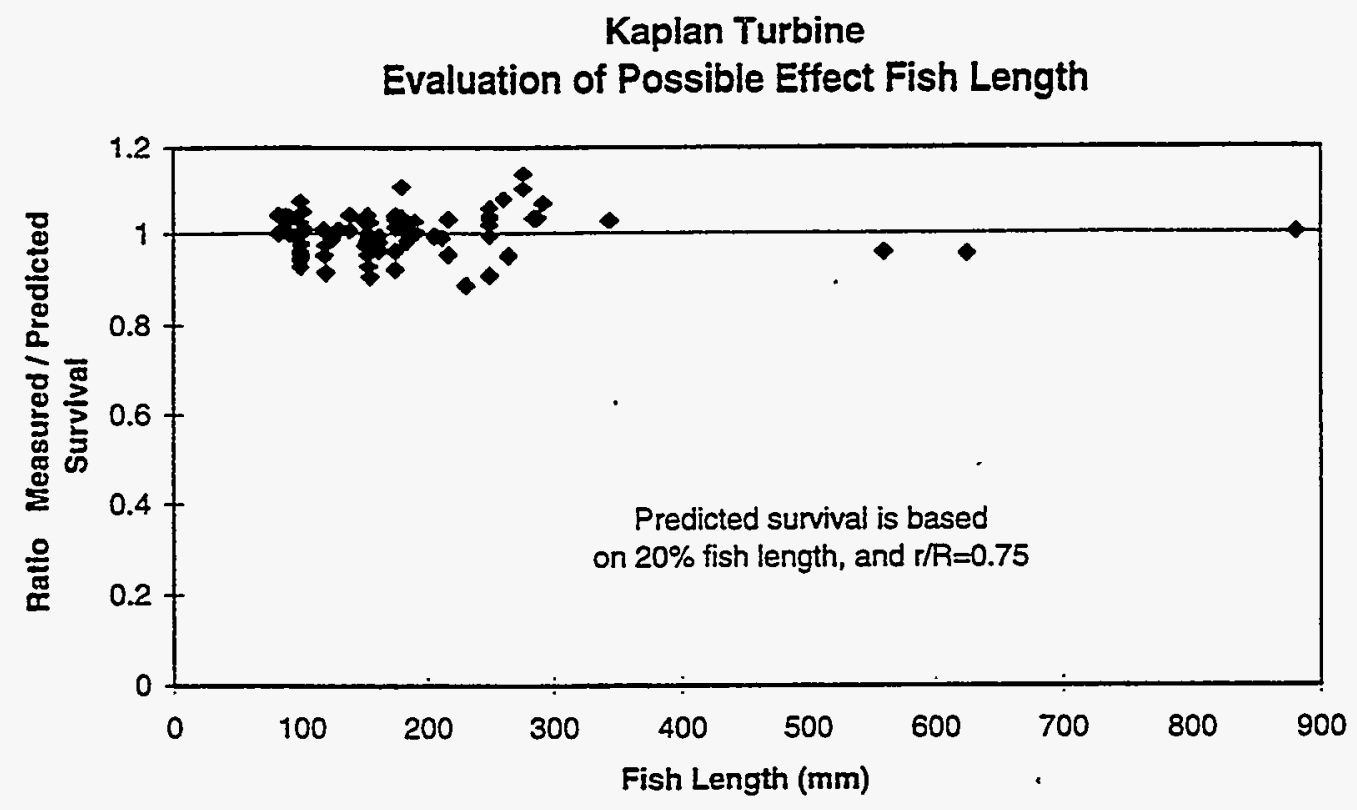

Figure 4.4.3-2a Evaluation of Fish Length Shows Good Correlation with Measurements if Fish Enter the Runner at $75 \%$ of the Blade Tip Radius

\section{Kaplan Turbine \\ Evaluation of Possible Effect Fish Length}

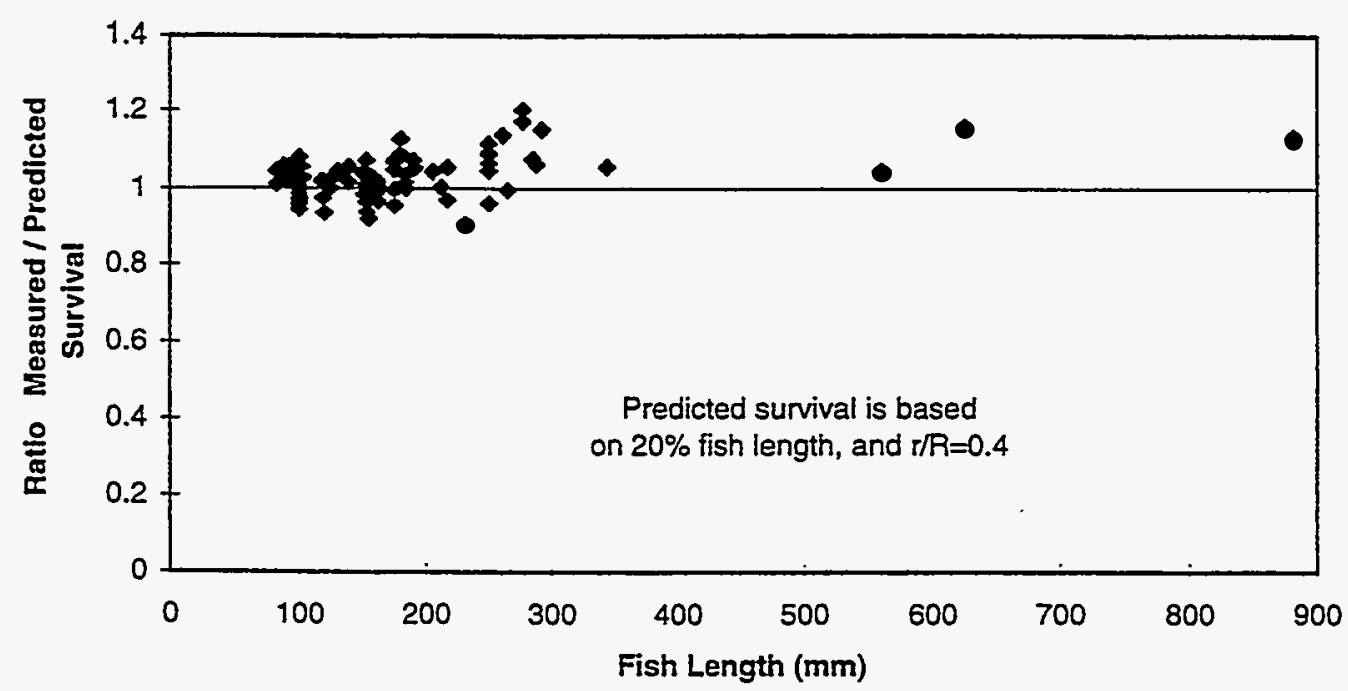

Figure 4.4.3-2b Evaluation of Fish Length Shows Reduced Correlation with Measurements if Fish Enter the Runner at $40 \%$ of the Blade Tip Radius 


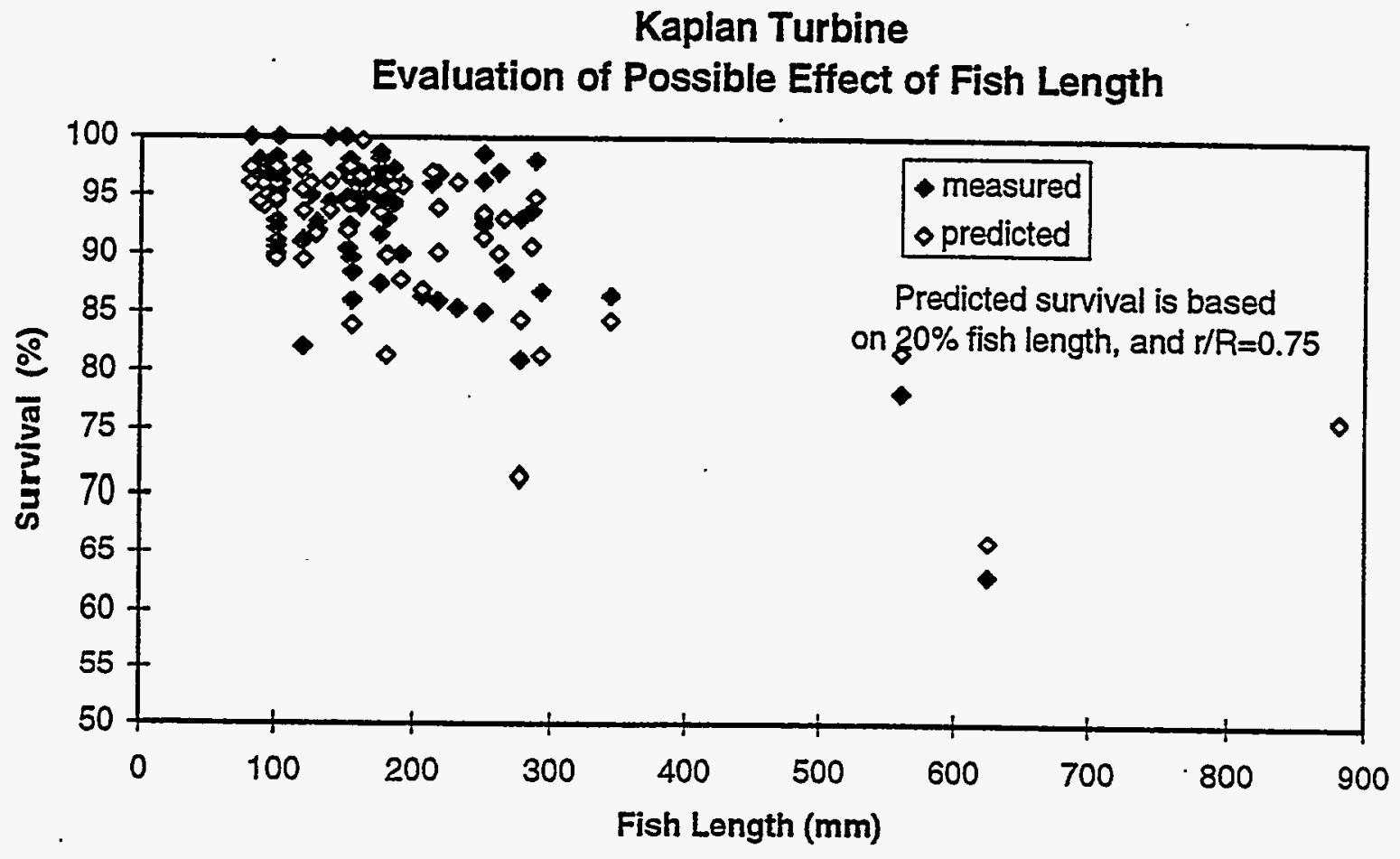

Figure 4.4.3-3 Survival Is Related To Fish Length But Simultaneous Variation Of Other Effects Prevents Clear Insights 
Not accounting for Number of Blades

Lambda $=0.2$

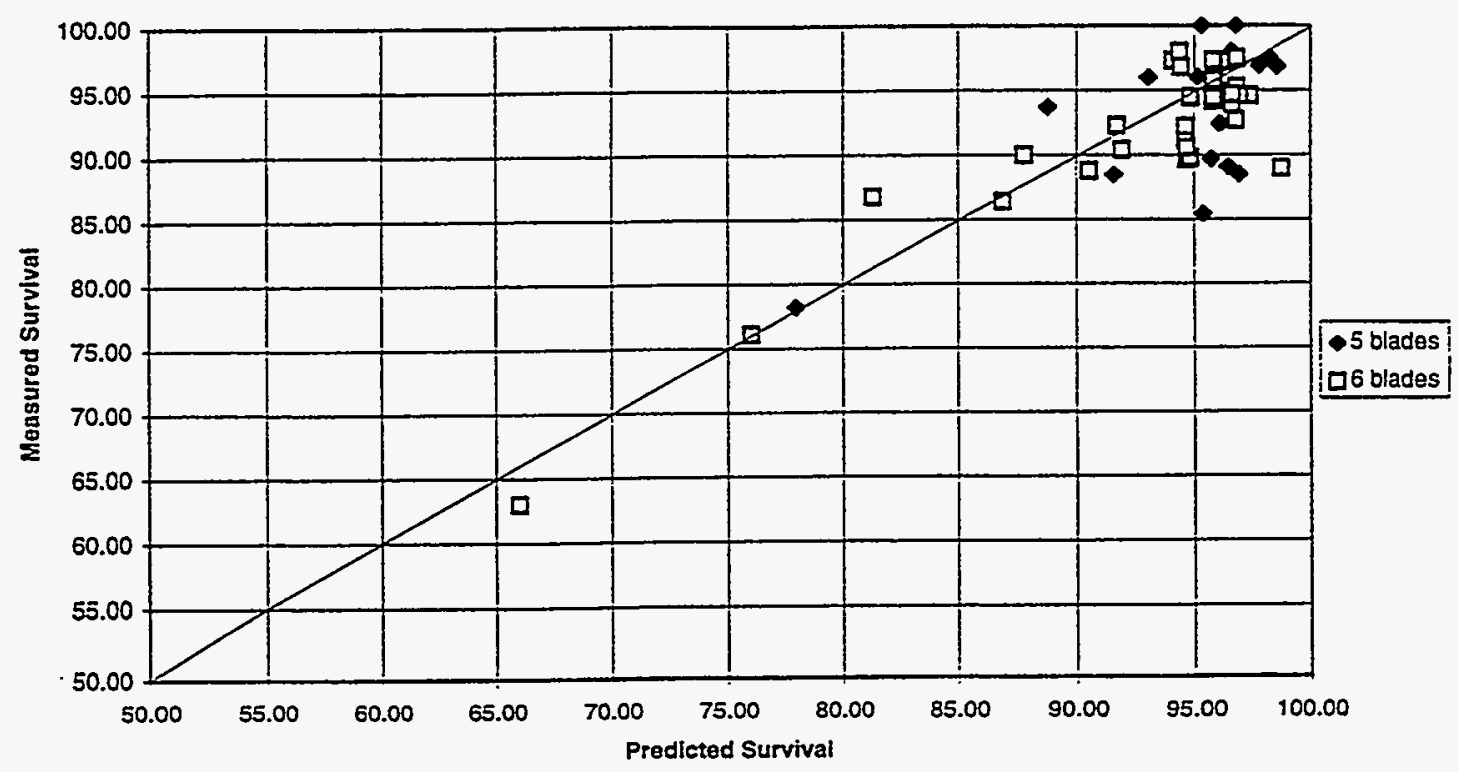

Figure 4.4.3-4a Predicted Survival is Insensitive to Five or Six Bladed Kaplans

\section{Accounting forNumber of Blades}

Lambda $=0.2$

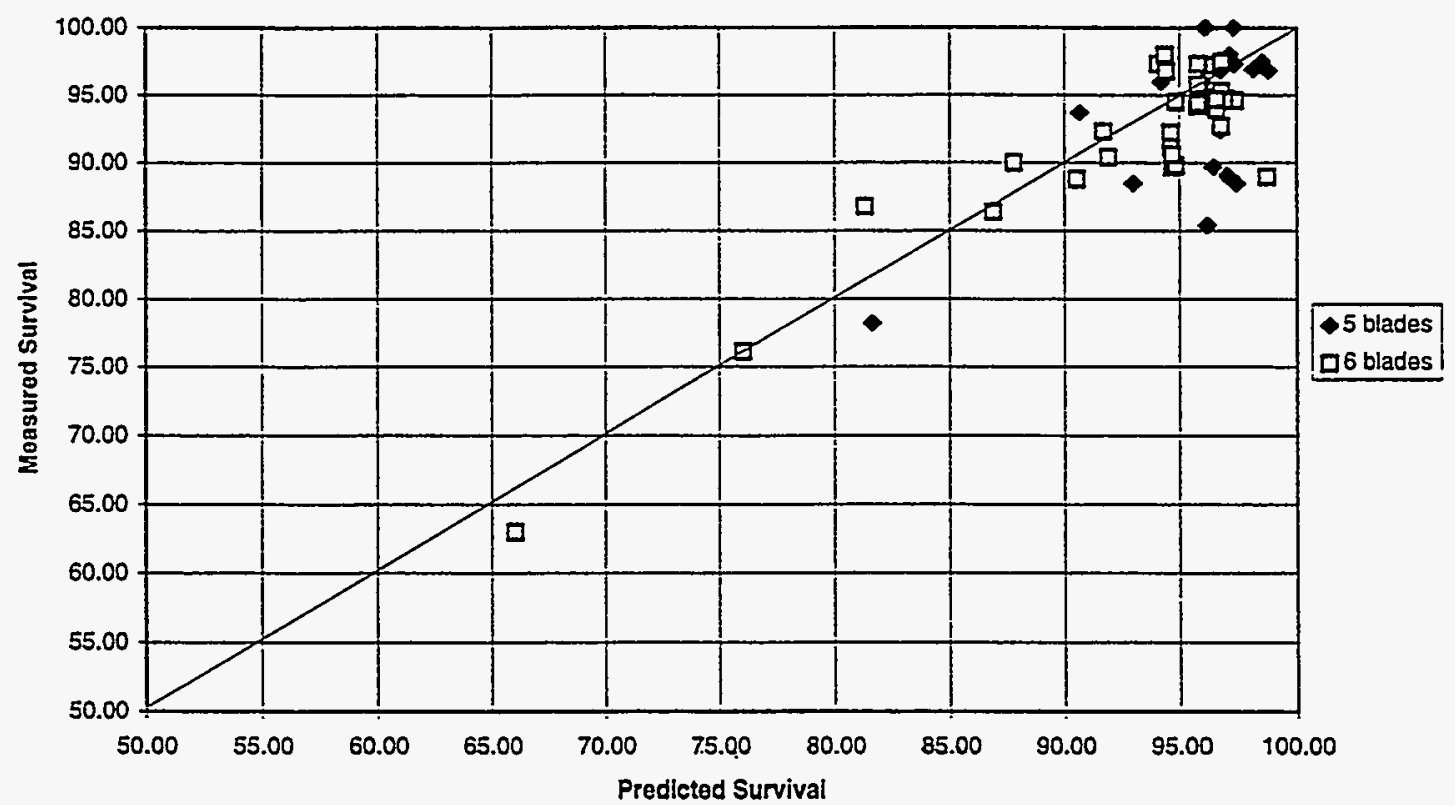

Figure 4.4.3-4b Predicted Survival is Not Materially Changed by Accounting for Five or Six Blades 
Not accounting for Number of Blades

Lambda $=0.2$

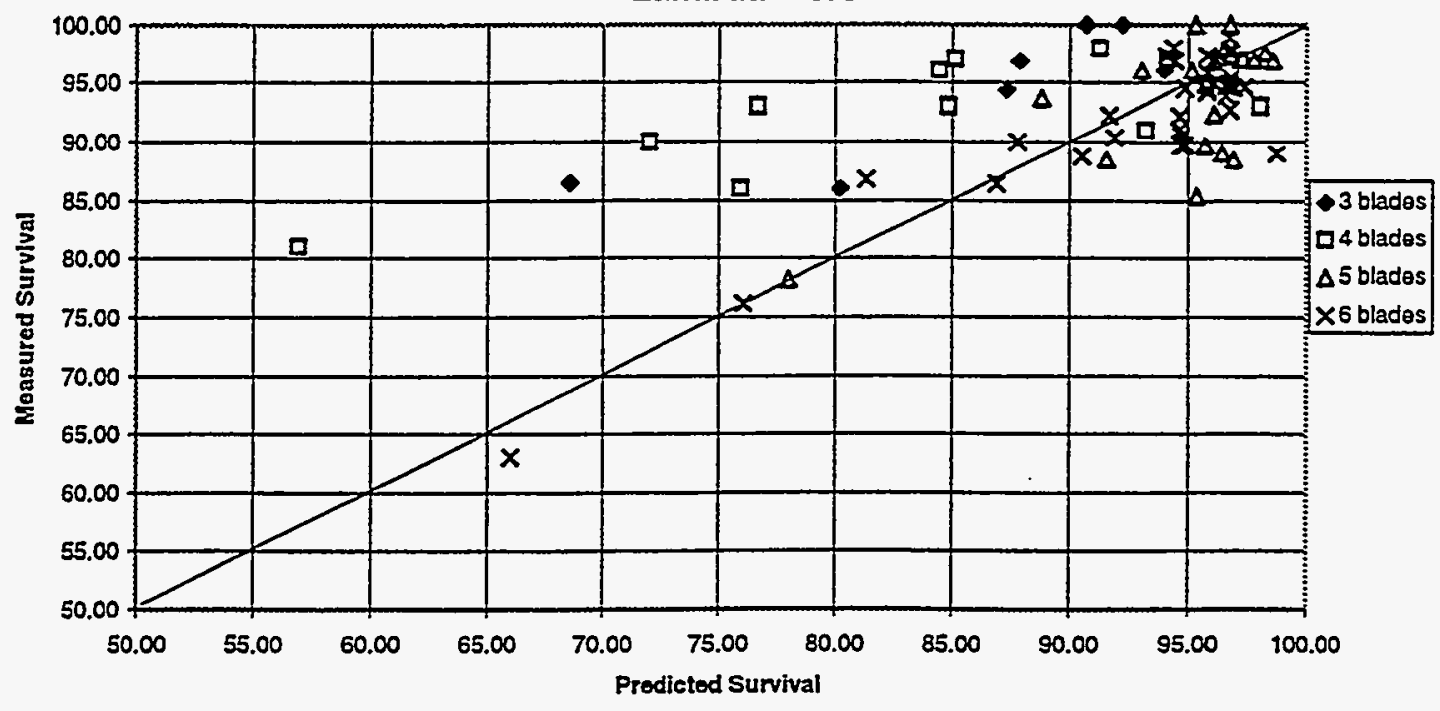

Figure 4.4.3-5a Predicted Survival is Degraded by Not Accounting for Number of Blades

\section{Accounting for Number of Blades}

Lambda $=0.2$

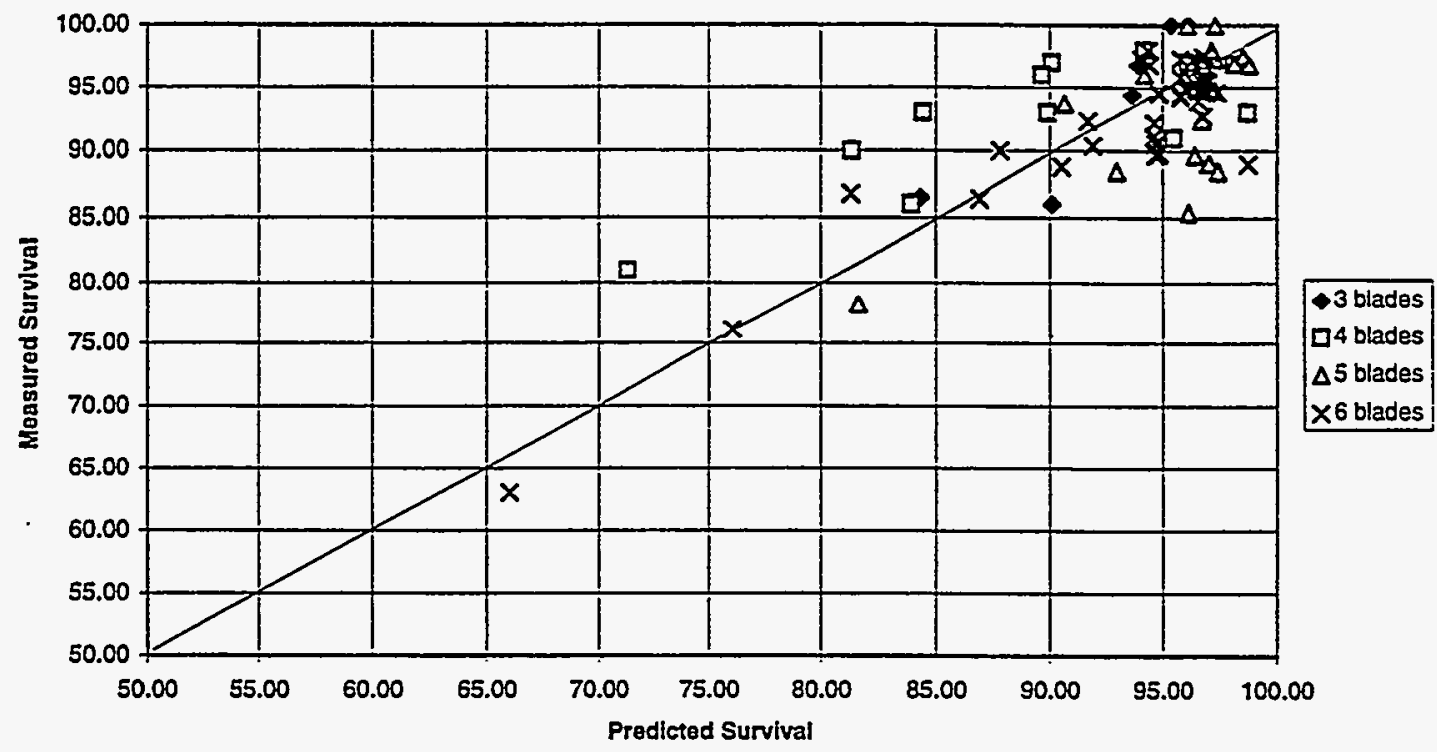

Figure 4.4.3-5b Prediction is Improved by Accounting for Number of Blades 
Estimate of lambda

for Kaplan Turbines

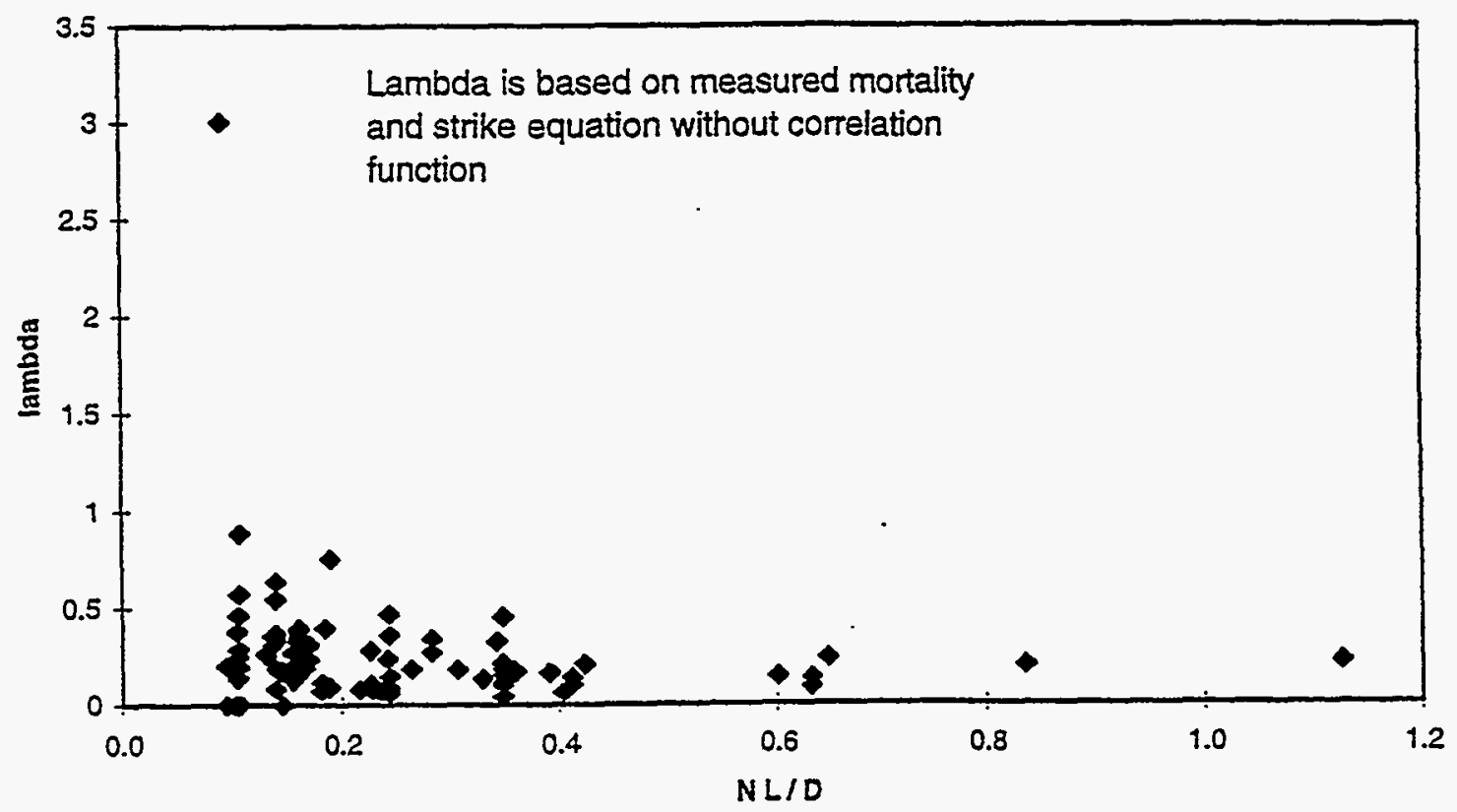

Figure 4.4.3-6 Calculated Lambda Factor For All Test Data 


\subsubsection{INVESTIGATION OF PERIPHERAL SPEED, TURBINE HEAD, INDIRECT EFFECTS, AND SPECIES}

\section{Summary}

Using the data sets selected in Section 4.2, little correlation between fish survival and peripheral speed, turbine head, indirect effects, or species was observed.

\section{Discussion of Peripheral Speed}

One of the mechanisms associated with fish mortality is strike. While it had been suggested in the literature that peripheral speed was related to fish passage mortality, the following analysis of existing test data shows little correlation between fish survival and runner peripheral speed. All data from Tables 4.2-1 for Kaplan turbines and Table 4.2-2 for Propeller turbines was used. The use of all data introduces the variability of different test protocols, species used, fish length, fish injection location, internal turbine geometry, and other effects. These effects may introduce scatter to the data set, or, since the effects are not well understood, may introduce bias.

In an axial flow turbine, the peripheral speed varies with radius. Since the actual radius that would be appropriate for each passage test point is unknown, the peripheral speed at the blade tip is used. Figure 4.4.4-1a shows the ratio of measured to predicted survival for the Kaplan turbine data. If any clustering of the data exists, it's magnitude is modest compared to the scatter of the data. Figure 4.4.4-1b shows the result of Propeller turbine data analysis. Since no significant clustering of the data exists, no significant role of peripheral speed in fish survival can be demonstrated.

Several factors support this empirical finding. Peripheral speed is related to both energy of impact and the size and intensity of the shear zone near blade leading edges. The discussion of Section 4.3.5.4 indicates that for most turbine runners, independent of size and $\mathrm{rpm}$, the peripheral speed of the entrance edge is above the critical value for injury and mortality due to mechanical impact. The theoretical analysis of Section 4.3.3.3 showed that although the blade entrance edge fluid shear zone intensity and size increases with peripheral speed, the size of the region having a lethal shear value is relatively small compared to the blade. Also, the total lethal zone (including mechanical and fluid effects) grows slowly with increasing runner peripheral speed. Virtually all runner blades have sufficient impact energy for a direct impact to cause mortality. Thus, that the mortality is insensitive to peripheral speed is not surprising.

\section{Discussion of Turbine Head}

The available data from Table 4.2.1 was analyzed for evidence that the head influences survival. This could occur due pressure reduction effects, or possible TAL or other energy dissipation mechanisms. Within the scatter of the data, no mortality differences were found (Figure 4.4.4-2).

\section{Discussion of Direct and Indirect Effects}

Several data sets are available that quantify the combined effects of direct and indirect mortality. Figure 4.4.4-3a and $b$ and Figure 4.4.4-4 contrast the comparison of predicted and measured mortality for these effects. Since the effect of the location of fish during runner passage is unknown, calculations were performed for $r / R=0.4$ and $r / R=0.75$ for the direct data. For the rather narrow range of $N L / D$ of the combined direct and indirect data, that only partially overlaps the direct effect data, no trend is evident.

\section{Discussion of Species}

The available data from Table 4.2.1 was analyzed for evidence that species have different susceptibility to injury. Within the scatter of the data, no mortality differences were found (Figure 4.4.4-5). 
Evaluation of Possible Effect of Peripheral Speed

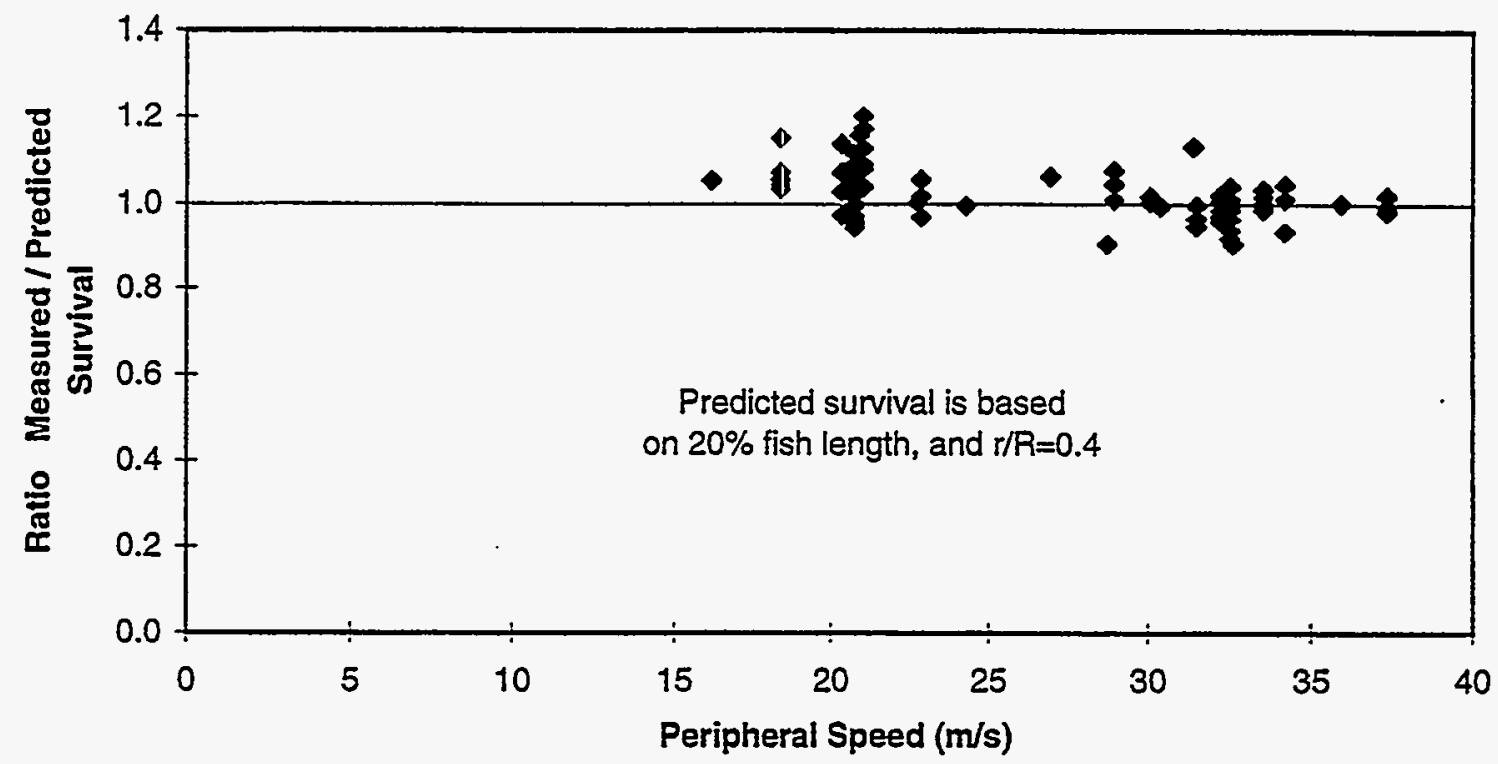

Figure 4.4.4-1a Peripheral Speed is Shown To Have No Significant Effect For Kaplan Turbines

Propeller Turbine

Evaluation of Possible Effect of Peripheral Speed

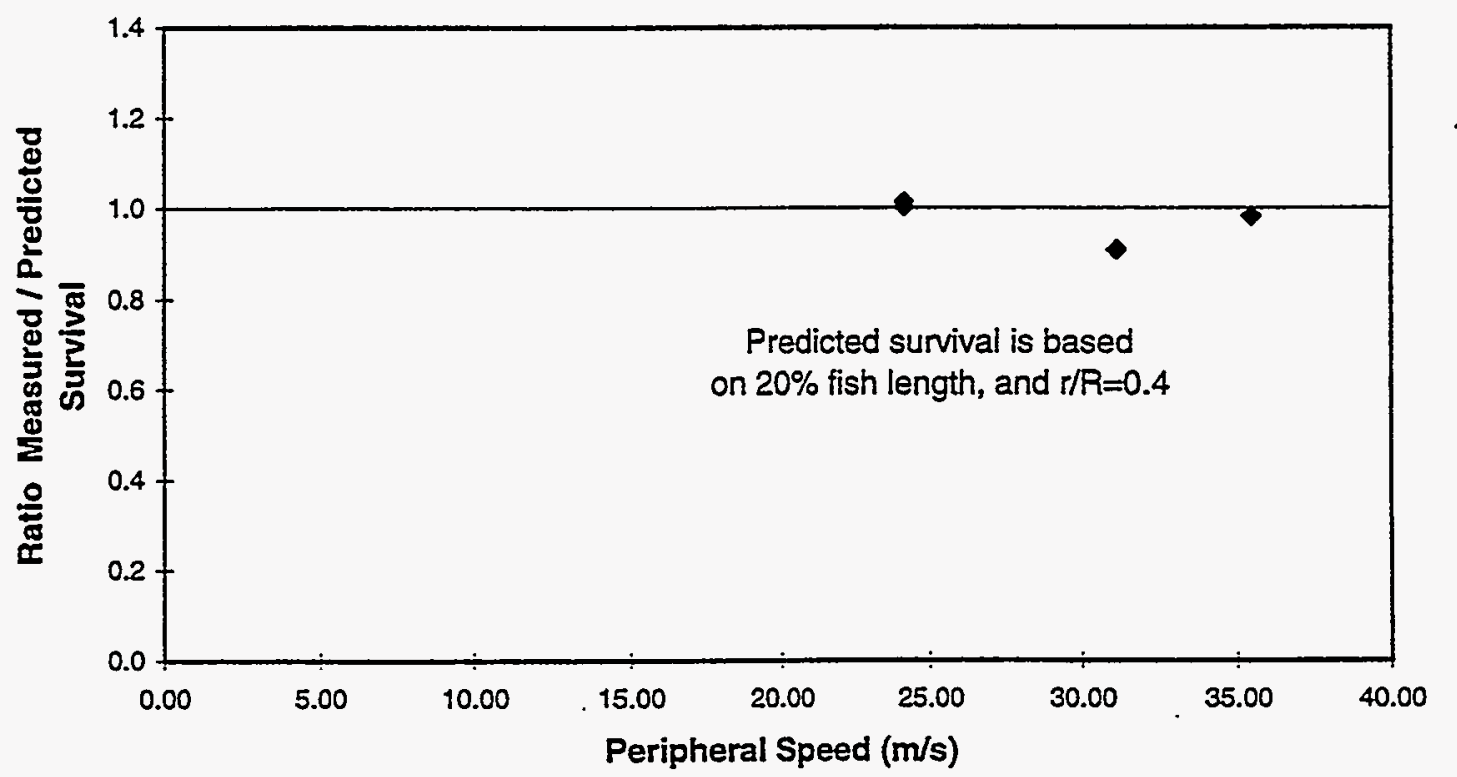

Figure 4.4.4-1b Peripheral Speed is Shown To Have No Significant Effect For Propeller Turbines 


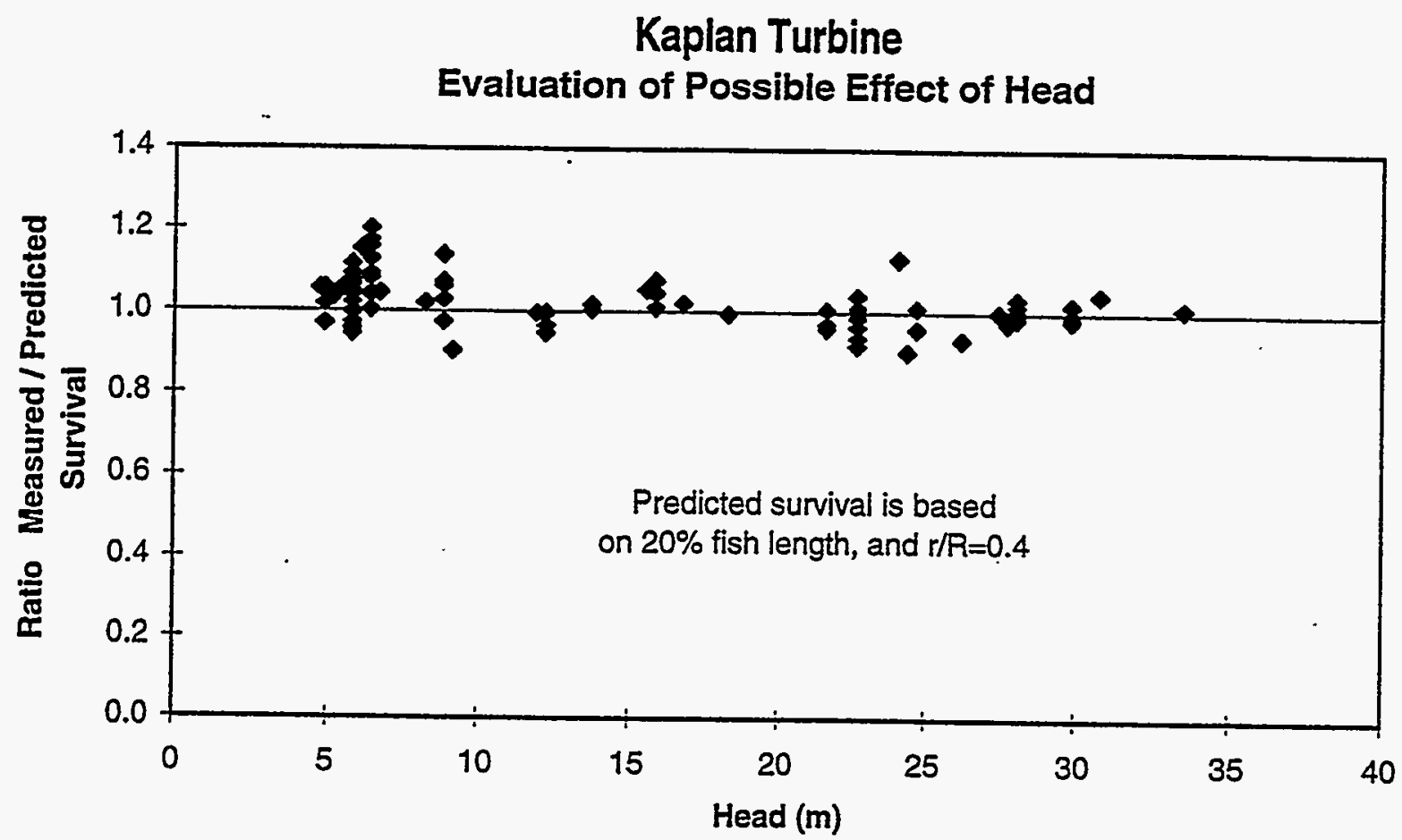

Figure 4.4.4-2 Head Is Shown To Have No Significant Effect For Kaplan Turbines 


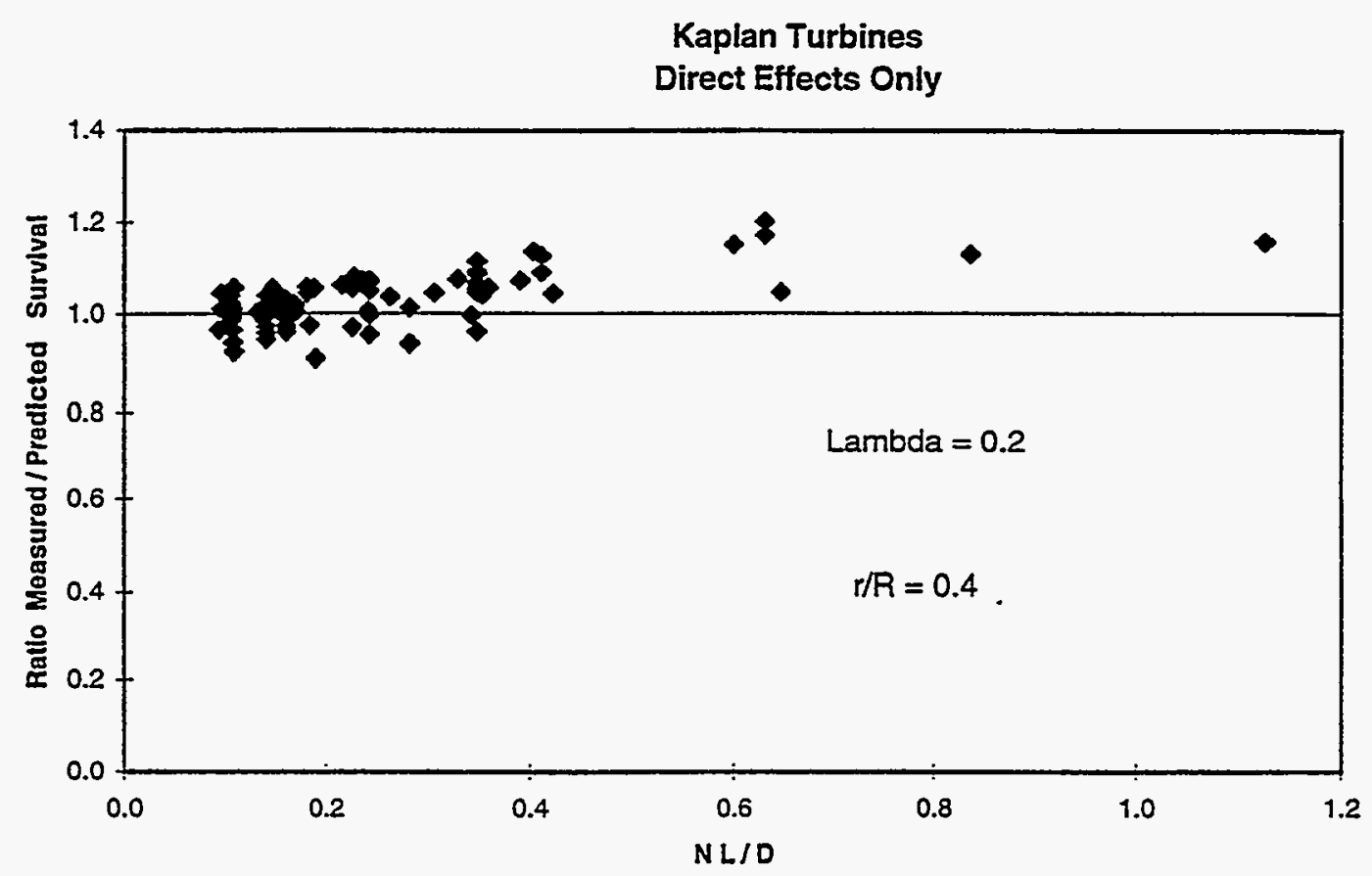

Figure 4.4.4-3a Direct Effects For Kaplan Turbines Are Well Correlated By N L I D - The Position Where The Fish Enter The Runner Has An Effect

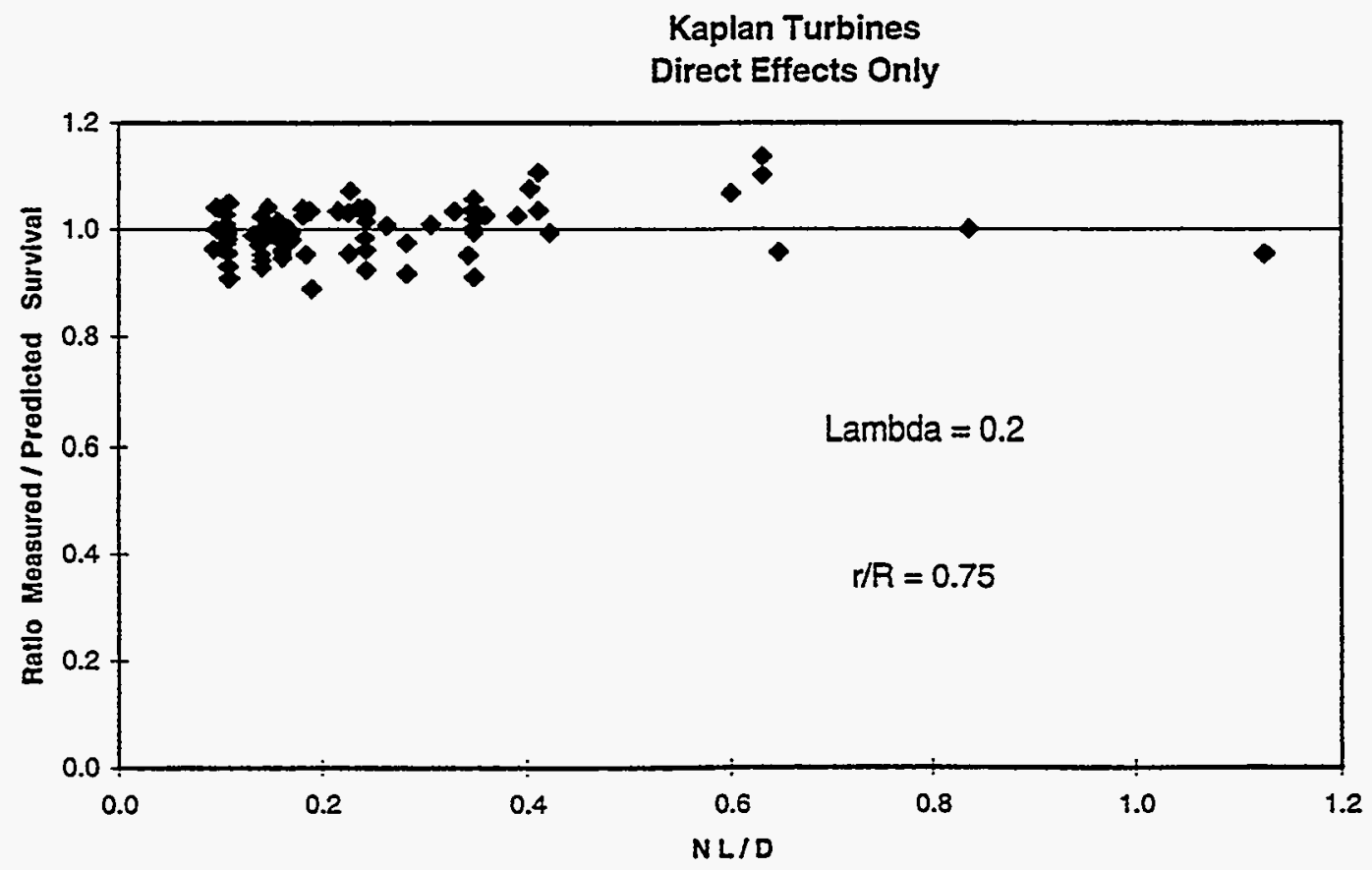

Figure 4.4.4-3b Direct Effects For Kaplan Turbines Are Well Correlated By N L I D - The Position Where The Fish Enter The Runner Has An Effect 
Kaplan Turbines

Direct and Indirect Effects

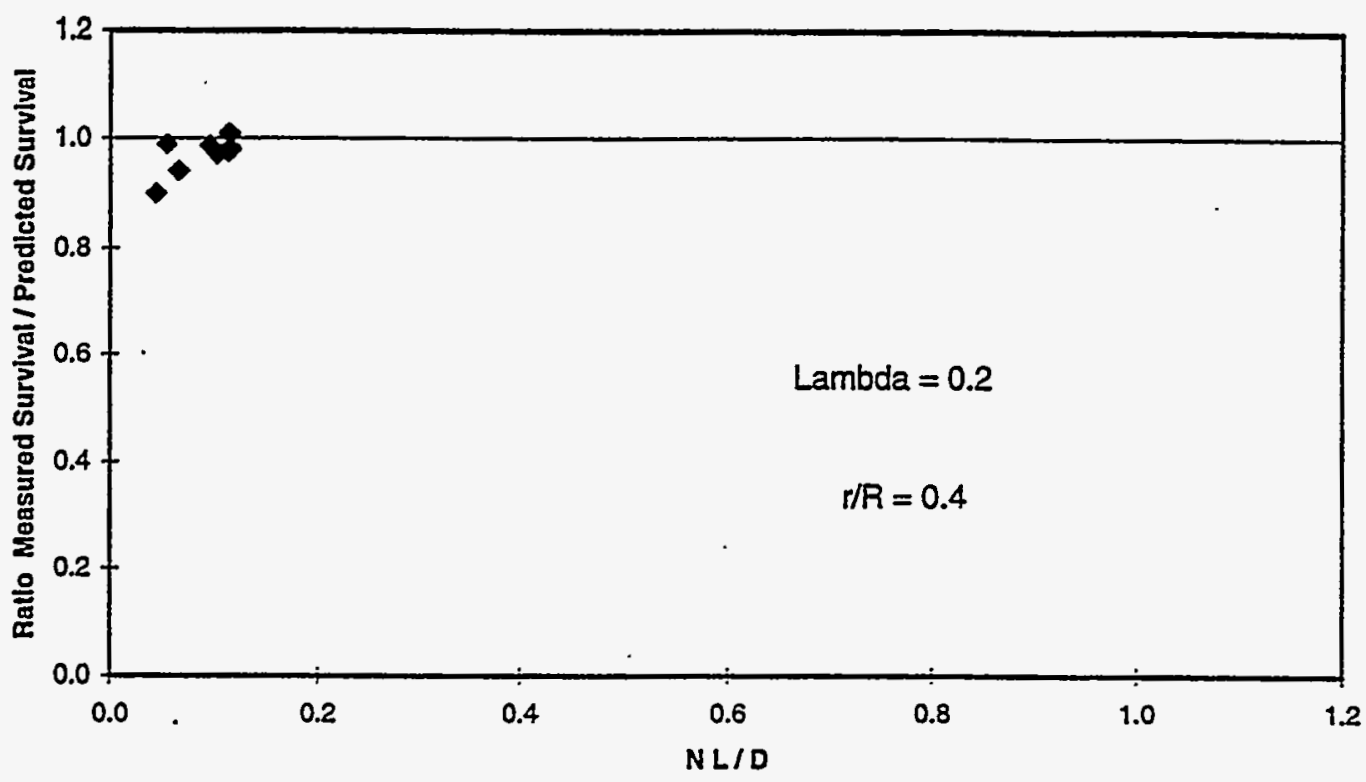

Figure 4.4.4-4 No Conclusion Is Drawn Regarding Possible Differences Between Direct And Combined Direct And Indirect Effects

Kaplan fish survival comparison

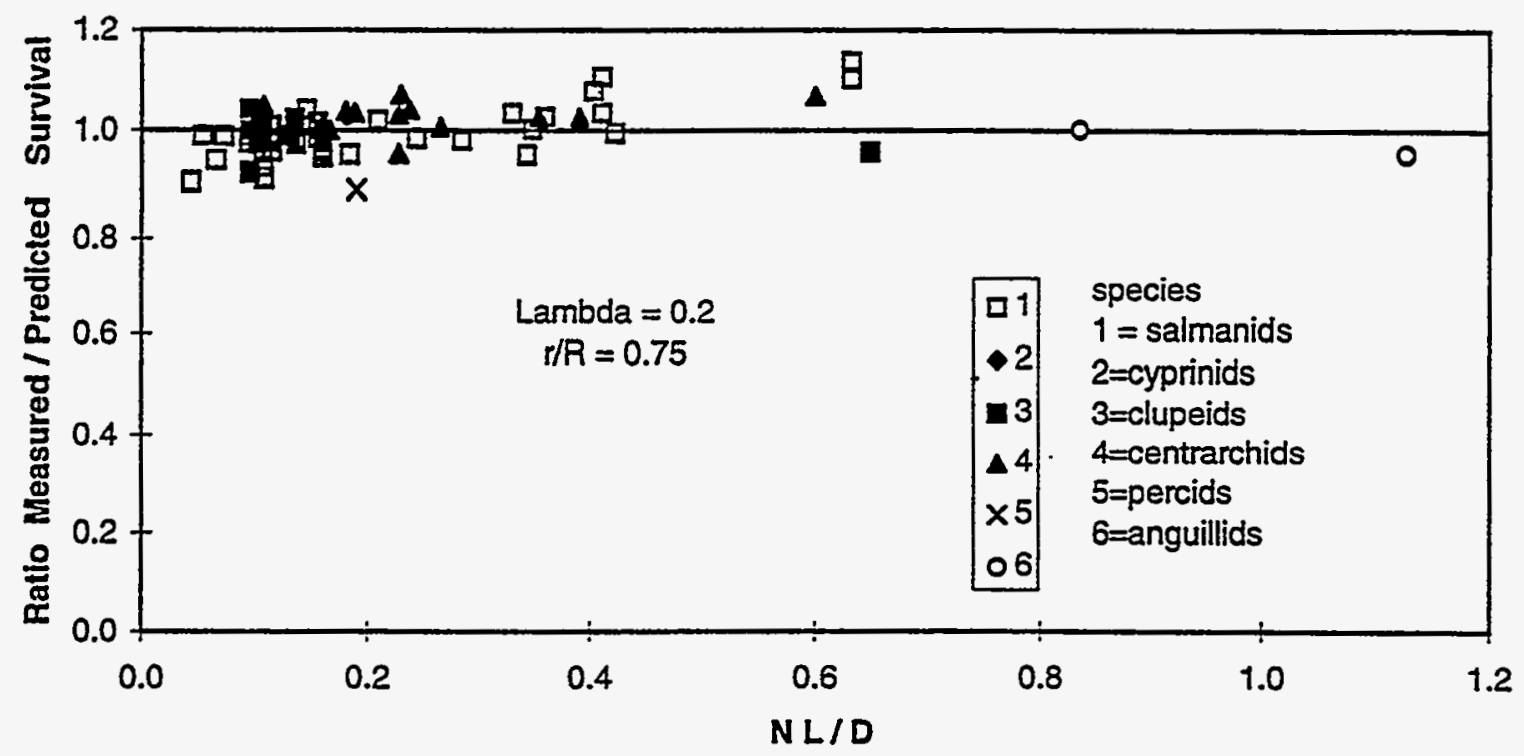

Figure 4.4.4-5 No Effect Of Species is Observed For Fish Survival Through Kaplan Turbines 


\subsubsection{CLUES TO GAP RELATED INJURY}

\section{Summary}

Fish passage tests at Rocky Reach provided data used to estimate fluid and mechanical mechanisms associated with gap related injury. At smaller blade tilts a gap exists between the blade trailing edge and the hub. For one blade tilt, a filler piece was installed to close this gap. When fish were injected to enter the runner blade zone near the hub, a minimum improvement in fish survival of approximately $4.4 \%$ with the trailing edge gap filled could be inferred from the reported data.

\section{Discussion}

Passage tests of a new Kaplan turbine runner at Rocky Reach Dam using chinook salmon smolts were conducted at a range of blade tilts providing power outputs between $60 \mathrm{MW}$ and $100 \mathrm{MW}$. The new Kaplan runner design closed the leading edge hub gaps upstream of the blade rotational axis over the full range of blade angles, but conventional Kaplan blade gaps were present downstream of the spherical portion of the hub. Fish were injected into the turbine intake at locations $3 \mathrm{~m}$ (10 ft) and $9 \mathrm{~m}(30 \mathrm{ft})$ below the intake ceiling. The lower $(88.8 \%)$ than expected survival rate of fish entrained at $3 \mathrm{~m}(10 \mathrm{ft})$ depth at $60 \mathrm{MW}$ prompted exploration of potential causes and subsequent solutions. It was suspected that the fish released at $3 \mathrm{~m}$ (10 ft) depth may have been transported through the gaps between the blade inner edge and the hub downstream of the spherical portion of the hub at the turbine operating point tested. Therefore, an additional test using the same sized chinook salmon smolts was performed at a blade tilt corresponding to $60 \mathrm{MW}$, where a filler piece was constructed to temporarily fill in the gap between the hub and the blade, downstream of the spherical portion of the hub near the outlet edge for testing purposes. The primary purpose of these fish releases (for testing purposes) was to evaluate whether the injury rates were the same. Because no concurrent controis were released to adjust for the potential effects of tagging, handing, release, and recapture, survival probability was not reported (Normandeau Associates and Skalski 1996). However, the $48 \mathrm{~h}$ control survival rate of the same stock and size of chinook smolts used in the primary releases was slightly greater than $99 \%$. Therefore, it may be reasonable to assume that the effects of tagging, handling, induction, and recapture may not change over a short time period. Similar observations have been made in other investigations lasting two to three weeks (RMC et al. 1994; Normandeau Associates et al. 1995, 1996a,b,c,d). The reported data suggest that if the rate of severe injury decreased then survival should have correspondingly increased. The injury rate declined from $5 \%$ with gaps to $2.8 \%$ with closed gaps. A minimal improvement in survival of about $4.4 \%$ compared to the unmodified turbine could be inferred from the reported data. The closure of the gap, and the minimization of its associated fluid and mechanical injury mechanisms, could be related to an increase of survival of approximately $4.4 \%$ in this zone. 


\subsubsection{INSIGHT FROM THE TESTS AT WANAPUM DAM}

\section{Summary}

Tests at Wanapum Dam were designed, conducted and evaluated to shed light on injury mechanisms and how they changed with zone and the point of operation. The overall survival was correlated with the new leading edge strike equation. A value of 0.1 was estimated for the lambda coefficient of the strike equation. The effect of the point of operation on fish passage survival provided insight to the TAL relationships and the cavitation effects. Peak survival did not coincide with peak efficiency, but occurred at a discharge where the blade strike probabilities were low while the TAL were at a minimum and before cavitation began to be significant. Additional mortality was attributed to flow phenomena in the zone of geometry near the vicinity of the hub. There, a dramatic decrease in survival occurred for fish injected at 3 $\mathrm{m}$ ( $10 \mathrm{ft}$ ) below the intake ceiling compared to those injected at $9 \mathrm{~m}$ ( $30 \mathrm{ft}$ ) below the intake ceiling, and was attributed to gaps between the blade and the hub.

\section{Discussion}

For Unit 9 at the Wanapum Dam on the Columbia river, fish passage survival tests were conducted at the originally designed Kaplan turbines. The tests were sponsored by the Public Utility District No. 2 of Grant County as part of its on going efforts to improve fish passage survival at the project. The dam houses 10 vertical Kaplan turbines, each rated at $89.5 \mathrm{MW}(120,000 \mathrm{HP})$ at $24.4 \mathrm{~m}$ ( $80 \mathrm{ft})$ net head. Rehabilitation of the existing turbines is underway to improve turbine performance and fish survival (Hron et al, 1997). Model testing of the original turbine design was conducted as part of the testing to develop an upgraded design. The tested Unit 9 has 5 adjustable runner blades, a speed of $85.7 \mathrm{rpm}$, and runner diameter of $7.2 \mathrm{~m}$ (285 inches). A systematic variation of turbine discharge (and therefore, efficiency, blade and wicket gate gap geometry and cavitating conditions) and fish injection location was performed. Four blade positions were selected for evaluation covering a range of discharge from below the peak efficiency to nearly maximum output; $250,310,425$, and $480 \mathrm{cms}(9,000,11,000,15,000$, and 17,000 cfs), Figure 4.4.6-1. Two fish injection locations were used, $3 \mathrm{~m} \mathrm{(10} \mathrm{ft)} \mathrm{and} 10 \mathrm{~m}$ (30 ft) from the intake ceiling. Based on CFD analyses, Figures 4.4.6-2 through 4.4.6-5, these heights in the intake are believed to transport fish to the runner entrance edge at $52 \%$ and $75 \%$ of the blade maximum radius. No information regarding possible fish volitional movement or dynamic effects on three-dimensional fish shaped bodies was simulated in the CFD analyses, so these locations must be considered as tentative. The $10 \mathrm{ft}$ location fish are assumed to pass through an annular zone relatively near the hub and therefore in the vicinity of the hub gaps, while the $30 \mathrm{ft}$ location fish are assumed to pass through the blades in an annular zone near the middle of the blade, Figure 4.4.6-6.

In addition to the fish passage survival testing, scale model test measurements and visual observations of a 1:20 scale model operated at the equivalent conditions to the $9,000,11,000,15,000$, and $17,000 \mathrm{cfs}$ discharges were made. These observations were used to document turbine efficiency and define cavitation patterns associated with gap leakage and blade surface cavitation at the highest discharge. To complement the model and field testing, CFD analyses of selected turbine geometries were made.

The geometry of the 5 bladed turbines is such that the blades have a leading edge hub to blade gap upstream of the spherical portion of the hub. Figure 4.4.6-7. A special three-dimensional localized contour on the hub exists downstream of the spherical portion of the hub to minimize the gap between the blade inner edge and the hub, Figures 4.4.6-8a and $b$. Along the hub surface at low blade tilts (Figure 4.4.6-8a) and especially at high blade tilts (Figure 4.4.6-8b), the special hub contour is oriented in a way that it creates a flow distortion as water passes along the hub surface. At the blade tip, a gap exists between the runner blade and the discharge ring upstream of the runner centerline because the discharge ring is machined cylindrically upstream of the blade centerline to allow removal of the runner. The wicket. 
gate geometry is such that the gates overhang the discharge ring at higher gate openings. Characteristics of the Unit 9 turbine gaps as a function of discharge are shown in Figure 4.4.6-9.

A sequence of reasonable assumptions and data comparisons were made to draw conclusions about sources of mortality that refine the prediction methods.

- The mortality of fish at the $30 \mathrm{ft}$ location (assumed to pass the blade in the mid blade annular zone centered around $r / R=0.75$ ) is assumed to be due to leading edge strike and TAL. This assumption was made because the runner gaps and the special three-dimensional localized contour on the hub are relatively far from the middle of the blade, and no cavitation was present in the middle of the blade according to model test observations.

- The gaps between the blade and the hub are minimum at the maximum blade tilt tested (17,000 cfs ). Therefore, fish mortality for the $10 \mathrm{ft}$ location at the maximum flow rate includes no contribution from gaps.

- Some cavitation was observed in the model on the blade near the hub at the maximum tilt tested $(17,000 \mathrm{cfs})$. Figure $4 \cdot 4 \cdot 6-10$

- There is an entrance edge gap. There is essentialiy no blade to hub gap downstream of the spherical portion of the hub due to a special three-dimensional localized contour on the hub.

- At flows above $15000 \mathrm{cfs}$ there is a wicket gate overhang gap.

- At all flows there is a blade tip to discharge ring gap at the blade leading edge.

- The mortality attributed to the flow conditions in the annular zone along the hub, including the entrance edge gap, was $3 \%$ higher than the mortality in the mid blade zone.

$30 \mathrm{ft}$ location (mid blade zone) Figure 4.4.6-11 presents the measured survival data with uncertainty bands and a prediction of survival based on the strike equation with a lambda value of 0.2 . Using the leading edge strike equation with a 0.2 factor for lambda would indicate that virtually all of the mortality for each test point at the $30 \mathrm{ft}$ location would be attributed to strike and at the $15000 \mathrm{cfs}$ condition, survival is higher than the strike equation would indicate is possible. Also, no mortality would be due to any other source. As this seems unrealistic, a value of lambda equal to 0.1 was arbitrarily chosen for the strike equation and leading edge strike mortality was recalculated. This choice of a value of lambda equal to 0.1 allows other damage mechanisms to exist and gives a survival prediction for the $15000 \mathrm{cfs}$ condition that is within the experimental uncertainty band. It is recognized that future tests can be expected to refine this estimate. In order to assign damage mechanisms to the remaining mortality, several damage mechanisms were evaluated specifically for this location:

$\Rightarrow$ Gap grinding effects are not believed to exist because the fish are assumed to enter the runner near the mid blade zone.

$\Rightarrow$ Cavitation effects are not believed to exist because no cavitation was observed at the three lower discharges and for the higher discharge, no cavitation occurred on the mid blade region.

$\Rightarrow$ Pressure reduction effects are not believed to be significant. At the 15,000 cfs test condition no mortality was attributed to probable pressure related changes (Normandeau Associates et al. 1996c). The pressure reduction effect would be the same for all test points, if it is based on the acclimation pressure and the final pressure.

The remainder of the mortality for the mid blade position were assumed to be related to TAL. TAL related losses are in a sense a one number characterization of the fluid energy losses which may cause damage to fish. They are not distributed spatially throughout the machine as a function of location (stay vanes, runner, draft tube) or blade radius even though the fluid mechanisms related to the losses (shear, turbulence ) are localized mechanisms. It is beyond the scope of the current work to be able to predict which percentage of the losses are of a characteristic which may cause mortality to fish and where those 
occur. Even though the magnitude of the losses associated to TAL are somewhat arbitrary, it can be seen from Figure 4.4.6-12 that the shape of the TAL assumed mortality characteristics as a function of discharge correspond to the calculated total TAL based on the observed model efficiency distribution. For a different choice of lambda, the magnitude of the TAL induced mortality would change, but the shape of the curves would be similar. The distribution of the estimated mortality sources is shown on Figure 4.4.613.

The above assessment related to pressure reduction related mortality contrasts with the field observations made during the fish passage testing. For the Wanapum study, the field attribution of pressure related mortality varied with operating condition. While some operating conditions had no mortality attributed to probable pressure related causes, overall, $23 \%$ of the injuries were attributed to pressure related causes. However, a lack of reliable quantifiable criteria for such mortality assignments appears to be a significant obstacle to obtaining an accurate mechanism causal assessment of the mortality.

$10 \mathrm{ft}$ location (near hub zone) Figure 4.4.6-14 presents the measured survival data with uncertainty bands. The leading edge strike equation with a 0.1 factor for lambda was used with the radius ratio ( $r / R=$ 0.52) for the $10 \mathrm{ft}$ location to calculate the portion of mortality due to strike. The same TAL induced mortality from the $30 \mathrm{ft}$ location was assigned to the $10 \mathrm{ft}$ data. The remaining mortality is assigned to specific sources based on experimental guidance, estimation, or the process of elimination. Hub gap mortality was assigned as $0 \%$ at the maximum tilt ( $17,000 \mathrm{cfs})$ and $2.5 \%$ at minimum blade tilt $(9,000 \mathrm{cfs})$. The value of $2.5 \%$ was chosen based on consideration of the Rocky Reach study of blade trailing edge gap mortality in Section 4.4.5. The hub gap related mortality versus discharge is distributed in a manner that assumes that some gap creates a leakage velocity jet and shear values high enough to cause mortality and that gap grinding also occurs. The sources of mortality that were assigned so far were based on results of the $30 \mathrm{ft}$ location analysis, or on other specific tests. The assignment of the remaining mortality requires more arbitrary judgments. At the minimum tilt, the remaining unassigned mortality was assumed to be caused by a higher concentration of flow induced mortality arising from unfavorable geometry in the hub annular zone including the abrupt sharp edge disturbance between blades and under the runner hub. A flow calculation that was developed for a different purpose illustrates the potential for injury in the hub region. Figure 4.4.6-15 shows a vortex located under a runner hub. At larger tilts, and discharges, this fluid induced mortality was assigned an increasing value. At the maximum tilt, $3.3 \%$ mortality remained unassigned and was attributed to cavitation related effects both by the process of elimination and by guidance from model observations. Figure 4.4.6-10 shows the cavitation pattern observed during the model testing. Note that based on the CFD streamline tracing cavitation occurred in this flow zone. The resulting distribution of mortality is shown on Figure 4.4.6-16. 


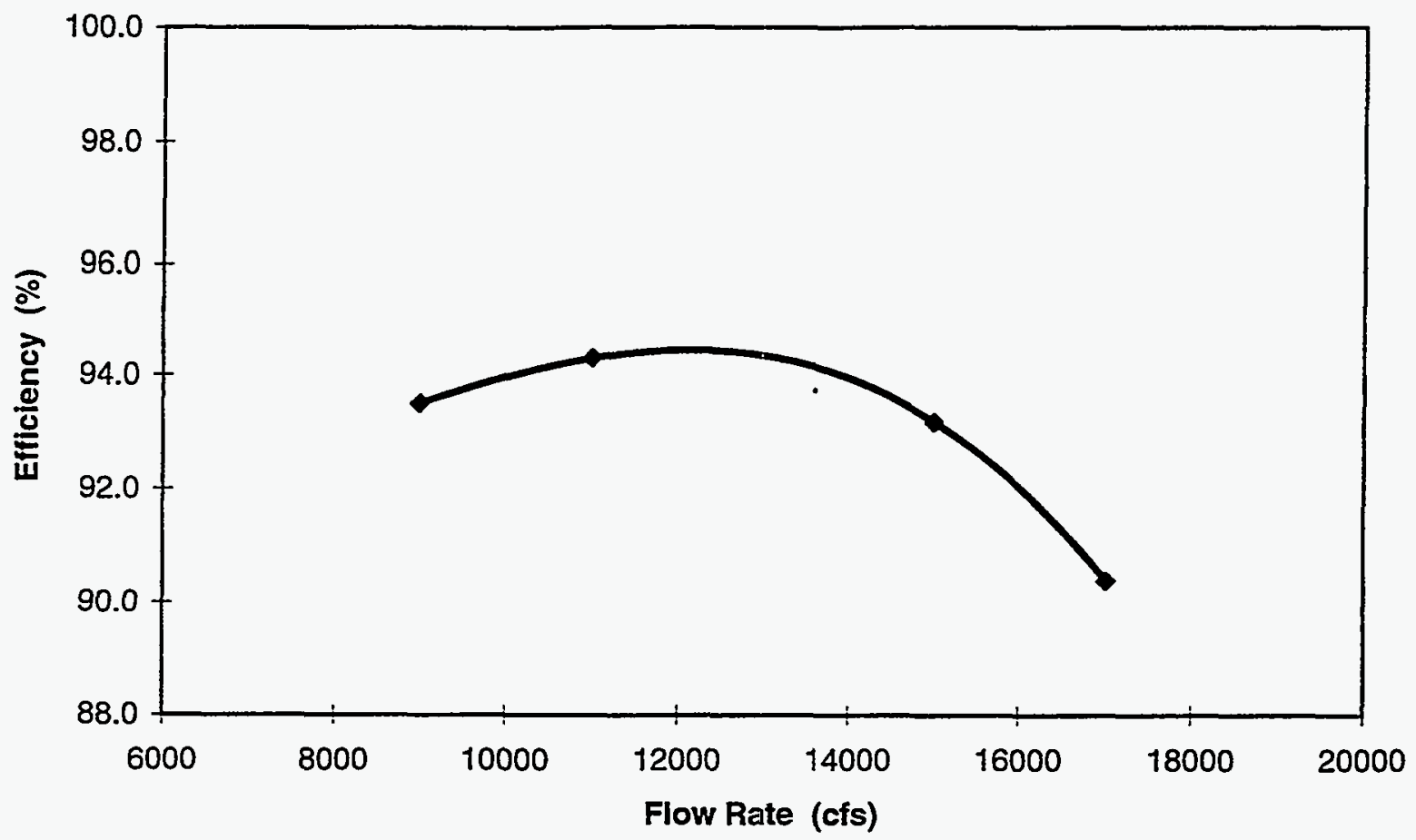

Figure 4.4.6-1 Fish Survival Test Points for Wanapum 


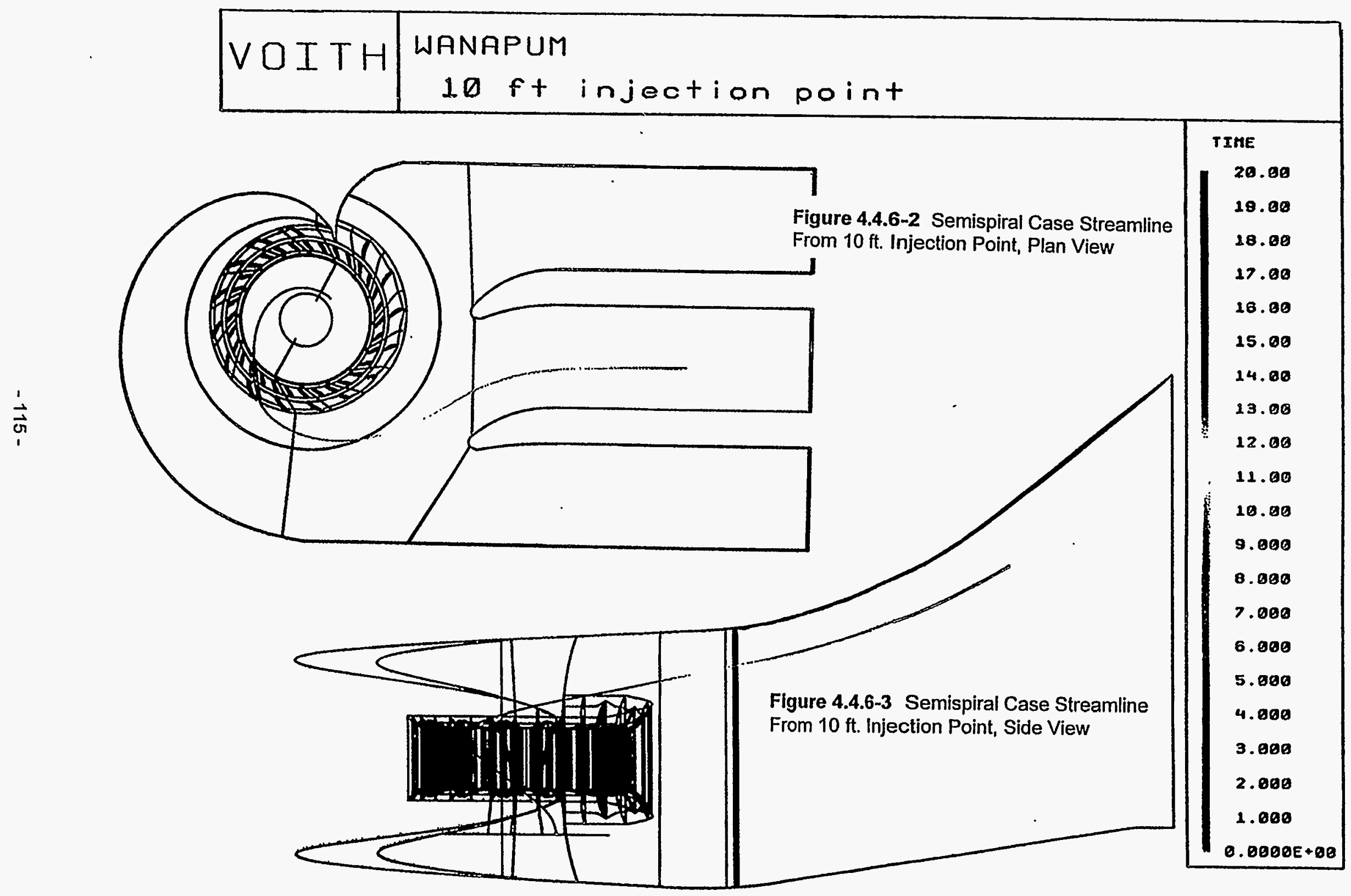




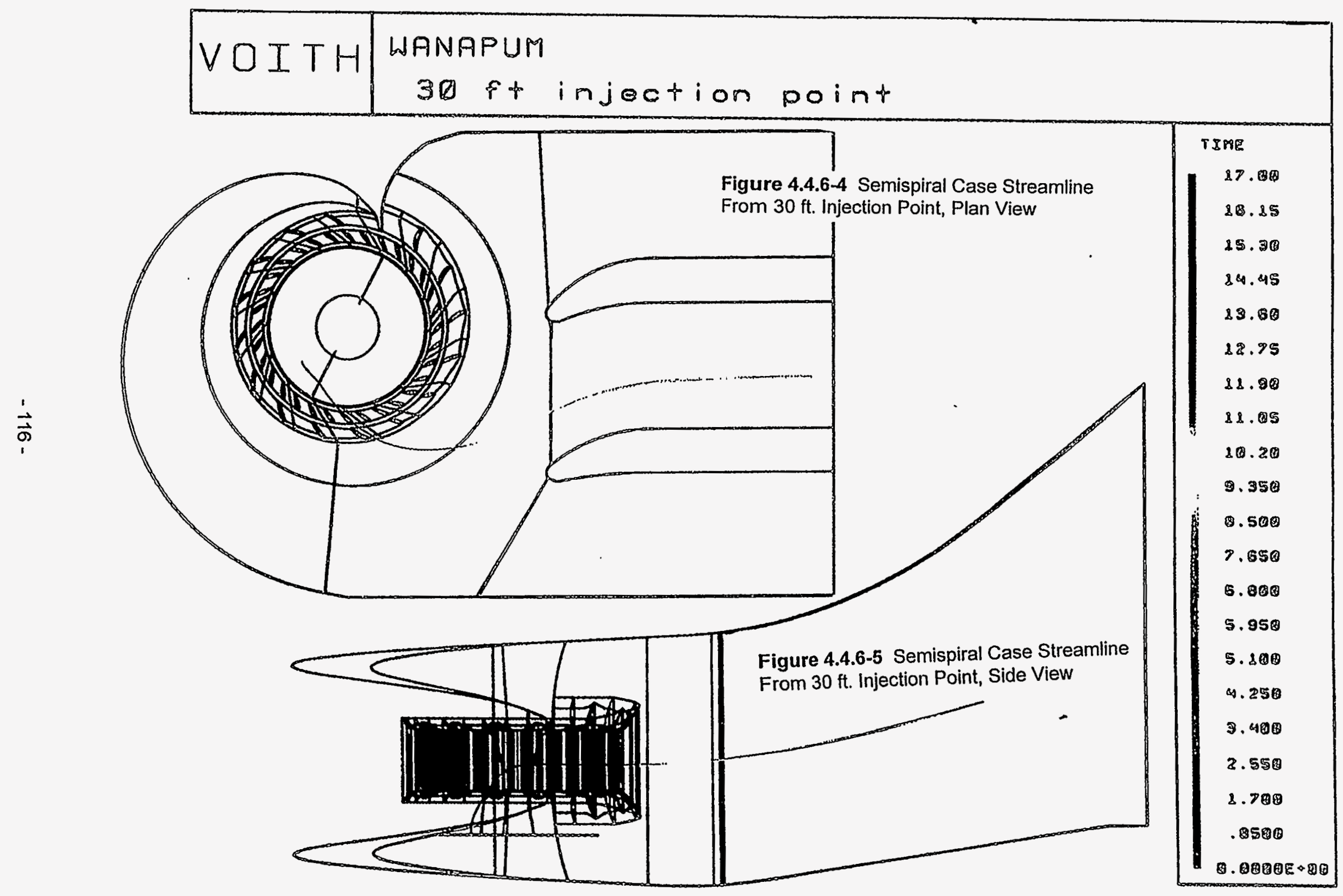




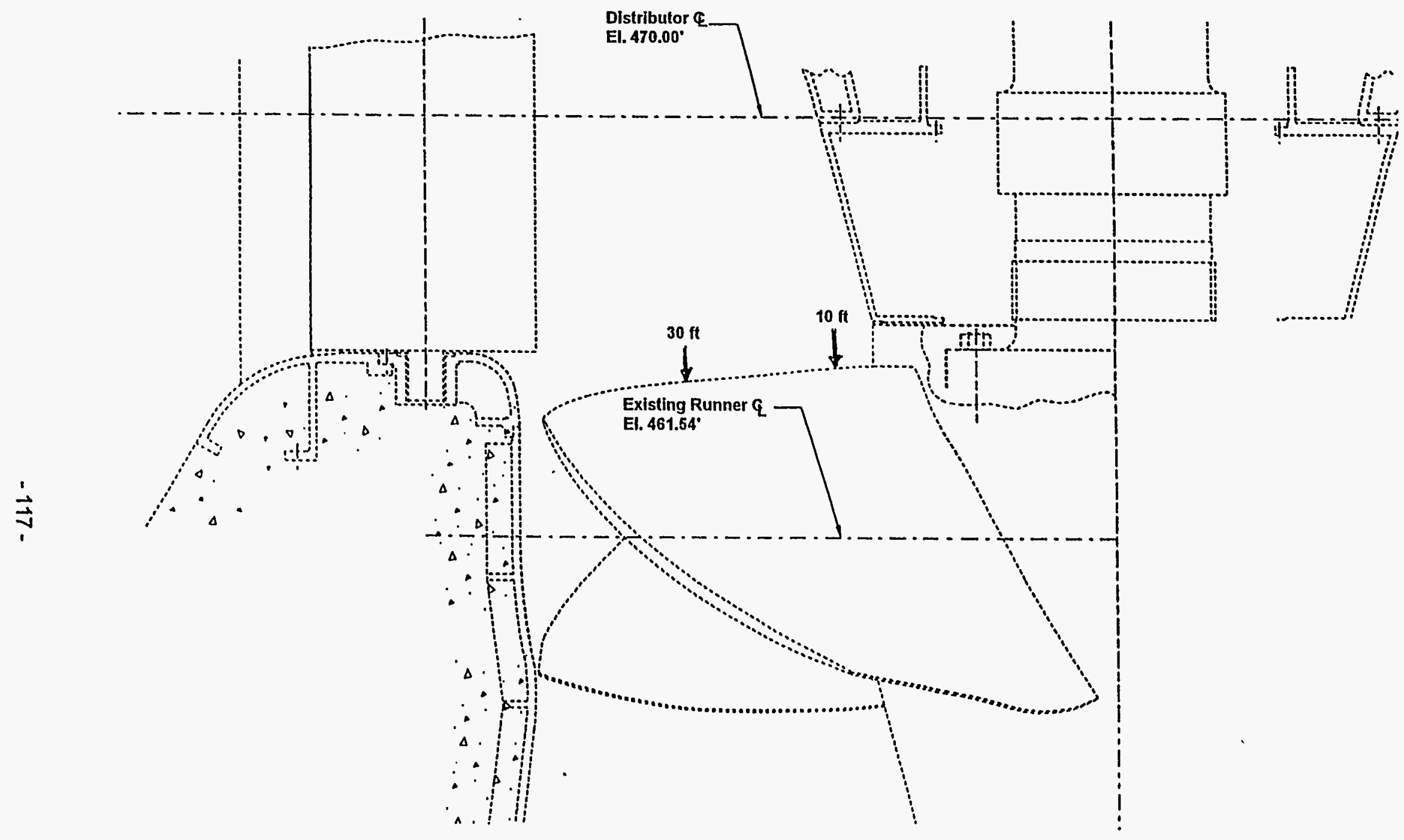

Figure 4.4.6-6 Expected Fish Location for $10 \mathrm{ft}$ and $30 \mathrm{ft}$ Injection Points at Wanapum 


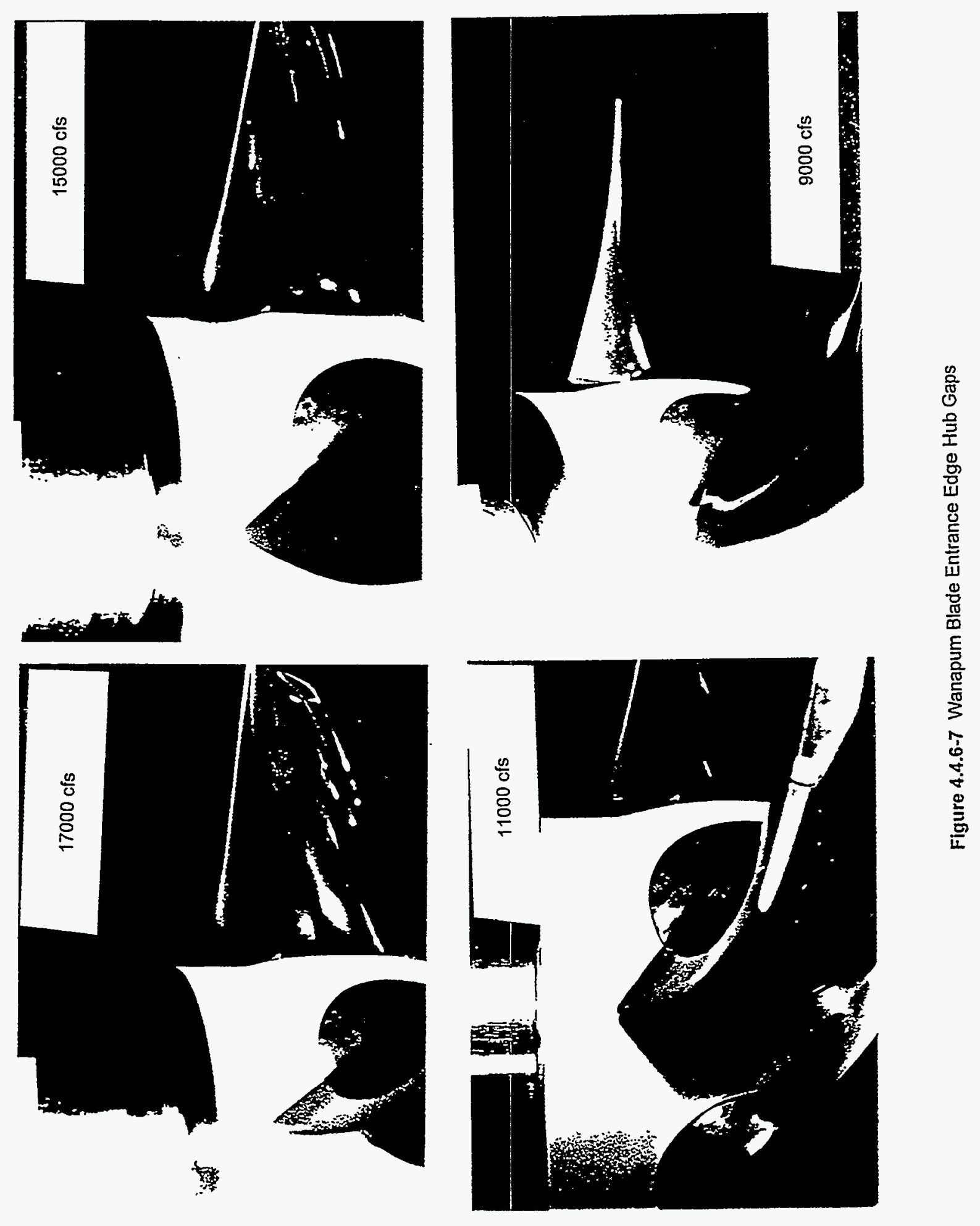




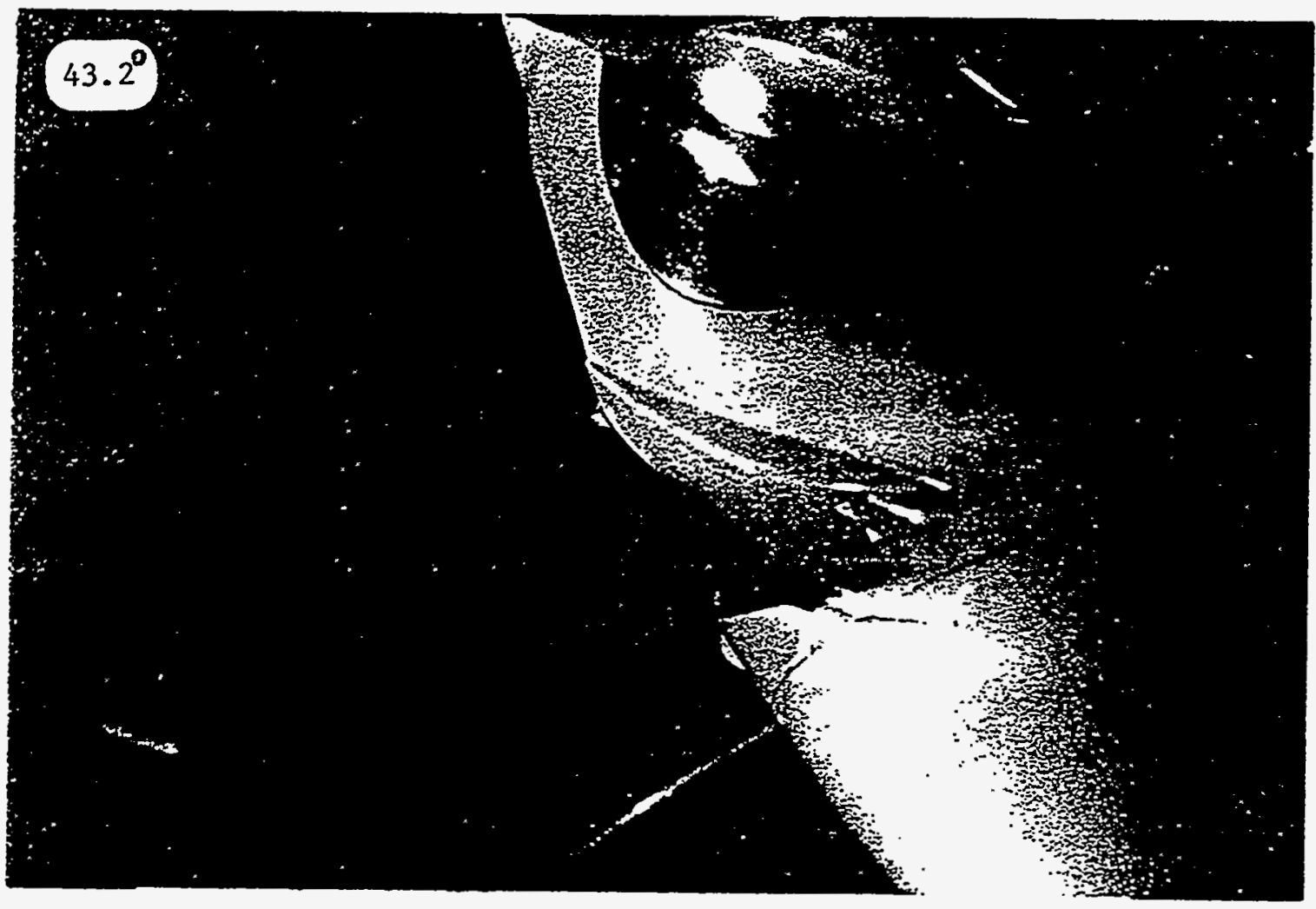

Figure 4.4.6-8a Wanapum Special Hub Contour at Higher Blade Tilt

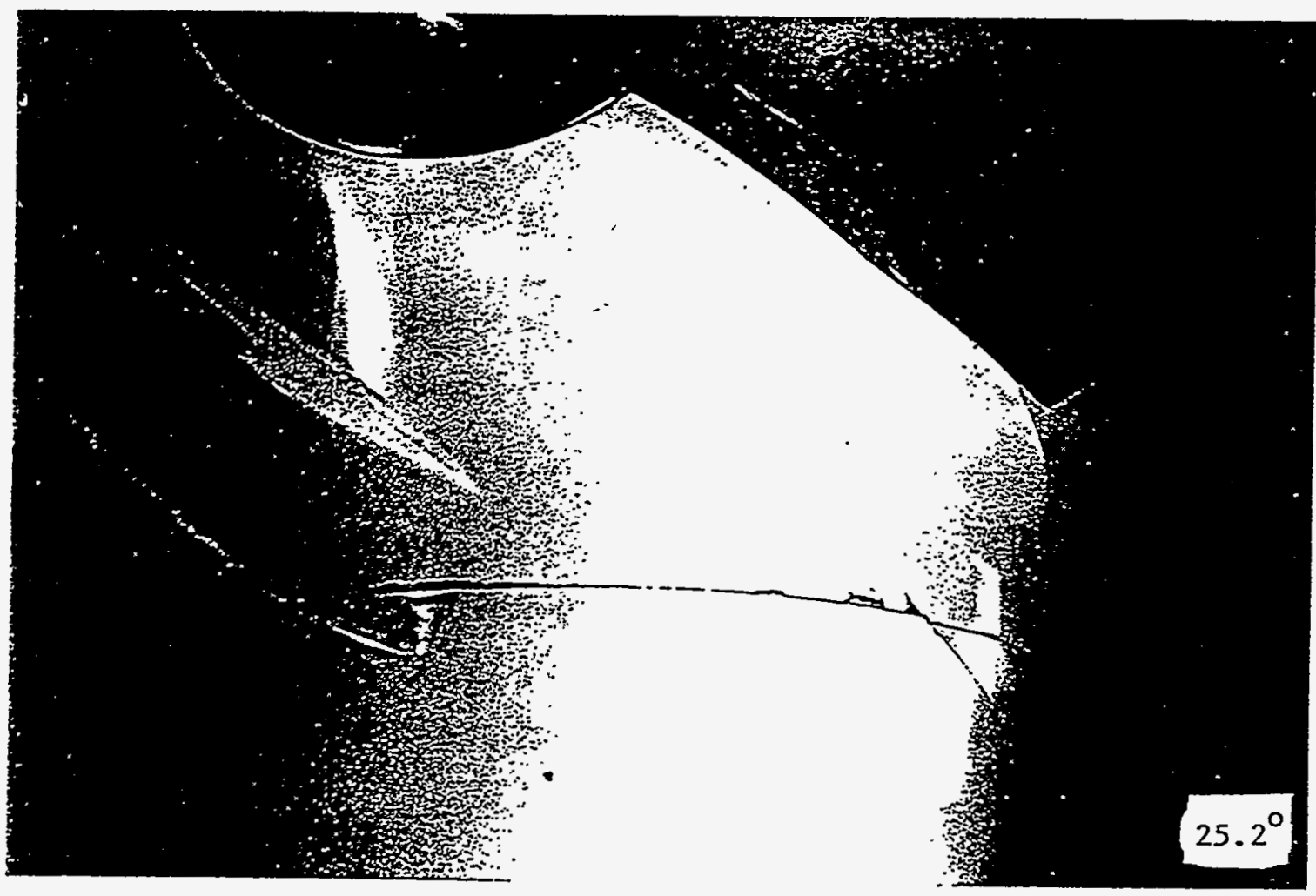

Figure 4.4.6-8b Wanapum Special Hub Contour at Lower Blade Tilt 


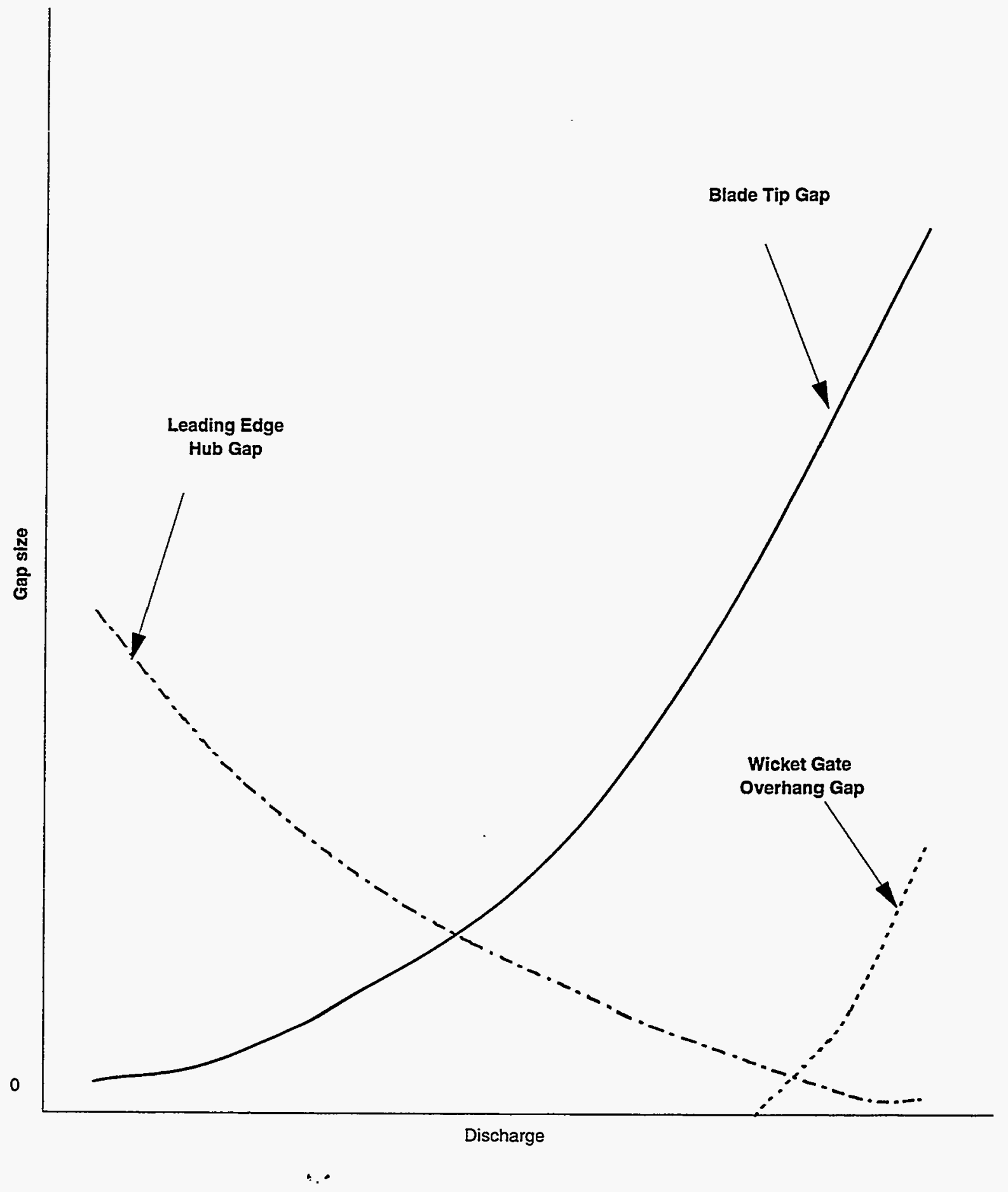

Figure 4.4.6-9 Tendencies for Blade Gaps and Wicket Gate Overhang 
$\stackrel{\overrightarrow{\vec{N}}}{\grave{1}}$

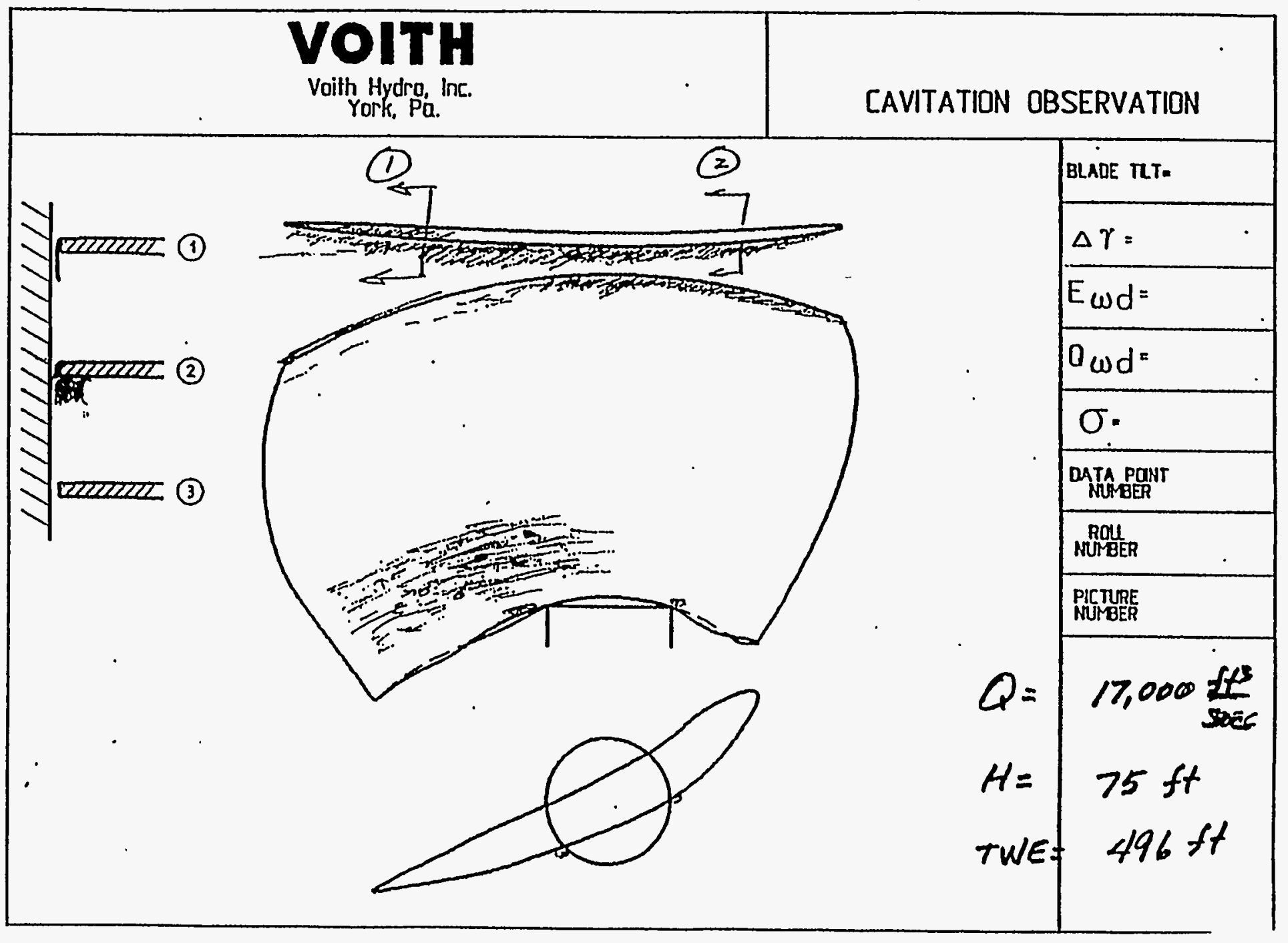

Figure 4.4.6-10 Wanapum Cavitation Sketch at 17,000 CFS 


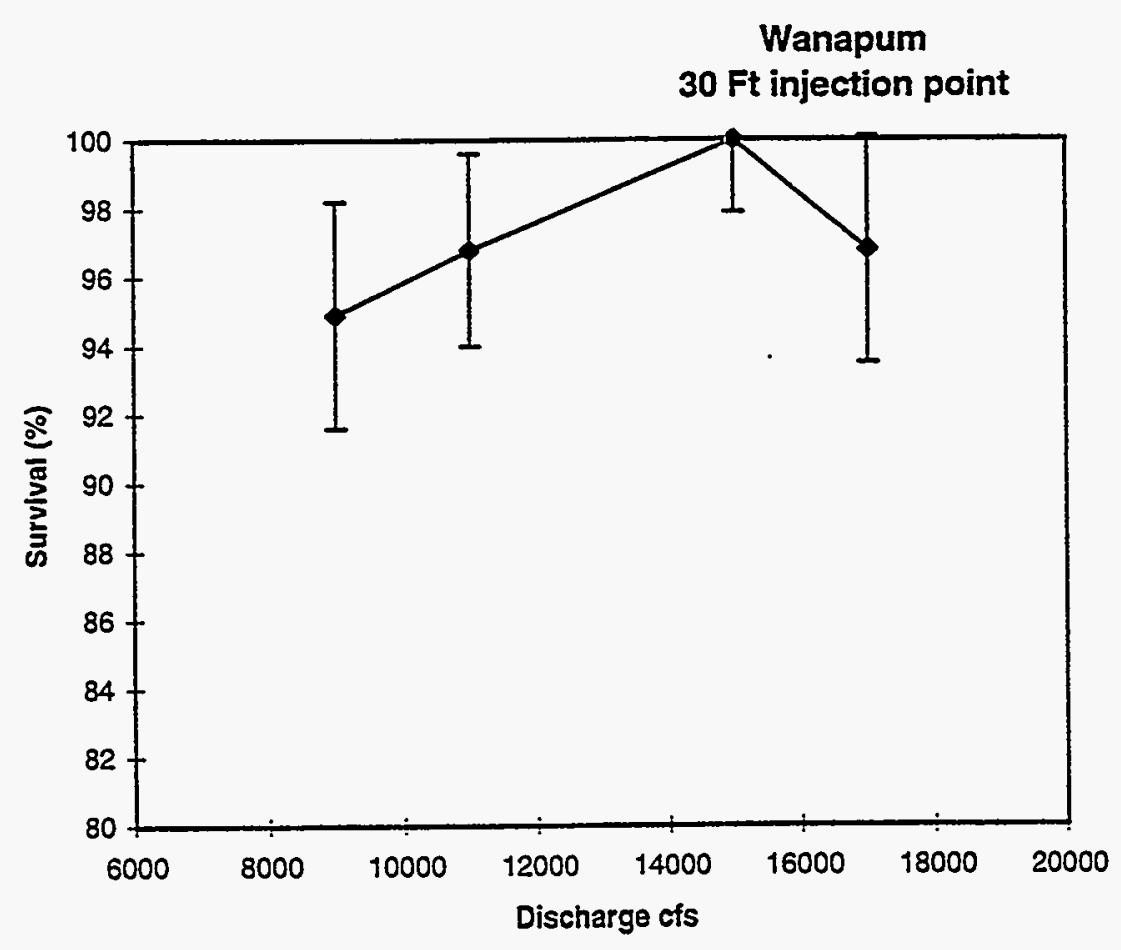

Figure 4.4.6-11 Wanapum Measured Survival For $30 \mathrm{Ft}$. Injection Location

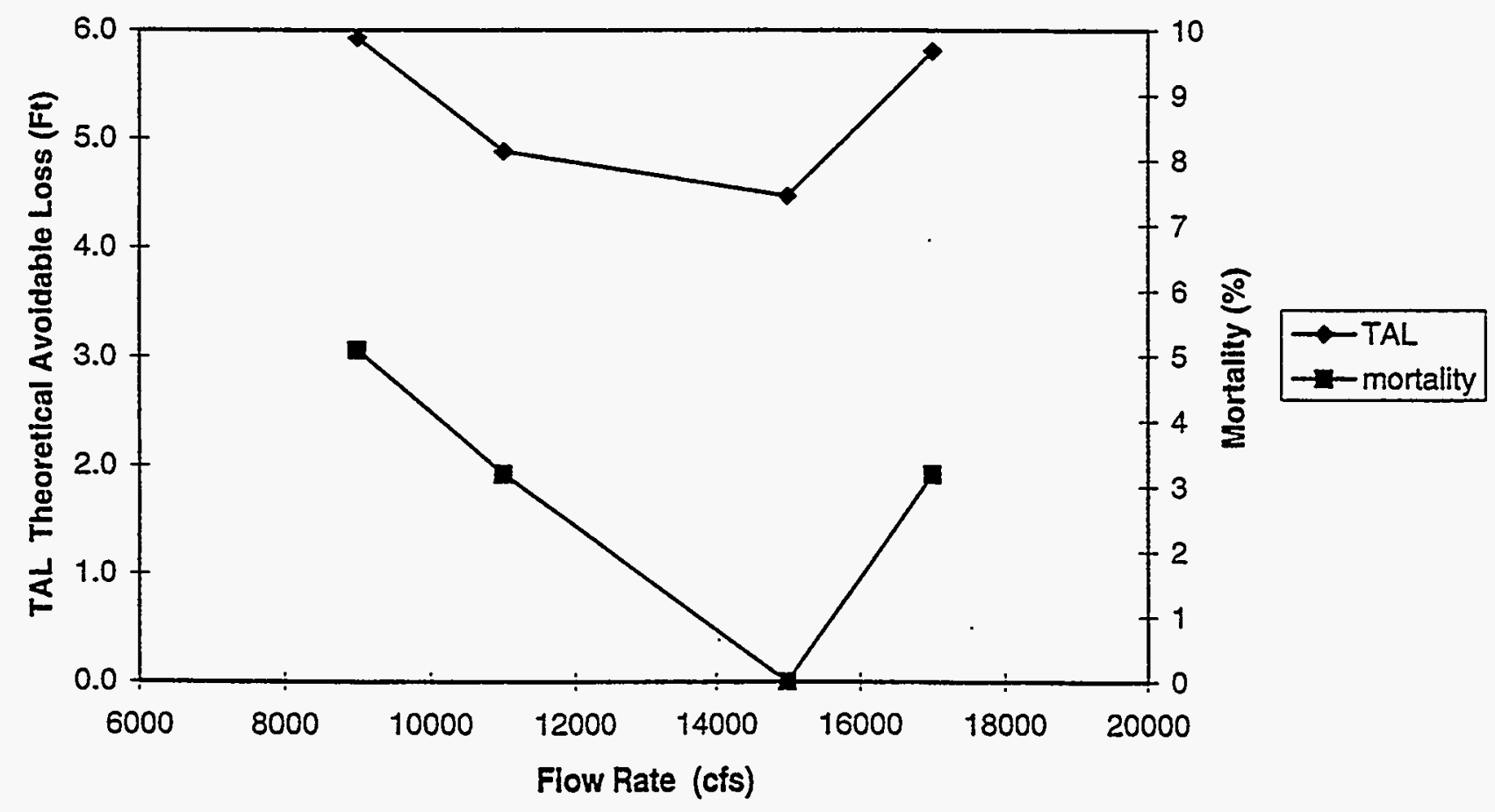

Figure 4.4.6-12 Mortality due to TAL has similar shape to TAL 


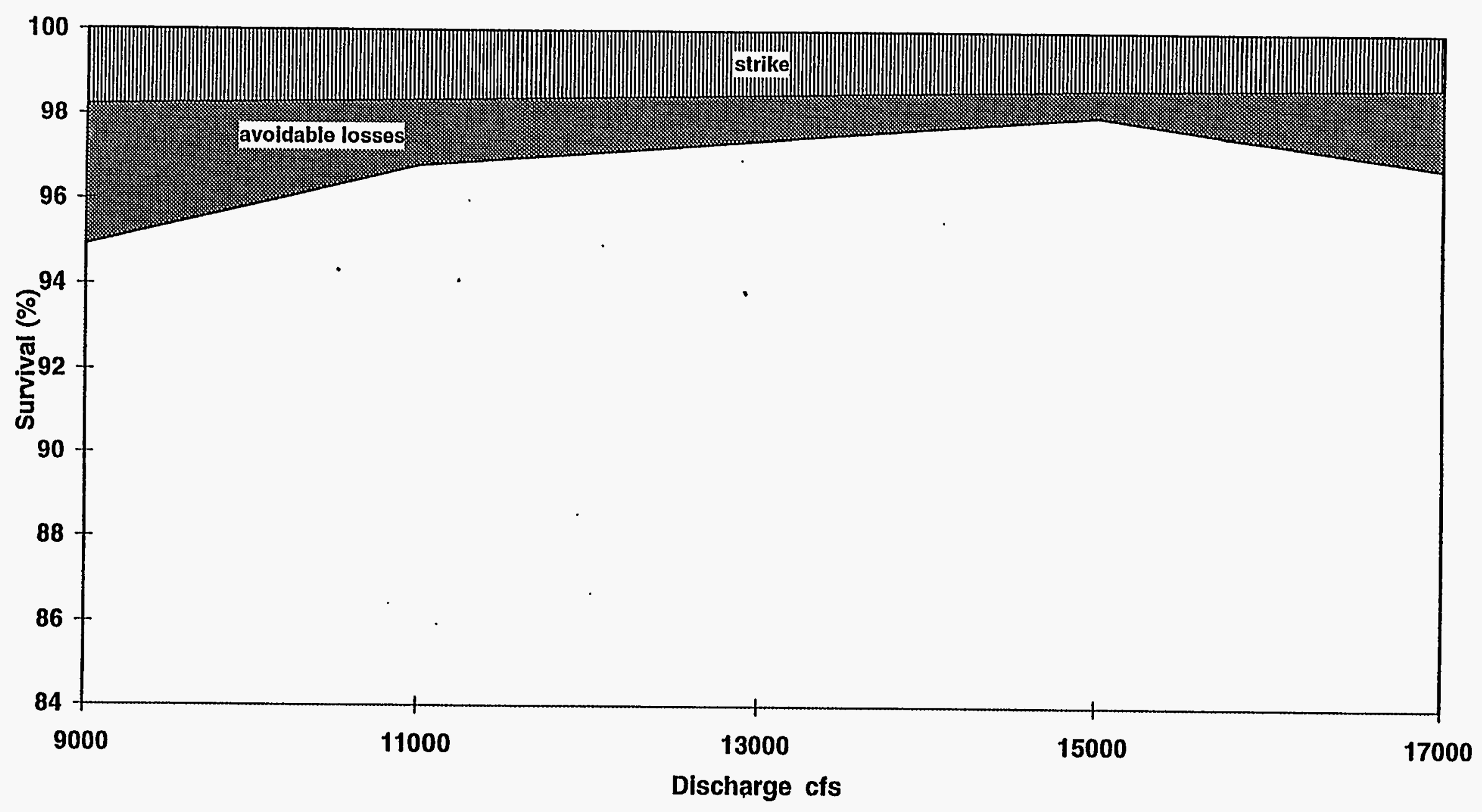

Figure 4.4.6-13 Distribution of Mortality Sources for $30 \mathrm{ft}$. Injection Location 


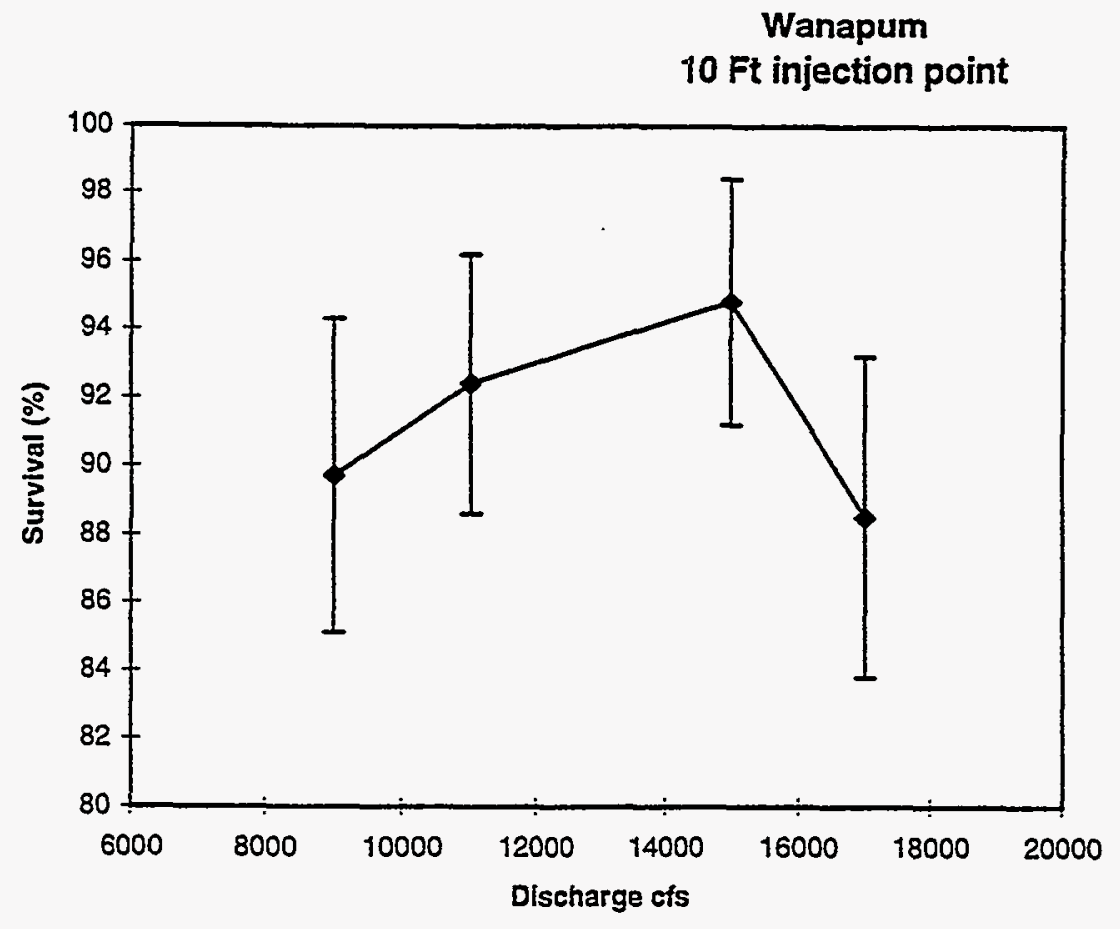

Figure 4.4.6-14 Wanapum Measured Survival For $10 \mathrm{Ft}$. Injection Location 


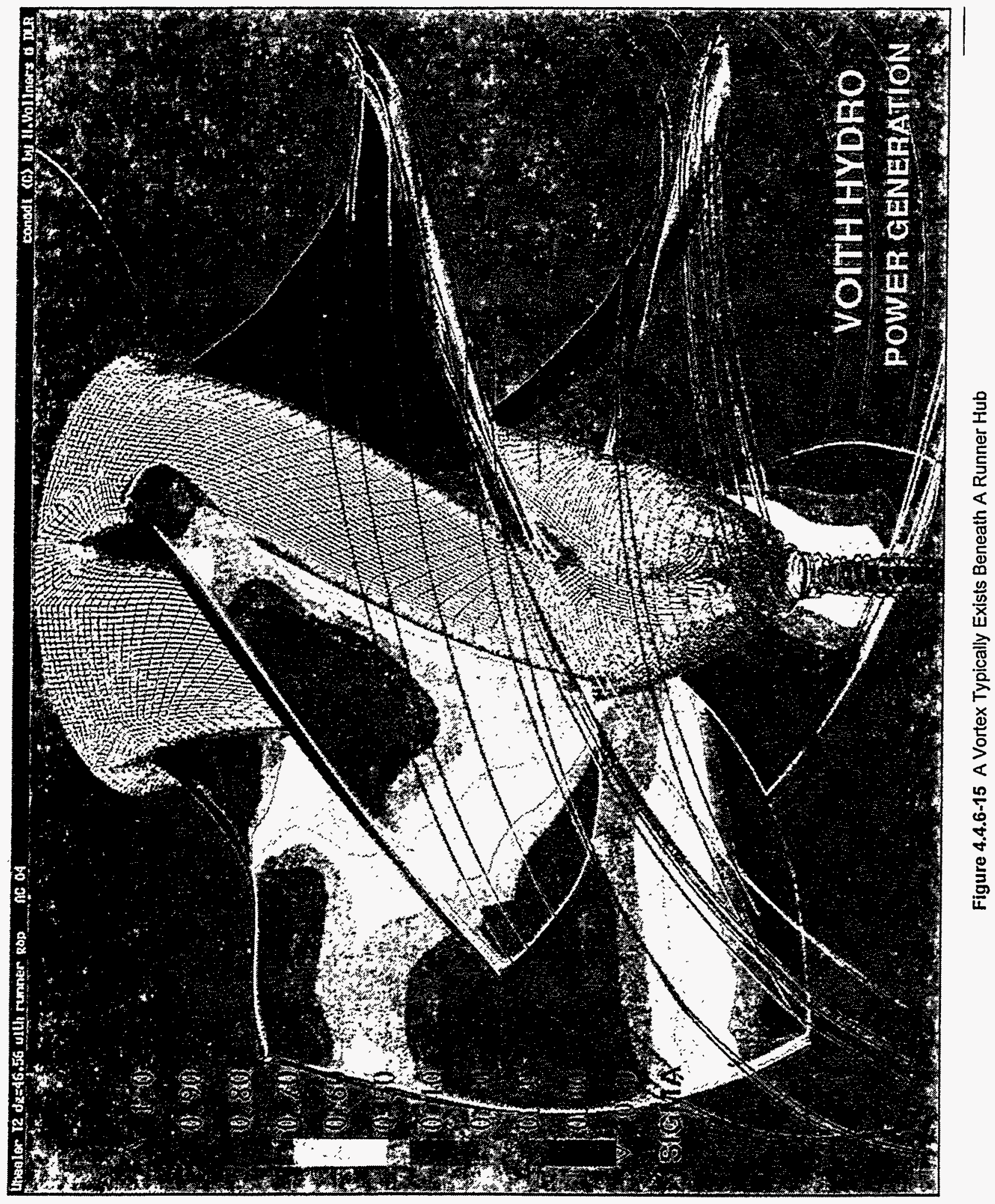




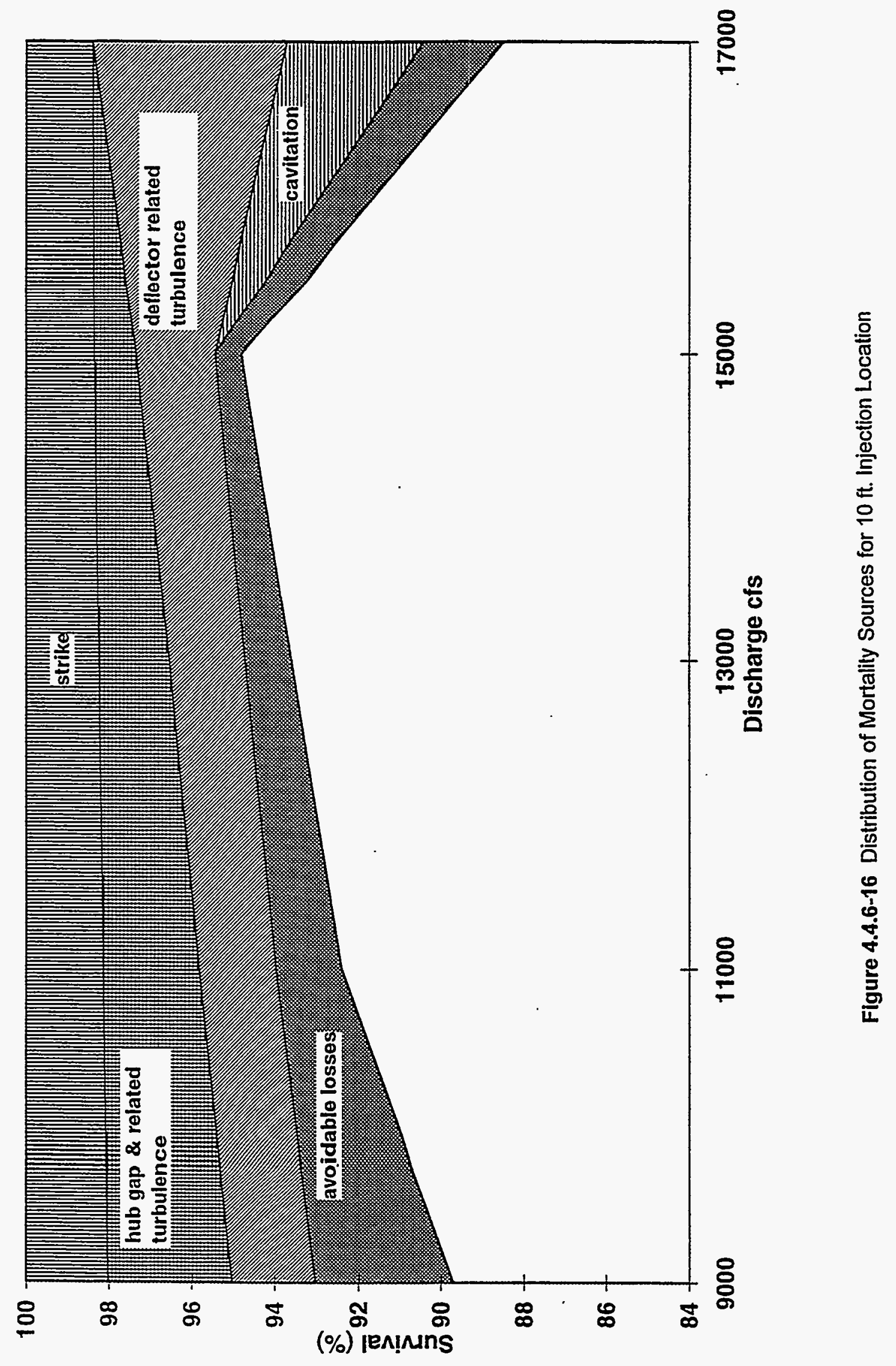




\subsubsection{KAPLAN TURBINE OPERATION FOR MAXIMUM FISH SURVIVAL}

\section{Summary}

The proposition that operation at discharges within $1 \%$ of peak efficiency will maximize fish survival was examined. Historical data that had been generally believed to support this belief, from the Big Cliff and Foster Kaplan turbines was reanalyzed. This data does not show that maximum fish survival occurs at discharges within $1 \%$ of peak efficiency. Analysis of the complex factors involved reveal tendencies for fish survival that operate in opposing directions. That is, some factors maximize survival at high discharges while other factors maximize survival at low discharges. For the geometry of the Wanapum Dam turbines and for fish located predominately in the upper water column, fish survival was enhanced by operation at higher discharges where efficiency is more than $1 \%$ lower than maximum, where TAL is a minimum, the hub gaps are small, and no cavitation is present in the blade region.

\section{Reexamination of the $1 \%$ Criteria}

Three separate studies containing survival measurements over a range of discharges were evaluated.

The data from Oligher and Donaldson (1966) were reexamined. A series of survival tests were conducted at three heads at Big Cliff Dam on the North Santiam River, Oregon. Although uncertainty estimates were not provided, the description of the experimental protocols used compare favorably with those used today. Plots of all their data are reproduced in Figure 4.4.7-1. The general trend that maximum fish survival occurred in the area of highest operating efficiency, concluded by the authors, does not hold. In fact, in some cases survival increased at turbine discharges greater than the best efficiency point.

At Foster Dam, a series of tests were conducted to evaluate the effects of turbine operating efficiency on fish survival (Figure 4.4.7-2, adapted from Bell, 1991). Tests were conducted for on cam and off cam operation. Only the on cam data are presented here. Generally, no trend is evident except at the lowest head tested where survival was a maximum at a discharge less than the peak efficiency.

Data from the tests at Wanapum were discussed in detail in Section 4.4.6., Figures 4.4.6-11 and 4.4.6-14 show the measured survival, and Figure 4.4.6-1, shows the turbine efficiency. Maximum fish survival occurs at a discharge greater than those discharges having efficiencies less than $1 \%$ below the maximum efficiency.

\section{Current Understanding of Operation To Maximize Survival}

Since factors affecting fish survival do not uniformly increase or decrease with changes in turbine operation (Figure 4.4.7-3) each factor is briefly reviewed, and the consequence for fish survival is summarized.

The strike probability equation for a Kaplan turbine as presented in Figure 4.3.2-7 shows that the probability of strike and also blade zone encounter is lowest at highest discharges and also varies somewhat as a function of head. Generally, lower strike and BZE probabilities occur at higher heads.

The injury effects of gaps between the blade and the hub, both fiuid induced and mechanically induced, are related to the size of the gap. This gap size varies with operating point and the turbine design and is minimized at higher discharges (higher blade tilts), and is at maximum at lowest discharges. Therefore, survival due to hub gaps is increased at higher discharges. The actual variation of survival with the size of the gap has not been studied experimentally, thus requiring an assumption of survival as a function of gap size. 
The injury effects of gaps between the blade and the periphery are presumed to cause fluid and mechanically induced damage to fish similar to hub gaps. However, fish have not been introduced in a controlled way in the vicinity of these gaps to verify survival mortality effects. The size of these gaps also varies with operating point, but in contrast to the hub gaps, is minimal at low discharges. Therefore, for fish passing through the runner near the periphery, survival is greater at lower discharges.

The location of fish in the water column has been shown to be important. For fish that do not traverse the runner in zones including the hub or periphery gaps, the gap related mortality tendencies do not apply. These fish may be more affected by strictly fluid induced effects such as TAL. In this case, survival may be enhanced by operation at the minimum TAL condition. TAL losses are a one dimensional representation of the energy available to injure fish. While the losses are zonal, the distribution of TAL to different zones is not possible with the algebraic calculation method employed in this study. Therefore, quantitative predictions are not made.

Cavitation bubbles typically do not appear for operating points near the best efficiency. As discharge increases, cavitation bubbles may appear, and with further increases in discharge, may grow to form larger regions. At heads larger or smaller than the head at the best efficiency point, cavitation may begin at lower discharges compared to the discharge at the best efficiency point. Operating conditions having cavitation are presumed to reduce survival, and should be avoided. A detailed analysis of cavitation patterns is required to make an assessment for a specific turbine and operating point.

Some turbines may also have somewhat uncommon features, such as the three-dimensional surfaces on the hub of the Wanapum turbines (Figures 4.4.6-8a and b). These surfaces function to essentially eliminate the gap between the hub and the inner edge of the blade downstream of the spherical portion of the hub, but also create rather sudden changes in the local contour of the water passage. Possible mortality effects of these surfaces is difficult to predict without the use of CFD and a "virtual fish".

All of these effects operate simultaneously. The aggregate of all effects may be examined through analysis of carefully planned fish survival tests designed to evaluate zonal survival, such as were conducted at Wanapum. There, it was found that fish survival was a maximum at discharges greater than the best efficiency discharge. The maximum fish survival occurred at an operating discharge that had an efficiency that was more than $1 \%$ lower than the best efficiency. 
Big Cliff Kaplan Turbine

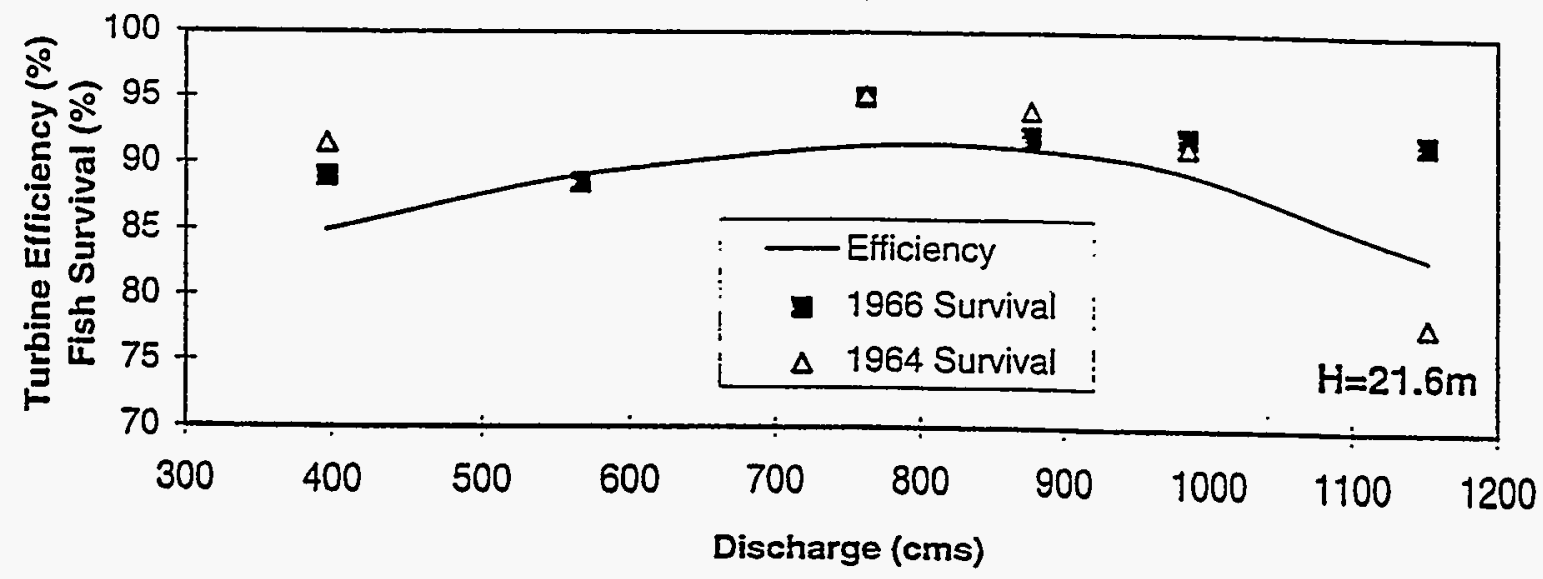

Big Cliff Kaplan Turbine

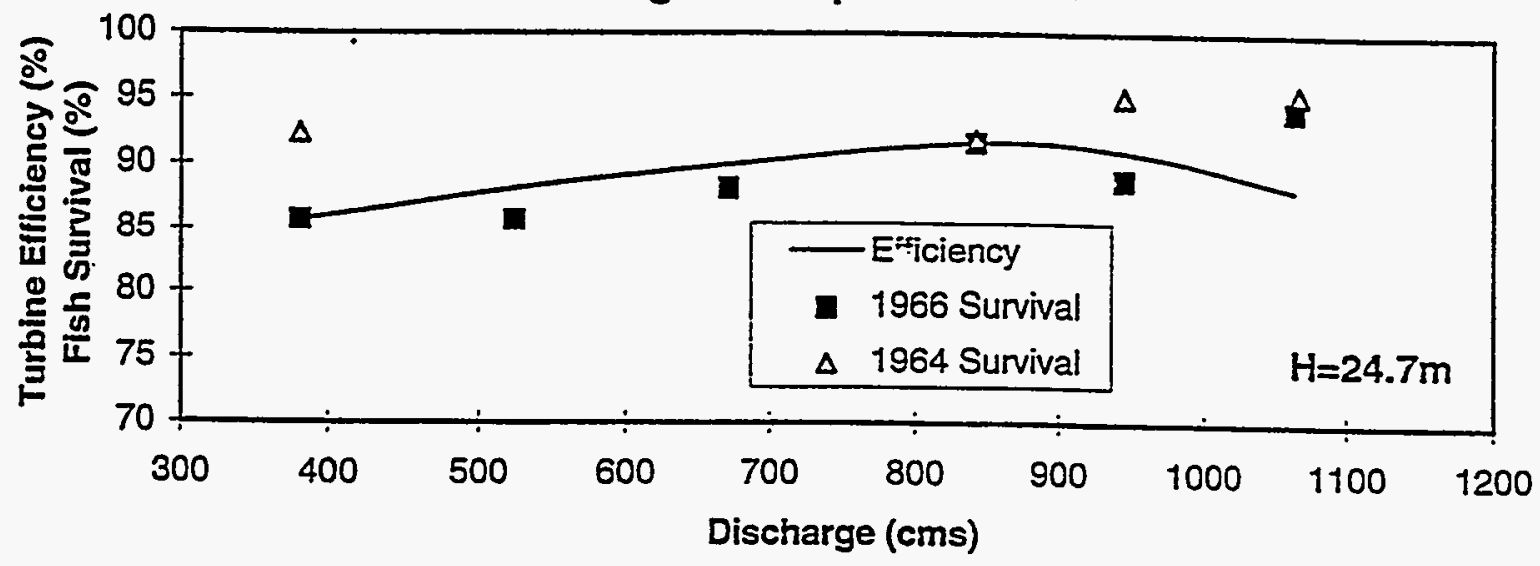

Big Ciiff Kaplan Turbine

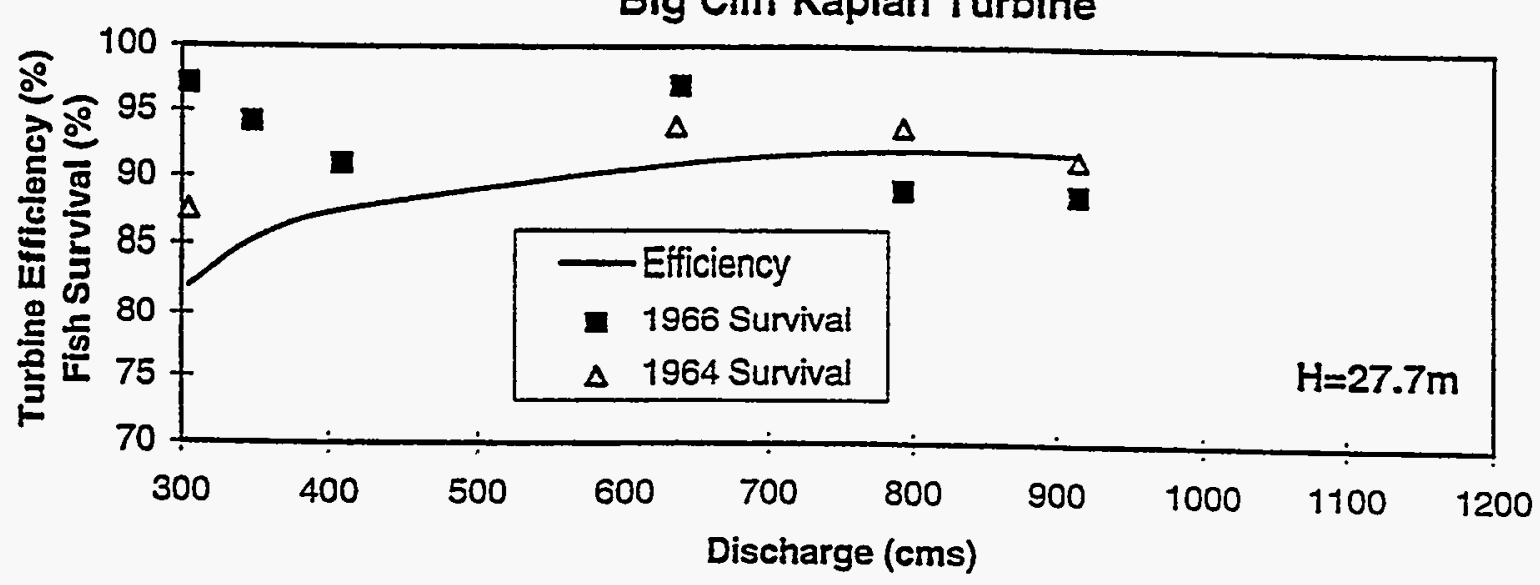

Figure 4.4.7-1 Survival and Eficiency at Big Ciiii 


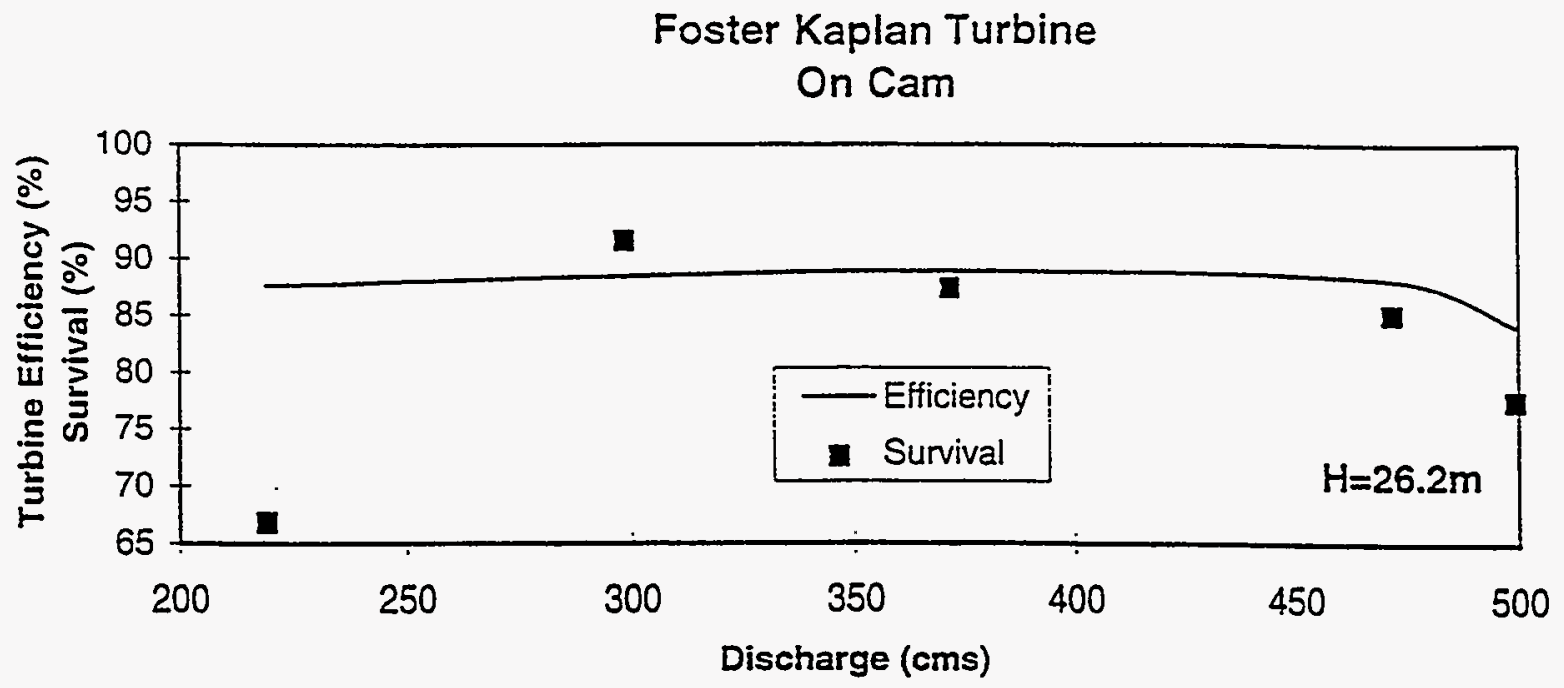

Foster Kaplan Turbine

On Cam

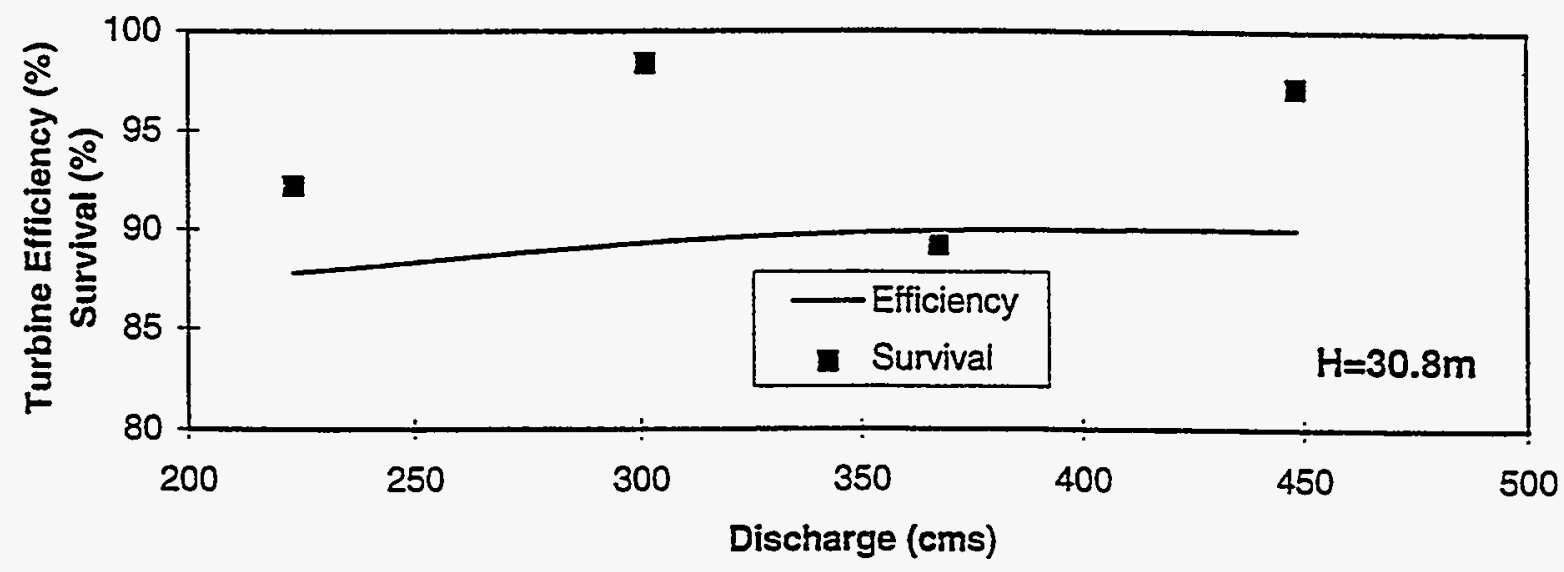

Foster Kaplan Turbine

On Cam

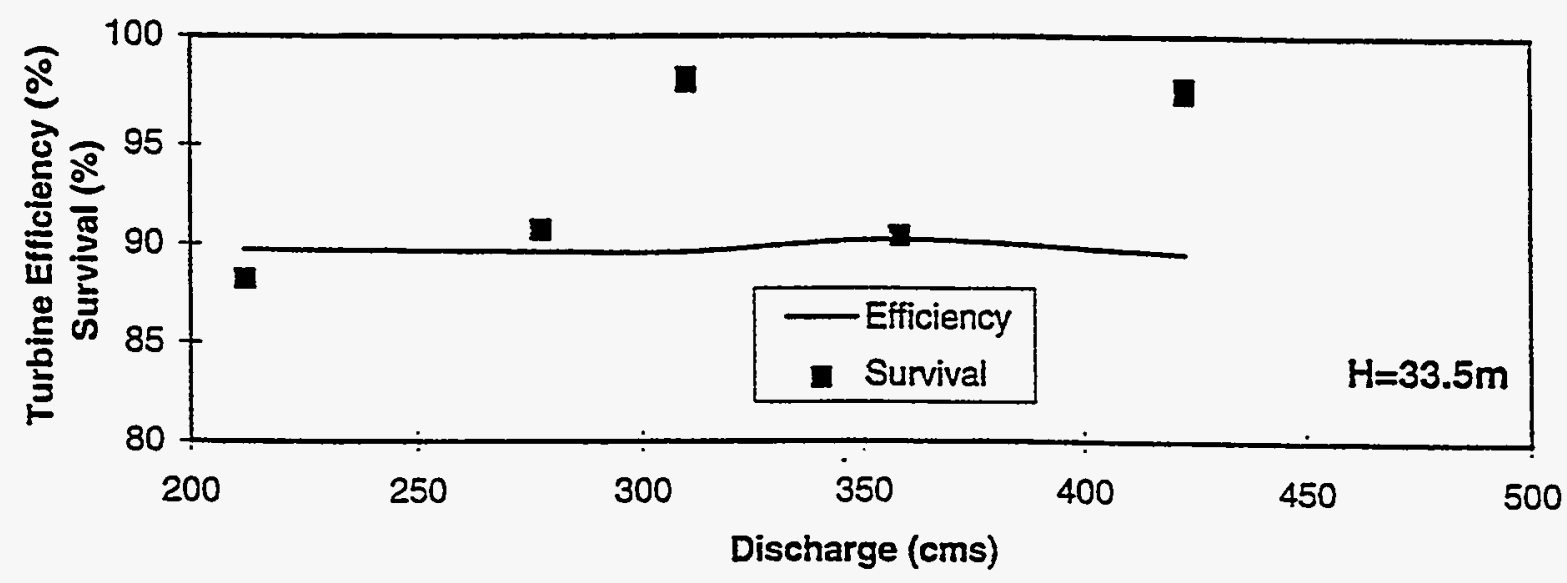

Figure 4.4.7-2 Survival and Eificiency at Foster, On Cam Data Only, From Bell, 1991 

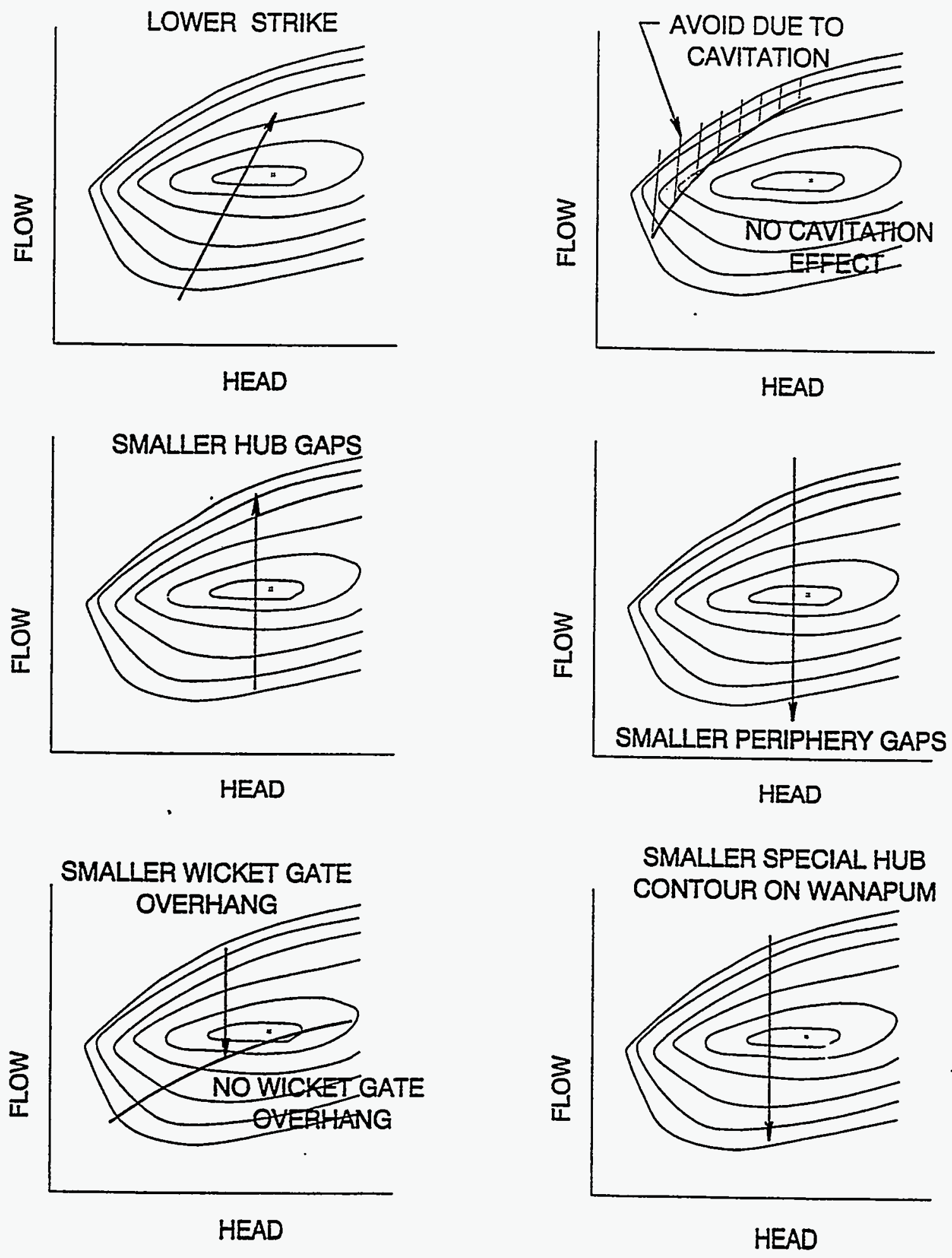

Figure 4.4.7-3 Mortality Tendencies for Several Factors in Kaplan Turbines 


\subsubsection{EFFECT OF FISH SCREENS AND FLOW DISTURBANCES ON FISH PATHS}

\section{Summary}

Physical model testing and CFD analyses have investigated the impact of the presence of fish screens on velocity distributions in turbine intakes. Physical model tests indicate significant redistribution of flow takes place. Fish screen effectiveness testing has shown that the exclusion of fish entering the turbine is not $100 \%$. Therefore, some portion of the unguided fish go under the fish screen either by being carried there by the water or by their own free will. Fish passing the intake under the fish screens may then find themselves in the lower portion of the water column where they are expected to pass through the lower zone on the wicket gates and near the outer radius zone of the blades. These fish will experience a different set of turbine geometry and associated fluid effects compared to fish passing through the upper portion of the wicket gates and the mid to inner regions of the blades. Compared to units without fish screens, the presence of fish screens may cause different fish survival characteristics.

Results from Lower Granite Dam show the importance of site-specific characteristics (i.e., whether intakes are equipped with screens or not), entrainment depth, point of operation of turbine, experimental protocols, and perils of extrapolating data from one site to another for the purposes of turbine rehabilitation. For tests at Lower Granite turbines, when equipped with extended length fish guidance screens, survival was highest for fish introduced at lower elevation when turbine operated towards its lower end of operating efficiency range. No significant differences in survival of fish introduced in the three intake bays at the same depth and turbine operation occurred. Survival in cavitation mode was similar to that at turbine operating modes. Injuries due to gaps between the runner and the hub were more common for fish introduced at upper elevation than at lower elevation.

\section{Discussion}

Despite efforts to exclude fish entry into turbines by installation of intake guidance screens or a surface bypass collector system some proportion of fish population remains unguided and is transported through the turbines. The entry of these fish into turbines most likely occurs differently than through turbines not equipped with protection devices. Thus, the development of "fish friendly" passage through these turbines needs to consider the altered hydraulic conditions, depth and trajectory of fish entrainment, fish distribution, etc. Limited field experiments have been conducted to offer some insights into potential sources of fish injury/mortality at turbines equipped with protective devices. Two separate tests were conducted at Lower Granite Dam turbine Unit 4, one in 1994 and the other in 1995.

The 1994 test was conducted to establish benchmarks of turbine passage fish survival prior to the proposed reservoir drawdown so that a pre- and post-drawdown comparison could be made. This test involved introducing fish at about $9 \mathrm{~m}$ ( $30 \mathrm{tt}$ ) below the turbine Unit 4 intake ceiling (Bay B) equipped with standard length screens; the turbine operated near the upper discharge limit of the within $1 \%$ of normal peak operating efficiency discharge range (about $513 \mathrm{cms}$ or $18,000 \mathrm{cfs}$ discharge). The 1995 test was conducted to evaluate the potential effects of (1) extended length screens. installed at turbine Unit 4, (2) passage through different intake bays, (3) turbine operation, and (4) entrainment depth in one intake bay (A).

Although in Appendix Section 10.1 only immediate survival rates $(1 \mathrm{~h})$ from Lower Granite are presented for consistency with other studies the experimental protocols utilized at Lower Granite Dam were identical in 1994 and 1995 and $120 \mathrm{~h}$ survival estimates were made (RMC et al. 1994; Normandeau Associates et al. 1995). These data are discussed herein for drawing general conclusions for this site. The potential effect of extended length screen on fish survival was almost non-existent, in 1994 the $120 \mathrm{~h}$ survival was estimated at $93.4 \%$ and $94.0 \%$ in 1995 . In both years, the turbine operated within the discharge limits set by a $1 \%$ drop in efficiency from the peak efficiency at the head of operation. However, the probable 
sources of fish injury differed between the two years. In $1994,67 \%$ of the injuries were attributed to probable mechanical causes, $21 \%$ to shear and pressure, and remainder to multiple sources. In 1995, mechanically caused injuries accounted for $40 \%$, shear and pressure $40 \%$, and the remainder to multiple sources. Again, we emphasize that these were field determinations of probable causes of injury mechanisms and some uncertainty exists in exact classifications.

Tests to determine the impact of turbine operation were conducted at $385 \mathrm{cms}$ or $13,500 \mathrm{cfs}$ (lower discharge limit of the $1 \%$ down from peak efficiency at the head, at $513 \mathrm{cms}(18,000 \mathrm{cfs})$, the upper discharge limit, and at $541 \mathrm{cms}(19,000 \mathrm{cfs})$,. beyond the upper discharge limit, off cam and above the discharge for the beginning of cavitation. The effects of the point of turbine operation on fish survival were evident. The highest survival $(97.2 \%)$ was estimated at lowest turbine operating efficiency (within $\pm 1 \%$ towards the lower end of efficiency, discharge of $385 \mathrm{cms}$ or 13,500 cfs) for fish introduced in intake bay $A$ at $3 \mathrm{~m}(10 \mathrm{ft})$ below the extended length screens. The estimated survival at a discharge of $19,000 \mathrm{cfs}$ was $94.1 \%$ and comparable to that estimated $(93.6 \%)$ at the discharge of $513 \mathrm{cms}(18,000 \mathrm{cfs})$.

The question remains; where did the fish go and into which zones of the turbine were they transported. What mechanical and fluid mechanisms for fish injury were associated with the zones transited by the fish, and what survival models could be associated with the transit. To shed light on this issue, a closer look at the Lower Granite Dam Unit 4 data are discussed below.

The presence of fish screens alters the velocity field in the intake (Figure 4.2-2). The velocity field alteration results in fish passing the screen being transported to deeper portions of the intake. CFD studies of a similar Kaplan intake with a screen are presented in Section 5.3.2. From these studies it can be seen that water from the lower region of the intake under the screens is transported to the lower portion of the stay vanes and wicket gates and then into the runner blades at the mid to outer radius of the blades. In this region, fish near the lowest region of the wicket gates are in a fluid environment which is affected by the wicket gate overhang gaps. In the runner blades, fish transiting the zone near the outer radius experience fluid and mechanical injury mechanisms which are strongly influenced by the blade tip gaps. Lower Granite turbines have a design where the upper portion of the discharge ring is cylindrical. At small blade tilts, the gaps are at a minimum. At larger tilts associated with higher discharges, the gaps are large and the gap flow characteristics provide strong vortices, high turbulence, shear and leakage cavitation. Mechanically, the gap shapes are sharp edged and tapered providing for a high potential for gap grinding. At high discharges, the wicket gates overhang the discharge ring and give rise to a leakage vortex.

To examine the effects of the above fluid and mechanical mechanisms, an analysis of the observed fish mortality was done. Fish injection was conducted at a location approximately $3 \mathrm{~m}$ (10 ft) below the bottom of the extended length screen but downstream of the screen. Velocity patterns are unknown here but would affect the fish transport path. Whether or not fish injected into the flow would be transported near the lower portion of the stay vanes and gates is unknown. The experimental results are shown in Figure 4.4.1-1. Test results including those from injection in three bays and at two elevations in bay $A$ as well as 1 hour survival and 120 hour survival are presented. Maximum survival occurred at the minimum discharge. The survival trends for higher discharges is less clear. Consideration of the overlapping nature of the estimated uncertainty bands leads to the conclusion that survival trends with discharge cannot be established. No support for any survival hypothesis is inferred from these data.

It can be concluded that experiments designed to specifically address a single issue are best able to advance the understanding of fish survival. 


\subsubsection{PROPELLER TURBINES}

\section{Summary}

Although measured data are few, good correlation was achieved between the new leading edge strike equation with lambda $=0.1$ and the measured survival data. This improved correlation compared to Kaplan turbines may be due to the absence of blade gaps and limitations of the dataset.

\section{Discussion}

Few data for propeller turbines exist. Table 4.2-2 summarizes the available data from three installations. Two turbines are conventional propeller designs, the units at Safe Harbor (which are sometimes referred to as a mixed flow design) were included in the propeller turbine analysis. This was based on a judgment that the runner experiences an inflow that is substantially axial rather than the radial inflow that was assumed to exist for the development of the Francis turbine strike equations. All of these survival tests were conducted at the best efficiency point. Therefore, the propeller performance characteristic is virtually the same as that of a Kaplan at this point, and the strike prediction equation is also the same as a Kaplan. An appropriate value of lambda may be different than for a typical Kaplan turbine. Considering that a propeller turbine has no hub or periphery gaps, a value of lambda lower than 0.2 may be expected. A value of lambda equal to 0.1 was inferred for the strike only portion of Kaplan mortality. Because of sources of mortality in addition to strike lambda would be expected to be larger than a strike only value. Although little cavitation is likely to exist at the best efficiency point, some TAL is expected, and some deflector vortex rope phenomena may occur, a value of lambda may be greater than 0.1 . Without additional data, a value for lambda could not be further refined, so a value of lambda equal to 0.1 was used and all fish were presumed to enter the runner at $r / R=0.4$. The strike prediction equation and the measured mortality are compared in Figure 4.4.9-1. Good correlation between predicted and measured mortality is observed when correlated with the variable $N$ L / D. 


\section{Propeller Turbine}

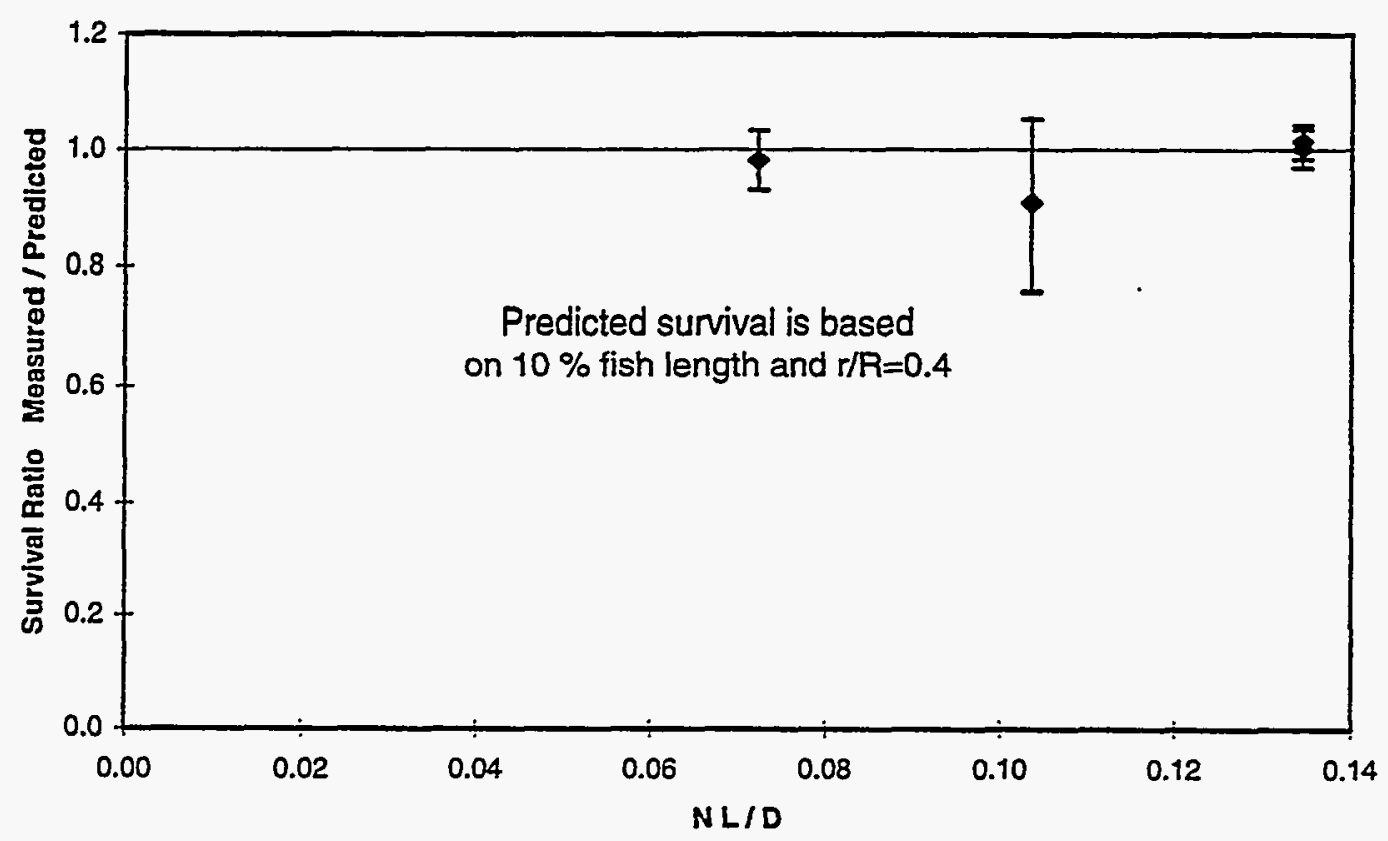

Figure 4.4.9-1 Survival Through Propeller Turbines is Well Correlated by N L / D 


\subsubsection{FRANCIS TURBINE EVALUATION OF PREDICTION METHODS}

\section{Summary}

Poor correlation was achieved between measured survival and the strike equation prediction. Data inaccuracies, reduced applicability of the strike equations for high specific speed turbines, and pressure reduction inducted mortality are possible causes.

\section{Discussion}

The Francis turbine data is more extensive than the Kaplan data. It encompasses a greater range of turbine sizes, thus leading to a greater range of the variable $N L / D$. The specific speed range is also large. The accuracy of the Francis turbine strike (BZE) equations is believed to decrease as specific speed increases. It also appears that the credibility of the turbine operating data is not as high as the Kaplan data. In spite of this, all available data (Table 4.2.4) was used to evaluate the strike prediction formula. The correlation coefficient, lambda, was reevaluated for Francis turbines. Figure 4.4.10-1 shows considerable scatter for the calculation of lambda for each survival data point. $A$ value of lambda equal to 0.2 was chosen, based on Kaplan turbine results, and on the absence of a reliable estimation method. Figure 4.4.10-2 shows poor correlation between measured and calculated survival. The use of data obtained from balloon tag experiments, which may have higher accuracy, does have less scatter.

Injury types were examined for two studies at Shasta and Cushman No. 2. At Shasta, injury allocation was as follows: 74.4 to $76.8 \%$ due to mechanical causes; $7.6 \%$ to $13.4 \%$ due to pressure, $6.2 \%$ to $7.1 \%$ shear related; $2 \%$ to cavitation (in one test); and the remainder to unknown causes. At Cushman, probable causes of injury were $57.1 \%$ to mechanical causes and $42.9 \%$ to pressure related causes.

The literature contains occasional references to correlation to runner tip speed. Section 4.3.3.3 presented a mechanism by which higher heads will increase the strike energy available. The experimental data were also used to examine a possible correlation. Figure 4.4.10-3 shows large scatter in the data. No such correlation is evident. High head Francis turbines, with typically longer penstocks than low head turbines, could have increased mortality due to pressure effects, if longer penstocks provide time for fish to acclimate to higher pressures. No correlation is evident for the effect of turbine head (Figure 4.4.10-4).

Different velocity profiles at the runner entrance were noted to occur for different specific speed designs in the strike equation development (Section 4.3.2.1) and it was speculated that the accuracy of the strike equation may decrease with higher specific speeds. No correlation is evident for the effect of specific speed (Figure 4.4.10-5).

The available experimental data does contain some interesting information. Figure 4.4.10-6 compares the value of the non-dimensional length parameter $\mathrm{N}$ L / D for Francis and for Kaplan turbines. Due to the generally smaller size and larger number of blades of Francis turbines, the non-dimensional length parameter is an order of magnitude larger than for Kaplan turbines. It is presumed therefore, that fish survival would be significantly lower 


\section{Estimate of Lambda \\ for Francis Turbines}

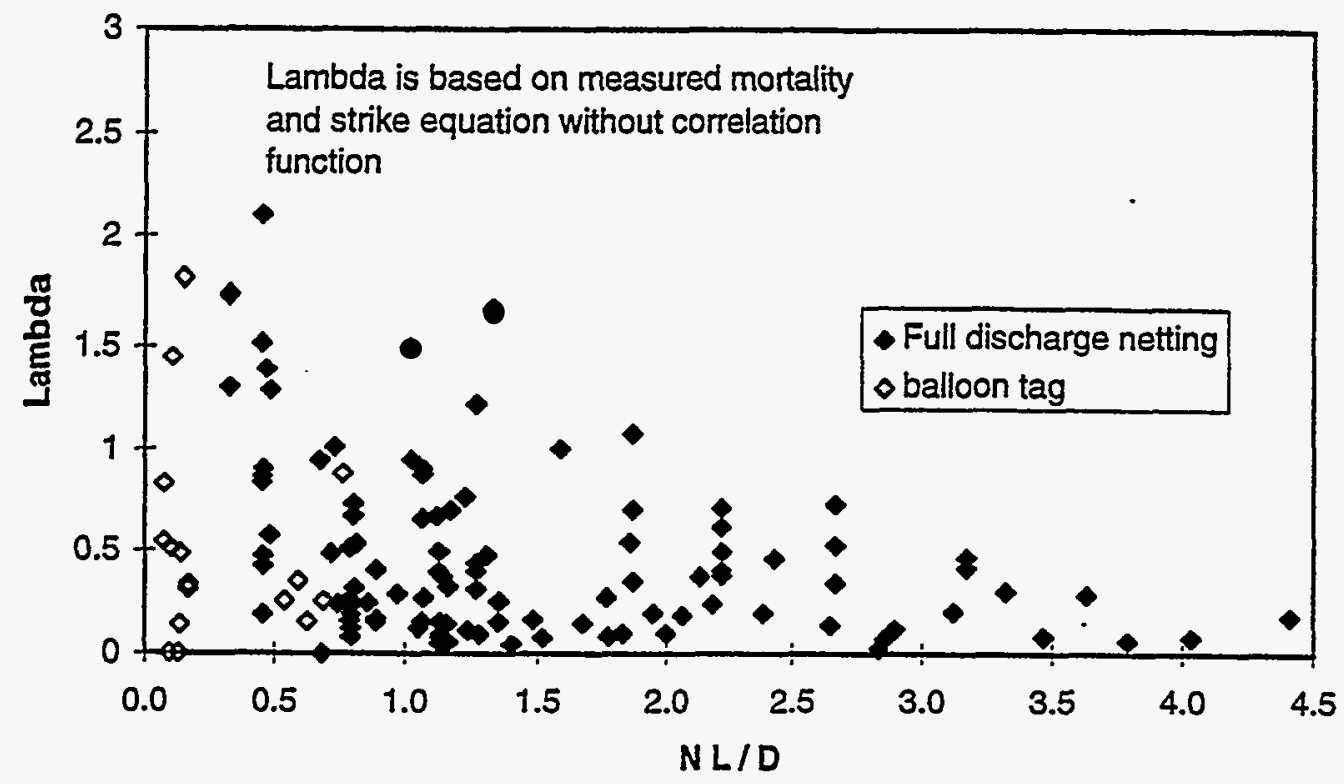

Figure 4.4.10-1 Calculation Of Correlation Coefficient For The Francis Turbine Data Set

Francis Turbines

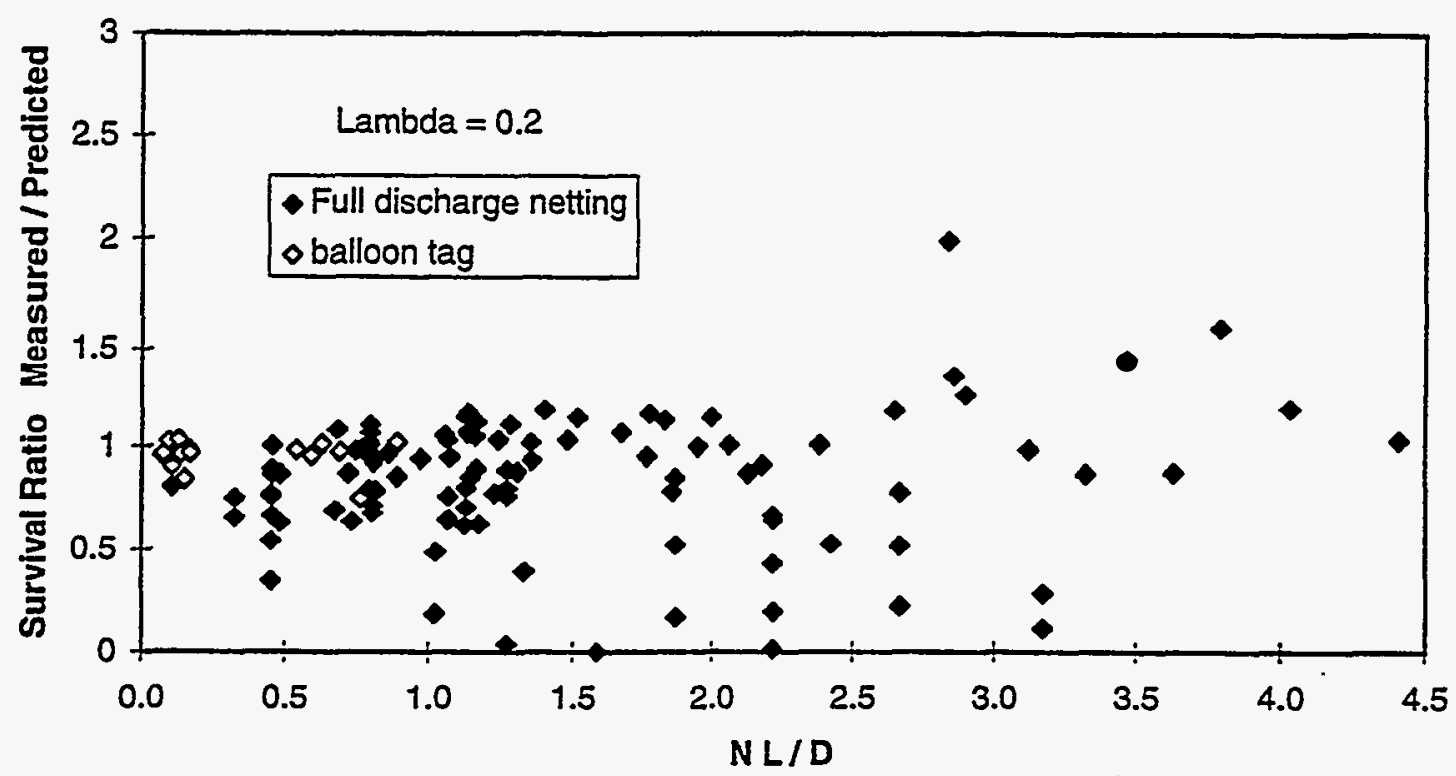

Figure 4.4.10-2 A Correlation Of The Francis Turbine Data Set Shows Large Scatter 


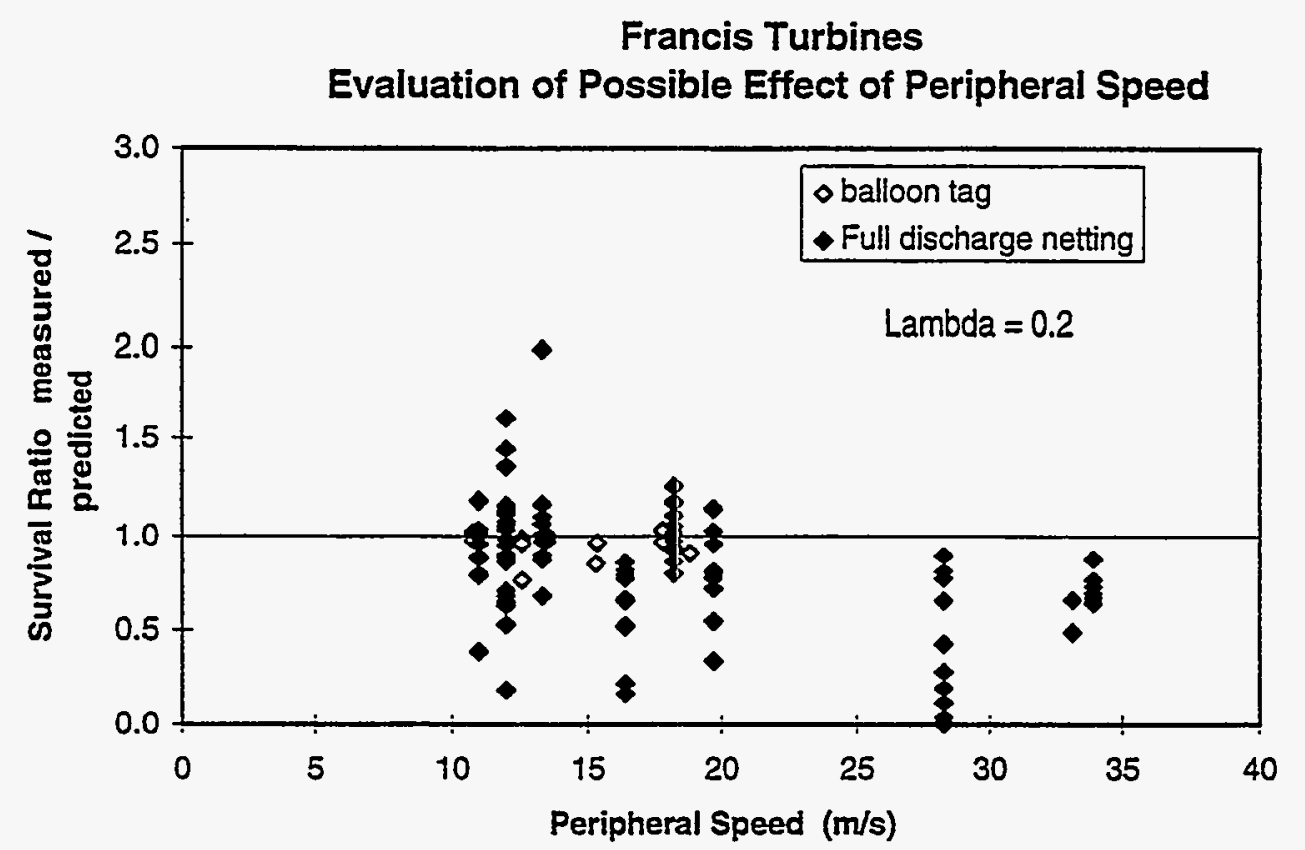

Figure 4.4.10-3 The Variable Peripheral Speed Shows No Significant Trends for Francis Turbines

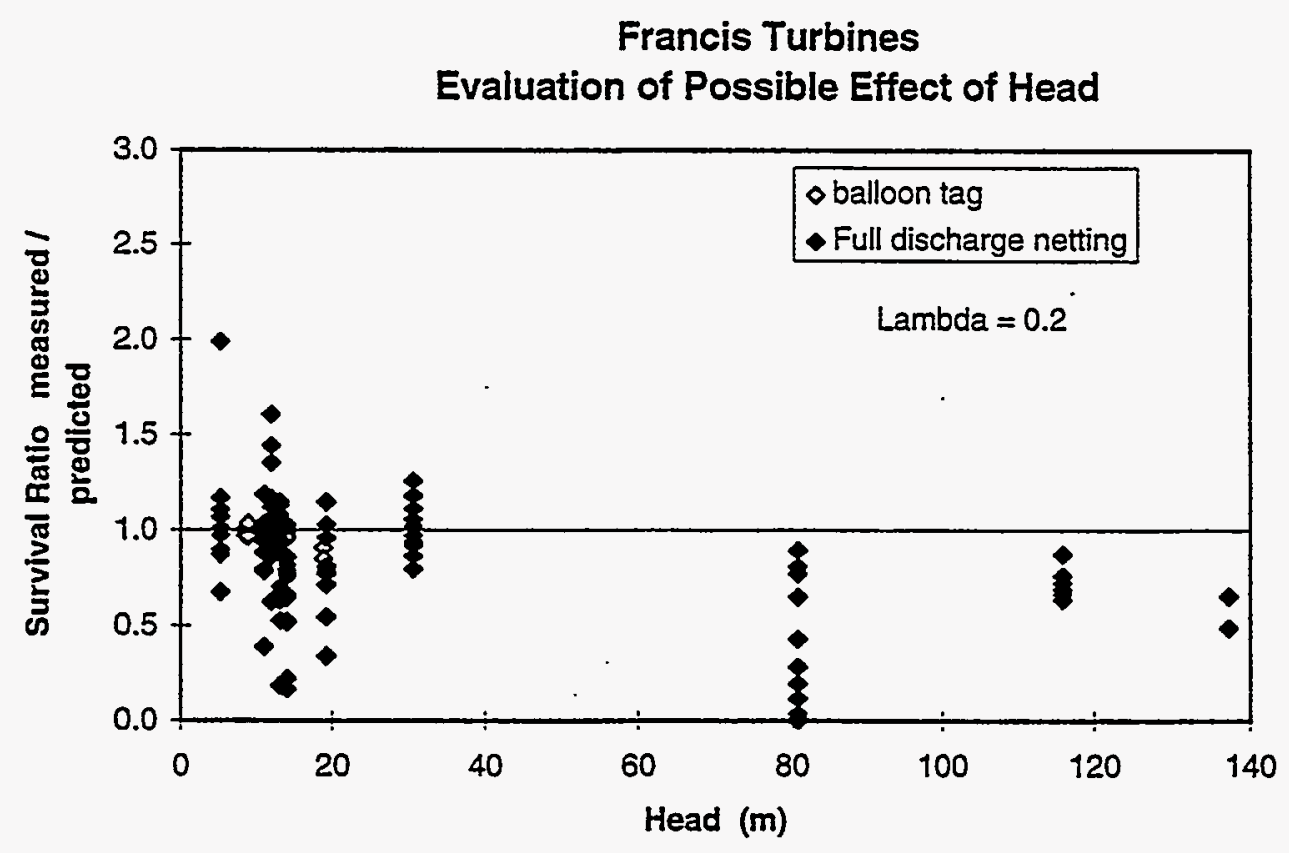

Figure 4.4.10-4 The Variable Peripheral Head Shows No Significant Trends for Francis Turbines 


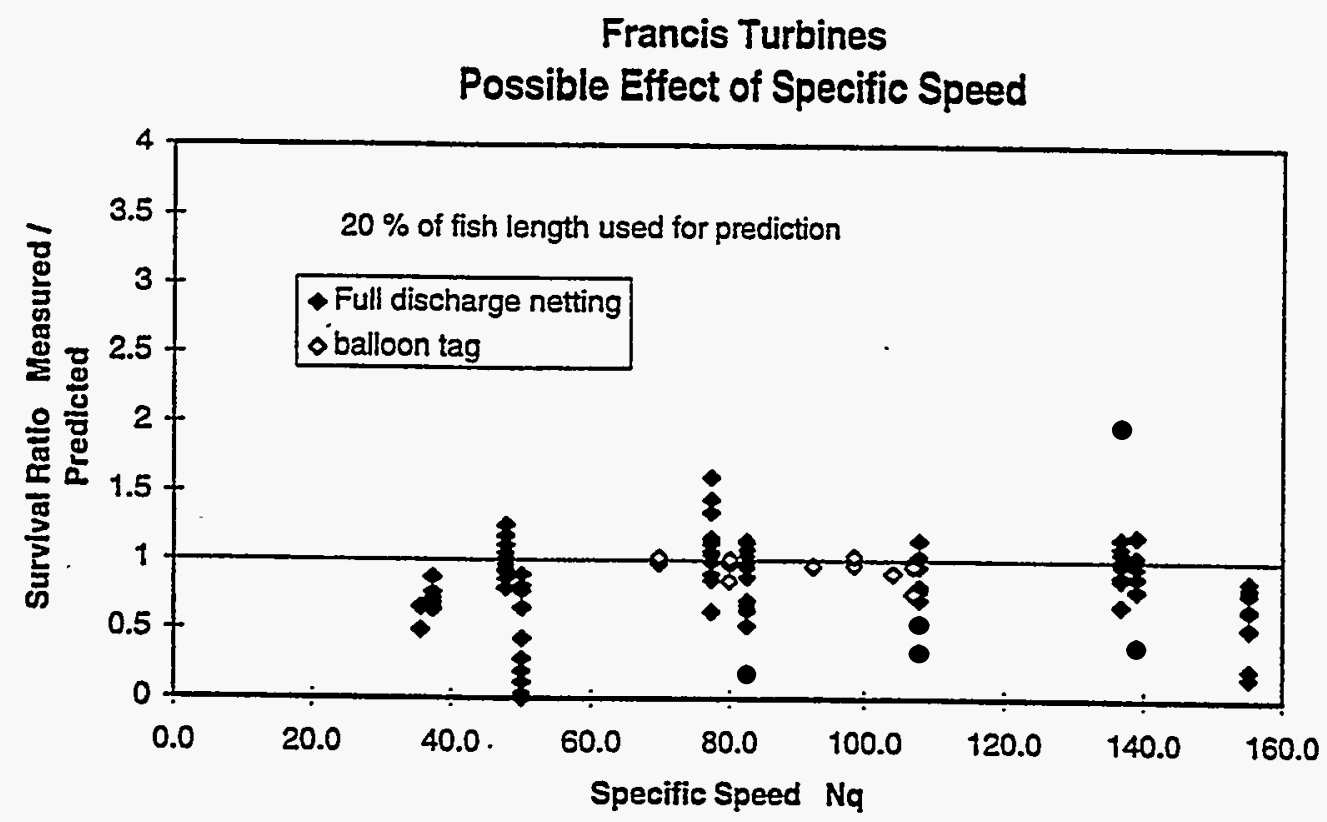

Figure 4.4.10-5 The Variable Peripheral specific Speed Shows No Significant Trends for Francis Turbines

Comparison of $\mathrm{N} L / D$ for Francis and Kaplan turbines

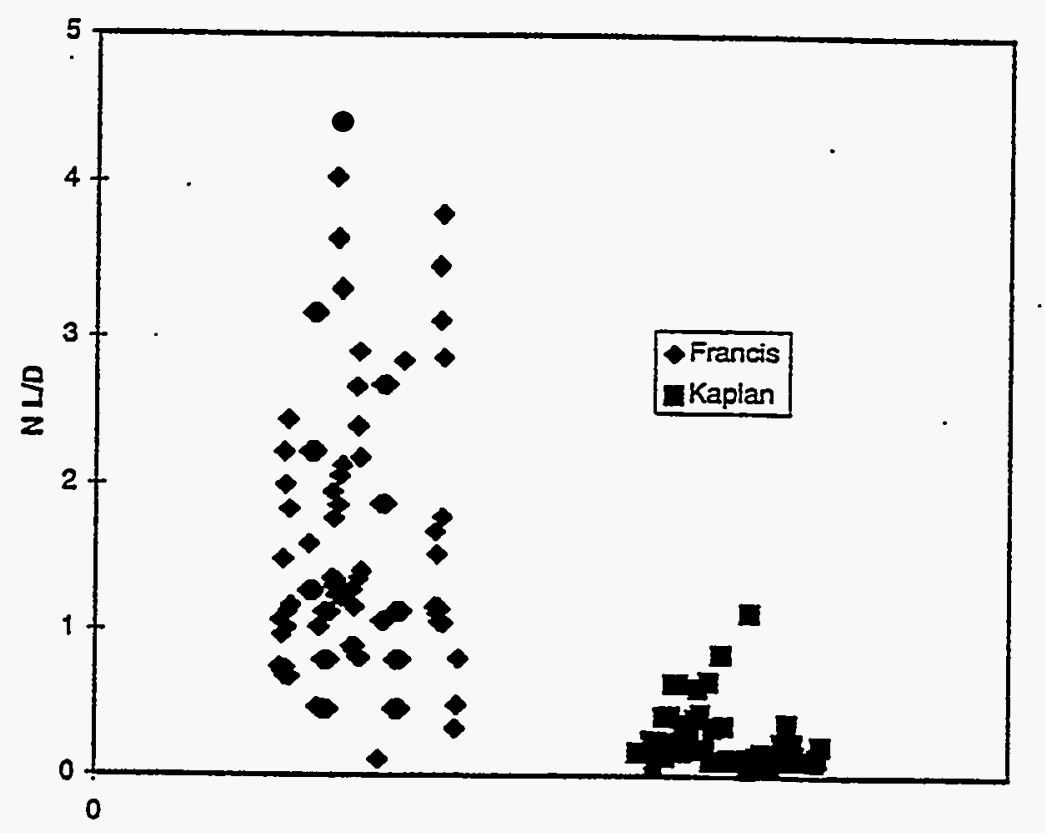

Figure 4.4.10-6 Higher Values Of N L / D For Francis Turbines Indicate Greater Strike Potential 


\subsubsection{EFFICIENCY AND FISH SURVIVAL AT FRANCIS SITES}

\section{Summary}

Tests at the relatively high head turbines at Shasta and Cushman are the only data available to evaluate the effect of turbine operating point on fish survival. Survival does not appear to reach a maximum at flows less than peak efficiency, but there is no conclusive evidence that survival is highest at peak efficiency. The data do not preclude the possibility that the complex factors involved in survival cause maximum survival to occur at discharges greater than the peak efficiency discharge.

\section{Discussion}

In contrast to the fish survival data on Kaplan and propeller turbines, data on Francis turbines are characterized by studies at high head ( $>30 \mathrm{~m}$ or $100 \mathrm{ft}$ ) dams (primarily prior to 1970's) and those conducted in the 1990's, primarily at low head dams. Only two studies, prior to 1970, were conducted specifically to evaluate fish survival at several turbine operating efficiencies (Cramer and Oligher 1964). Both these studies were conducted at relatively high head dams (Cushman No. 2, head of about $136 \mathrm{~m}$ (450 ft), and Shasta, head of about $124 \mathrm{~m}$ or $410 \mathrm{ft}$ ). At Cushman No. 2, although two years of testing occurred, data presentation was different for each year. For the tests conducted in 1960 a composite survival rate of mixed salmonid species was given for each wicket gate opening; for the 1961 tests survival rates for individual species were provided (Cramer and Oligher 1964). Because of the different sizes of species tested (chinook salmon averaged $102 \mathrm{~mm}$, steelhead $152 \mathrm{~mm}$, and rainbow trout $254 \mathrm{~mm}$ ) pooling of data may mask the effects of interest. Results of these studies are discussed below.

Studies by other investigators have generally involved tests either at the prevailing turbine operating condition (with no accompanying data) or at the "worst case" scenarios (narrowing of the wicket gates to the lowest operable level). Many of these studies utilized small sample size, no controls, poor experimental protocols, use of mixed species, unknown fish lengths, unknown depth of fish introduction, etc. and thus are of little value for the present discussion. These deficiencies are apparent from data listings given in Appendix 10.1.

For the tests at Shasta, discharges were not available, so the relationship between wicket gate opening, efficiency, and fish survival was used, and is shown in Figure 4.4.11-1. Significant variability between the January and November tests is evident. Fish length varied with species, but different species had the best survival for different test points, with no pattern being evident. For the same species at similar wicket gate openings, survival differed up to $30 \%$; the largest difference $(30 \%)$ occurred between the January and November tests for chinook saimon at the highest wicket gate opening tested. Differences in survival between the two test periods for any species were generally less than $21 \%$. No survival data could be obtained at discharges equal to or greater than the best efficiency discharge due to limitations on generator output. The highest survival did not consistently coincide with the discharge nearest to the best efficiency discharge. These data do not support a conclusion that operation at best efficiency enhances fish survival.

Two test series at Cushman No. 2 (Cramer and Oligher 1964), also provide survival information at different operating conditions. In the 1960 test data, Figure 4.4.11-2, changes in tailwater elevation had a large and perhaps dominant effect. Survival was extremely similar at the best efficiency discharge and at $100 \%$ gate opening , except for the low tailwater data. This point would have the most severe cavitation effects which may have caused disproportionate mortality. The 1964 data (Figure 4.4.11-3) show considerable variation as a function of gate opening. Maximum survival for Steelhead trout occurred at $50 \%$ gate opening (51.9\%)and nearly the same survival was obtained at $76 \%$ gate opening $(50.0 \%)$. Maximum survival for silver salmon occurred near the best efficiency point $(72.0 \%)$, but nearly the same survival was obtained at $90 \%$ gate opening $(71.7 \%)$. Overall these data do generally support the conclusion that survival is maximized near the best efficiency point, but due to the large variability in survival rates, the reliability is not high. 
January

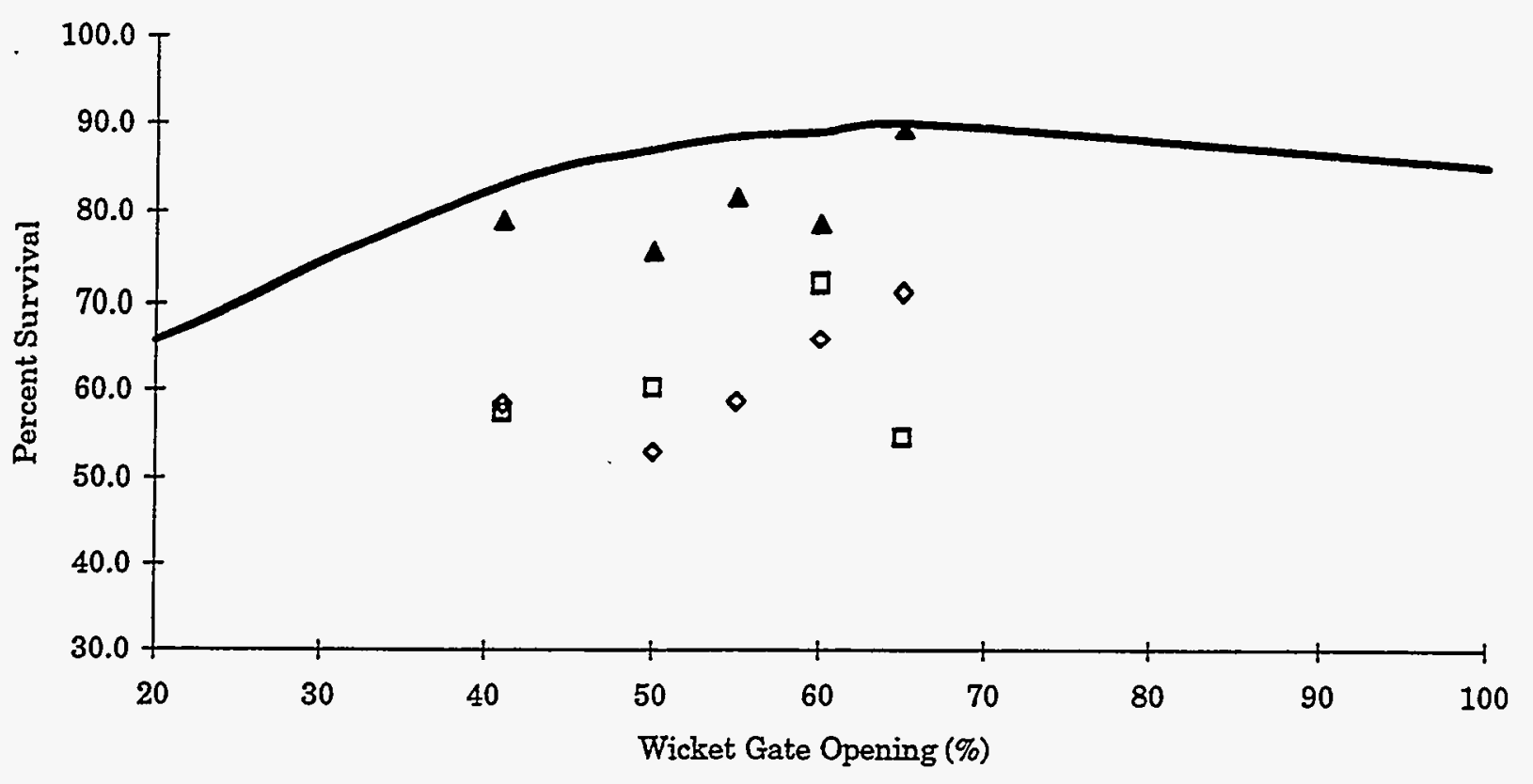

- Turbine Efficiency (\%) $\quad$ 口 Chinook salmon $\Delta$ Steelhead trout $\diamond$ Rainbow trout

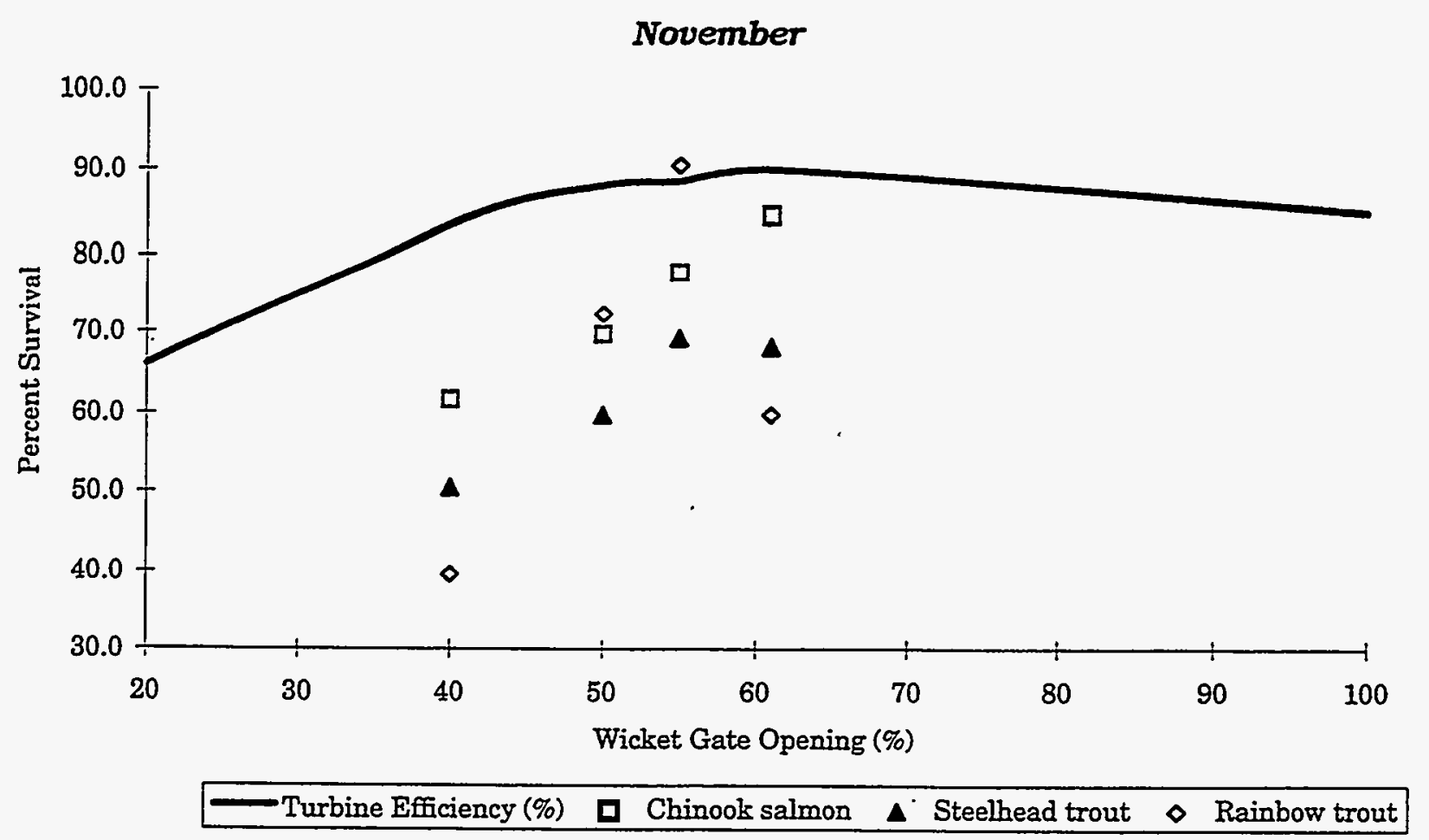

Figure 4.4.11-1 Survival Data at Shasta 


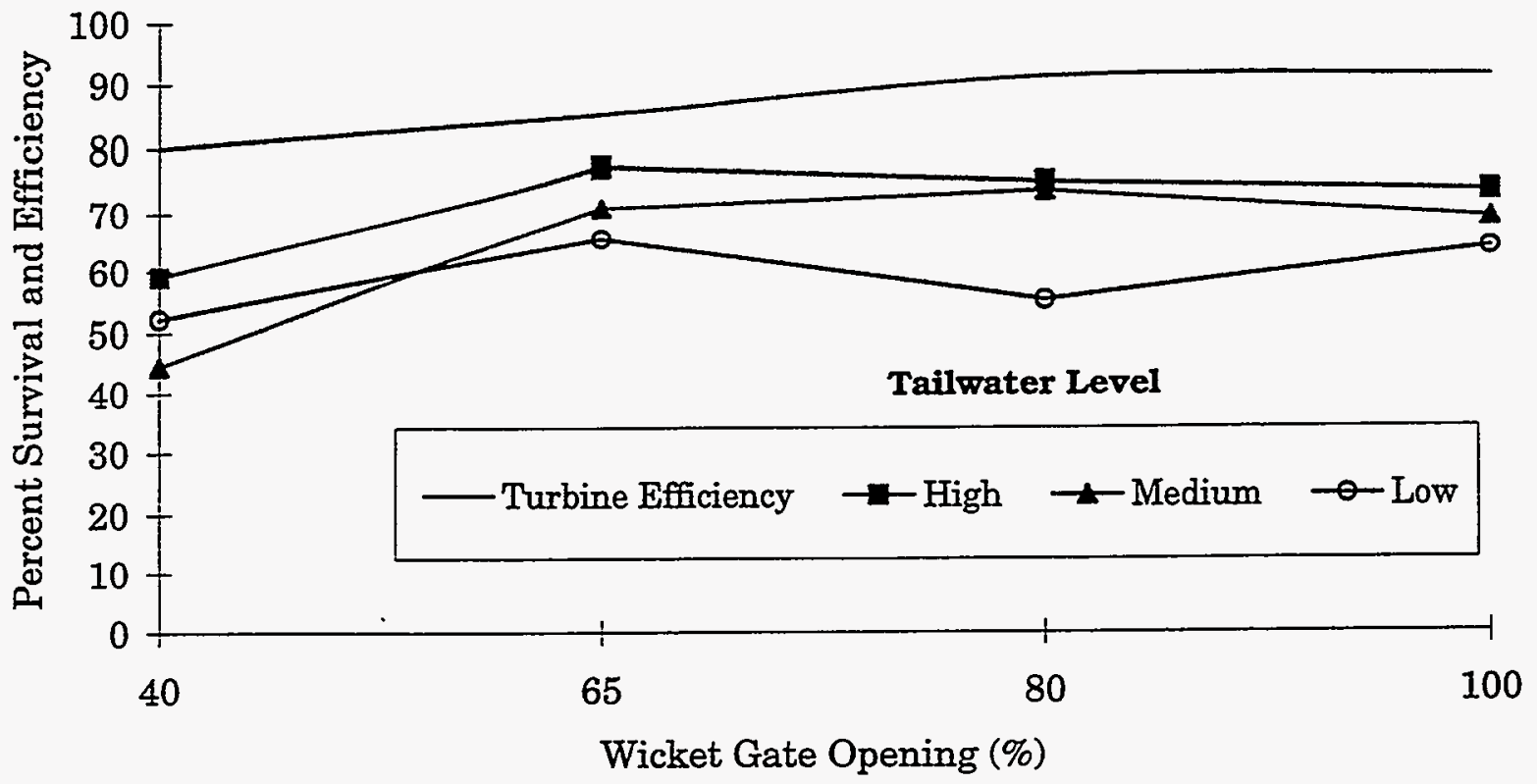

Figure 4.4.11-2 Survival Data at Cushman No. 2, 1960 Data

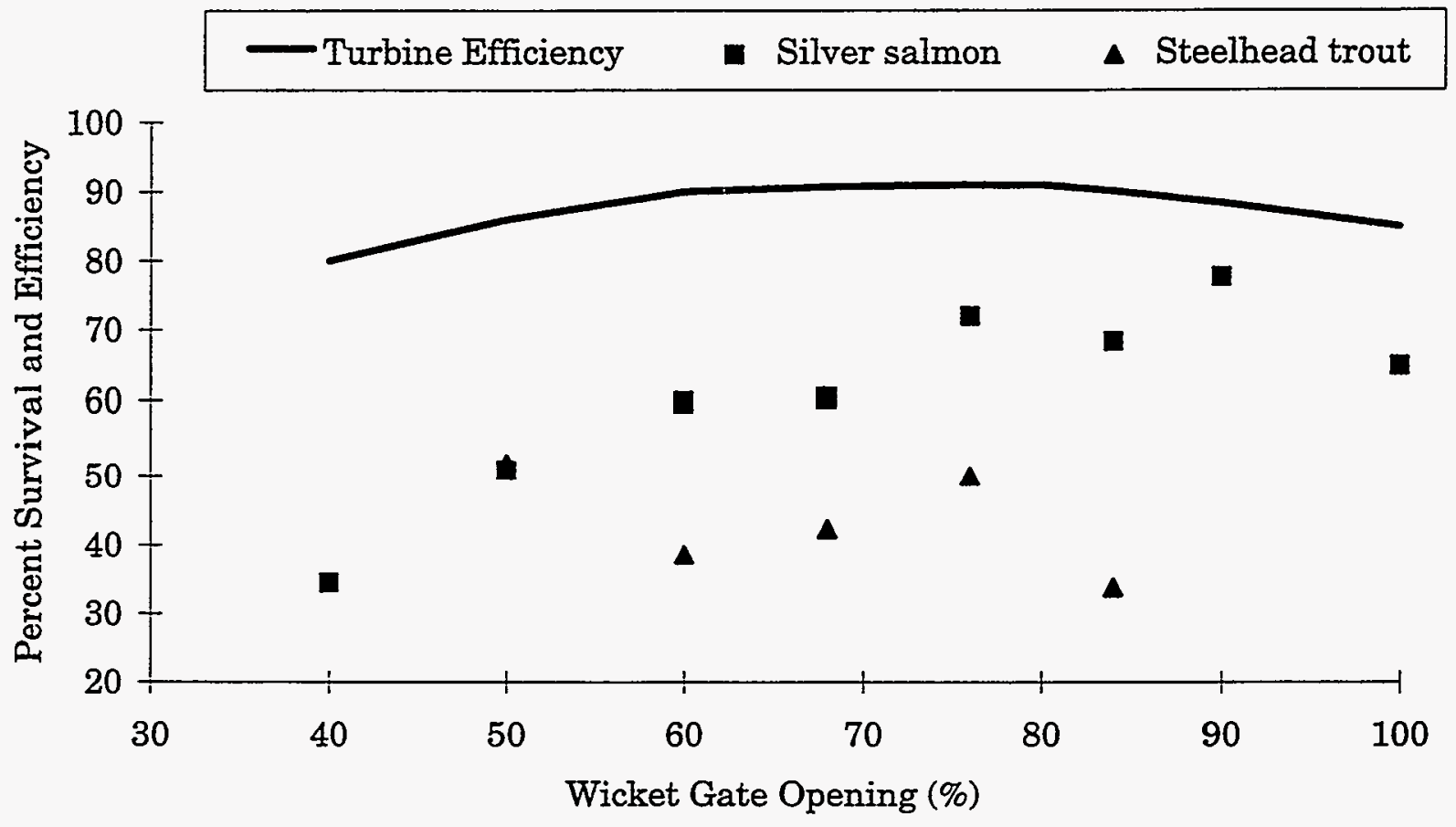

Figure 4.4.11-3 Survival Data at Cushman No. 2, 1964 Data 
Development Of Environmentally Advanced Hydropower Turbine System Design Concepts Section 4.0

\subsection{SURVIVAL THROUGH SLUICES/SPILLWAYS}

\section{Summary}

Fish survival in passage through exit routes without moving parts (sluices, spillways, etc.) is not $100 \%$ at all sites; most likely because these passage routes were constructed primarily to transport excess river flow and debris, and not fish. Survival rates vary between sites and may be reflective of differences in unique physical and hydraulic features. However, fish transported through these conduits must contend with the potential effects of the same hydraulic forces (e.g., impact velocity, pressure change, shear, cavitation, etc.) as those passing the turbines. Thus, fluid related information obtained at these passage routes may be applied to the Advanced Hydropower Turbine System Program.

\section{Discussion}

Historically, spillways and sluiceways (Figures 4.5-1 and 4.5-2) at hydroelectric dams were deemed strictly as conduits for transporting excess river flow or debris with little focus on their potential for fish passage routes. In recent times, however, these conveyances are increasingly viewed as viable fish passage routes. Consequently, at many hydro dams, particularly on the Columbia River Basin, spill is used as an alternative to turbine passage because of reported higher survival rates for juvenile salmonid emigrants (Bell 1981; Eicher Associates 1987). However, spill is expensive in terms of lost power generation and with some spillway configurations can result in potentially lethal levels of total dissolved gas in the river. Additionally, many spillways are equipped with bottom opening tainter gates and the surface oriented fish, such as salmonids, may not be effectively guided by these spilways. These fish would be required to sound approximately 6 to $18 \mathrm{~m}$ (20 to $60 \mathrm{fi})$ to exit at such a conventional spillway.

To alleviate the dissolved gas saturation problem and to take advantage of the surface oriented behavioral patterns of fish, two major structural modifications of spillways have occurred at some hydro dams: installation of flow deflectors for total dissolved gas abatement (Figure 4.5-3), installation of top flow structures such as overflow weirs (Figure 4.5-4) or vertical slots to improve spill effectiveness for attracting surface oriented salmonid emigrants. Although there are no moving parts that fish encounter in passage through sluices or spillways, they are subjected to varying hydraulic forces (e.g., turbulence, pressure changes, variable terminal velocity), potential impact collisions with rock outcrops, abrasive surfaces, obstructions in flow path, etc. (Rugglés and Murray 1983). Therefore, the survival data obtained at these passage routes can provide some insight into factors (exclusive of mobile mechanical parts) that affect fish survivability and perhaps a better perspective on survival through turbines. The importance of impact velocity, pressure change, cavitation, and collision with structural objects has been noted mostly in laboratory experiments (Muir 1959; Harvey 1963; Groves 1972; Bell et al. 1972; Tumpenny et al. 1992). However, some recent survival studies at several hydro projects where fish were immediately recaptured upon passage through sluices and spillways provide empirical estimates of survival, injury types, and probable sources of injury/mortality (RMC 1992f, Normandeau Associates et al. 1996b,c,d). 


\subsubsection{SPECIFIC DATA}

Survival rates of fish passage through siuices or over spillways have been estimated almost exciusively for juvenile migratory fish (e.g., salmon, American shad, and herrings) and only at limited sites. However, comparable survival rates in passage through turbines are not available from all sites. Table 4.5-1 shows some recent fish survival data along with the discharge, estimated impact velocity, species size, and head. The velocity data in Table 4.5-1 were estimated from the equation $v=\sqrt{2 g h}$, where g=gravitational acceleration, $10 \mathrm{~m} / \mathrm{s}(32 \mathrm{ft} / \mathrm{s})$, and $h=h e i g h t$ (Bell 1972). As in the case of turbine passage survival database little species-related differences are evident. Additionally, the effects of head, discharge, or fish size on survival are difficult to discern from these limited data.

The effect of estimated impact velocity entering stilling basin on fish survival can differ with site, exit route, flow volume, and spillbay configuration Table 4.5-1. At spillways, with estimated impact velocities $18 \mathrm{~m} / \mathrm{s}$ (60 ft/s) entering stilling basin survival exceeded 95\%; while velocities greater than $18 \mathrm{~m} / \mathrm{s}(60 \mathrm{ft} / \mathrm{s})$ seemed to produce variable results depending upon the type of structural modification and flow volume. At Wanapum Dam, the survival was $92.0 \%$ at $57 \mathrm{cms}(2,000 \mathrm{cfs})$ and $96.9 \%$ at $114 \mathrm{cms}(4,000 \mathrm{cfs})$ in passage through a spillbay equipped with an overflow weir (estimated velocity was $19 \mathrm{~m} / \mathrm{s}$ or $62 \mathrm{ft} / \mathrm{s}$ ). At sluiceways, survival ranged from $93 \%$ to $99 \%$; the impact velocities ranged from 13 to $22 \mathrm{~m} / \mathrm{s}$ ( 41.6 to $71.1 \mathrm{fts})$. The three lowest survivals $(92.0 \%, 93.0 \%$, and $93.3 \%)$ observed included for Atlantic salmon in passage through sluiceways at Vernon and Wilder dams, and chinook salmon in passage through an overflow weir at Wanapum Dam, respectively. Results of some laboratory experiments reported in Bell (1984) and reproduced here in Figure 4.5-5 show that velocities of up to $18 \mathrm{~m} / \mathrm{s}$ (60 ft/s) entering water had little effect on fish survival, however, velocities of $15 \mathrm{~m} / \mathrm{s}(50 \mathrm{ft} / \mathrm{s})$ striking against a solid object caused about $50 \%$ mortality. Velocities of $<6 \mathrm{~m} / \mathrm{s}(20 \mathrm{ft} / \mathrm{s})$ striking solid objects caused little mortality. Turnpenny et al. (1992) reported similar findings for several species.

The potential effect of differential flow volume was observed only at two sites, Wilder and Wanapum dams (Table 4.5-1). The sluice passage survival of Atlantic salmon at Wilder Dam was lowest at intermediate spill volume tested, $9 \mathrm{cms}$ ( $300 \mathrm{cfs}$ ), and highest at the lowest volume $(6 \mathrm{cms}$ or $200 \mathrm{cfs})$ tested. Water cascades down a sioping concrete channel with two concrete pillars adjacent to the discharge from the sluice. It is possible that passage conditions at $6 \mathrm{cms}$ (200 cfs) were such that the probability of collision with the pillars was lower than at other discharges. At Wanapum Dam overflow weir an opposite effect of increasing flow on survival was observed (Table 4.5-1). At $57 \mathrm{cms}(2,000 \mathrm{cfs})$ the estimated survival was only $92 \%$ but increased to $96.9 \%$ at $114 \mathrm{cms}(4,000 \mathrm{cfs})$. Whether the hydraulic conditions improved at the higher spill volume is unknown. Field observations indicated great turbulence in the area between the overflow weir and tainter gate, but the difference in turbulence levels between $57 \mathrm{cms}(2,000 \mathrm{cfs})$ and 114 cms $(4,000 \mathrm{cfs})$ could not be quantified.

The principal causal mechanisms for injury/mortality to fish transported via spillways have been attributed to shear forces, turbulence, rapid deceleration after high terminal velocity, impact against the base of the spillbay, scraping against the concrete face of the spillbay, and rapid pressure change (Ruggles and Murray 1983). Although experiments have not been conducted to identify the relative importance of these factors in affecting fish condition/mortality at most spillways, reported injury types sustained included eye damage, embolism, hemorrhaging, and abrasions (Ruggles and Murray 1983). At Wanapum Dam, the scrape, cut, and bruise wounds were suspected to be caused by the fish physically contacting structural components at the spillbay including the frame of the weir, tainter gate, and flow deflector (Normandeau Associates et al. 1996d). The internal injuries (ruptured or hemorrhaged organs) could have resulted from pressure changes; bulging or hemorrhaged eyes have been attributed to pressure effects, as have corroborating symptoms such as expanded or burst air bladders and entrapped gas bubbles (Cramer and 
Oligher 1964). A relatively high proportion of suspected pressure-related injuries was observed on overflow weir and sluiceway fish (Figures 4.5-6 and 4.5-7). The passageways for these fish are different; the sluiceway fish do not have to sound and presumably are not subject to significant pressure changes. However, fish attracted by surface currents to the overflow weir must sound to exit; thus, these fish may be exposed to pressure changes. Wanapum spillbay 2 is equipped with.a flow deflector and the overflow weir was characterized by severe turbulence. Sluiceway fish experience a substantial vertical drop and the plunge pool is quite turbulent (Figure 4.5-1).

Injury rates and types may vary with site-specific exit route characteristics (Normandeau Associates et al. 1996b,c). At The Dalles Dam, chinook salmon smolts exhibited primarily hemorrhaging eyes and body injuries (Figures 4.5-8 and 4.5-9) in passage through an overflow weir, the estimated injury rate was $2.5 \%$. At another spillbay modified with an "I" slot configured overfiow weir, the injury was characterized by hemorrhaging and bulging eyes; the injury rate was estimated at $1.5 \%$. The primary causative mechanisms for fish injury was attributed to collisions with structural components of the spillbay (tainter gate, baffles, or downstream end sill) and large boulders in the stilling basin. No observed injury was attributed to pressure, cavitation, or shear-related causes. At the unmodified spillbay the injury rate was 0.5\% (Normandeau Associates et al. 1996c).

At Bonneville Dam, the injury rates of chinook salmon smolts in passage through a spillbay equipped with a flow deflector and a standard spillbay were similar (1.8\% and $2.2 \%$, respectively) and were attributed to contact with flow deflectors, tainter gates, or downstream dentates. Which of the structural components contribute most to injuries was not apparent (Normandeau Associates et al. 1996b). 
Table 4.5-1

Short-term (one hour) fish survival over spillways or ice-log sluices at hydro projects. All studies utilized balloon tag-recapture technique.

\begin{tabular}{|c|c|c|c|c|c|c|}
\hline Station/Location & $\begin{array}{l}\text { Passage } \\
\text { Route }\end{array}$ & Species & Height (m) & $\begin{array}{l}\text { Estimated } \\
\text { Velocity }(\mathrm{m} / \mathrm{s})^{\star}\end{array}$ & $\begin{array}{l}\text { Discharge } \\
\text { (cms) }\end{array}$ & Survival (\%) \\
\hline Bellows Falls, VT & Sluice & Atlantic salmon & 18.0 & 18.7 & 8.5 & 96.0 \\
\hline Wilder, VT & Sluice & Atlantic salmon & 15.8 & 17.6 & 5.7 & 99.0 \\
\hline Wilder, VT & Sluice & Atlantic salmon & 15.8 & 17.6 & 8.5 & 93.0 \\
\hline Wilder, VT & Sluice & Atlantic salmon & 15.8 & 17.6 & 14.2 & 98.0 \\
\hline Vernon, VT/NH & Sluice & Atlantic salmon & 8.2 & 12.7 & 1.1 & 93.3 \\
\hline Cabot, MA & Sluice & American shad & 21.0 & 20.3 & $\begin{array}{l}6.4 \\
0.0\end{array}$ & 98.0 \\
\hline Crescent, NY & Spillway ${ }^{\star \star}$ & Blueback herring & 4.0 & 8.8 & 1.1 & 100.0 \\
\hline Bonneville, WA & Spillway ${ }^{\star \star}$ & Chinook salmon & 7.6 & 12.2 & 339.8 & 100.0 \\
\hline Bonneville, WA & Spillway $^{\star \star}$ & Chinook salmon & 7.6 & 12.2 & 339.8 & 100.0 \\
\hline The Dalles, WA & Spillway ${ }^{\star *}$ & Chinook salmon & 15.2 & 17.3 & 297.4 & 95.4 \\
\hline The Dalles, WA & Spillway** & Chinook salmon & 15.2 & 17.3 & 297.4 & 99.2 \\
\hline The Dalles, WA & Spillway** & Chinook salmon & 15.2 & 17.3 & 127.4 & 98.9 \\
\hline Wanapum, WA & Spillway ${ }^{* *}$ & Chinook salmon & 6.4 & 11.2 & 121.8 & 99.6 \\
\hline Wanapum, WA & Spillway ${ }^{\star *}$ & Chinook salmon & 6.4 & 11.2 & 121.8 & 95.7 \\
\hline Wanapum, WA & Spillway** & Chinook salmon & 18.3 & 18.9 & 56.6 & 92.0 \\
\hline Wanapum, WA & Spillway ** & Chinook salmon & 18.3 & 18.9 & 113.3 & 96.9 \\
\hline Wanapum, WA & Sluice & Chinook salmon & 24.1 & 21.7 & 56.6 & 97.4 \\
\hline
\end{tabular}

Estimated velocity $(V)=2 g h ; g=$ gravitational acceleration, $h=$ head or height (Bell et al. 1972).

** Modified spillbay with flow deflectors or overflow weir. 


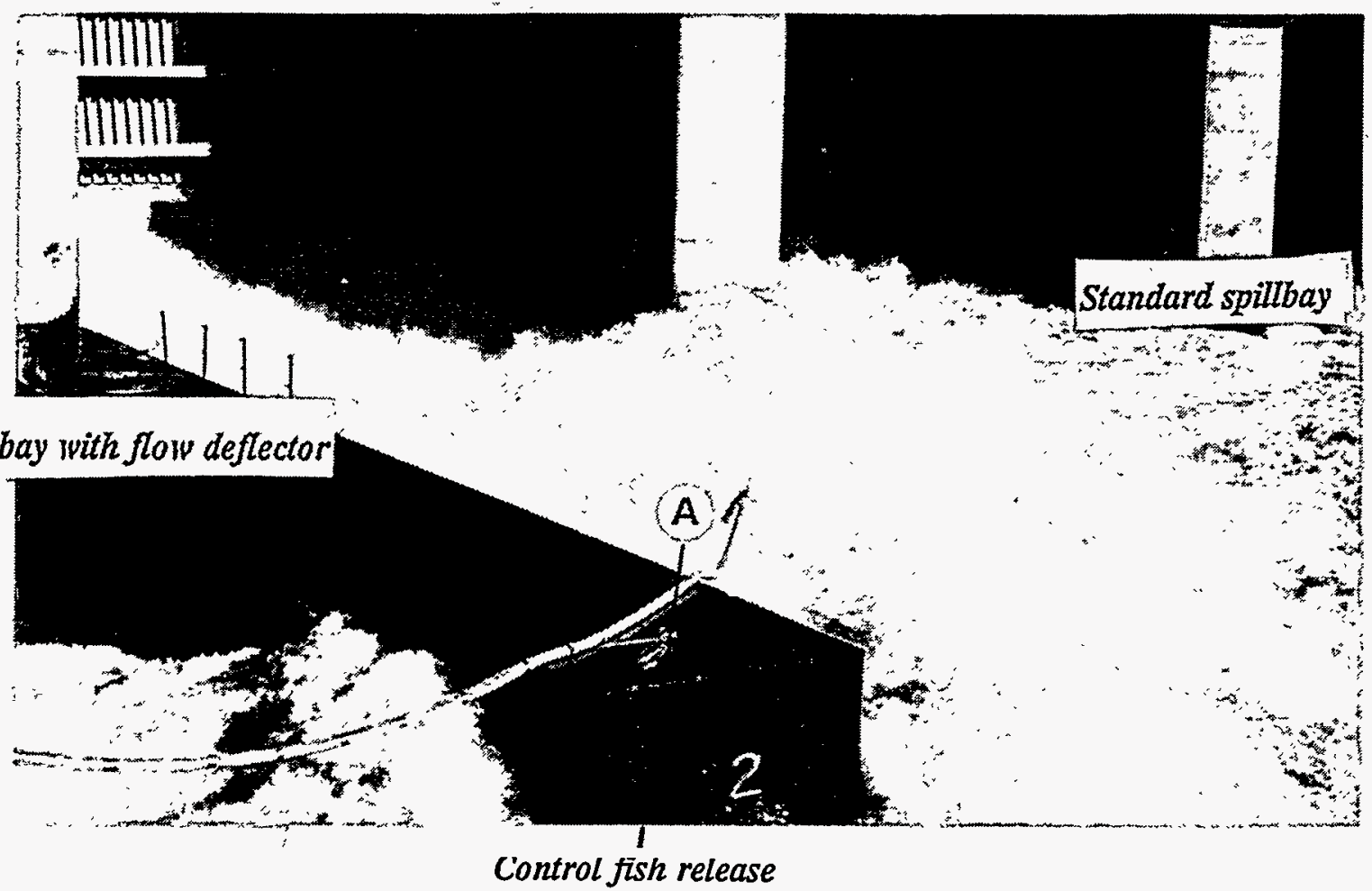

Spillbay with flow deflector

Control fish release

Sluice fish release

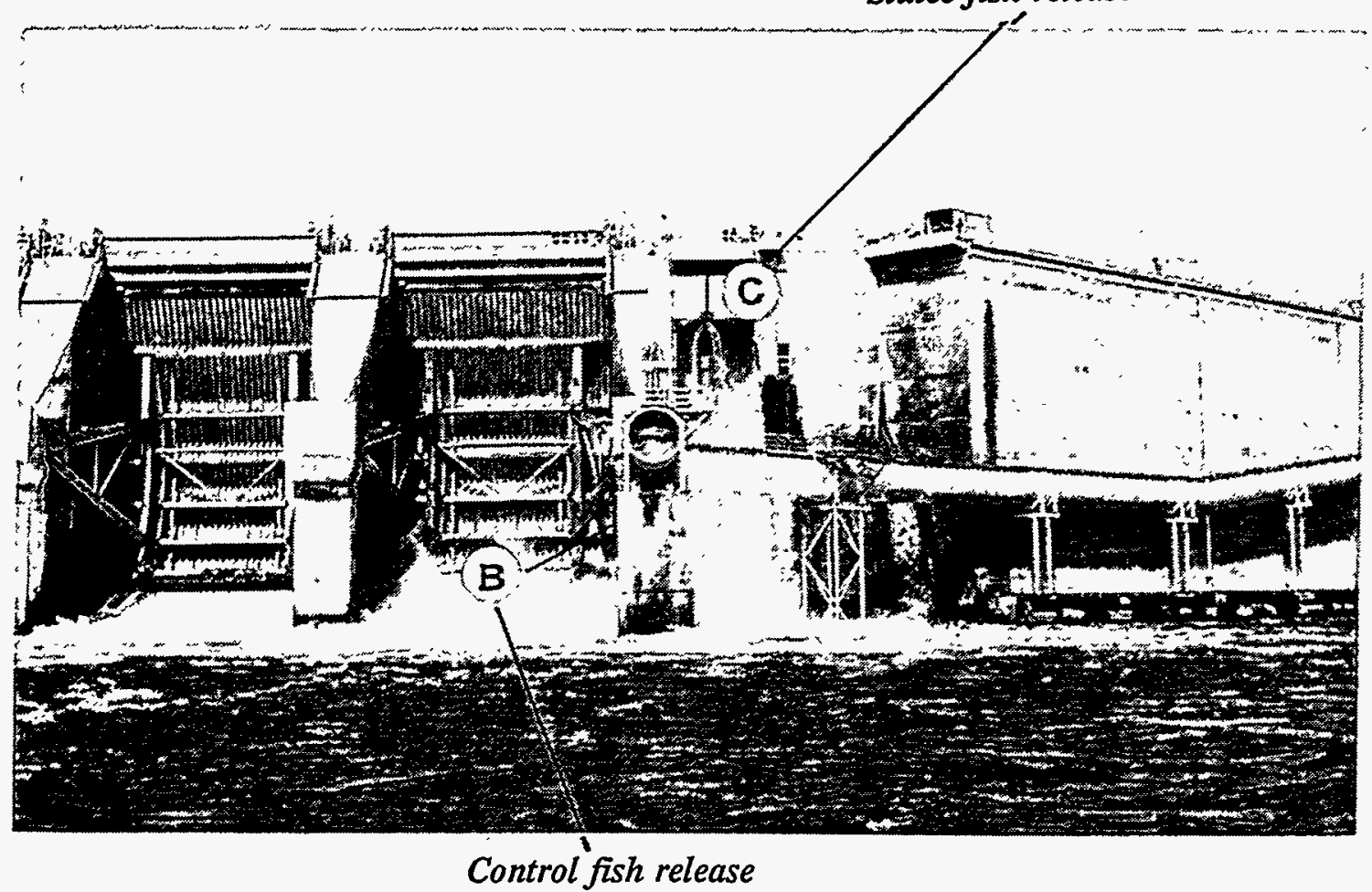

Figure 4.5-1

Spillbay and Sluice Discharge Conditions. From Normandeau et al. (1996d) 

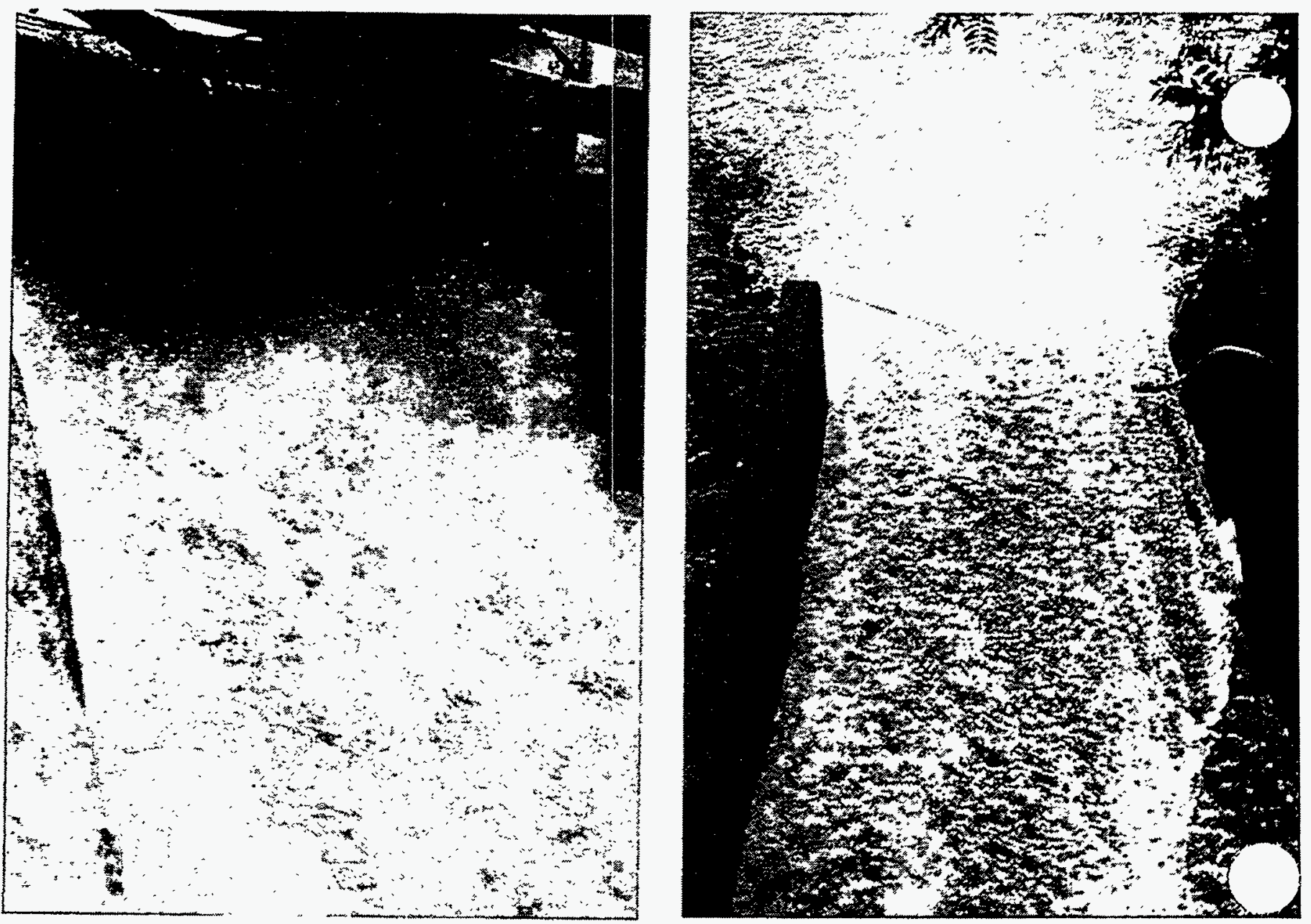

Deflection spill at bottom of sluice

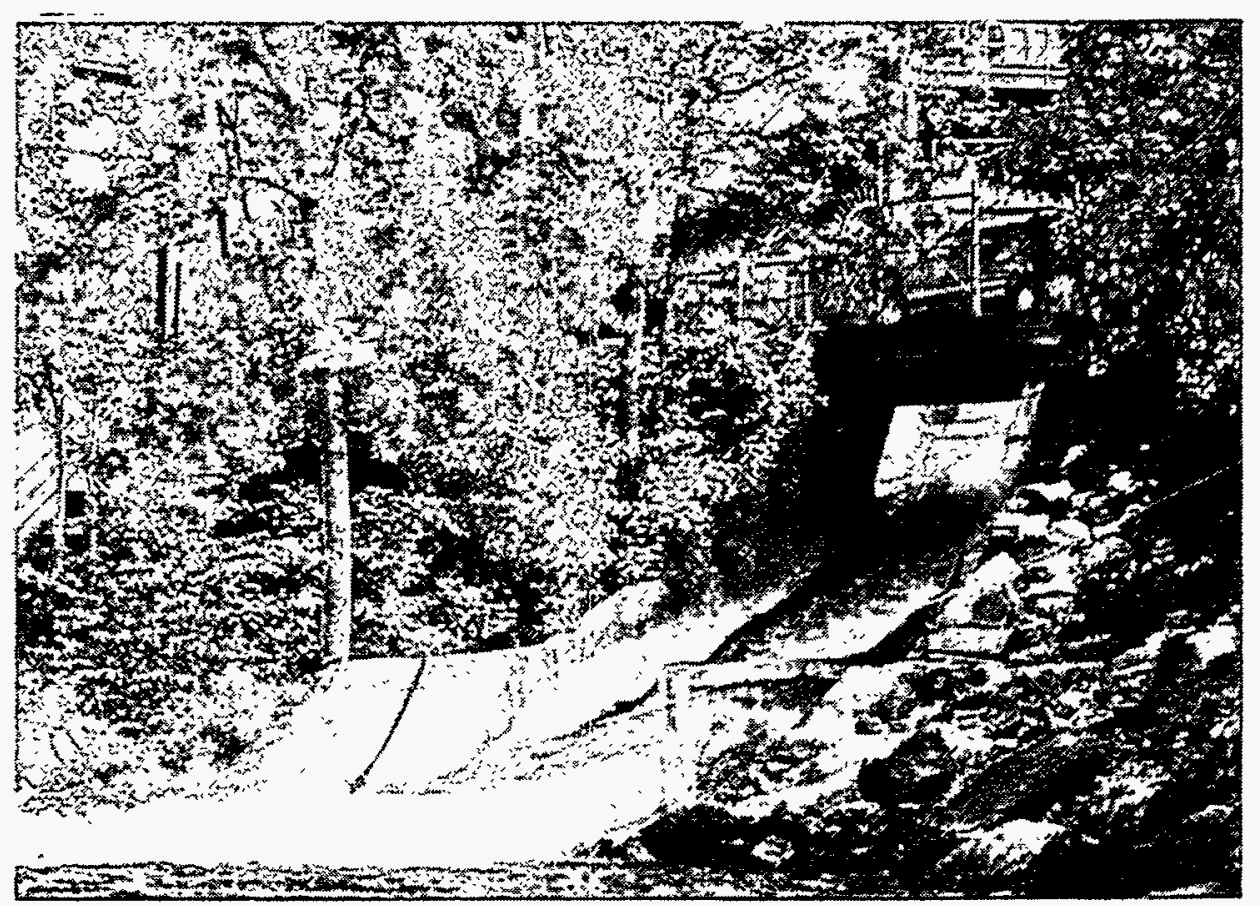

Figure 4.5-2 Log sluice bypass; note deflection spill in C. From RMC (1994c). 


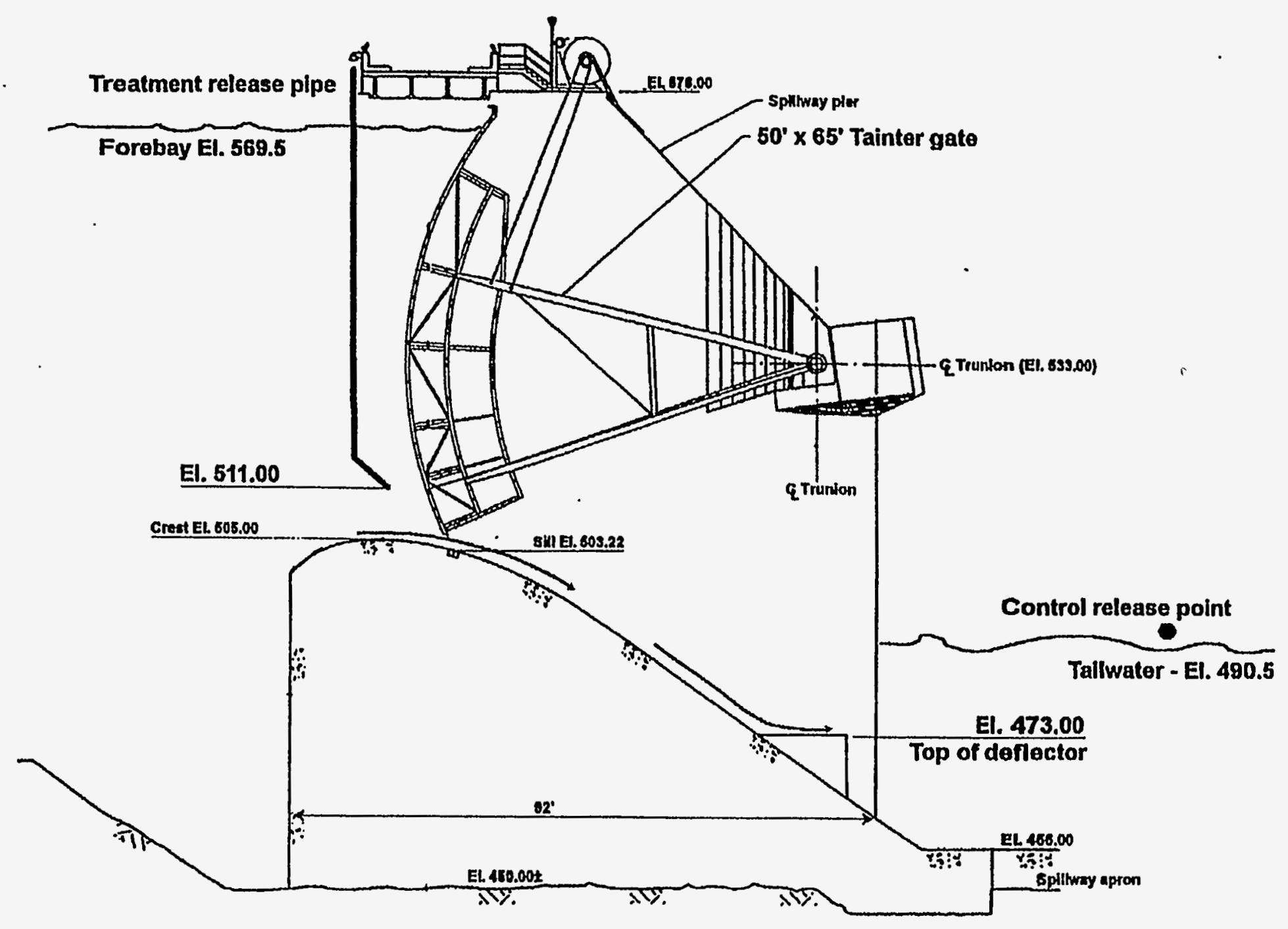

Figure 4.5-3

Schematic of a spillbay equipped with flow deflector. 

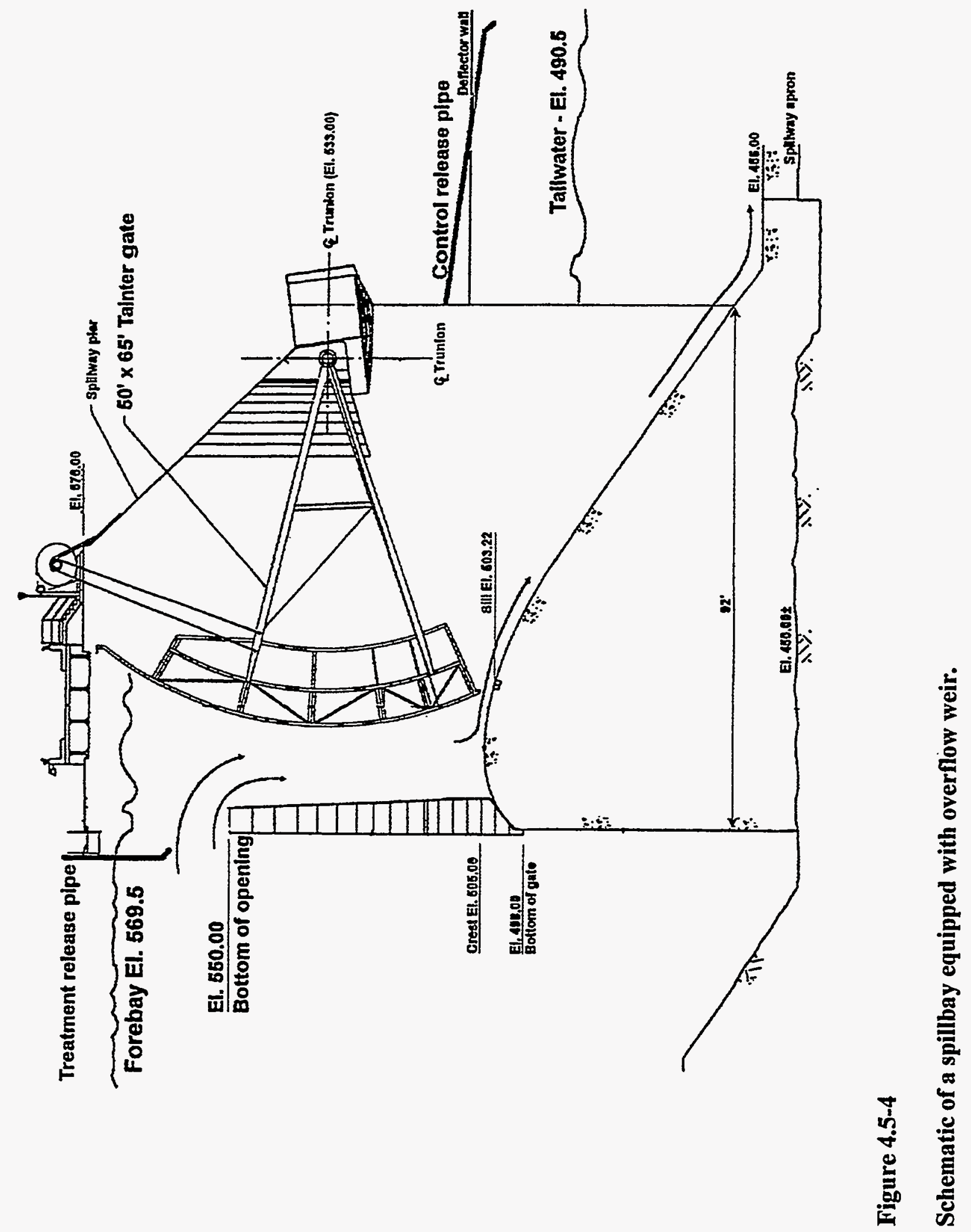

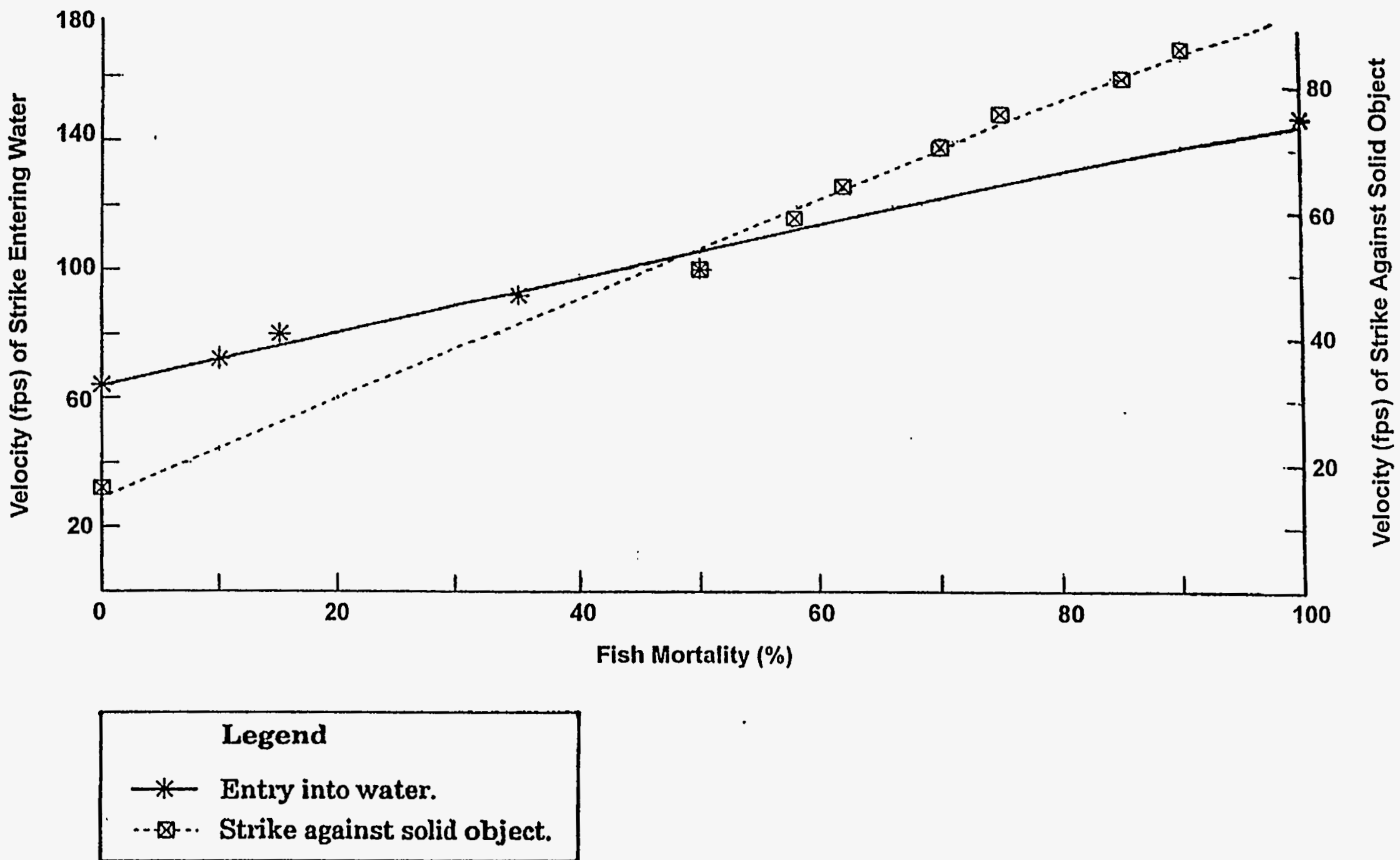

Figure 4.5-5

Relationship of velocity (fps) and fish mortality. (From Bell 1991). 


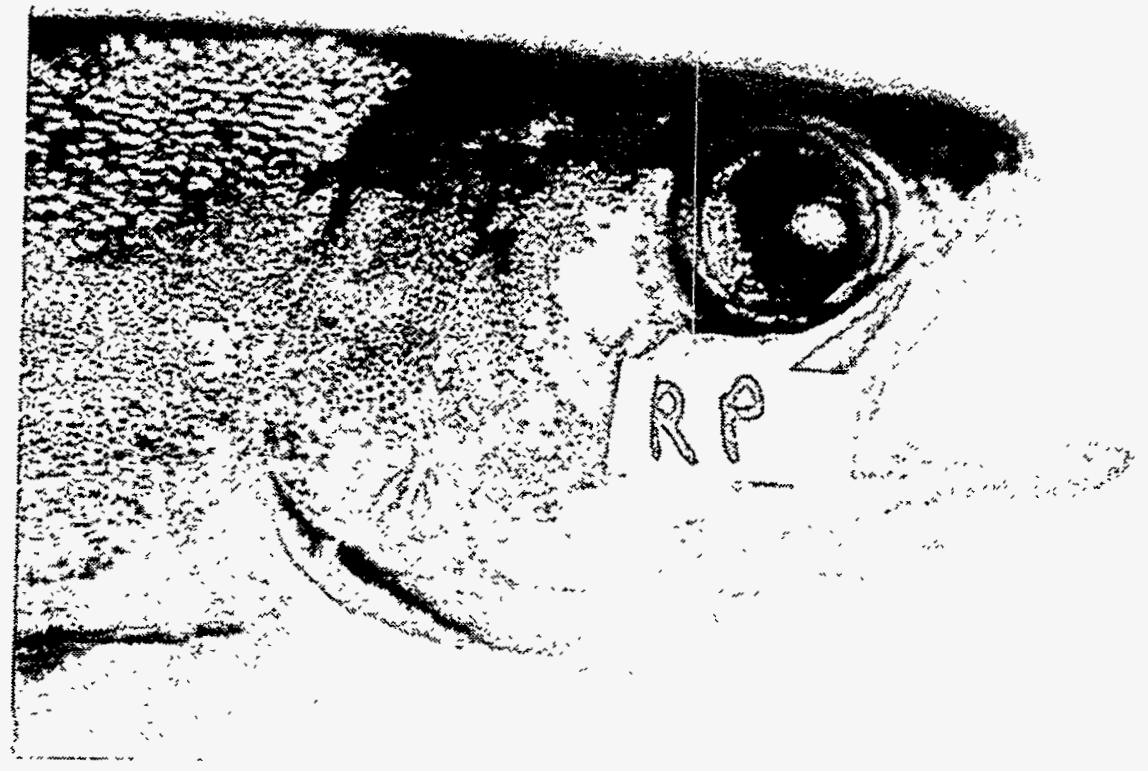

Figure 4.5-6

Example of pressure related injury (hemorrhaged eyes) at a spillway. From Normandeau Associates et al. (1996d). 


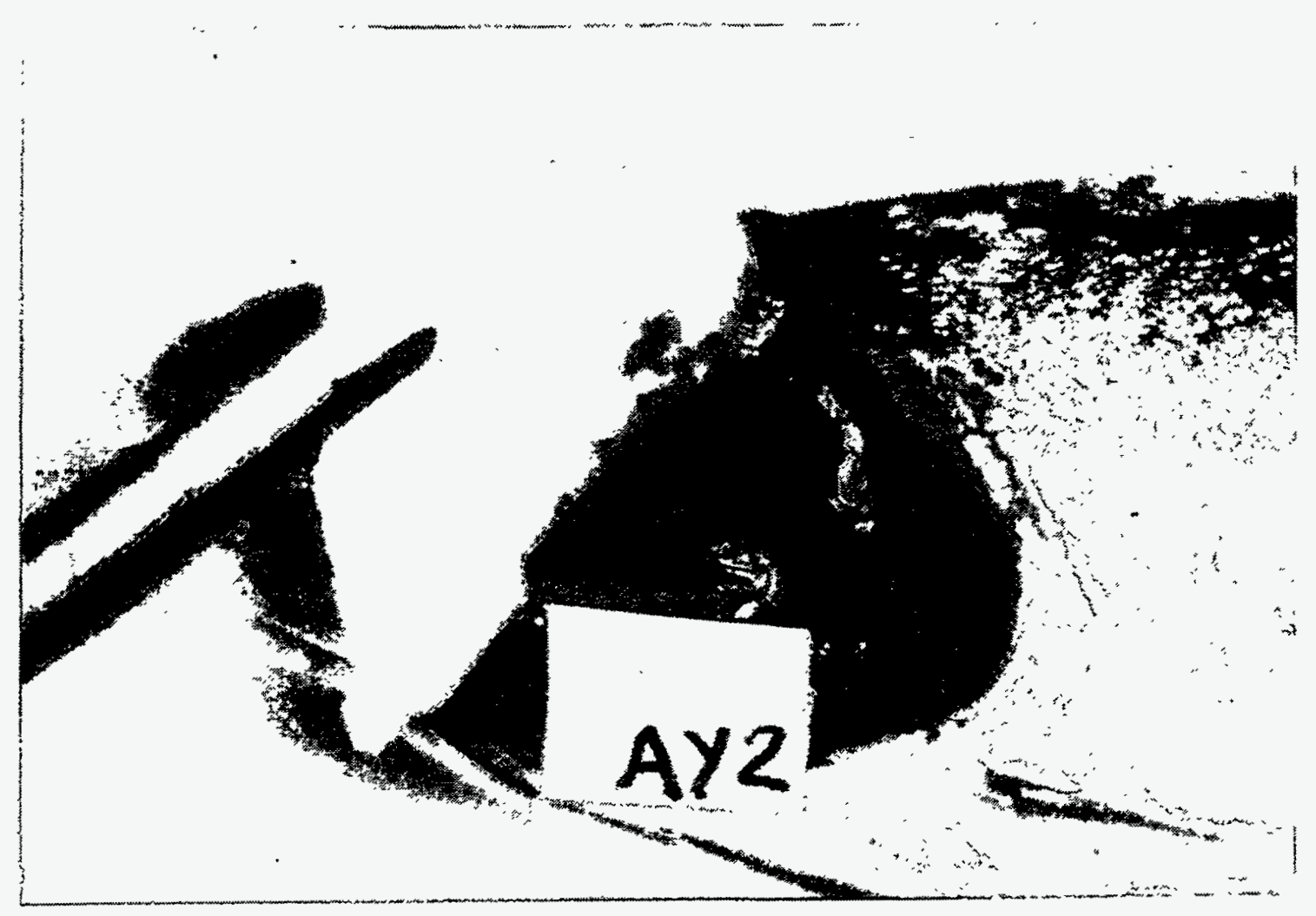

Figure 4.5-7

Example of probable shear/mechanical injury in passage at a spillway. Note torn/bent left operculum. From Normandeau Associates et al. (1996d). 


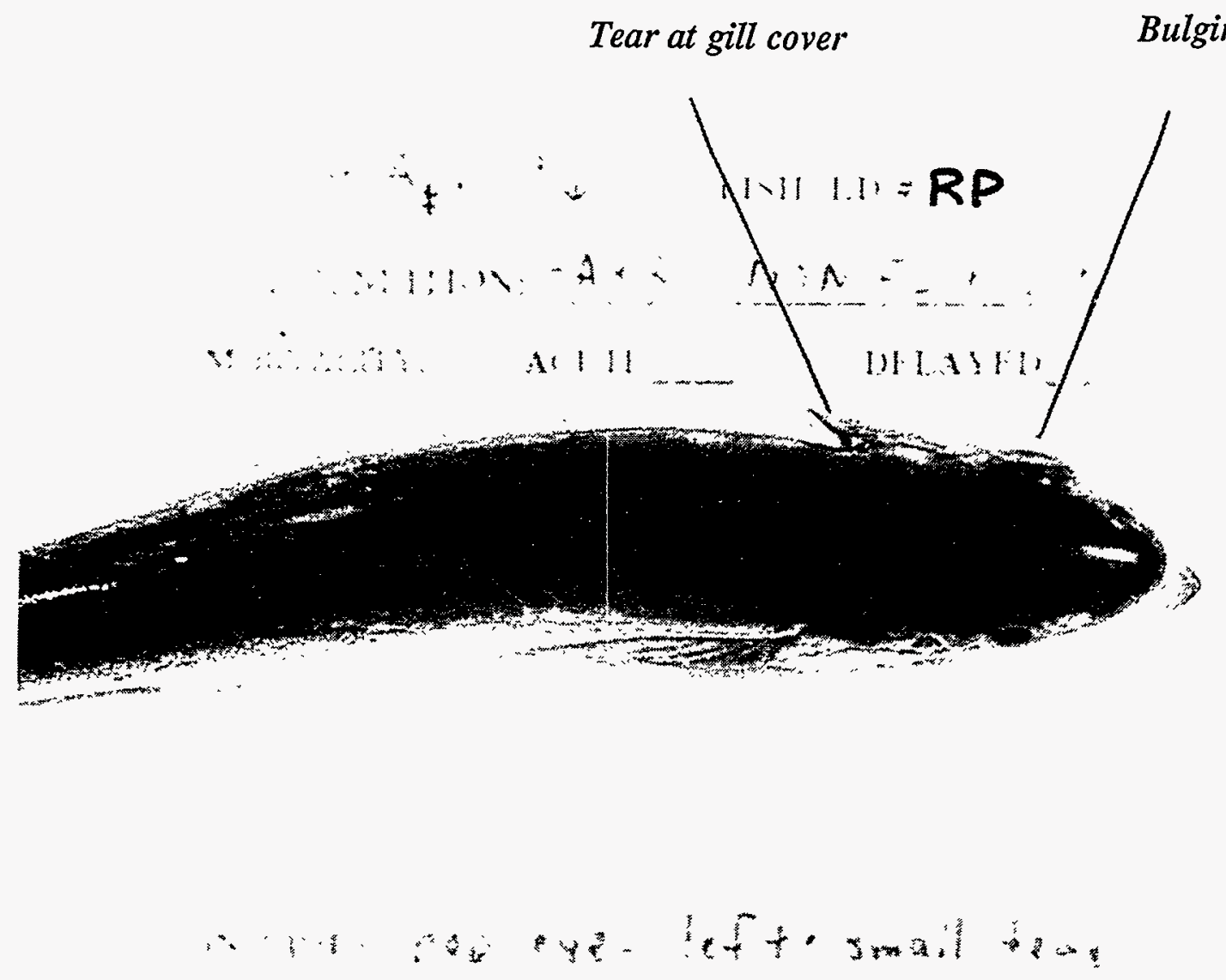

Figure 4.5-8

Example of pressure/shear injuries in passage at a spillway with flow deflector. Note bulging left eye, tear at top of gill cover. From Normandeau Associates et al. (1996d). 


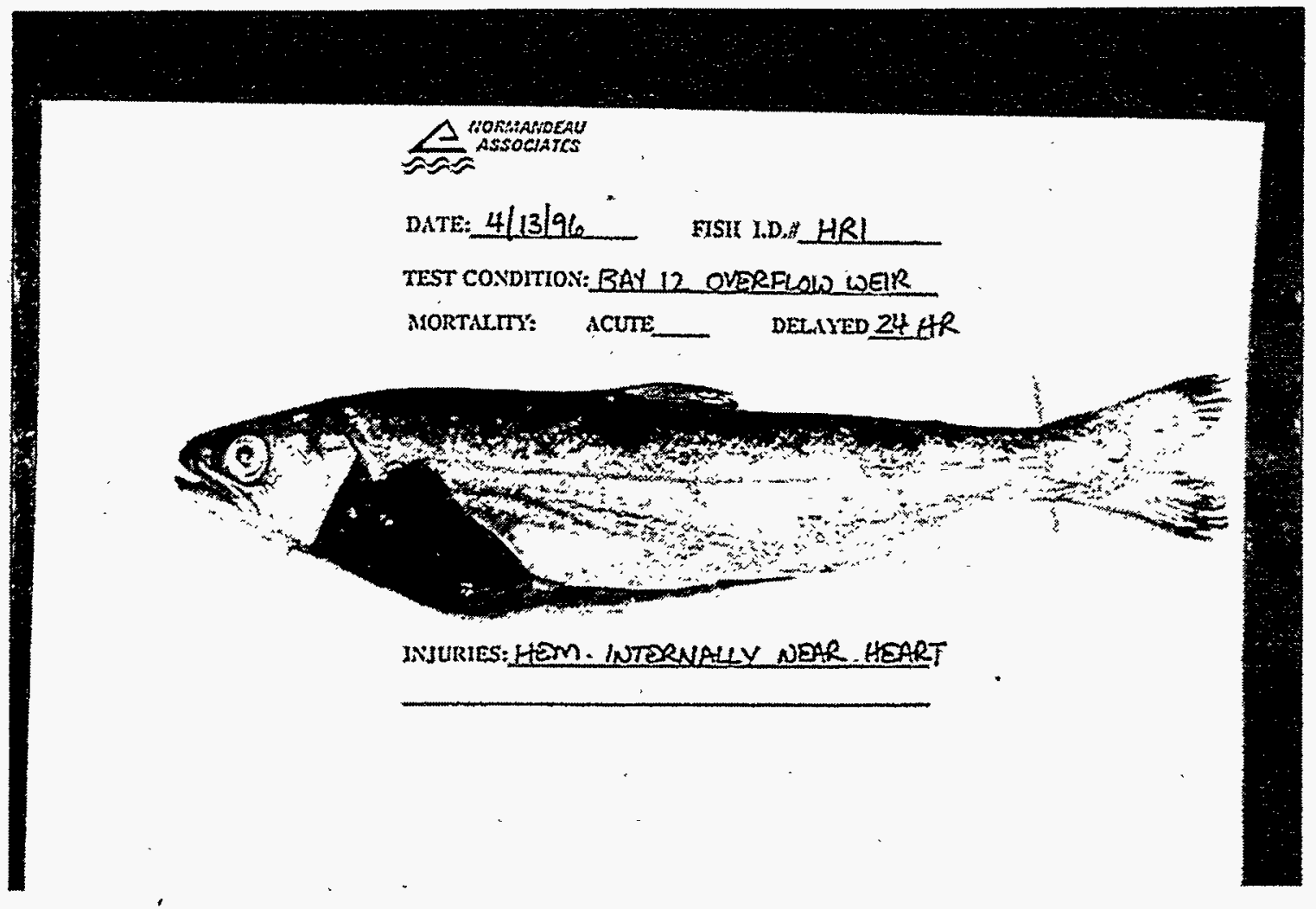

Figure 4.5-9

Example of injuries sustained by fish in passage through overflow weir at Wanapum Dam. From Normandeau Associates et al.(1996d). 


\subsection{PERSPECTIVE ON IMPROVEMENTS OF FISH PASSAGE SURVIVAL}

\section{Summary}

The fish passage survival of any turbine design should be evaluated against a standard of comparison (benchmark) survival rate based on the "best of class" alternatives for passage including bypass systems or spillways, other turbines of similar type with similar LD ratios, or other turbines of any type and characteristic. Fish passage survival of any modified turbine design should be evaluated angainst a benchmark where the passage survival has been evaluated in a before and after manner using comparative controlled experiments. The Rocky Reach experiments with the new turbine show that the relative effectiveness of engineering solutions (e.g., closure of gaps at the trailing edge of the runner blade) can be quantified by comparative controlled experiments performed before and after implementation of engineering solution to enhance fish survival.

\section{Discussion}

A quantitative evaluation of a turbine design for its enhanced fish passage survival capability should be an integral component of the AHT program. It should include considerations for the establishment of guidelines for "best of class" survival and for "comparative" survival and use these benchmarks to determine a magnitude of improvement that is achievable or possible or that was obtained, and could contain the following steps:

1. establishment of "best of class" benchmarks for survival rates; these may be established using the existing databases (passage through turbines or alternative exit routes such as bypasses, spillbays, ice-log sluiceways, etc.), or be based on new experiments utilizing well designed comparative controlled experiments. These "best of class" benchmarks would establish the maximum possible limit of improvement in fish survival. For example, if the benchmark is established at $95 \%$ at a hydroelectric project scheduled for rehabilitation, then the possible improvement would not be measured based on the ideal of $100 \%$ survival, but rather on the difference between the actual survival and the benchmark. Whether this benchmark survival rate is achievable for the particular installation is unknown but it can help in comparisons with other acceptable passage alternatives.

2. actual tests to determine the fish friendliness of the modified design. The same experimental protocols used in establishment of the "comparative" benchmark survival rates (in this case, the unmodified design) should again be used to obtain the new data.

The passage survival study at Rocky Reach Dam on chinook salmon smolts (Normandeau Associates and Skalski 1996), having well designed comparative controlled experiments, used the "comparative" benchmark to evaluate whether changes in fish injury/survival due to engineering design modifications of turbines can be detected. Results from the secondary fish releases showed that the zonal injury rate was reduced from $5 \%$ to $2.8 \%$ and a minimal improvement in survival rate of $4.4 \%$ for chinook salmon smolts introduced at $3 \mathrm{~m}$ (10 ft) depth below the intake ceiling after a temporary engineering solution was implemented (a steel wedge was placed to close the gap between the runner trailing edge and the hub) could be inferred from the reported data. Although controls were not released concurrently with the secondary releases to evaluate the effects of tagging, handling, and induction results from primary releases of chinook showed control survival rate exceeded $99 \%$. The probable sources of zonal injuries changed as well; prior to the interim engineering solution most injuries appeared to be pressure- and shear-related. After the modification most of the injuries were attributed to probable mechanical causes. Obviously, the hydraulic conditions were altered due to "re-engineering" the turbine's local geometry by closing the gap and changing the zonal injury mechanisms. 


\subsection{SUMMARY AND CONCLUSIONS}

Section 4 combined insights of biologists and turbine designers to develop an understanding of the mechanisms of injury/mortality which may occur within hydropower projects. The combined work of the team in discussing the problems and probable causal relationships as well as the reevaluation of existing data and evaluation of new data sets to achieve an insight "oward potential mechanisms led to some new understandings, some perceptions which need further tesing through future experiments, and to some conclusions for design concepts. Based on the material presented, the criteria for improvements to features of existing turbines and for new turbine designs are derived based on causal mechanisms.

\section{Zonal Observations}

The mechanisms of injury/mortality are zonal. Some zones of geometry within the turbine are relatively free of injury/mortality mechanisms. Others exist having high mechanism concentrations. The zones a fish traverses in its passage through a turbine has a significant effect on its injury/mortality. At Rocky Reach, a change to the geometry of the blade-hub zone led to the inference of a $4.4 \%$ increase in survival. At Wanapum, fish that were believed to pass through the runner near the hub zone experienced a $5 \%$ increase on mortality compared to fish passing through the middle zone of the runner.

The development of the blade encounter zone (BEZ) concept and the development of an improved encounter equation with the significant parameter $N \mathrm{~L} / \mathrm{D}$ led to a better analysis technique whereby new correlations and insight were achieved. The BEZ contains a number of injury/mortality mechanisms. Some of these are related to blade strike. Others are related to blade end gaps and local fluid effects. Quantification of exact sources of injury/mortality of fish transported through turbines is difficult due to a lack of controlled experiments and to the fact that the observed symptoms could be manifested by two different sources. Correlation of predictive methods with zonally planned and executed fish passage survival testing is the key to understanding injury mechanisms and developing improved survival prediction methods. Historical studies primarily focused on juvenile salmonids of limited size range. Most studies did not provide turbine operating data or location of fish injection.

In spite of the limitations of the existing data, they are the basis for correlations with the BEZ prediction method. Some of the new insights obtained through this correlation effort are:

- The combined variable N L / D plays a major role. Individual values of N, L, or D play no significant role.

- Because impact velocities related to peripheral speed are always above the critical value where direct impact is assumed to be fatal, peripheral speed has no observable effect on survival in data analyzed for Kaplan turbines, and for Francis turbines plays no obvious role. Other analyses of the shear damage mechanism have provided the physical basis to explain this observation.

- Data did not show a species effect.

A new concept of theoretical avoidable loss (TAL) is introduced, and in tests at Wanapum, has provided a tool to further understand the relationship between fish injury/mortality and energy dissipation within a turbine. For these tests, low values of TAL correlated with high survival. However the TAL concept treats the entire turbine as a single zone and does not lead to specific injury/mortality insight.

A number of zones in a turbine have regions of fluid shear. Effects of shear induced forces have been studied primarily under laboratory conditions. However, these studies indicate that shear effects may be species and size specific and are related to the orientation of fish in the shear zone. Larger sized fish and those facing the water jet appear to suffer less injuries. CFD studies have been used to estimate a threshold value of shear $(450 / \mathrm{s})$. Shear values greater than this threshold or critical value can cause 
mortality. Through a consistent application of the shear principles, a velocity of greater than $5 \mathrm{~m} / \mathrm{s}$ adjacent to a structure will generate a shear zone above the critical value to cause mortality to fish. Velocities of this magnitude can exist in several zones in a typical turbine.

In all zones fish experience pressure changes. Pressure-related injuries appear to be more a function of acclimation history of fish upstream of turbine than passage through turbines per se. At dams $>30 \mathrm{~m}$ or $100 \mathrm{ft}$ head), without hydro turbines, fish transported through bottom sluices or openings suffer decompression trauma (as evident by rupture of air bladder and other internal organs) when rapidly exposed to shallow tailrace conditions. Inside of turbines, the pressure distribution and the rate of change of pressure with time can be determined accurately by CFD analysis. Transit times from the high pressure region at the turbine spiral case inlet to the exit of the draft tube are relatively short, even for big turbines. Transit times through low pressure regions in the runner blade region are quite short. The rapid transit through this low pressure region in the blades is felt to cause no significant mortality. More important is the change in pressure from that to which the fish has become acclimated to a lower value at the draft tube exit.

It is perceived that fish passing through zones with cavitating flow fields can be damaged by fluid effects arising because of cavitation and subsequent vapor bubble collapse. The turbine operating condition that coincides with the onset of cavitation can be determined by CFD analysis. Designs for existing turbines can be developed to eliminate cavitation while increasing power production. Operational guidelines to minimize operation in cavitation regimes will reduce maintenance costs and reduce fish mortality associated with fluid induced loading on fish bodies related to cavitation.

Physical model testing and CFD analyses have investigated the impact of the presence of fish screens on velocity distributions in turbine intakes. Physical model tests indicate significant redistribution of flow takes place. Fish screen effectiveness testing has shown that the exclusion of fish entering the turbine is not $100 \%$. Therefore, some portion of the unguided fish go under the fish screen. Fish passing the intake under the fish screens may then find themselves in the lower portion of the water column where they are expected to pass through the lower zone on the wicket gates and near the outer radius zone of the blades. These fish will experience a different set of turbine geometry and associated fluid effects compared to fish passing through the upper portion of the wicket gates and the mid to inner regions of the blades. Compared to units without fish screens, the presence of fish screens may cause different-fish survival characteristics.

\section{Operation}

The operation point of turbines has a large effect on fish survival. Tests at Wanapum Dam were designed, conducted and evaluated to shed light on injury mechanisms and how they changed with zone and the point of operation. Peak survival did not coincide with peak efficiency, but occurred at a discharge where the blade strike probabilities were low, while the TAL were at a minimum, and before cavitation began to be significant. The proposition that operation at discharges within $1 \%$ of peak efficiency will maximize fish survival was examined. Historical data that had been generally believed to support this belief, from the Big Cliff and Foster Kaplan turbines, was reanalyzed. This data does not show that maximum fish survival occurs at discharges within $1 \%$ of peak efficiency. Analysis of the complex factors involved reveal tendencies for fish survival that operate in opposing directions. That is, some factors maximize survival at high discharges while other factors maximize survival at low discharges. Tests at the relatively high head turbines at Shasta and Cushman are the only data available to evaluate the effect of Francis turbine operating point on fish survival. Survival does not appear to reach a maximum at discharges less than peak efficiency, but there is no conclusive evidence that survival is 
highest at peak efficiency. The data do not preclude the possibility that the complex factors involved in survival cause maximum survival to occur at discharges greater than the peak efficiency discharge.

Fish survival in passage through exit routes without moving parts (sluices, spillways, etc.) is not $100 \%$ at all sites; most likely because these passage routes were constructed primarily to transport excess river flow and debris, and not fish. Survival rates vary between sites and may be refiective of differences in unique physical and hydraulic features. However, fish transported through these conduits must contend with the potential effects of the same hydraulic forces (e.g., impact velocity, pressure change, shear, cavitation, etc.) as those passing through turbines.

\section{Design Observations}

For Kaplan turbines, blade end gaps are judged to be a significant source of injury/mortality.

Adjustable turbine and generator speed offers the possibility of improved fish survival. Adjusting the speed to compensate for head changes will allow the head coefficient characterizing the turbine performance location on the turbine performance hill curve to be kept at a more favorable operating point than a design having constant speed.

The effects of some of the injury/mortality mechanisms are significantly greater than others and depend on turbine type, size and project variables. For some Kaplan turbine projects, increasing the number of blades to reduce gaps results in a significant fish passage survival improvement. For other projects, decreasing the number of blades may be the correct solution. The effect is project related. Fewer blades for Francis turbines appears to be a feasible design concept. For large turbines passing small fish, high survival can be achieved. For small Francis turbines with large fish, the best solution for fish survival may be to keep the fish out of the turbines.

\section{Other}

The fish passage survival of any turbine design should be evaluated against a standard of comparison (benchmark) survival rate based on the "best of class" alternatives for passage including bypass systems or spillways, other turbines of similar type with similar L/D ratios, or other turbines of any type and characteristic. Fish passage survival of any modified turbine design should be evaluated against a benchmark where the passage survival has been evaluated in a before and after manner using comparative controlled experiments. 


\subsection{REFERENCES}

Abbott, I. H. and A. E. Von Doenhoff. 1959. Theory of wing sections. Dover Publications, Inc., New York, NY.

Acres International, Inc. 1995. Report on the fish entrainment study at the Feeder Dam Hydroelectric Project, November 1993 to November 1994. Vol. I. Prepared for Moreau Manufacturing Corporation, Syracuse, NY.

Alden Research Laboratory (ARL). 1997. Development of a more fish-tolerance turbine runner, Advanced Hydropower Turbine Project. Report prepared for U. S. Dept. Energy, DOE Idaho Operations Office and Hydropower Research Foundation, Inc., DOE/ID-10571.

ASCE 1995. Guidelines for design of intakes for hydroelectric plants. Amer. Soc. Civil Engineering, New York, NY. 469 p.

ASME Hydro Power Technical Committee. 1996. The guide to hydropower mechanical design. $\mathrm{HCl}$ Publications, Kansas City, MO.

Bell, M. C. 1980. Relationship between turbine operating efficiency and fish passage efficiency at Rock Island Dam bulb turbine Unit No. 5. Appendix B in F. W. Olson and V. W. Kaczynski, Survival of downstream migrant coho salmon and steelhead trout through bulb turbines. Report prepared for Public Utility District No. 1 of Chelan County, Wenatchee, WA.

Bell, M. C. 1981. Updated compendium on the success of passage of small fish through turbines. Prepared for U. S. Army Corps of Engineers, North Pacific Division, Portland, OR.

Bell, M. C., A. C. Delacy, and H. D. Copp. 1972. A compendium on the survival of fish passing through spillways and conduits. Prepared for U.S. Army Corps of Engineers, North Pacific Division, Portland, OR.

Bell, C. E., and B. Kynard. 1985. Mortality of adult American shad passing through a 17-megawatt Kaplan turbine at a low-head hydroelectric dam. N. Amer. J. Fish. Mgt. 5:33-38.

Burnham, K. P., D. R. Anderson, G. C. White, C. Brownie, and K. H. Pollock. 1987. Design and analysis methods for fish survival experiments based on release-recapture. American Fisheries Society Monograph 5, Bethesda, MD. 437 p.

Cada, G. F. 1990. A review of studies relating to the effects of propeller-type turbine passage on fish early life stages. N. A. Jour. Fish. Mgt. 10:418-426.

Cada, G. F., C. C. Coutant, and R. R. Whitney. 1997. Development of biological criteria for the design of advanced hydro power turbines. DOE/10-10578. Prepared for Office of Geothermal Technologies, U.S. DOE, Idaho Falls, ID.

Cramer, F. K. and R. C. Oligher. 1964. Passing fish through hydraulic turbines. Trans. Am. Fish. Soc. 90:243-259. 
Dadswell, M. J., R. A. Rulifson, and G. R. Daborn. 1986. Potential impact of large scale tidal power developments in the upper Bay of Fundy on fisheries resources of the northwest Atlantic. Fisheries 11:26-35.

Desrochers, D. 1995. Suivi de la migration de l'anguille d'Amérique (Anguilla rostrata) au complexe, Beauharnois. 1994. [par] MILIEU \& Associès Inc., [pour] le Milieu naturel, vice-présidence Environnement, Hydro-Québec, $107 \mathrm{p}$.

Eicher Associates, Inc. 1987. Turbine-related fish mortality: review and evaluation of studies. Research Project 2694-4. Prepared for Electric Power Research Institute, Palo Alto, CA.

Electric Power Research Institute (EPRI). 1992. Fish entrainment and turbine mortality, review and guidelines. EPRI TR-101231. Project 2694-01. Palo Alto, CA.

Electric Power Research Institute (EPRI). 1997. Guidelines for hydro turbine fish entrainment and survival studies. Prepared by Alden Research Laboratory, Holden, MA.

Feathers, M. G., and A. E. Knable. 1983. Effects of depressurization upon largemouth bass. N.A. Jour. Fish. Mgt. 3:86-90.

Ferguson, J. W. 1993. Improving survival through turbines. Hydro Review 12(2):54-61.

Fisher, R. K., S. Brown, and D. Mathur. 1997. The importance of the point of operation of a Kaplan turbine on fish survivability. Waterpower '97 (in press).

Groves, A. B. 1972. Effects of hydraulic shearing actions on juvenile salmon. Northwest. Fisheries Center, NMFS, Seattle, WA.

Hanvey, H. H. 1963. Pressure in the early life history of sockeye salmon. Ph.D Thesis. University of British Columbia, Vancouver, BC.

Harza Engineering Company. 1991. Escanaba River Hydroelectric Project, Evaluation of Entrainment of fish through turbines at Dam 1 and Dam 3. Prepared for the Mead Corporation, Escanaba, MI.

Harza Engineering Company. 1992a. Park Mill Hydroelectric Station, (FERC No. 2744). Article 401 Fish Entrainment Study, April 1990-March 1991, Final Report (Volumes I and II). Prepared for Scott Woridwide, Scott Paper Company, Marinette, WI.

Harza Engineering Company. 1992b. Final -Report on fish entrainment studies at the Centralia Hydroelectric Project, FERC Project No. 2255. Prepared for BVMCA, Kansas City, MO and Netroosa papers, Inc., Port Edwards, WI.

Harza Engineering Company. 1993. Fish entrainment studies at the Wisconsin River Division Hydroelectric Project, Final Report. Prepared for Consolidated Water Power Company, Wisconsin Rapids, WI.

Harza Engineering Company. 1995. Peshtigo River Hydroelectric Projects fish Entrainment Mortality Study, Final Report (Volumes I and II). Prepared for Wisconsin Public Service Corporation, Green Bay, W. 
Heinle, D. R., and F. W. Olson. 1981. Survival of juvenile coho salmon passing through the spillway at Rocky Reach Dam. Report prepared for Chelan County Public Utility District, Wenatchee, WA.

Heisey, P. G., D. Mathur, and T. Rineer. 1992. A reliable tag-recapture technique for estimating turbine passage survival: application to young-of-the-year American shad (Alosa sapidissima). Can. Jour. Fish. Aquat. Sci. 49:1826-1834.

Heisey, P. G., D. Mathur, G. A. Nardacci, and M. Anderson. 1993. Survival of Atlantic Salmon smolts in passage through ice-log sluices determined by the HI-Z Turb'N Tag. Proc. ASCE Hydraulics Engineers Conf., San Francisco, CA.

Heisey, P. G., D. Mathur, and E. T. Euston. 1995. Fish injury and mortality in spillage and turbine passage, pages 1416-1423. In J. J. Cassidy (ed.) Proc. Intl. Conf., Hydropower, Waterpower '95, San Francisco, CA.

Heisey, P. G., D. Mathur, and E. T. Euston. 1996. Passing fish safely: a closer look at turbine versus -spillway survival. Hydro Review 15(4):2-6.

Hogan, J. 1941. The effects of high vacuum on fish. Trans. Am. Fish. Soc. 70:469-474.

Hron, J. J., J. B. Strickler, and J. M. Cybularz. 1997. Wanapum turbine replacement. Waterpower '97, Atlanta, GA.

Iwamoto, R. N., W. D. Muir, B. P. Sandford, K. W. Mclntyre, D. A. Frost, J. G. Williams, S. G. Smith, and J. R. Skalski. 1993. Survival estimates for the passage of juvenile chinook salmon through Snake River dams and reservoirs, 1993. Report prepared for the U. S. Department of Energy, Bonneville Power Administration. Division of Fish and Wildlife, Contract DE-Al79-93BP10891, Project 93-29. $139 \mathrm{p}$.

Jernezcic, F. 1986. Walleye migration through Tygart Dam and angler utilization of the resulting tailwater and lake fisheries, p. 294-300. In G. E. Hall and M. J. Van Den Avyle (eds.). Reservoir Fisheries Management: Strategies for the 80's, Reservoir Comm., South. Div. Amer. Fish. Soc., Bethesda, MD.

Johnson, R. L. 1970a. Fingerling fish mortalities at 57.5 fps. Report No. 22. U. S. Army Corps. Engineers North Pacific Division, Portland, OR.

Johnson, R. L. 1970b. Fingerling fish mortalities at 67 fps. Report No. 23. U. S. Army Corps. Engineers North Pacific Division, Portland, OR.

Johnson, R. L. 1972. Fingerling fish research, high-velocity flow through four-inch nozzle. Report No. 24. U.S. Army Corps. Engineers, North Pacific Division, Portland, OR.

Jones, F. R. H. 1951. The swimbladder and the vertical movements of teleostean fish. I. Physical factors. Jour. Expt. Biol. 28:553-566.

Kilgore, K. J., A. C. Miller, and K. C. Conley. Effects of turbulence on yolk-sac larvae of paddle fish. Trans. Amer. Fish. Soc. 116:670-673. 
Kleinschmidt Associates. 1996a. Fish entrainment and mortality study, Black River Project. Report prepared for Niagara Mohawk Power Corp., Syracuse, NY.

Kleinschmidt Associates. 1996b. Fish entrainment and mortality study, Lower Raquette River Project. Report prepared for Niagara Mohawk Power Corp., Syracuse, NY.

Knapp, W. E., B. Kynard, and S. G. Gloss. 1982. Potential effects of Kaplan, Ossberger, and bulb turbines on anadromous fish of the northeast United States. USFWS, Newton Corner, MA.

Lawler, Matusky \& Skelly Engineers (LMS). 1991. Turbine entrainment survival study on fish species. Prepared for Consumer Power Company.

Ledgerwood, R. D., E. M. Dawley, L. G. Galbreath, P. J. Bentley, B. P. Sandford, and M. H. Schiewe. 1990. Relative survival of sub-yearling chinook salmon which have passed Bonneville Dam via the spillway or the second powerhouse turbines or bypass system in 1989 , with comparisons to 1987 and 1988. Report prepared for Department of the Army, Corps of Engineers, Contract E85890024/E86890097, 64 p. + Appendices.

Long, C. W., R. F. Krema, and F. J. Ossiander. 1968. Research on fingerling mortality in Kaplan turbines. 1968 Bur. Comm. Fish., Seattle, WA.

Lucas, K. C. 1962. The mortality of fish passing through hydraulic turbines as related to cavitation and performance characteristics, pressure change, negative pressure, and other factors; p. 307-335. In Proc. Symp. on Cavitation and Hydraulic Machinery, Sendai, Japan.

Mathur, D., and P. G. Heisey. 1992. Debunking the myths about fish mortality at hydro plants. Hydro Review 11(2):54-60.

Mathur, D., P. G. Heisey, and D. A.'Robinson. 1994. Turbine-passage mortality of juvenile American shad in passage through a low-head hydroelectric dam. Trans. Am. Fish. Soc. 123:108-111.

Mathur, D., P. G. Heisey, E. T. Euston, J. R. Skalski, and S. Hays. 1996a. Turbine passage survival estimation for chinook salmon smolts (Oncorhynchus tshawytscha) at a large dam on the Columbia River. Can. Jour. Fish. Aquat. Sci. 53:542-549.

Mathur, D., P. G. Heisey, K. J. McGrath, and T. R. Tatham. 1996b. Juvenile blueback herring (Alosa aestivalis) survival via turbine and spillway. Water Res. Bull. 32:155-161.

Monten, E. 1985. Fish and turbines: fish injuries during passage through power station turbines. Norstedts Tryckeri, Stockholm, Sweden. $111 \mathrm{p}$.

Muir, J. F. 1959. Passage of young fish through turbines. Proc. Amer. Soc. Civil. Engineering 85(PO1):23-46.

Muir, W. D. et al. (eleven coauthors). 1995. Survival estimates for the passage of juvenile salmonids through Snake River dams and reservoirs, 1994. Annual report prepared for Bonneville Power Administration, Portland, OR and U. S. Army Corps of Engineers, Walla Walla, WA. Contract DE93-29A179-93BP10891, Project 93-29, 187 p. 
Nelson, W. E., R. A. Simmons, and A. E. Knight. 1992. Differential turbine passage survival of Atlantic salmon smolts and post smolts. Prog. Rept. Proc. Atlantic Salmon Workshc; , Rockport, Maine. U. S. Fish and Wildlife Service, NE Fishery Center.

Normandeau Associates, Inc. 1994. Survival of Atlantic salmon smolts (Salmo salar) in passage through a Kaplan turbine at the Wilder Hydroelectric Station, Connecticut River, Vermont/New Hampshire. Report prepared for New England Power Co., Westborough, MA.

Normandeau Associates, Inc. 1995a. Log sluice passage survival of juvenile clupeids at Cabot Hydroelectric Station, Connecticut River, Massachusetts,. Report prepared for Northeast Utilities Service Co., Hartford, CT.

Normandeau Associates, Inc. 1995b. The Vernon Bypass Fishtube: Evaluation of survival and injuries of Atlantic salmon smolts. Report prepared for New England Power Co., Westborough, MA.

Normandeau Associates, Inc. 1996a. Estimation of survival and injuries of Atlantic salmon smolts in passage through two Francis turbines at the Vernon Hydroelectric Station, Connecticut River, Vermont. Report prepared for New England Power Co., Westborough, MA.

Normandeau Associates, Inc. 1996b. Estimation of survival and injuries of juvenile American shad in passage through a Francis turbine at the Vernon Hydroelectric Station, Connecticut River. Draft Report prepared for New England Power Co., Westborough, MA.

Normandeau Associates, Inc. 1997. Final report to evaluate effectiveness with respect to survival and injury rates of blueback herring after passage through the Little Falls Hydro bypass pipe. Report prepared for Little Falls Hydro Associates, L.P. Woodcliff Lake, NJ.

Normandeau Associates, Inc., and J. R. Skalski. 1996. Relative survival of juvenile chinook salmon (Oncorhynchus tshawytscha) in passage through a modified Kaplan turbine at Rocky Reach Dam, Columbia River, Washington. Report prepared for Public Utility District No. 1 of Chelan County, Wenatchee, WA.

Normandeau Associates, Inc., J. R. Skalski, and MCC. 1995. Turbine passage survival of juvenile chinook salmon (Oncorhynchus tshawytscha) at Lower Granite Dam, Snake River, Washington. Report prepared for U.S. Army Corps Engineers, Walla Walla, WA.

Normandeau Associates, Inc., J. R. Skalski, and MCC. 1996a. Fish survival investigation relative to turbine rehabilitation at Wanapum Dam, Columbia River, Washington. Report prepared for Grant County Public Utility District No. 2, Ephrata, WA.

Normandeau Associates, Inc., J. R. Skalski, and MCC. 1996b. Potential effects of spillway flow deffectors on fish condition and survival at the Bonneville Dam, Columbia River. Report prepared U.S. Army Corps Engineers, Portland District, OR.

Normandeau Associates, Inc., J. R. Skalski, and MCC. 1996c. Potential effects of modified spillbay configurations on fish condition and survival at The Dalles Dam, Columbia River. Report prepared for U.S. Army Corps of Engineers, Portland District, OR. 
Normandeau Associates, Inc., J. R. Skalski, and MCC. 1996d. Fish survival in passage through the spillbay and sluiceway at Wanapum Dam on the Columbia River, Washington. Report prepared for Grant Count Public Utility District No. 2, Ephrata, WA.

Oligher, R. C. and I. J. Donaldson. 1966. Fish passage through turbines: Tests at Big Cliff Hydroelectric Plant, Progress Report No. 6. Report prepared for Dept. of Army, Corps of Engineers. Walla Walla District, WA.

Olson, F. W. and V. W. Kaczynski. 1980. Survival of downstream migrant coho salmon and steelhead trout through bulb turbines. Prepared for Public Utility Dis:rict No. 1 of Chelan County, Wenatchee, WA.

Olson, F. W., Jr., E. S. Kuehl, K. W. Burton, and J. S. Sigg. 1990. Use of radio telemetry to estimate survival of saugers passed through turbines and spillways at dams. Amer. Fish. Soc. Symp. 7:357-363.

Parametrix, Inc. 1986. Survival of steelhead smolts during passage through Wells Dam turbines and spillway. Prepared for Douglas County PUD No. 1, East Wenatchee, WA.

RMC Environmental Services, Inc. (RMC). 1990. Assessment of flow requirements for down migrant American shad at Conowingo Hydroelectric Station, Maryland (Project No. 405). Report prepared for Philadelphia Electric Company, Philadelphia, PA.

RMC. 1991a. Turbine passage survival of juvenile American shad, Alosa sapidissima, at the Safe Harbor Hydroelectric Station (FERC Project No. 1025), Pennsylvania. Report prepared for the Safe Harbor Water Power Corporation, Conestoga, PA.

RMC. 1991b. Survival of Atlantic Salmon smolts passing through the ice-log sluice at Bellows Falls Hydroelectric Station, Vermont. Report prepared for New England Electric Power Company, Westborough, MA.

RMC. 1991c. Prickett Hydroelectric Project entrainment and turbine mortality report. Prepared for Stone \& Webster Michigan, Englewood, $\mathrm{CO}$.

RMC. 1992a. Final report on study plan to assess the impact of power plant operations on fish resources at the Youghiogheny Hydroelectric Project. Report prepared for D/R Hydro Co., Monroeville, PA.

RMC. 1992b. Turbine-related mortality of juvenile American shad (Alosa sapidissima) at the Hadley Falls Hydroelectric Station, Massachusetts. Report prepared for Harza Engineering-Northeast Utilities Service Company, Hartford, CT.

RMC. 1992c. Juvenile blueback herring (Alosa aestivalis) survival in powerhouse/turbine passage and spillage over the dam at the Crescent Hydroelectric Project, New York. Report prepared for New York Power Authority, White Plains, NY.

RMC. 1992d. Turbine passage survival of juvenile American shad (Alosa sapidissima) at the Holtwood Hydroelectric Station, Pennsylvania. Report prepared for Pennsylvania Power \& Light Company, Allentown, PA. 
RMC. 1992e. Applicability of the HI-Z Turb'N Tag for estimating turbine passage survival of juvenile American shad at the Riviere-des-Prairies Hydroelectric Station. Report prepared for HydroQuebec, Montreal, Canada.

RMC. 1992f. Survival of Atlantic salmon smolts passing the Log-lce sluice at the Wilder Hydroelectric Station, Vermont/New Hampshire. Report prepared for New England Electric Power Company, Westborough, MA.

RMC. 1992g. Survival of fishes in turbine passage at the White Rapids Hydroelectric Project (FERC Project No. 2357). Prepared for Wisconsin Electric Power Co.

RMC. 1992h. Study of steelhead and chinook salmon outmigration in the St. Joseph River Buchanan Hydroelectric Project, Buchanan, Michigan. Report prepared for Indiana Michigan Power Company and American Electric Power Service Corporation, Columbus, $\mathrm{OH}$.

RMC. 1993a. Turbine passage survival of fish at the Chalk Hill Hydroelectric Project (FERC Project No. 2394). Report prepared for Wisconsin Electric Power CO., Milwaukee, Wl.

RMC. 1993b. Final Report: Entrainment study McClure Hydroelectric Station, Dead River, Marquette, MI. Prepared for Stone and Webster Michigan, Inc., Englewood, CO.

RMC. 1993c. Final report Entrainment study Hoist Hydroelectric Station Dead River, Marquette, MI. Report prepared for Stone \& Webster Michigan, Inc., Englewood, CO.

RMC. 1994a. Source and extent of injuries to juvenile fall chinook salmon (Oncorhynchus tshawytscha) in passage through Unit 7 at the Rocky Reach Dam, Washington. Report prepared for Public Utility District No. 1 of Chelan County, Wenatchee, WA.

RMC. 1994b. Survival of fishes in turbine passage through the Townsend Dam, Pennsylvania (FERC Project No. 3451). Report prepared for Beaver Falls Municipal Authority, Beaver Falls, PA.

RMC. 1994c. Survival of Atlantic salmon smolts (Salmo salar) in passage through a Kaplan turbine at the Wilder Hydroelectric Station, Conne :ticut River, Vermont/New Hampshire. Prepared for New England Power Company, Westborough, MA.

RMC. 1994d. Turbine passage survival of juvenile American shad (Alosa sapidissima) at Conowingo Hydroelectric Station (FERC Project No. 405), Susquehanna River, Maryland. Prepared for Susquehanna Electric Company, Darlington, MD.

RMC. 1994e. Turbine passage survival of fish at the Stevens Creek Hydroelectric Plant (FERC Project No. 2535), Savannah River, Georgia. Prepared for South Carolina Electric \& Gas Company, Columbia, SC.

RMC. 1994f. Entrainment and fisheries studies at the Twin Branch Hydroelectric Project, St. Joseph River, Mishawaka, Indiana. Report prepared for Indiana Michigan Power Co., American Electric Power Corp., Columbus, $\mathrm{OH}$.

RMC. 1996. Entrainment and turbine mortality studies at the Bond Falls Hydroelectric Project, Victoria Powerhouse, Ontonagon River, Michigan. Report prepared for Stone and Webster Michigan, Inc., Englewood, $\mathrm{CO}$. 
RMC and J. R. Skalski. 1994a. Survival of yearling fall chịnook salmon smolts (Oncorhynchus tshawytscha) in passage through a Kaplan turbine at the Rocky Reach hydroelectric dam, Washington. Report prepared for Public Utility District No. 1 of Chelan County, Wenatchee, WA.

RMC and J. R. Skalski. 1994b. Survival of juvenile fall chinook salmon (Oncorhynchus tshawytscha) in passage through a fixed blade Kaplan turbine at the Rocky Reach Dam, Washington. Report prepared for Public Utility District No. 1 of Chelan County, Wenatchee, WA.

RMC, MCC, and J. R. Skalski. 1994. Turbine passage survival of spring migrant chinook salmon (Oncorhynchus tshawytscha) at Lower Granite Dam, Snake River, Washington. Report prepared for Dept. of Army, Corps of Engineers, Walla Walla District, WA.

Rowley, W. E., Jr. 1955. Hydrostatic pressure tests on rainbow trout. Calif. Fish. and Game 41:243-284.

Ruggles, C. P. 1980. A review of the downstream migration of Atlantic salmon. Can. Tech. Rept. Fish. Aquat. Sci. No. 952:39 p.

Ruggles, C. P. 1993. Effect of stress on turbine fish pessage mortality estimates, pages 39-57. In V.P. Williams, D. A. Scruton, R. F. Gooney, C. E. Bourgeois, D. C. Orr, and C. P. Ruggles (eds.), Proc. Workshop on Fish Passage at Hydroelectric Developments, St. Johns, New Foundland, Canada.

Ruggles, C. P. and T. H. Palmeter. 1989. Fish passage mortality in a tube turbine. Can. Tech. Rept. Fish. Aquat. Sci. No. 1664:50 p.

Ruggles, C. P., T. H. Palmeter, and K. D. Stokesbury. 1990. A critical examination of turbine passage fish mortality estimates. Report prepared for Canadian Electrical Assoc. Research and Development, Montreal, Quebec. 57 p.

Schoeneman, D. E., R. T. Pressey, and C. O. Junge, Jr. 1961. Mortalities of downstream migrant salmon at McNary Dam. Trans. Am. Fish Soc. 90:58-72.

Shepard, S. 1993. Survival and timing of Atlantic salmon smolts passing the West Enfield hydroelectric project. Bangor Pacific Hydro Associates, Bangor, ME.

Smith, E. J. and J. K. Anderson. 1984. Attempts to alleviate fish losses from Allegheny Reservoir, Pennsylvania and New York using acoustics. N. Amer. Jour. Fish. Manage. 4:300-307.

Solomon, D. J. 1988. Fish passage through tidal energy barrages. Rept. No. ETSU TID 4056, Energy Tech. Support Unit, Harwell, England.

Stier, D. J. and B. Kynard. 1986. Use of radio telemetry to determine the mortality of Atlantic salmon smolts passed through a 17-megawatt Kaplan turbine at a low-head hydroelectric dam. Trans. Amer. Fish. Soc. 115:771-775.

Stokesbury, K.D.E., and J. J. Dadswell. 1991. Mortality of juvenile clupeids during passage through a tidal, low-head hydroelectric turbine at Annapolis royal, Nova Scotia. N.A. Jour. Fish. Manager. 11:149-154. 
Taylor, R. E. and B. Kynard. 1985. Mortality of juvenile American shad and blueback herring through a low-head Kaplan hydroelectric turbine. Trans. Amer. Fish. Soc. 114:430-435.

Thorne, R. E. and G. E. Johnson. 1993. A review of hydroacoustic studies for estimation of salmonid downriver migration past hydroelectric facilities on the Columbia and Snake Rivers in the 1980 s. Review Fisheries Science 1(1):27-56.

Tsvetkov, V. I., D. S. Pavlov, and V. K. Nezdoliy. 1972. Changes in hydrostatic pressure lethal to the young of some freshwater fish. Jour. Ichthyology 12:307-318 (Cited in Cada et al. 1997).

Turbak, S. C., D. R. Reichle, and C. R. Shriner. 1981. Analysis of environmental issues related to smallscale hydroelectric development. IV: Fish Mortality resulting from turbine passage. Oak Ridge Natl. Lab., Environ. Sci. Div., Publication 1597, Oak Ridge, TN.

Turner, A. R., Jr., J. W. Ferguson, T. Y. Barila, and M. F. Lindgren. 1993. Development and refinement of turbine intake screen technology on the Columbia River, pages 123-128. In K. Bates (ed.), Proc. Symp. Fish passage policy and technology. Bioengineering. Section, Amer. Fish. Soc., Portland, OR.

Turnpenny, A. W. H., M. H. Davis, J. M. Fleming, and J. K. Davies. 1992. Experimental studies relating to the passage of fish and shrimps through tidal power turbines. Marine and freshwater biology unit, National Power, Fawley, Southampton, Hampshire, England.

VonGunten, G. H. 1960. Effects of cavitation and negative pressures on the passage of fish in hydraulic turbines. ASCE Hydraulics Div. Conf., Seattle, WA. 


\subsection{TASK 3 REPORT -- INVESTIGATION OF INDIVIDUAL DESIGN ELEMENTS}




\subsection{TASK 3 REPORT - INVESTIGATION OF INDIVIDUAL DESIGN ELEMENTS}

\subsection{INTRODUCTION}

Different aspects of individual design elements were investigated by three team members. Voith utilized its family of CFD tools to provide details of the flow fields in many locations in Kaplan and Francis turbines. The goal was to demonstrate the nature of internal turbine flows, quantify velocity and pressure fields, and sharpen knowledge regarding fluid mechanisms leading to possible fish injury. Georgia Institute of Technology studied more basic flow physics to improve our understanding of advanced CFD methods. TVA reviewed the state of the art in mitigation of low dissolved oxygen flows, and reported on the testing, and operation of aerating turbines.

\subsection{DISCUSSION}

Voith analyzed the entire water passage of Kaplan and Francis turbines. Several computer programs were used in this study including proprietary and commercial codes. Detailed CFD calculations were performed using a commercial three-dimensional Navier-Stokes turbulence modeled code, TASCflow, developed by Advanced Scientific Computing Ltd. (Raw 1995, Thomas et al. 1989). A standard K epsilon method was applied for the turbulence modeling. The calculations were applied for semi-spiral intakes, spiral case, stay vanes and wicket gates, runners and draft tube. Many of these calculations were performed explicitly for this project. Some results were taken from ongoing efforts. The goals included:

- ascertain probable fish paths

- illustrate the complex flow fields that exist in turbines

- evaluate and sharpen expectations regarding fluid induced injury mechanisms of shear, rate of pressure reduction, cavitation, and gap flows.

- examine draft tube flow conditions for recirculation (entrapment regions), draft tube pier impact, and disorienting effects

Georgia Institute of Technology developed and tested advanced numerical methods and turbulence models for simulating hydroturbine flows. The combined effects of numerical resolution and turbulence modeling on the accuracy of complex flow predictions were investigated in great detail. An advanced turbulence model was proposed which was shown to yield superior results as compared to existing models. A computational framework for predicting unsteady flow phenomena in Francis-type hydroturbines was also developed and applied to simulate formation of rope-like vortices. These advancements provide us with a better understanding of the complex flow environment inside the powerplant which, in turn, will lead to more accurate evaluations of fluid induced fish injuries. The potential of coupling advanced.CFD methods with a virtual fish numerical model, capable of estimating fish trajectories and flow induced loads on fish bodies, was also demonstrated.

TVA reviewed the state of the art in mitigation of low dissolved oxygen flows, and studied the testing, and operation of aerating turbines. 


\subsection{THREE-DIMENSIONAL CFD STUDIES}

\subsubsection{KAPLAN INTAKE}

A Kaplan turbine intake with no fish screen was analyzed. The region from the trashracks through the runner, including all stay vanes and wicket gates was calculated. The purpose of the calculation was to analyze the semi-spiral case with an emphasis on flow through the stay vanes and wicket gates and into the runner. This calculation does not contain features that would permit accurate calculations through or below the runner. The inlet flow boundary to the intake was assumed to have constant total pressure. This simulates inflow from a large quiet reservoir, and permits a velocity profile to develop. The exit plane, below the runner, was specified to have the desired mass flow. The presence of the runner was simulated by applying a tangential body force to remove swirl that was induced by the stay vanes and wicket gates. The grids on the outer surface of the model are shown on Figure 5.3.1-1

The results of the calculation are demonstrated by streamline plots, Figures 5.3.1-2 through 5.3.1-4. The path of a streamline is not affected by forces on a three-dimensional body, centrifugal effects, or buoyancy. In the absence of a "virtual fish" calculation that could account for more realistic fish effects, streamlines are tentatively accepted as an approximation of fish paths. Streamlines at a given height at the trash racks travel to a constant radius in the runner region. Generally, streamlines near the roof travel to the hub and streamlines near the floor travel to the periphery. The results for this geometry support the previously assumed hypothesis that fish from the near surface region would tend to be discharged through the runner near the hub. These streamlines are colored by transit time for a laboratory scale model turbine. Figure 5.3.1-5 shows a transit time of 30 seconds for a prototype size (Wanapum) intake. 


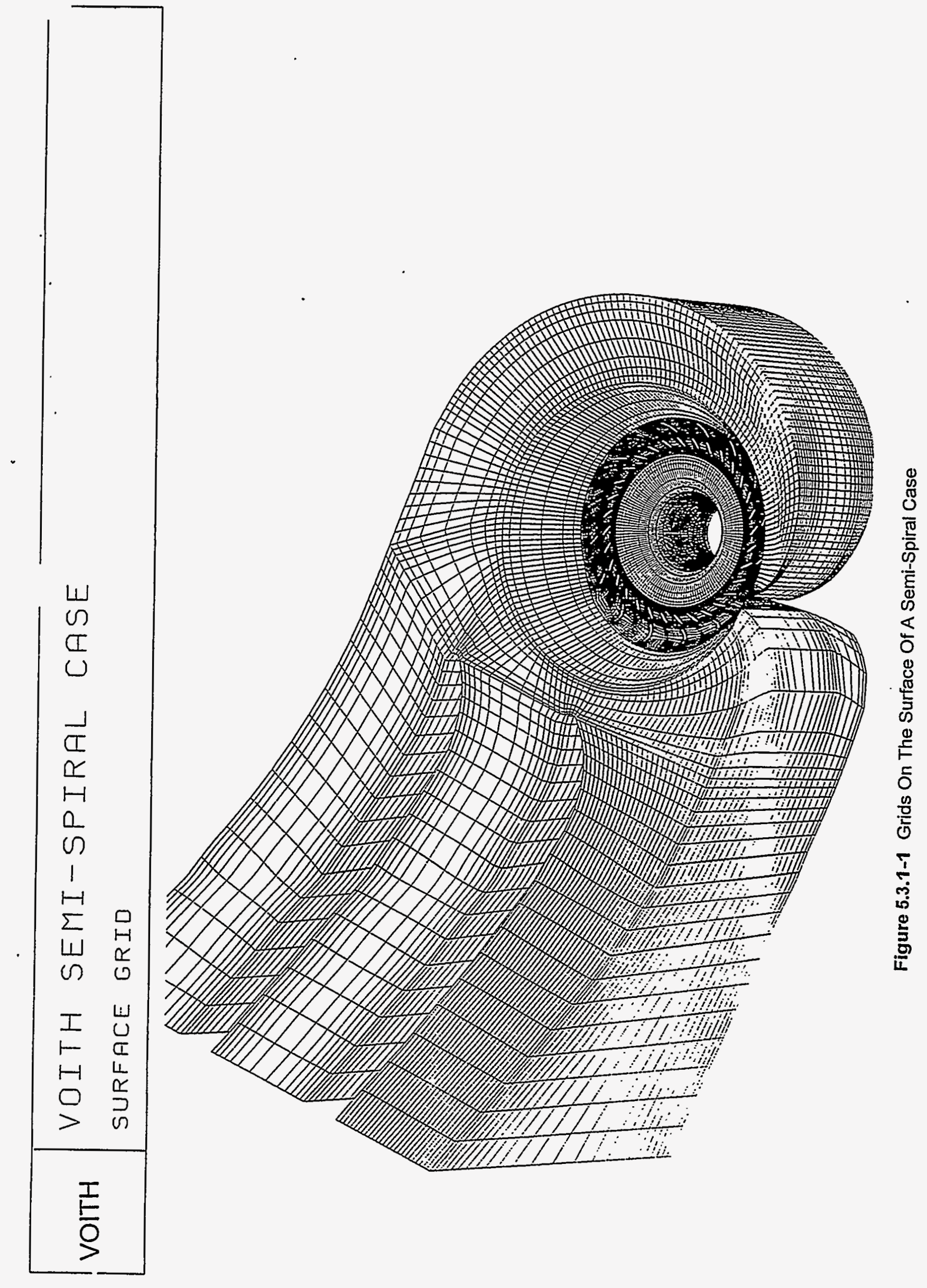




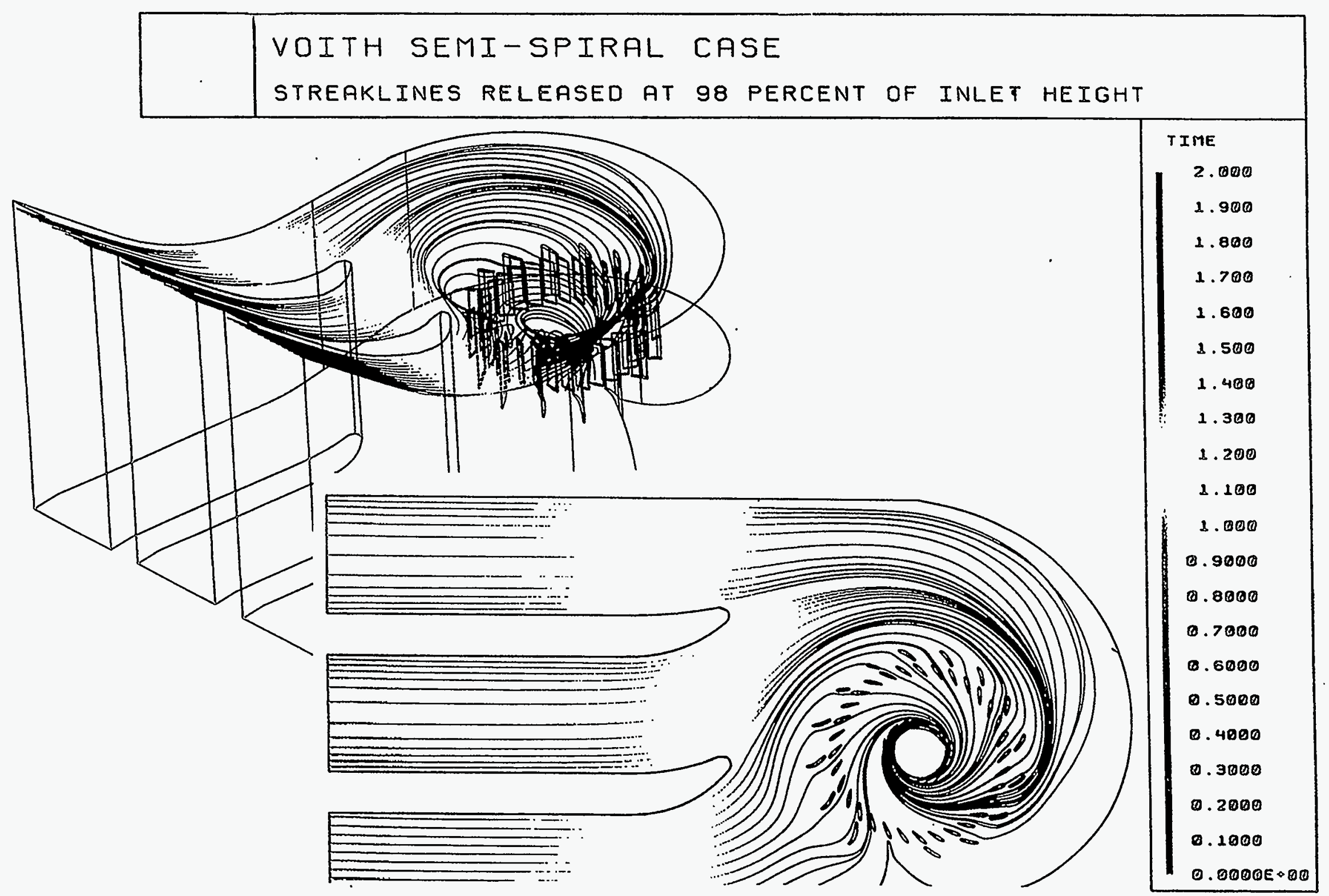

Figure 5.3.1-2 Isometric and Plan View Of Streamlines Released At 98\% Of Inlet Height 


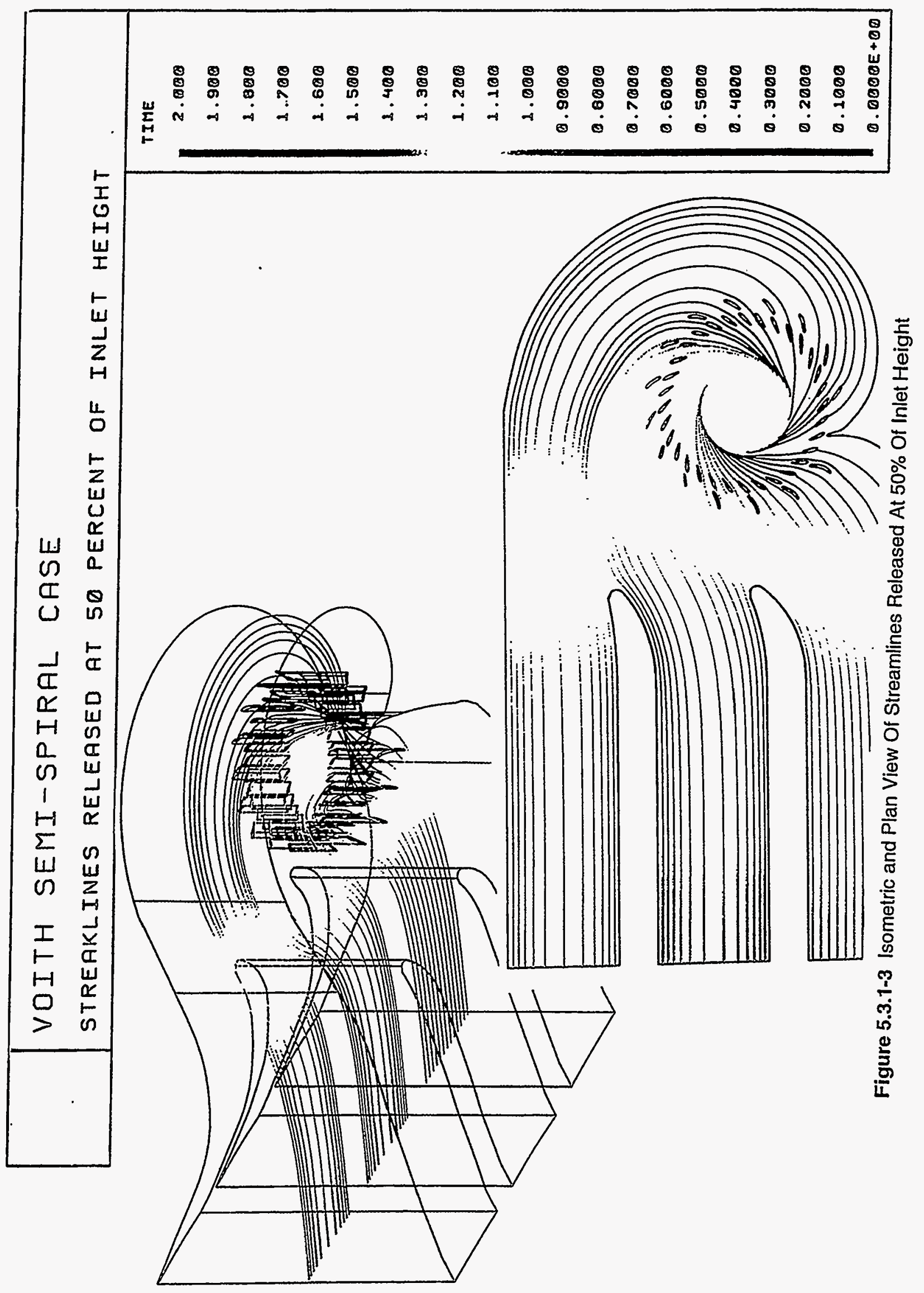




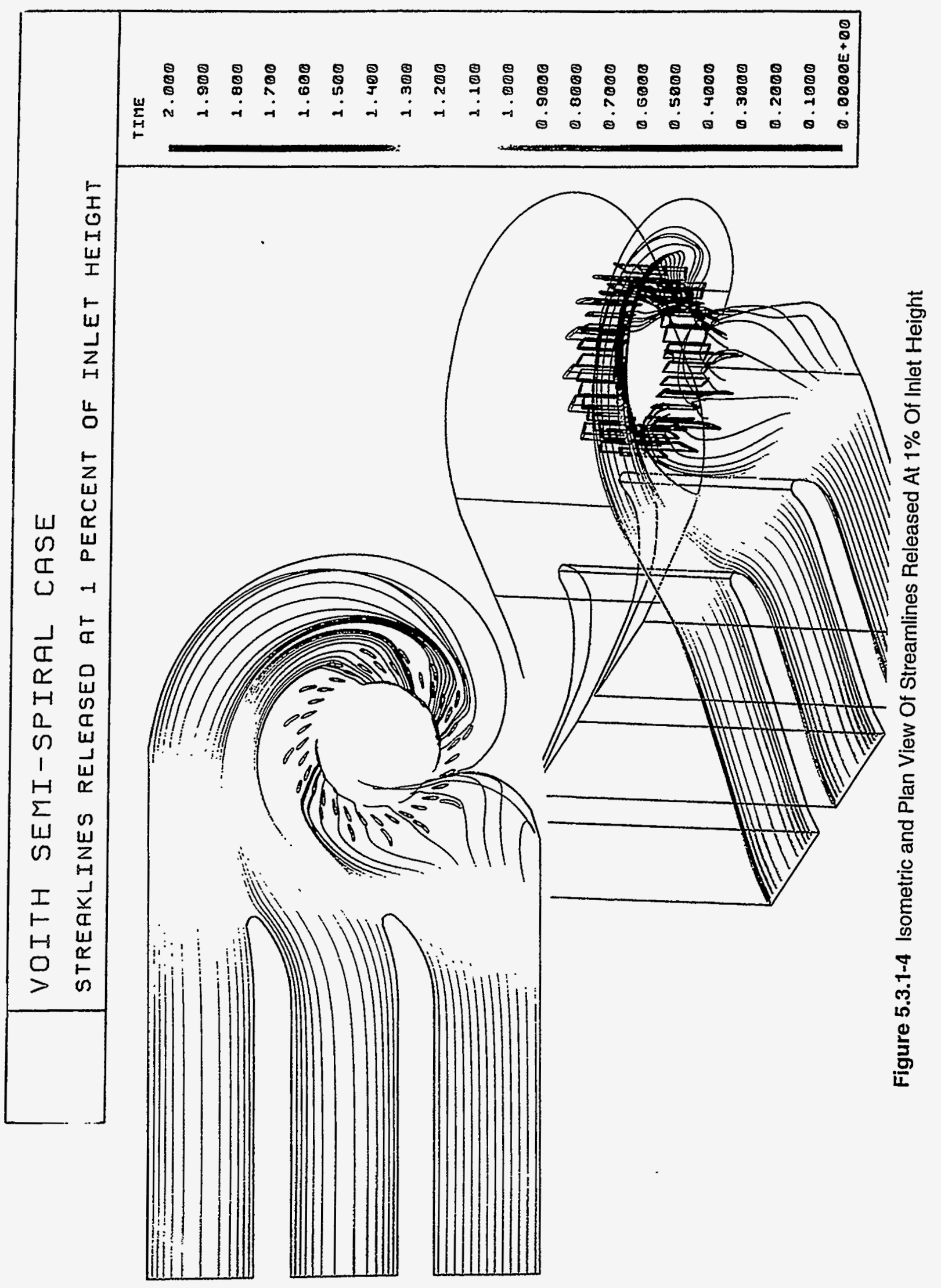




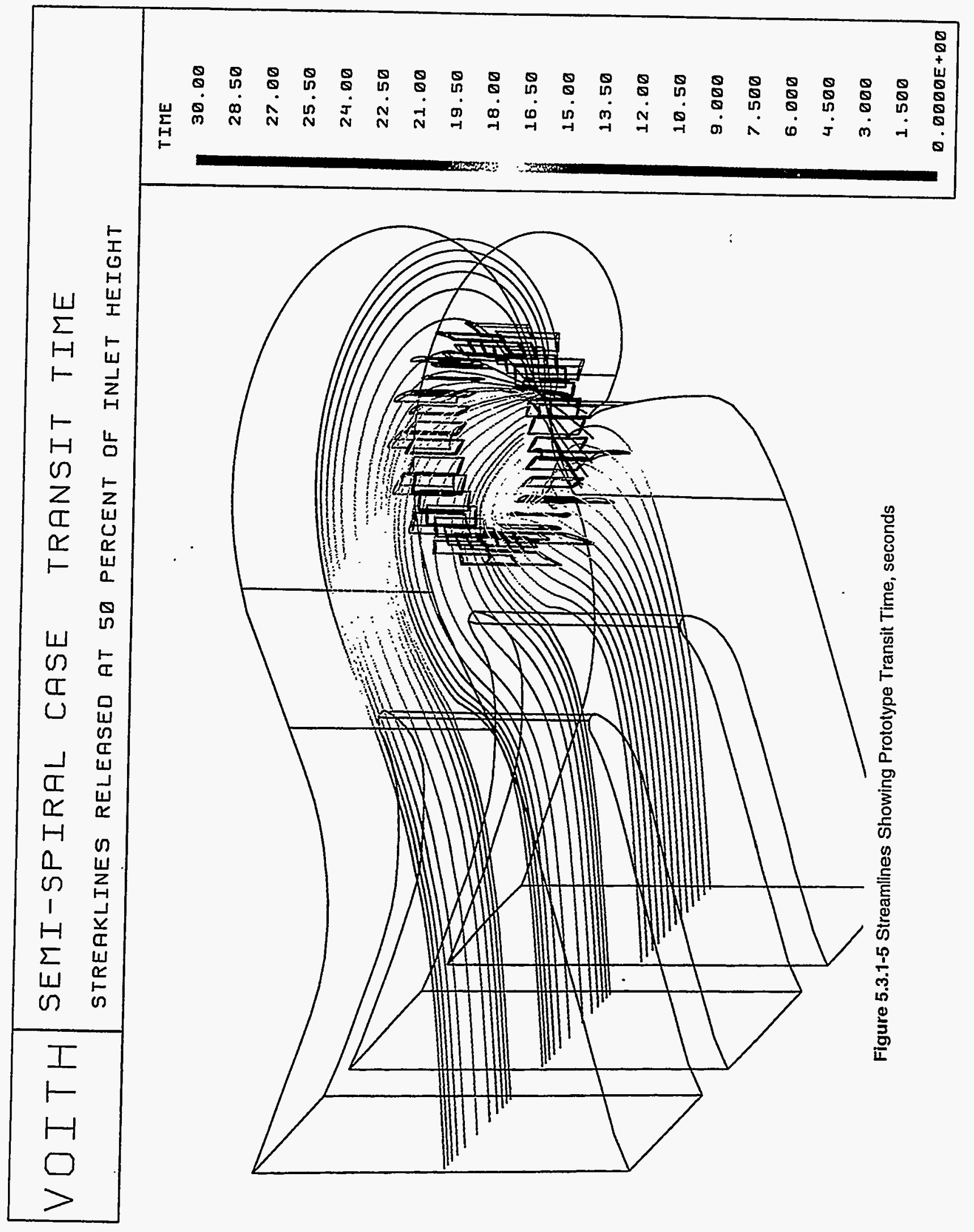




\subsubsection{KAPLAN INTAKES WITH FISH SCREENS}

Upon recognizing the significant influence that a fish screen would have on the internal intake flow, the previous grids were altered to include additional grids that could simulate a typical fish screen (from the Wanapum project) and to remove grids in the runner region. The runner grids were removed to prevent the large total pressure drop across the runner from overwhelming the relatively smaller total pressure loss due to the fish screen. The calculation outlet boundary was near the stay vane outer diameter. The fish screen region with more refined grids, shown on Figure 5.3.2-1 (note that this figure shows stay vane and wicket gate grids that were not used) was specified to have properties of a porous media to simulate the fish screen, or was specified to have no special properties to simulate the absence of the fish screen. The properties of the porous media were adjusted to cause a total pressure loss of 0.73 times the local velocity head. Subsequent analysis of model screen testing on the Bonneville project indicated that screen caused a loss of total pressure equal to 2.24 times the local velocity head. The current analysis therefore, has insufficient total pressure loss and would have less flow disruption than an equivalent Bonneville type screen. The diversion of flow through the gate slot was also modeled. $10 \%$ of the flow was specified to be discharged from the model at the gate slot location.

The results of the calculation are demonstrated by streamline plots. Plots are shown in a sequence of side and plan views with no fish screen present and with the fish screen active. Figures 5.3.2-2 and 5.3.23 show streamlines released at the inlet from $87 \%$ of the inlet height (100\% is the top at the inlet). Note that the outline of the all grid blocks are shown in black, including the fish screen, even if the porous feature of the fish screen is not active. Streamlines near the roof are deflected significantly upwards due to the flow entering the gate slot. This $87 \%$ of the inlet height is approximately the dividing surface between flow entering the gate slot and flow entering the turbine. Streamlines released at the inlet from $30 \%$ of the intake height are shown in Figures 5.3.2-4 through 5.3.2-5. This height is approximately the dividing surface between flow passing beneath the fish screen and flow through the screen. These streamines are affected by both the upward deflection of the flow entering the gate slot and a downward diversion of the flow that would tend to flow around the obstruction of the fish screen. The result is an approximate cancellation of these effects, and the $30 \%$ height streamline is approximately the dividing streamline both with a fish screen and in the absence of a fish screen. The presence of the fish screen affects the streamline paths for both release locations. While streamline paths in the absence of the fish screen terminate at a nearly constant height, the presence of the fish screen causes a redistribution of the flow, and subsequent variation in the location of the streamline paths. Presumably, fish trajectories would also be similarly affected. Velocity vectors and total pressure plots that also highlight the flow disturbance caused by the fish screen are shown on Figure 5.3.2-6 while Figure 5.3.2-7 compares streamlines released behind the fish screen with and without the fish screen.

Flow disturbances that the fish screen generate which could alter the details of flow in the stay vane, wicket gate, or runner could not be analyzed with this calculation. Such a calculation would require a grid fine enough to model the turbulent mixing behind the fish screen. The calculation model used 300,000 nodes. A model of. this size was nearly impossible several years ago and even today requires an advanced workstation. 


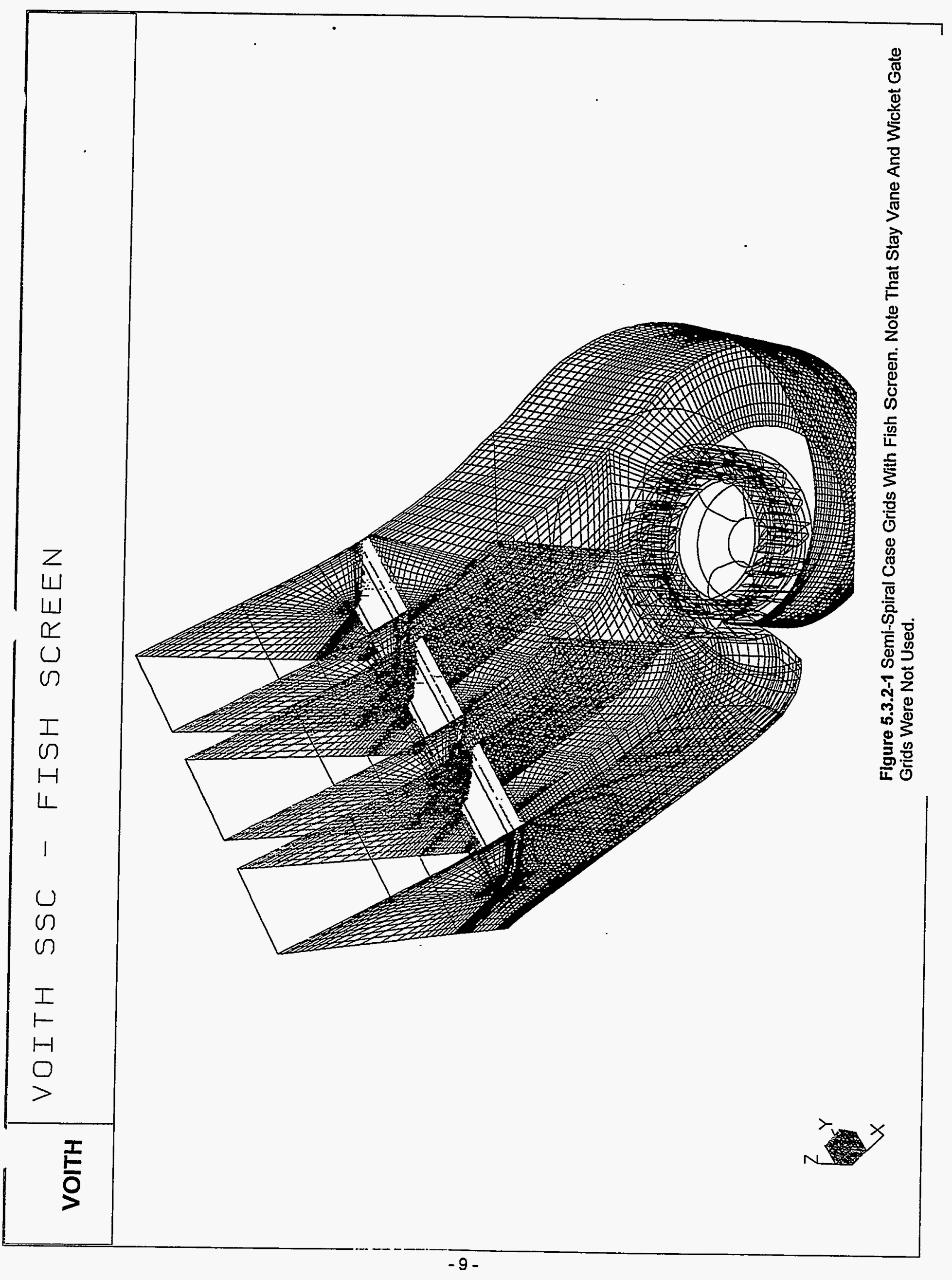




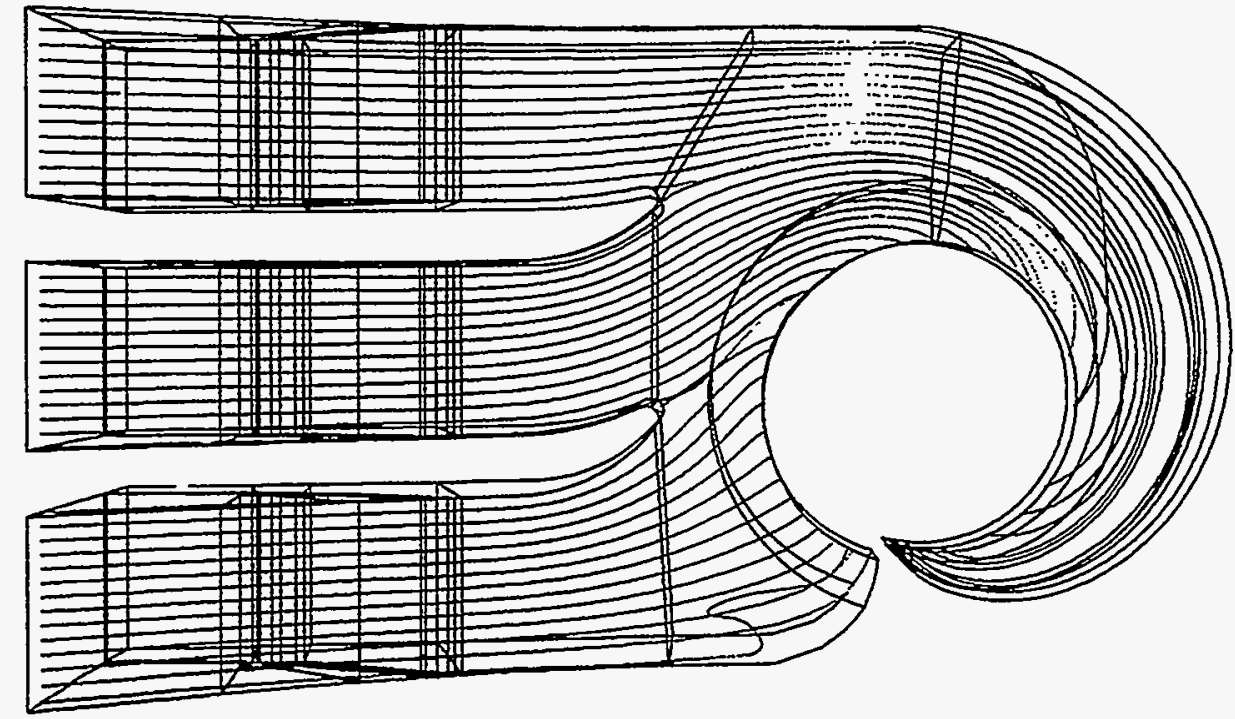

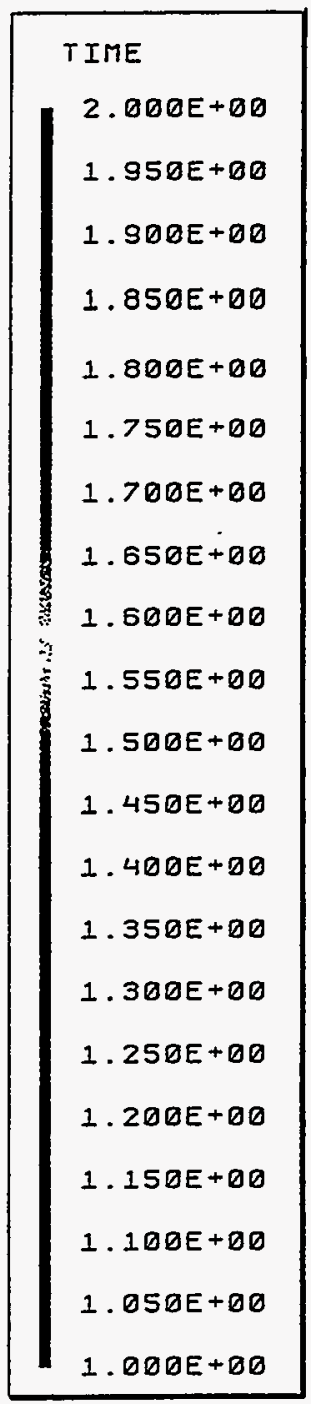

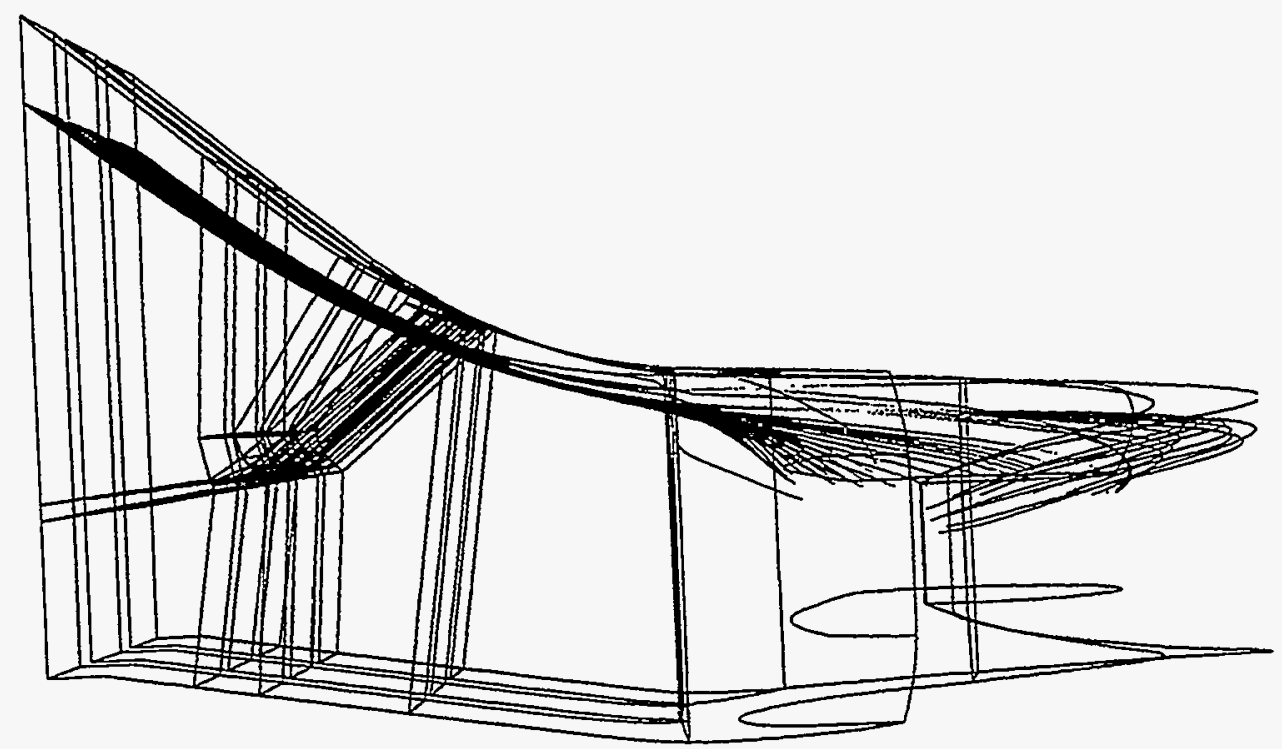

Figure 5.3.2-2 Plan and Side View of Streamlines Released From $87 \%$ Of Inlet Height. Fish Screen Not Activated. 

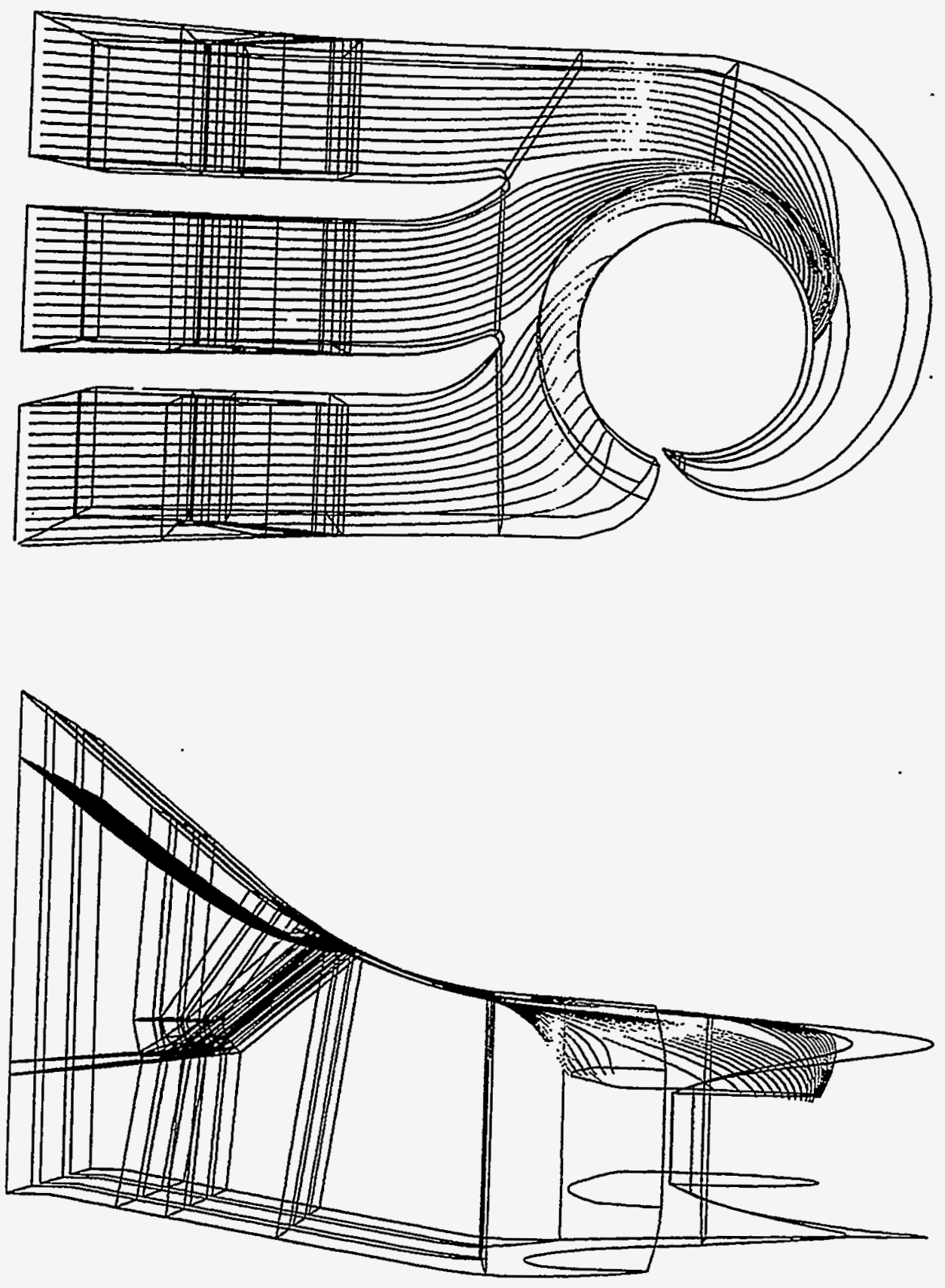

TI.TE

2. DEDE+ + Dด

$1.950 E+00$

1. $900 E+00$

$1.850 E+00$

1. $800 E+00$

1. $750 E+00$

1.7DOE +00

$1.650 E+00$

$1.500 E+\theta 0$

$1.550 E+\theta 0$

1. $500 E+00$

1. $450 E+00$

1. $400 E+00$

$1.350 E+00$

$1.300 E+00$

1. $250 E+\theta 0$

1. $2000+00$

1. $150 E+00$

$1.100 E+00$

$1.050 E+00$

$1.000 E+00$ Figure 5.3.2-3 Plan and Side View of Streamlines Released From $87 \%$ Of Inlet Height. With
Fish Screen Activated. 

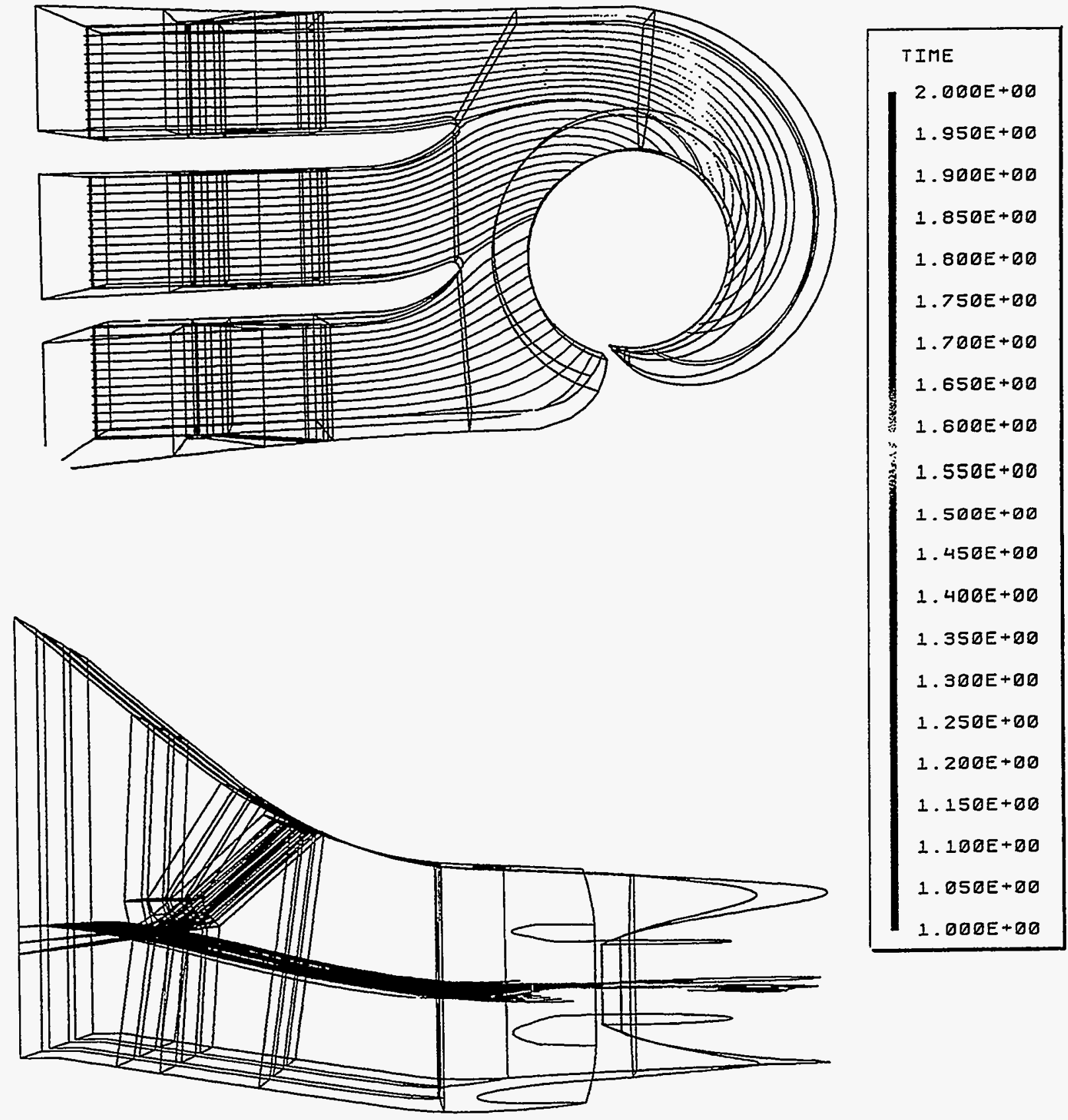

$1.300 E+\theta 0$
$1.250 E+\theta 0$
$1.200 E+\theta 0$
$1.150 E+\theta 0$
$1.10 \theta E+\theta 0$
$1.050 E+\theta 0$
$1.000 E+00$

Figure 5.3.2-4 Plan and Side View of Streamlines Released From $30 \%$ Of Inlet Height. Fish Screen Not Activated. 

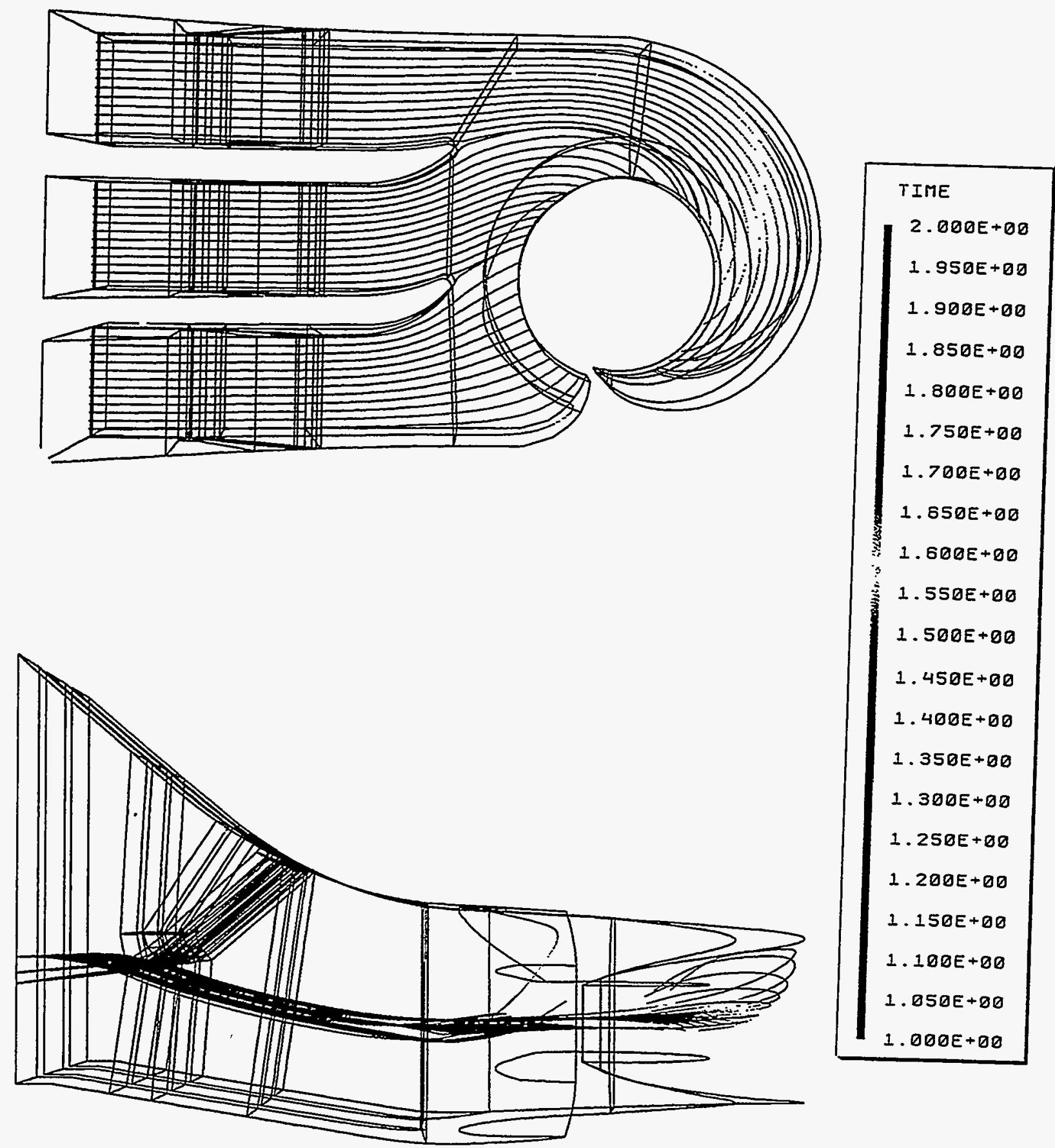
Figure 5.3.2-5 Plan and Side View of Streamlines Released From $30 \%$ Of Inlet Height. With
Fish Screen Activated. 

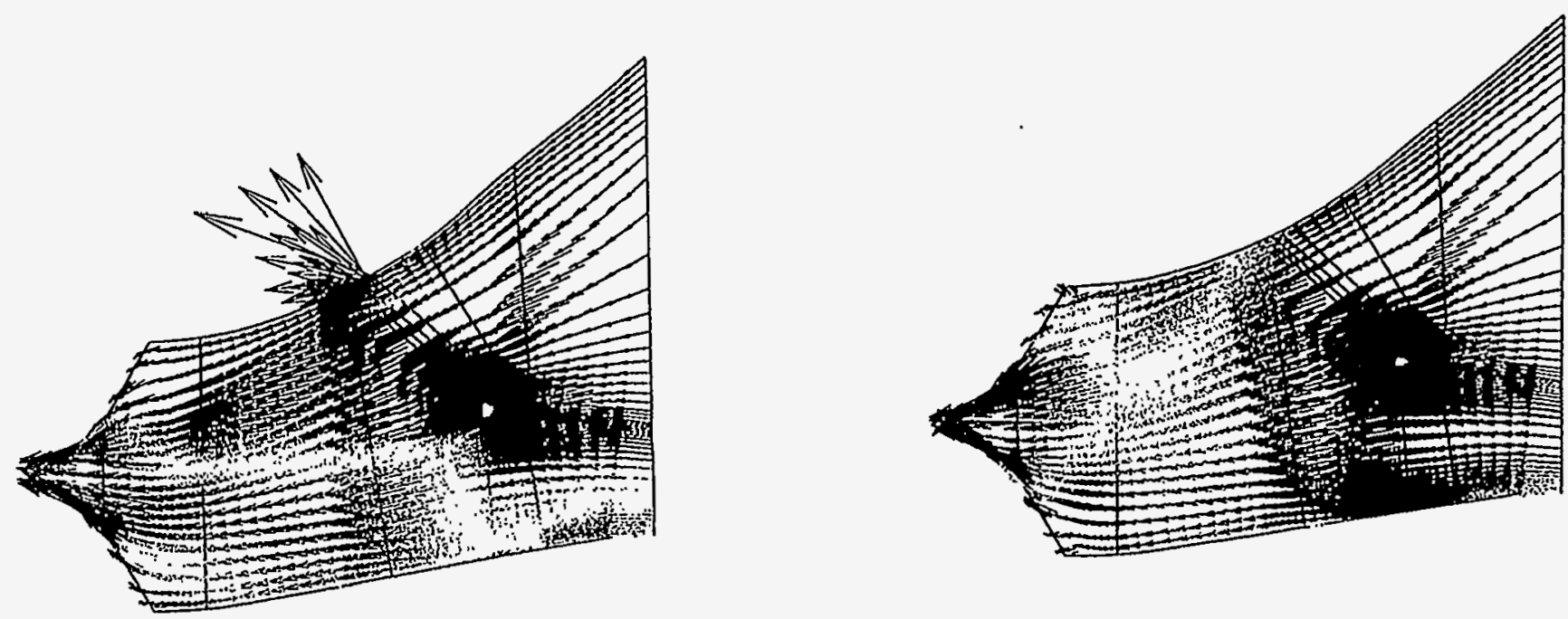

$2.125 E+00$

$2.050 \mathrm{~g}+00$

$1.975 E+8 B$

$1.900 \mathrm{E}+00$

$1.025 E+00$

$1.758 E+00$

$1.075 E+00$

$1.606 \mathrm{E}+\mathrm{aB}$

$1.525 \mathrm{E}+60$

$1.450 E+00$

$2.375 E+60$

$1.980 E+88$

$1.2258+00$

$1.150 E+80$

$1.075 E+00$

$1.800 E+00$
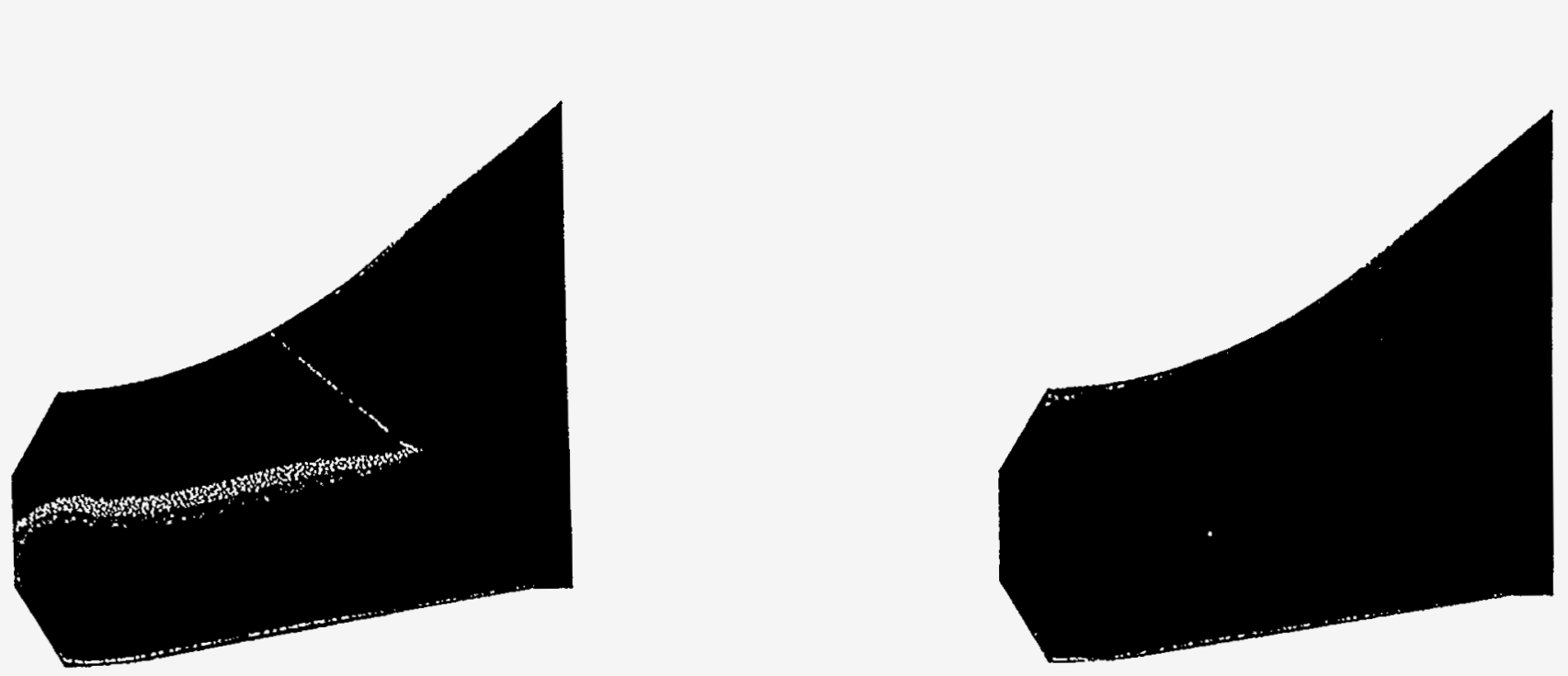

Figure 5.3.2-6 Velocity Vectors And Total Pressure Contours. With Fish Screen Activated (Left Side) And With Fish Screen Not Activated (Right Side).

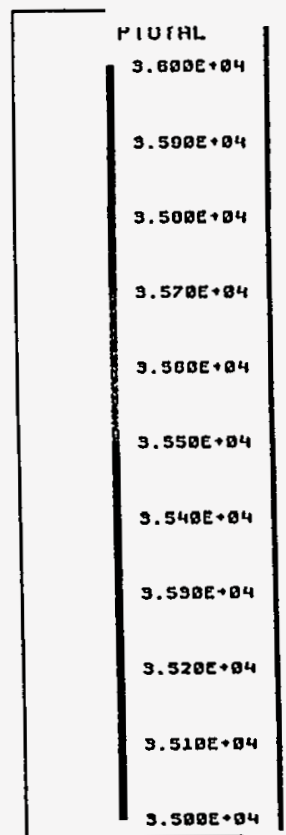



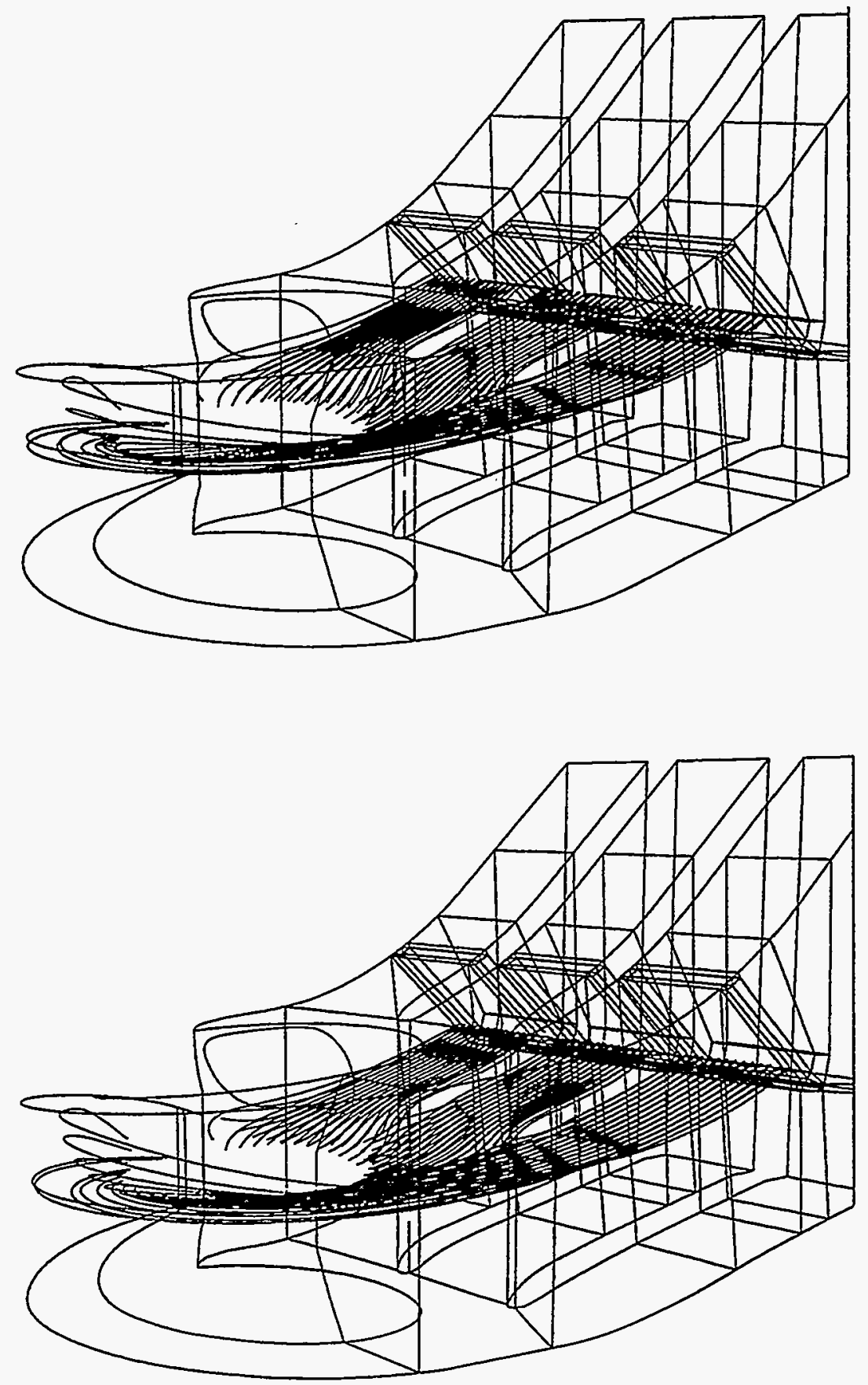

Figure 5.3.2-7 Streamlines Released Behind Fish Screen At 50\% Height (Top) And 30\% Height (Bottom). Green Indicates Fish Screen Activated, Red Indicates Fish Screen Not Activated. 


\subsubsection{STAY VANES AND WICKET GATES}

\section{Kaplan and Francis Turbines}

The flow field in stay vanes and wicket gates and related fish damage mechanisms are generally the same for Kaplan and Francis turbines. One modest difference between typical Kaplan and typical Francis turbine stay vanes and wicket gates is related to the difference between a spiral case and a semispiral case. Streamline tracings in a spiral case, as is more commonly used for Francis turbines, show that initial position in the spiral case inlet does not coincide in a clear manner to a definite position at the runner inlet (Figure 5.3.3-1).

Stay vanes and wicket gates are analyzed from the spiral case centerline to approximately the runner entrance. Periodic boundaries are used assuming that all fiow channels are identical and therefore, only one flow channel needs to be analyzed. A typical grid of the water passage wetted surface is shown on Figure 5.3.3-2. Velocity fields, shear magnitude and pressure gradients are analyzed. Two cases were studied.

A gate and vane that are not optimized was analyzed. This gate and vane were existing shapes that were encountered during a turbine rehabilitation project (Wanapum). The velocity and shear field are shown in Figures 5.3.3-3 and 5.3.3-4. In general, the result is unremarkable. At the stay vane leading edge, velocities are low enough to prevent the occurrence of critical shear values, as shown in a magnified view of the stay vane leading edge, Figures 5.3.3-5 and 5.3.3-6. Shear values greater than the critical value were found at the stay vanes trailing edge and at the wicket gate leading edge, Figures 5.3.3-7 and 5.3.38. However, the region having shear greater than the critical shear $(450 / \mathrm{s})$ is quite small. Pressure gradients were small, varying from zero to approximately $500 \mathrm{psi} / \mathrm{sec}$. As these local pressure gradients are presumed to have little effect on fish survival, figures are not provided.

To illustrate the effect of design modifications on flow field characteristics, improvements were made to the shape of both the stay vanes and wicket gates. The stay vane shape was modified to reduce the angle of attack and the wicket gate shape was also changed. The flow field analyzed in this case is not precisely the same as the first case. At a different circumferential location in the semi-spiral case, the inflow to the stay vanes is more tangential. The velocity and shear field are shown in Figures 5.3.3-9 and 5.3.3-10. In general, the flow field is smoother and values of shear are reduced. Values of critical shear no longer occur on the gate leading edge. Only a smaller region of critical shear is observed near the stay vane trailing edge, Figures 5.3.3-11 and 5.3.3-12. This optimized gate and vane was found (through laboratory testing) to increase turbine efficiency.

The wicket gate openings analyzed above were chosen to avoid large openings where the gate overhangs the bottom ring. At higher gate openings, a gap is created at the bottom of the gate, allowing a leakage flow to develop. No CFD calculations were made to verify the unfavorable flow field that is presumed to exist at the higher gate opening.

In summary, the risk of fish mortality for optimized stay vanes seems low for Kaplan turbines at typical heads, and a good indicator of fish friendliness is a hydraulic design that gives good efficiency. Higher velocities on the wicket gates may have greater potential for injury. Although not analyzed, other gate openings that occur at different operating conditions will cause different flow fields and will have different mortality. In general, it seems that good turbine designs that optimize turbine efficiency are beneficial for fish survival. 

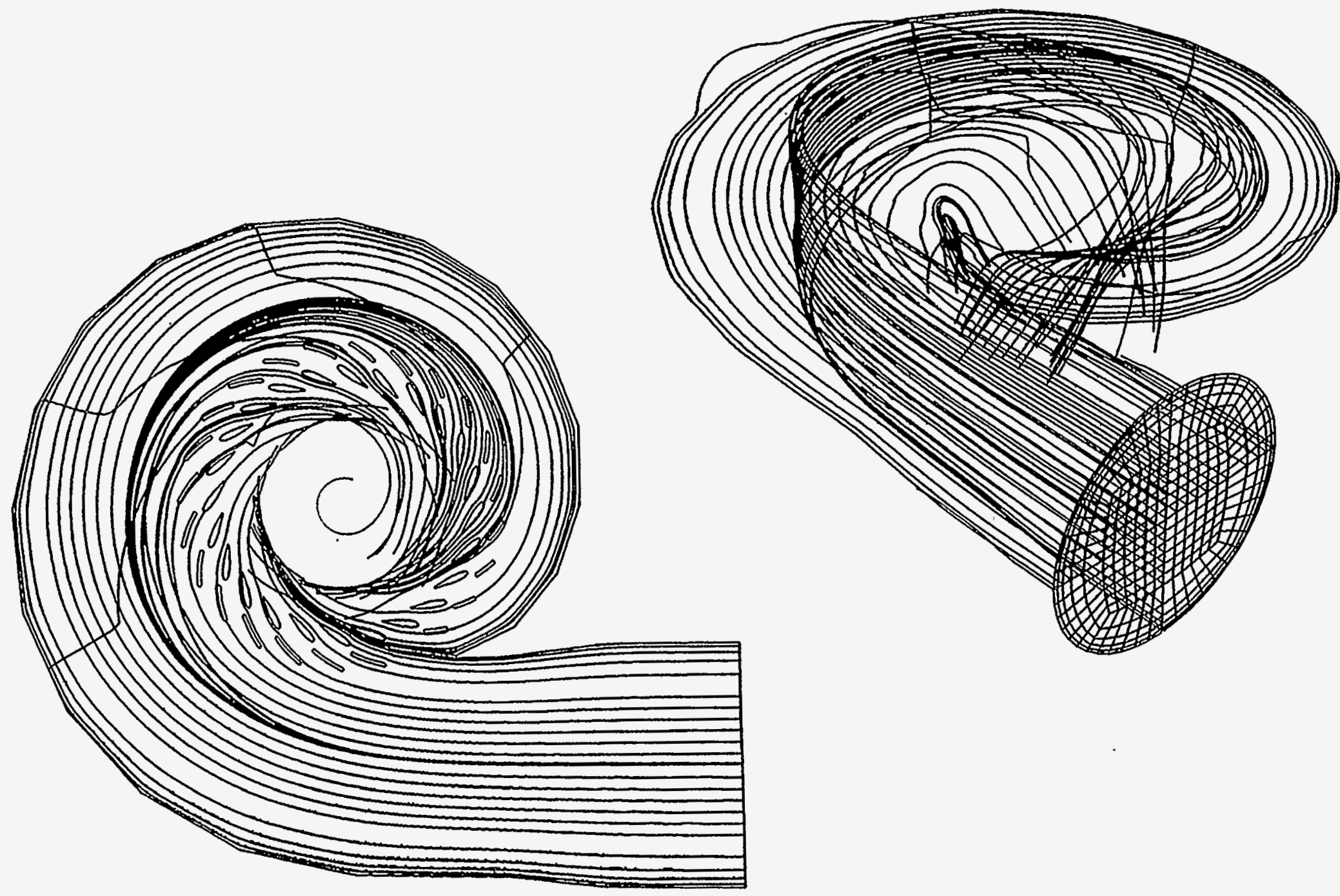

Figure 5.3.3-1 Streamlines in a Spiral Case. Initial Position Does Not Correspond to a Particular Runner Inlet Position 


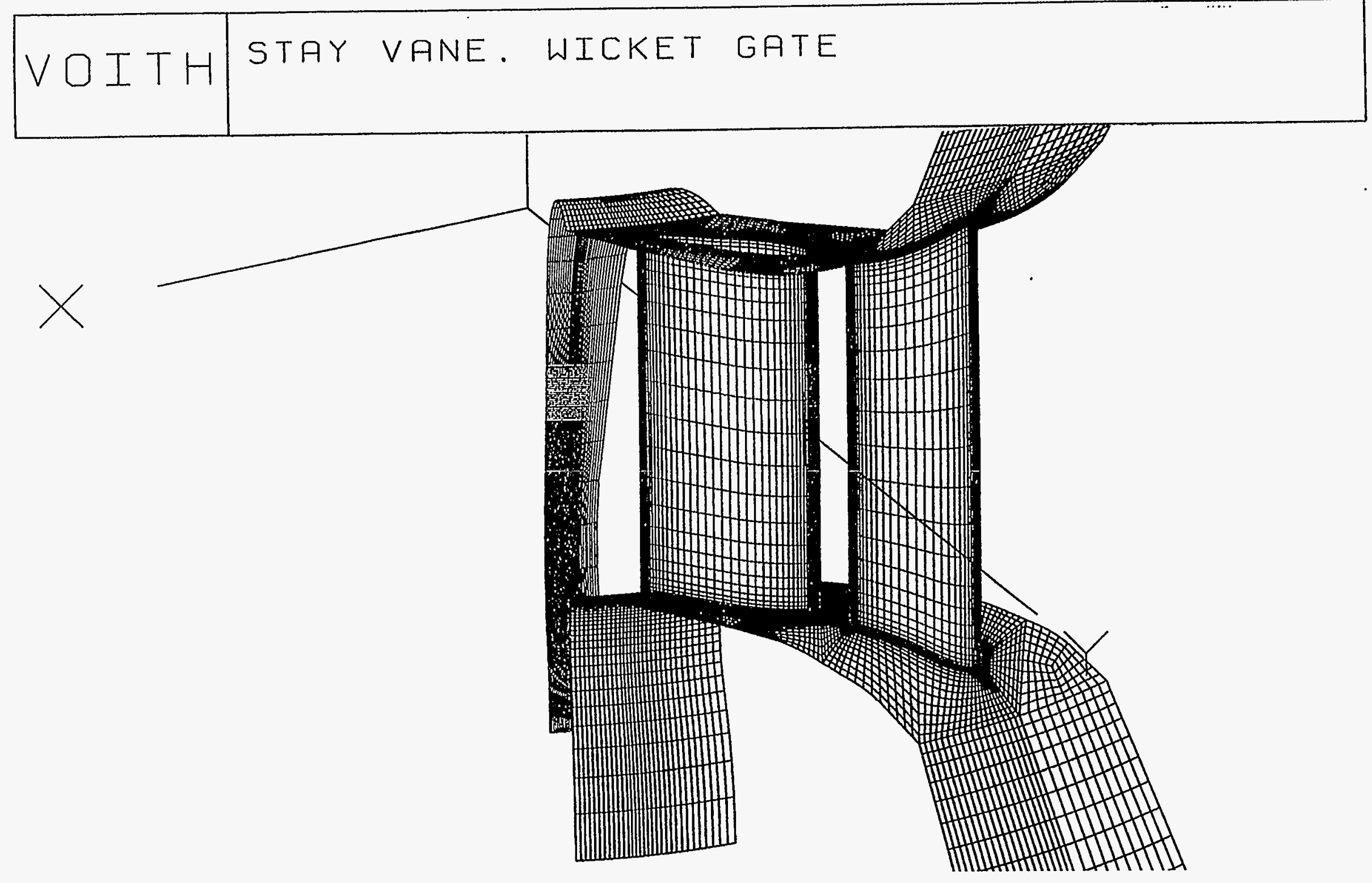

Figure 5.3.3-2 Typical Grid Showing Wetted Surfaces Of A Typical Stay Vane And Wicket Gate 


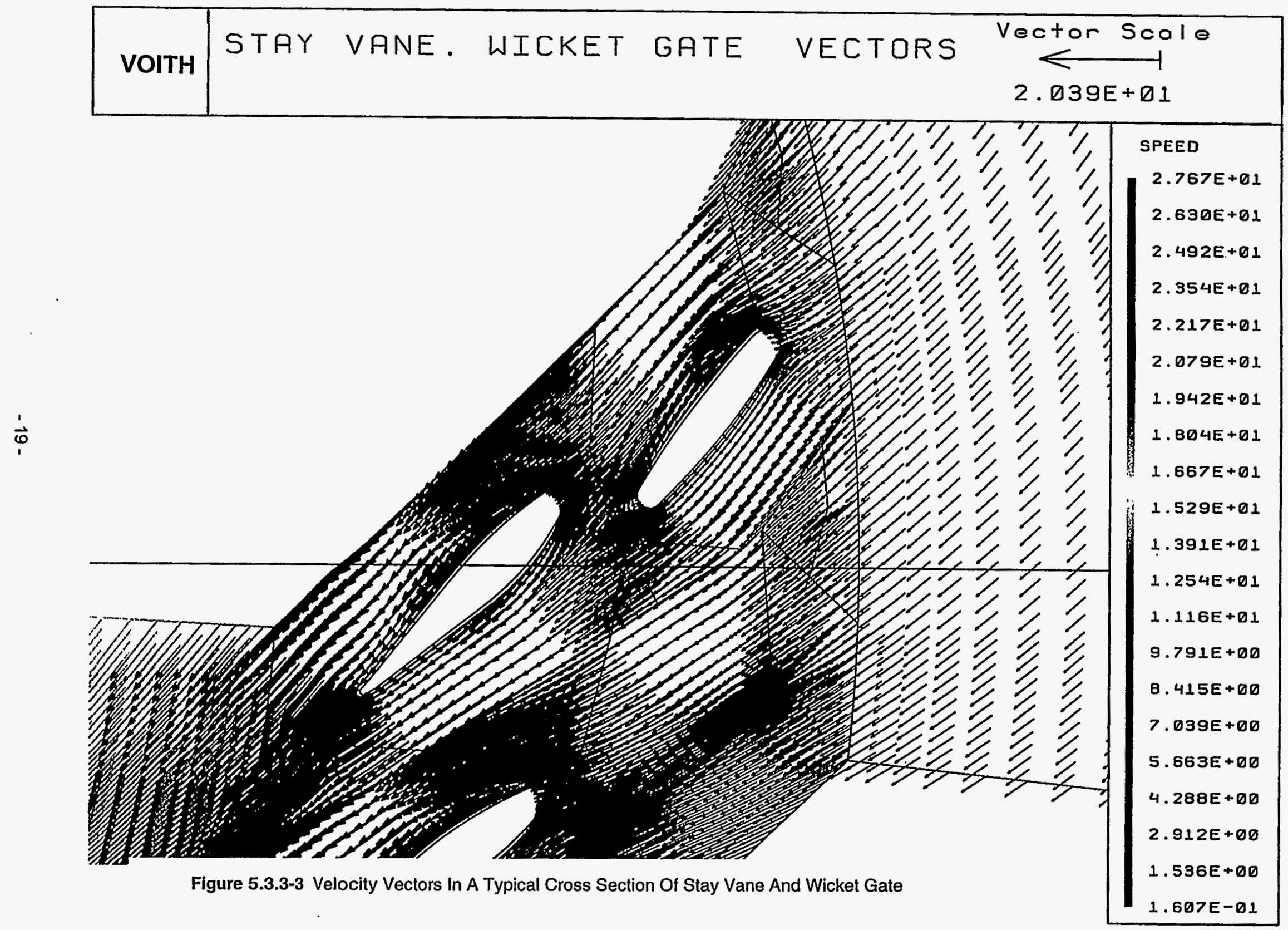




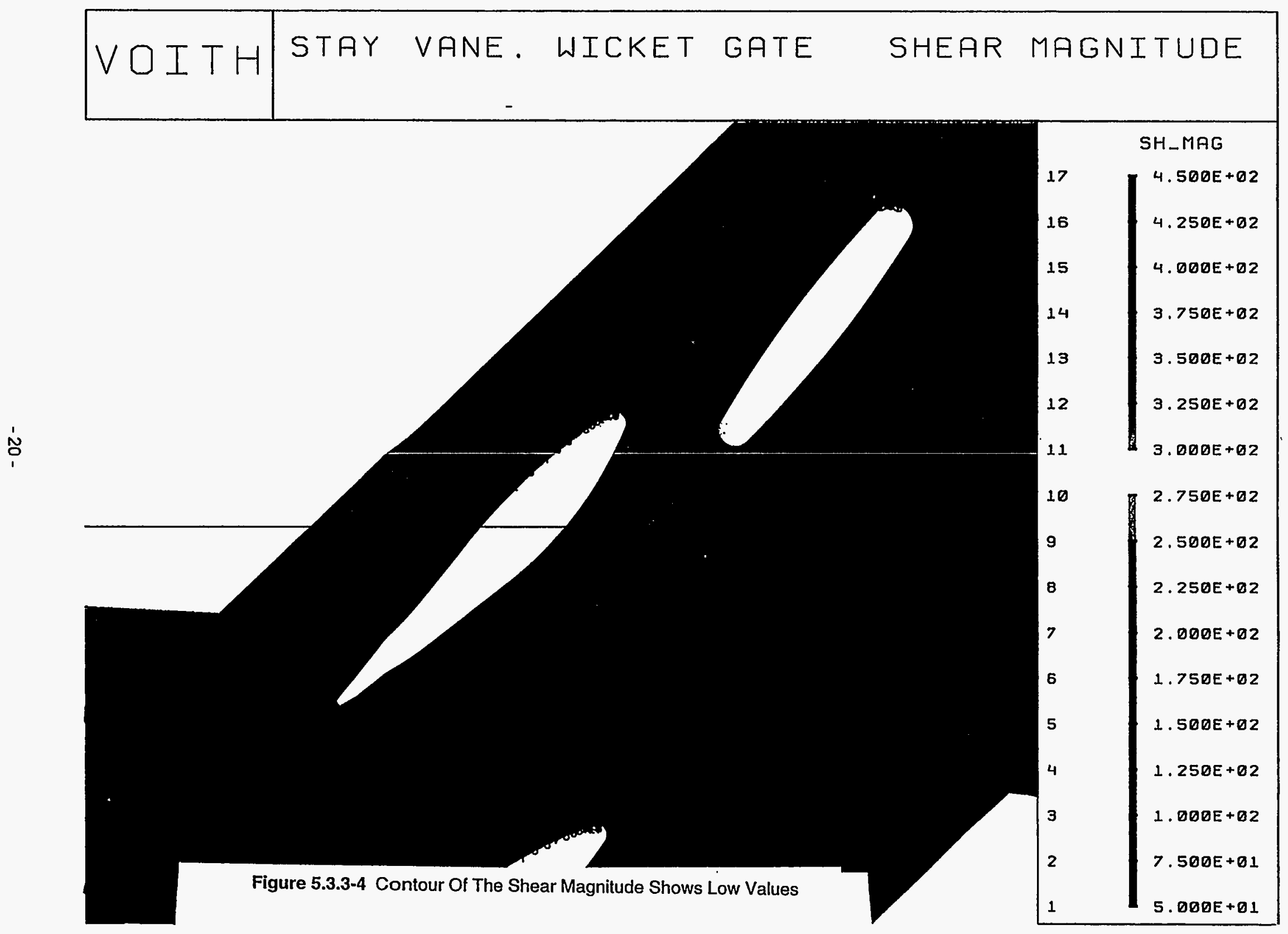




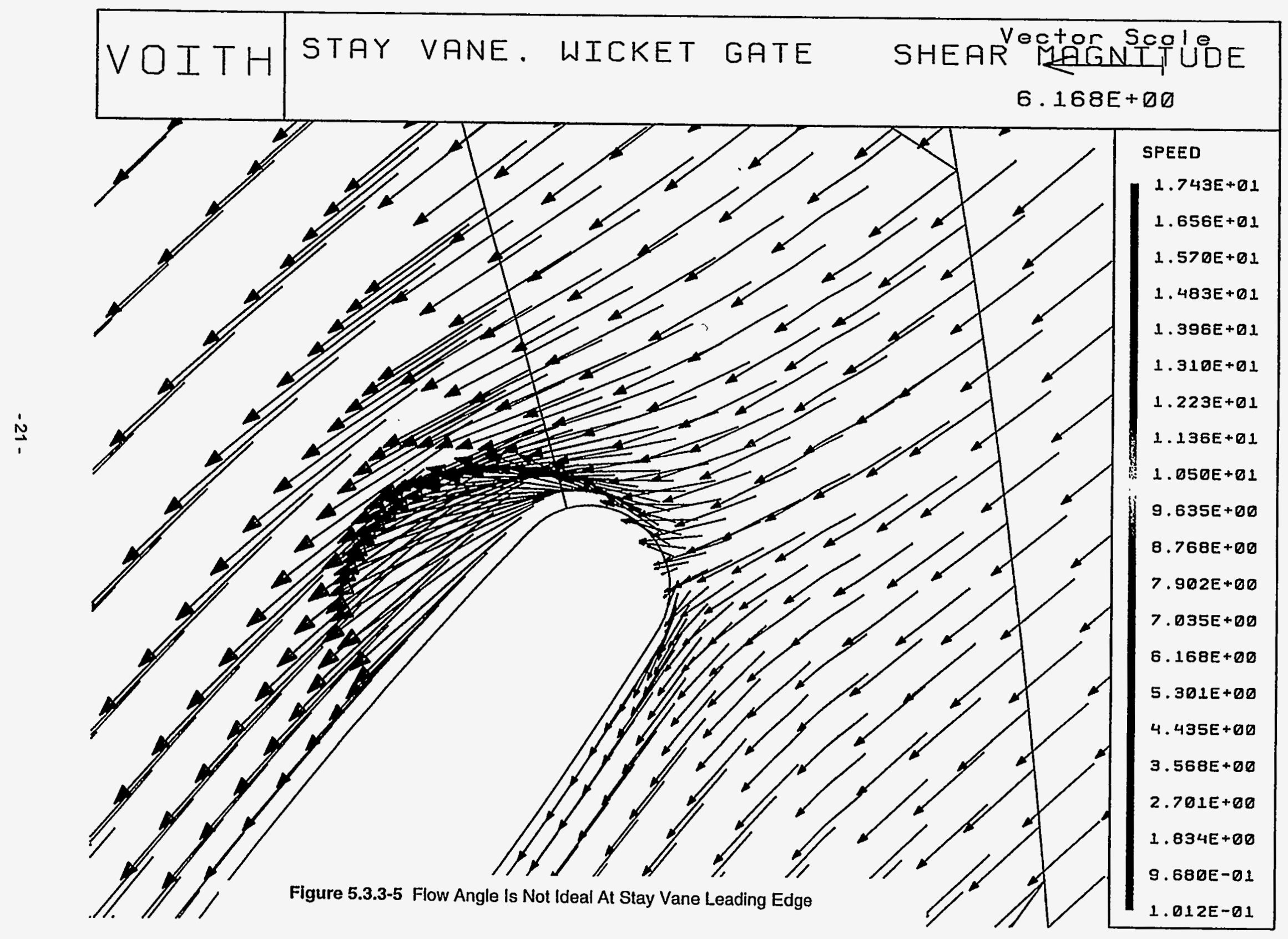




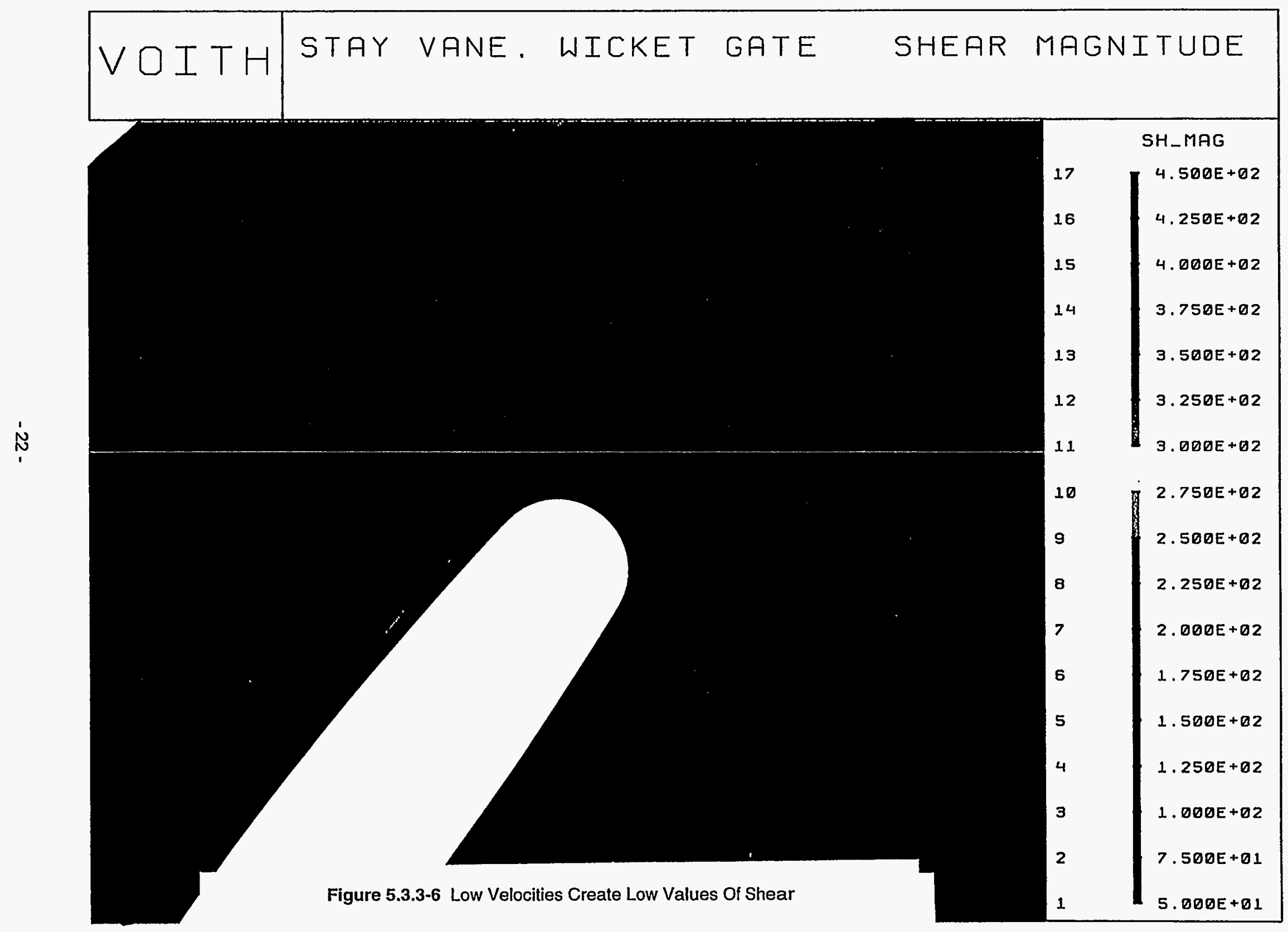




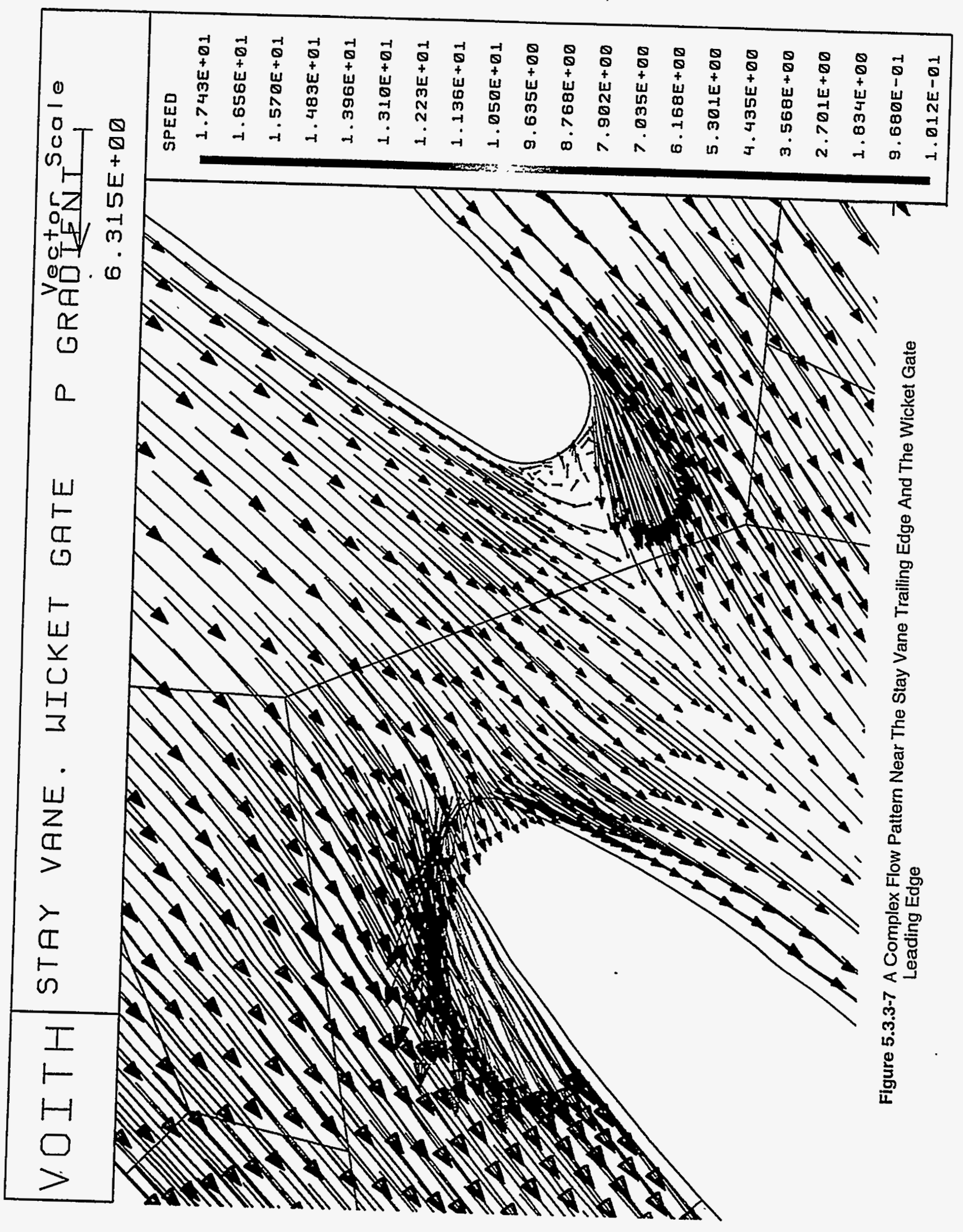




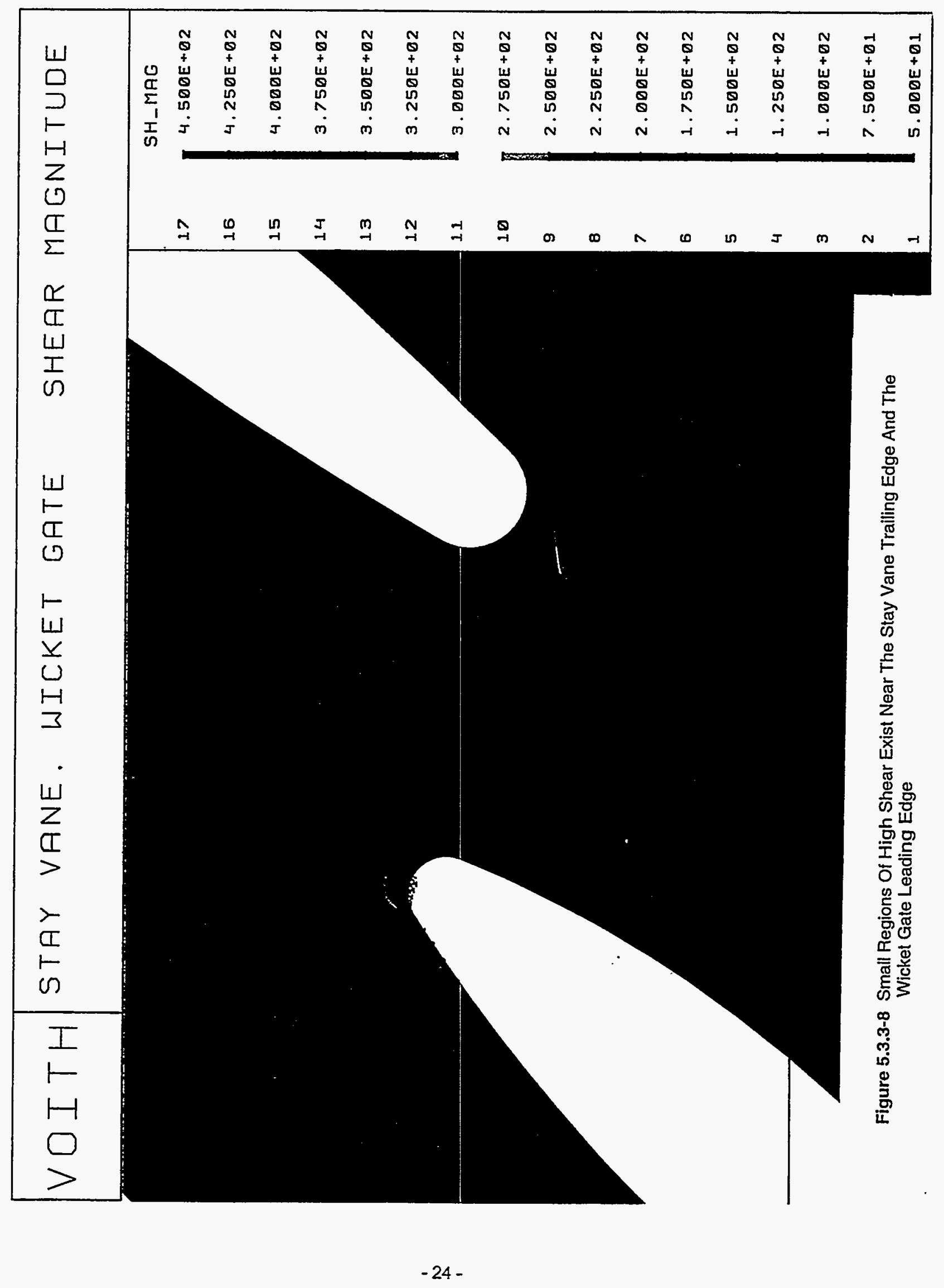




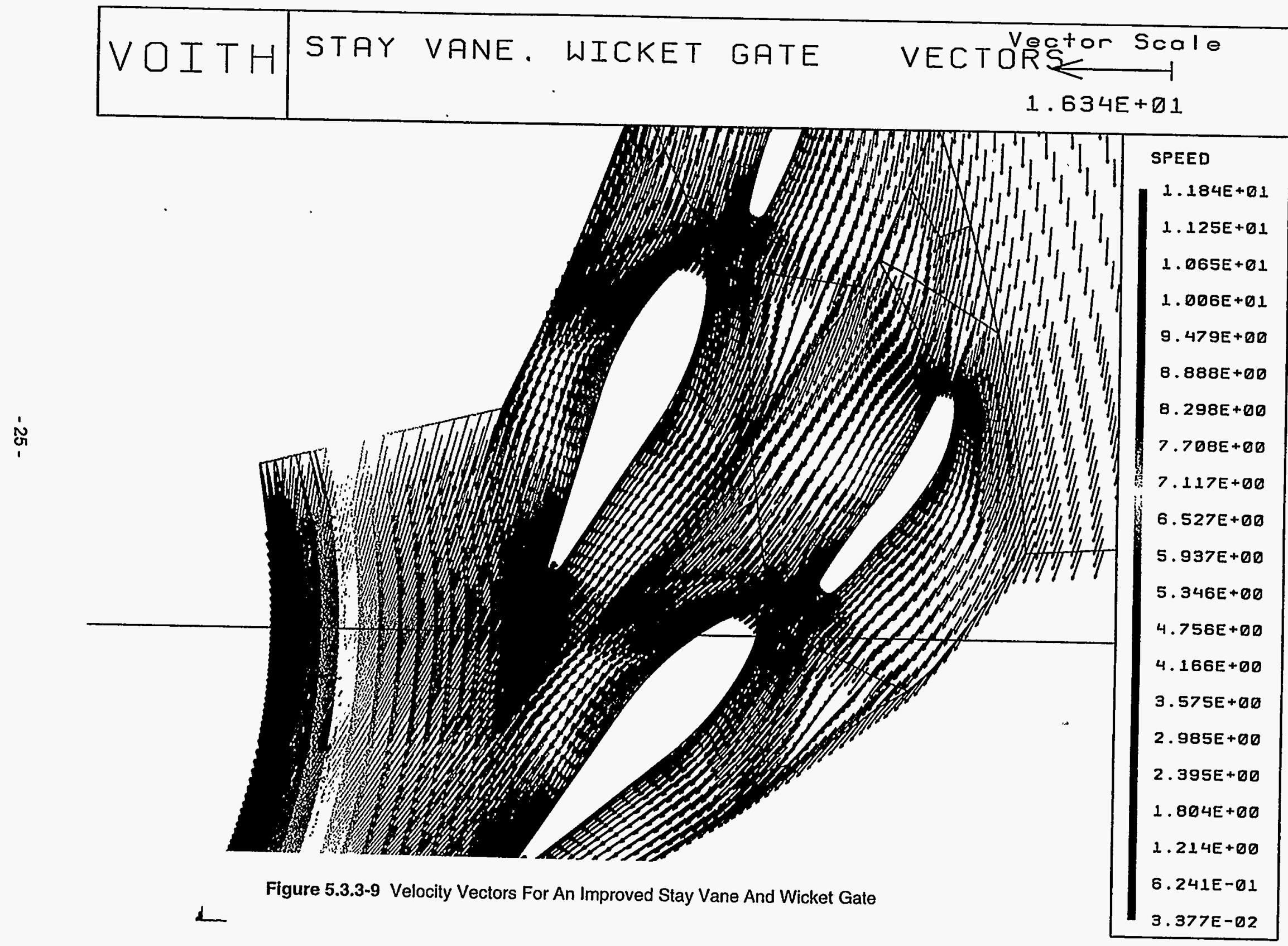




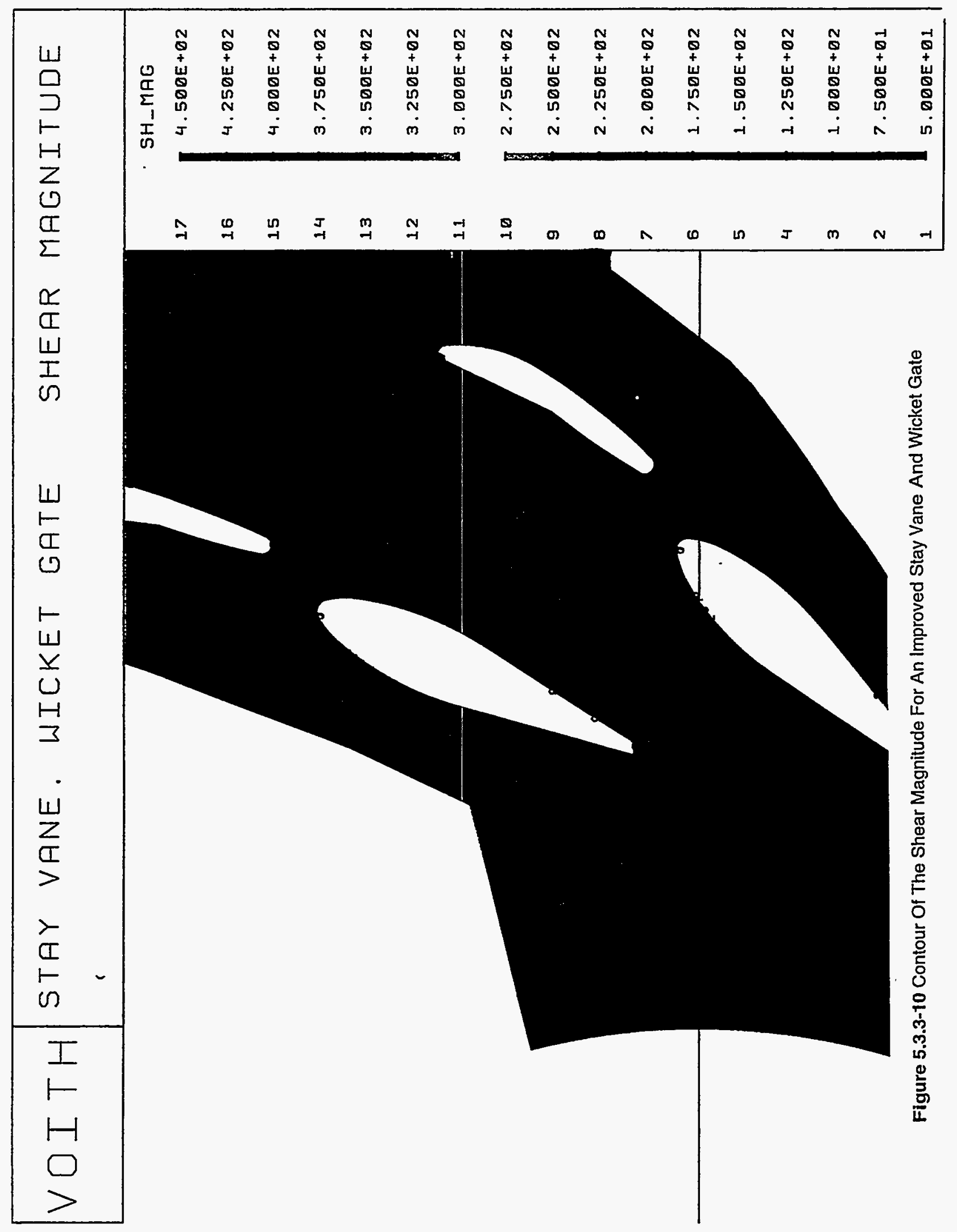




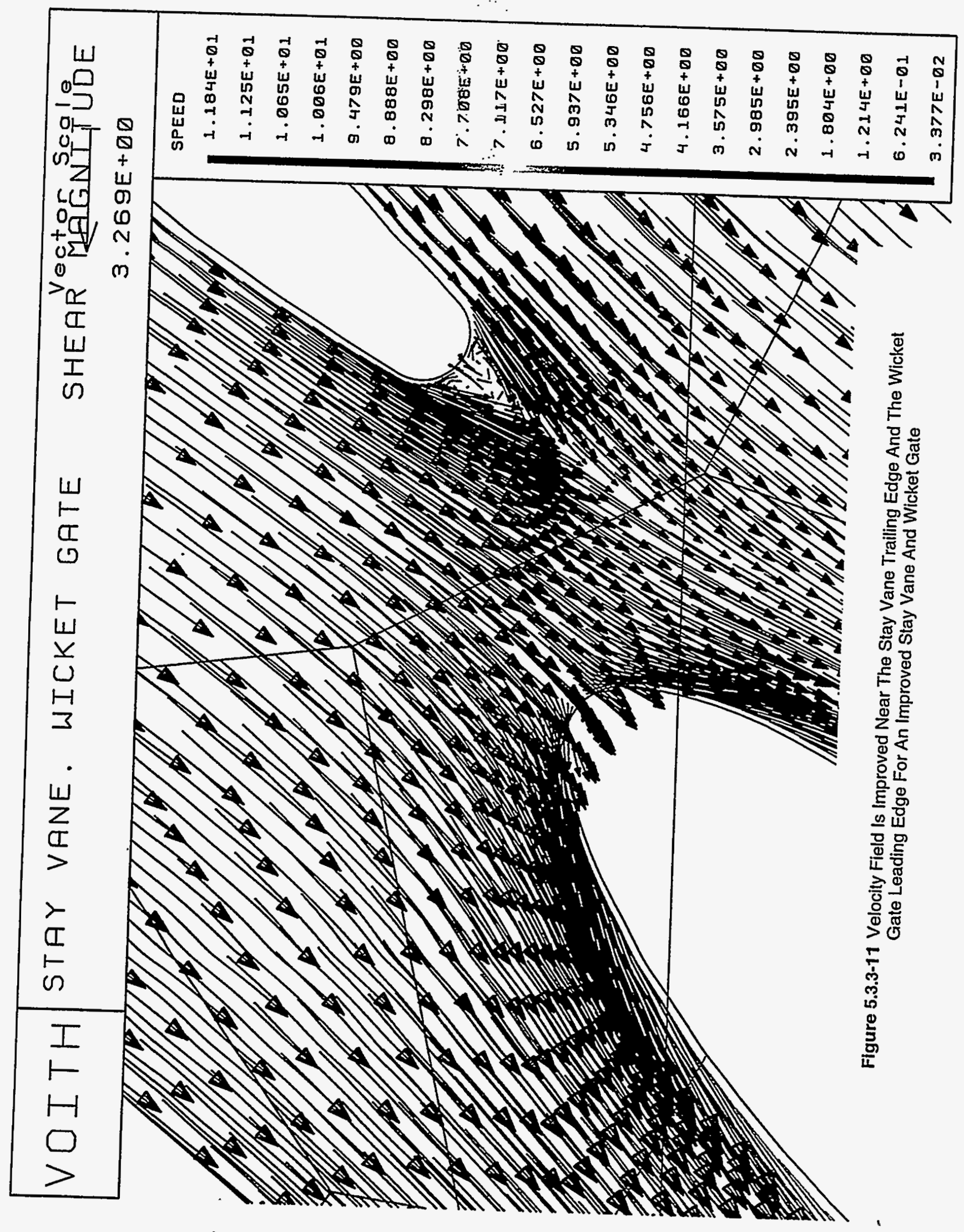




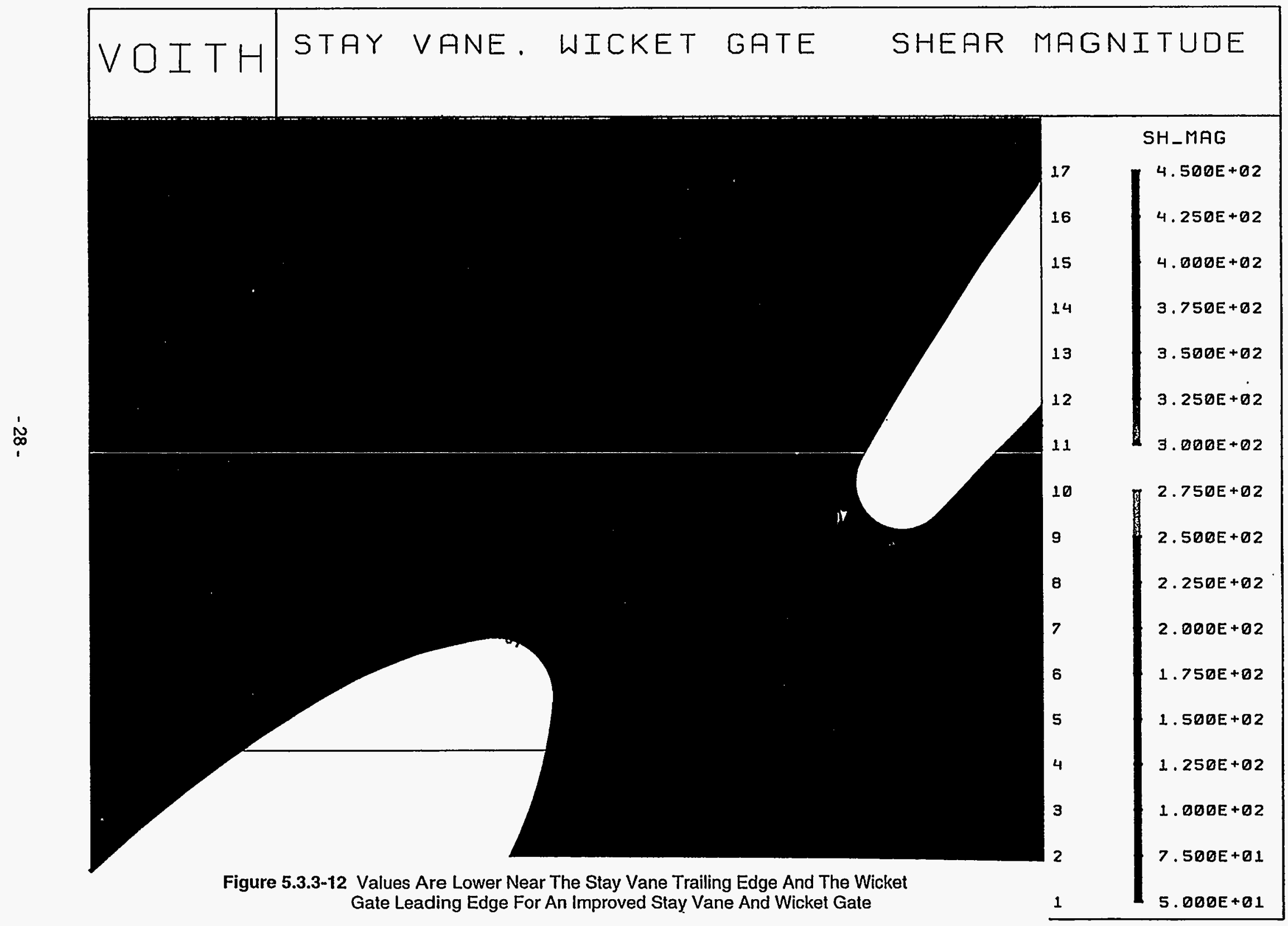




\subsubsection{KAPLAN TURBINE RUNNER}

Kaplan turbine runner blades were analyzed at an on cam condition. The inflow condition to the runner is obtained from a stay vane and wicket gate analysis. Periodic boundary conditions are used so that only one flow channel needs to be analyzed. The runner blade extended completely from hub to periphery, without any gaps or clearances.

Figure 5.3.4-1 shows a typical grid as well as streamlines that have been colored to show prototype transit time. Streamlines typically exit the runner in approximately 0.2 to $0.3 \mathrm{sec}$.

The prediction of cavitation is important for avoiding fish injury as well as for achieving good operating characteristics. Figure 5.3.4-2 shows a prediction of cavitation on the suction side of the blade and 5.3.43 is a prediction for the pressure side. The results are presented such that the pressure reaches vapor pressure if the values shown reach the plant sigma parameter. Based on a plant sigma of 0.7 , this blade shape is not ideal as cavitation would occur on both pressure side, on a small region near the periphery leading edge, as well as on larger regions of the suction side.

Two locations through the runner blade were analyzed to study fluid-induced damage mechanisms, near the periphery, and near the hub. Figures 5.3.4-4 through 5.3.4-10 present velocity, shear, pressure gradient, and absolute pressure at a location near the periphery. Figures 5.3.4-11 through 5.3.4-15 present similar information for a location near the hub. Overall critical shear values are small when viewing the entire blade, but in the detailed views of the leading and discharge edges, values of critical shear exist at the leading edge near the periphery. The lower flow velocities near the hub do not induce regions of critical shear. The higher speed fiow at the periphery also causes a thin layer of critical shear on both the pressure and suction sides of the blade. This identifies another possible mechanism of fish injury. Secondary flows that might cause a fish to move toward the blade surface could cause injury that might be independent of possible fish scrape or contact with the blade. This shear region is quite thin and is therefore, not suspected as a major mechanism of injury. Pressure gradients are greater in the runner than in the stay vanes and wicket gates, achieving values in excess of $750 \mathrm{psi} / \mathrm{sec}$. These values are not believed to induce any fish injury. Generally, high pressure gradients occur near the leading edge and near the trailing edge. These regions are somewhat larger for the periphery than the hub.

In general, a well designed Kaplan blade operating on cam, having no gaps, and operating without cavitation, seems to cause only small local regions of critical shear that might cause fish injury.

A preliminary analysis was made of a conventional Kaplan blade at its mid range tilt position with hub and periphery gaps. This calculation was a first effort and results are viewed as preliminary. Two analyses were made, one analysis assumed the blade extended exactly to the hub and periphery, so that no gaps existed. A second analysis included gaps at the hub entrance and discharge and the periphery entrance and discharge. Figure 5.3.4-16 shows the blade and hub grid to permit visualization of the hub gap. Visualization of the results is presented with streamlines that have been colored to show the value of shear. Streamlines were released in all gap locations. In Figure 5.3.4-17, streamlines were seeded in the gap at the blade periphery and also the blade was colored according the value of local velocity. High shear values exist on the streamlines in the gap and for a short distance downstream of the gap. Subsequently, the flow moves downstream without evidence of vortices or other significant flow disturbance. Figures 5.3.4-18 and 5.3.4-19 show shear in a region near the periphery leading edge for both gap and no gap calculations. The calculation that includes the gap has a larger region of critical shear. Streamlines seeded in all four gap locations (hub entrance edge and discharge edge, and periphery entrance edge and discharge edge) are shown in Figure 5.3.4-20. The periphery gap leakage flow seems to not form a strong vortex at this particular operating condition, but the hub entrance edge 
leakage forms a large vortex and the streamlines do not travel along the hub, but move radially outward and are at a rather large radius when they leave the blades. The implications for a fish traversing such a vortex can not be quantified at this time, but are presumed to be significant. The flow through the hub discharge edge gap also forms a strong vortex, with similar implications, and indeed with tested adverse consequences for fish survival (see Section 4.4.5). 


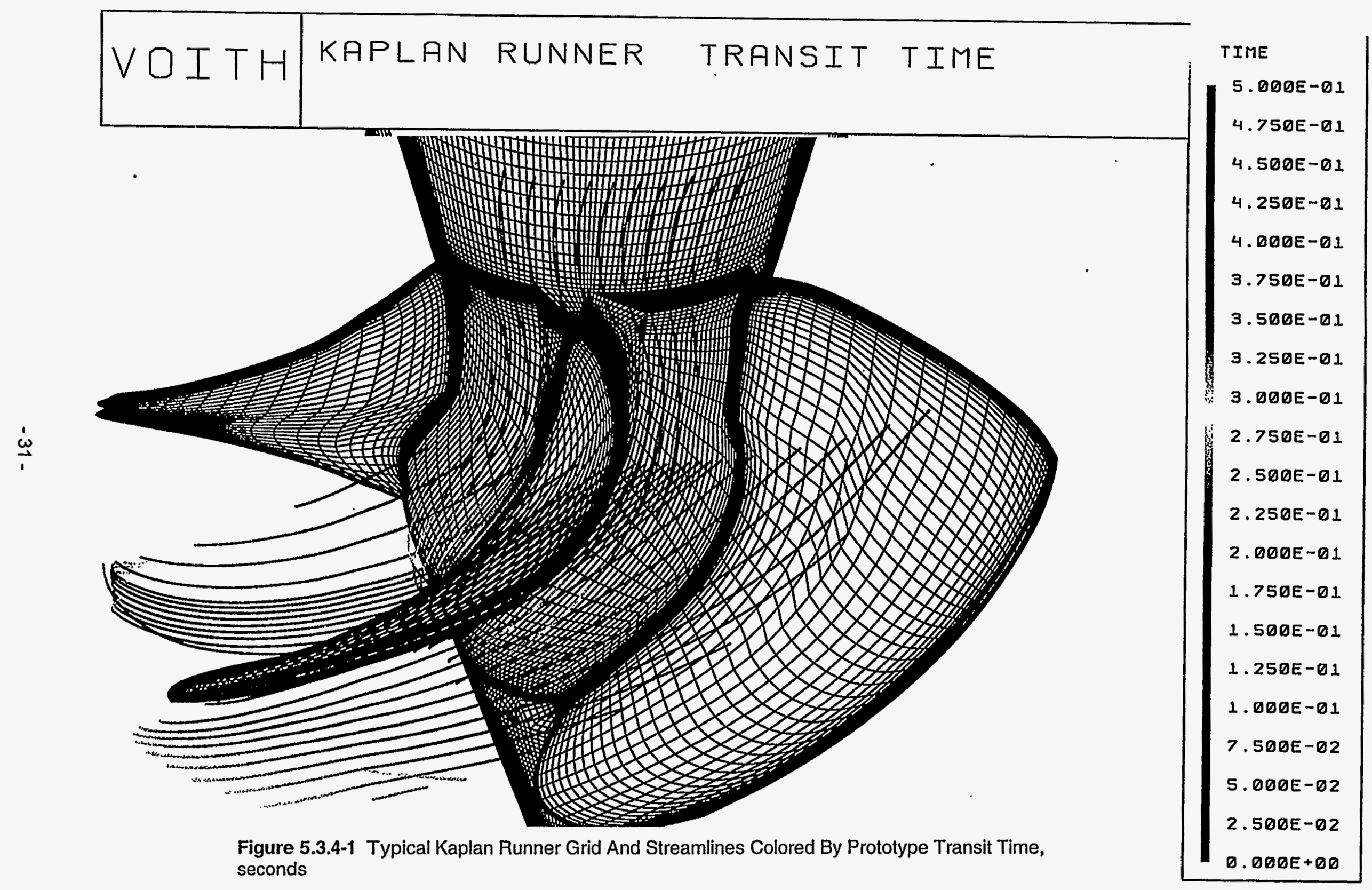




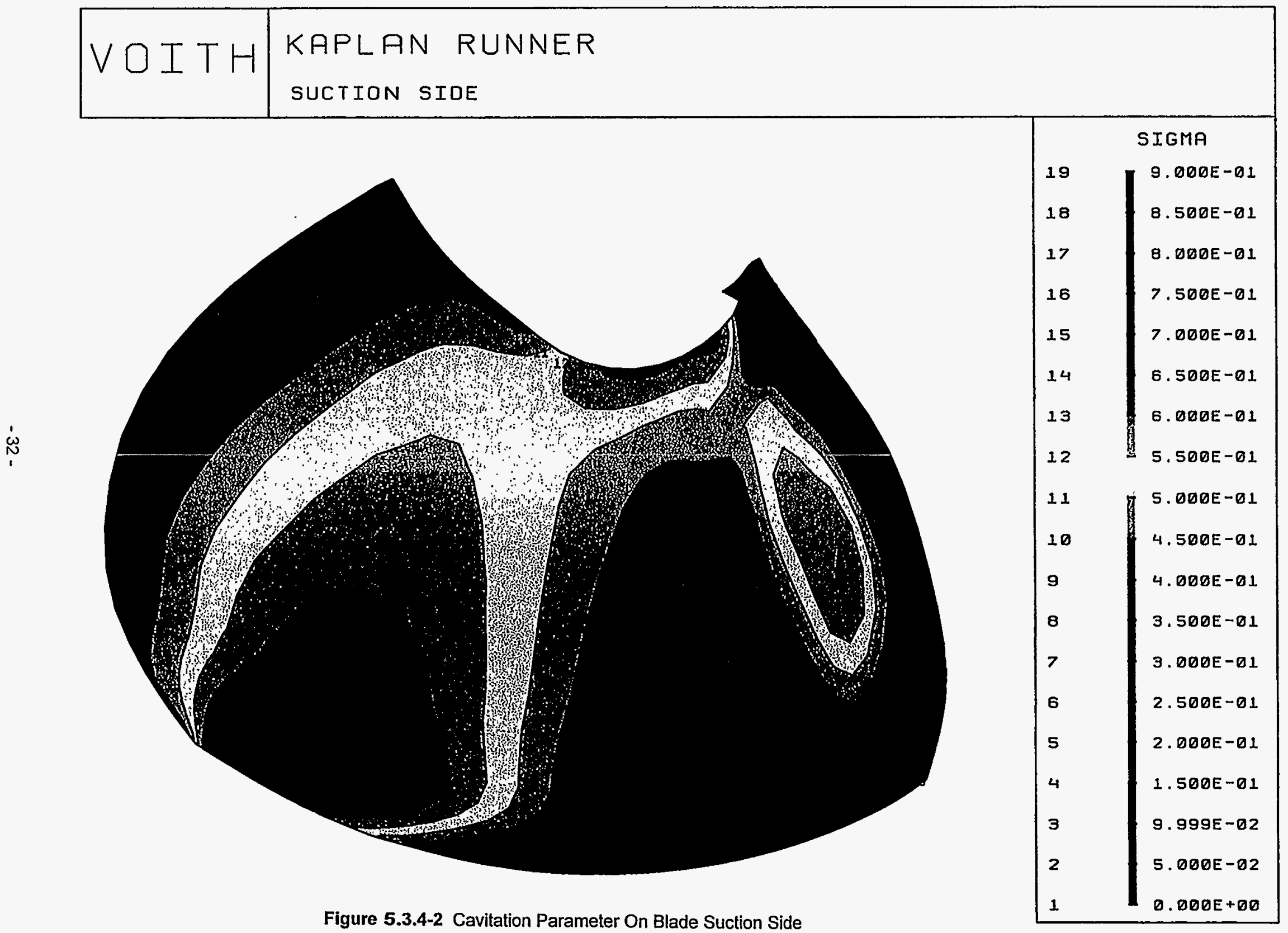




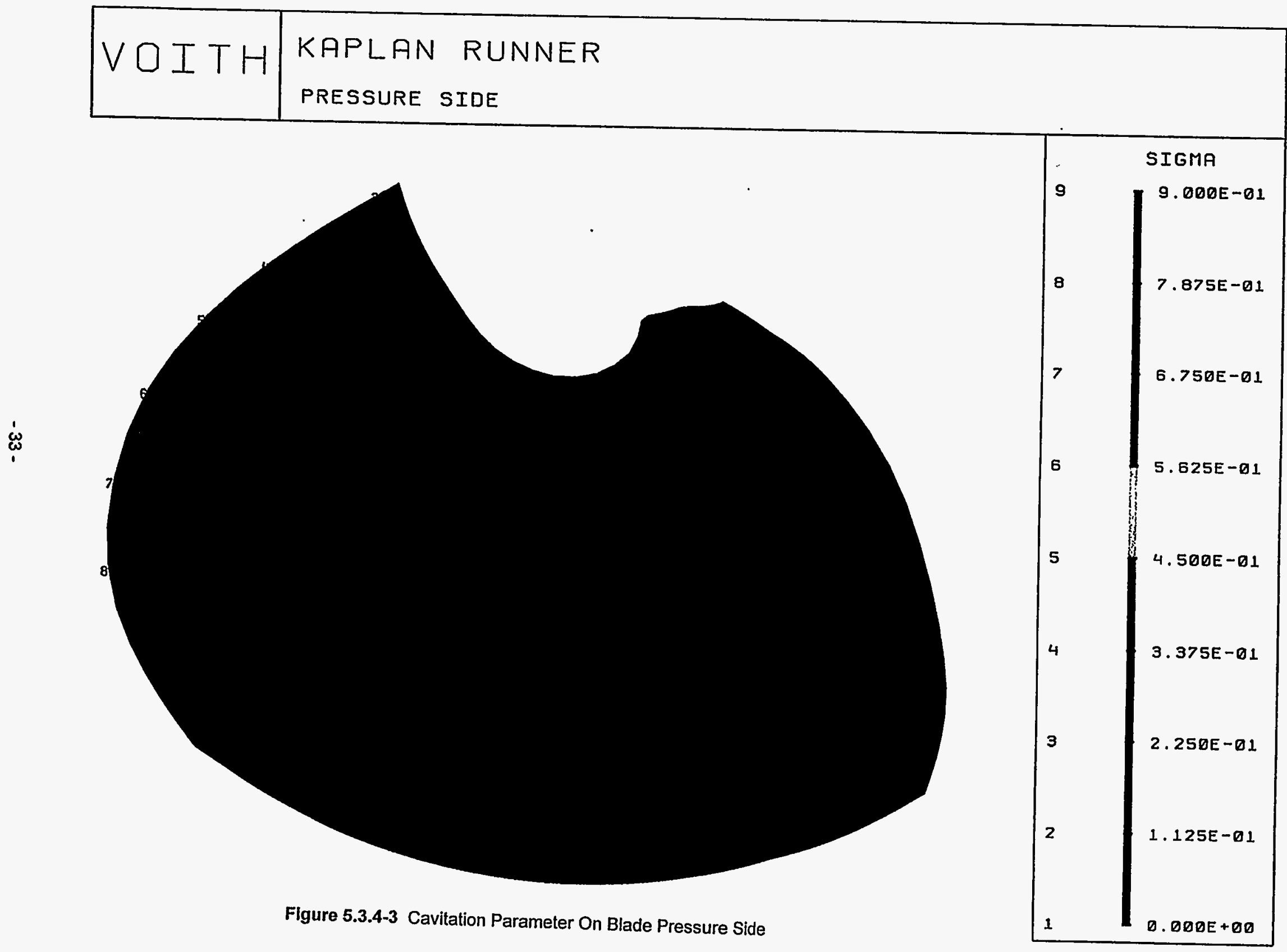




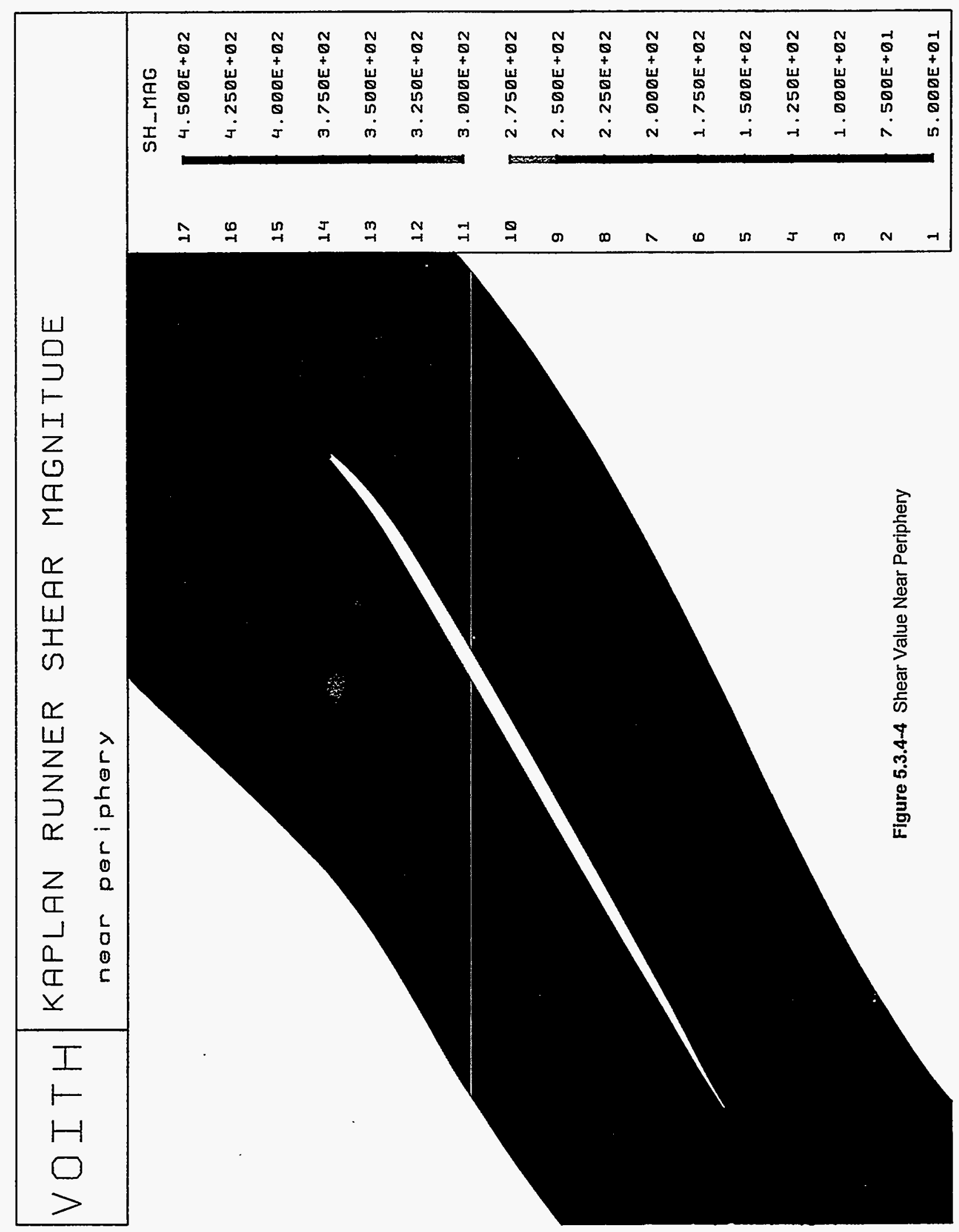




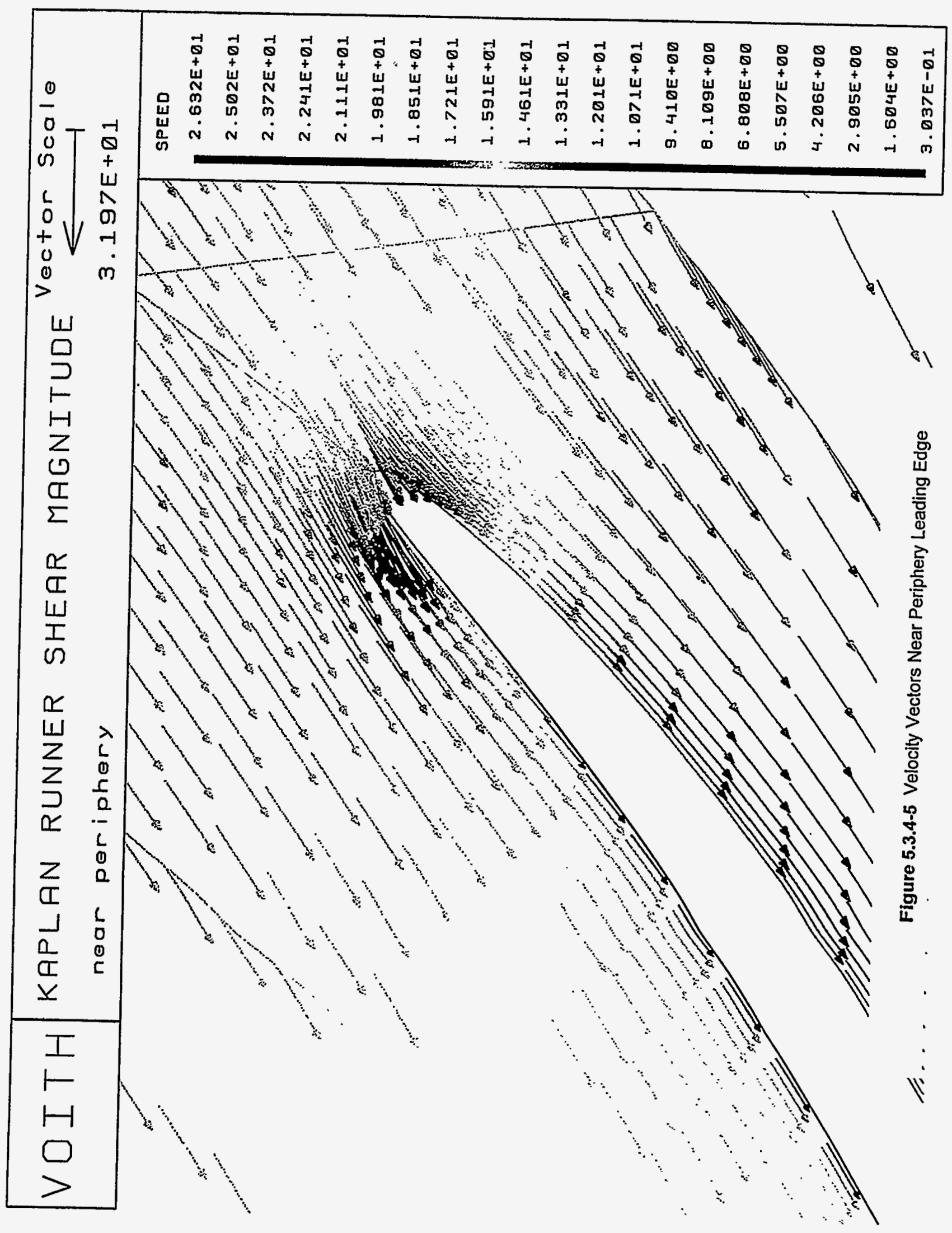




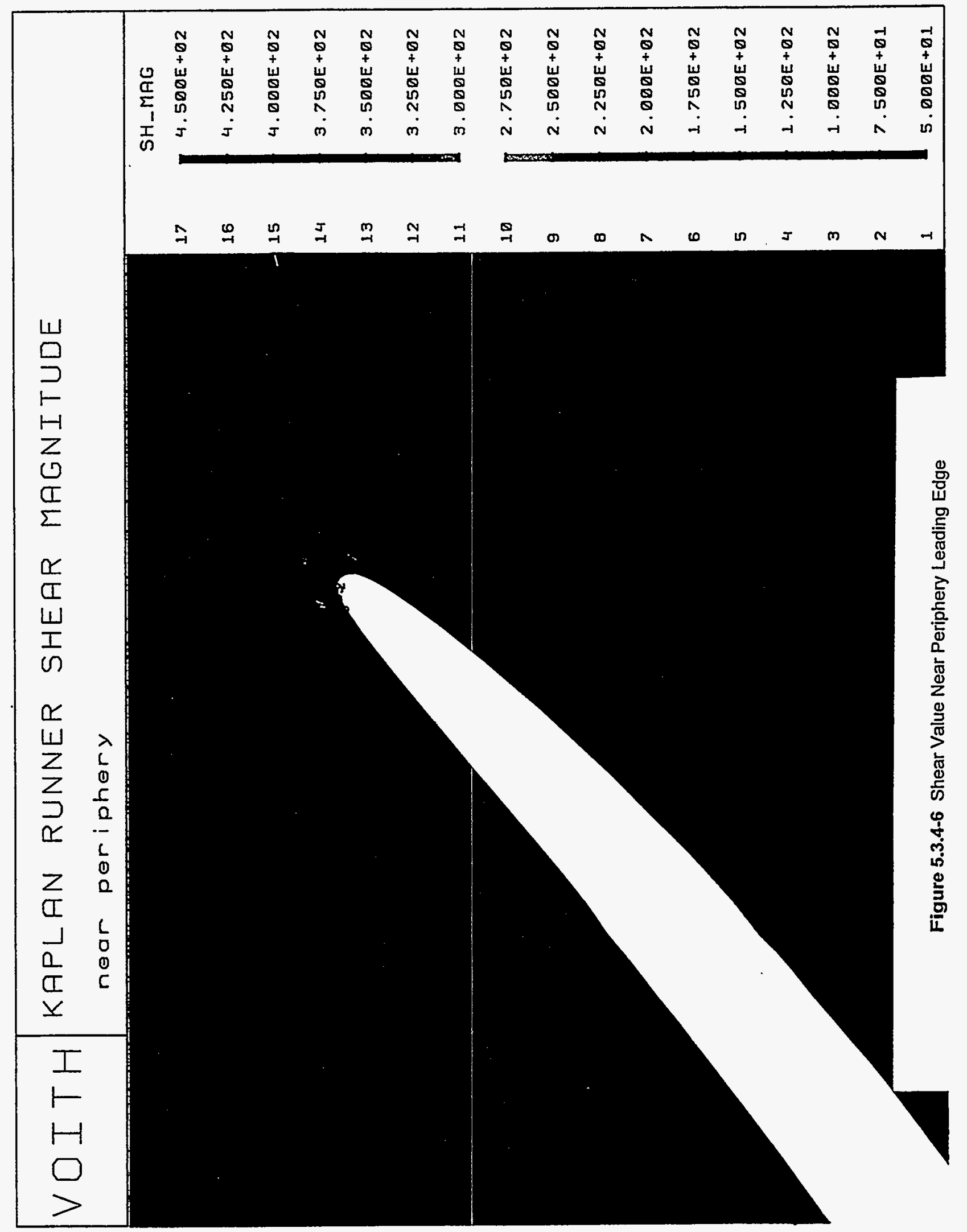




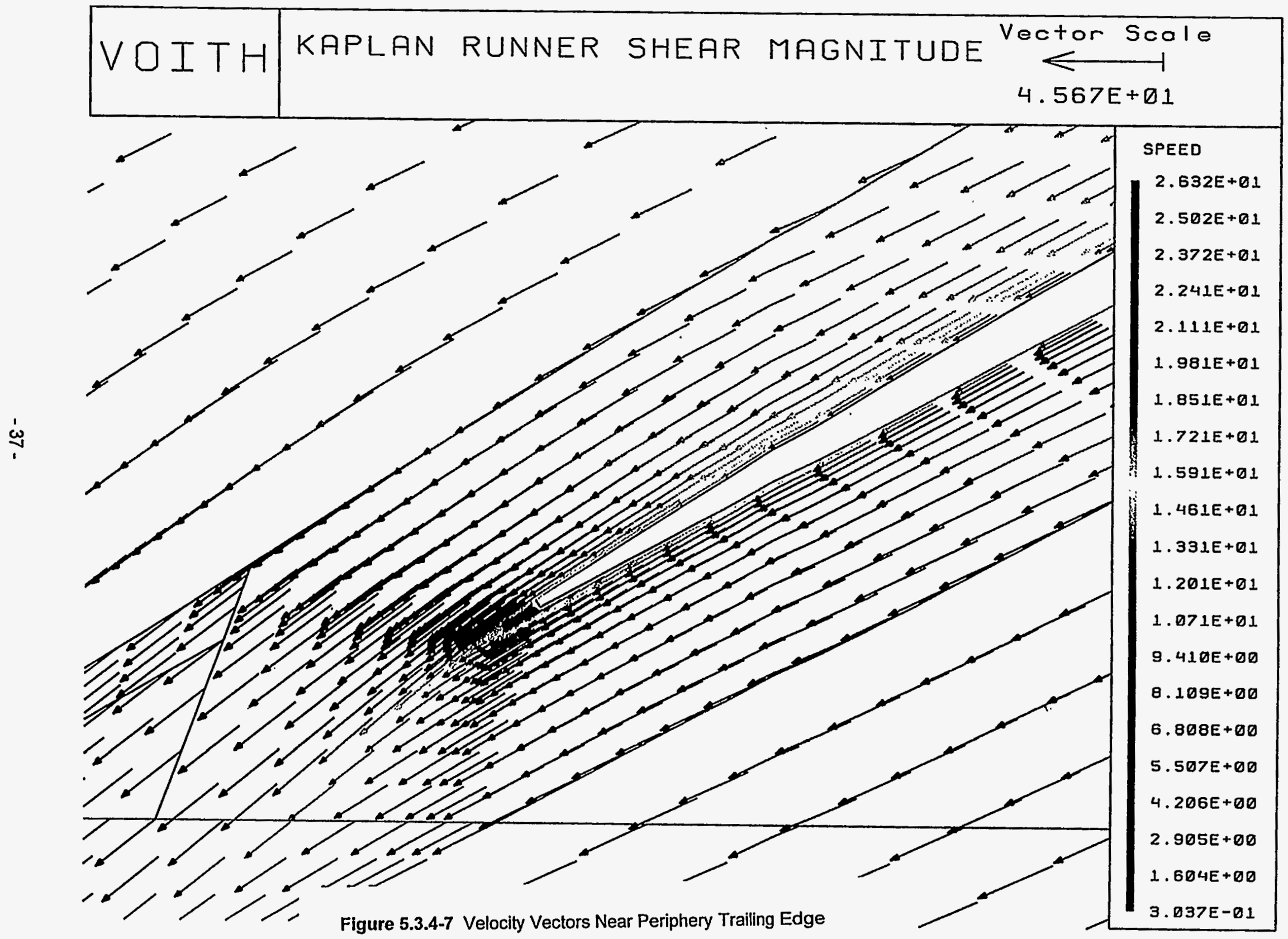




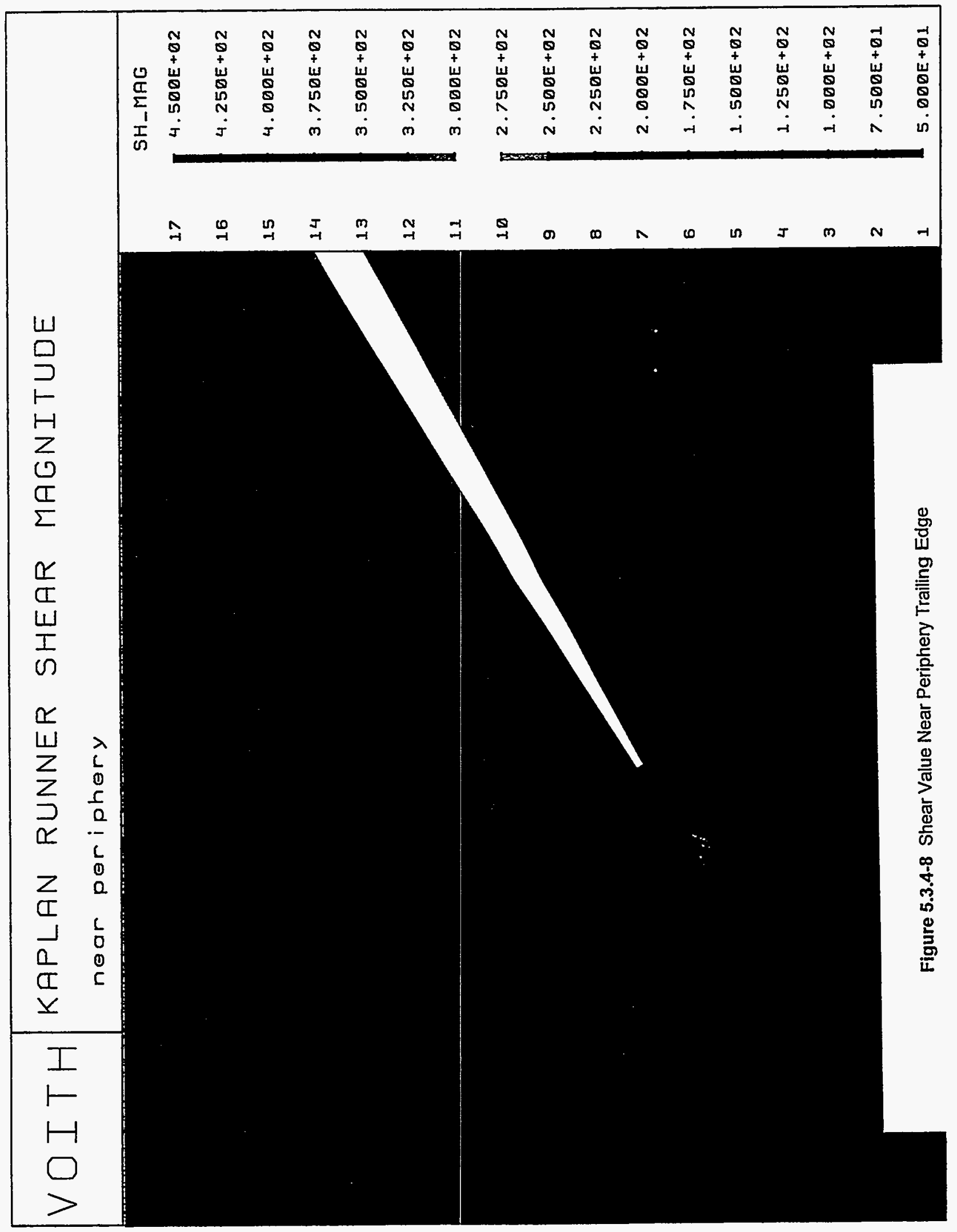




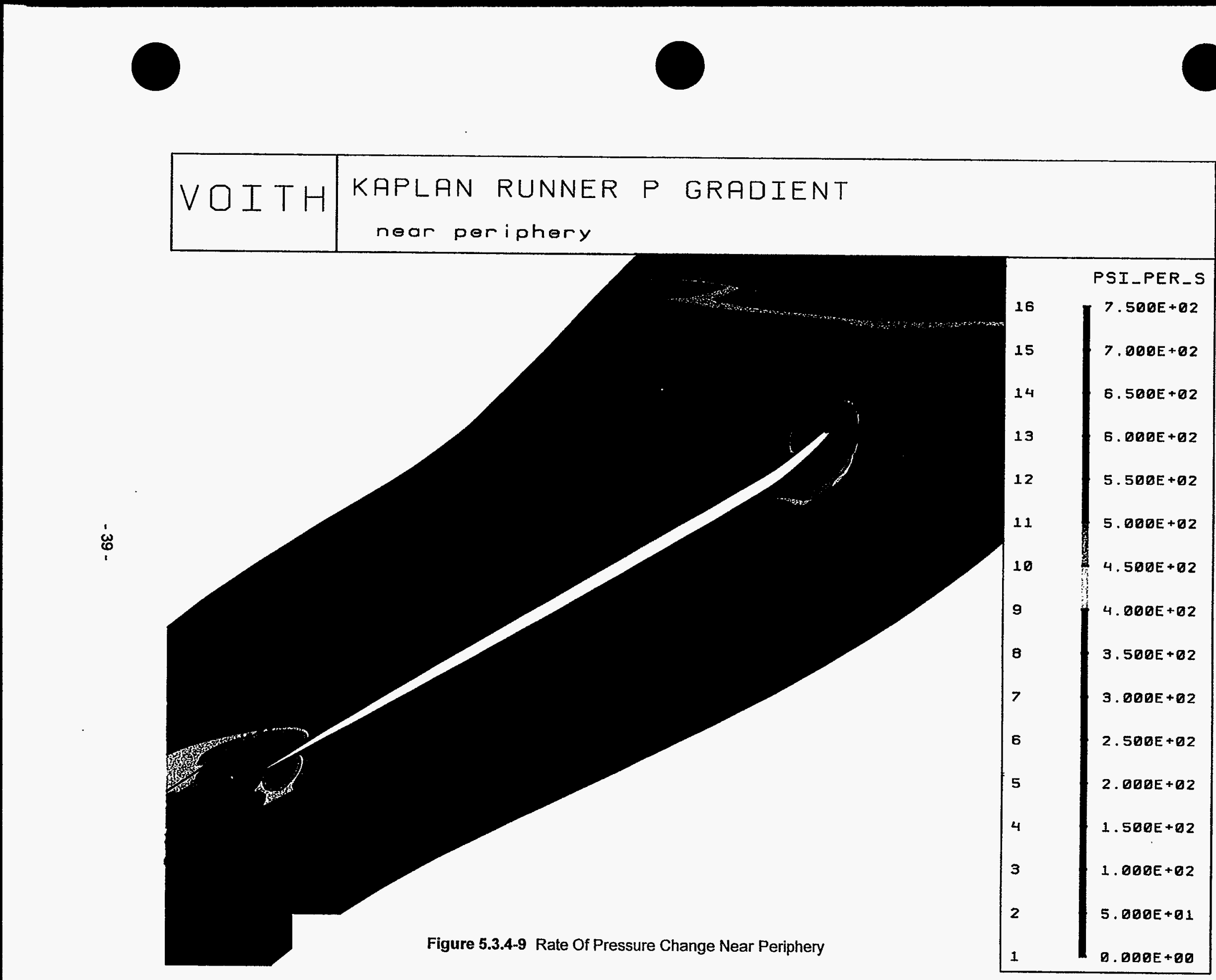




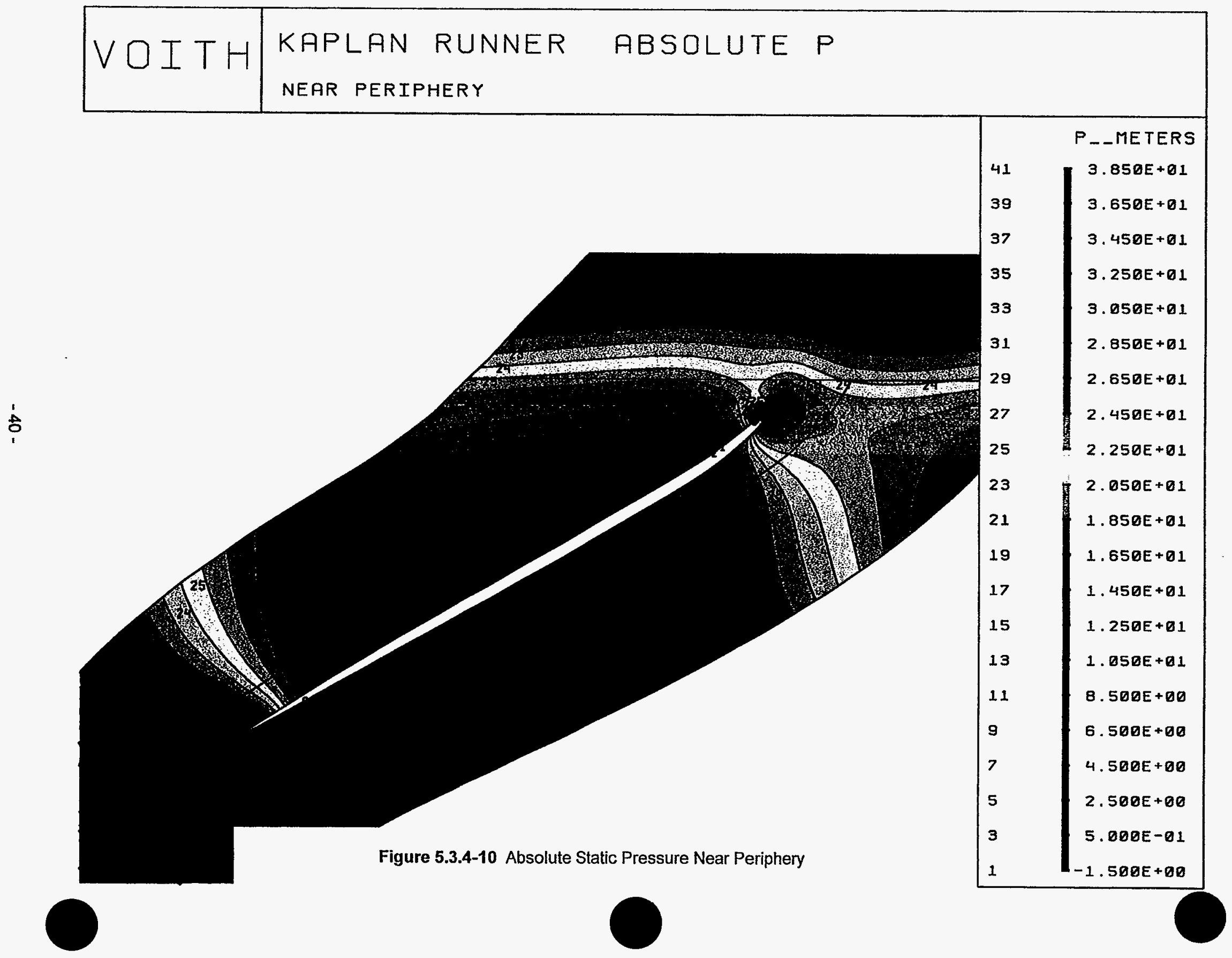




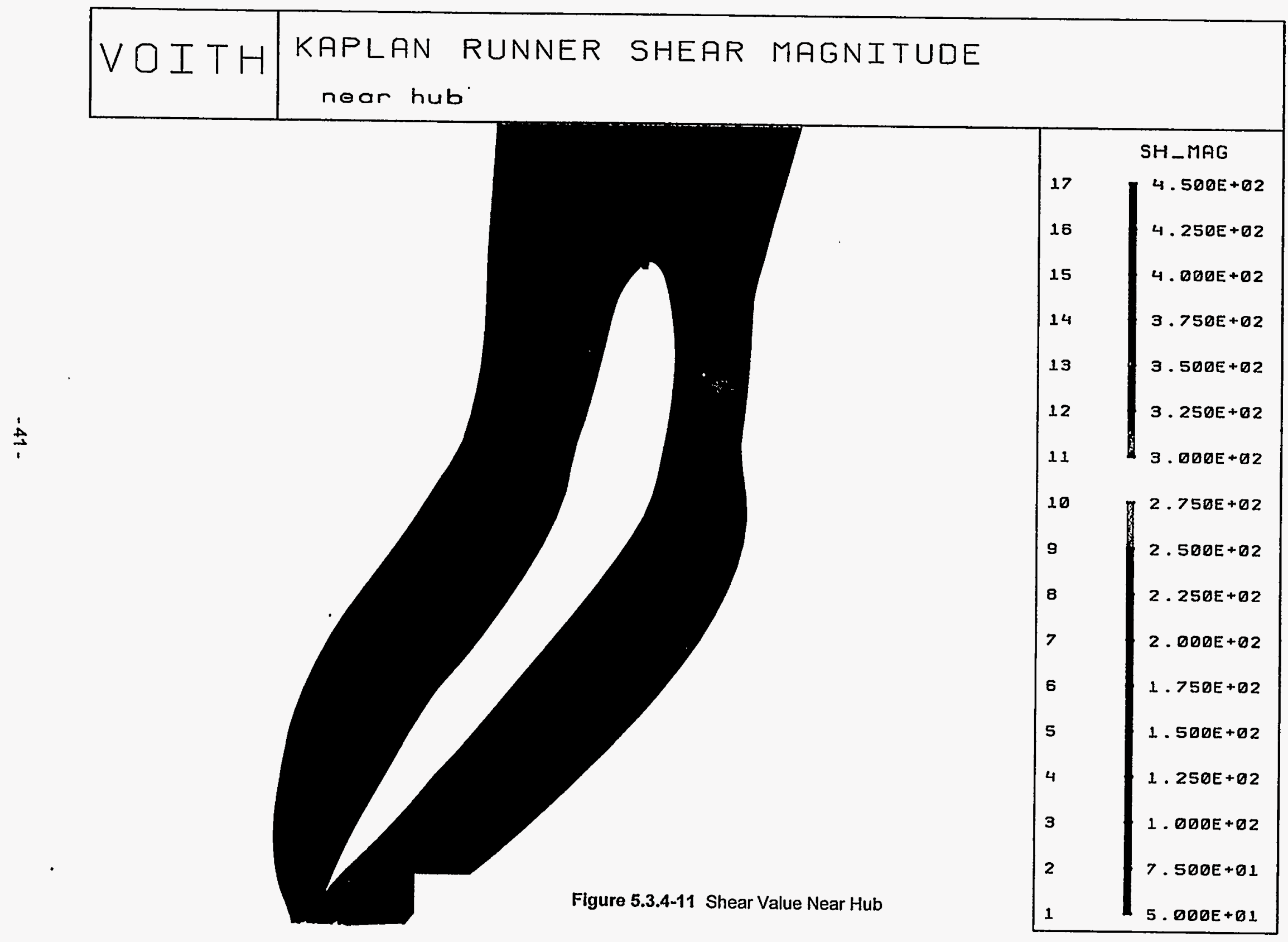




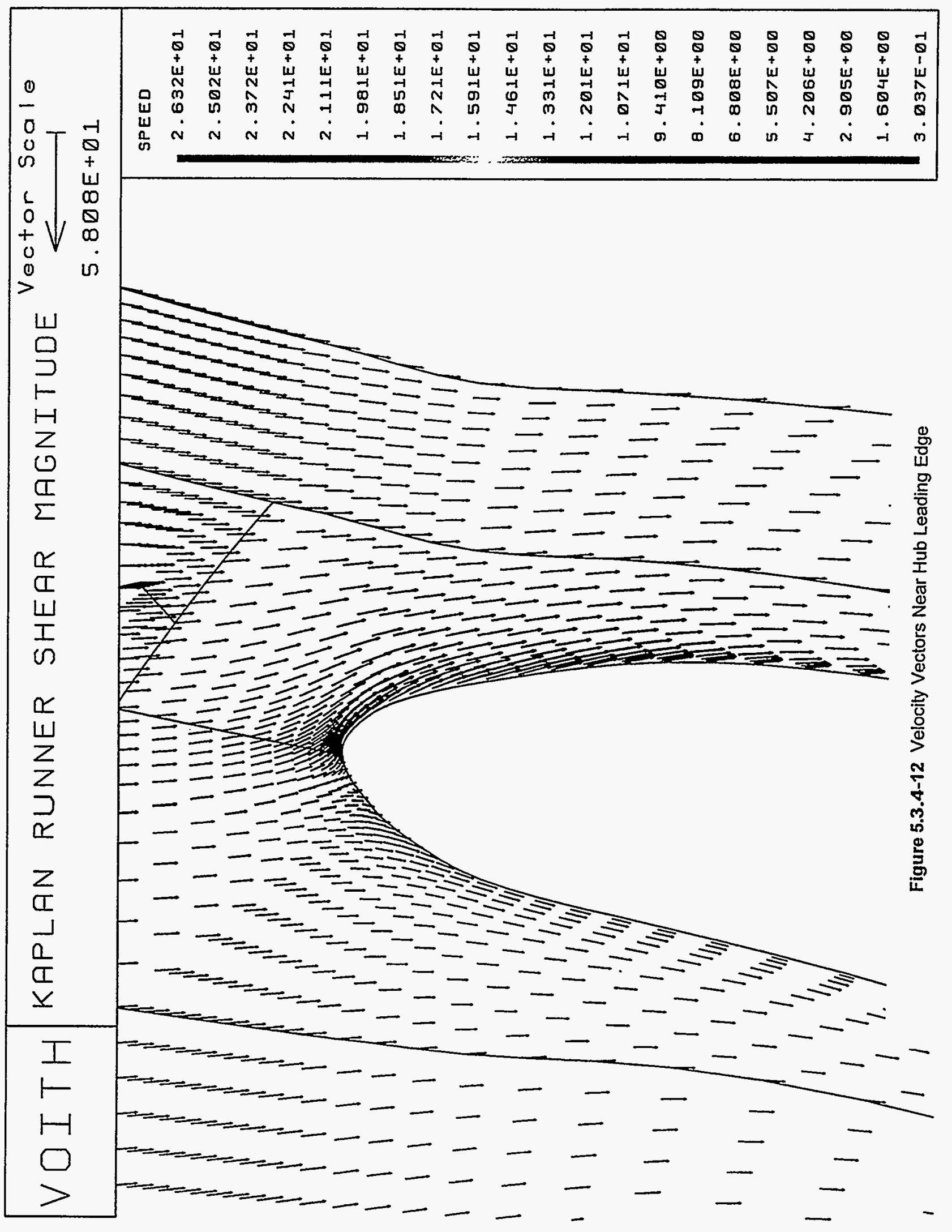




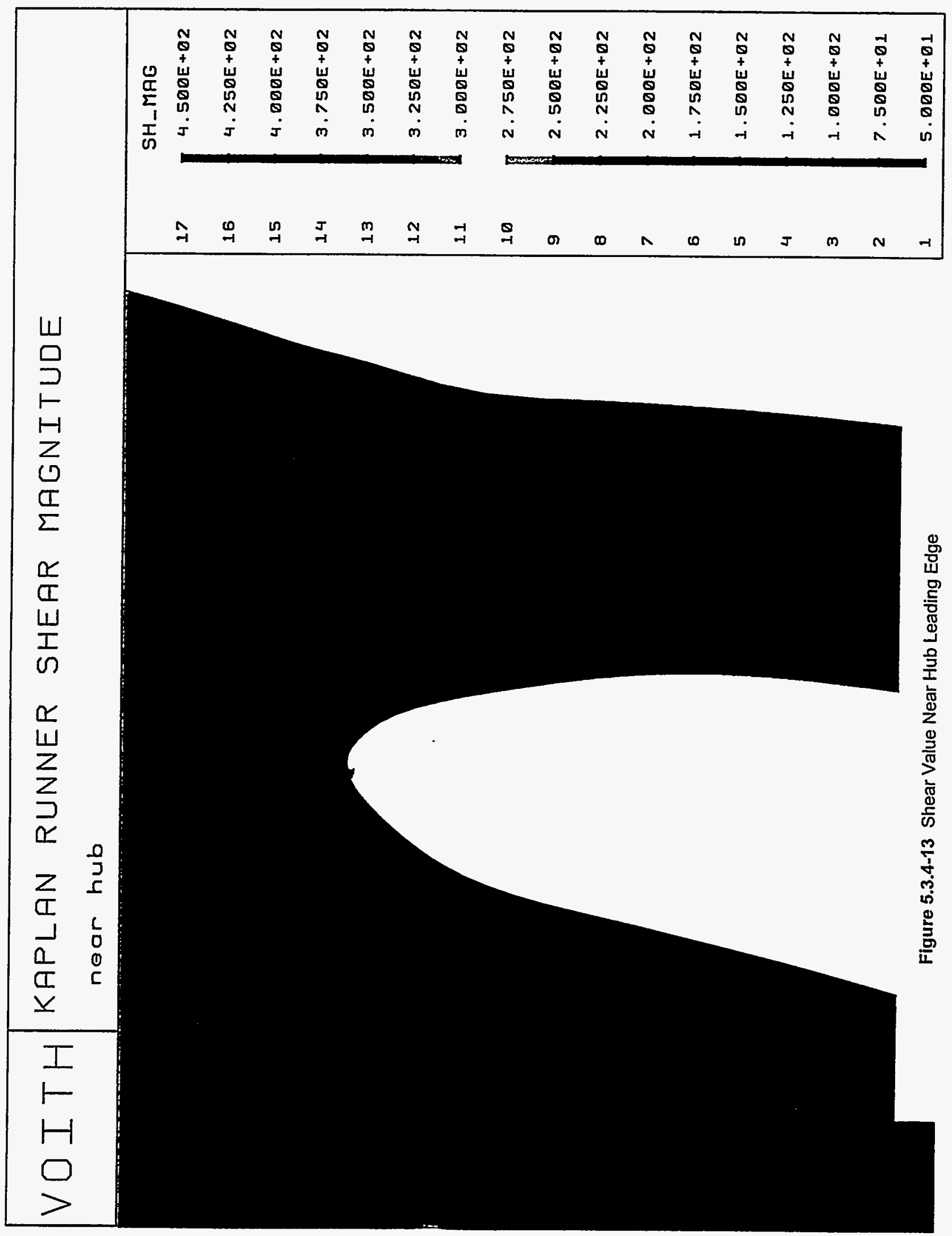




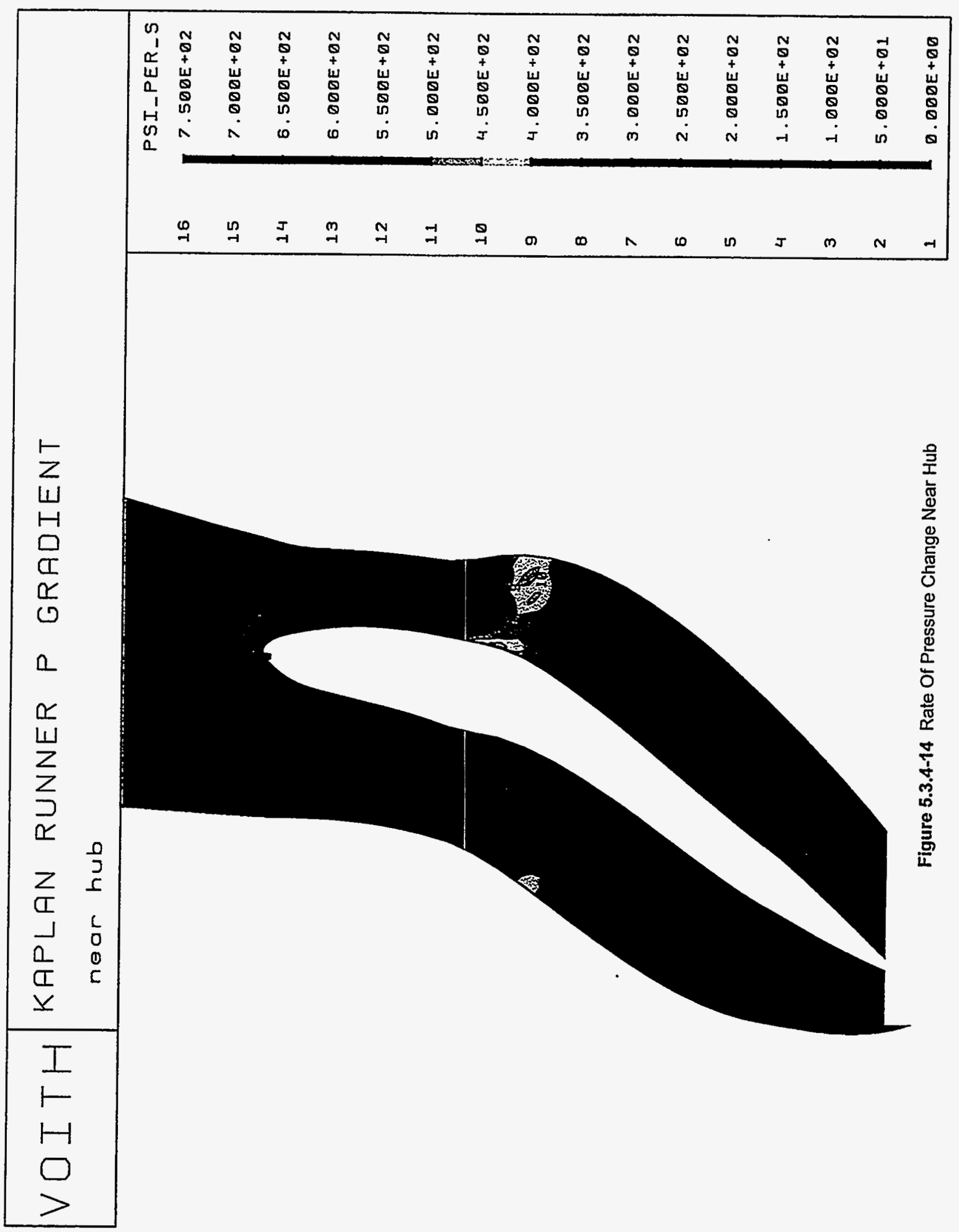




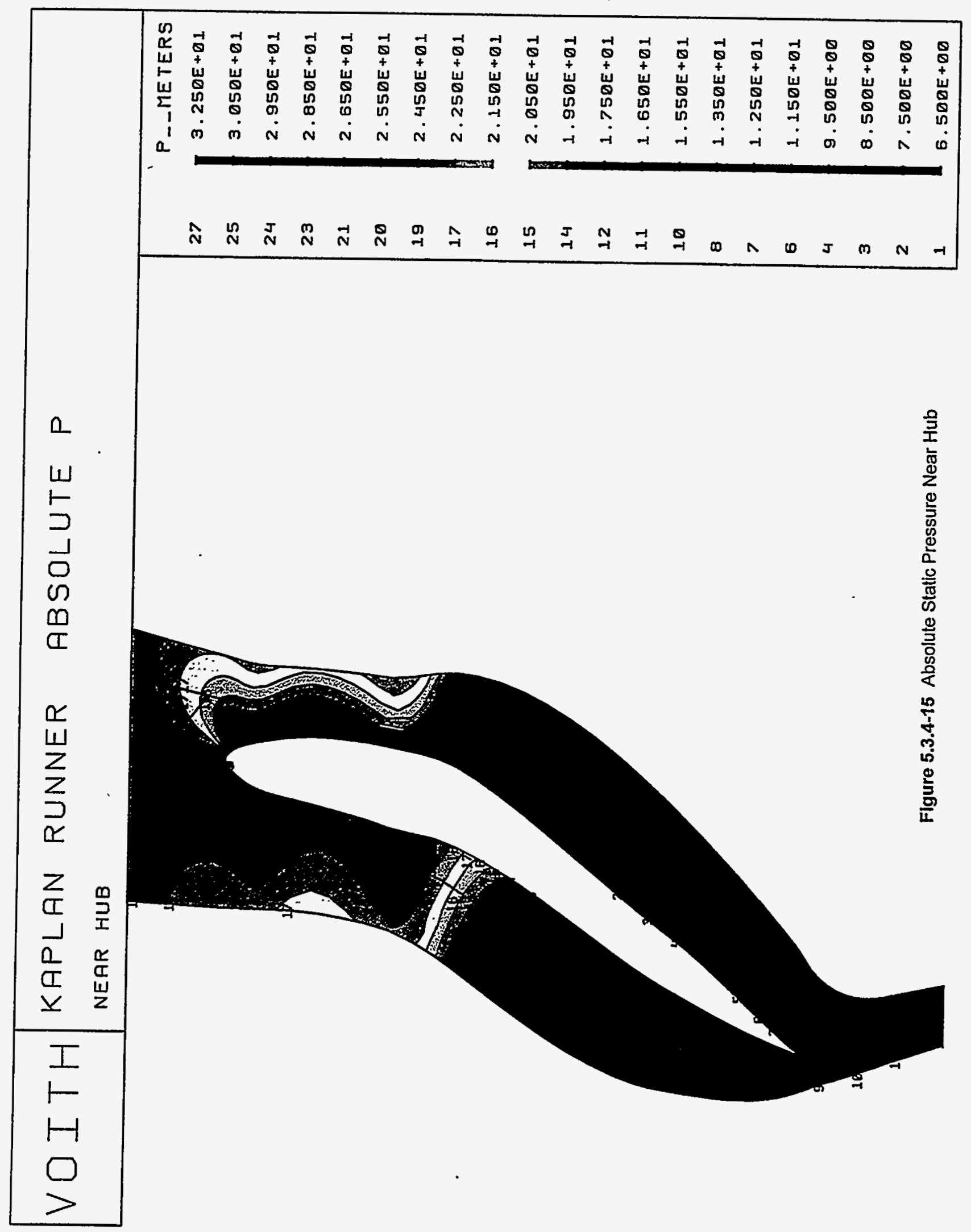




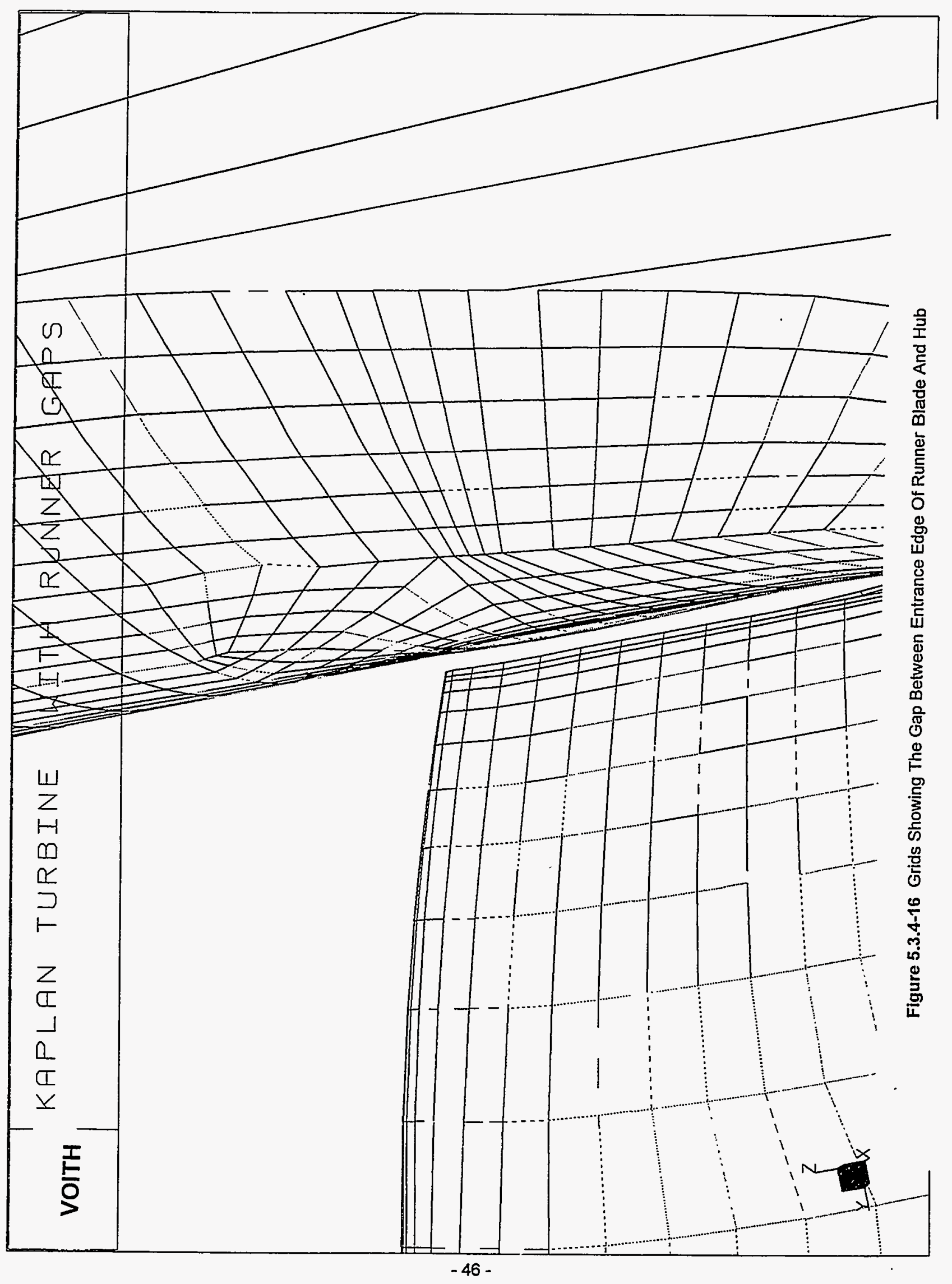




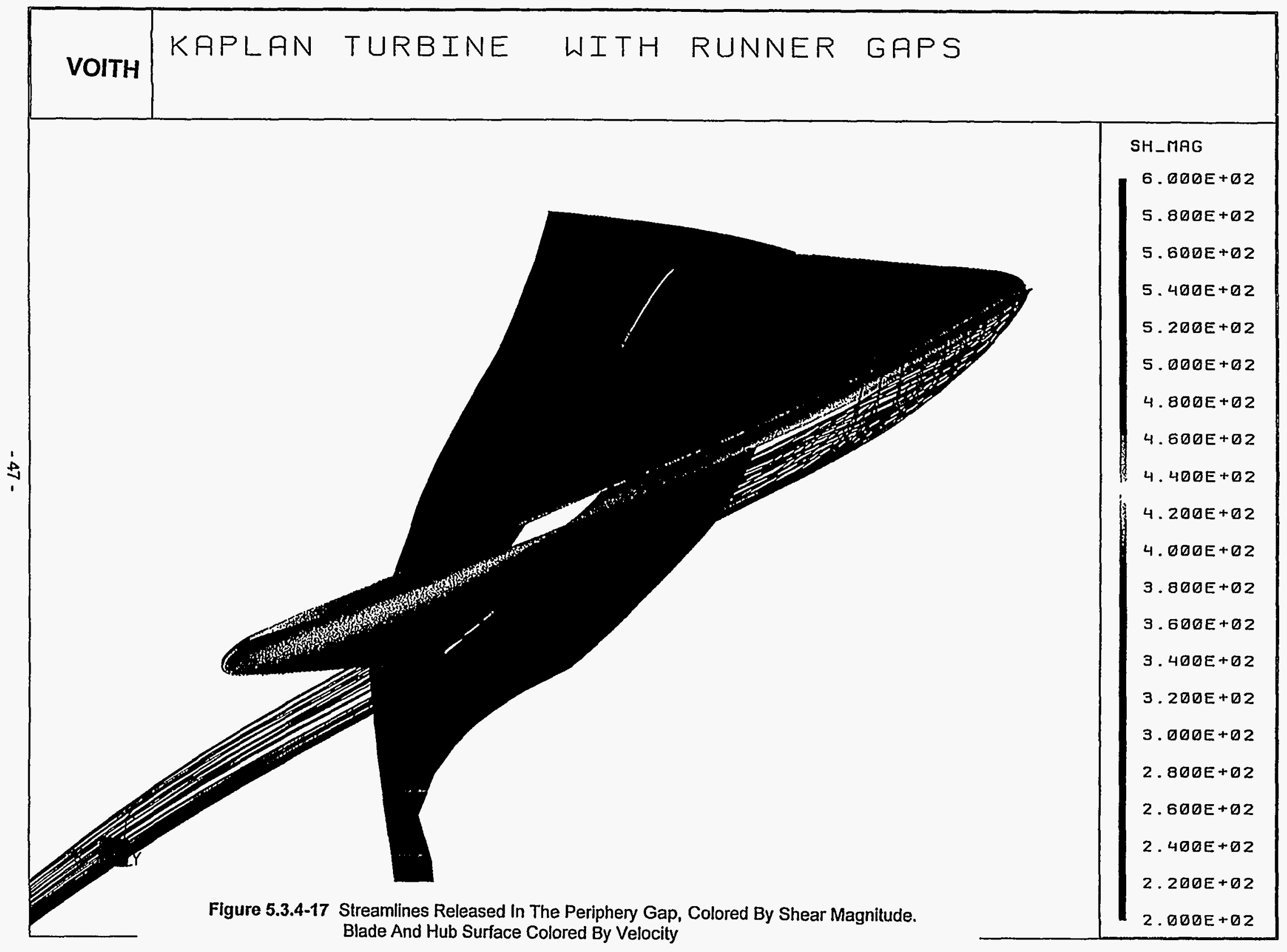




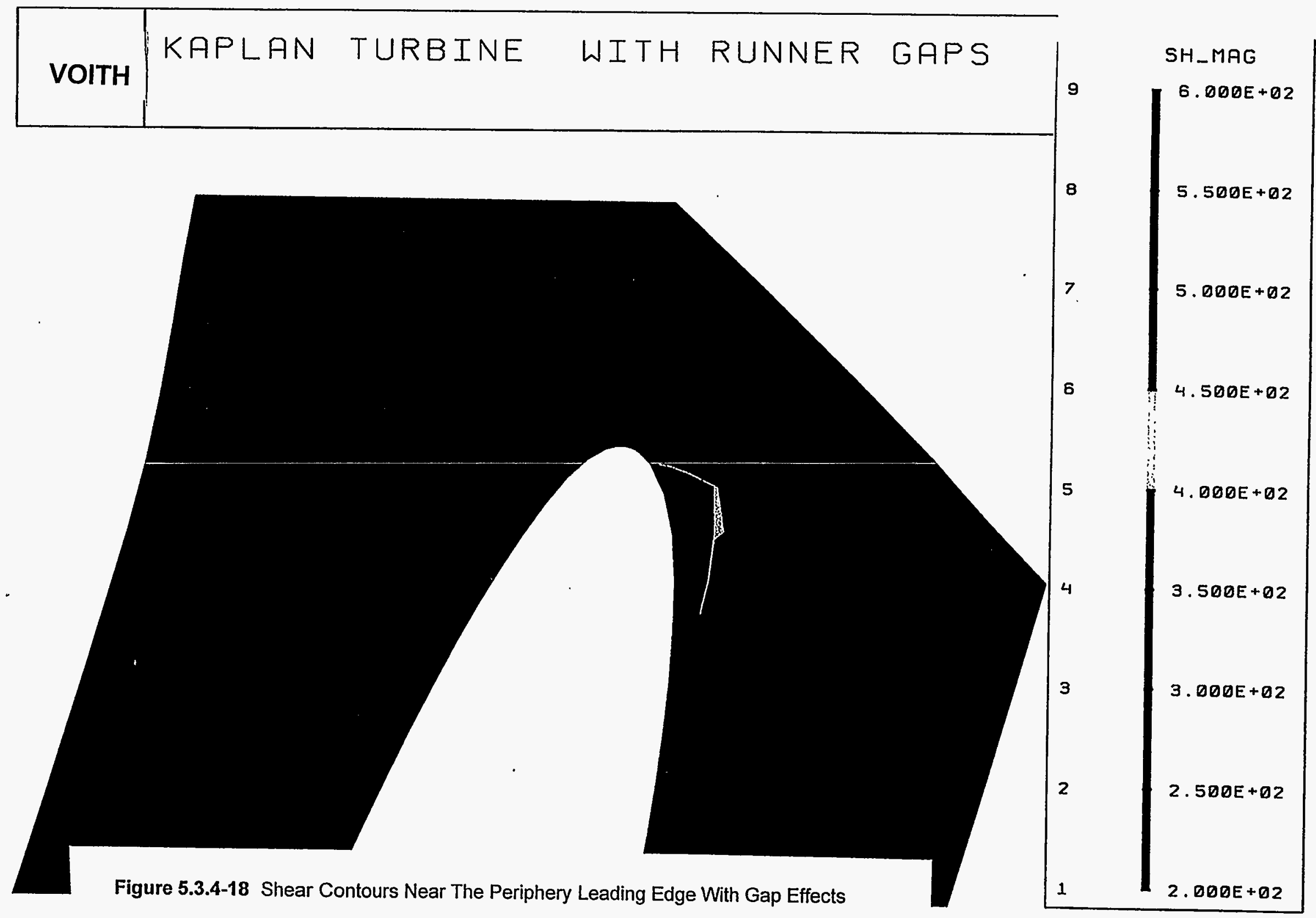




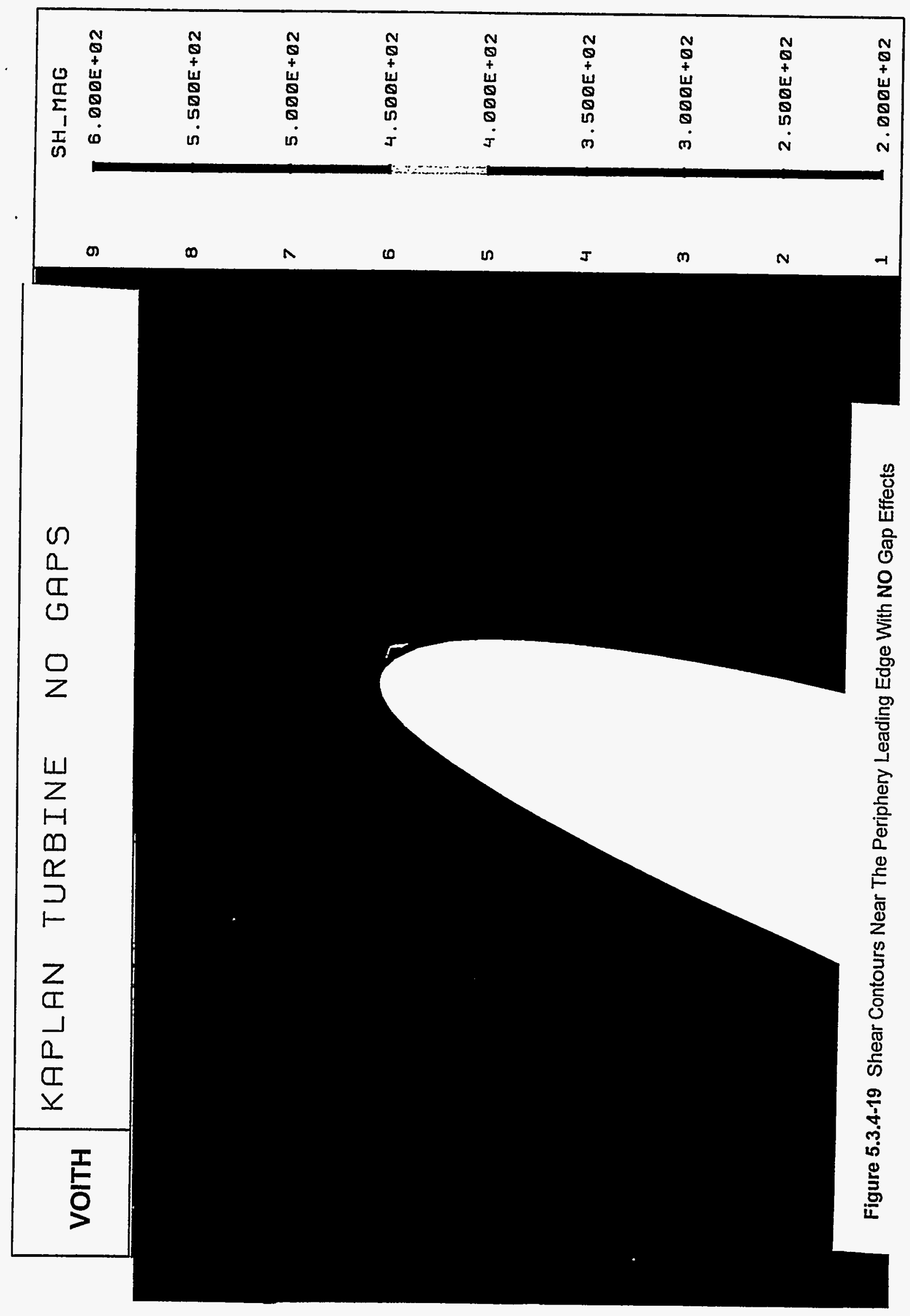




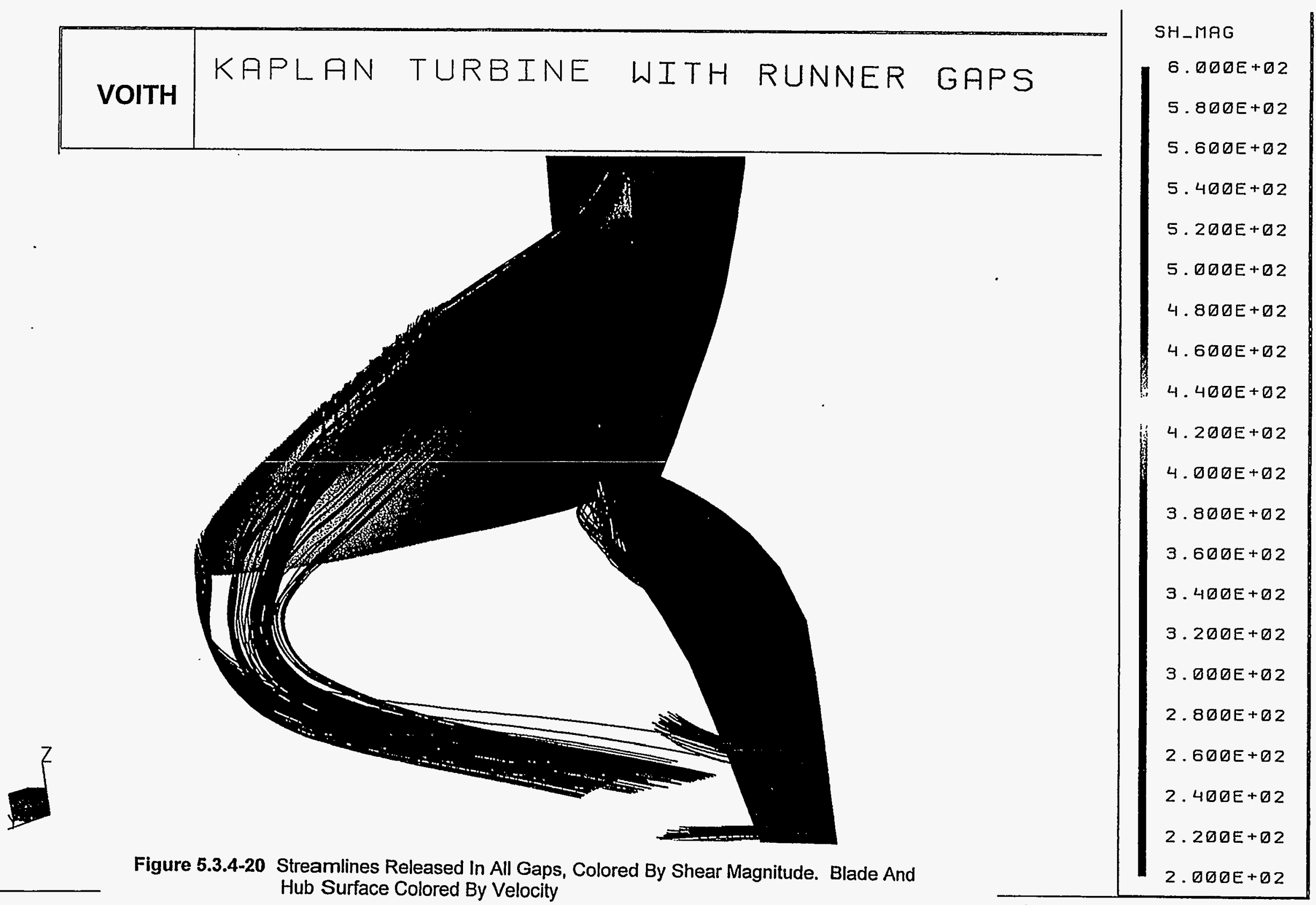




\subsubsection{FRANCIS TURBINE RUNNER}

Two aspects of Francis turbine operation were evaluated, blade shape and off design operation. An ongoing project was used, with the following characteristics: Inlet diameter of $6.4 \mathrm{~m}$, Rated speed of 107 RPM. The best efficiency point occurs at head of $112 \mathrm{~m}$ and a discharge of $296 \mathrm{~m} 3 / \mathrm{s}$. Two blade shapes were analyzed, one blade having a relatively thin leading edge near the crown, and a second blade with a considerably thicker leading edge near the crown. Off design effects were evaluated by analyzing operation at a low head ( $70 \%$ of the best efficiency head). Section 10.2 reviews terminology that may be useful on this section. Grids for a typical calculation are shown of Figure 5.3.5-1. This figure also shows streamlines colored by prototype transit time. Near the band, transit time is typically $0.2 \mathrm{sec}$ while at the crown, transit time can be up to $0.4 \mathrm{sec}$. The streamlines near the crown also demonstrate unexpected flow paths that occur due to secondary flows, even at the best efficiency point. Some of these streamlines remain near the crown, while others respond to the complex flow field and travel toward the band. This phenomenon has a variety of fish survival implications, affecting leading edge strike, zones of shear and / or energy dissipation, scrape, etc.

\section{Operating Condition Evaluation with a Thick Entrance Edge Shape}

Operation at the best efficiency condition for the thicker blade is shown in Figures 5.3.5-2 through 5.3.5-6. This condition is characterized by smooth flow. The blade shape has been carefully chosen to minimize flow disturbances at this head and discharge. The resulting flow field shows minimal shear regions both near the crown and near the band. The shear magnitude is higher at the band than at the crown due to the higher velocity near the band. Figure 5.3.5-2 shows that critical shear regions are small and occur near the blade and in the wake flow at the discharge edge. Figures 5.3.5-3 and 5.3.5-4 show in greater detail the velocity and shear values near the band entrance edge. The pressure gradient is significantly larger than for a low head Kaplan turbine, is shown on Figure 5.3.5-5. Shear values near the crown are low (Figure 5.3.5-6). Values of absolute pressure are shown on Figure 5.3.5-7.

In contrast to the best efficiency point, at the low head operating condition, the blade is operating at an angle of attack. Flow conditions are considerably more complex at an "off design" point of operation. The same series of figures as for the best efficiency point are shown in Figures 5.3.5-8 through 5.3.5-12. The resulting flow field shows higher shear values, especially at the band. Figures 5.3.5-9 and 5.3.5-10 show the leading edge details near the band where the region having a value of shear greater than the critical value extends noticeably away from the blade. On Figure 5.3.5-12, it is observed that shear levels are higher than for the best efficiency point, but the lower velocities at the crown, in combination with the blade shape do not create large shear regions. Values of absolute pressure are shown on Figure 5.3.513.

\section{Blade Thickness Evaluation}

Figure 5.3.5-14 shows two blade shapes, referred to as thin and thick. Near the band, both blades have equal maximum thickness. Near the crown, however, the "thin" blade is approximately one fourth as thick as the "thick" blade. The blades do however, have subtle differences in the shape of the blade nose. The thin blade actually has a slightly thicker region very close to the leading edge.

At the best efficiency operating point, the thin blade has good performance. The flow field and in particular the values of shear are basically the same as for the thick blade at both the crown and band, Figures 5.3.5-15 through 5.3.5-18.

At the low head operating condition, the thin blade has significant differences compared to the thick blade. Near the crown, the thin blade is unable to maintain smooth attached fiow. Figures 5.3.5-19 and 5.3.5-20 show the resulting separated region has induced a recirculation zone and a significant region having high 
shear values. The critical value of shear has been exceeded. Also shown is a circular flow pattern that is a cross section of a vortex. Streamlines further showing the significant extent of the vortex are shown on Figure 5.3.5-21. Near the band, Figures 5.3.5-22 and 5.3.5-23 show that the "thin" blade, with it's superior local shape near the nose, has lower shear values compared to the "thick" (but locally slightly sharper) blade.

Additionally, a blade was designed having a thin entrance edge along it's entire entrance edge, from crown to band. The analysis of this blade at the low head operating condition shows increased shear values at the band compared to the previous "thin" blade (that actually was not thin at the band), Figure 5.3.5-24. 


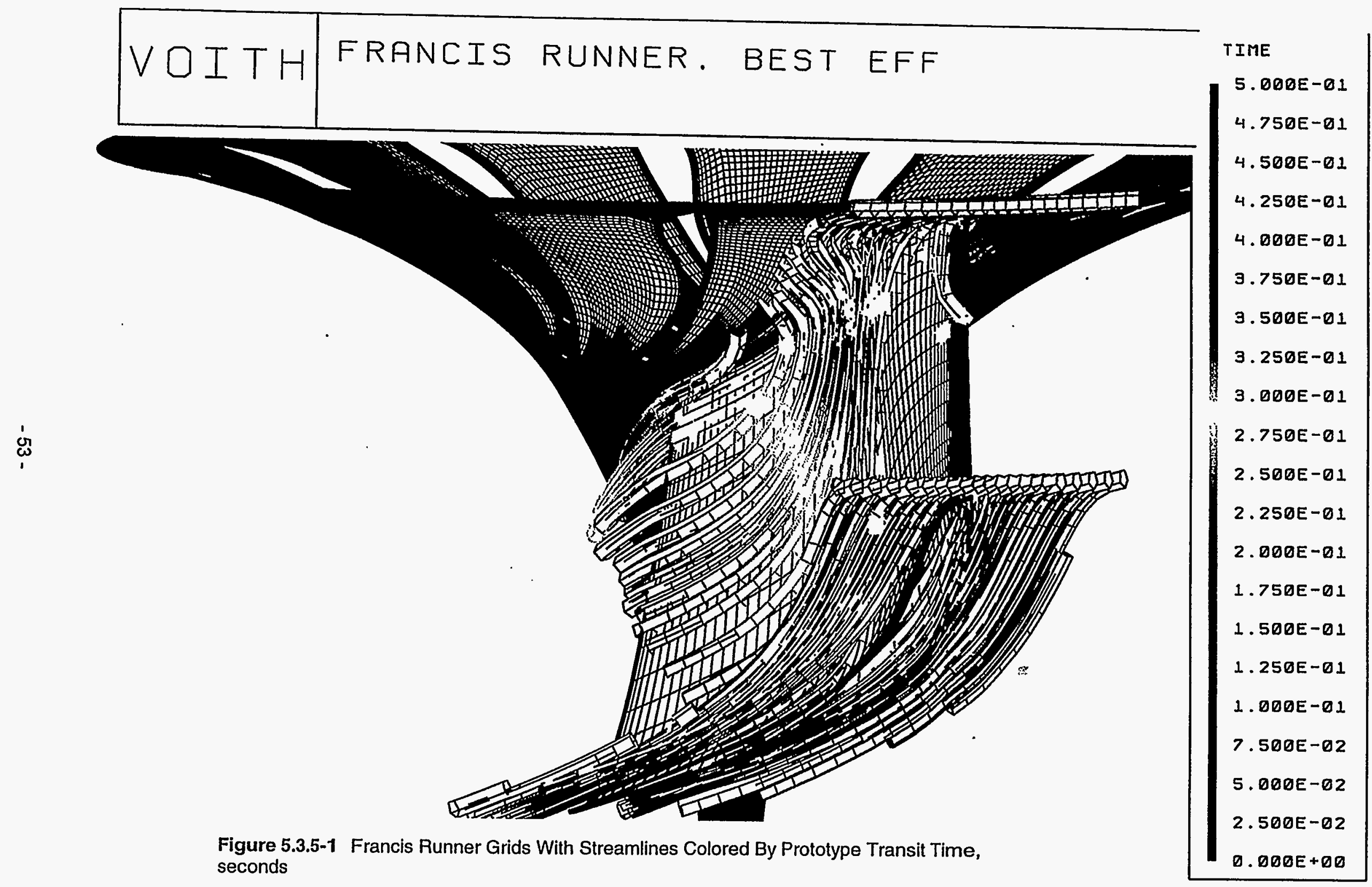




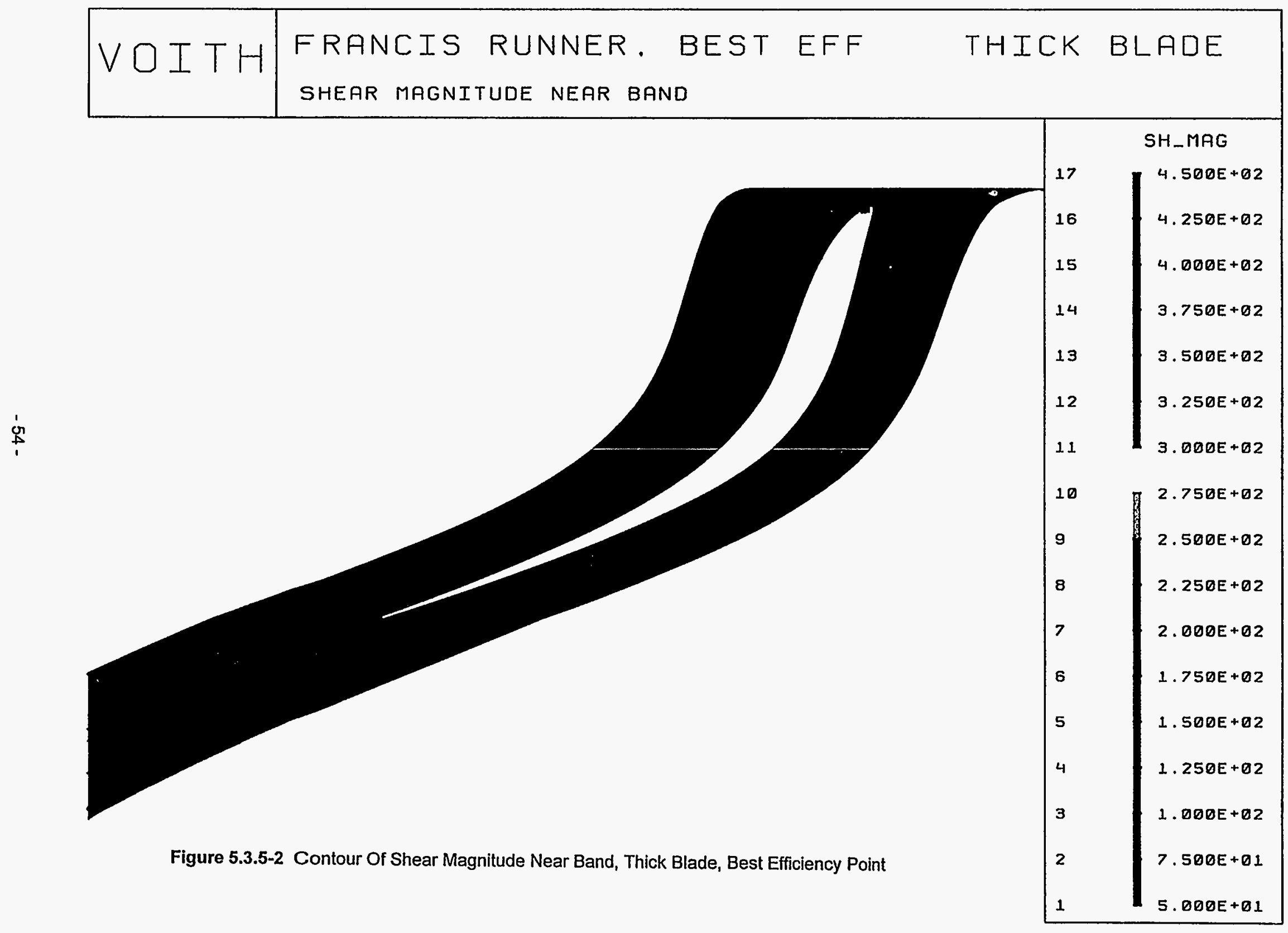




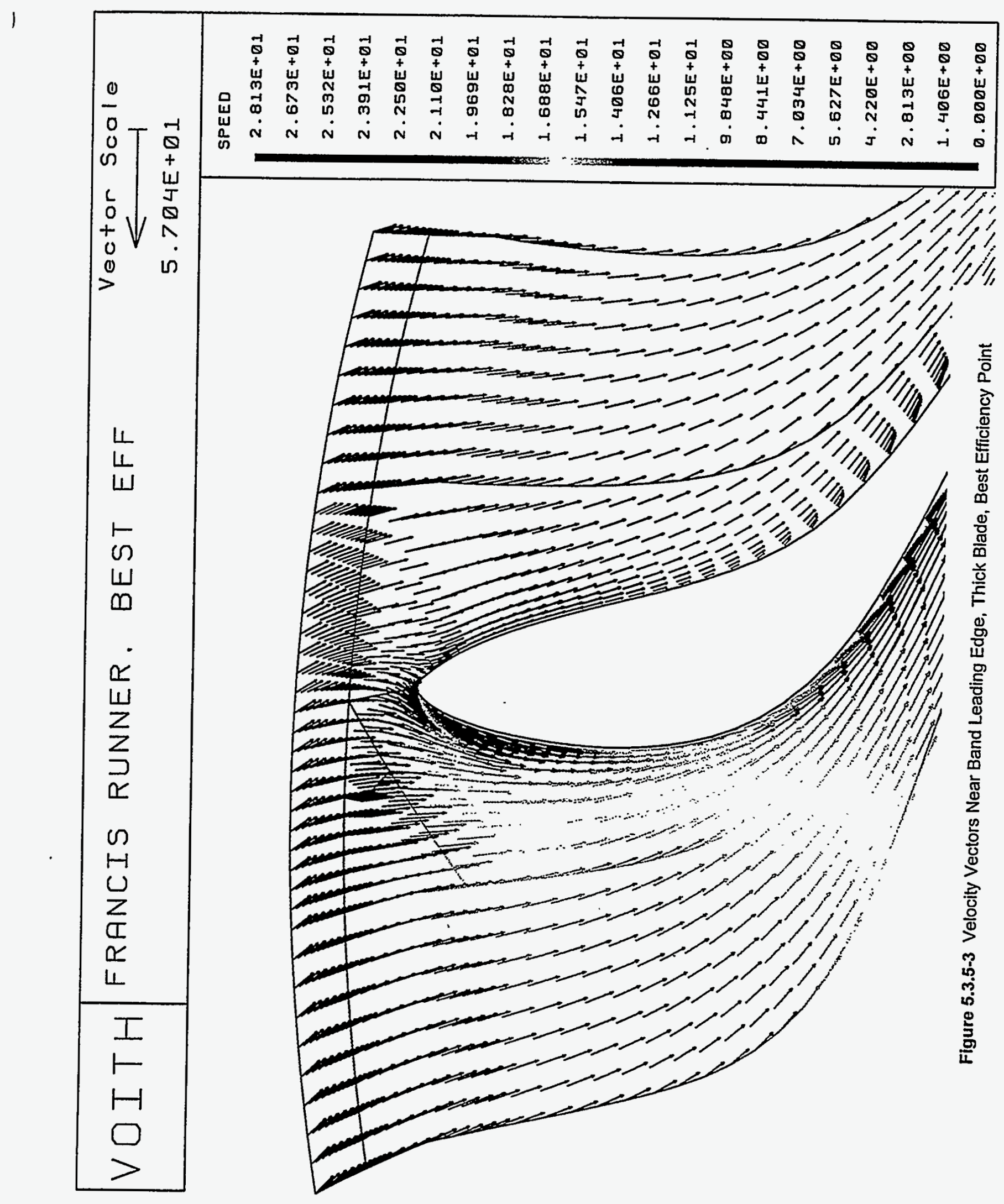




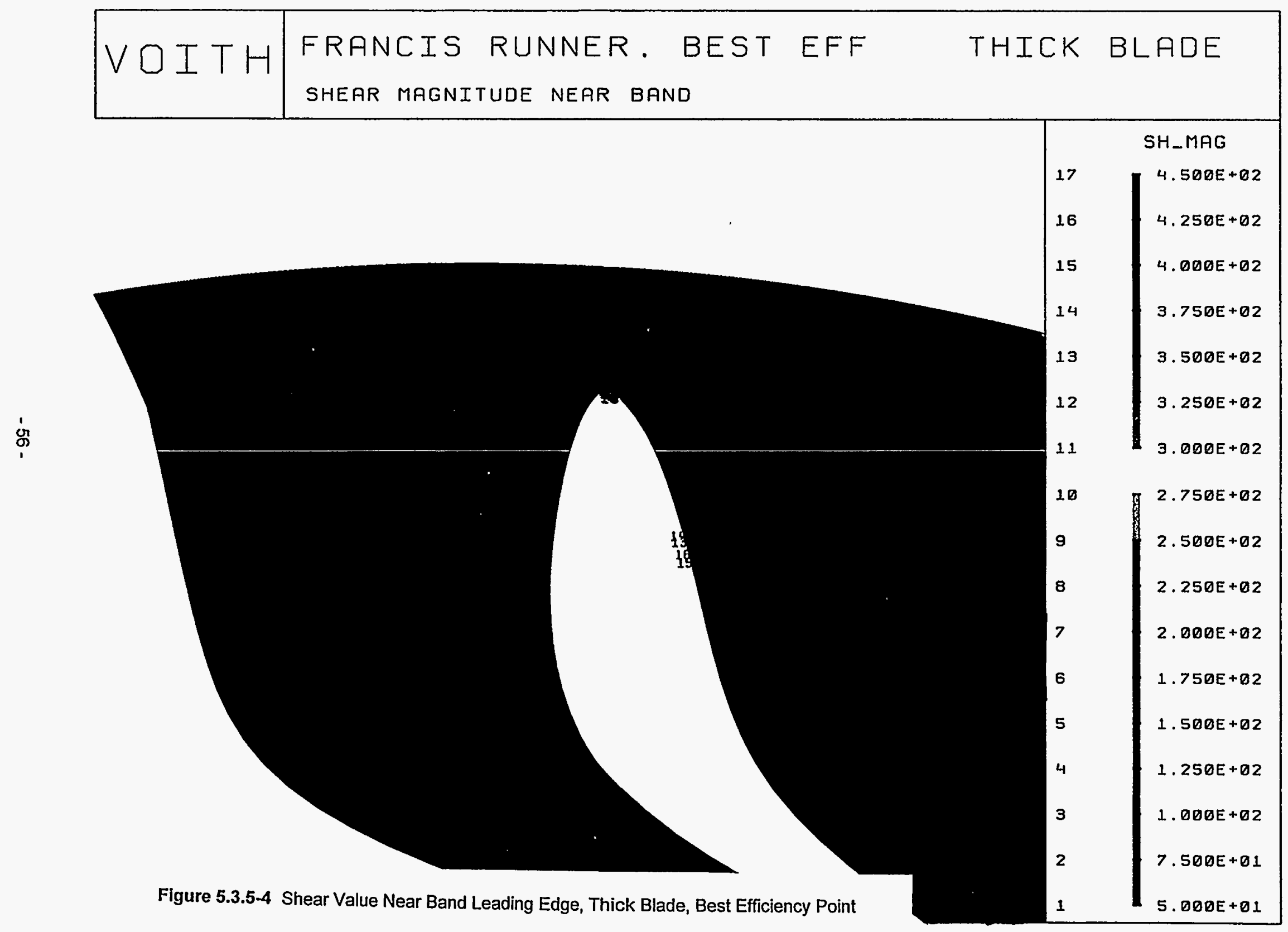




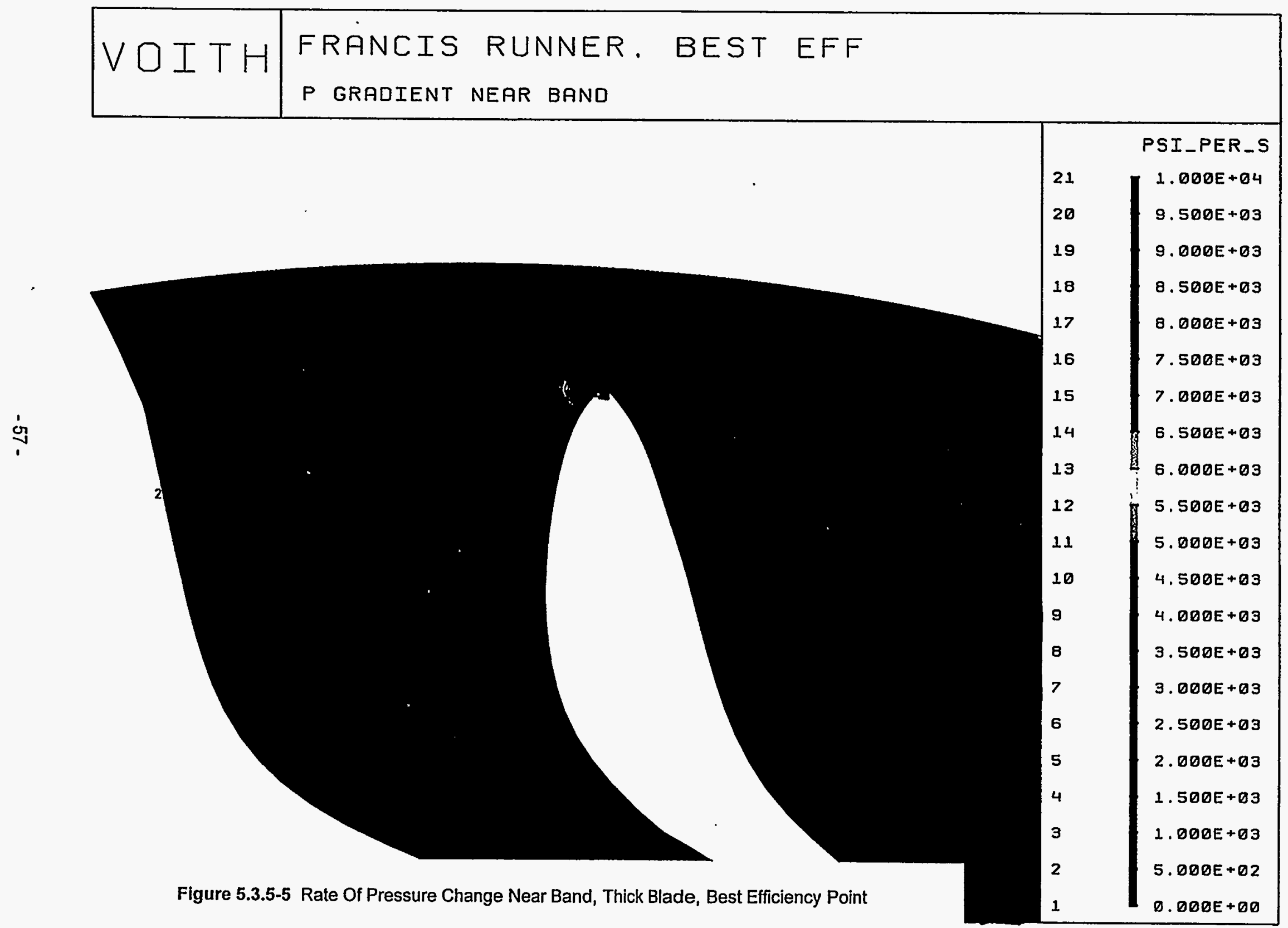




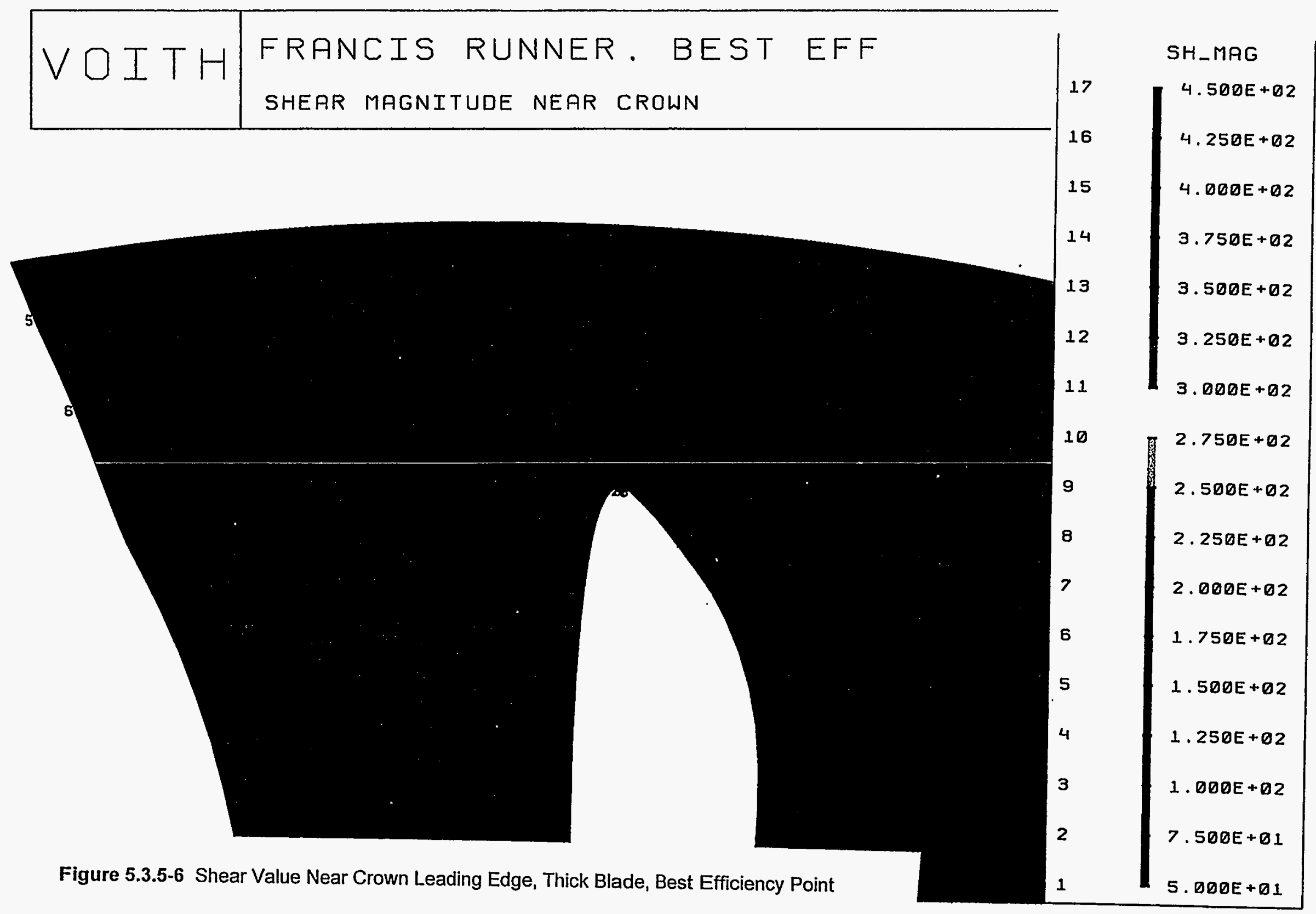




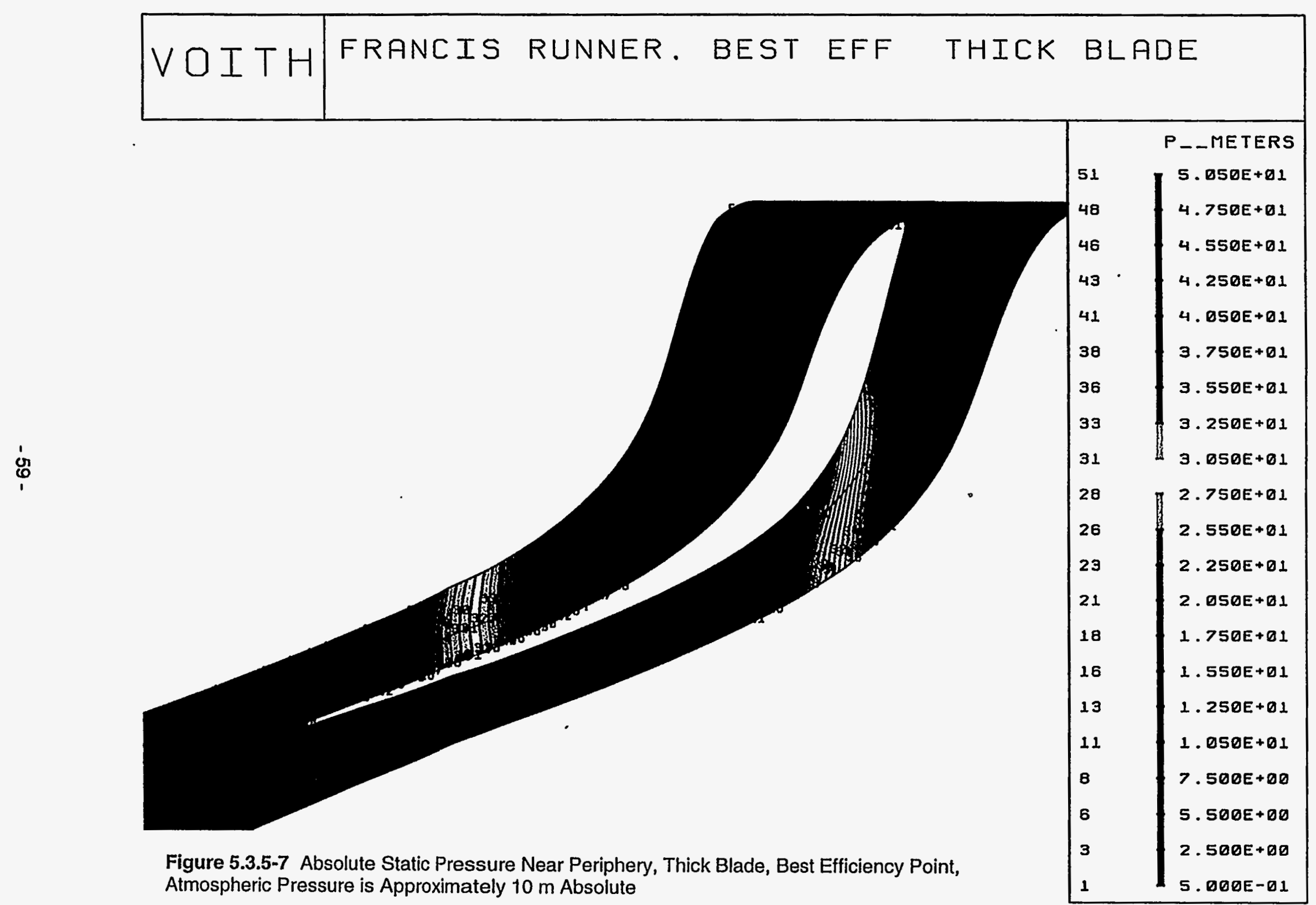




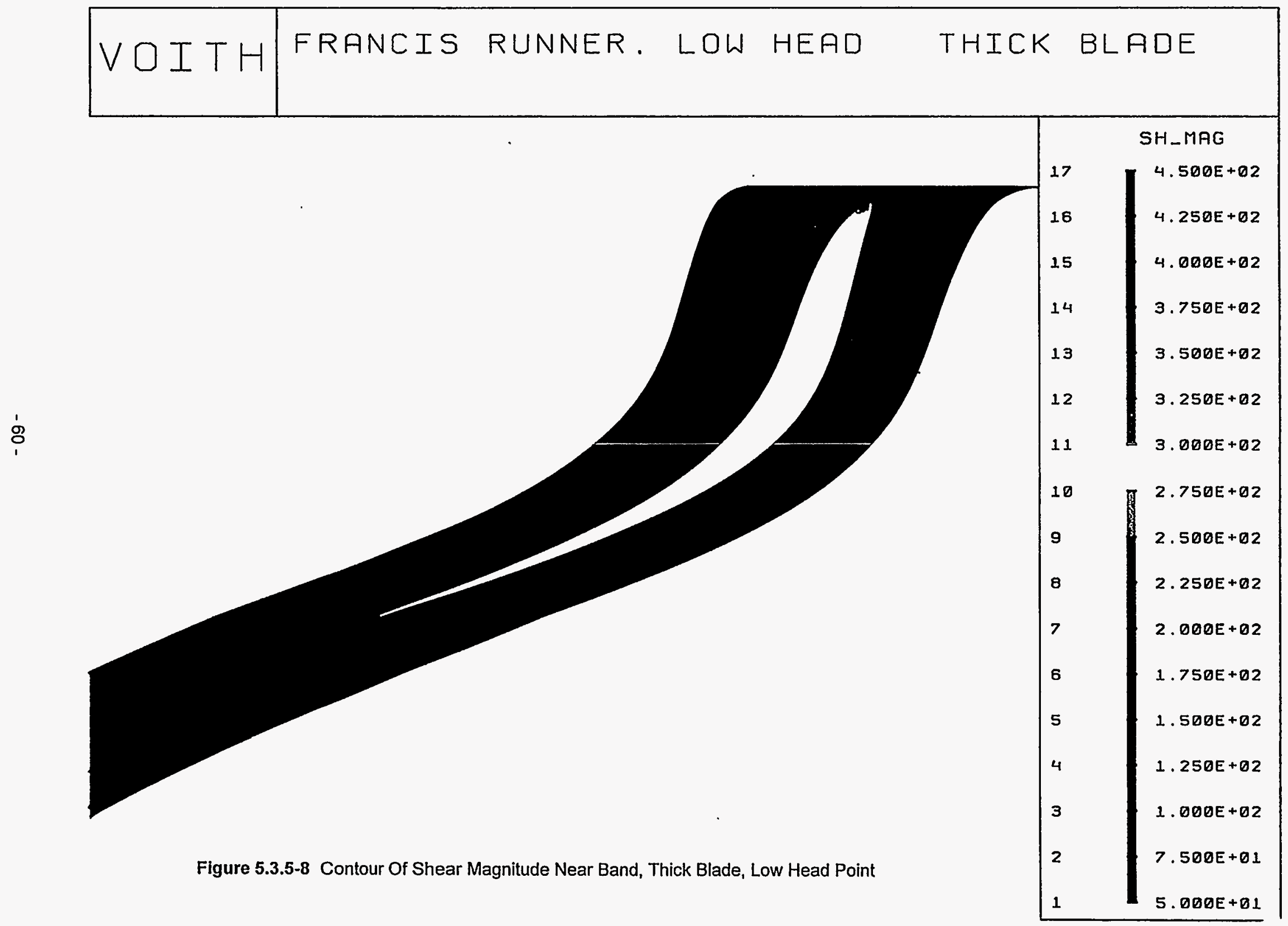




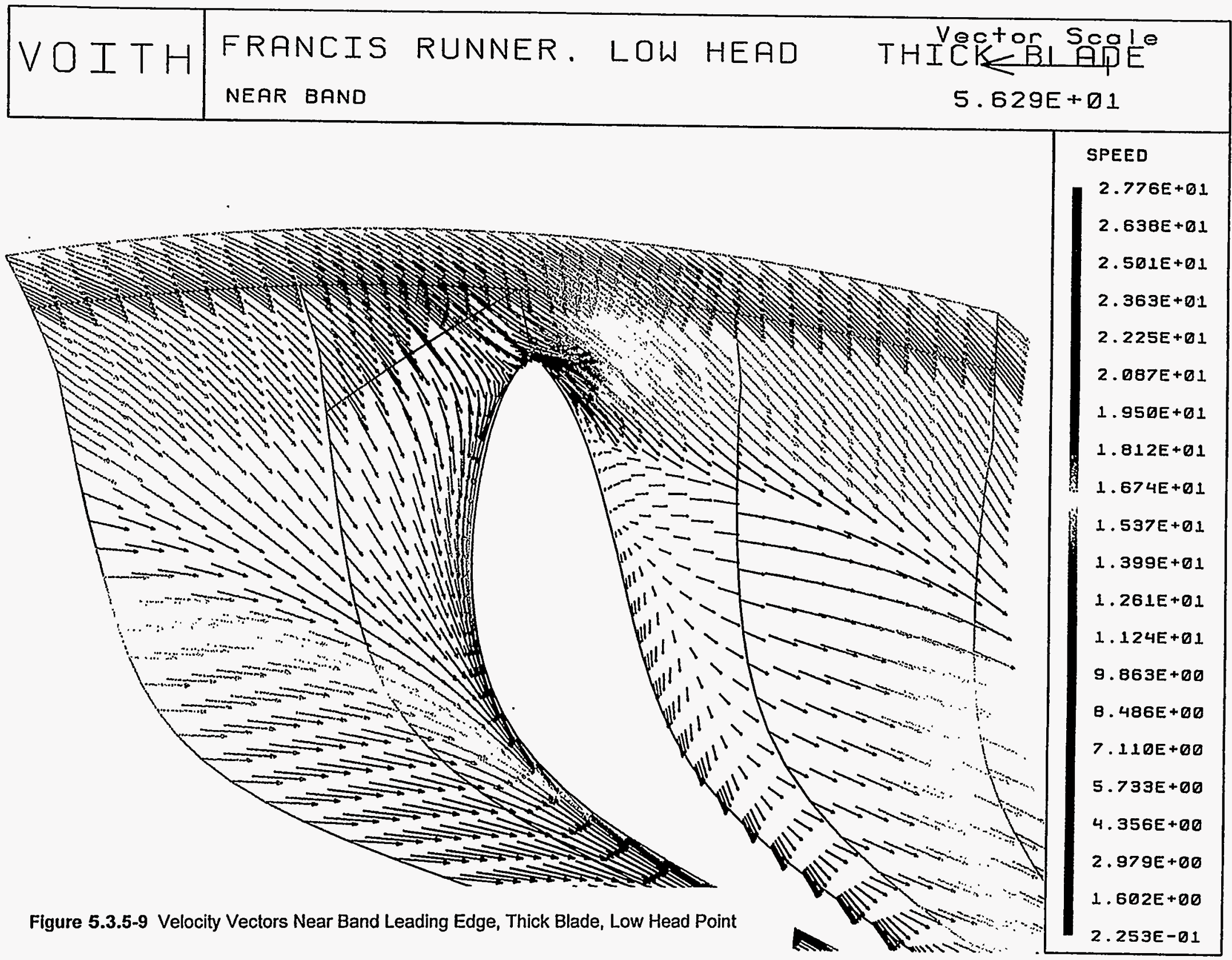




\begin{tabular}{|l|l|}
\hline VOITH & $\begin{array}{l}\text { FRANCIS RUNNER, LOW HEAD } \\
\text { SHEAR MAGNTUDE NEAR BAND }\end{array}$ \\
\hline
\end{tabular}

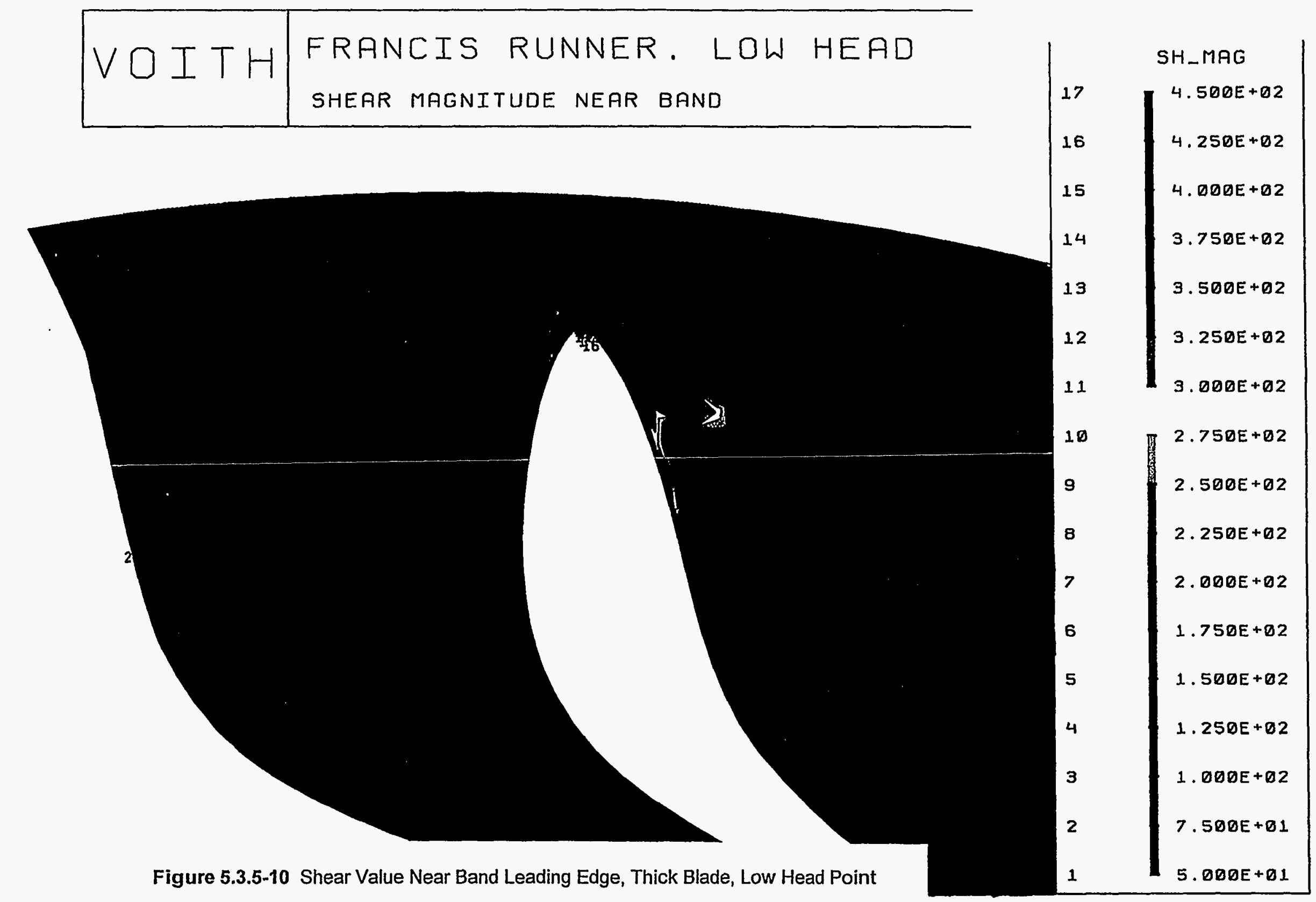




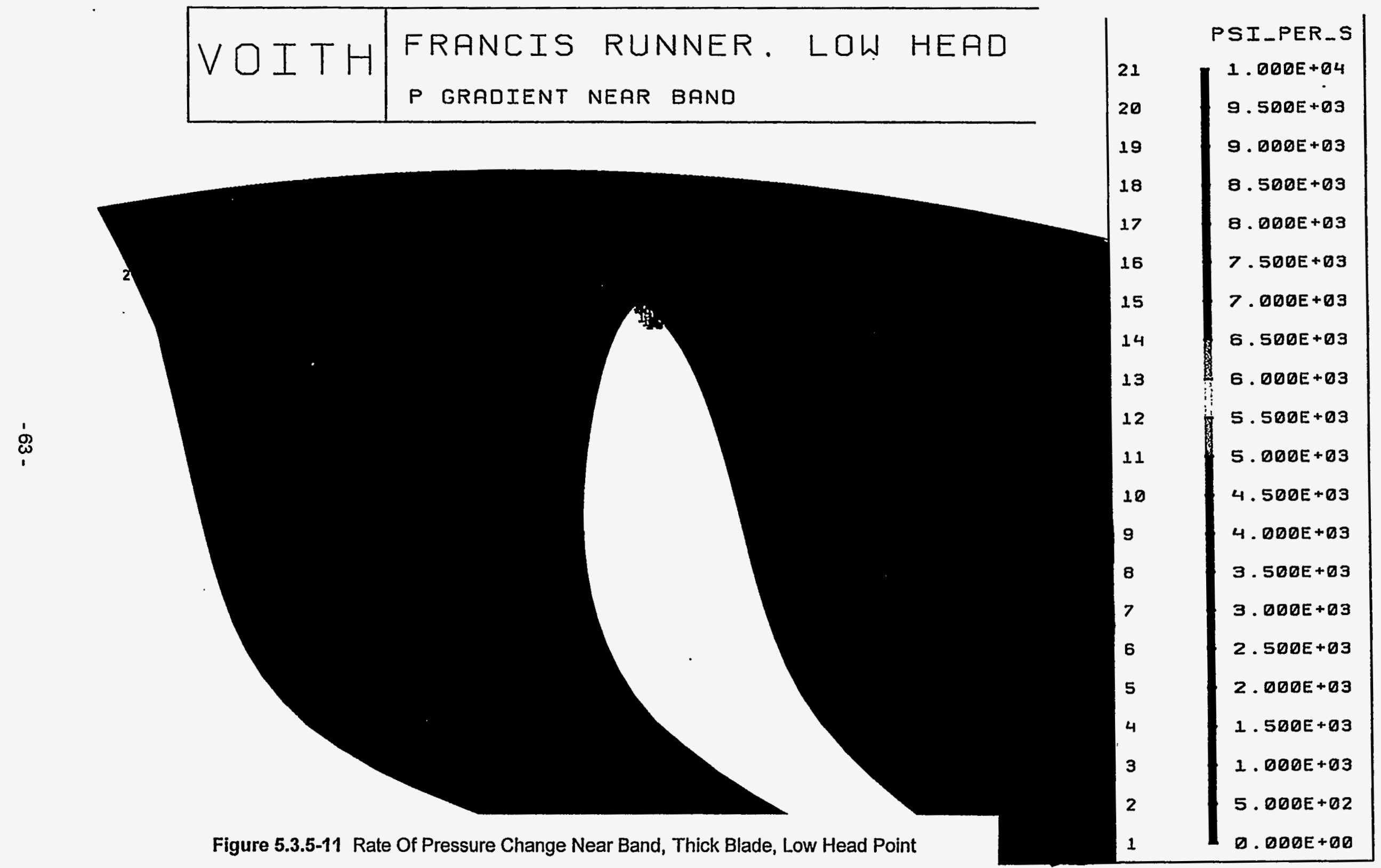



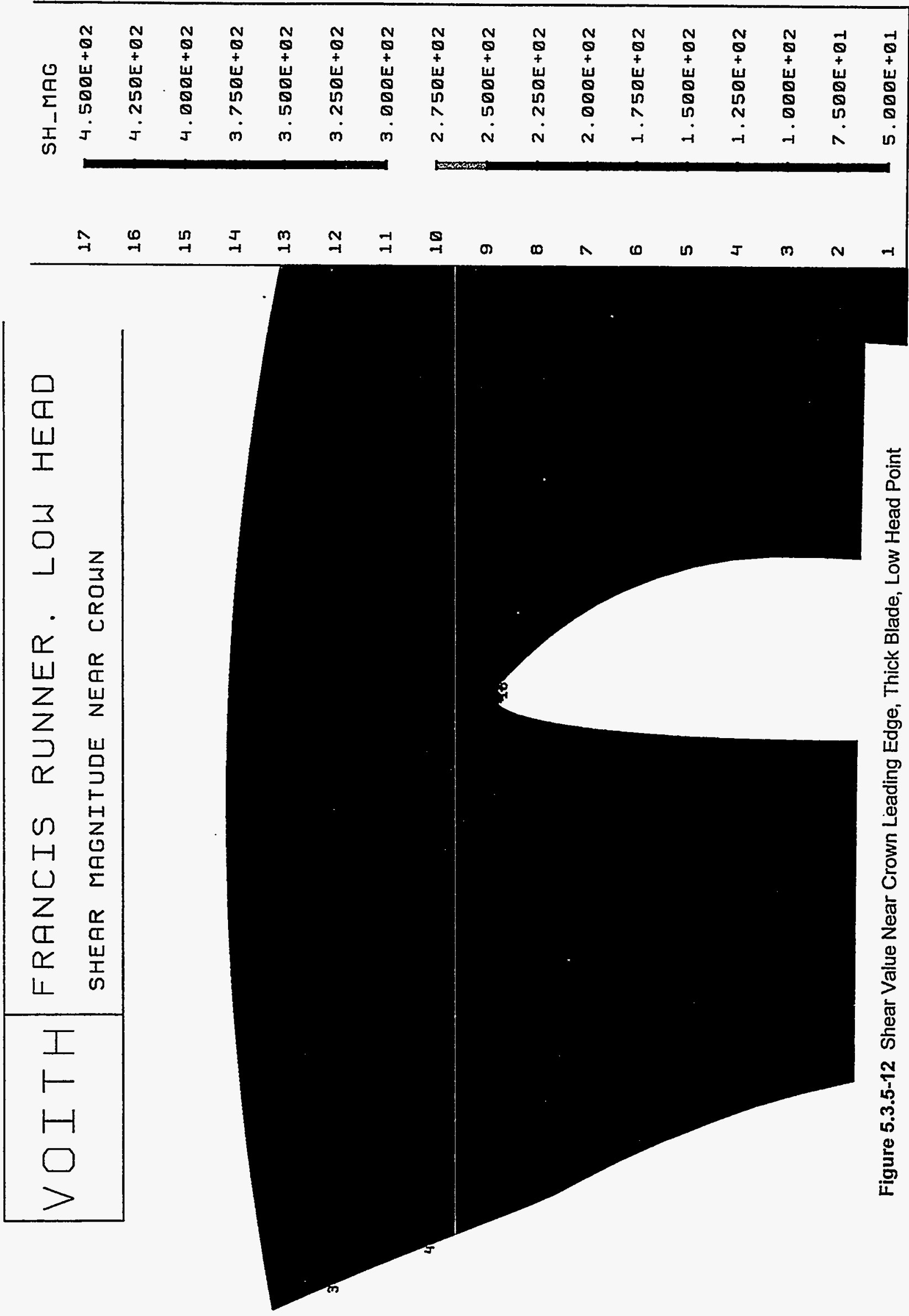


\section{VOITH FRANCIS RUNNER. LOW HEAD THICK BLADE}

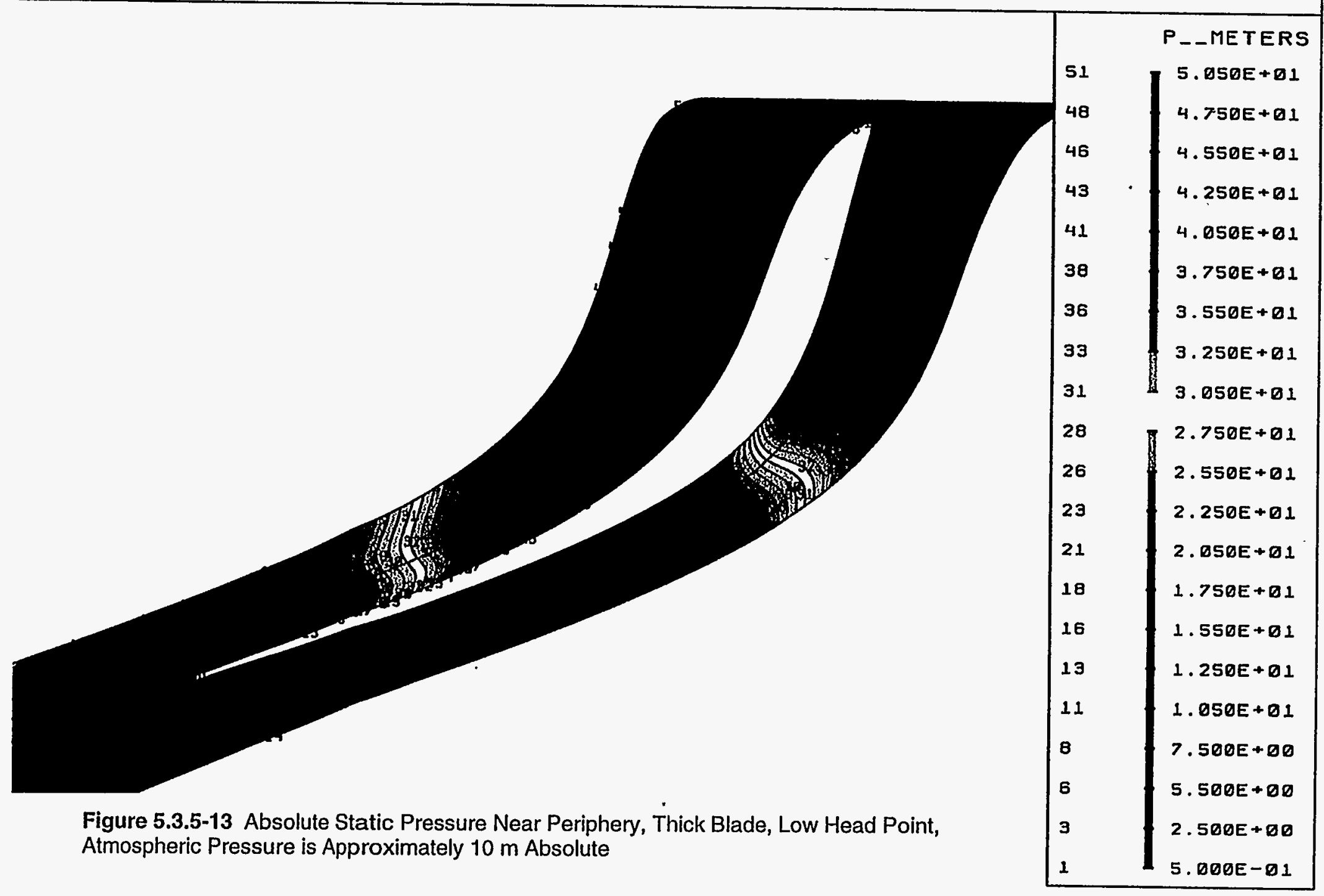




\section{VOITH FRANCIS RUNNER BLADE COMPARISON GREEN-THICK BLADE BLACK-THIN BLADE}
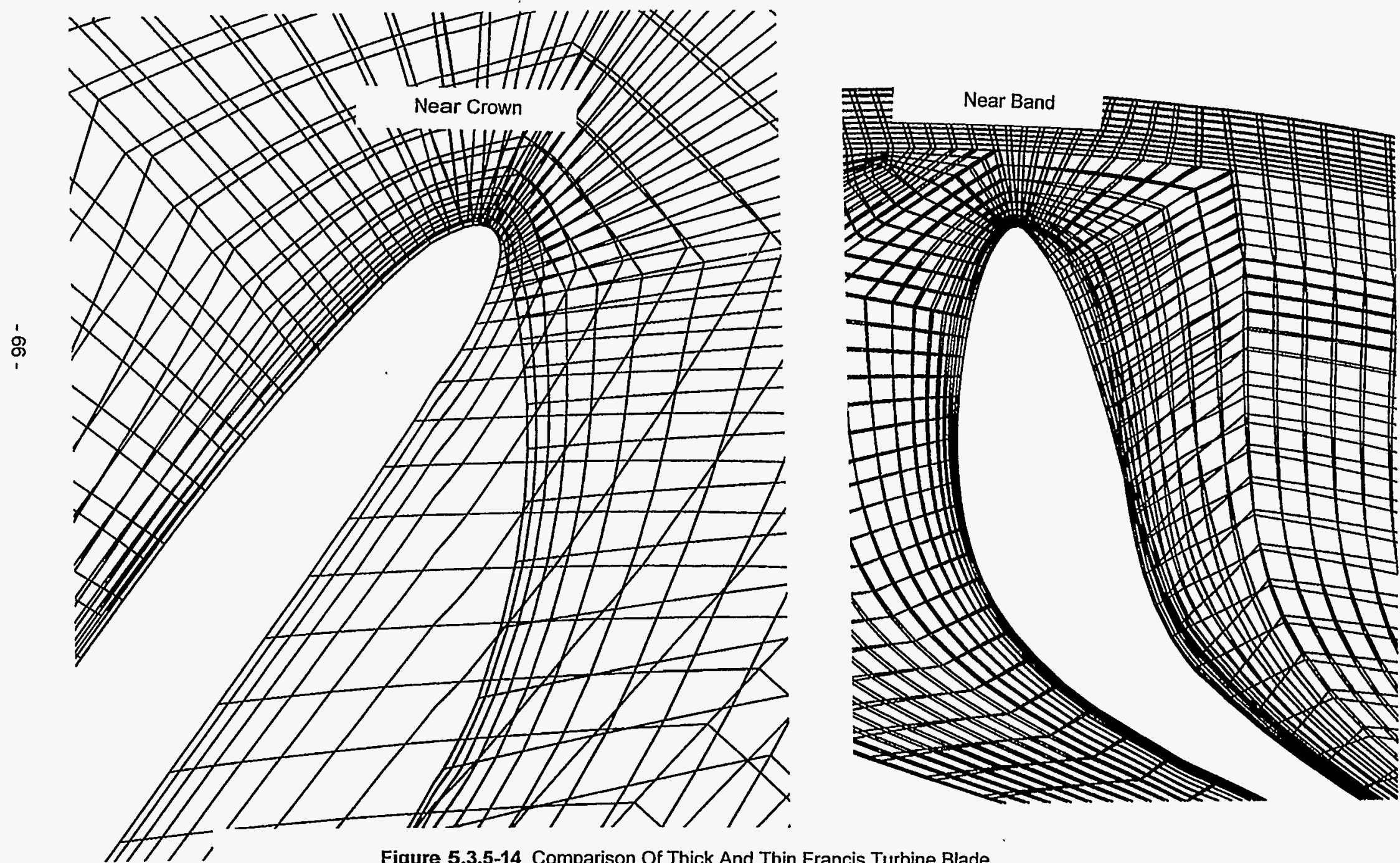

Figure 5.3.5-14 Comparison Of Thick And Thin Francis Turbine Blade 


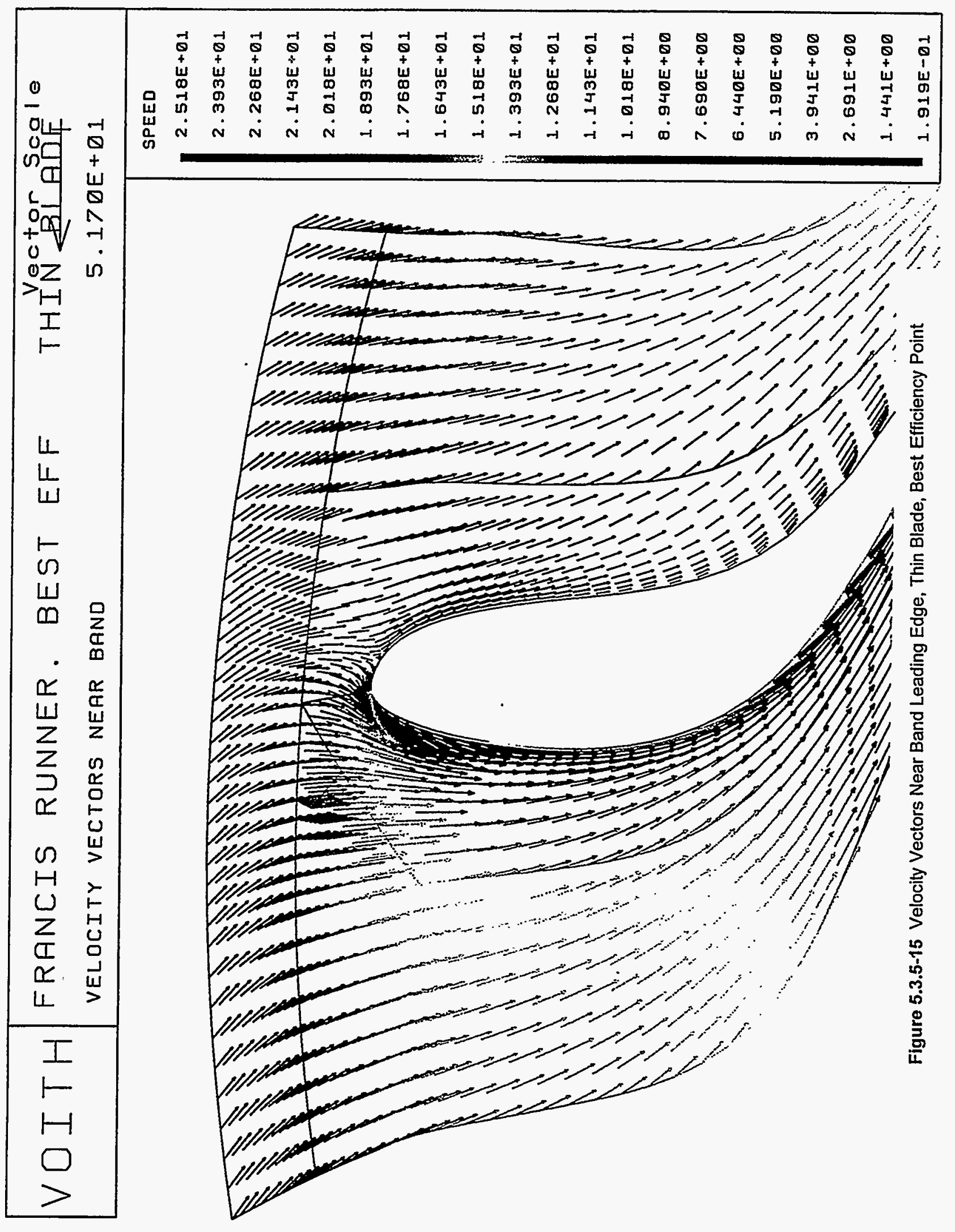




\section{VOITH FRANCIS RUNNER. BEST EFF

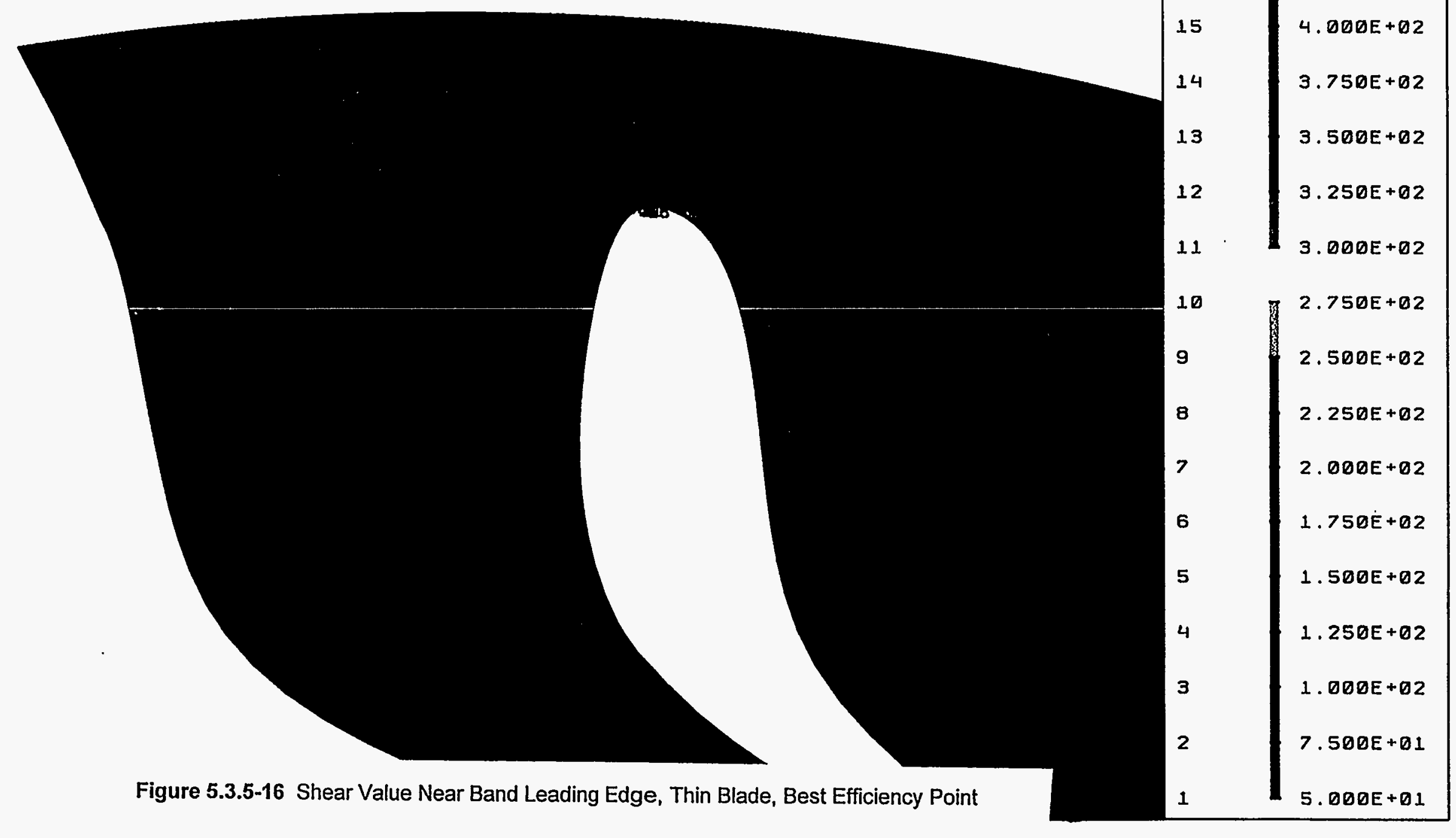




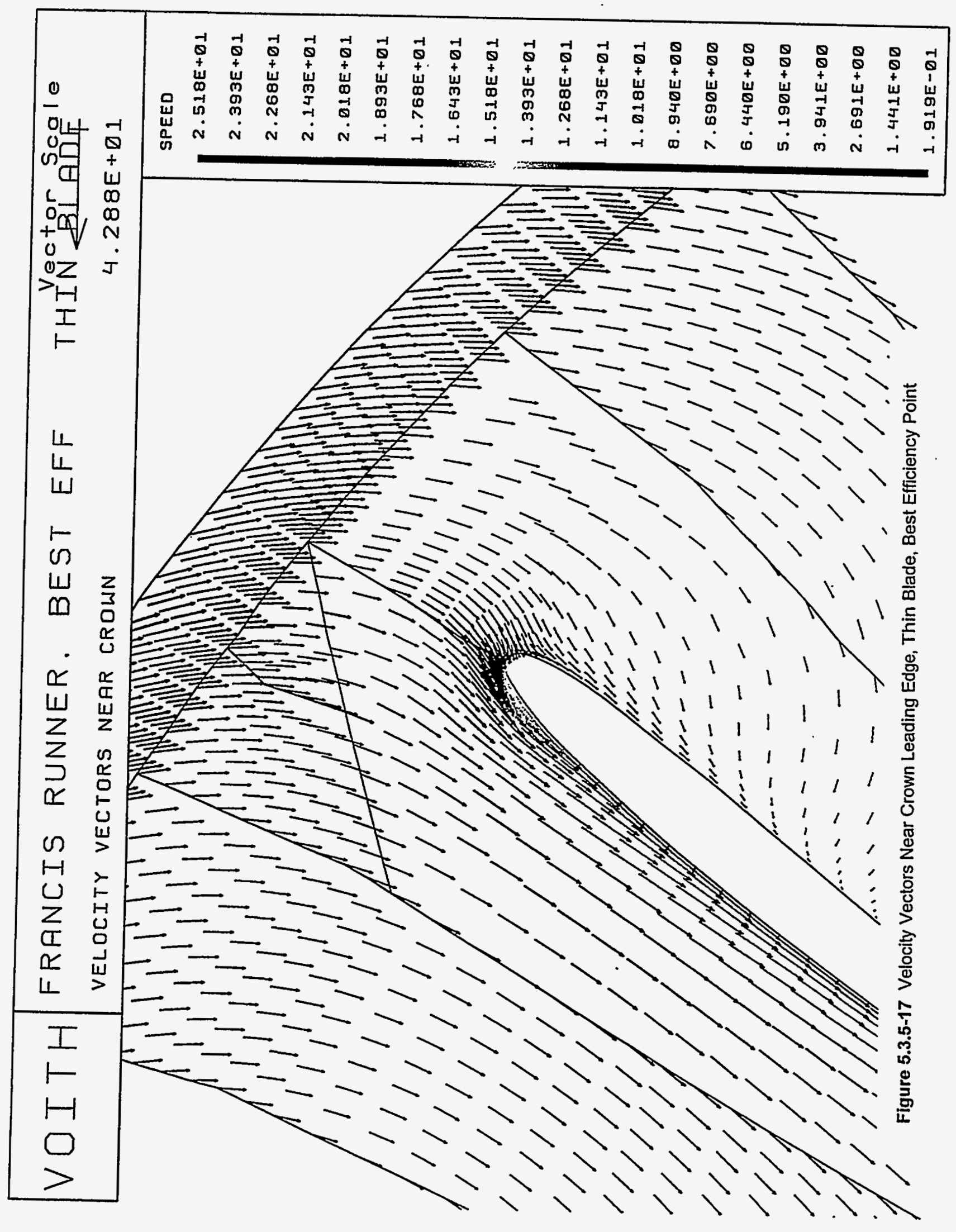




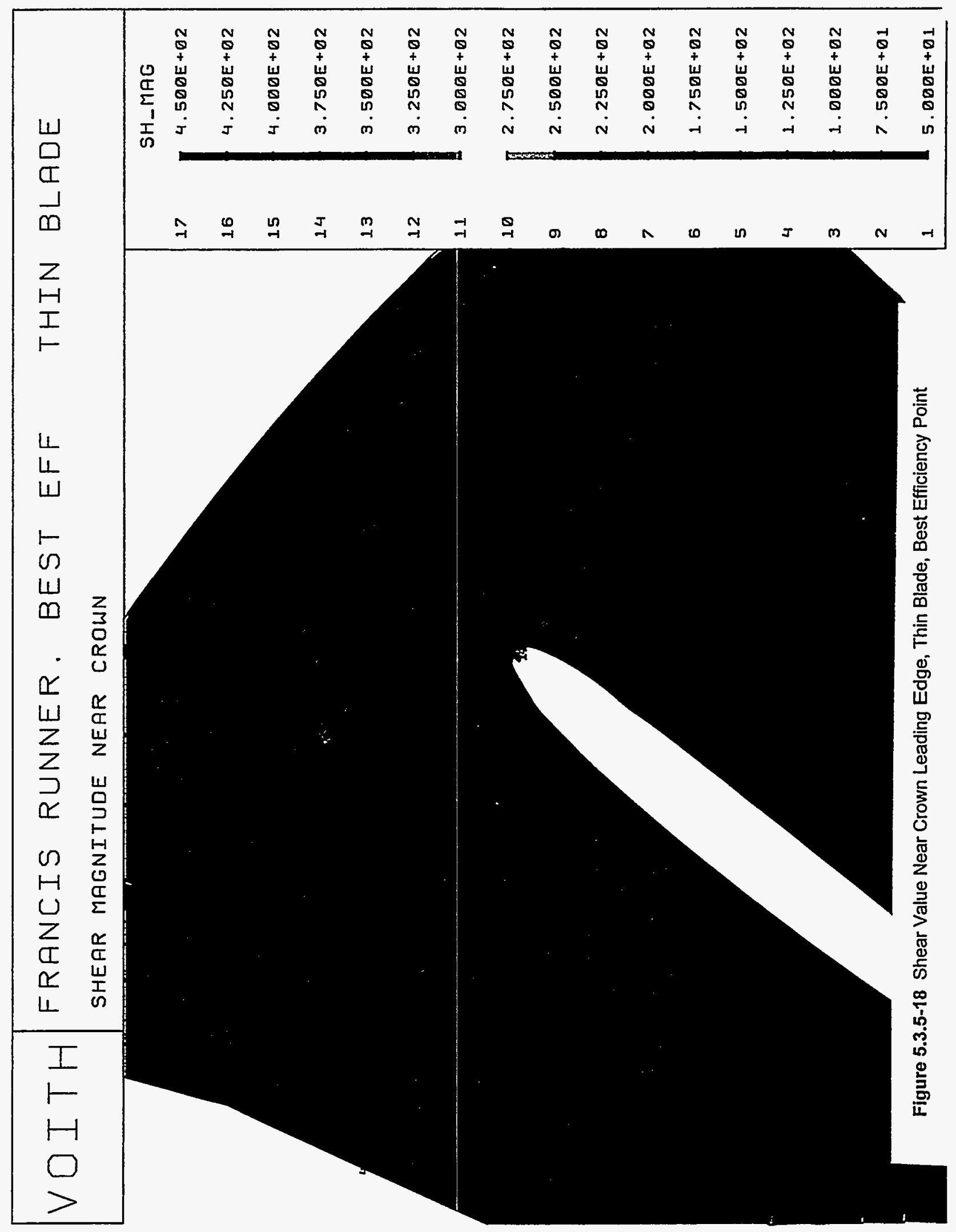



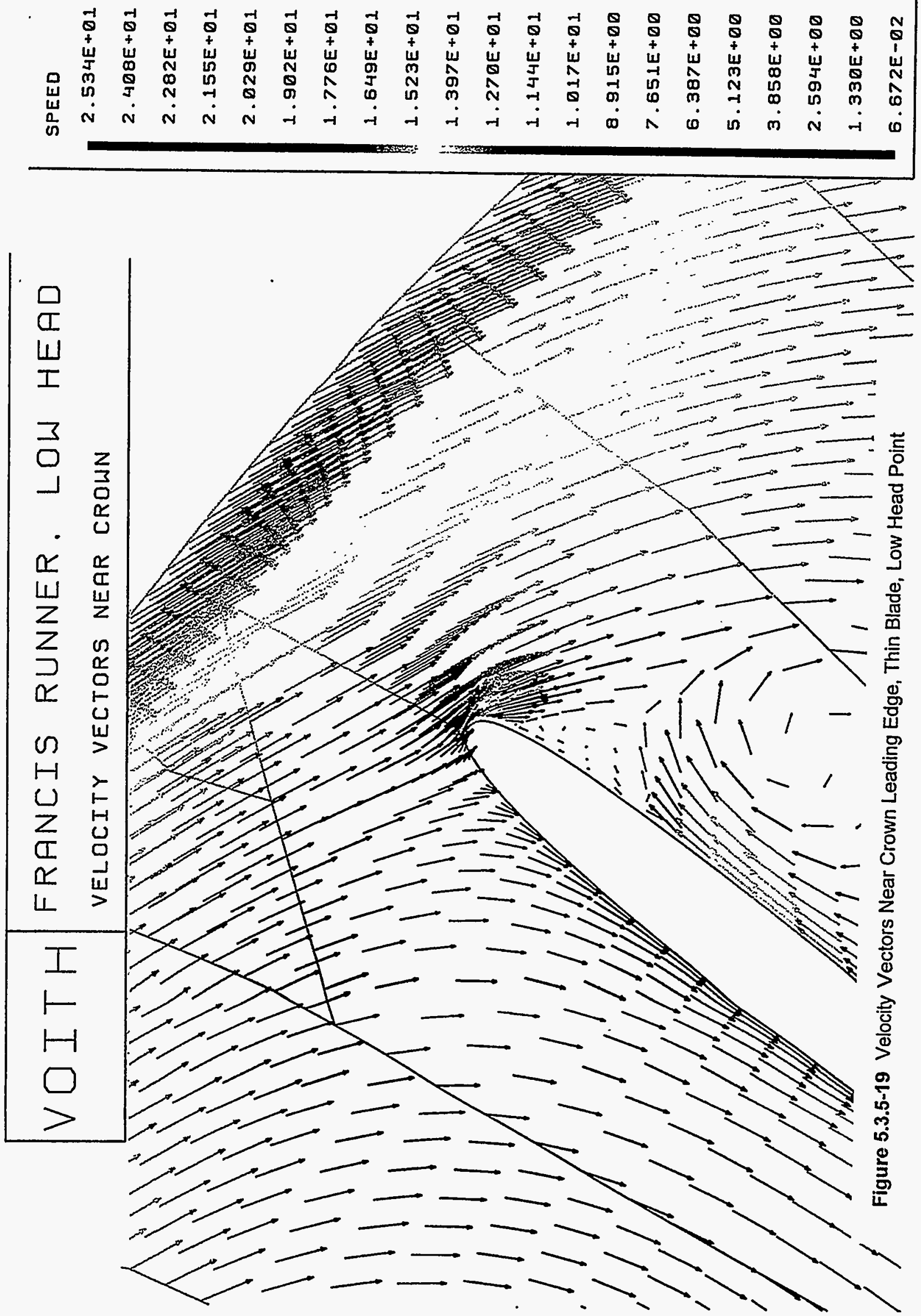


\section{VOITH FRANCIS RUNNER. LOW HEAD SHEAR MAGNITUDE NEAR CROWN}

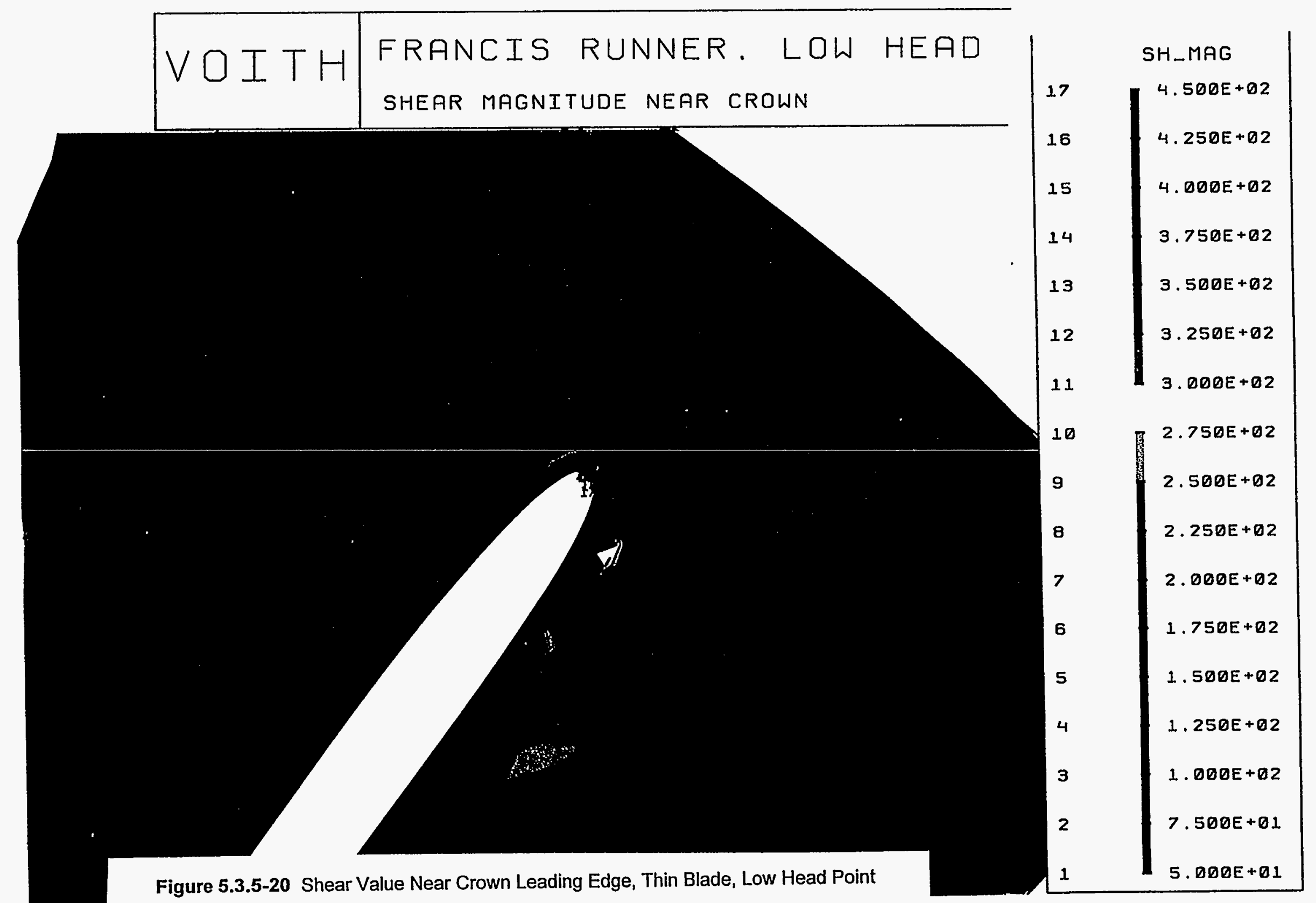




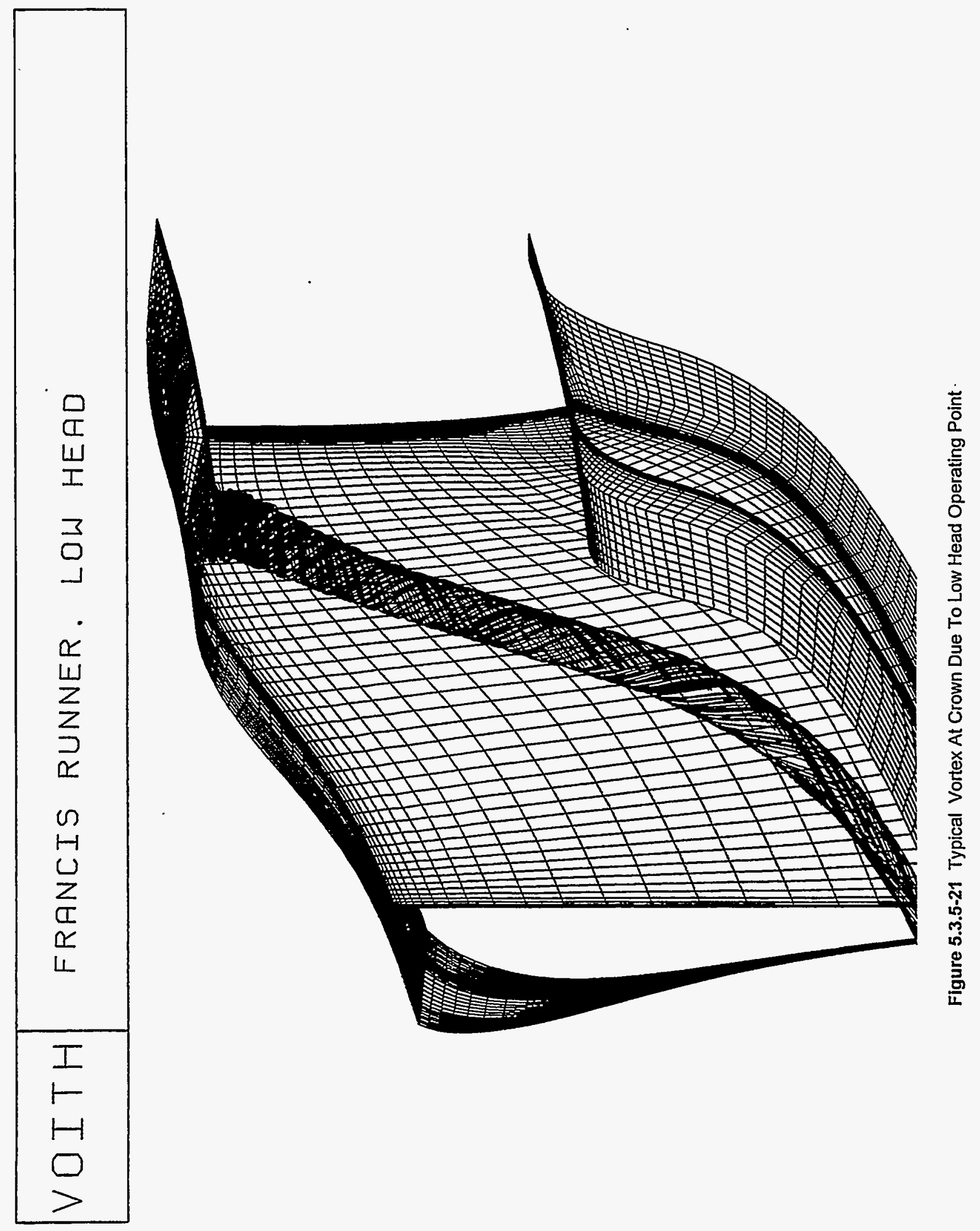




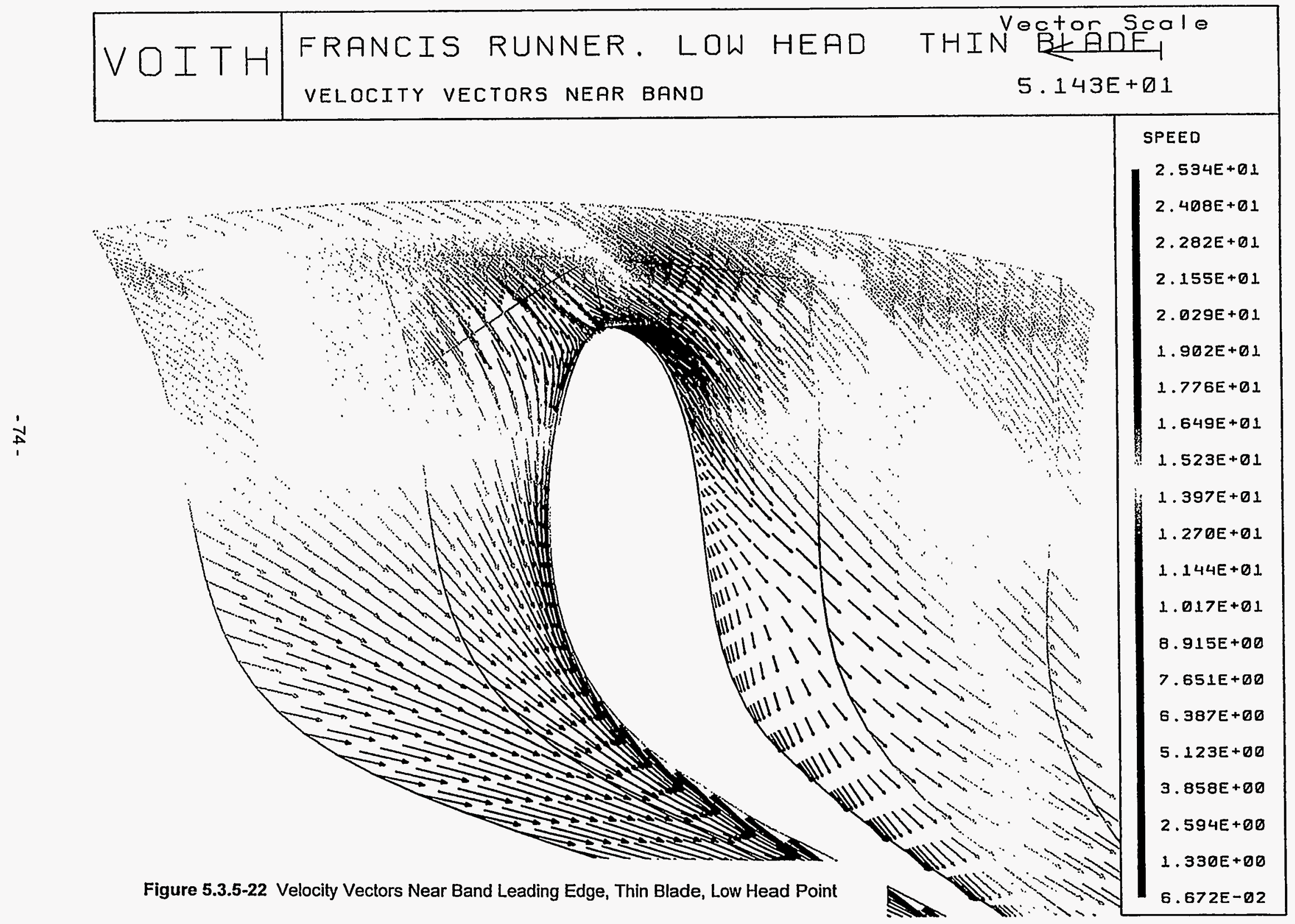




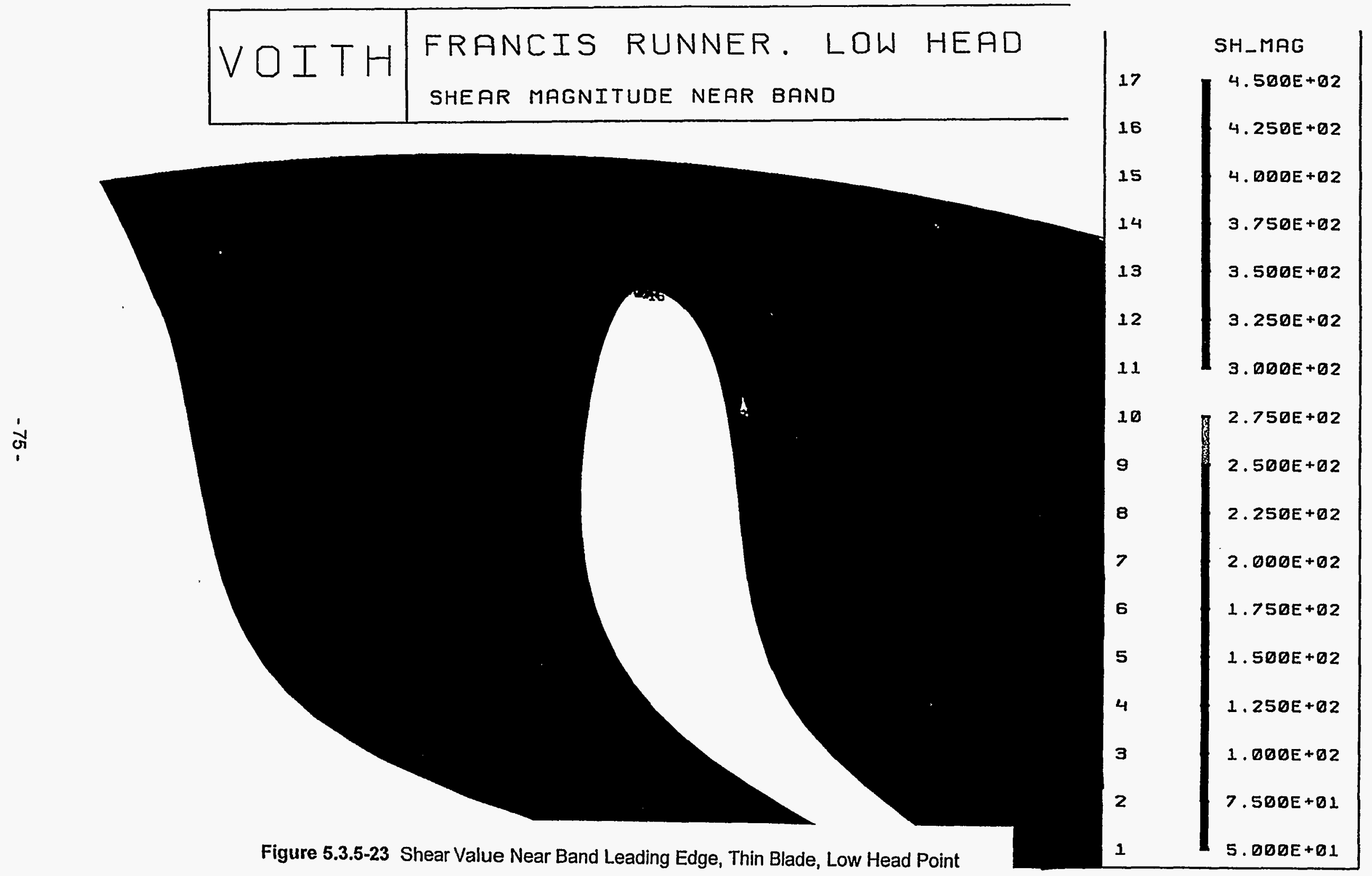




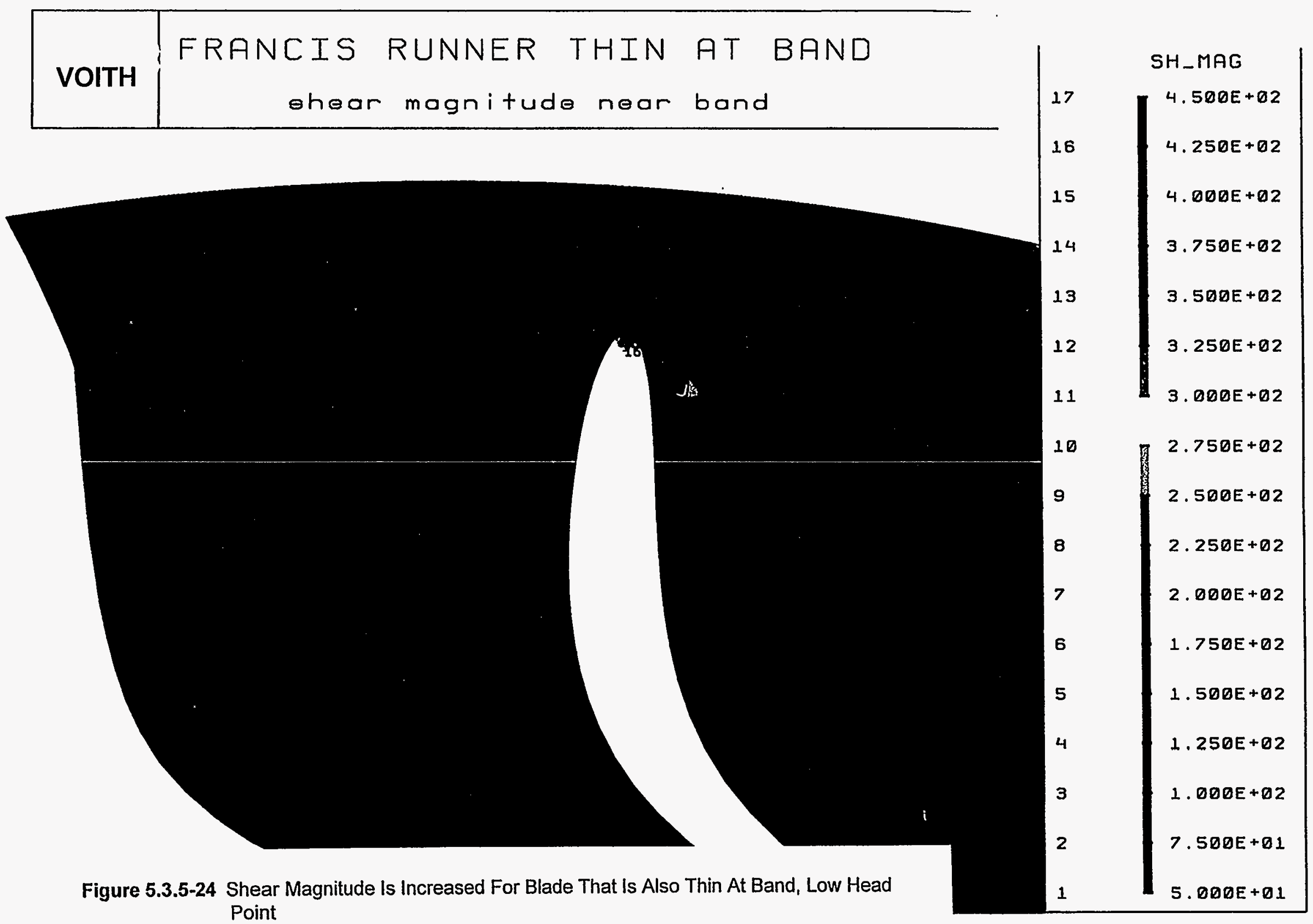




\subsubsection{KAPLAN TURBINE DRAFT TUBE}

Since Kaplan turbines operate on-cam, the runner discharge conditions do not vary drastically. It is the experience that the draft tube flow field therefore, remains relatively similar at all operating conditions. For this reason an extensive operating range was not examined.

For an on cam condition, a typical Kaplan draft tube (Bonneville) with a single pier was analyzed. The inflow condition was determined from laboratory measurements. The grid on the outer walls is shown on Figure 5.3.6-1. A combination of streamline plots and total pressure contours are used to characterize the results, Figures 5.3.6-2a and $b$ and 5.3.6-3. The streamlines show what is a common theme throughout draft tube analyses performed during this study (also in Sections 5.3.7 and 5.4). The decelerating flow responds to pressure gradients and numerous other factors to create a highly complex pattern. Some streamlines flow in a direct and smooth path to the exit, while adjacent streamlines exhibit features of a vortex or recirculation zone. The existence of such phenomena in a Kaplan turbine draft tube, where one would expect that the on cam or maximum efficiency condition would yield the optimum draft tube conditions, indicates that these complex flow features are unavoidable aspects of decelerating flow in a bended channel that cannot be designed away. Figure 5.3.6-3 shows a section through the centerline of the draft tube, ending on the pier nose. It also shows that the bottom of the hub extends into the draft tube. The flow disturbance in this region (also shown by streamline vortex patterns in Figure 4.4.6-15) is shown her by total pressure contours. Total pressure is a measure of the energy in the flow, a combination of static pressure and kinetic energy. This figure illustrates that the area of the draft tube affected by the hub flow is quite large and is expected to have a significant influence on the entire flow field. 

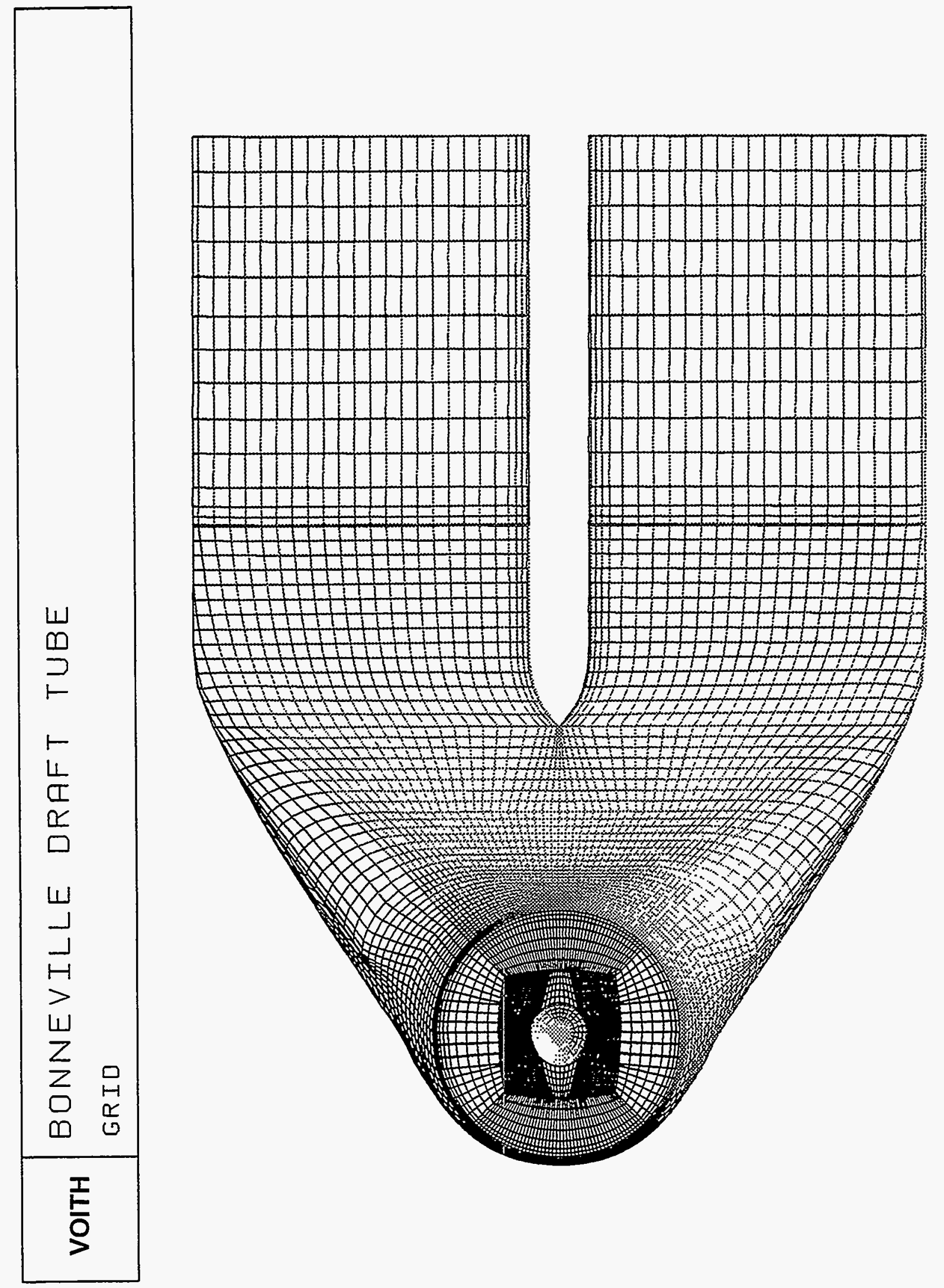

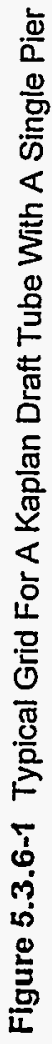




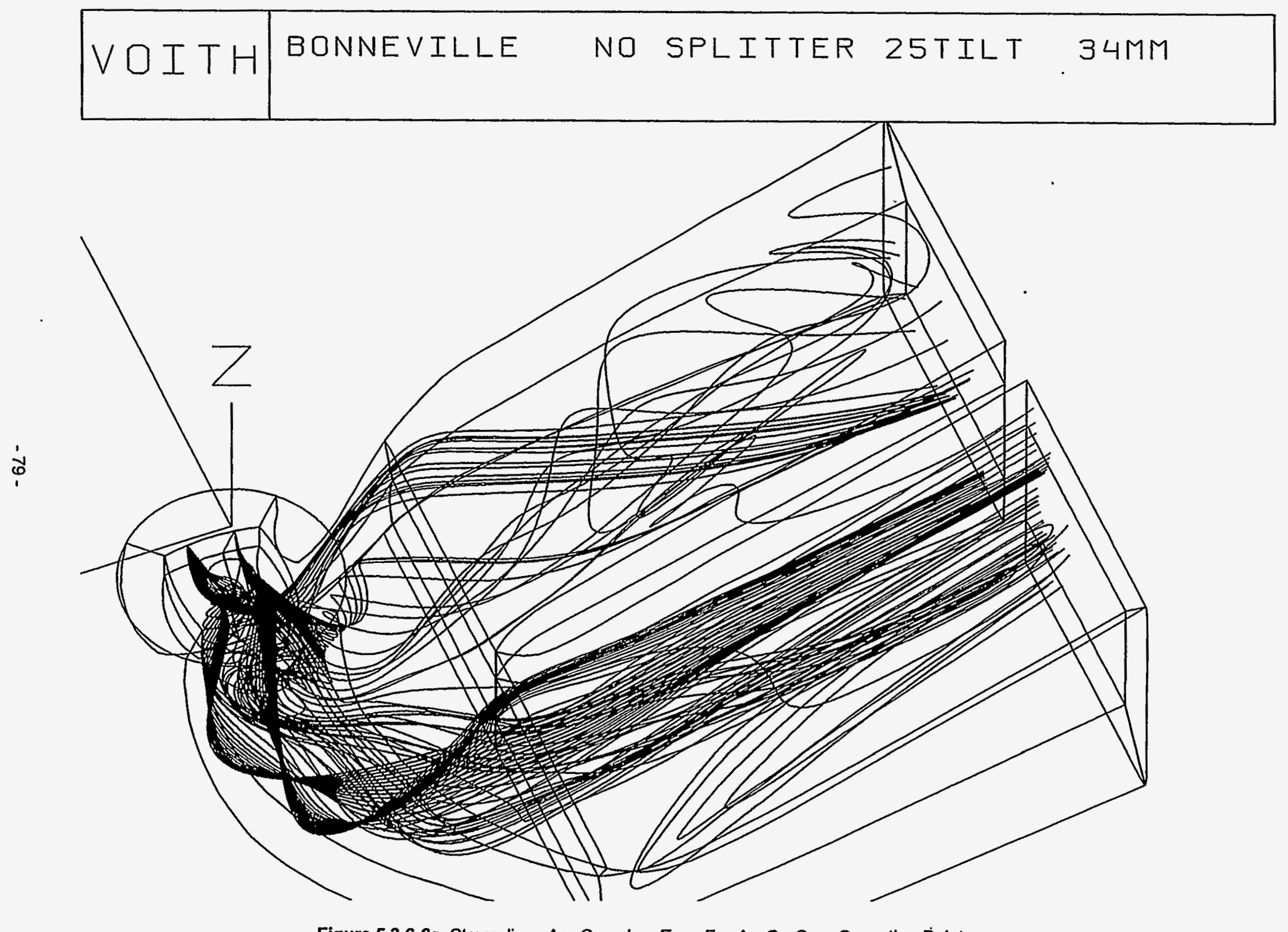

Figure 5.3.6-2a Streamlines Are Complex, Even For An On Cam Operating Point 

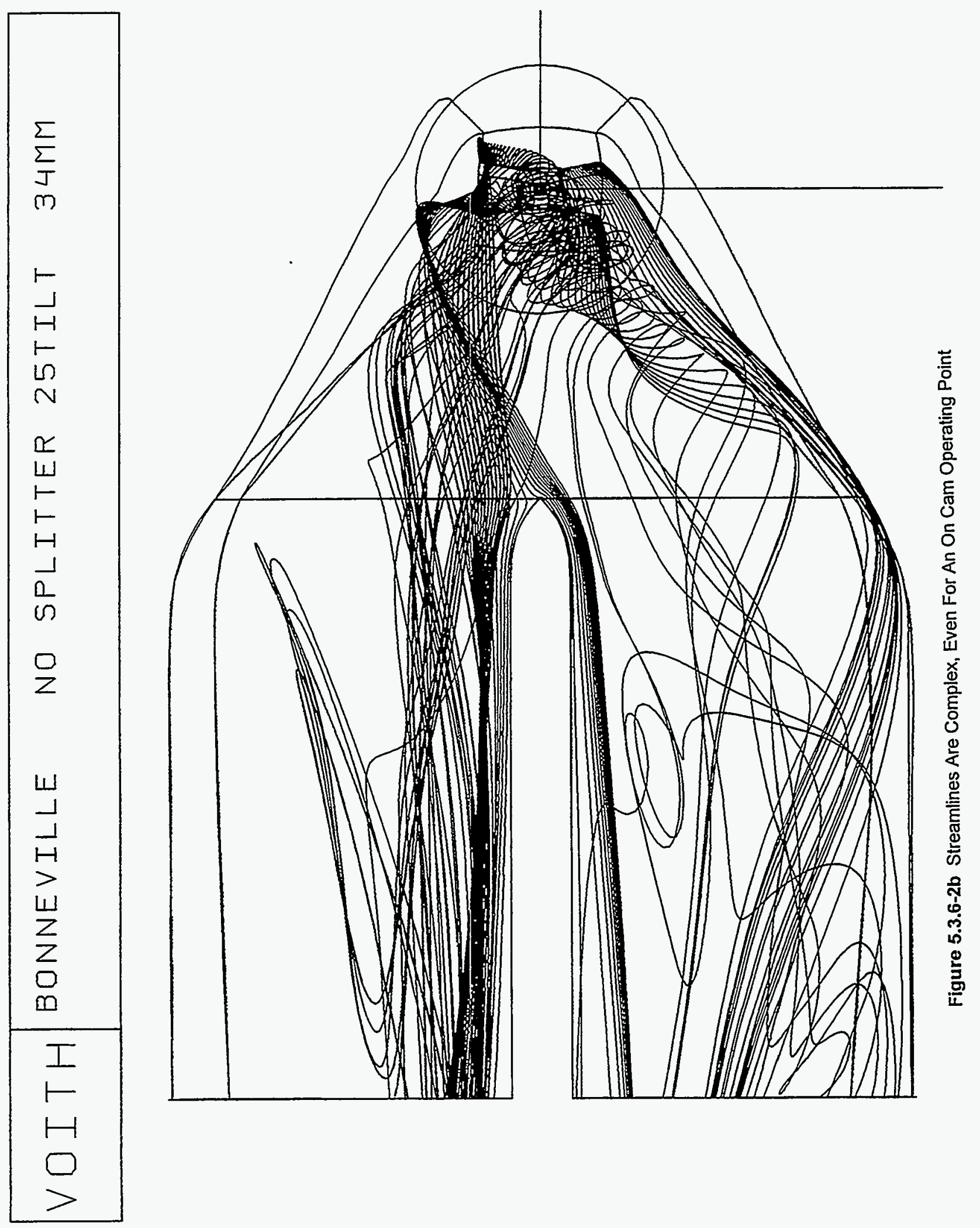


\begin{tabular}{|l|lll}
\hline VOITH & BONNEVILLE NO SPLITER 25TILT 34MM
\end{tabular}

Figure 5.3.6-3 Total Pressure Contour On The Centerline Plane, Up To Nose Of Pier, Showing Hub Contour In Draft Tube And Large Region Of Low Energy

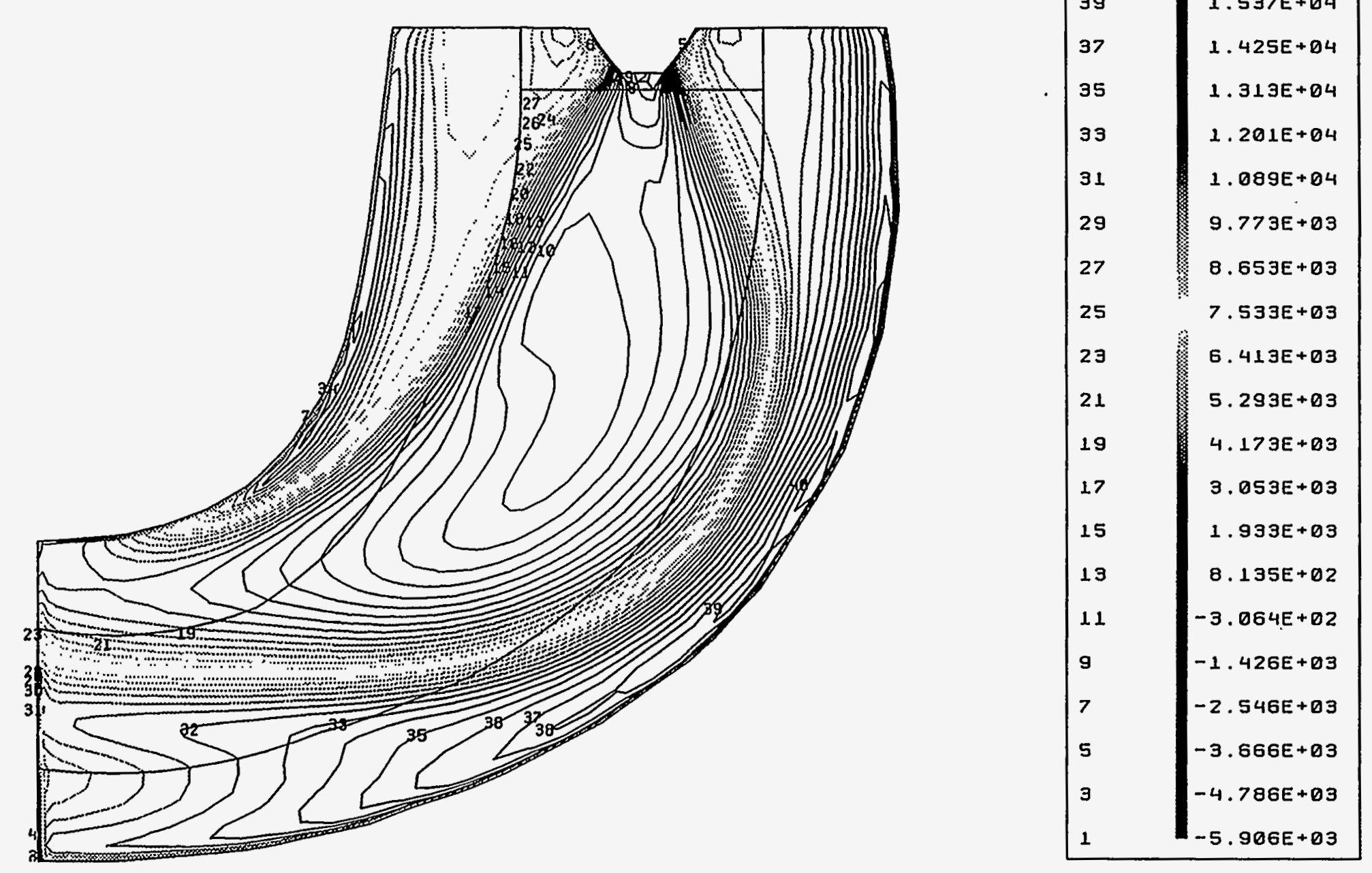




\subsubsection{FRANCIS TURBINE DRAFT TUBE}

A Francis turbine draft tube without piers was chosen for analysis. Three operating points were calculated: maximum output, best efficiency, and low power output. The different discharge characteristics of a Francis turbine runner have different effects on the draft tube flow field. Grids on the outer surface are shown on Figure 5.3.7-1.

Figures 5.3.7-2 through 5.3.7-6 show velocity vectors, and streamlines for the maximum output condition. This condition has a complex inlet condition with a combination of clockwise and counterclockwise swirl. Velocity nonuniformities become accentuated, the secondary flows form a complex pattern, and streamlines show considerable vortex like behavior.

For the best efficiency condition, Figures 5.3.7-7 through 5.3.7-11 show the same flow field information as for the maximum power figures. The inlet flow field is much more uniform, resulting in a much more uniform velocity pattern. Complex secondary flows still exist and vortex patterns are still evident in the streamlines.

At low output, Figures 5.3.7-12 through 5.3.7-15 show a variety of velocity vectors and the total pressure on the symmetry plane. The pattern of the inflow is essentially opposite of the high power condition. A low velocity region in the center region dominates the flow field, resulting in a large recirculation region that extends to the draft tube inlet surface. This flow would have a tendency to reenter the runner. Typically, this operating condition is not stable, and the unsteady flow is manifest in pressure pulsations that are a limitation in plant operation. Unsteady calculations are discussed in Section 5.4.3. 


\section{VOITH ARAPUNI DRAFT TUBE ANALYSIS \\ SURFACE GRID}

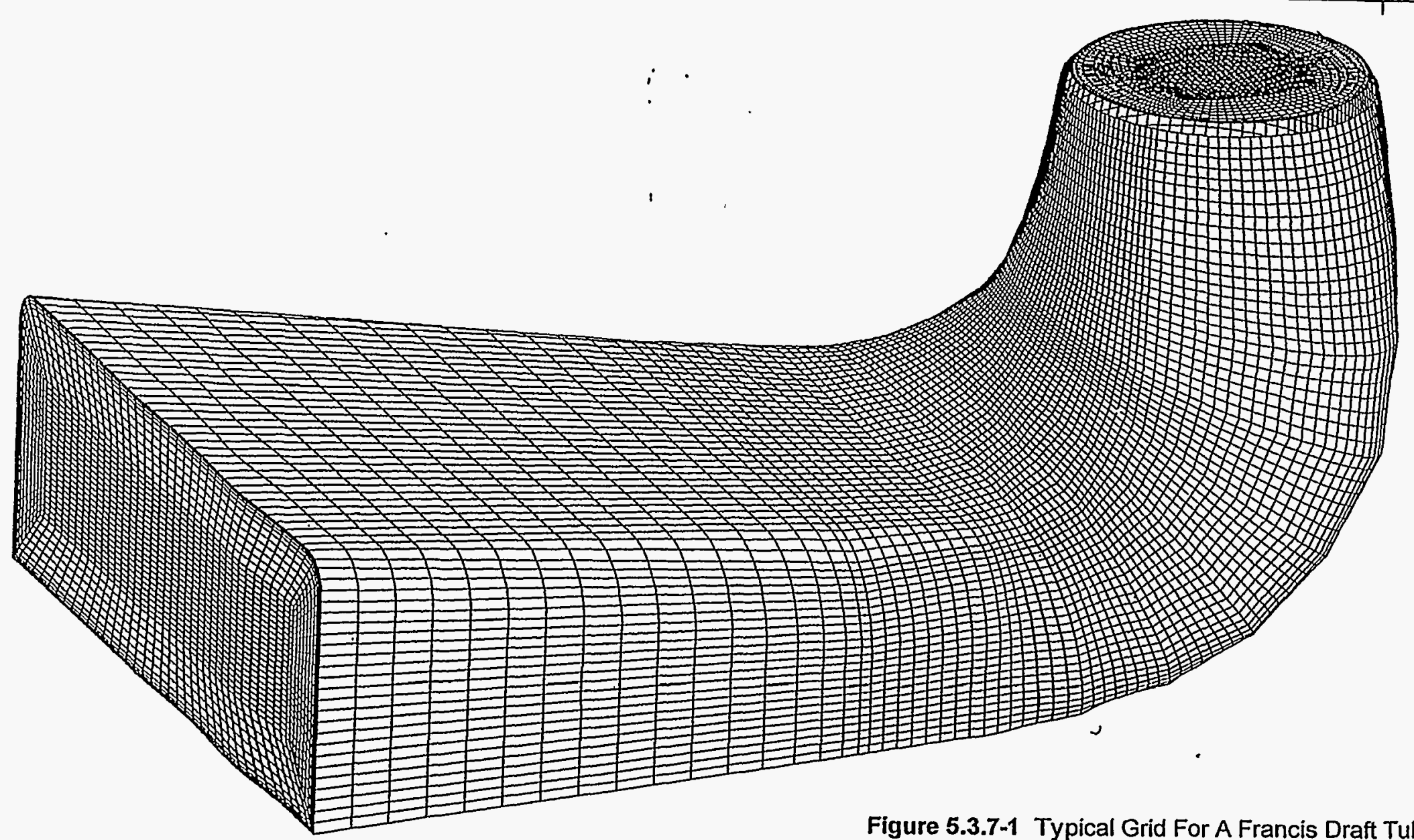

Figure 5.3.7-1 Typical Grid For A Francis Draft Tube With No Pier 


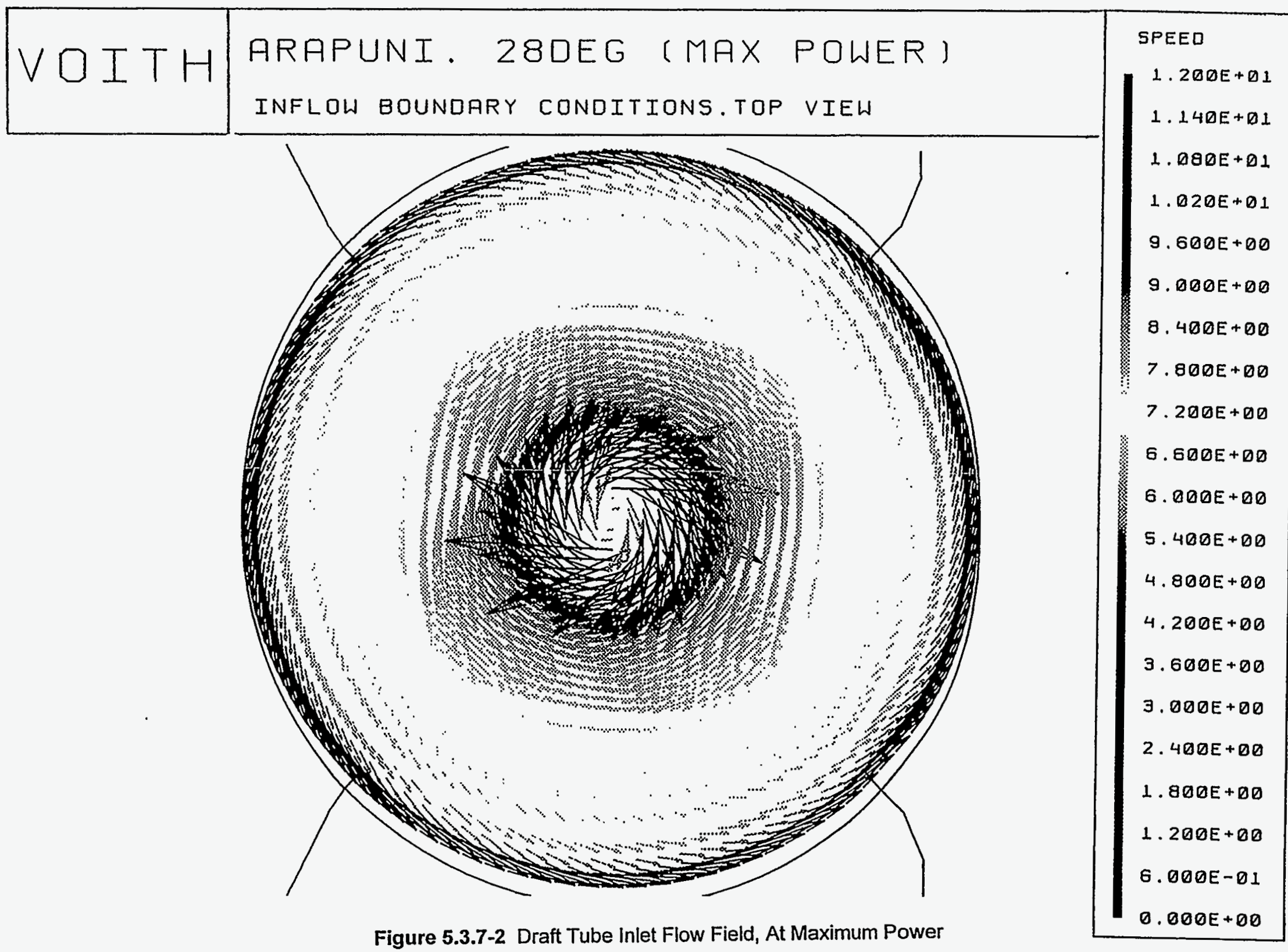




\begin{tabular}{|l|l|}
\hline VDITH & $\begin{array}{l}\text { ARAPUNI. 28DEg (MAX POWER) } \\
\text { Velocity Vectors at dRaft tUbe symmetry Plane }\end{array}$ \\
\hline
\end{tabular}

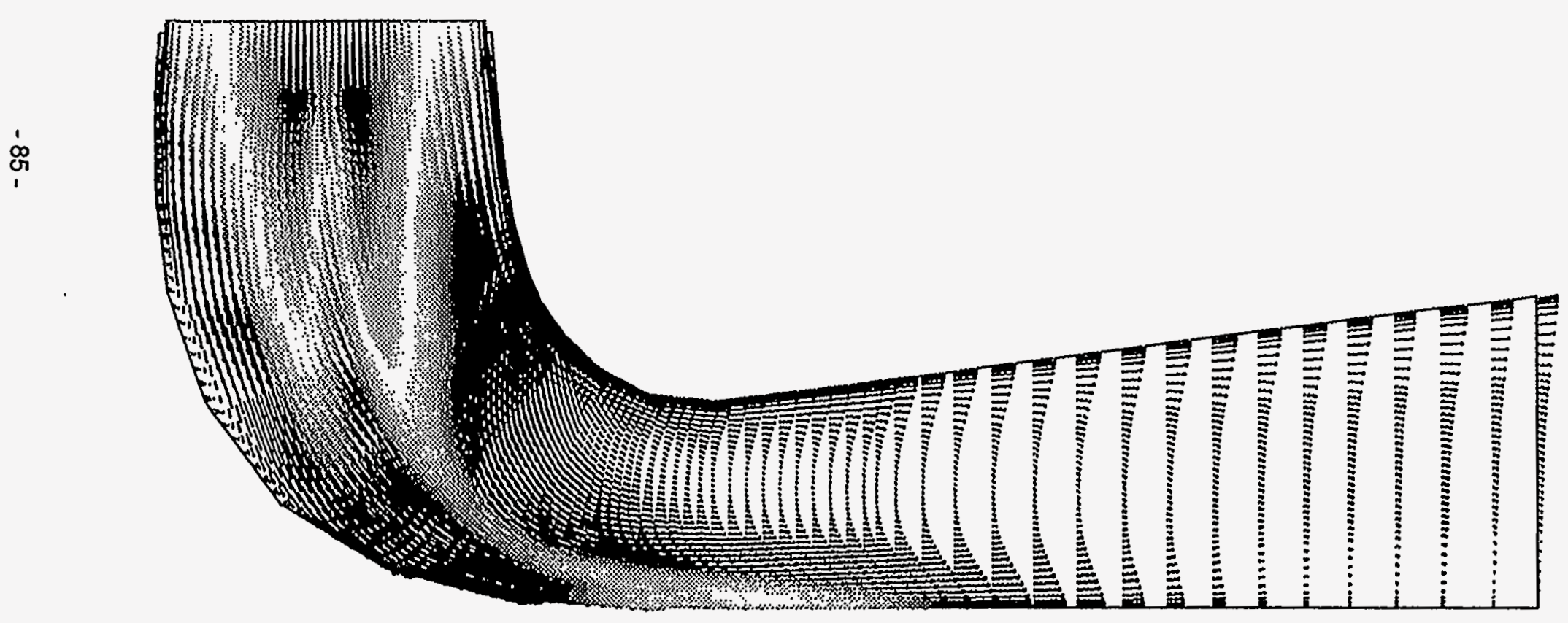

$1.200 E+01$
$1.140 E+01$
$1.080 E+01$
$1.020 E+01$
$9.600 E+00$
$9.000 E+00$
$8.400 E+00$
$7.800 E+00$
$7.200 E+00$
$6.600 E+00$
$6.000 E+00$
$5.400 E+00$
$4.800 E+00$
$4.200 E+00$
$3.600 E+00$
$3.000 E+00$
$2.400 E+00$
$1.000 E+00$
$1.200 E+00$
$6.000 E-01$
$0.000 E+00$

Figure 5.3.7-3 Velocity Vectors On Symmetry Plane, At Maximum Power 


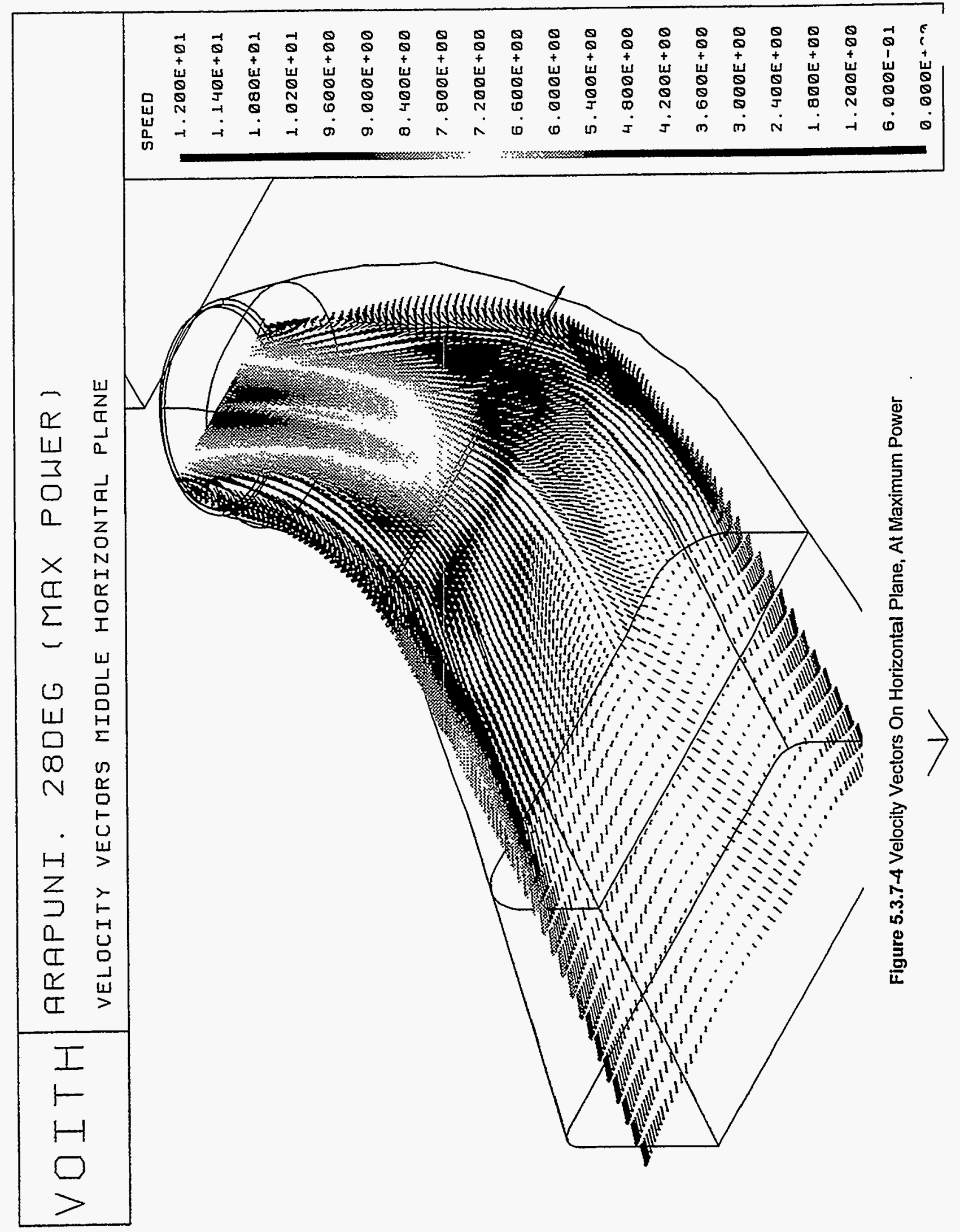



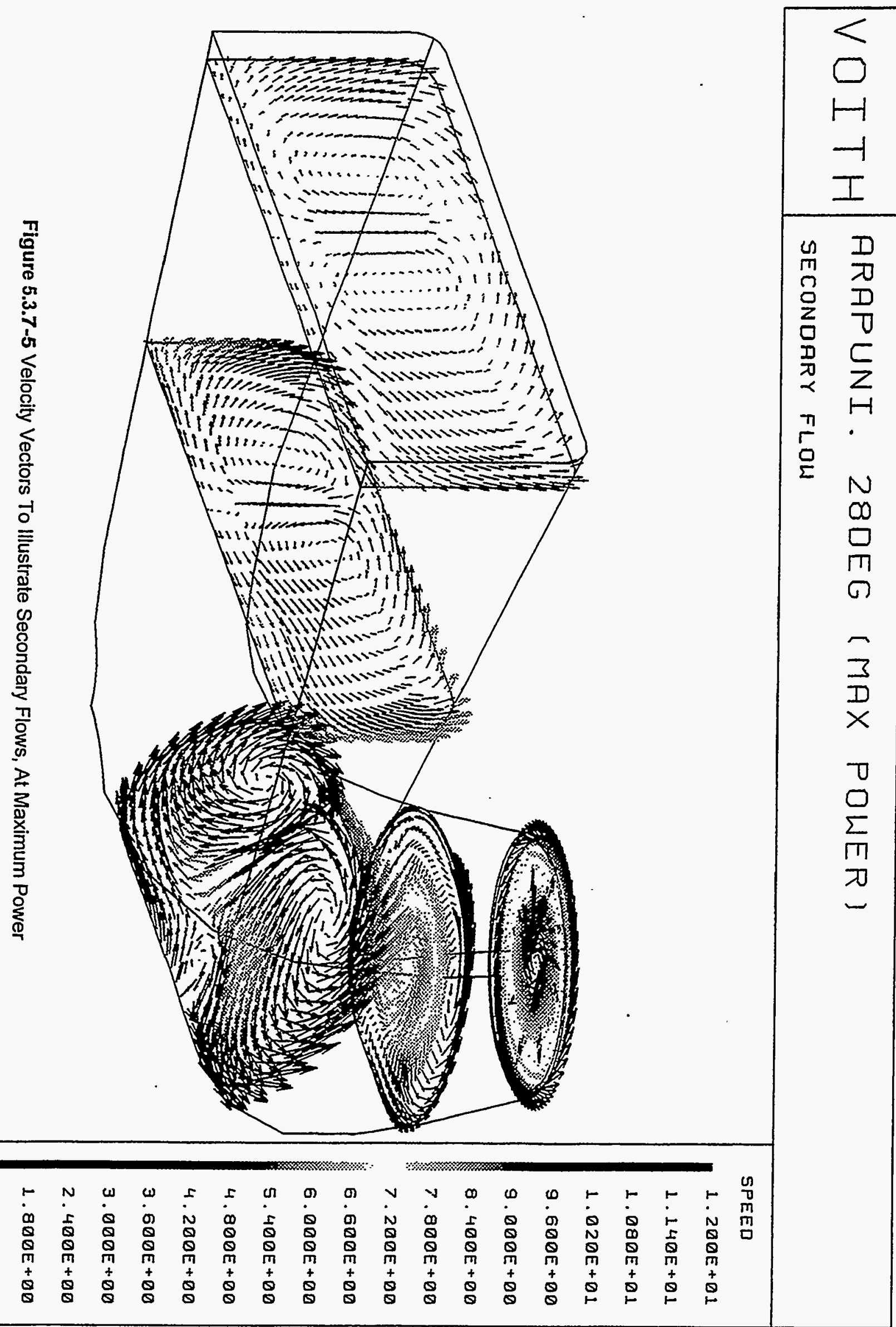


\section{VDTTH ARAPUNI. 28DEG (MAX POWER)}

STREAKLINES

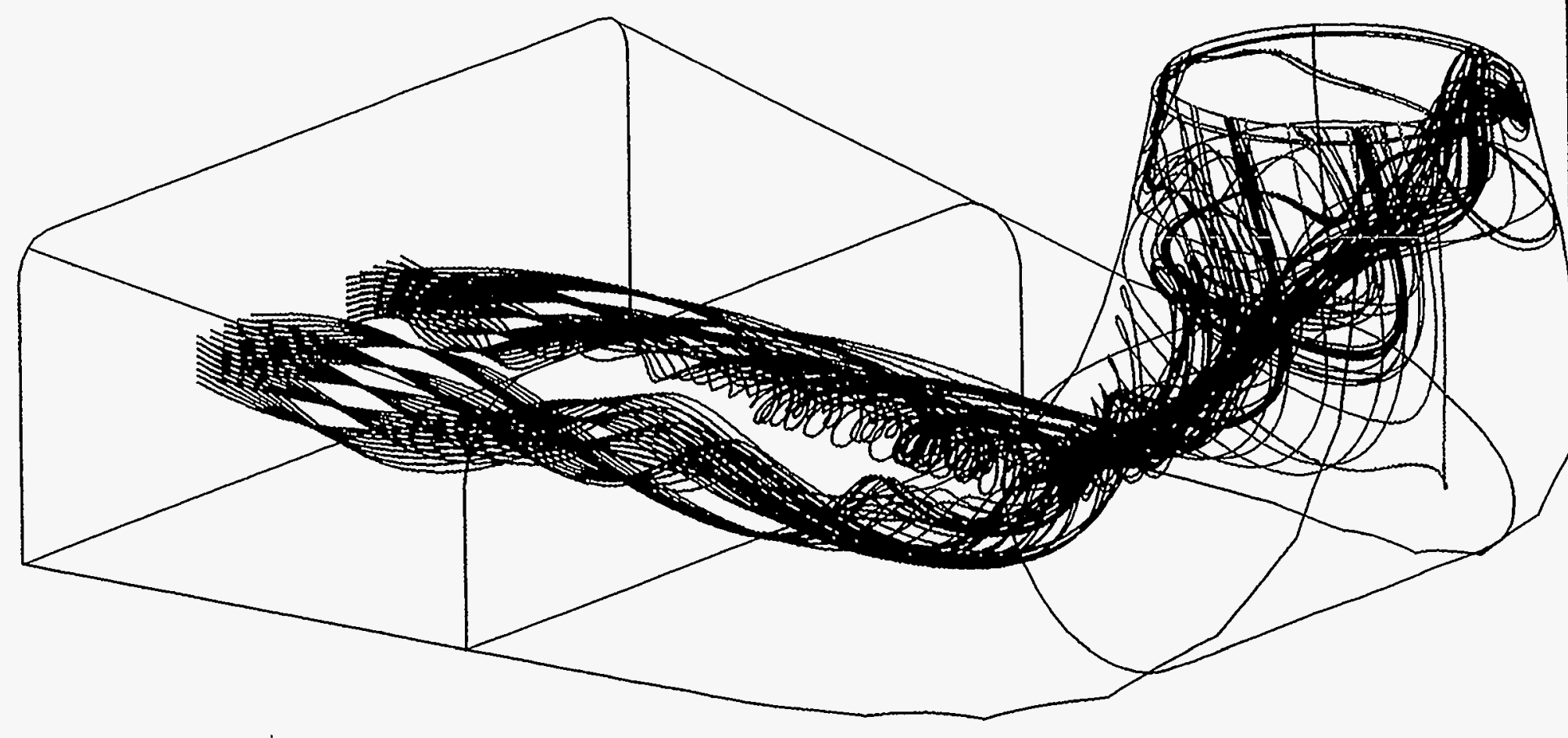

Figure 5.3.7-6 Complex Streamlines, At Maximum Power

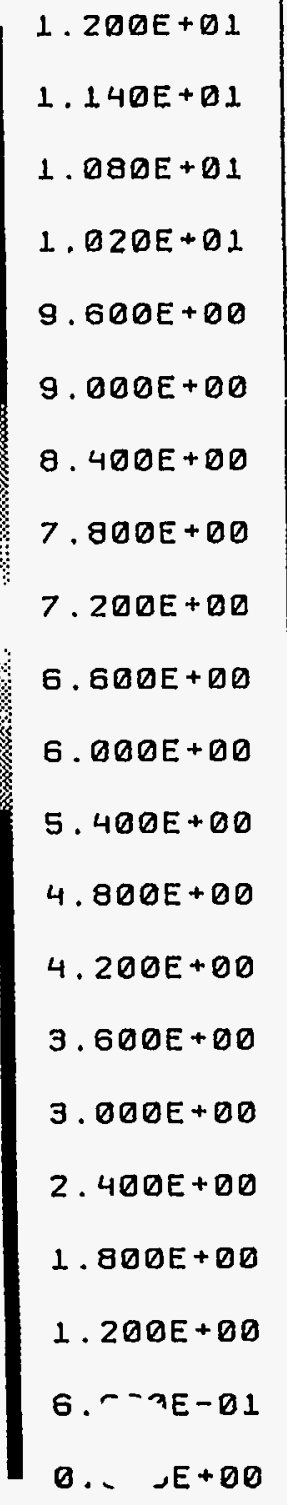




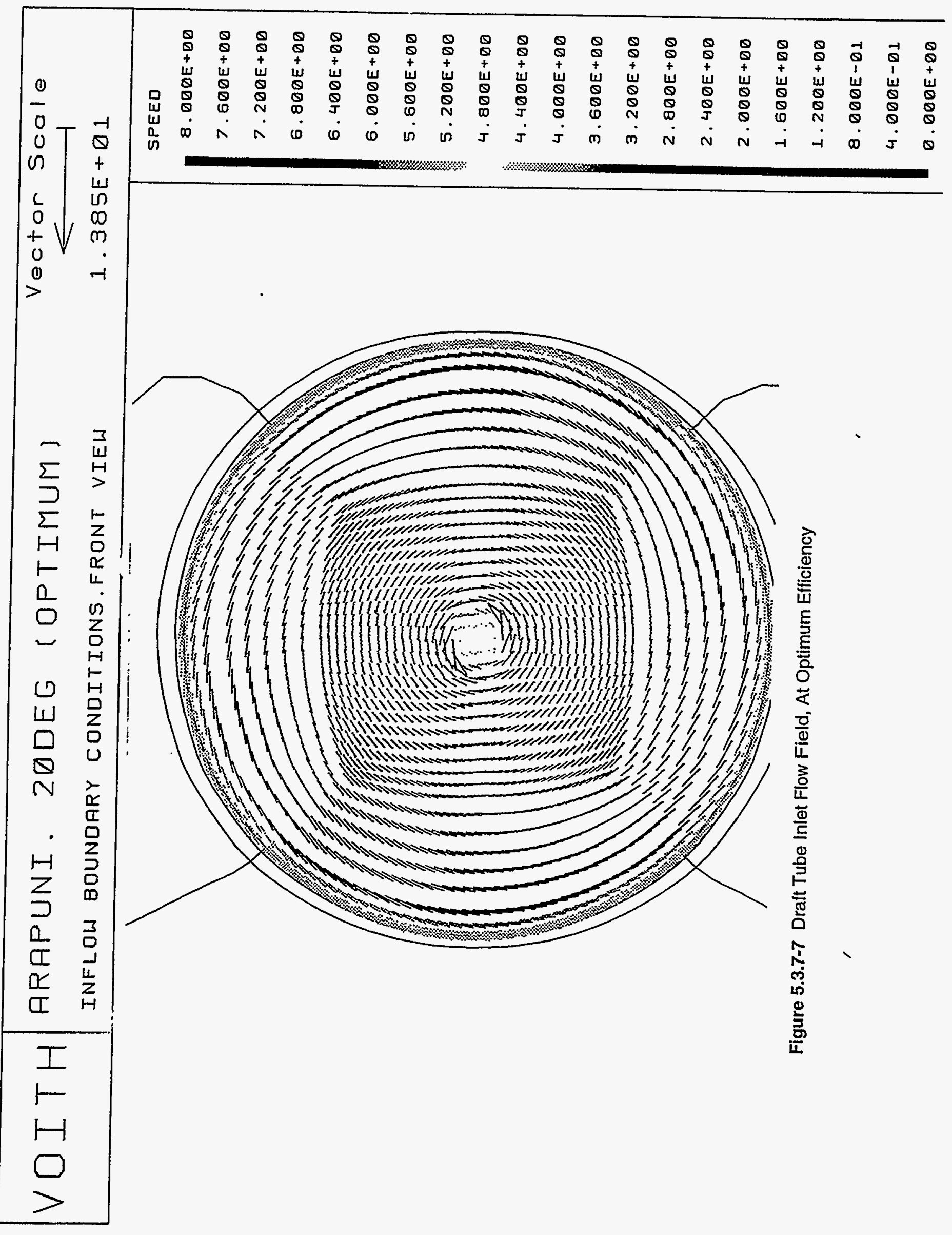




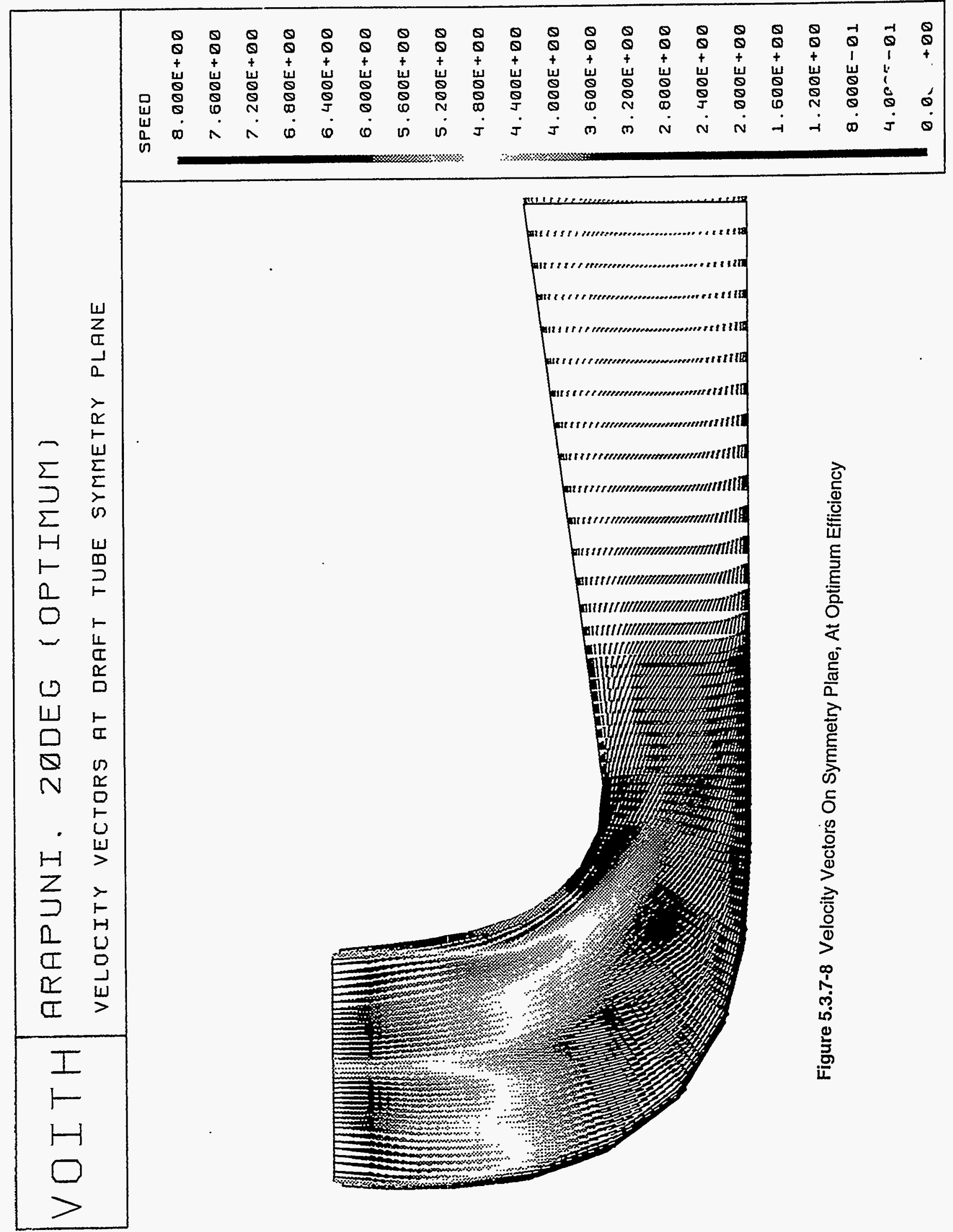




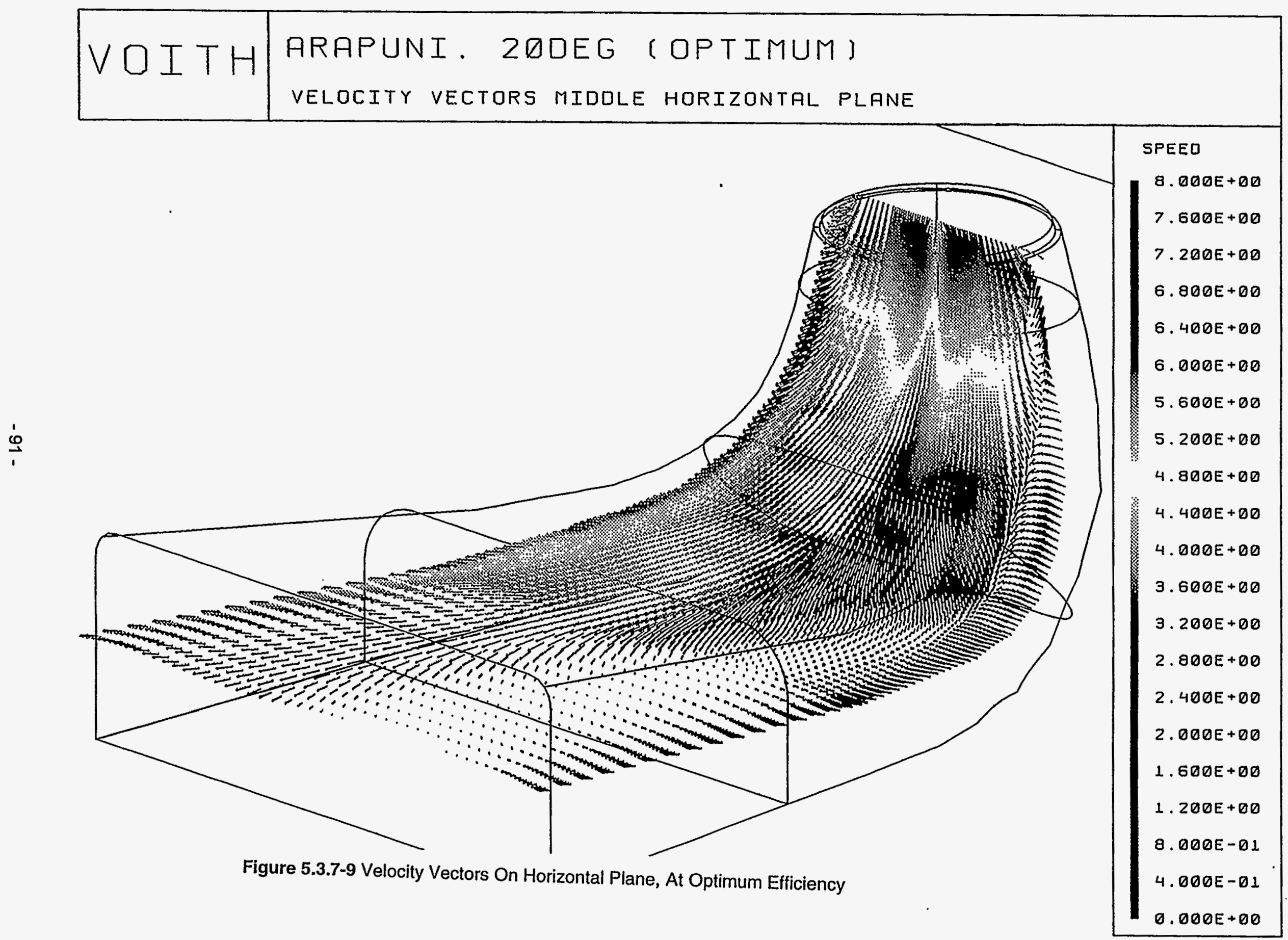




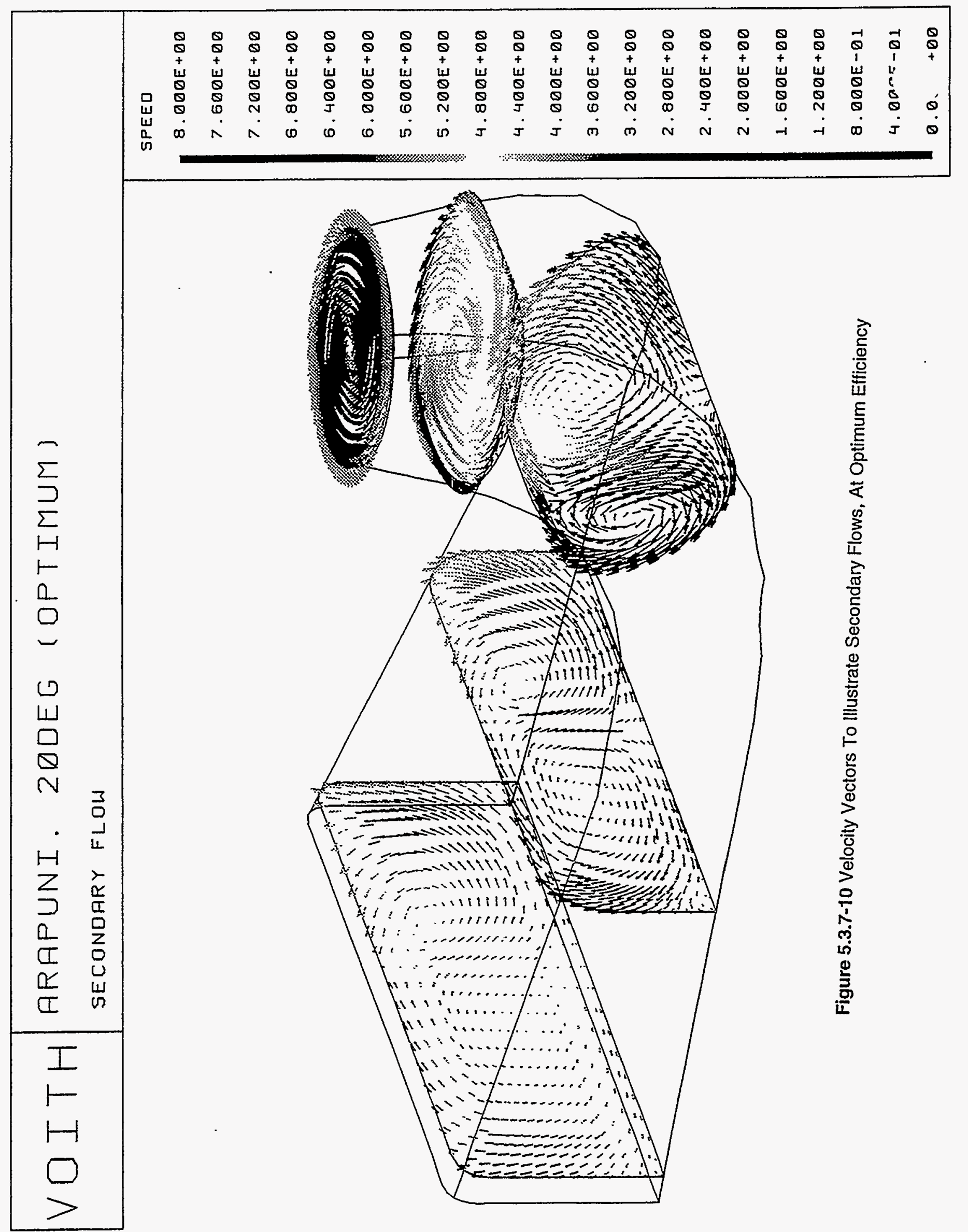




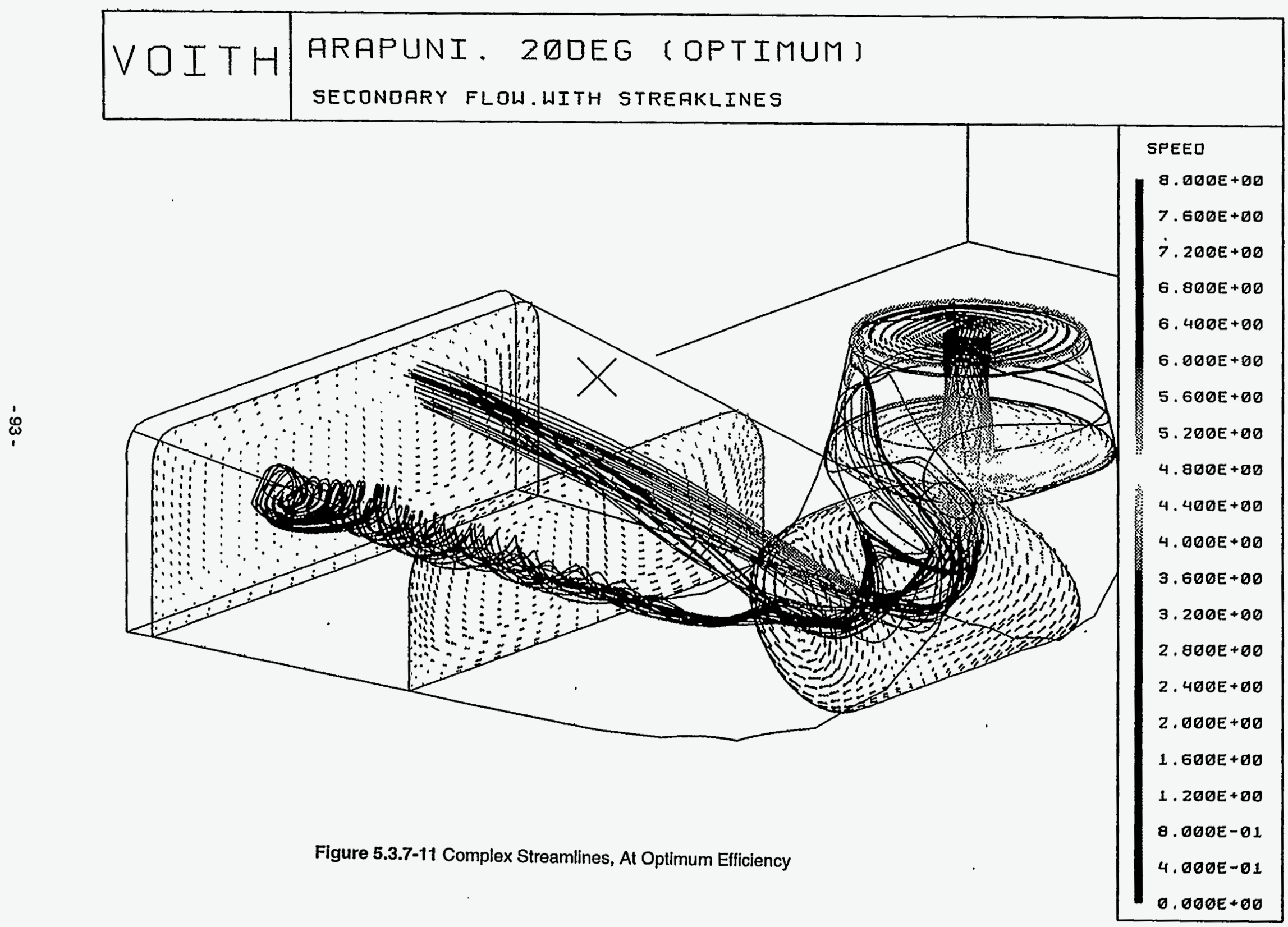




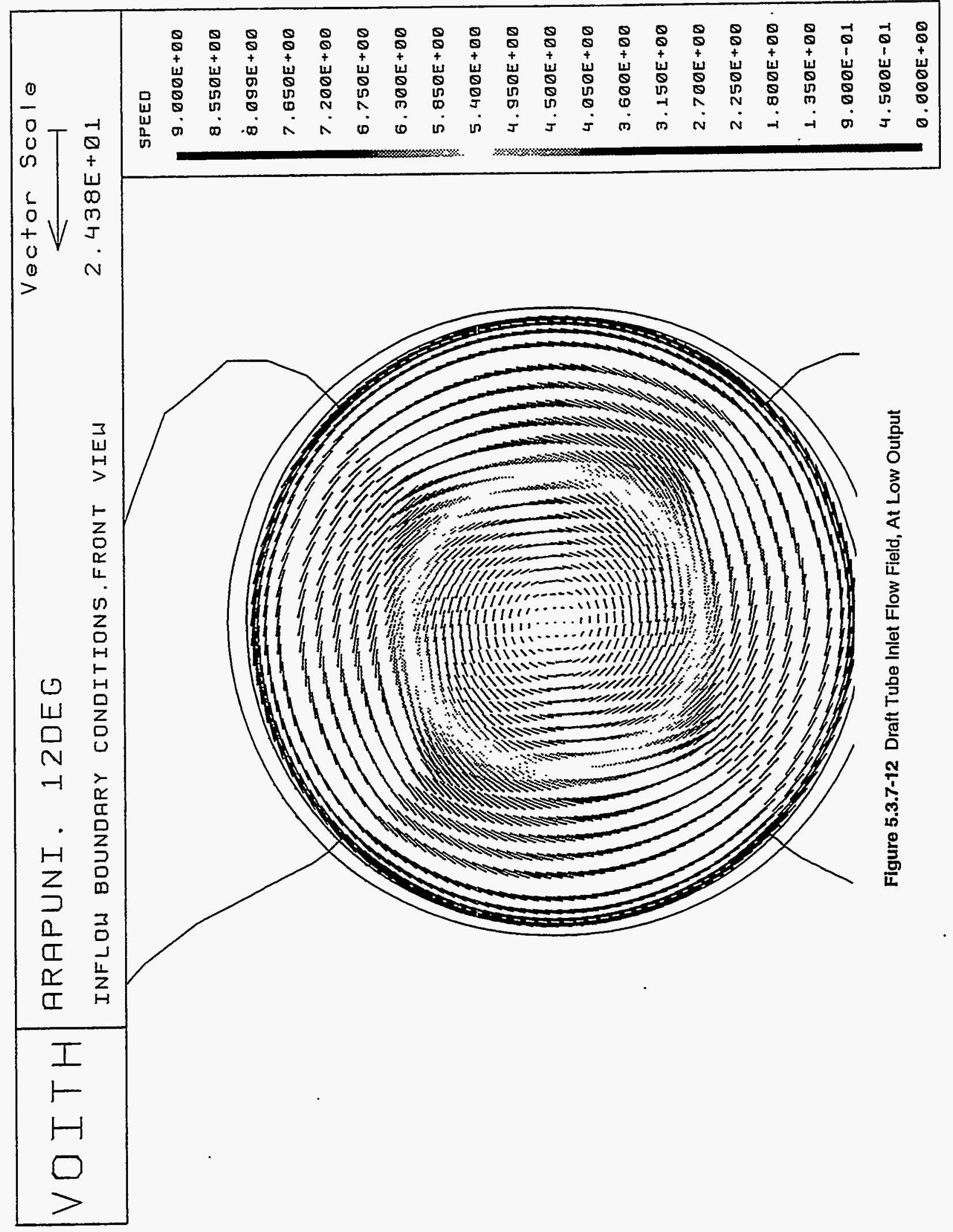




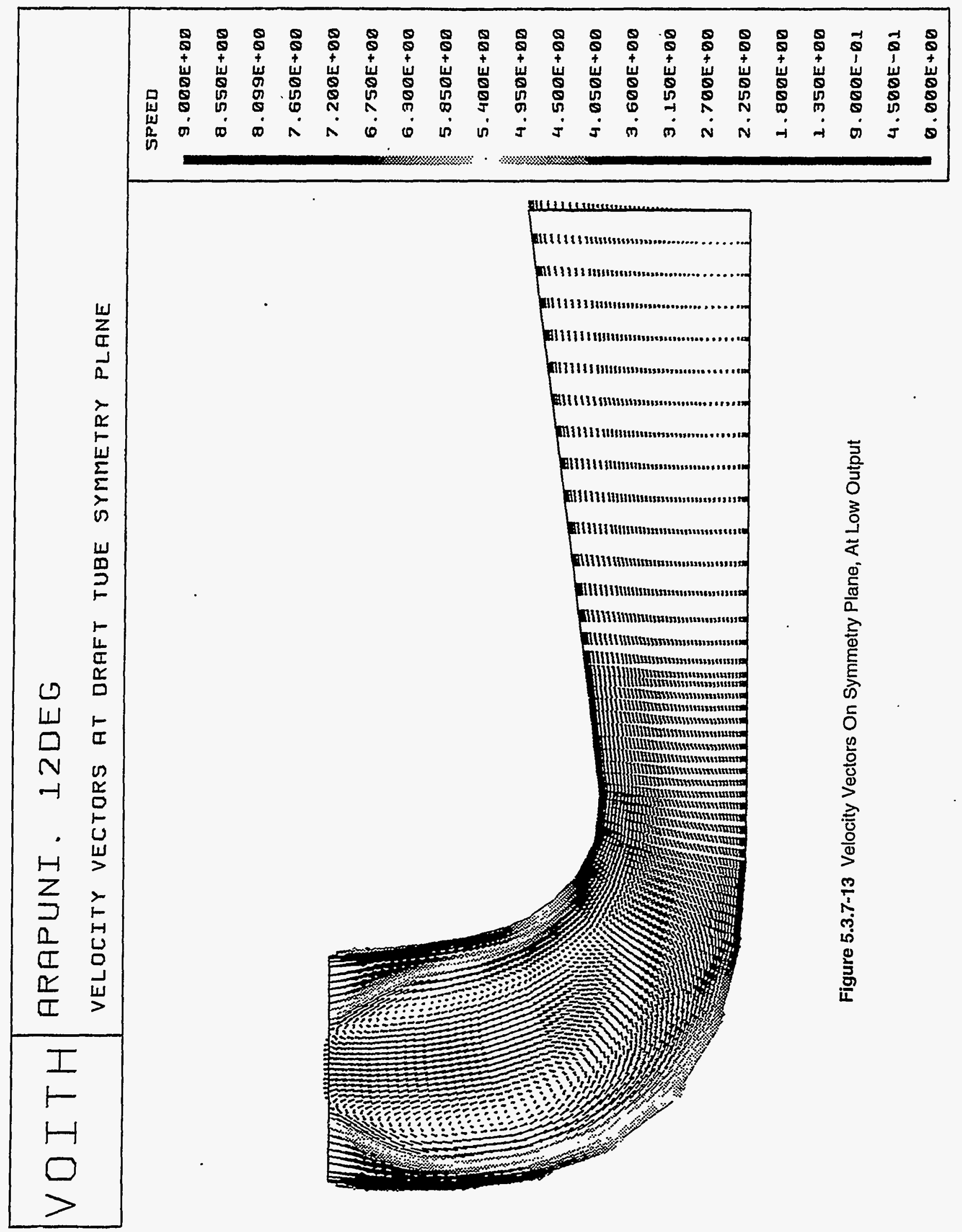




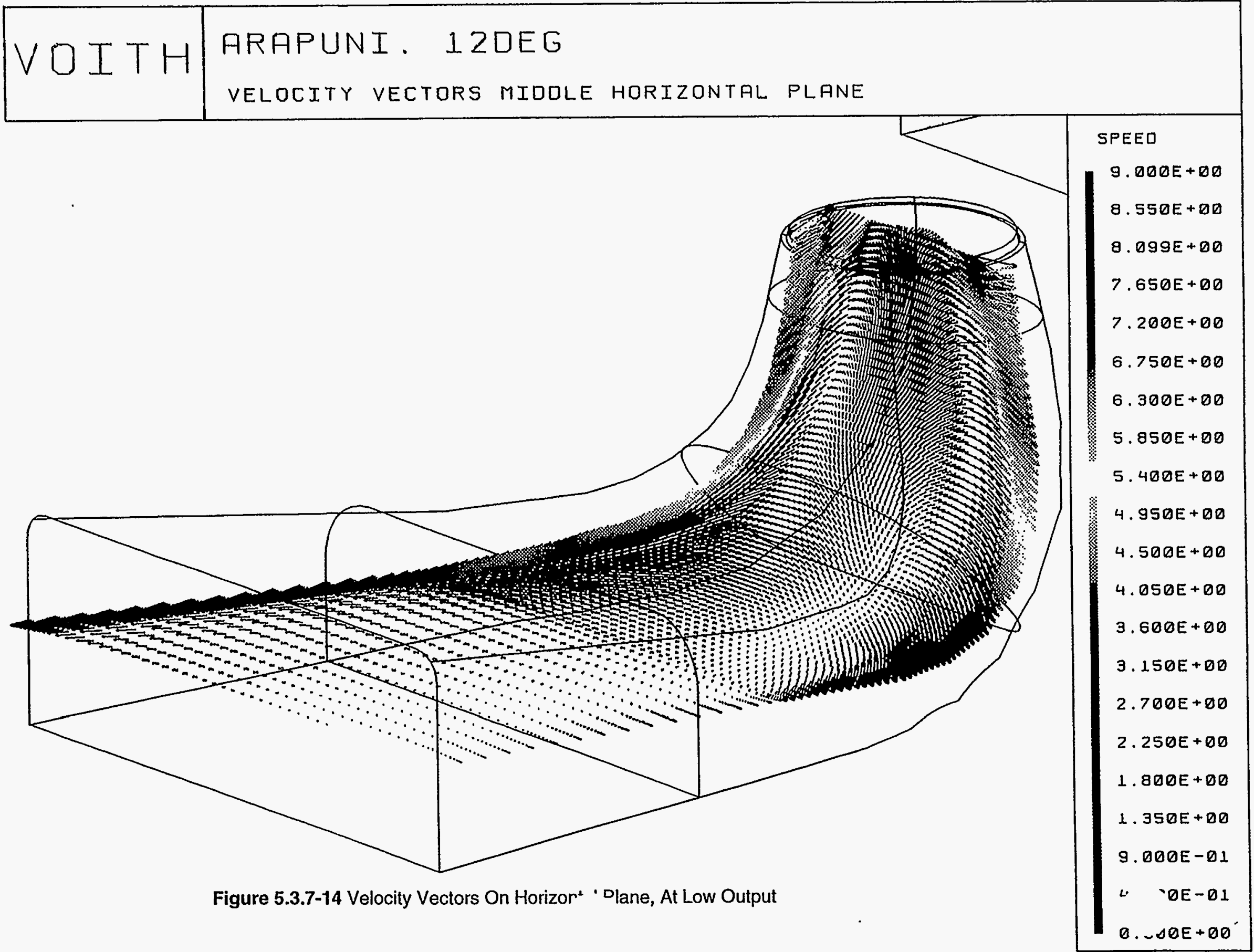




\section{VOITH ARAPUNI. $120 E G$ SECONDARY FLOW}

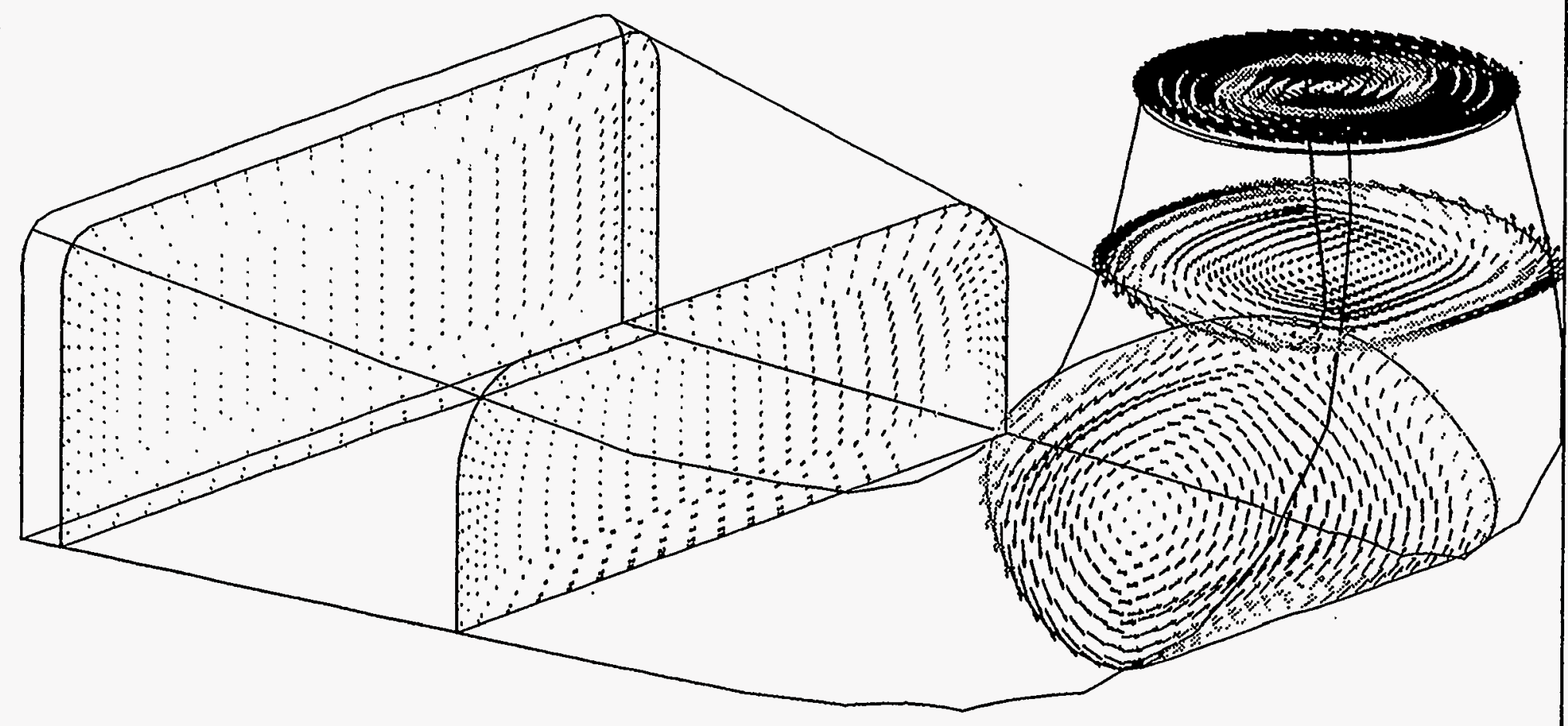

Figure 5.3.7-15 Velocity Vectors To Illustrate Secondary Flows, At Low Output

$6.750 E+00$

6. $300 E+00$

$5.850 E+D E$

$5.40 D E+D D$

$4.950 E+00$

$4.500 E+D 0$

$4.050 E+00$

$3.600 E+00$

3. $150 E+00$

$2.700 E+00$

$2.250 E+\emptyset 0$

1. $800 E+\emptyset \emptyset$

1. $350 E+00$

9. $000 E-01$

4. $500 E-01$

$0.000 \mathrm{E}+00$ 


\subsubsection{SUMMARY AND CONCLUSIONS OF THREE-DIMENSIONAL CFD STUDIES}

Three-dimensional viscous flow analysis capabilities are effective today for use in quantifying flow field characteristics within turbines and provide valuable insight to designers allowing significant improvements in turbine design sophistication in comparison to designs of the past. The use of CFD tools, coupled with carefully planned experimental investigations, provides a means of quantifying fluid flow characteristics and can lead to a better understanding of the causal mechanisms leading to fish mortality. CFD tools allow the prediction of flow paths, times of passage, local pressures, rates of pressure change, rates of shear, and so forth. To effectively use their capabilities, a skilled user needs an effective computer aided geometry definition system, a grid mesh generator, a numerical calculation system, a post processor, and a means of correlating the results of the calculations with real world flow measurements and observations. The skill of the user in interpreting the results based on a history of correlations is important as the numerical tools improperly applied can lead to erroneous results.

Missing in the tool set of today is a method to integrate fluid forces on fish bodies. Only though the quantification of the loads and the correlation of the calculations with the results of physical experiments can criteria for fish injury/mortality be developed.

Today's tools can benefit from advancements. Grid generation methodologies can be improved to reduce the effort related to this phase of the analysis. Grid densities and grid quality can be improved to improve the accuracy of the results. Turbulence models used in the tools are kept simple to keep calculation times and computer costs to affordable levels. More sophisticated turbulence models using more efficient numerical algorithms will allow better numerical simulation. Particularly in decelerating flow fields, the effect of different turbulence models can be surprising leading to significantly different flow characteristics. Using the CFD tools to map flow particle location (fish paths) versus time will be more meaningful with better turbulence models being used. Postprocessors can be improved to allow the user to more easily detect the regions of flow having characteristics of interest. Solvers and computer hardware can be improved to facilitate finer grids, more advanced turbulence modeling so as to allow computation of the flow field in reasonable time frames. Some of these advancements and their impact will be addressed in the next section. 


\subsubsection{REFERENCES}

Raw, M. A Coupled Algebraic Multigrid Method for the 3D Navier-Stokes Equations Proceedings of the $10^{\text {th }}$ GAMM - Seminar Kiel, January $14-16,1994$. Notes on Numerical Fluid Mechanics Vol. 49. Vieweg - Verlag, Braunschweig, Weisbaden, Germany, 1995.

Thomas, M.E., Shimp, N.R., Raw, M.J., Galpin, P.F., and Raithby G.D. The Development of an Efficient Turbomachinery CFD Analysis Procedure AIAAASMEISAE/ASEE $25^{\text {th }}$ Joint Propulsion Conference, Monterey, CA, July $10-12,1989$. 


\subsection{ADVANCED CFD MODELING FOR FISH-FRIENDLY HYDROTURBINES}

\subsubsection{INTRODUCTION}

The objective of Georgia Tech's contribution in Task 3 was to investigate the role of advanced Computational Fluid Dynamics (CFD) as a tool for enhancing the fish-friendiness of hydro-power installations. The term advanced CFD refers herein to computational methodologies which are currently at the leading edge of CFD research. Such methodologies feature state-of-the-art turbulence models, capable of quantitatively accurate predictions of complex three-dimensional flows, in conjunction with advanced numerical techniques for the efficient solution of the turbulence model and mean flow equations. At their current state of development, such methods are not practical enough (in terms of the computational resources they require for obtaining solutions) to be used in the turbine design process but will provide the basis for the next generation of industrial CFD codes.

In the context of the AHT project, the contribution of advanced CFD methods is twofold. First, such methods may be employed to obtain quantitatively accurate predictions of the flow through the various components of a hydropower installation over a broad range of operating conditions. This is a crucial prerequisite for: i) understanding the details of the very complex flowields encountered in hydraulic turbines; ii) identifying flow phenomena which may be responsible for increased fish mortality rates associated with specific turbine design elements; and iii) suggesting and evaluating rehabilitation remedies for alleviating the adverse effects of such elements. It should be emphasized that achieving the two latter objectives further necessitates the development of computational tools capable of calculating fish trajectories and fish body loads through a given pre-computed flowrield. Such tools must treat fish as three-dimensional bodies with physical and geometrical characteristics closely approximating those of the species under consideration. Demonstrating the need for developing such tools is our second contribution in the AHT project.

In the following sections we outline the progress we made in both areas of accurate flow predictions and numerical modeling of fish passage. In the first area, we demonstrate the ability of advanced CFD methods to yield quantitatively accurate results for complex flows, as well as their potential for predicting hydroturbine discharges at off-design conditions, which are typically associated with complex unsteady flow phenomena. In the area of fish passage, we demonstrate the inadequacy of modeling fish as fluid particles and point to the need for future research aimed at the development of advanced fish passage numerical tools. 


\subsubsection{ADVANCED TURBULENCE MODELS FOR HYDROTURBINE FLOWS}

The original objectives of this task were to apply a number of advanced turbulence models to hydroturbine geometries, correlate their predictions with experimental measurements, and identify models suitable for quantitatively accurate predictions of real-life hydroturbine flows. Unfortunately, however, existing measurements for hydroturbine geometries are not sufficiently detailed to facilitate a meaningful validation of advanced turbulence models. For that reason, we chose to carry out a comprehensive model validation study for a test case for which detailed three-dimensional measurements (in terms of three velocity components, pressure and skin-friction distributions, and turbulence quantities) are available in the literature. The specific case selected is flow through a stronigly curved rectangular duct (Kim, 1991). Although geometrically simpler than typical components of hydraulic turbines, the flow in this curved duct exhibits a number of complex phenomena similar to those encountered in various subsystems of hydropower installations--strong streamline curvature, curvature induced axial and transverse pressure gradients, secondary flows, formation, growth and decay of intense streamwise vortices, turbulence anisotropy, etc. It is, therefore, a very challenging test case for exploring the predictive capabilities of advanced turbulence models. Calculations were also carried out for a typical draft-tube geometry (the TVA Norris Dam draft tube) using two different turbulence models. The computed results for this case were compared with the measurements of Hopping et al. (1992) who reported streamwise velocity profiles at few sections within the three bays of the draft tube.

The results of the two studies are summarized in the following sections. More details can be found in Sotiropoulos and Ventikos (1997) and Ventikos et al. (1996) which are included in Appendix 10.5.

\subsubsection{Flow through a Strongly Curved Rectangular Duct}

\section{Summary}

The non-linear two-equation turbulence model (non-linear $k$-w model) that was developed and tested in this study was shown to yield significantly improved predictions of complex three-dimensional flows with strong streamwise vortices. It is, therefore, a very promising tool for quantitative accurate simulations of real-life hydroturbine flows.

\section{Discussion}

The experiment of Kim (1991) is selected as a test case for this study. Kim (1991) reported detailed mean flow and turbulence measurements for flow through a $90^{\circ}$ rectangular duct, of aspect ratio 6 , at Reynolds number $R e=224,000$ (based on the duct width and the mean bulk velocity). An overall view of the wind tunnel and duct geometry, as well as the sections at which measurements were reported, are shown in Figure 5.4.2-1. As seen in the figure, the flow enters the inlet tangent of the curved duct through a short transition duct (a two-dimensional 6:1 contraction). The transverse pressure gradients on the top wall of the contraction induce a pair of vortices inside the top-wall boundary layer resulting in a complex threedimensional flow at the inlet of the upstream straight tangent (Kim, 1991). In order to ensure that the inlet conditions for the numerical calculations properly represent the experimental situation, the experimental data at station $\mathrm{U} 1$ are used to construct appropriate inlet distributions for the mean velocity components and the turbulent quantities (see Kim (1991) for more details on using the measurements to construct inlet conditions for the calculations). The computational domain starts $4.5 \mathrm{H}$ upstream from the inlet of the bend (station $\mathrm{U}_{1}$ ) and extends up to $30 \mathrm{H}$ downstream from the exit of the bend. A numerical mesh with $98 \times 69 \times 52$ nodes, in the streamwise, radial and normal directions, respectively, is used for all subsequently reported calculations. 
A total of five turbulence models were evaluated. These included $k-e$ and $k-w$ models combined with linear (isotropic) and non-linear (non-isotropic) constitutive relations for expressing the turbulent stresses in terms of mean velocity gradients. The details of the various models can be found in Sotiropoulos and Ventikos (1997a). Here we only include a small but representative sample of the computed results. Figure 5.4.2-2 compares measured and computed contours of streamwise vorticity component at the exit of the bend (section D1 in Figure 5.4.2-1) near the inner lower corner of the duct cross-section. The streamwise vorticity component is selected herein because it provides a direct measure of the intensity of the secondary motion that develops inside the bend. As seen in Figure 5.4.2-2, the measurements reveal a very complex secondary motion structure characterized by $\mathrm{C}$-shaped vorticity contours and five distinct vorticity peaks. Out of the five turbulence models tested, we include in Figure 5.4.2-2 only two predictions which clearly gage the progress we made in the course of this work. The first model, denoted in Figure 5.4.2-2 as linear $k$-e model, is the standard two-layer $k$-e model of Chen and Patel (1988) which is widely used today in computations of complex flows of practical interest. The second model, denoted as nonlinear $k$-w model in Figure 5.4.2-2, was developed in the course of this study and is a non-isotropic version of the $k-w$ model of Wilcox (1988). It is seen that the two-layer k-e model of Chen and Patel fails to capture even qualitatively the measured features of the vorticity contours. The proposed non-linear $k-w$ model, on the other hand, reproduces almost every experimental trend with remarkable accuracy. This very promising result underscores the potential of the proposed turbulence model as a practical tool for quantitatively accurate predictions of complex hydroturbine flows.

\subsubsection{Flow Through a Francis-Turbine Draft Tube}

\section{Summary}

Several improvements were incorporated in the Georgia Tech CFD code to make it applicable to complex draft-tube geometries with piers. Calculations were carried out for the TVA Norris Dam draft-tube, using a very fine computational grid, and the computed results were shown to be in good quantitative agreement with available measurements. Lack of detailed experimental data, however, is a major obstacle that hinders further advancements in the numerical simulation of real-life draft-tube flows.

\section{Discussion}

The draft tube configuration, used for the present computations, is one of the TVA Norris Autoventing Power Plant (Norris, Tennessee) draft tubes designed to operate with $50 \mathrm{MW}(66,000 \mathrm{HP})$ Francis hydroturbines. The area expansion ratio for this draft tube (ratio of the exit to inlet cross-sectional area) is approximately 4.4:1 while the radius of curvature of the elbow is 1.34 diameters of the inlet circular crosssection. Two vertical piers, symmetrically placed about the centerline, support the downstream rectangular diffuser.

The computational grid for every cross-section is generated using an efficient algebraic grid generation method which employs linear and third-order spline interpolation. The grid lines are concentrated near the walls using the hyperbolic tangent stretching function. The cross-sectional grids are then stacked along the centerline of the tube to complete the three-dimensional grid. To accurately resolve the flow in the vicinity of the piers, the streamwise planes are clustered around the pier leading edges also using hyperbolic tangent stretching. Typical cross-sectional views of the computational mesh and the relevant coordinates are shown in Figure 5.4.2-3. All the subsequently reported calculations were carried out on a grid with $85 \times 73 \times 193$ nodes (a total of approximately $1.2 \times 10^{5}$ nodes), in the streamwise, vertical, and horizontal $(x, h$, and $z$ ) directions, respectively, which is the finest mesh to be used so far for draft-tube calculations.

The numerical method employed herein is based on the work of Lin and Sotiropoulos $(1997 a, b)$ who 
developed an efficient time-marching procedure for solving the three-dimensional Reynolds-averaged Navier-Stokes (RANS) equations, in conjunction with two-equation, near-wall, turbulence closures, in generalized curvilinear coordinates. Several improvements were required in order to make the method of Lin and Sotiropoulos (1997) applicable to complex hydroturbine geometries. These include, among others, the ability to handle multiple connected domains, use of variable residual smoothing coefficients, and implementation of Total Variation Diminishing (TVD) schemes (Yee and Harten, 1987). This latter development was found critical for accurate high Reynolds number turbulent flow simulations for geometries involving stagnation points (such as the piers of a draft tube). None of the high-resolution non-monotone schemes tested. by Lin and Sotiropoulos (1997a) were robust enough to handle draft-tube flows. In fact stable simulations could be carried out only when first-order flux-difference splitting upwind was implemented for discretizing the convective terms. The resulting solutions, however, are contaminated due to excessive numerical viscosity. The dramatic effect of spatial accuracy in predictions of draft-tube flows is demonstrated in Figure 5.4.2-4 which compares solutions obtained using the firstorder upwind scheme with those obtained using the up-to-second order accurate symmetric TVD scheme of Yee and Harten (1987). Both calculations were carried out on the same mesh using the two-layer k-e model. The particle traces in both figures have been released from exactly the same points located just upstream of the right pier.

Figure 5.4.2-5 shows comparisons of measured (Hopping, 1992) and calculated streamwise mean velocity profiles at two streamwise locations, downstream the start of the piers, in all three bays--these results were obtained using the linear $k-w$ model of Wilcox (1988). The present simulations correspond to experimental run No. 1 (see Hopping, 1992) which was performed with runner speed $898 \mathrm{rpm}$; and net head $24.8 \mathrm{~m}$. These conditions correspond to a Reynolds number $R e=1.1 \times 10^{6}$, based on the diameter $D$, and bulk velocity $U_{b}$ at the inlet of the draft tube. The velocity profiles, are plotted at two $y=$ constant planes (see Figure 5.4.2-5a for axis definition) along the horizontal (Figure 5.4.2-5a), and vertical (Figure 5.4.2-5b) centerlines of each cross-section. Figures 5.4.2-5a and $b$ also include the measured streamwise and swirl velocity components at the inlet section, which were used to provide inlet conditions for the calculations (all velocities in these figures have been scaled by the bulk velocity at the inlet of the draft tube). It should be noted that the inlet measurements, which were obtained along two mutually perpendicular radii, suggest that the flow is not circumferentially symmetric. Due to lack of more detailed data, however, the calculations were carried out by arbitrarily choosing one of the two profiles and assuming that the inlet flow is axisymmetric. The measurements in Figure 5.4.2:5 suggest that most of the flow passes through the left (with respect to an observer standing at the draft-tube inlet looking downstream) bay. This is evident by the overall larger velocities through that bay and is obviously associated with the clockwise direction of the inflow swiri. The calculations reproduce this flow feature and appear to capture reasonably well most experimental trends. Some discrepancies are observed at the downstream location in the right bay (Figure 5.4.2-5a), where the calculated streamwise velocity profile indicates the presence of a small reversed flow region near the inner wall. Contour plots of the calculated streamwise velocity component, not shown here due to space considerations, reveal a recirculating flow region starting upstream of that section and ending immediately downstream. The measurements, on the other hand, suggest a fuller and almost uniform velocity profile there which appears to have recovered very rapidly from its upstream distorted shape. Similar discrepancies, albeit not as pronounced, are observed at the downstream section in the left bay as well. It should be noted, however, that the experimental measurements are not detailed enough to allow a comprehensive assessment of the accuracy of the numerical solutions. Given the continuous area expansion downstream of the elbow, it is very likely that reversed flow does exist in the experiment, although may be not at the same locations indicated by the calculations, but could not be resolved by the few available velocity measurements. Yet another source of uncertainty is the lack of detailed velocity measurements at the inlet. As discussed in the previous section, the inlet flow was assumed axisymmetric, although the limited available measurements do not support such an assumption (see inlet swirl profile in Figure 5.4.2- 
5a). Given the complexity of the draft-tube geometry, even small differences in inlet conditions could account for the observed discrepancies. Obviously, the present calculations can not offer positive answers to all these questions. They do, however, underscore the need for carefully designed, very detailed laboratory experiments.

Figures 5.4.2-6, 5.4.2-7 and 5.4.2-8 depict particle traces released at strategically selected locations to clarify various three-dimensional flow features. A global view of the flowfield is given in Figure 5.4.2-6, which shows the paths of particles originating along two mutually perpendicular diameters at the inlet plane. It is seen that most of the flow passes through the left bay and the left half of the center bay, which is consistent with the trends exhibited by the velocity profiles discussed above. Particles released near the center of the inlet section are seen to form a coherent, rope-like, vortical structure which appears to pass through the left half of center bay. Significant secondary motion is also present in the right bay as indicated by the twisting particle trajectories there. Figures 5.4.2-7 and 5.4.2-8 reveal some very complex three-dimensional flow patterns along the flat wall of the right pier. Figure 5.4.2-7 indicates the existence of a recirculation region which is located near the top (diverging) wall of the draft tube-although not shown herein due to space limitations, the particles that are trapped in this area originate from the nearwall region at the left side of the inlet section. Underneath this recirculating flow region there is a very intense longitudinal vortical structure, shown in Figure 5.4.2-8, which appears to be similar to horse-shoe like vortices known to form at wing-body junctions. These flow patterns serve to demonstrate the enormous complexities of such flows, underscore the challenges for advanced CFD methods, and point, once again, to the need for very detailed laboratory experiments to provide data for numerical validation.

It is important to emphasize that the complex, three-dimensional flow features discussed above may have significant implications from the fish-passage standpoint. One may speculate, for instance, that the strong secondary motion and intense longitudinal vortices forming at various locations inside the draft-tube would tend to disorient passing fish and increase the probability for scrape and de-scaling related injuries. Furthermore, such vortices re-distribute the axial momentum within the draft-tube cross-section, thus, inducing areas of intense velocity gradients, which may result in increased shearing forces acting on the fish body. Therefore, in order to assess the fish-friendliness of a given draft-tube design it is of crucial importance to be able to predict numerically the various flow details identified above. Due to the geometrical complexity of real-life draft tubes, however, this necessitates the use of very fine computational meshes and advanced numerical and turbulence models, such as those employed herein. This further underscores the need for continuing our research efforts to refine and validate advanced CFD techniques for hydraulic turbine flows. 


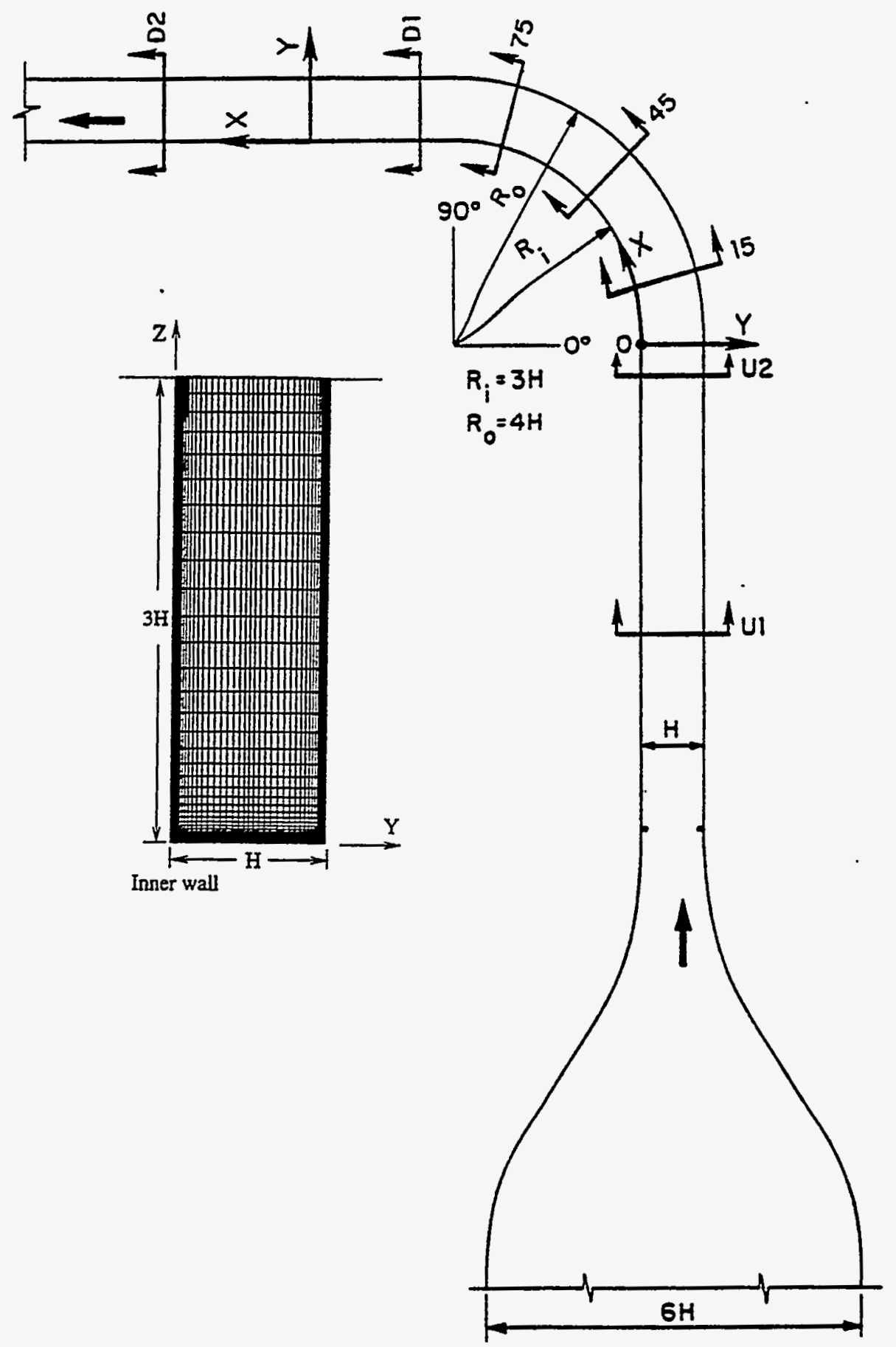

Figure 5.4.2-1 Coordinates, measurement locations, and cross-sectional mesh for the curved duct of Kim (1991). 


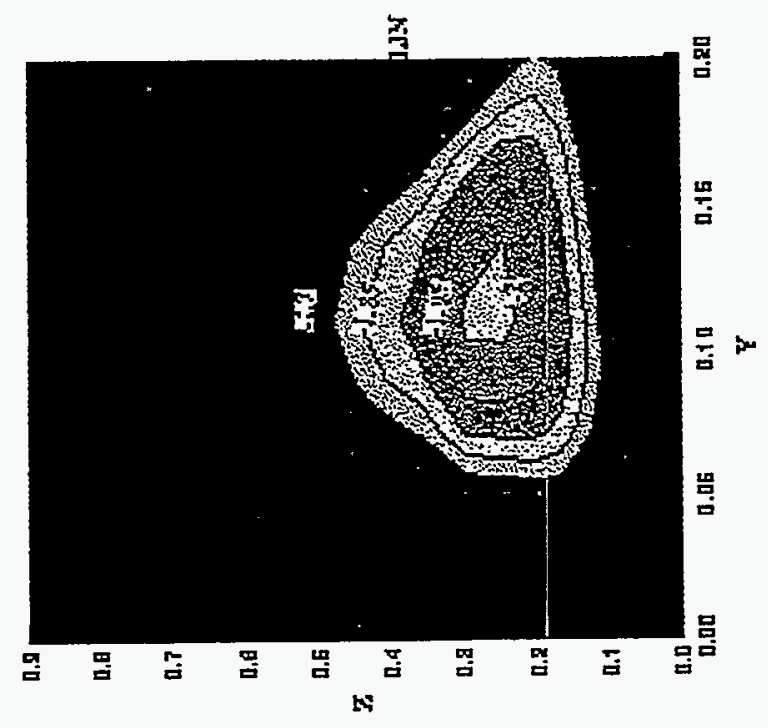

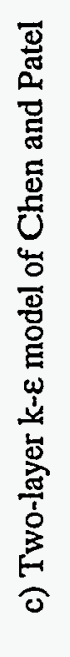

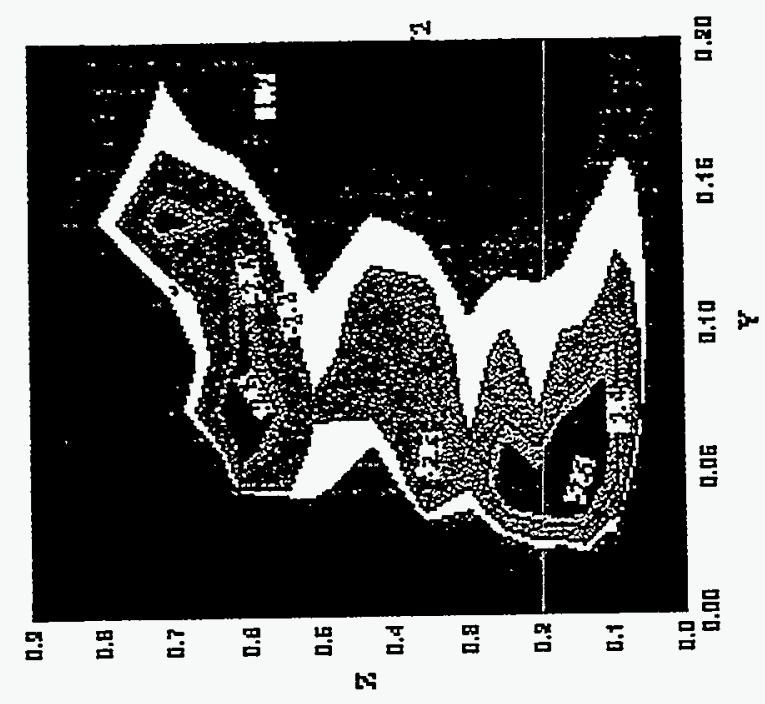

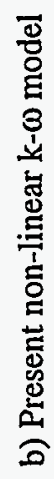
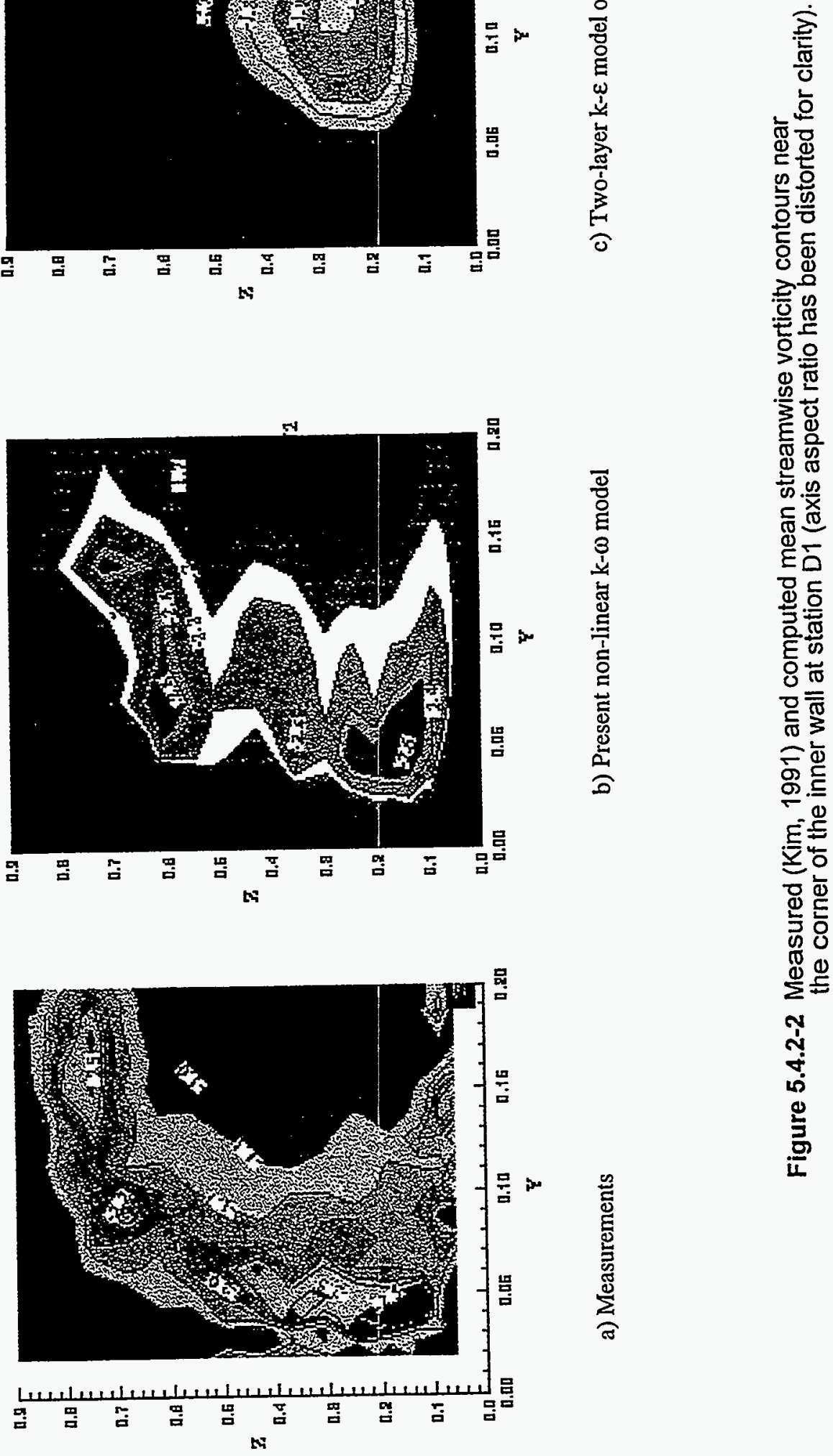

苋 


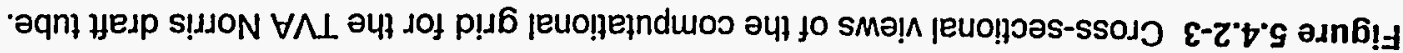

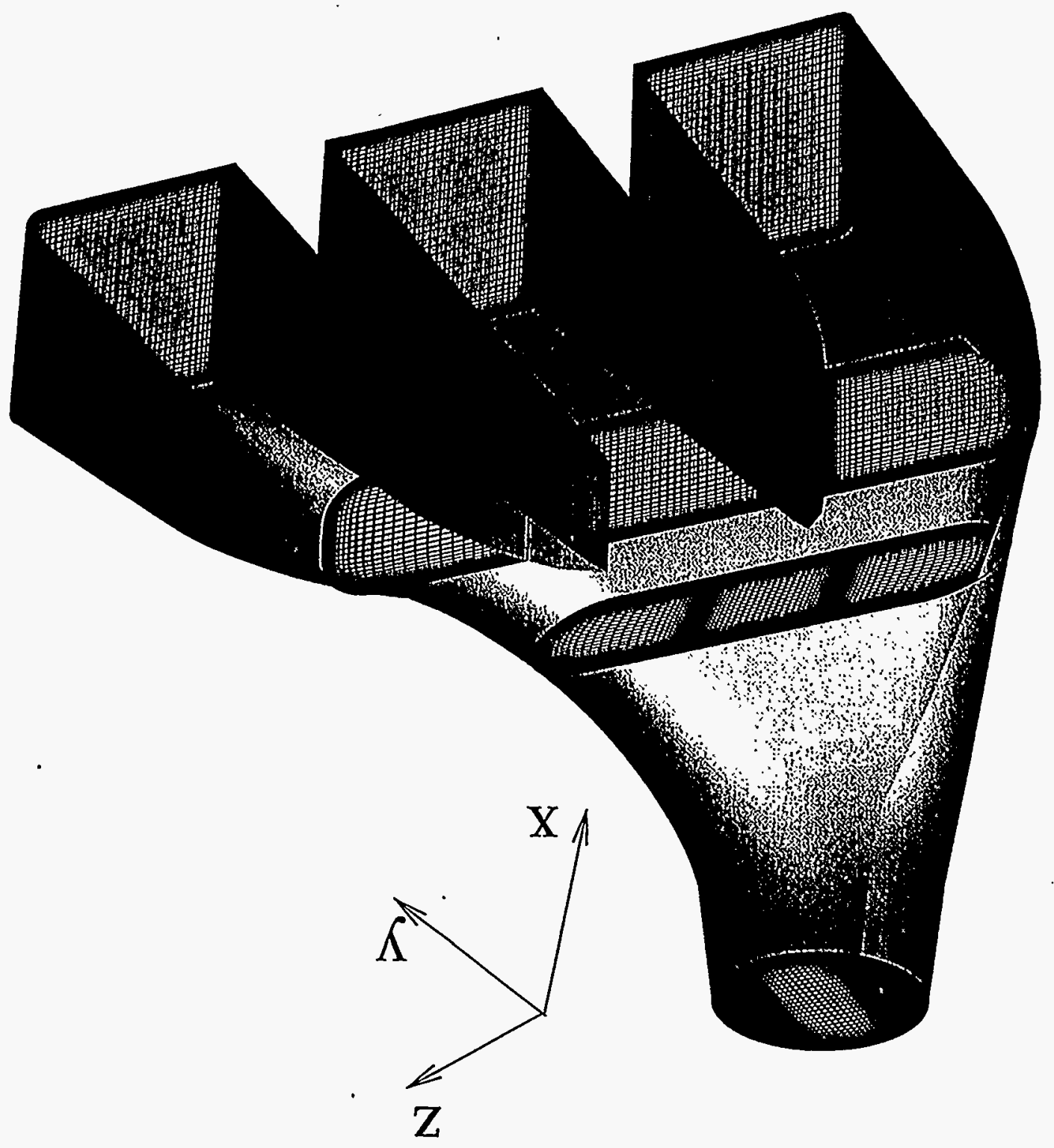




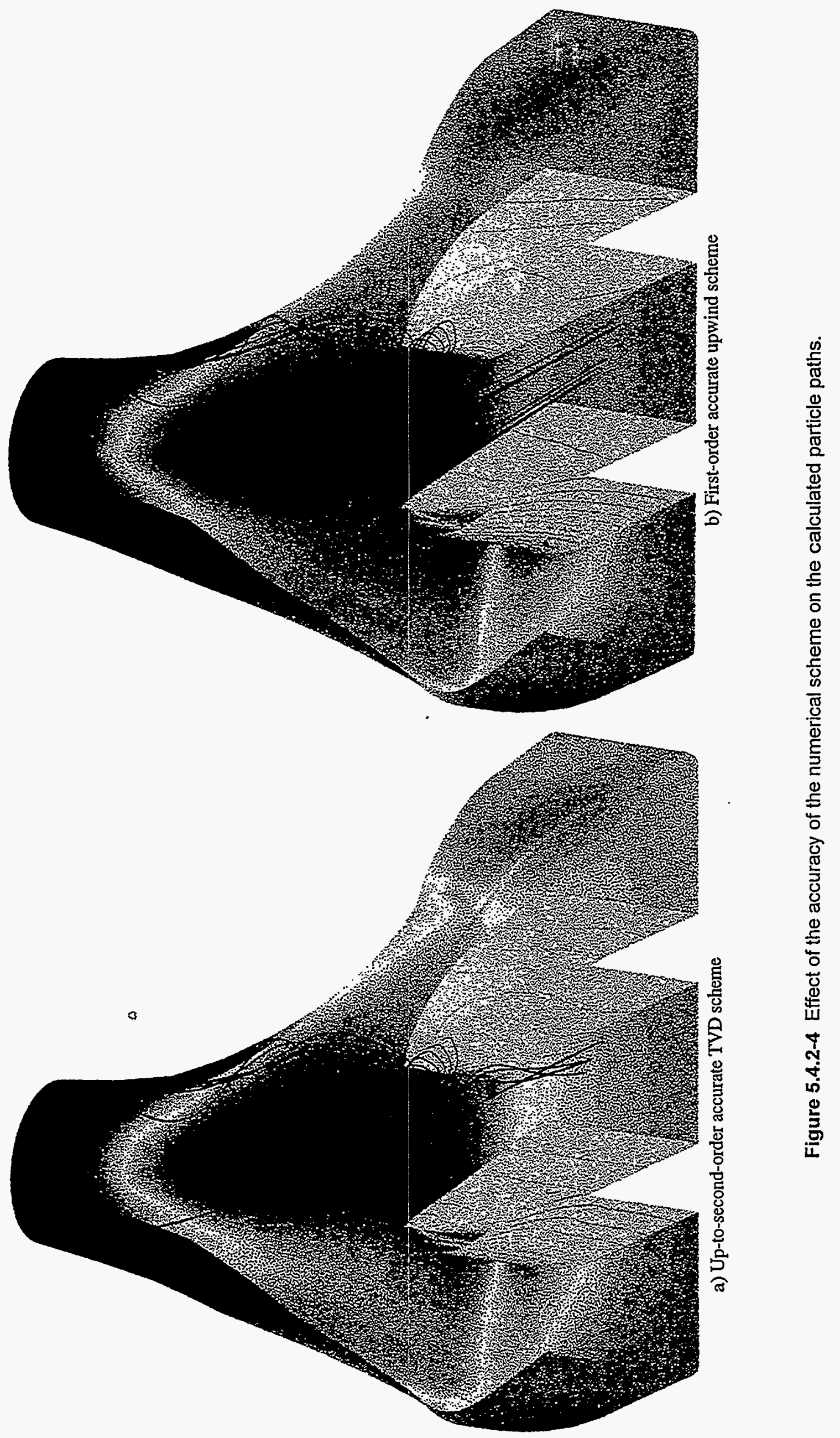

$-108$ 


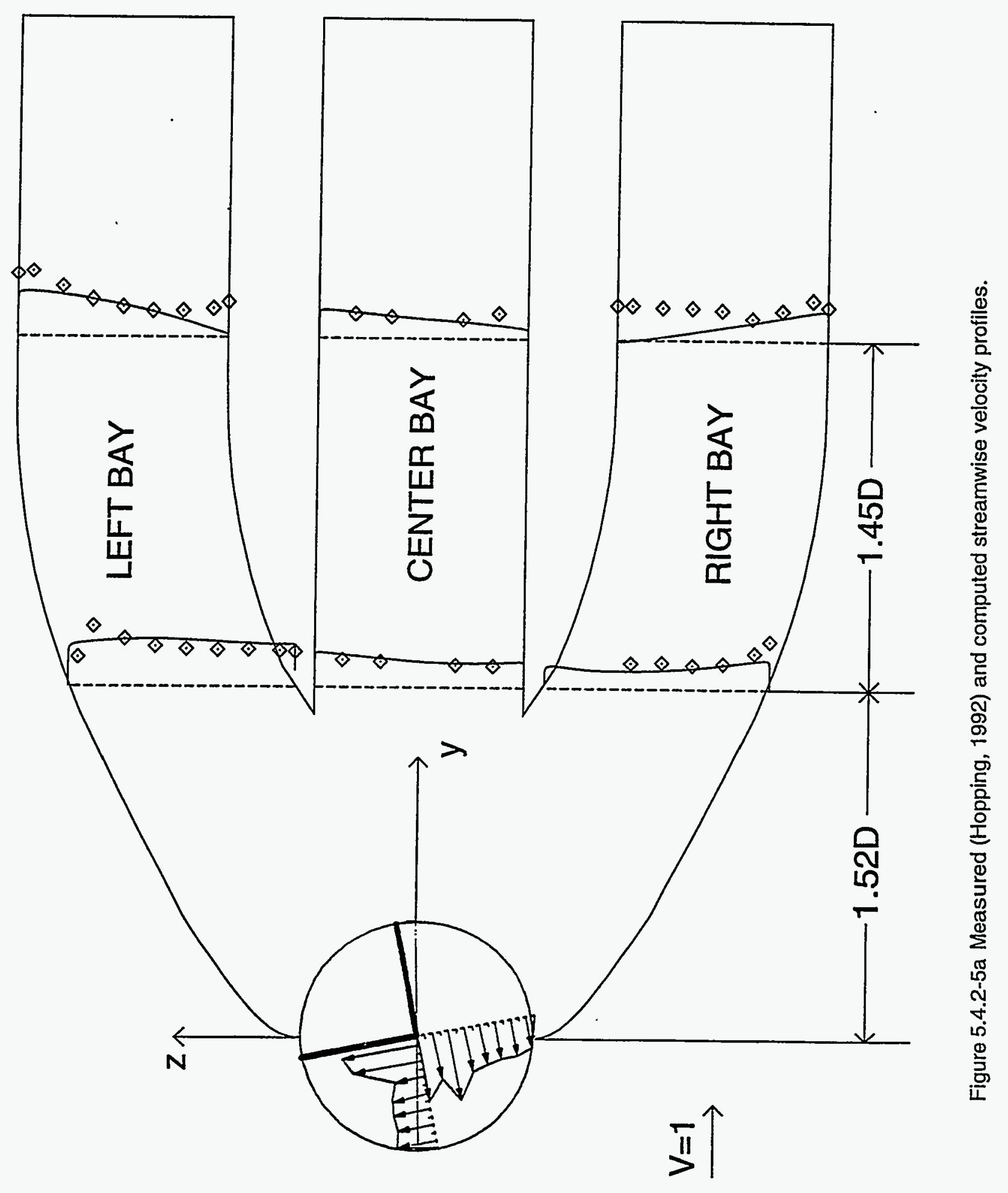



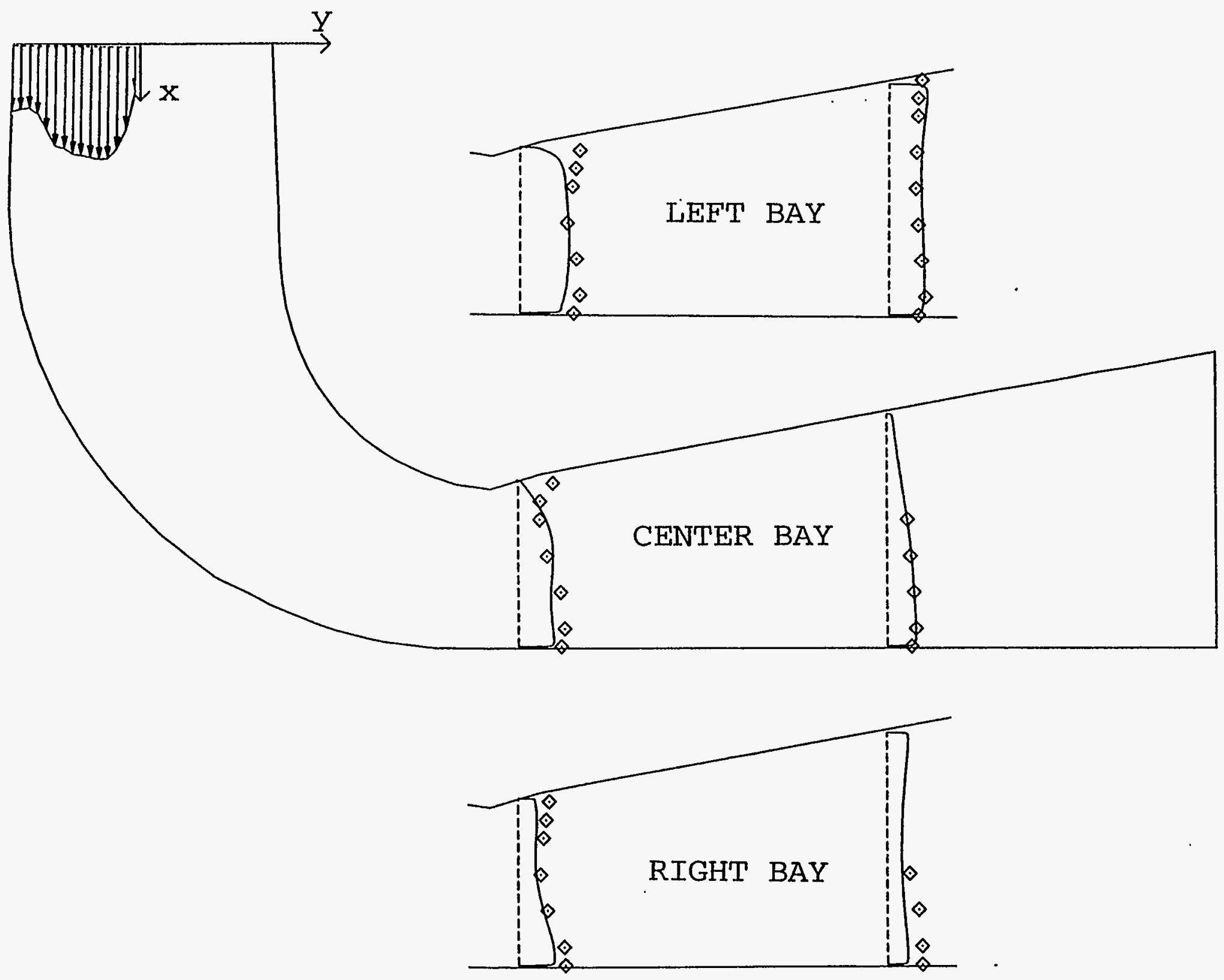

Figure 5.4.2-5b Measured (Hopping, 1992)

:omputed streamwise velocity profiles. 


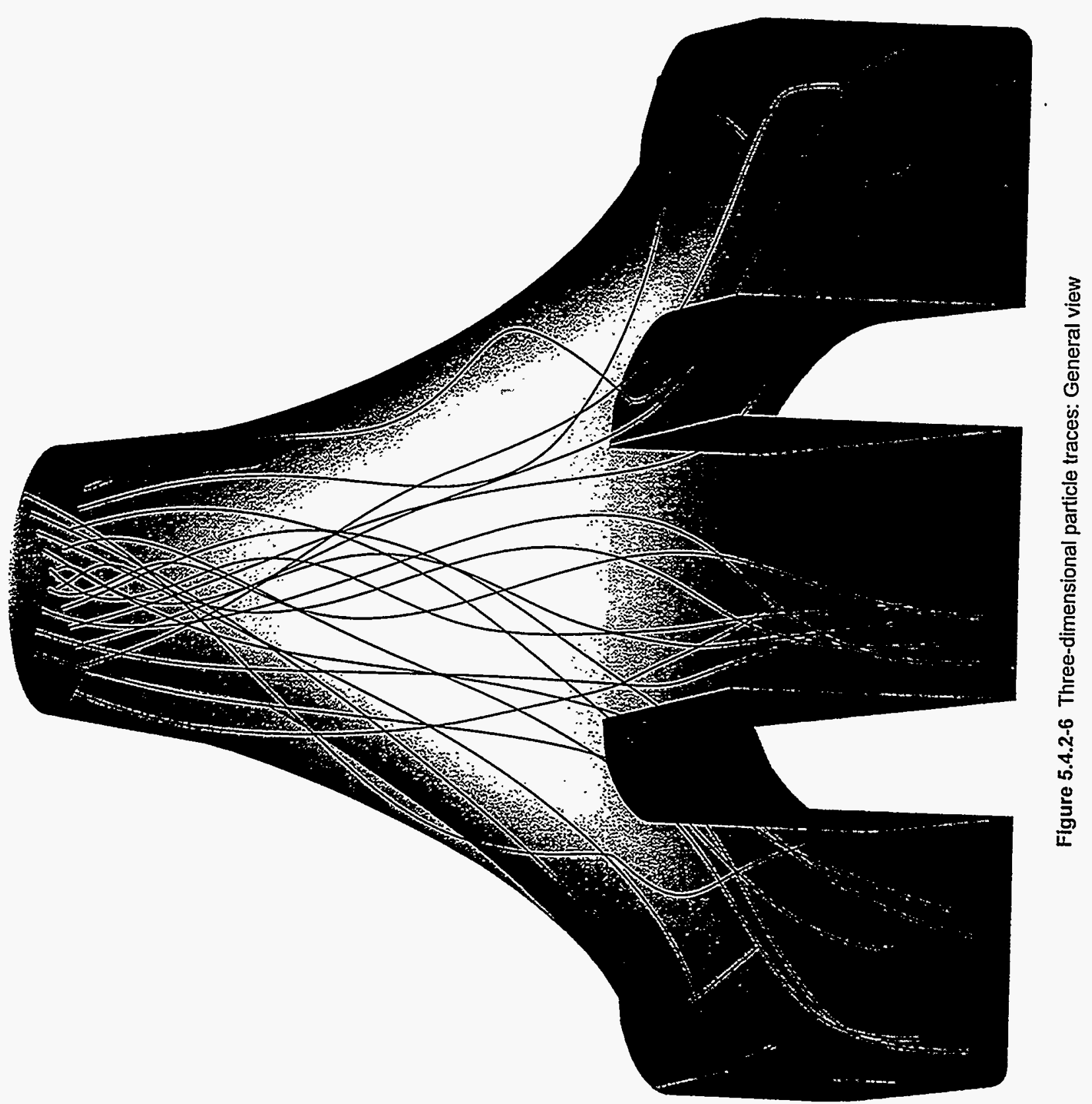




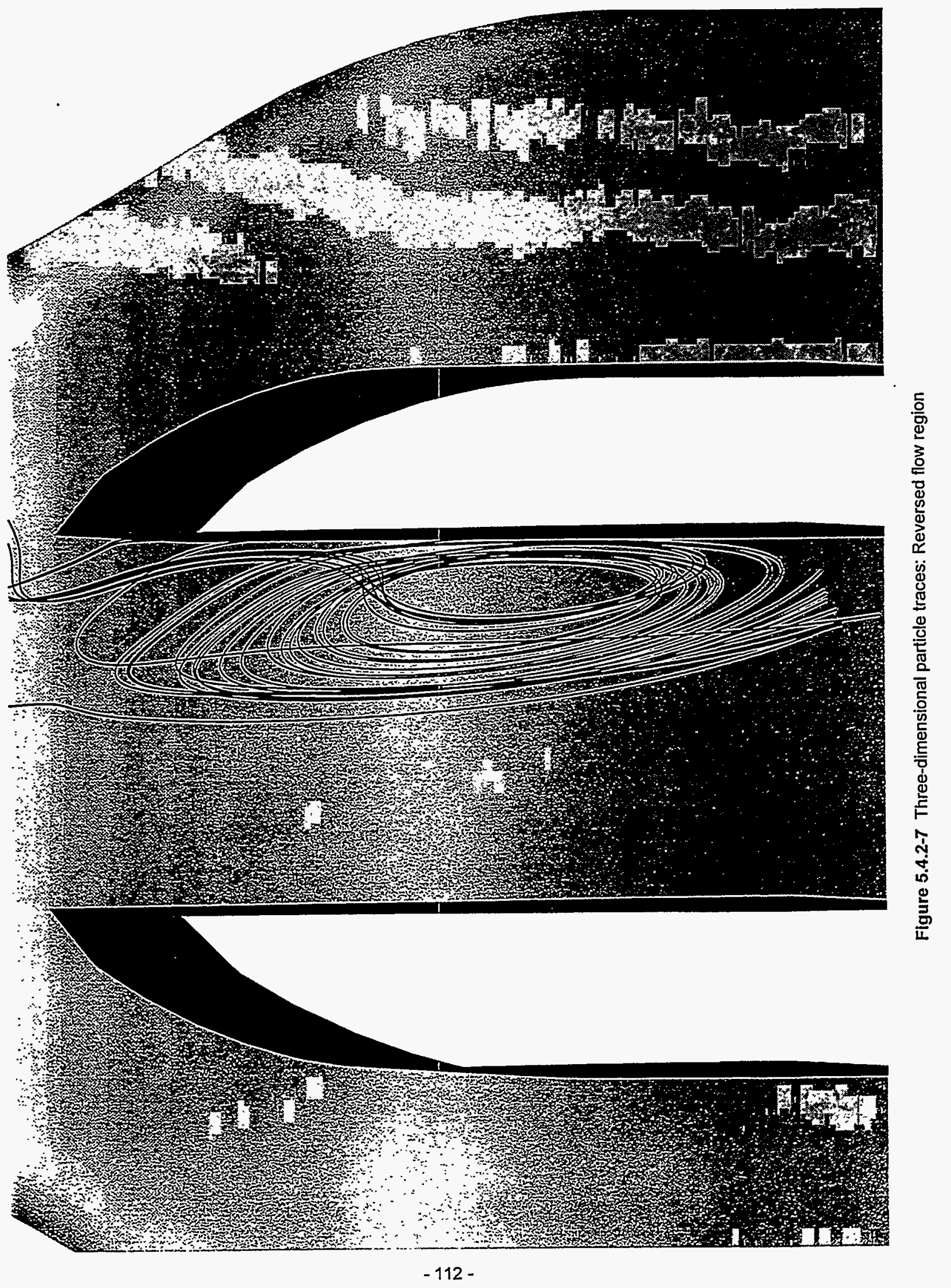




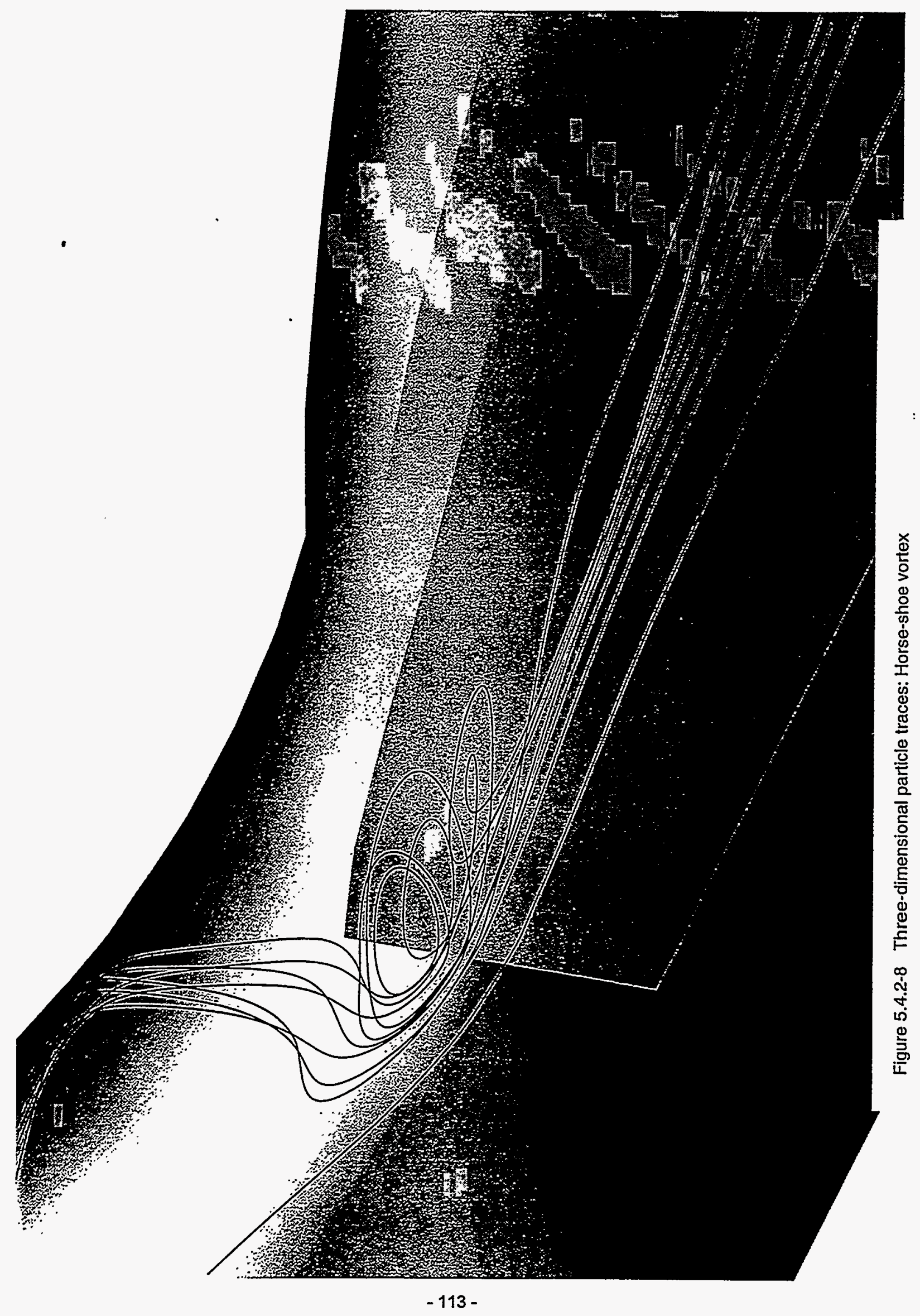




\subsubsection{UNSTEADY VORTEX PHENOMENA IN FRANCIS TURBINES DRAFT TUBES}

\section{Summary}

A new numerical method was developed for simulating unsteady, three-dimensional flows and applied to calculate the evolution of swirling flow through a straight circular diffuser. The computed results reveal the formation of a precessing spiral vortex core whose general structure resembles that of a rope vortex known to be associated with draft-tube surge phenomena. This study, which is the first to calculate numerically the formation of such a vortex, underscores the potential of the proposed method for predicting hydroturbine flows at off-design operating conditions.

\section{Discussion}

Powerplants with Francis runners are known to experience undesirable pressure pulsations when operating at off-best-efficiency output, a phenomenon known as draft tube surge. When the system operates near best efficiency, the swirling flow exiting the runner forms a vortex core whose axis is stationary and more or less aligned with the geometrical axis of the draft tube (Figure 5.4.3-1.a). At offdesign operating conditions, the residual swirl at the exit of the runner could exceed a threshold level causing the vortex core to become unstable and undergo dramatic transformations (Figure 5.4.3-1.b). The specific flow scenario that would emerge depends on the operating conditions and could include, among others, the formation of an unsteady bubble-like structure, with reversed flow entering the runner, as well as spiral or 'rope'-like vortex core which precesses about the draft tube axis. The rotating vortex core causes unsteady variations of the net head across the unit and could result in efficiency losses, noise, power swings, vibrations, and even catastrophic structural failure. Furthermore, these unsteady variations may induce significant pressure and shear loads on passing fish, thus, increasing the potential for serious injuries and possibly mortality. Understanding, therefore, the physics of such unsteady flow phenomena is a crucial prerequisite for not only improving the mechanical performance and extending the stable operational envelope of Francis powerplants but also for enhancing fish-friendliness. Given the complexity and time-dependent nature of these phenomena, experiments alone, such as the flow visualizations shown in Figure 5.4.3-1, can offer only limited insight into the relevant flow physics and should be supplemented by comprehensive time-accurate computations. Our objective herein is to demonstrate the ability of advanced CFD methods to simulate the formation of unsteady rope vortices in hydroturbine draft-tube.

A numerical method was developed for solving the unsteady, Navier-Stokes equations in generalized curvilinear coordinates. The method was applied to simulate unsteady swirling flow through a simplified draft-tube geometry, the straight circular diffuser shown in Figure 5.4.3-2. Detailed description of the computational procedure and analysis of the results can be found in Sotiropoulos and Ventikos (1997) (see Appendix 10.5). A sample of the computed results is shown in Figure 5.4.3-2 which depicts the evolution in time of a surface of constant circumferential vorticity component. As seen, the swirling flow entering the diffuser section breaks down into a spiral vortex (or rope vortex) whose structure resembles that observed in the flow visualization shown in Figure 5.4.3-1. The rope-vortex precesses about the diffuser axis along the same direction as the swirling flow at the inlet. The present results, which are the first to reproduce computationally the formation and precession of a rope-vortex, clearly demonstrate that numerical computation of unsteady flow phenomena in hydraulic turbines is now well within the reach of state-of-the-art CFD methodologies. 


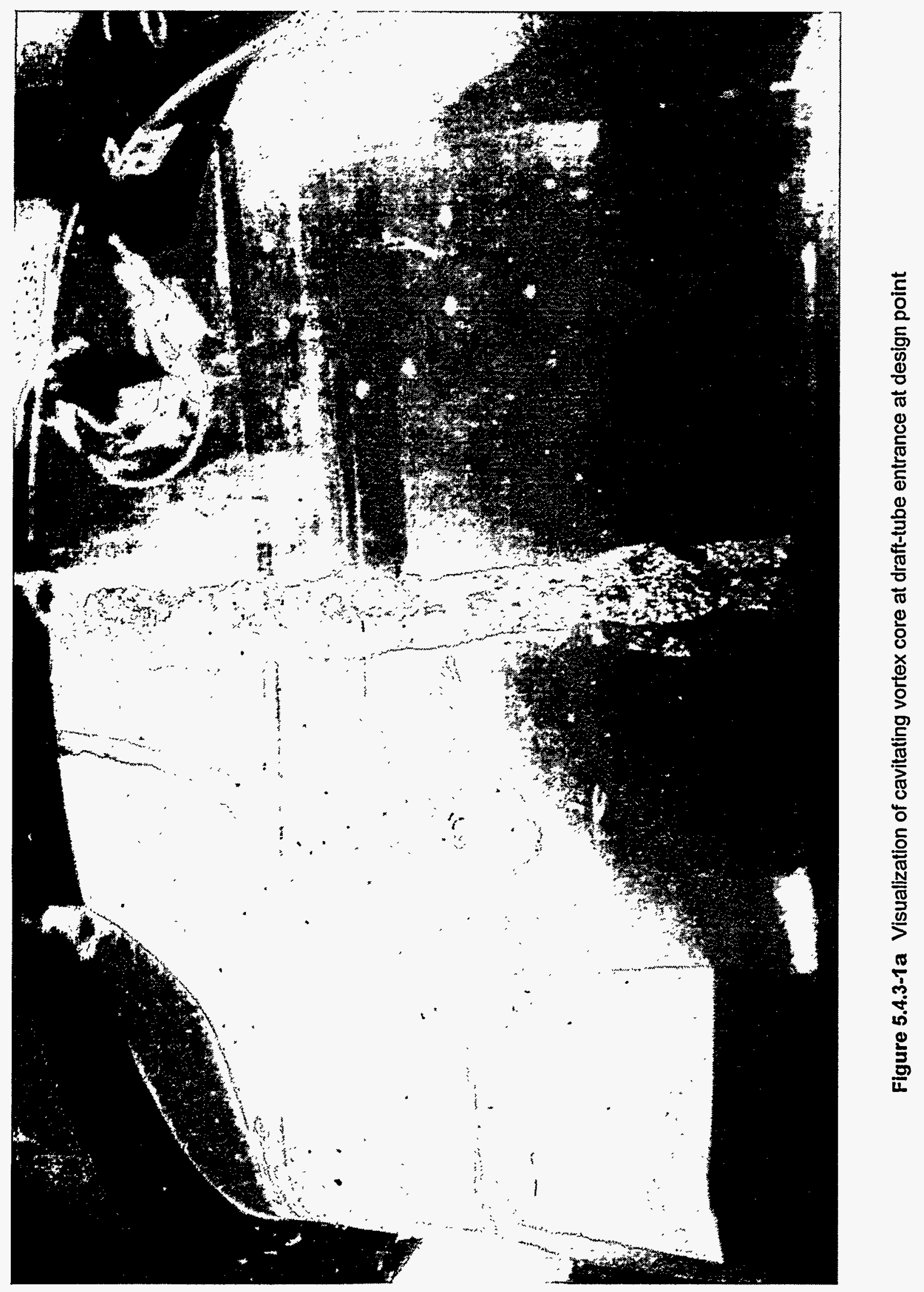




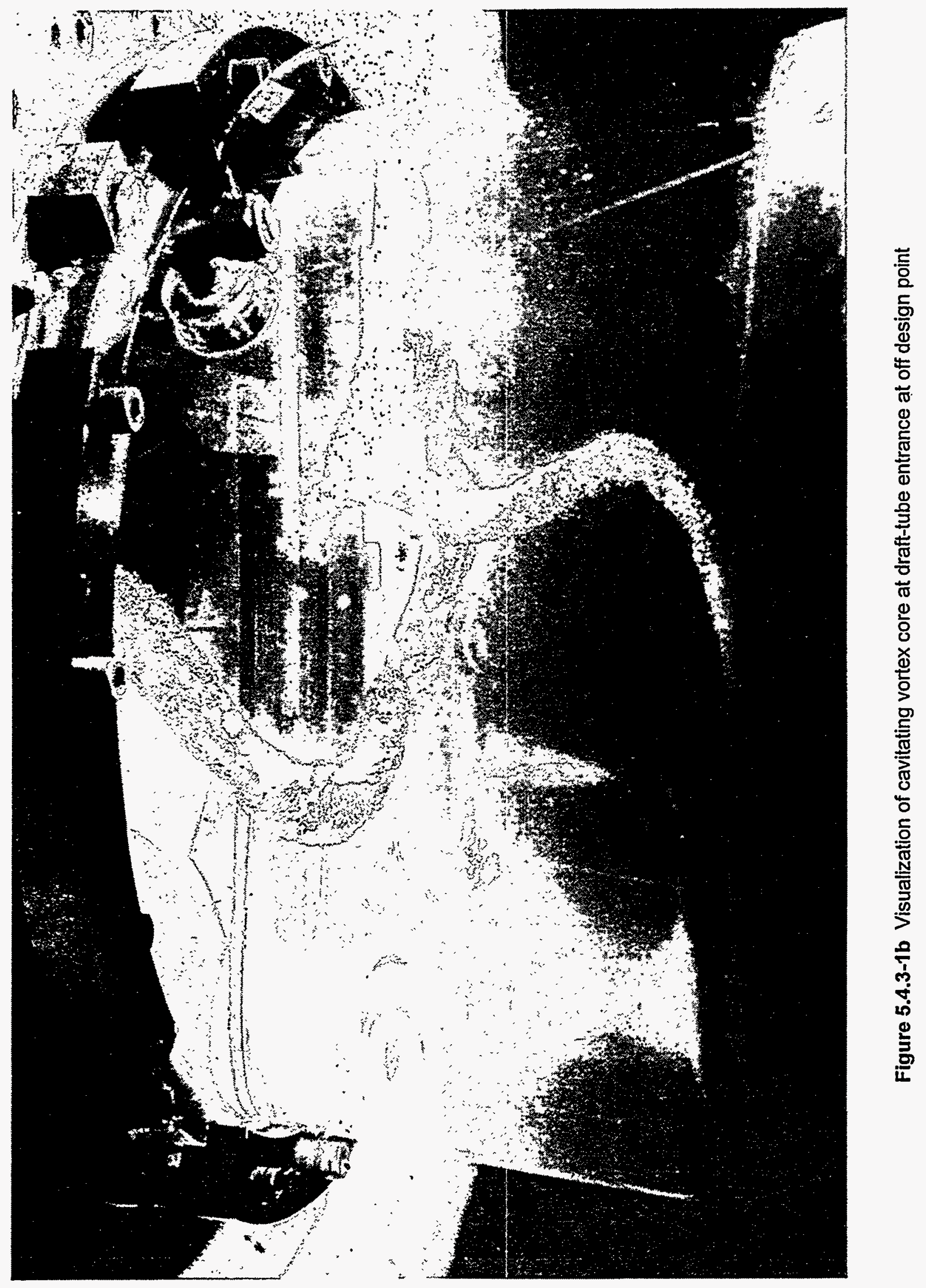


$\stackrel{\overrightarrow{\vec{*}}}{1}$
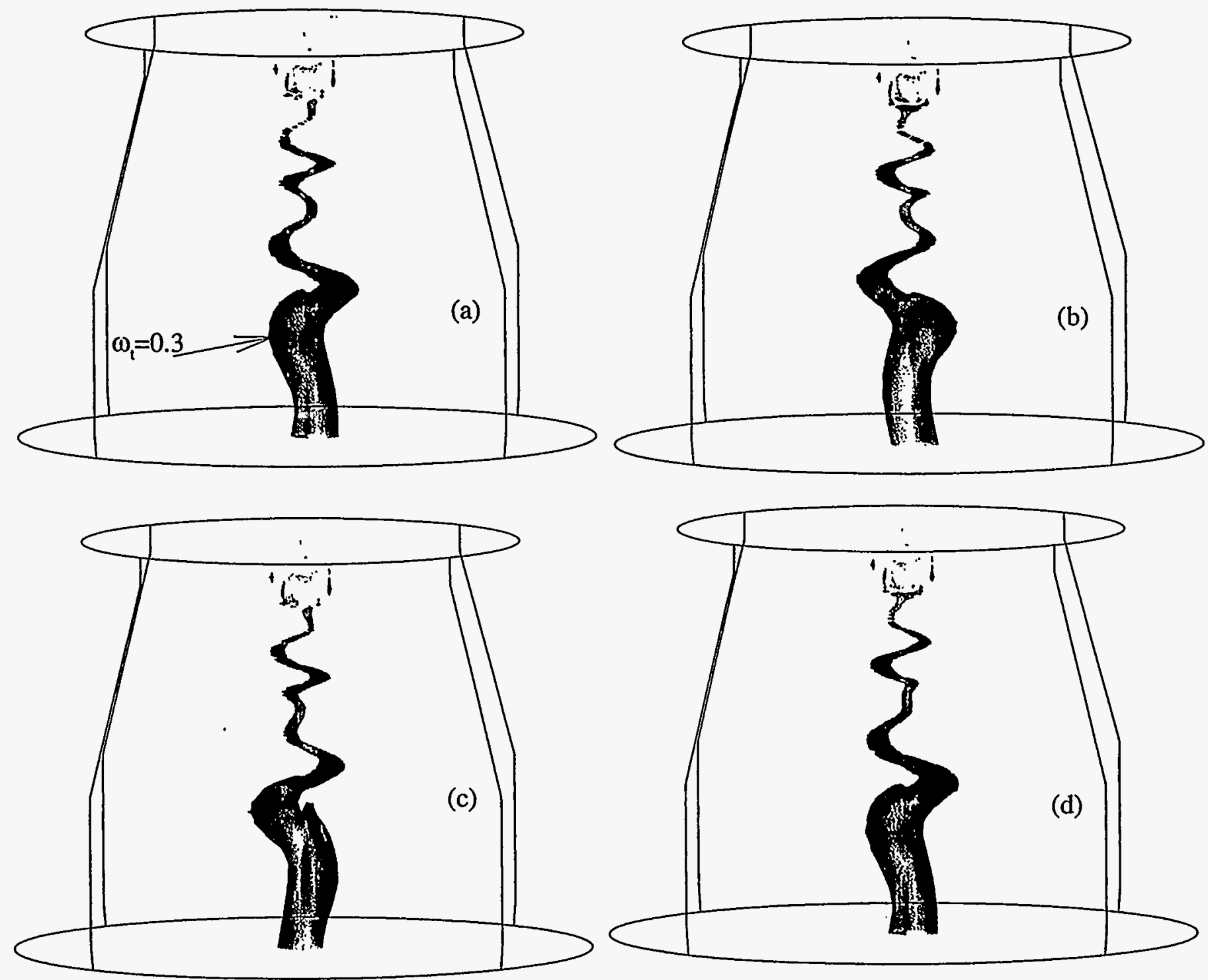

Figure 5.4.3-2 Instantaneous iso-surface of transverse vorticity magnitude for a straight diffuser, depicting the precession of a rope vortex, a) $t=30 \mathrm{sec}$ b) $t=31.5 \mathrm{sec} c$ ) $t=33 \mathrm{sec}$ and d) $t=34.5 \mathrm{sec}$. Axis aspect ratios have been distorted for clarity. 


\subsubsection{NUMERICAL SIMULATION OF FISH PASSAGE: CAN FISH BE MODELED AS FLUID PARTICLES?}

\section{Summary}

A preliminary fish-passage numerical model was applied to calculate fish trajectories through a typical draft-tube geometry. The model treats fish as three-dimensional bodies with realistic physical and geometrical characteristics. The results demonstrate the inadequacy of modeling fish as fluid particles, underscore the potential of the proposed numerical model, and point to the need for future research in order to transform the present approach into a useful design tool.

\section{Discussion}

The progress we have made so far in the numerical simulation of hydroturbine flows clearly shows that advanced CFD methods can greatly enhance our understanding of the complex flow physics inside the powerplant. Understanding and being able to predict the flow details, however, is not, by itself, sufficient for evaluating the fish-friendliness of a given hydroturbine design. Achieving such an objective, further requires the development of a tool that can estimate the trajectories of fish inside a given complex flow environment. A first obvious attempt to develop such a tool could be based on treating fish as fluid particles which would imply that fish behave like material points moving with the local flow velocity. If this assumption were adequate, the output of a three-dimensional CFD calculation could be readily postprocessed, by calculating particle paths, to estimate fish trajectories through the entire powerplant. Unfortunately, however, such an approach is not suitable for a number of reasons. First and foremost, a model which treats fish as fluid particies is not capable of predicting mechanical strike, scrape and abrasion related injuries, since a particle will always move with the flow around the various solid structures (vanes, runner blades, piers, etc.). Furthermore, in the vicinity of the runner even very small fish are likely to experience centrifugal forces, due to the runner rotation, which are known to have a profound effect on their trajectories (Cada et al., 1997). Obviously such effects can not be accounted for correctly if fish is modeled as a material point. Therefore, there is a need for developing a computational tool that models fish as three-dimensional bodies with geometrical (body length and thickness distribution) and physical (weight, locations of center of gravity and buoyancy, etc.) characteristics closely resembling those of the species under consideration.

In this section we present some results from the application of a preliminary three-dimensional fishpassage model to a typical draft-tube geometry. The model is based on the assumption that a fish swimming through a complex flow environment, obtained via a separate CFD calculation, can be approximated as a simplified, yet fish-like, geometrical body whose motion does not affect the precomputed flowileld. The motion of this fish-like body is governed by six ordinary differential equations, for the components of the linear and angular acceleration vectors, whose source terms include hydrodynamic (lift, drag, pressure forces, inertial forces, etc.) and biological (fish "free-will") forces. A preliminary version of this model-which accounts only for inertial forces acting on the fish body-was applied to calculate fish trajectories through TVA's Norris Dam draft tube. It should be emphasized that all subsequently shown results are preliminary and serve only to demonstrate the need for further research on fish modeling. Figures 5.4.4-1 and 5.4.4-2 compare the trajectories of two different fish "species", respectively: a material particle (i.e. fish trajectories coincide with particle paths), and a three-dimensional fish-like body of $0.05 \mathrm{~kg}$ weight. One important attribute can be readily observed: the fish-like body enters the draft-tube with much more inertia and tends to hit the walls of the tube. As discussed above, this trend underscores the effect of centrifugal forces exerted on even small fish and points to the inadequacy of treating fish as fluid particles. 
Further research is necessary to transform the preliminary fish-passage model into a useful design tool. Specific topics that need to be addressed include: i) accurate implementation of the various hydrodynamic forces acting on the fish body; ii) development of a fish free-will model; iii) execution of carefully designed field and laboratory experiments with real fish to collect data necessary for the calibration and validation of the model; and iv) formulation of the model so that it is applicable to the entire powerplant. It is important to point out that in most of these areas close collaboration. will be necessary between the CFD modelers, fish biologists, turbine manufacturers, and powerplant operators. 


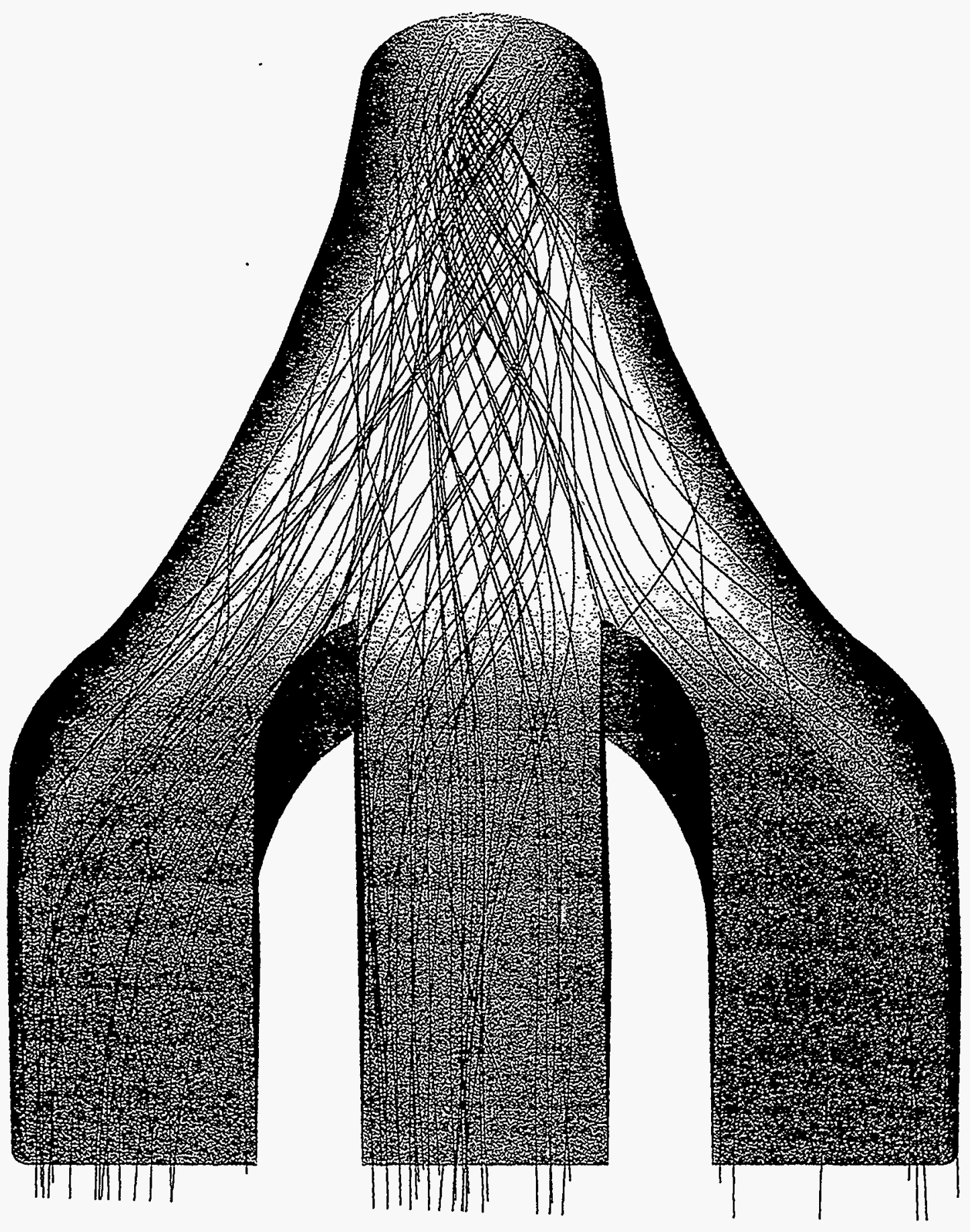

Figure 5.4.4-1 Calculated trajectories for fish modeled as flow particles. 


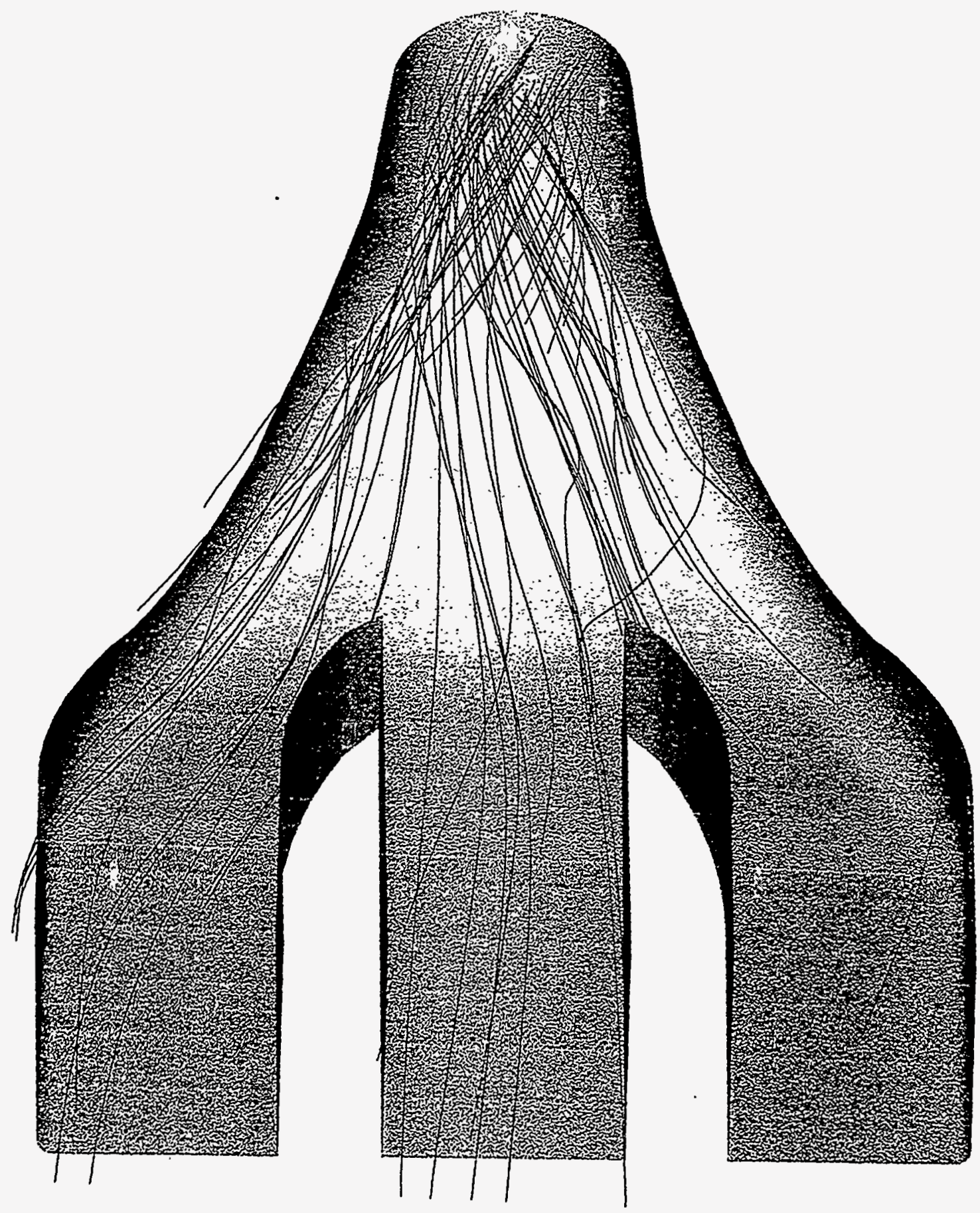

Figure 5.4.4-2 Calculated trajectories for fish-like bodies of $0.05 \mathrm{Kg}$ weight. 


\subsubsection{SUMMARY AND CONCLUSIONS}

The most important findings of this study are summarized as follows:

The non-linear $k-w$ turbulence model developed herein was shown to reproduce the measured very complex vortex structure inside a strongly curved duct with remarkable accuracy. Calculations of the same test case with a number of other advanced turbulence models failed to capture, even qualitatively, essential physics of this flow. Therefore, the proposed non-linear $k-w$ model is a very promising turbulence closure for quantitatively accurate predictions of complex flows of engineering interest. It should be emphasized that this model does not require the distance from the wall which facilitates its application to geometries involving multiple intersecting walls, such as those encountered in components of a hydropower installation. Furthermore, this model is computationally very efficient, as it requires the solution of only two additional transport equations and, thus, provides us with a practical tool for engineering calculations on fine computational meshes. Future work will focus on evaluating the performance of this model in real-life hydroturbine flows.

Calculations of flow through a typical draft-tube geometry, with two downstream piers, were carried out using linear $k-e$ and $k-w$ models. The computed results were compared with few mean streamwise velocity measurements taken at selected locations within the three bays downstream of the elbow. The calculations reproduce most experimental trends with reasonable accuracy. Three-dimensional particle traces revealed the presence of very complex three-dimensional flow patterns around the piers. These include longitudinal and horse-shoe vortex formation, and regions of reversed flow. Lack of detailed three-dimensional measurements and uncertainties in the specification of inlet boundary conditions, however, prohibited a comprehensive evaluation of various turbulence models. The present study clearly underscores the need for detailed three-dimensional experiments for draft-tube geometries in order to make further progress in developing and evaluating advanced turbulence models for such flows.

A three-dimensional numerical method was developed for simulating unsteady hydroturbine flows. The method was applied to calculate the time evolution of swirling flow through a simplified draft-tube geometry. Analysis of the computed results revealed the formation of a rope-like vortex precessing in a periodic fashion about the tube axis. The general structure and temporal evolution of this vortex are in qualitative agreement with laboratory and prototype observations of similar unsteady vortex phenomena which occur when Francis units operate at off-design conditions. The present results demonstrate that the numerical computation of complex unsteady hydroturbine flows-which is a crucial prerequisite for understanding such flows over the entire range of possible operating conditions-is now well within reach. Future work will focus on applying the method developed herein to real-life draft-tube geometries as well as extending the present methodology to simulate unsteady coupling of runner and draft-tube configurations.

A preliminary three-dimensional numerical model was applied to calculate trajectories of fish-like bodies through a typical draft-tube geometry. The main conclusion of this study is that treating fish as particles which passively follow the flow is inadequate for realistic simulations. A fully three-dimensional model is, therefore, needed which takes into account the major geometrical and physical characteristics of a given species as well as the various hydrodynamic forces exerted by the flow on the fish body. Such a fishpassage model may be utilized in conjunction with flow solutions obtained via CFD methods to estimate fish trajectories through the various components of a hydroturbine installation. With input from fish biologists and carefully designed laboratory experiments and field measurements with real fish, such a model could be used to estimate the fish friendliness of a given turbine design. It can, thus, provide the hydropower industry with a powerful tool for developing and evaluating innovative rehabilitation strategies for improving the environmental compatibility of its facilities. 


\subsubsection{REFERENCES}

Cada, G. F., Coutant, C. C., and Whitney, R. R. (1997), "Development of Biological Criteria for the Design of Advanced Hydropower Turbines," Environmental Sciences Division report, Oak Ridge National Laboratory, Oak Ridge. TN.

Chen, H. C. and Patel, V. C. (1988), "Near-Wall Turbulence Models for Complex Flows Including " AlAA J., Vol. 26, pp. $641-648$.

Hopping, P. N. (1992), "Draft Tube Measurements of Water Velocity and Air Concentration in the 1:11.71 Scale Model of the Hydroturbines for Norris Dam," Tennessee Valley Authority Engineering Laboratory, Report No. WR28-2-2-116, Norris, Tennessee.

Kim, W. J. (1991), "An Experimental and Computational Study of Longitudinal Vortices in Turbulent Boundary Layers," Ph.D. Thesis, Department of Mechanical Engineering, The University of lowa, lowa City, lowa.

Lin, F., and Sotiropoulos, F. (1997a), "Assessment of Artificial Dissipation Models for Three-Dimensional, Incompressible Flow Solutions," to appear in the ASME J. of Fluids Engineering (April 1995).

Lin, F., and Sotiropoulos, F. (1997b), "Strongly-Coupled Multigrid method for 3-D Incompressible Flows Using Near-Wall Turbulence Closures," to appear in the ASME J. of Fluids Engineering.

Sotiropoulos, F., and Ventikos, Y. (1997a), "Prediction of Flow Through a 90 Deg Bend Using Linear and Non-Linear Two-Equation Turbulence Models," submitted for publication to the AIAA Journal.

Sotiropoulos, F., and Ventikos, Y. (1997b), "Numerical Simulation of Three-Dimensional Unsteady VortexBreakdown in Confined Swirling Flows," FEDSM97-3671, to be presented at the 1997 ASME Fluid Engineering Division Summer Meeting, June 22-26, Vancouver.

Ventikos, Y., Sotiropoulos, F., and Patel, V. C. "Prediction of Turbulent Flow through a Hydroturbine Draft-Tubes Using a Near-Wall Turbulence Closure," Proc. of XVII IIAHR Symp. on Hydraulic Machinery and Cavitation (Cabrera, Espert, and Martinez, Eds.), vol. I, pp. 140-149.

Wilcox, D. C. (1988), "Reassessment of the Scale Determining Equation for Advanced Turbulence Models," AIAA Journal, Vol. 26, pp. 1299-1310.

Yee, H. C., and Harten, A. (1987), "Implicit TVD-Schemes for Hyperbolic Conservation Laws in Curvilinear Coordinates," AIAA J. 25, 266. 


\subsection{DISSOLVED OXYGEN ENHANCEMENT USING TURBINE AERATION}

A variety of methods are available to provide dissolved oxygen (DO) in hydropower releases. For the most part, these methods can be grouped into one of four categories--reservoir techniques, powerhouse techniques, tailwater techniques, and operational techniques (see Bohac and Ruane, 1990, or EPRI, 1990). Examples of each are given in Table 5.5-1. Where applicable, turbine aeration is usually the method of choice. Consequently, any work to develop advanced hydroturbine technologies must include objectives for aeration, at least for projects containing low DO.

In general, turbine aeration can be provided by natural aspiration or forced injection. With natural aspiration, air is supplied to openings in the turbine where the pressure is subatmospheric. In some cases, subatmospheric conditions are created by adding small deflectors or baffles on flow boundaries in the turbine. Outside, the openings are vented to the atmosphere, thus providing the pressure difference to draw air into the water. A naturally aspirating turbine is also called an auto-venting turbine (AVT). With forced injection, the pressure in the turbine is above atmospheric, requiring compressors or blowers to push air into the water. In both the AVT and forced injection arrangements, the DO is increased by the transfer of oxygen from the entrained air to the water. Due to the minimal requirements for extra mechanical equipment, as well as reduced expenses for operation and maintenance, the AVT usually is the least-cost option for aeration in hydroturbines.

\begin{tabular}{|l|}
\hline Reservoir Techniques \\
\hline - Forebay Destratification \\
\hline - Hypolimnetic Air or Oxygen Diffusers \\
\hline - Epilimnetic Pumps \\
Powerhouse Techniques \\
\hline - Penstock Air or Oxygen Diffusers \\
\hline - Turbine Aeration \\
\hline Tailwater Techniques \\
\hline - Surface Aerators \\
\hline - Side-Stream Aeration \\
\hline - Aerating Weirs \\
\hline Operational Techniqués \\
\hline - Sluice or Spillway Aeration \\
\hline - Selective Withdrawal \\
\hline - Special Turbine Operations \\
\hline
\end{tabular}

Table 5.5-1 Methods for Improving DO in Hydropower Releases

In examining advanced technologies for turbine aeration, attention must be given both to existing units and to new units. For the latter, a wide range of design factors and, consequently, potential aeration alternatives exists to improve DO in the turbine discharge. This is attributable to the fact that within the overall constrains of most projects, there is usually some flexibility in selecting the shape and position of the turbine components and surrounding equipment. This especially is true in new construction. Although extra physical limitations can be imposed by existing structures, and this also can be true in upgrade situations involving new, modernized units. At most currently operating projects, however, new modernized turbines cannot be economically provided for the sole purpose of improving DO. Hence, any effort to develop advanced technologies for turbine aeration needs also to consider retrofit arrangements for existing units.

In this section, discussions focus on methods to provide aeration in existing and new turbines. Because TVA currently is the industry leader in using this technology, most of the cited experience includes examples of 
Development Of Environmentally Advanced Hydropower Turbine System Design Concepts Section 5.0

one or more of the agency's hydro projects. Summaries of state-of-the-art practice and advanced technology for turbine aeration are given. Methods of analysis for the environmental and hydraulic performance (i.e., DO uptake and aeration-induced efficiency loss) of aerating turbines are assessed. Recommendations for testing aerating turbines are presented, as well as requirements for efficient operation of these units. 


\subsubsection{STATE-OF-THE-ART PRACTICE AND ADVANCED TECHNOLOGY}

Research to mix air with the water flowing through a turbine for the purpose of improving DO in hydropower releases has been in progress for nearly half a century. Almost all these studies have focused on developing retrofit arrangements to provide aeration in existing turbines. This, of course, is due to the fact that almost all existing turbines are designed for the sole purpose of producing power, not for providing aeration. Since about 1990, however, the need for turbine upgrades combined with regulatory requirements for preserving and enhancing aquatic wildlife in tailrace channels has encouraged research for methods to include aeration as an integral part of the design of new turbines. The following discussions are given to summarize stateof-the-art practice and objectives for advanced technology in providing aeration in existing and new units.

\subsubsection{Existing Turbines}

\section{Background}

Studies by Wagner (1958) to improve water quality on the Neckar River in Germany are among the earliest examples of aeration for existing turbines. About the same time, turbine venting was introduced in the United States to mitigate the adverse impact on water quality of discharges from pulp and paper factories and municipal sewage systems in Wisconsin (Lueders, 1956). By 1961, turbine aeration was in use at eighteen hydroplants on the Flambeau, Lower Fox, and Wisconsin Rivers (Wiley et al., 1962; Wisniewski, 1965). This and other studies prior to 1982, including studies by both U.S. and European hydropower owners, are summarized by Bohac et al. (1983). A more recent summary of experience with TVA projects is given by Carter (1995).

In existing units, the evolution of turbine aeration has led to a variety of retrofit designs. These typically provide air at one of two locations, the vacuum breaker outlet or the draft tube. The best arrangements include turbines that contain subatmospheric pressures and airfow passageways large enough to insufflate the required amount of air without any changes to the unit. In these cases, natural aspiration is achieved merely by blocking open the control valve for the air supply passageway, typically the vacuum breaker valve. Often, however, physical modifications are required to enhance airflow and obtain the desired DO uptake. As mentioned earlier, baffles placed over the aeration outlets will locally decrease pressures. Ventilation pipes added to the turbine headcover can be used to reduce pressure losses due to friction, bends, valves, and other devices in the airflow passageways. Because these pipes usually "short-circuit" the vacuum breaker valve, they often are called bypass conduits. A typical installation of baffles and bypass conduits is shown in Figure 5.5-1. 


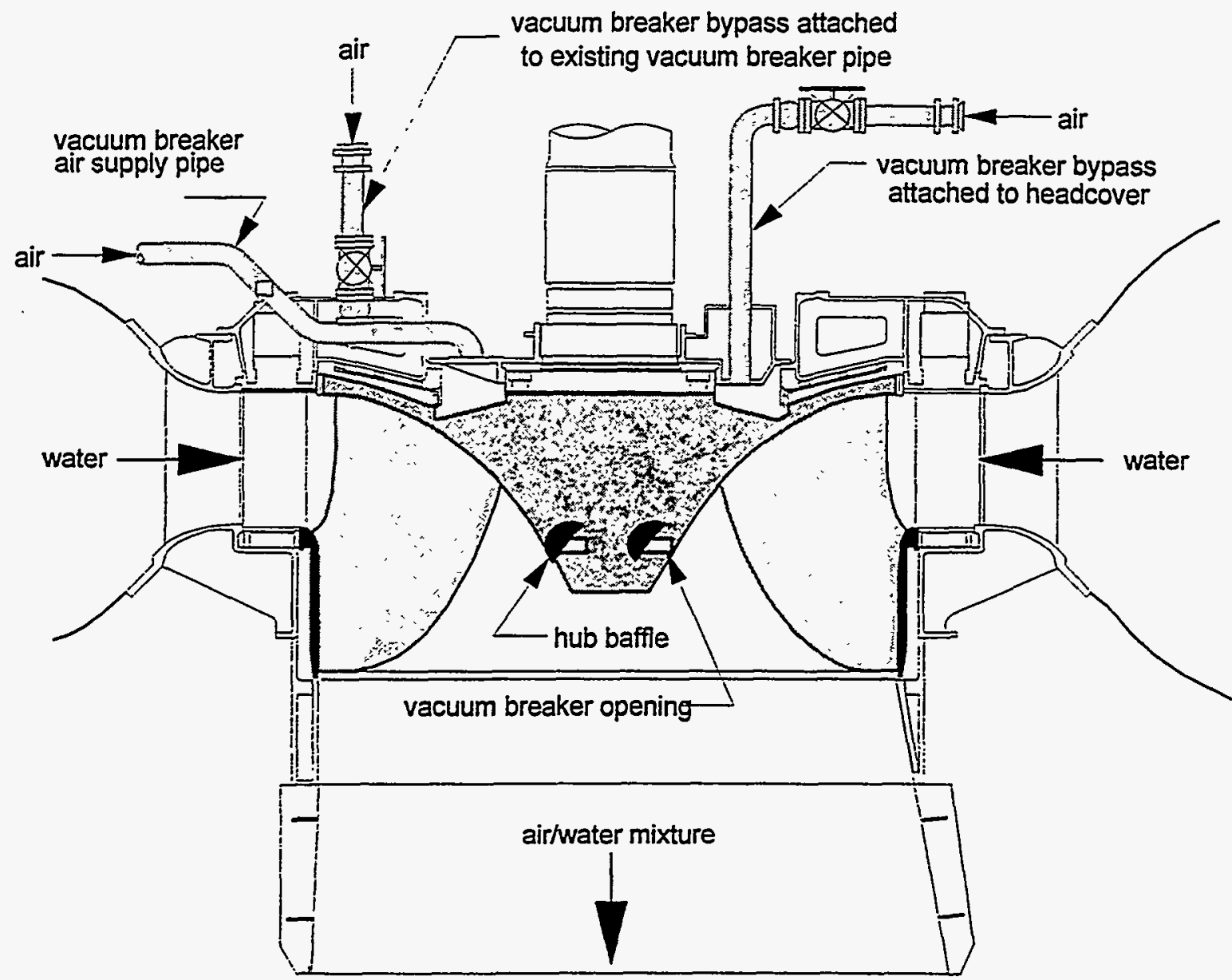

Figure 5.5-1 Francis Turbine Retrofitted with Hub Baffles to Enhance Aeration

If baffle and bypass modifications fail to provide the required airflow, two options remain-operational changes and forced injection. Subatmospheric pressures usually can be induced by operating the turbine at low settings below peak efficiency gate. Due to the resulting efficiency and capacity losses, as well as adverse surging and vibration, such operations are undesirable. However, in situations where an immediate solution is needed (e.g., to avoid a fish kill), operational changes may be the only option available to provide aeration. In forced injection, air is supplied to outlets in the turbine by blowers or compressors. The outlets usually include the vacuum breaker openings or circumferential manifolds near the entrance of the draft tube. The capital and operation and maintenance costs for forced air injection is almost always higher than costs for naturally aspirating turbines.

\section{Hub Baffles}

Baffles for retrofit Francis installations usually are positioned on the hub over the vacuum breaker openings (Figure 5.5-1). Two designs are common-streamlined and flat plate baffles. The basic geometry of each is given in Figure 5.5-2. The streamlined baffle is suitable for turbines containing vacuum breaker openings roughly 10 inches or more below the trailing edge crown fillet of the turbine buckets. Although exceptions occur, the clearance between the baffles and buckets is usually too small 


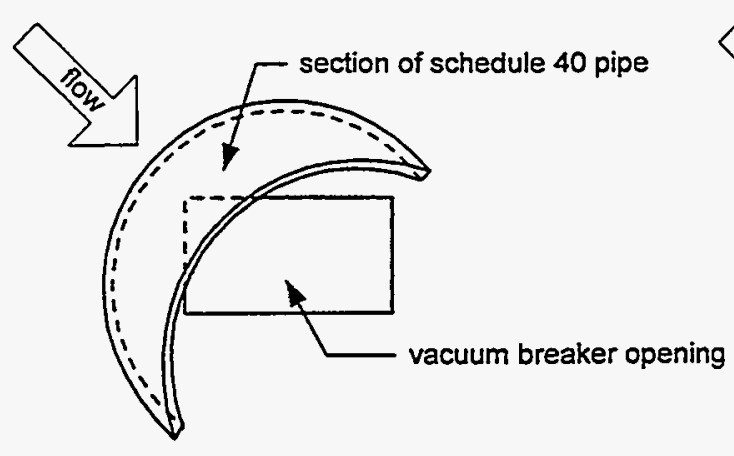

Streamlined Baffie
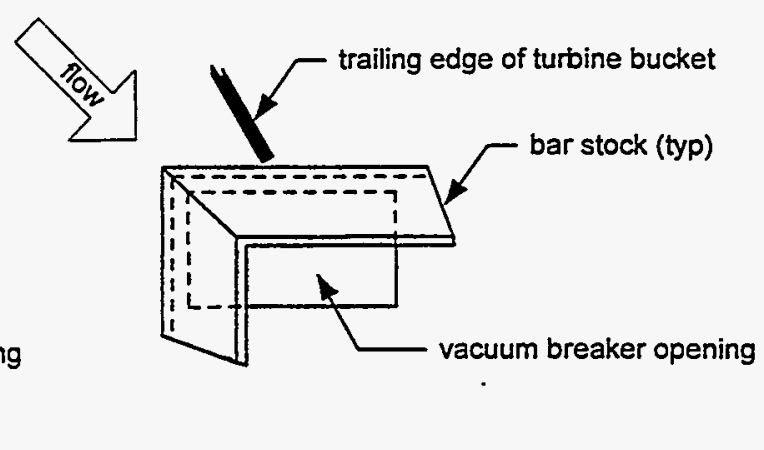

Flat Plate Baffle

Figure 5.5-2 Typical Hub Baffle Arrangements

for shorter distances. The streamined baffle is typically fabricated by cutting a wedge from standard $10-$ inch diameter schedule 40 pipe, creating an "eyelid-shaped" piece to shroud the vacuum breaker outlet (see Harshbarger, 1984). The baffle is positioned perpendicular to the direction of flow as determined by the typical erosion wear patterns on the turbine hub. In most cases, this position places the baffle at about $45^{\circ}$ from vertical. Along the centerline of the baffle, the deflection angle for flow along the hub is about $60^{\circ}$. An example installation of streamline hub baffles is shown for the original turbines at TVA's Norris Dam in Figure 5.5-3.

The flat plate baffle is typically fabricated from bar stock and is used for vacuum breaker outlets located on the turbine crown near the trailing edge of the buckets. The plates are situated $90^{\circ}$ horizontal-tovertical to create an L-shaped wedge over the openings (see Figure 5.5-2). Due to the narrow clearance between the hub and turbine blades, the overall height of the flat plate baffle is lower than that of the streamlined baffle. The deflection angle at the hub typically is near $45^{\circ}$. In designs used thus far, the baffle is situated so that the downstream edge of the horizontal plate is aligned with the center of the vacuum breaker opening. To permit access for welding, the upstream edge usually is mounted about 1inch above the top of the outlet. In some cases, an outlet may span the trailing edge of the turbine bucket and obstruct the upstream edge of the baffle. In these cases, the horizontal plate is notched to allow the trailing edge to bisect the baffie. 


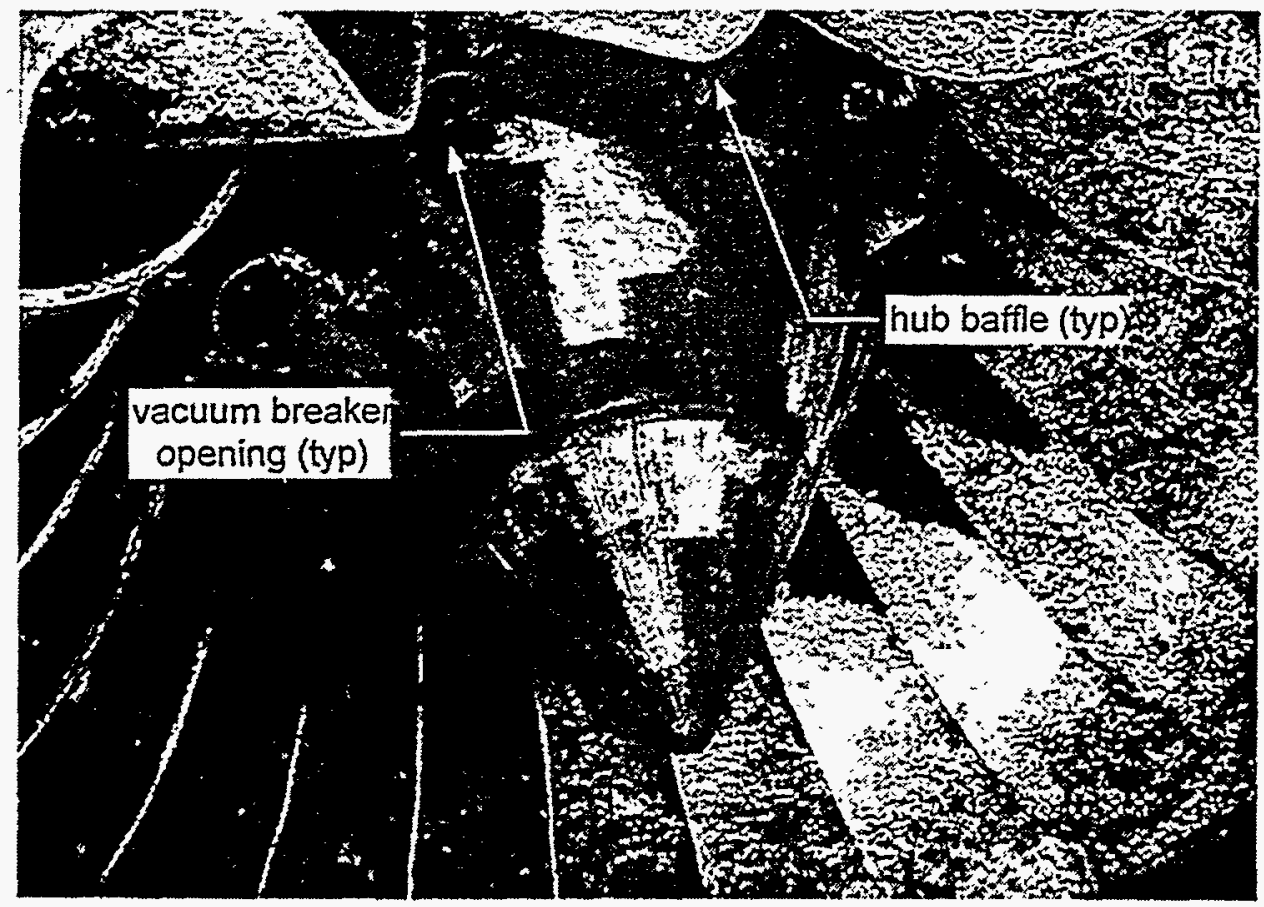

Figure 5.5-3 Streamlined Hub Baffles For TVA's Norris Dam

\section{Bypass Conduits}

Bypass conduits usually include a butterfly valve, a check valve, a debris strainer, and a bellmouth inlet. A typical arrangement is shown in Figure 5.5-4. The butterfly valve is used to control airfow, and the check valve is used to prevent the backflow of water from the turbine. The strainer is required to prevent loose objects from entering the bypass, which can damage turbine seals or obstruct vacuum breaker openings. The bellmouth inlet reduces both noise and pressure losses at the entrance of the conduit.

Two common locations for bypass conduits are illustrated in Figure 5.5-1. In the first, the bypass is attached to an opening cut in the turbine headcover. This arrangement provides the most direct and unobstructed flowpath for air entering the turbine. In the second location, the bypass is attached to an opening cut in the existing vacuum breaker air supply pipe, usually at a point downstream of the vacuum breaker valve. In most cases the conduits can be positioned at locations unobstructive to surrounding equipment and include a handwheel operator to open and close the bypass butterfly valve. 


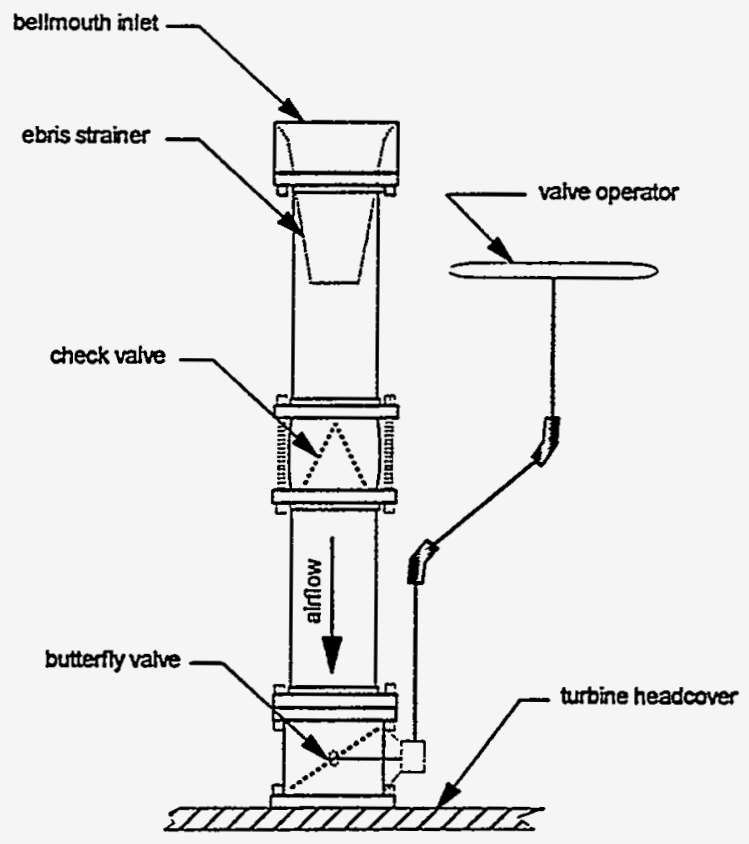

Figure 5.5-4 Typical Arrangement for Bypass Conouit

\section{Experience}

Table 5.5-2 provides a sample of projects containing experience for retrofitting existing turbines for aeration. This data was collected from published literature and personal contacts. The table includes information only for original equipment (e.g., some units have been upgraded with new turbines). At TVA, retrofit arrangements have been used on 23 units at 10 projects. Twenty-two of the units, all Frances turbines, include auto-venting capabilities provided by hub baffles and/or bypass conduits. The remaining unit, a mixed flow turbine at the Tims Ford Dam, uses forced air injection through the headcover (both in the original and new turbine). The DO uptake by the TVA retrofit arrangements typically is $2.0 \mathrm{mg} / \mathrm{L}$ or more. For this amount of oxygenation, the accompanying aeration-induced turbine efficiency loss usually is less than 2 percent (see March et al., 1992). In general, based on TVA experience with retrofit arrangements in low to medium-head Francis units ( 80 to 200 feet), the amount of aeration-induced turbine efficiency loss varies between 0.5 and 1.0 percentage points per $\mathrm{mg} / \mathrm{L}$ of uptake depending on the operating conditions of the unit (i.e., head, discharge, and incoming DO). This efficiency loss is experienced only when the air supply conduits are open to provide oxygenation of the turbine discharge. The efficiency loss due solely to the presence of the baffles is typically 0.5 percent or less.

Although aeration is not needed year round, TVA experience has found that the energy loss attributable to hub baffies is small compared to the cost to temporarily install these devices for the low DO season. As such, hub baffles for TVA projects are attached as permanent equipment. Also, cavitation damage has not been significantly increased by baffles, and in several cases enhanced airflow has reduced adverse surging, load swings, and turbine vibrations. 


\begin{tabular}{|c|c|c|c|c|c|c|}
\hline \multirow[t]{2}{*}{ Project } & \multirow[t]{2}{*}{ Owner } & \multicolumn{3}{|c|}{ Turbines } & \multirow[t]{2}{*}{ Aeration Features } & \multirow{2}{*}{$\begin{array}{l}\text { DO Uptake } \\
\text { (mg/L) }\end{array}$} \\
\hline & & Type & No.Units & $\begin{array}{l}\text { Power } \\
\text { (MW) }\end{array}$ & & \\
\hline Angrlcan Falls"i: & Idahopowate & : & 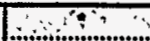 & 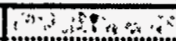 & forced aerátlon thrú draltlube & $\overline{2.0}$ \\
\hline Apalachia & ova & Francis & 2 & 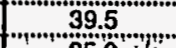 & 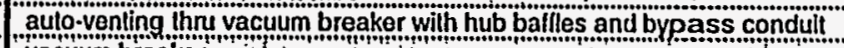 & \\
\hline gagnent... & 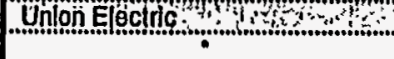 & Frangs & & 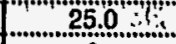 & & \\
\hline Baldengy & & & & & Torced aeralion & \\
\hline Bankged I r & Alabme pomer exp & Haplanj & $-1+1$ & $=8$ & 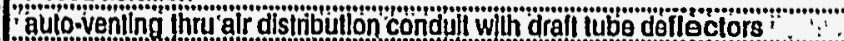 & 1.7 \\
\hline Banileils Ferry & $6 \mathrm{solpower}$ & & & 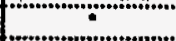 & 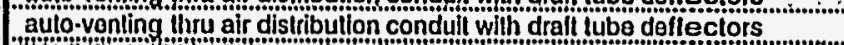 & \\
\hline 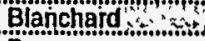 & 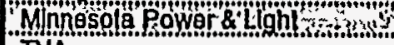 & 3 & & & 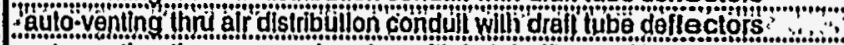 & \\
\hline Boong & NA & Francis & 3 & 25.7 & auto-venting hru vacuum breker will nub balles and bypass conduit & \\
\hline goxCanyon & $5 \mathrm{sin}$ & Froncis & & & 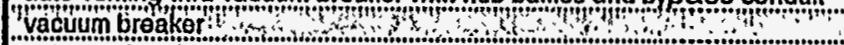 & \\
\hline Bull Shoals 14 & H UACE. & Francis & & 38.8 & 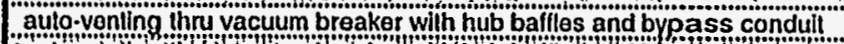 & \\
\hline Builshogls & 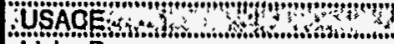 & Pranciss & 4 & 100 & ratovoning hifo valum treak & \\
\hline Cascade & idanopower & Kaplan & & 6.4 & Torced aeration infu drafilube & \\
\hline Cingroke & 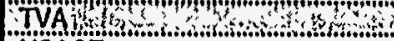 & Mirings: & 1 & $1:-1.80 .8$ & 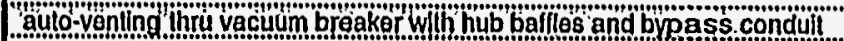 & \\
\hline Clarks Hili! & ZUSACE: & & & & auto-venting thru drail tube air distribulton conduilt & \\
\hline Conowingo: & 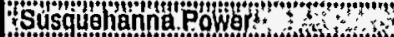 & Whos & anom & (n) & 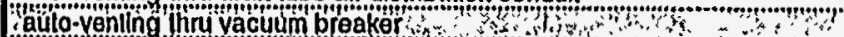 & \\
\hline coyolo: & & Francls & & & auloventing thru vacuum breaker & \\
\hline pesprogen & 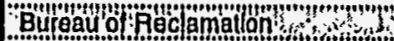 & Hengensing & 32 & $2,2.6$ & 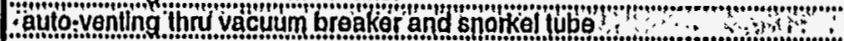 & \\
\hline Douglas. & TVA & Francls. & & 26.5 & aulo venling hru vacuum breaker with hub ballos and by & \\
\hline Fontena: & $\mathrm{NA}$ & IFrangin & (x) & 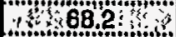 & 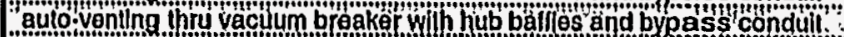 & \\
\hline Hiwasse日 & Tin & Francs & 1 & 597 & aulo.venlng thru vacuum breaker with nub bafllo and bypass co & \\
\hline Hoil!: & 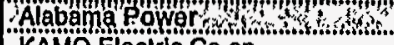 & 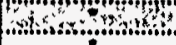 & Epen & 8 & 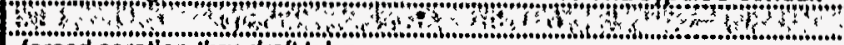 & \\
\hline & KaMopecircoopop & & & & 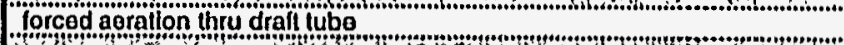 & \\
\hline Mimbigijy & menth & iupiopellor & 4 & 0.90 & Wno & 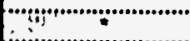 \\
\hline gan Martin & Alabame Power & Propeller & 3 & 42.0 & 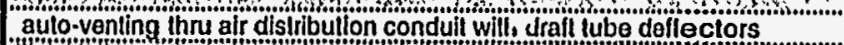 & 0.5 \\
\hline Martin........... & 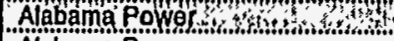 & 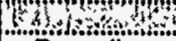 & 44 & 3.13 & 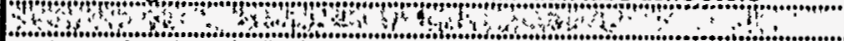 & \\
\hline Milchoil! & Algbama Power. & Propeller & & 500 & auto-venting unu air distribuilon conduil wilh drail tube deilectors & \\
\hline Montleollo & 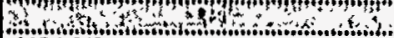 & Hinges & mene & 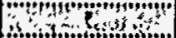 & Vacuim braker & \\
\hline Norforte & USACE & Francis & & 31,3 & auto-venting thru vacuum breaker with hub baffles and by & \\
\hline Norfs? & mo & Francis & me? & $64.7 \%$ & aulo venting inu vacuum breaker with hub baflios and byp & \\
\hline plixlex. & Hamboupapor & Francis & & 0.6 & auto-venting inru dralt lube & \\
\hline Poppowellepen & - & Kagni & (1) & 10 & aulo-vening itru dralf uibe air distribuilon condüil & \\
\hline Raplde & & Propeller & & 0.8 & aulo-veniling ihru vacuum breaker & \\
\hline Rat papolds & mons & mirnglow & 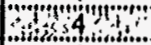 & 30 & 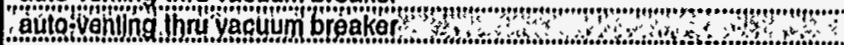 & \\
\hline BI- Harls & Alabama powe & Kaplan & & 67.5 & auto-venting thru air distribution conduit with dralt tubed & 20 \\
\hline hollisocillo: & HIn & Hrands: & 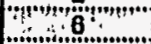 & 0.8 & 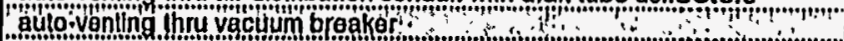 & 1.5 \\
\hline Salo Hainoo & 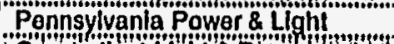 & & & & drailiu & \\
\hline shogug. of & 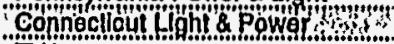 & H.1. Kaplan & (3) & . & 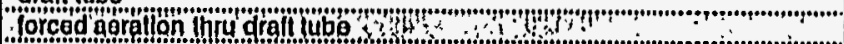 & 2.0 \\
\hline South Holston & TVA & Francis & 1 & 36.2 & ing inru vacuum breakor and by & 2.0 \\
\hline Tenkiller Fornist. & USACENYI & Mrancesping & 1.12 & $28.4 \%$ & 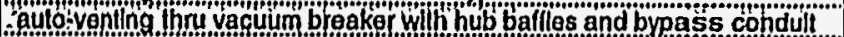 & \\
\hline tims Ford: & TNA & Mixed flow & 1 & & torced aeralion litru vacuum breaker & \\
\hline Walauga- & 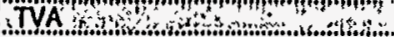 & SFrangisy & 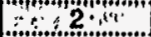 & 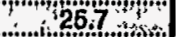 & aufo vening ithe vacuum breaker whth hy balios and & 2.0 \\
\hline Winifild & Ameican Eectic Power sevico & & & 6.15 & autoventing hur uacuum breake & 300 \\
\hline Wyllons & 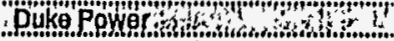 & "Frands! & ind & 3100 & imbraker: & $0-2$ \\
\hline Youghlogheny & & & & & lorced aeraltion thru drall lube & 2.5 \\
\hline
\end{tabular}

Missing informalion

Table 5.5-2 Aeration Experience In Retrofitting Existing Turbines 
Outside of TVA, a variety of retrofit experience is found. Of particular note is that for Kaplan turbines (e.g., see Miller and Sheppard, 1983). There presently are no feasible alternatives to retrofit Kaplan runners with devices such as hub baffles, and aeration is induced by adding deflectors in the draft tube. To offset lower velocities and higher pressures found at this location, such arrangements usually require a deflector of larger size than that of hub baffles. Favorable performance is reported for both the amount of turbine efficiency loss and DO uptake. However, based on the indicated volume of air entrainment, the reported turbine efficiency loss appears to be unrealistically low. Other Kaplan experience is found in the original work by Wagner (1958). One such installation included an aeration ring immediately below the runner plane. In this case, tests showed that airflow was highly sensitive to operation of the unit and that the efficiency losses were substantial.

\section{Advanced Technology}

In existing turbines, work to develop advanced aeration technology needs focus in several areas, including the following:

- Evaluation tools. Advanced numerical models using computational fluid dynamics (CFD) are needed to determine the detailed hydraulic characteristics of retrofit arrangements. In particular, the velocity, Reynolds stress, and pressure fields associated with the three-dimensional viscous flow around baffles and deflectors are needed to examine designs for these devices. The techniques need to be coupled with models for the overall flow through the unit to properly evaluate the effects of the turbine boundaries, runner rotation, draft tube swirl, tailwater, and so on. Numerical models for the single phase flow of water would provide abundant help in design efforts. However, to estimate the extent of cavity formation and entrainment in the wake of baffles and deflectors, models capable of determining the characteristics of two-phase air/water flow are needed. Models for multiphase flow also are required to compute the overall effect of aeration on turbine performance (i.e., efficiency loss).

- Validation data. Hand-in-hand with evaluation tools, model and prototype data for retrofit arrangements will be needed to validate computational techniques. Depending on the phenomenon being examined, validation experiments can range from simple water tunnel studies to full-scale turbine :ests.

- Retrofit optimization. Although the experience summarized in Table 5.5-2 includes many successful applications of retrofit technology, it is unknown whether or not these designs are optimal. The arrangements used by TVA have evolved over a number of "trial-anderror" experiments. Using evaluation tools as discussed above, variations of these designs could be examined to see if enhancements can be obtained by increasing the amount of DO uptake and decreasing the aeration-induced turbine efficiency loss. Deflector and baffe arrangements for projects with high tailwater are especially in need of improvement. For these cases, investigations should examine larger baffies and deflectors positioned at different locations in the turbine runner and draft tube.

- Airfow passageway improvements. Data from tests at TVA indicate that sealwater interference may be obstructing airflow through passageways feeding aeration outlets located in the turbine runner. Advanced retrofit technologies should consider turbine modifications that better isolate airflow passageways from seal leakage or backflow from the aeration outlets. 


\subsubsection{New Turbines}

\section{Background}

Discussions of including aeration as an integral part of the design of new turbines began in the early 1980 's. Formal action to implement ideas, however, did not emerge until 1987. At that time, TVA initiated the Hydraulic Turbine Aeration Research Program to develop physical and numerical modeling techniques to aid in the design of aerating units and to demonstrate the feasibility of this technology in a full-scale installation. The primary goal of the program was to develop methods of aeration in new turbines that would provide up to $6 \mathrm{mg} / \mathrm{L}$ of DO uptake in hydro releases while minimizing adverse sideeffects on turbine efficiency, capacity, and reliability.

Based on the success with hub baffles in the original units, TVA's Norris Dam was selected as the experimental site to demonstrate the application of aeration technology for new turbines. Norris Dam also was among the first projects containing discharges of low dissolved oxygen scheduled for runner replacement in TVA's Hydro Modernization Program. This program includes an aggressive plan to upgrade hydro facilities at twenty-four TVA projects, with the replacement of eighty-eight turbine runners. In 1988, TVA contracted two hydroturbine manufacturers to use existing numerical models in evaluating the performance of the turbines at Norris Dam. The manufacturers were asked to propose and evaluate alternatives for increasing aeration and to estimate the performance for the upgraded aerating turbines. The recommended alternatives received by this process ranged from a continuation of hub baffle technology to a variety of innovative methods to provide air at a number of sites inside and around the turbine. These sites, shown in Figure 5.5-5, include the headcover, bottom ring, runner crown, deflector, hub snorkel, discharge ring, runner band, runner entrance edge, runner discharge edge, draft tube cone, and draft tube coaxial diffuser (March et al., 1991).

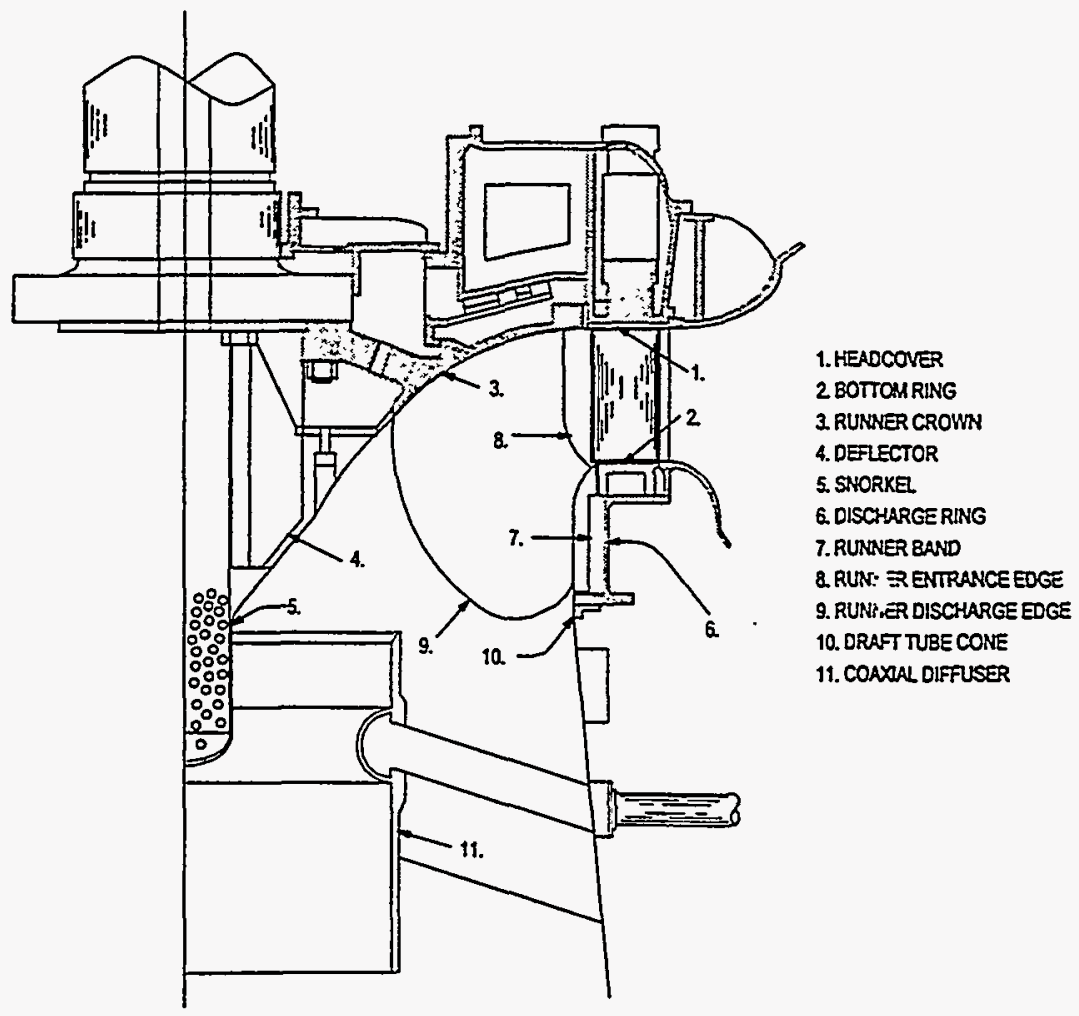

Figure 5.5-5 Aeration Alternatives for New Hydroturbines 
Based on results from the 1988 study, TVA and Voith Hydro, Inc., initiated, in 1991, an extensive physical model program to investigate performance of the turbine aeration alternatives for the new turbines at Norris Dam. The tests included measurements for efficiency, cavitation, runaway speed, pressures and pressure pulsations, airflow, and DO uptake (Cybularz et al., 1992). Procedures for measuring and scaling the aeration performance of turbines were developed during the course of the model test. To obtain a qualified set of data by which scaling relationships could be developed, a model test was performed of the original turbines. Prototype data for these units was available from field test previously conducted to evaluate the performance of hub baffles. The original turbines at Norris had a capacity of about $53 \mathrm{MW}$ at a net head of about 170 feet (Dodson, 1995). Major aspects of the testing and scaling procedures developed in the Norris model studies are presented later in this report. The major finding from this work is related to scale effects that occur in modeling air/water mixtures. Due to these scale effects, different model operating conditions are required to evaluate the environmental performance (i.e., DO uptake/gas transfer characteristics) than those needed to evaluate hydraulic performance (i.e., aeration-induced efficiency loss/energy dissipation characteristics) of aerating turbines. For non-aerating conditions, performance was determined using conventional procedures for modeling homologous hydraulic turbines.

Based on the model studies, the resulting designs chosen for the prototype turbines at Norris contain five aeration alternatives. Those for unit 2 (Figure 5.5-6 and 5.5-7) include the runner deffector (DEF), bucket discharge edge (DE), thrust relief (TR), and draft tube cone (DTC). Unit 1 is similar, but contains an airflow passageway to the runner discharge ring (DR) rather than the draft tube cone.

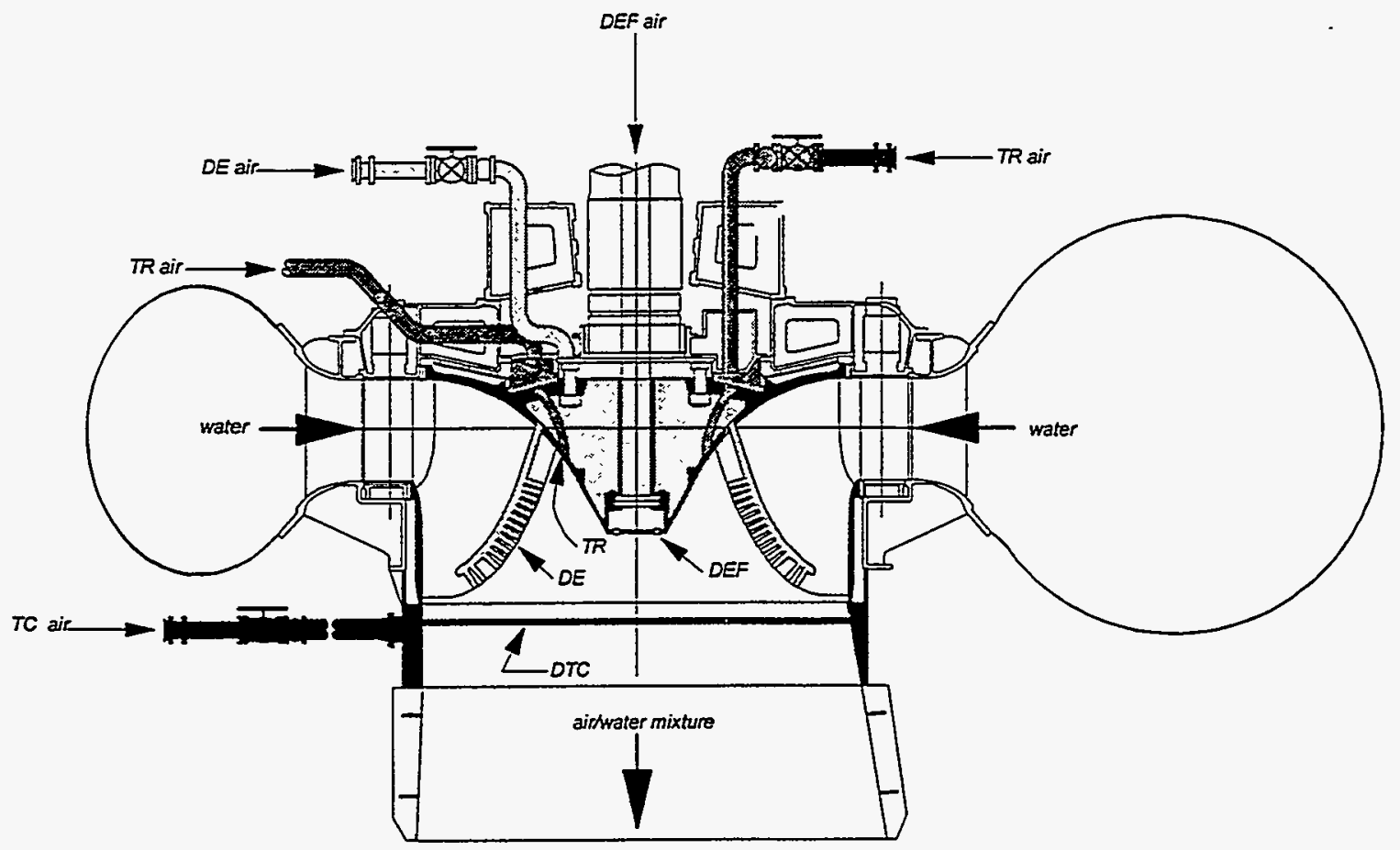

Figure 5.5-6 Aerating Turbine for Norris Hydro Project

The new turbines for Norris, installed in 1995 and 1996, have undergone extensive testing to evaluate the environmental and hydraulic performance of the various aeration alternatives (Hopping et al., 1996). The testing included single and combined operation of the alternatives over a wide range of turbine flow conditions. For environmental performance, results show that up to $5.5 \mathrm{mg} / \mathrm{L}$ of DO uptake can be 
obtained for single unit operation with all aeration options in service. In this case, the amount of air aspirated by the turbine is more than twice that obtained in the original turbines with hub baffles. The resulting bubble plume in the turbine discharge is shown in Figure 5.5-8. To meet the $6.0 \mathrm{mg} / \mathrm{L}$ target established for the project tailwater, an additional $0.5 \mathrm{mg} / \mathrm{L}$ of DO improvement is obtained by flow over a re-regulation weir downstream of the powerhouse. For hydraulic performance, efficiency losses ranging from 0 to 4 percent are obtained, depending on the operating condition and the aeration options. Compared to the original turbines, the Norris units provide overall efficiency and capacity improvements of 3.5 and 10 percent, respectively (March and Fisher, 1996). The new runners also have demonstrated significant reductions in both cavitation and vibration.

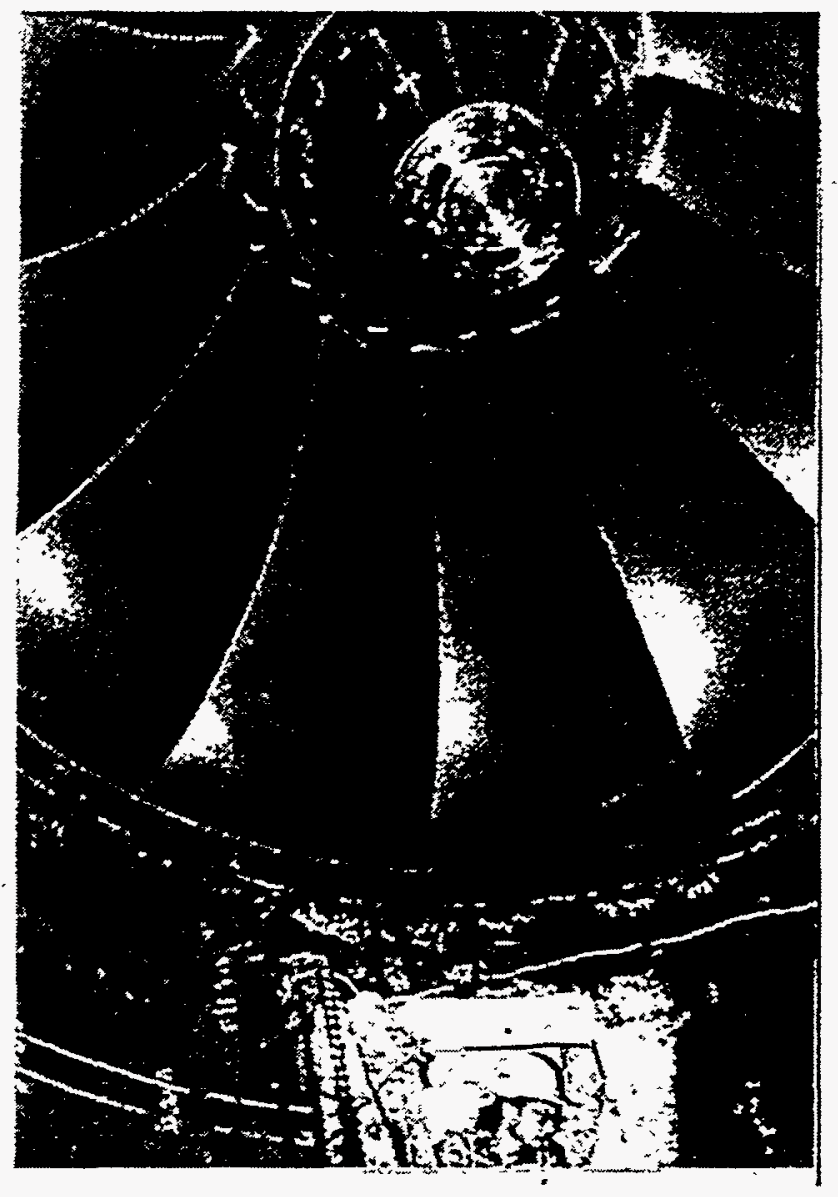

Figure 5.5-7 New Auto-Venting Turbine for Norris Dam Unit 2 


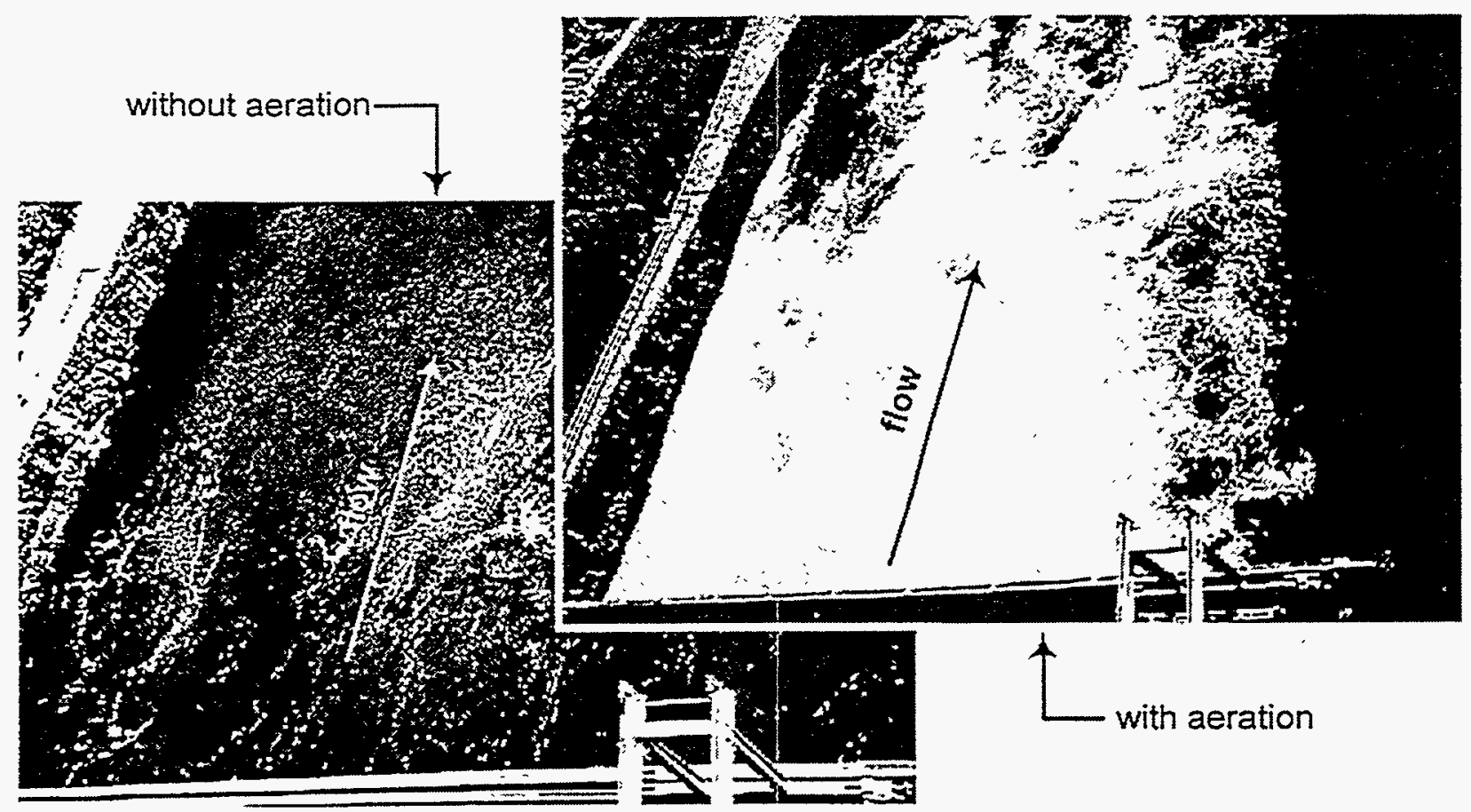

- Figure 5.5-8 Bubble Plume in Tailwater at Norris Dam

Design and Applicability

The fundamental requirement in the design of an aerating turbine is the ability to supply air to outlets inside the turbine in an efficient and cost-effective manner. In this, the shape and position of the turbine components and surrounding equipment need to be determined so that no degradation occurs in the nonaerating performance of the unit. In general, auto-venting alternatives that aspirate air as a natural consequence of the turbine geometry provide the best aeration alternatives. Auto-venting technology is applicable only for turbines containing locations where subatmospheric pressures can be found or created. Aeration sites without baffles or other obstructive devices are desired.

Compared to other alternatives to improve dissolved oxygen (i.e., Table 5.5-1), turbine aeration in new units usually is optimal at projects where the aeration-induced head loss is small compared to the overall turbine head. Such projects tend to include Francis units. As previously emphasized, aeration-induced losses in the draft tube can limit the feasibility of aeration in low head projects containing propeller-type units. At this time, no attempts to include objectives for turbine aeration as an integral part of the design of new Kaplan turbines (i.e., that is for DO improvement in reservoir releases) are underway.

In supplying AVT technology for new turbines, a wide range of design factors and, consequently, potential air supply arrangements exist. The environmental performance and hydraulic performance of a given aeration alternative are sensitive to the detailed layout of the turbine components, including the size, shape, and orientation of the airflow passageways, scrollcase, runner, and draft tube. The basic requirements for these components vary from project to project depending on the head, flow, and other local conditions. The design of an aeration alternative tends to be site-specific - a single arrangement with fixed dimensions will not apply at all projects. However, within the geometrical limits of most installations, enough flexibility usually exists in the size, shape, and orientation of the turbine components to find workable arrangements for aeration alternatives. The complex aspects of the flow through turbines 
and airflow passageways underscore the importance of a detailed hydraulic analysis to obtain functional aeration solutions.

The range of applicability of turbine aeration in new units can be demonstrated in terms of TVA's Hydro Modernization (HMOD) Program. Sixteen of the twenty-four projects in the HMOD program presently experience problems with seasonally low dissolved oxygen. Of these, current plans call for the use of twenty-seven new aerating turbines at thirteen of the projects. A summary is given in Table 5.5-3. Except for Tims Ford, all of the projects contain Francis turbines. Tims Ford is a diagonal flow unit and includes a forced air system. Overall, turbine aeration is expected to supply roughly 75 percent of the total required median DO uptake at these sites, including 100 percent at six of the projects.

\begin{tabular}{|c|c|c|c|c|c|c|c|}
\hline \multirow{3}{*}{ Project } & \multicolumn{3}{|c|}{ Turbines } & \multirow{3}{*}{$\begin{array}{c}\text { Target } \\
\text { DO in } \\
\text { Reservoir } \\
\text { Release } \\
\text { (mg/L) }\end{array}$} & \multirow{3}{*}{$\begin{array}{l}\text { Median DO } \\
\text { Improvement } \\
\text { Required } \\
\text { (mg/L) }\end{array}$} & \multirow{2}{*}{\multicolumn{2}{|c|}{$\begin{array}{c}\text { DO Improvement } \\
\text { by } \\
\text { Turbine Aeration }\end{array}$}} \\
\hline & \multirow[t]{2}{*}{$\begin{array}{l}\text { No. } \\
\text { Units }\end{array}$} & \multirow{2}{*}{$\begin{array}{l}\text { Head } \\
\text { (m) }\end{array}$} & \multirow{2}{*}{$\begin{array}{l}\text { Power } \\
\text { (MW) }\end{array}$} & & & & \\
\hline & & & & & & (mg/L) & $\begin{array}{l}\% \text { of Median } \\
\text { DO Required }\end{array}$ \\
\hline Apalachia & 2 & 110 & 40 & 6.0 & 0.8 & 2.0 & $100 \%$ \\
\hline $\begin{array}{l}\text { Blue Ridge } 1 \\
\text { Blue Ridge } 2^{(1)}\end{array}$ & $\begin{array}{l}1 \\
1\end{array}$ & $\begin{array}{l}45 \\
45\end{array}$ & $\begin{array}{l}22 \\
1.5\end{array}$ & 6.0 & 2.6 & 3.0 & $100 \%$ \\
\hline Boone & 3 & 27 & 26 & 4.0 & 0.0 & 2.0 & $100 \%$ \\
\hline Chatuge & 1 & 39 & 10 & 4.0 & 2.9 & 1.0 & $34 \%$ \\
\hline Cherokee & 4 & 30 & 31 & 4.0 & 3.8 & 25 & $65 \%$ \\
\hline $\begin{array}{l}\text { Douglas } 183 \\
\text { Douglas } 2 \& 4\end{array}$ & $\begin{array}{l}2 \\
2\end{array}$ & $\begin{array}{l}30 \\
24\end{array}$ & $\begin{array}{l}31 \\
26\end{array}$ & 4.0 & 3.3 & 2.0 & $60 \%$ \\
\hline Fontana & 3 & 100 & 68 & 6.0 & 1.5 & 25 & $100 \%$ \\
\hline Hiwassee 1 & 1 & 58 & 60 & 6.0 & 2.1 & 1.0 & $47 \%$ \\
\hline Norris & 2 & 58 & 65 & 6.0 & 5.3 & 5.5 & $100 \%$ \\
\hline Nottely & 1 & 38 & 16 & 4.0 & 2.9 & 1.0 & $34 \%$ \\
\hline South Holston & 1 & 55 & 36 & 6.0 & 4.2 & 20 & $47 \%$ \\
\hline Tims Ford (3) & 1 & 41 & 41 & 6.0 & 5.6 & 4.0 & $71 \%$ \\
\hline Watauga. & 2 & 66. & 26 & 6.0 & 2.0 & 20 & $100 \%$ \\
\hline
\end{tabular}

Notes: (1) New small turbine for minimum fiow requirements.

(2) Upgrade with new turbines complete.

(3) Upgrade with new diagonal flow turbine complete. Aeration provided by forced air system.

Table 5.5-3 TVA Plans for New Auto-Venting Turbines

\section{Advanced Technology}

Experience at TVA's Norris Dam has demonstrated the feasibility of integrating objectives for DO improvement in the design of new turbines. At projects containing low dissolved oxygen where upgrades or new construction of Francis units are planned, turbine specifications should include performance requirements for the combined environmental and hydraulic performance of the units.

Despite progress made in recent years, continued work is needed for the development of advanced aeration technology for new turbines. As emphasized for existing units, work to improve evaluation tools, validation data, and airflow passageways also are needed for new aerating turbines. Enhanced methods to supply and entrain air need to be examined to expand the range of applicability in new turbines and to reduce costs. New options should consider aeration at projects where the total dissolved gas or dissolved nitrogen in the may be too high, as well as the unique aeration problems of propeller-type units. Other 
Development Of Environmentally Advanced Hydropower Turbine System Design Concepts Section 5.0

needs for continued work related to improvements in analysis, specification requirements, testing, and operational support are provided in the ensuing sections of this report. 


\subsubsection{ANALYSIS OF AERATING TURBINES}

The analysis of aerating turbines focuses on the estimation of three parameters - aiflow, DO uptake, and performance effects (Greenplate and Cybularz, 1993). In general, airflow is the additional fluid parameter that distinguishes zerating turbines from conventional turbines. If $Q_{A}$ and $Q_{W}$ are, respectively, the air and water flow through a turbine, the ratio $Q_{A} / Q_{W}$ emerges from a dimensional analysis as the additional parameter that must be considered in the dynamic similitude of the unit. Most studies express the air and water contributions in terms of the mean void fraction (or mean air concentration), given by

$$
\phi=\frac{Q_{A}}{Q_{A}+Q_{W}} .
$$

In the analysis of aerating turbines, DO uptake and performance effects typically are expressed in terms of $\phi$.

Prediction of airflow requires a balance between the pressure loss for flow through the turbine air supply passageways and the pressure at the aeration outlets based on flow through the runner and draft tube. The latter involves the turbulent, two-phase flow of an air/water mixture and cannot be reliably evaluated using current state-of-the-art computational tools. Due to these complexities, the prediction of airflow at this time is based primarily on dimensionless parameters (e.g., pressure coefficients) derived from testing model and prototype turbines.

The focus of work summarized herein is for DO uptake and performance effects. The DO uptake provides a measure of the environmental performance of an aerating turbine. In some cases, other water quality parameters also may contribute to the turbine environmental performance, such as total dissolved gas in the tailwater. Dissolved oxygen uptake is given by

$$
\triangle D O=D O_{T w}-D O_{S C},
$$

where $D O_{s c}$ and $D O_{T w}$ are the dissolved oxygen concentrations in the scrollcase and tailwater, respectively. Depending on the site-specific spatial distribution of flow, the location of dissolved gas samples taken from the scrollcase and tailwater can have a significant impact on the measured $\triangle D O$ (see Section 5.5.3). To be complete, the values of $D O_{T W}$ and $D O_{S C}$ in Eq. 5.5.-2 should be defined as mean values based on the total flux of dissolved oxygen upstream (above scrollcase inlet) and downstream (below tailwater bubble zone) of the turbine.

Performance effects refer to the impact of aeration-related changes in the turbine on the efficiency of the unit. This impact, called the hydraulic performance of an aerating turbine, is measured by the aerationinduced efficiency loss, given by

$$
\Delta \eta=\eta_{0}-\eta_{a},
$$

where $\eta_{a}$ and $\eta_{0}$ are the turbine efficiency with and without aeration, respectively. Discussions of methods to evaluate the environmental and hydraulic performance of aerating turbines follow.

\subsubsection{Environmental Performance}

The fundamental relationship for estimating the DO uptake in turbine aeration is the familiar first order differential equation of oxygen transfer across the surfaces of bubbles dispersed in a flow, given by

$$
\frac{d C}{d t}=K_{L} a\left(C-C_{S}\right)
$$


In Eq. $5.5-4 C$ is the DO concentration, $K_{L}$ is the liquid film mass transfer coefficient, $a$ is the interfacial bubble surface area density, and the subscript $s$ refers to saturation conditions. Equation $5.5-4$ describes the gas transfer occurring between a parcel of water passing through a draft tube and the bubbles encountered along its journey. In general, the simplicity of this equation masks the complexity of oxygen transfer in aerating turbines. The liquid film coefficient is a spatially varying parameter that describes the effect of local turbulence on the transfer of oxygen across the bubble surfaces. To account for the breakup and coalescence of bubbles in the flow, the interfacial density also is spatially dependent. As written, use of Eq. 5.5-4 requires detailed knowledge of the distributions of water and bubble velocities, bubble sizes, temperature, and pressure throughout the draft tube.

Because the detailed characteristics of the flow are difficult to obtain, integration of Eq. 5.5-4 over the ensemble of water parcel trajectories in the draft tube is seldom practical. At this time, the only efforts to account for local effects are based on one-dimensional analyses that use the average pressure and velocity along the center streamline of the flow (Wilhelms et al., 1987; Buck et al., 1980). In this model, Eq. 5.5-4 is integrated in combination with the pressure-time history of the flow to account for local variation in saturation concentration. Also, the liquid film coefficient is assumed to be proportional to the air/water ratio, with the constant of proportionality occurring as an empirical coefficient to be determined from field data. In applications to the U.S. Army Corps of Engineers J.S. Thurmond Project (formerly Clarks Hill), the standard error in the predicted tailwater DO is of magnitude $0.5 \mathrm{mg} / \mathrm{L}$ whereas the maximum error is of magnitude $1.0 \mathrm{mg} / \mathrm{L}$. In practice, errors of this size can have significant impact on the cost of meeting environmental limits, hence the need to improve these models is obvious.

Other efforts to predict the environmental performance of aerating turbines have considered the problem of scaling oxygen transfer using test data from existing geometrically similar prototypes or models. For models, the classical problem of how to properly account for scale effects in the behavior of air/water mixtures arises. The relative characteristics of air and water are not easily controlled in the model or prototype. Not all of the pertinent forces occur in the same fraction in the model and the prototype. Although geometric similarity is achieved (except perhaps in the tailwater), differences in the dominant forces will degrade dynamic and kinematic similarity. Despite these difficulties, scaling relationships are often the tools of choice for predicting environmental performance of aerating turbines. As discussed below, the primary focus in this approach is in how to properly consider the liquid film coefficient and the interfacial surface area density.

\section{Mass Transfer Scaling}

\section{Liquid Film Mass Transfer Coefficient}

Schroeder (1977) summarizes surface renewal models of mass ransier across an air and water interface. The liquid film mass transfer coefficient in such models is scaled by the relationship

$$
K_{L} \propto(D r)^{1 / 2},
$$

in which $r$ is the surface renewal rate, or the frequency of arrival of turbulent eddies at the interface (the bubble surface). The molecular diffusivity, $D$, is a property of the oxygen and water mixture and depends primarily upon the local pressure and temperature.

\section{Bubble Interfacial Density}

If the bubbles in an aerated flow are assumed spherical and possessed of a single common diameter, $d_{b}$, one may show that the interfacial density scales according to the relationship

$$
a \propto \frac{1}{d_{b}} \frac{\phi}{1-\phi} .
$$

Gulliver et al. (1990) determined from analysis of self-aerated flows an alternative relationship given by 


$$
a \propto \frac{1}{d_{b}} \phi .
$$

In aerating turbines, for which air void fractions are low (typically $\phi<0.06$ ), the difference between these two relationships is negligible. Scaling relationships for the bubble diameter usually employ the energy balance between turbulent shear and bubble surface tension forces, expressed by Hinze (1955) as

$$
d_{m} \propto\left(\frac{\sigma}{\rho}\right)^{3 / 5} \varepsilon^{-2 / 5}
$$

where $d_{m}$ is the bubble diameter for which $95 \%$ of the air is contained in bubbles of size $d_{m}$ or smaller, $\sigma$ and $\rho$ are the surface tension and density for water, respectively, and $\varepsilon$ is the rate of mixture energy dissipation per unit mass. A typical assumption is that $d_{b}$ is proportional to $d_{m}$, with the constant of proportionality dependent on the nature of the aerated flow (e.g., open channel versus internal flows). With this assumption, $d_{m}$ may be replaced by $d_{b}$ in the above equation.

\section{Scaling of the KLa Product}

Using the above yields the scaling relationship for $K_{L} a$, given by

$$
K_{L} a \propto(D r)^{1 / 2}\left(\frac{\rho}{\sigma}\right)^{3 / 5} \varepsilon^{2 / 5} \phi .
$$

Further development of Eq. 5.5-9 requires scaling relationships for the surface renewal rate, $r$, and the dissipation rate, $\varepsilon$. Alternatives for these relationships are discussed below. It is typical to assume that both $r$ and $\varepsilon$ are related to the "integral" velocity and length scales, $u_{t}$ and $L_{t}$ respectively, of the turbulent flow. The appropriate relationships are

$$
r \propto u_{\imath} / L_{t}
$$

and

$$
\varepsilon \propto \frac{u_{t}^{3}}{L_{t}} .
$$

Tennekes and Lumley (1972) provide a discussion of integral velocity and length scales in turbulent flows.

\section{Aeration Scaling Relationship of Thompson and Gulliver}

Thompson and Gulliver (1997) develop a scaling relationship for the liquid film mass transfer coefficient by extending work originally presented by Azbel (1981). Azbel combined an equation for the rate of interfacial gas mass transfer (moles/area/time) in a dispersed bubbly flow developed Levich (1962),

$$
\frac{d m}{d t}=2\left(\frac{\pi D v_{f}}{d_{b}}\right)^{1 / 2} d_{b}^{2}\left(C_{s}-C\right) \text {. }
$$

with a relationship for the relative velocity of air in a bubble swarm, given by

$$
v_{r} \propto \frac{u_{t}^{3 / 2} d_{b}}{\left(v L_{t}\right)^{1 / 2}} F(\phi)
$$


where $v$ is the kinematic viscosity of water and $F(\phi)$ is defined by

$$
F(\phi)=\frac{(1-\phi)}{\left(1-\phi^{5 / 3}\right)^{1 / 2}}
$$

Thompson and Gulliver compare Eqs. 5.5-12 and 5.5-13 with Eq. 5.5-4 to deduce a scaling relationship for the liquid film mass transfer coefficient. One may use the comparison to obtain an equivalent scaling relationship for the surface renewal rate,

$$
r \propto \frac{u_{t}}{L_{t}} R e_{t}^{\beta-1},
$$

where $R e_{t}=u_{t} L_{t} / v$ is a turbulent Reynolds number. The $\phi$ dependence in Eq. 5.5-14 has been ignored, since $F(\phi) \approx 1$ for small $\phi$. Eq. 5.5-15 can be compared to Eq. 5.5-10, in which $R e_{\text {, }}$ does not appear. Thompson and Gulliver suggest an augmentation of the turbulent Reynolds number exponent ( $\beta$ in Eq. 5.5-15) to account for differences in the motion of bubble swarms in a draft tube relative to the buoyancydriven turbulent motion of bubble swarms in an otherwise quiescent fluid. A value of $\beta=1.5$ is theorized for the latter case. The value of $\beta$ for turbine draft tubes must be determined empirically.

Substitution of Egs. 5.5-11 and 5.5-15 into Eq. 5.5-9 yields a scaling relationship for $K_{L} a$ given by

$$
\operatorname{Tr} \propto W e_{t}^{3 / 5} P e_{t}^{-1 / 2} R e_{t}^{(\beta-1) / 2} \frac{d_{r}}{L_{t}} \phi,
$$

in which $\operatorname{Tr} \equiv K_{L} a /\left(u_{t} / d_{r}\right)$ is a non-dimensional mass transier rate, $W e_{t} \equiv \rho u_{t}^{2} L_{t} / \sigma$ is the turbulent Weber number, $P e_{t} \equiv u_{t} L_{4} / D$ is the turbulent Peclet number, and $d_{r}$ is the turbine runner diameter. To enable application of the scaling relationship to actual aerated flows through model and prototype turbines, Thompson and Gulliver relate the velocity and length scales of the turbulent flow to the velocity and length scales of the turbine runner. Stated explicitly,

$$
u_{t} \propto N d_{r} \text { and } L_{t} \propto d_{r},
$$

where $N$ is the rotational speed of the runner. According to Eq. 5.5-17, the runner diameter and rotational speed determine completely the structure of the turbulent flow field, the evolution of gas bubble sizes within the draft tube, and the gas transfer across the surface of the bubbles.

\section{An Aeration Scaling Relationship Incorporating Draft Tube Losses}

Draft tube losses can be incorporated into a scaling relationship for the $K_{L} a$ by relating the integral length scale, velocity scale, and dissipation rate to the draft tube loss coefficient or Darcy-Weisbach friction factor $f$. Jun and Jain (1993) express this relationship by

$$
\frac{L_{t}}{d_{r}} \propto f^{-1 / 4} R e^{-3 / 4}
$$

where $R e=U d, N$ is the bulk flow Reynolds number for the draft tube and $U$ is the average water velocity through the draft tube. Falvey (1980) suggests modeling turbulent dissipation as $\varepsilon=g S, U$, where $g$ is the acceleration of gravity and $S_{f}$ is the slope of the hydraulic grade line. Use of the Darcy-Weisbach equation to estimate $S_{f}$ gives the result

$$
\varepsilon=f \frac{U^{3}}{2 d_{r}} .
$$


The turbulent velocity scale may be related to the friction factor as follows:

$$
u_{t} \propto u_{8}=\left(\frac{f}{8}\right)^{1 / 2} U
$$

in which $u_{\tau}$ is the shear velocity of the draft tube flow. Substitution of Eqs. 5.5-18 through 5.5-20 into Eqs. 5.5-9 and 5.5-10 gives

$$
\operatorname{Tr} \propto W e_{t}^{3 / 5} P e_{t}^{-1 / 2}\left(\frac{d_{r}}{L_{t}}\right)^{3 / 5} f^{3 / 5} \phi,
$$

which may be compared to Eq. 5.5-16.

\section{Analysis of Turbine Aeration Data}

TVA has employed both of the similitude relationships (i.e., Eqs. 5.5-16 and 5.5-21) to investigate the aeration performance of hub baffle turbines at its Cherokee, Fontana, and Norris Dam sites. Because draft tube energy loss data is not available for the Fontana and Cherokee sites, the second procedure was not applied to those sites.

Figure 5.5-9 shows aeration data from the aforementioned projects scaled according to the procedure of Thompson and Gulliver (1997), Eq. 5.5-16. Values of $K_{L} a$ are computed from a linearized, integrated form of Eq. 5.5-4,

$$
K_{L} a=t \ln \left(\frac{C_{S}-C_{S C}}{C_{S}-C_{T w}}\right),
$$

where $C_{s c}$ and $C_{T w}$ are the dissolved oxygen concentrations measured in the scrollcase and tailrace, respectively. The draft tube transit time is computed as $t=1 / N$ (Thompson and Gulliver, 1997). The value of $\beta=1.1$, determined by Thompson and Gulliver in their analysis of the Norris model and prototype data, is used also for the Fontana and Cherokee data.

Figure 5.5-10 shows aeration data for the Norris model and prototype, scaled using the draft tube loss procedure, Eq. 5.5-21. Draft tube transit times are computed by integrating the mean velocity of the air/water mixture (via the one-dimensional energy equation) along the draft tube centerline. 


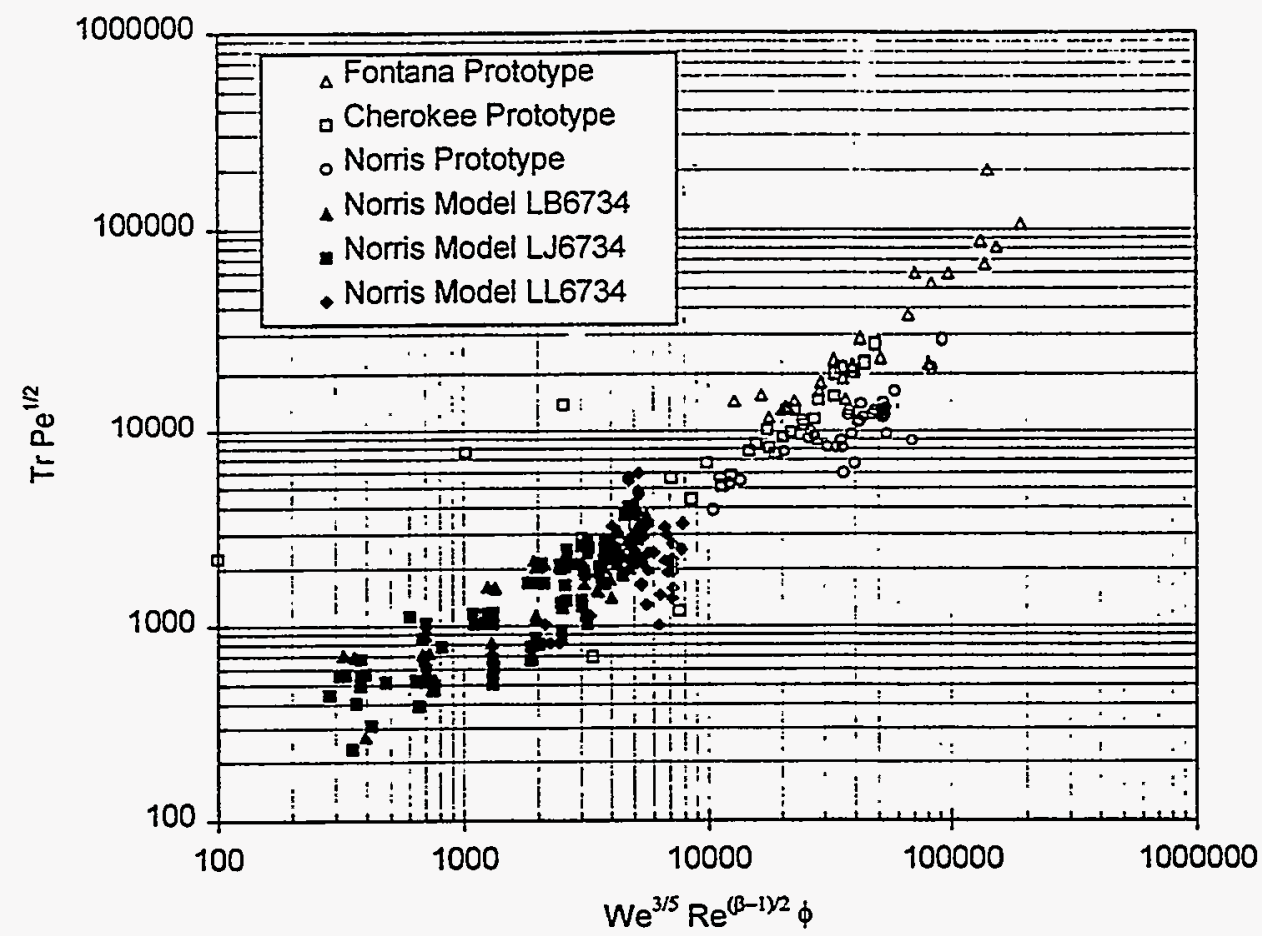

Figure 5.5-9 Analysis of Hub Baffle Aeration Data from TVA's Norris, Fontana, and Cherokee Dams Using the Procedure of Thompson and Gulliver (1997)

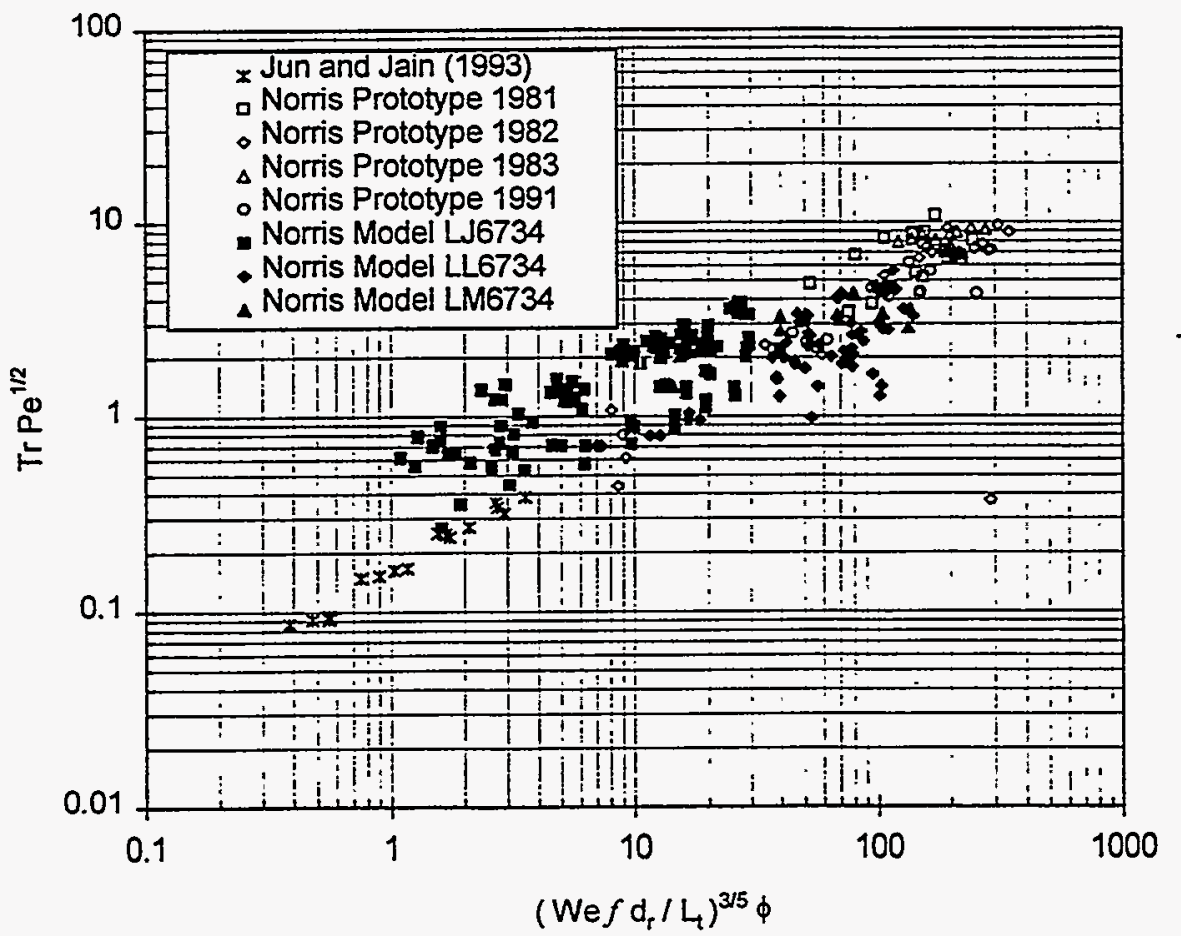

Figure 5.5-10 Analysis of Hub Baffle Aeration Data from Laboratory Experiments and TVA's Norris Dam Using the Draft Tube Loss Procedure 
Although the data are scattered widely in Figures 5.5-9 and 5.5-10, the linearity of the data suggests a power-law relationship for Eqs 5.5-16 and 5.5-21. Both procedures appear to account for the essential mechanisms of aeration. In particular,

- Increased turbulence in the draft tube promotes more frequent surface renewal, increased bubble splitting, and higher interfacial density, with a resulting increase in oxygen transfer.

- Increasing the air/water ratio increases the interfacial density, with a resulting increase in oxygen transfer.

In general, mechanisms that increase turbulence and airflow are undesirable because they tend to degrade hydraulic performance. Thus, one must balance the requirements for oxygen transfer against hydraulic efficiency loss. For this reason, there is need to minimize the uncertainty present in the data, and in the empirical relations embodied by Figures 5.5-9 and 5.5-10, if one is to use them in conjunction with hydraulic efficiency relations for economic analysis and design of aerating turbines. Possible causes of the uncertainty exhibited by the data include:

- Additional site and operating parameters. Parameters not included in the scaling procedures (for example, net head or net positive suction head), which affect the hydraulic performance of turbines, may cause systematic deviations from relationships expressed by Equations 5.5-16 and 5.5-21. It is unlikely that turbulent flows produced by adverse or off-peak operating conditions are adequately scaled by turbine runner geometry or a single-valued draft tube loss parameter. As Thompson and Gulliver acknowledge, there is a need for further research of these issues.

- Oxygen transfer in the tailrace. The aeration scaling procedures consider only oxygen transfer occurring in the draft tube. Because measurement of the dissolved oxygen concentration at the draft tube exit is difficult and unreliable, concentrations at a point downstream in the tailrace are used to compute transfer. Thus, tailrace hydrodynamics, which vary among prototype sites and model test facilities, influence the aeration data in a way that neither of the scaling procedures considers.

- Measurement uncertainty. Uncertainties in the measurement of dissolved oxygen contribute directly to the uncertainty of the liquid film mass transfer coefficient. TVA's experience with aerating turbine testing has shown that standardization of dissolved oxygen meters is difficult, but not impossible, to realize in the field. Measurement of air flowrates into the turbine and draft tube requires the use of nozzle and Venturi meters in less than ideal settings, which differ from site to site and from model to prototype. Uncertainties of measurements of air flowrates contribute directly to the uncertainties of calculated air void fraction values. Figure 5.5-10 also shows the data of Jun and Jain (1993), collected in a downward aerated flow in a pipe. This data is included here to illustrate the measurement quality attainable under ideal (laboratory) coriditions. Development and application of useful turbine aeration similitude theory will depend upon standardization of testing procedures for aerating turbines. (These issues are discussed in more detail in Section 5.5.3).

- Evaluation tools. As has been emphasized in previous discussions, advanced numerical models using CFD techniques need to be considered to evaluate and scale oxygen transfer in aerating turbines. Such models have already been employed to compute the detailed spatial characteristics for the single phase flow of water in draft tubes (e.g., see Ventikos et al., 1996). These models need to be expanded to include physics for the two-phase flow of an air/water mixture and gas transfer. To account 
for the entire domain of air/water flow, numerical models need to include both the draft tube and tailwater in a coupled fashion.

\subsubsection{Hydraulic Performance}

The design objective for hydraulic performance of conventional hydroturbines is to maximize efficiency over as wide a range of the expected operating conditions as possible. Without aeration, manufacturers currently can produce turbines with peak efficiencies near 95 percent. The design of aerating units poses a new challenge - that of providing highly efficient turbines which produce as much dissolved oxygen as possible while minimizing aeration-induced efficiency losses. A key issue in analyzing the hydraulic performance of aerating turbines is understanding the extra mechanisms of energy loss produced by the two-phase, air/water flow created by this process. Another related issue is how to predict the resulting aeration-induced loss. Brief discussions of these items foliow.

\section{Energy Loss Mechanisms}

According to Almquist et al. (1991), the energy loss associated with turbine aeration may be due to either reduced runner efficiency or reduced draft tube efficiency. Due to the complexity of the flow, the potential for reduced runner efficiency is difficult to assess. In general, however, most aeration alternatives introduce air at locations near the exit of the turbine. It seems unlikely that this practice, which typically provides air in amounts ranging as high as four to six percent by volume, would affect characteristics of flow in the runner to an extent sufficient to account for observed efficiency losses of two to four percent. A more likely explanation is that performance degradation occurs in the turbine component directly affected by the presence of air (i.e., the draft tube). According to Mosonyi (1987), draft tubes typically account for between ten and fifty percent of the total energy available to a hydroturbine, depending on the operating head.

Major mechanisms by which the admission of air at the exit of the runner may lower draft tube efficiency include the following.

- Increased hydraulic losses (e.g., expansion, bend, friction, and exit losses). Assuming the air/water mixture behaves as a homogenous fluid, analyses show that the average velocity of flow in the draft tube due to air admission will increase by a factor of $1+\phi$. Subsequently, the increase in draft tube head loss $\Delta H_{h l}$ can be scaled by

$$
\Delta H_{h l} \propto \phi k_{h l} \frac{U_{D T}^{2}}{2 g},
$$

where $k_{h l}$ is the loss coefficient for the draft tube hydraulic losses, $U_{D T}$ is the average velocity at the entrance of the draft tube, $g$ is the gravitational acceleration, and $\phi$ is as previousiy defined.

- Air Transport losses. These losses are incurred by the expenditure of energy to transport entrained air against the hydrostatic gradient in the vertical portion of the draft tube. In this case, the resulting draft tube transport loss $\Delta H_{y}$ can be sc ied by

$$
\Delta H_{t 7} \propto \phi h_{v},
$$

where $h_{v}$ is the vertical distance between the air admission location and the minimum centerline elevation of the draft tube. Note that the energy to transport air in this manner is assumed to be non-conservative. That is, the energy imparted to the air, which is manifested as high pressure at the low point of the draft tube, does not 
impart additional potential or kinetic energy to the flow as the bubbles emerge from the draft tube and rise to the water surface in the tailrace.

- Bubble losses. In general, due to the difference in density and fluid immiscibility, slippage will occur between entrained air bubbles and water. Energy dissipation subsequently occurs due to non-conservative forces arising from drag on the bubbles traveling through the draft tube. Based on the flow around entrained spherical particles, the resulting draft tube bubble loss can be scaled by

$$
\Delta H_{b / l} \propto \phi \frac{V_{D T}}{Q_{W}}\left(\frac{g d_{b}}{C_{d}}\right)^{1 / 2},
$$

where $V_{D T}$ is the volume of the draft tube, $C_{\delta}$ is a bubble drag coefficient, and $Q_{W}$ and $d_{b}$ are as previously defined.

Using field data for a medium-head Francis turbine, Almquist et al. (1991) compared the relative magnitude of each of the above mechanisms. The results, given in Table 5.5-4, were obtained from data in a test where the actual measured efficiency loss of the turbine was about 0.56 percentage points. In this case, the three mechanisms account for about 85 percent of the total observed efficiency loss. Although many simplifying assumptions are made, the analysis provides reasonable agreement between the total computed and measured losses.

\begin{tabular}{|c|c|}
\hline Mechanism & $\begin{array}{c}\text { Efficiency Loss } \\
\text { (percentage points) }\end{array}$ \\
\hline Hydraulic Losses & 0.04 \\
\hline Air Transport Losses & 0.30 \\
\hline Bubble Losses & 0.14 \\
\hline Total & 0.48 \\
\hline
\end{tabular}

Table 5.5-4 Efficiency Losses for Turbine Aeration

Before it can be concluded that the mechanisms given by Eqs. 5.5-23 to 5.5-25 encompass all the major sources of aeration-induced energy loss for an aerating turbine, analyses need to be performed using additional data from a broad range of turbine design and operation conditions, including information at both model and prototype scales. Refinement of scaling relationships is needed to evaluate applicability to other sites and to account for the remaining 15 percent of energy loss shown in Table 5.5-4. Further analyses may define other mechanisms for losses and/or improved methods of scaling. The greatest promise for obtaining a reliable procedure for analyzing and scaling the hydraulic performance of an aerating turbine lies in the development of advanced numerical models. Formulations currently are available for predicting the characteristics of two-phase air/water flow, including mechanism accounting for the additional dissipation of energy resulting from the increased flux, buoyancy, and relative velocity of the air phase.

\section{Predicting Efficiency Loss}

In the absence of model-prototype confirmation of the above energy loss mechanisms, the prediction of performance effects for prototype turbines has been limited to an examination of the relative change in turbine efficiency derived from model tests conducted over a range of operating conditions, with and without air admitted at the various aeration locations (Greenplate and Cybular, 1993). In particular, for the aeration-induced change in turbine efficiency, Cybularz et al. (1992) found $\Delta \eta$ in the prototype to be roughly the same as that in the model, if the model is operated at a speed which yields the same relative 
change in pressure through the unit. Based on the theory of homologous units, this requirement leads to Froude scaling for the discharge in the model turbine (Mobley and Brice, 1991). Results of prototype tests at Norris show that this procedure tends to overpredict the amount of aeration-induced efficiency loss. Although this leads to a conservative estimate of the hydraulic performance (i.e., the actual hydraulic performance will not be as severe), improved procedures are needed. This is true not only for assessing the quality of the turbine design, but also for effectively evaluating the cost of turbine aeration compared to that of other methods for enhancing dissolved oxygen.

\subsubsection{Economic Considerations}

In comparing options for increasing the dissolved oxygen for a hydro project, the cost of different oxygenation methods, such as those in Table 5.5-1, must be evaluated. The optimal method will be that which reliably provides the desired DO uptake at the lowest cost. Depending on the DO requirements and operational limits of the different alternatives, two or more oxygenation methods may be required.

Likewise, for turbine aeration, the proper selection of one or more aeration alternatives will depend on the cost of each. Optimal designs, both in new and retrofit situations, will be those providing the lowest cost per $\mathrm{mg} / \mathrm{L}$ of DO uptake. In general, costs include cipital and operation and maintenance (O\&M) expenses. Capital costs include that for the design, fabrication, installation, and testing of the aerationrelated features of the turbine. Operation and maintenance costs are those for the routine preventive maintenance of the aeration-related equipment and the aeration-induced efficiency loss of the turbine. Preventive maintenance includes that for valves, piping, controls, instrumentation, and blowers or compressors (for a forced injection system). In turbines where aeration-related modifications cause significant permanent efficiency losses, these should also be included.

Operation costs due to the aeration-induced efficiency loss should be determined based on the seasonal variation of required DO uptake, the aeration performance and operating procedures for the aeration alternative, and expected generation schedule. Note that for turbines with two or more alternatives (e.g., see Figures 5.5-5 and 5.5-6), the aeration performance and operating procedures may include that for combined operation of the alternatives. Depending on DO requirements and seasonal flow conditions, aeration may not be required in all turbines for a project containing multiple units. 


\subsubsection{TESTING OF AERATING TURBINES}

Performance testing, both at model and prototype scales, will play an important role in the development and commercial acceptance of advanced aerating turbine technology. Owners already have begun to issue specifications containing requirements for environmental and hydraulic performance of aerating turbines. This especially is true for new equipment. Similar requirements undoubtedly will emerge for those involved in upgrading exiting units with retrofit options for aeration.

In response to these trends, there is an obvious need for the develcement of formal test procedures for aerating turbines to evaluate conformance to contractual guarantees and, perhaps, to assess bonuses or penalties. In addition, to provide meaningful guarantees, suppliers also need a thorough understanding of how to analyze and predict the environmental and hydraulic performance of aerating turbines (i.e., DO uptake and aeration-induced turbine efficiency loss). The development of dependable analysis and prediction techniques, in turn, requires valid test data. It is also important to obtain data on a regular basis to monitor and update daily operations of aerating turbines. Updates are required, in general, because performance of an aerating turbine, both environmental and hydraulic, varies with changes in operating conditions (e.g., turbine head, tailwater elevation, power output, incoming DO concentration, etc.).

The following discussions are given to summarize the major issues involved in testing aerating turbines. Comments are provided regarding specification requirements and parameters required in testing. Recommendations focus on establishing a comprehensive test code for aerating turbines.

\subsubsection{Specification Requirements}

The major test codes used to define specification requirements for hydroturbines are PTC-18 (ASME, 1992) and IEC 41 (IEC, 1991). Because these codes address performance only of conventional nonaerating units, specification requirements for existing retrofit and new turbines containing arrangements to aerate hydro releases are not well defined. Until appropriate test codes emerge, the following general guidelines are given to help formulate specification requirements:

- Specifications for aerating turbines should include target requirements for DO improvement to be met by the aeration options. Depending on the aquatic community in the tailrace, specifications for aerating turbines also may include upper limits for total dissolved gas (TDG). Levels of TDG above about 110 percent can cause "gas bubble disease," which is fatal in sensitive species (see EPA, 1986). Depending on site-specific conditions, othe- water quality parameters that are influenced by turbine operation also could be included (e.g., temperature). The requirements for DO, TDG, and other water quality parameters comprise the guarantees for the aerating turbine's environmental performance. The conditions under which environmental guarantees are to be satisfied should be identified (e.g., head, gate, tailwater elevation, incoming DO concentration, flow).

- Specifications for aerating turbines should include maximum acceptable levels for the aeration-induced efficiency loss, $\Delta \eta$. These requirements comprise the guarantees for the aerating turbine's hydraulic performance. The conditions under which $\Delta \eta$ guarantees are to be satisfied should be identified (e.g., head, gate, tailwater elevation, incoming DO concentration, DO uptake, flow).

- Specifications for aerating turbines should place upon the manufacturer the burden of proposing the detailed design arrangements by which their turbine will supply the target DO and TDG guarantees (i.e., the environmental performance guarantees). The manufacturer should clearly identify the technology to be used, the conditions 
under which the aeration guarantees will be met, and the accompanying maximum aeration-induced efficiency loss (i.e., the hydraulic performance guarantees).

- Because there is not yet an industry-approved test code for evaluating the performance of aerating turbines, the exact methods by which DO, TDG, and $\Delta \eta$ will be measured and evaluated in the model and prototype units should perhaps be left open as negotiable during selection of the turbine contractor. Recommendations for a test code, provided below, should help in this process.

- Successful implementation of advanced aeration technology for hydroturbines requires expertise in site analysis, engineering, fabrication, installation, and testing. Without this, there is substantiai risk of obtaining an aerating turbine that fails to meet target environmental and hydraulic guarantees. As such, specifications for aerating units should require the turbine contractor to demonstrate their ability to supply aerating units. This can be accomplished by requiring statements of aeration expertise, such as staff capabilities (e.g., resumes and publications) and a list of projects where the contractor has successfully implemented aerating turbine technology. The methods of analyses used to determine predicted environmental and hydraulic performance should be provided (i.e., assumptions, data, computations, and references). Bid specifications should include "bonus points" for contractors with aeration experience. The owner also could ensure that qualified and experienced personnel carefully evaluate the bids and monitor the design, fabrication, installation, and testing of the aerating turbines.

\subsubsection{Test Parameters}

Testing of aerating turbines can be broadly divided into two categories, aeration and non-aeration performance (Figure 5.5-11). Non-aeration testing is performed with all aeration systems turned off and is the same as that for the mechanical performance of conventional turbines. Key parameters include turbine efficiency, maximum power output, cavitation level, vibration, shaft runout, and thrust load. Test codes PTC-18 and IEC 41 apply and include procedures to measure discharge, head, and power output to calculate the turbine efficiency. 


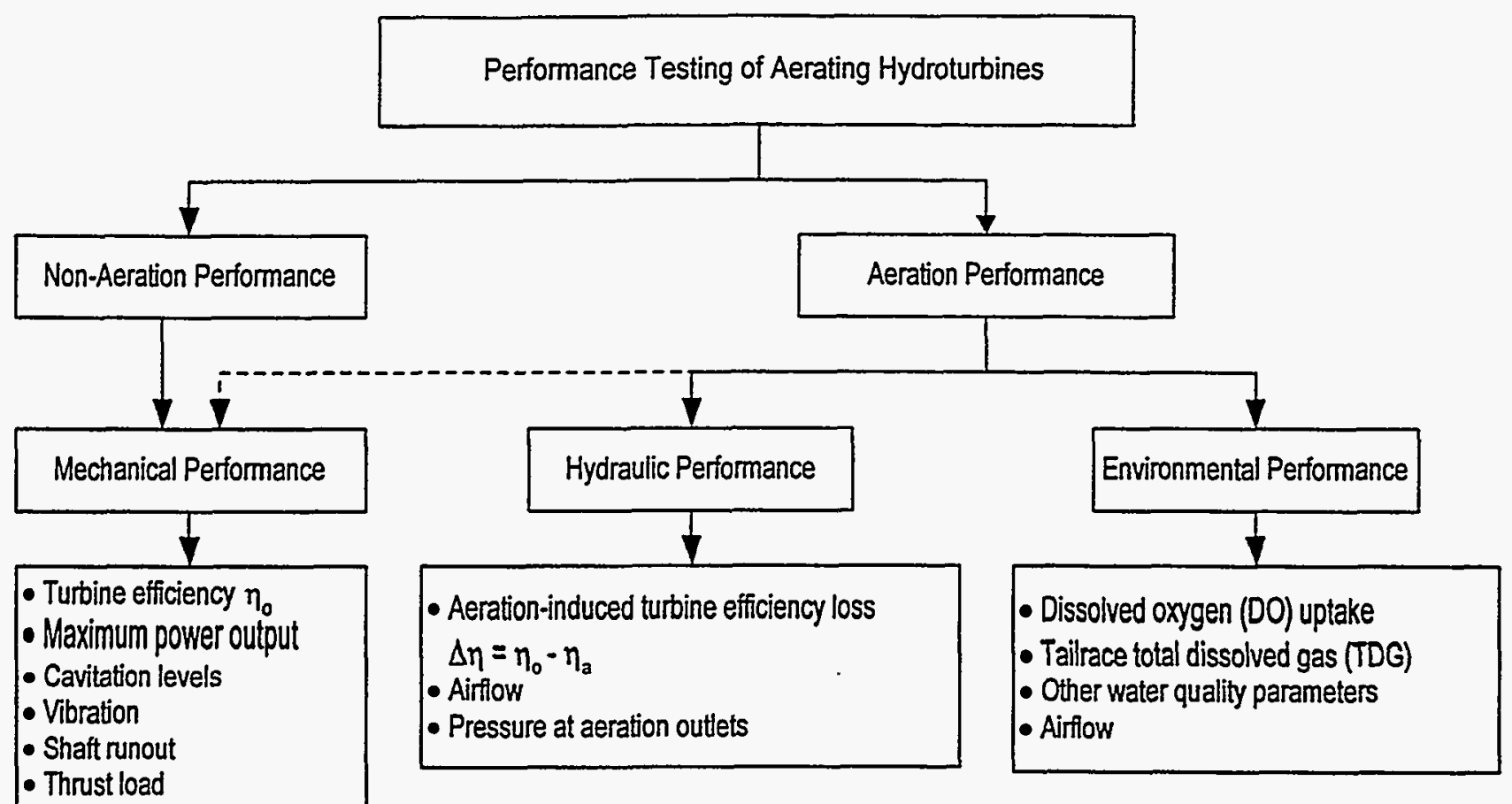

Figure 5.5-11 Flowchart for Testing Aerating Hydroturbines

Testing of an aerating unit focuses on evaluating the turbine hydraulic performance and turbine environmental performance. During aeration, hydraulic performance is measured by the aeration-induced efficiency loss $\Delta \eta=\eta_{0}-\eta_{a}$, where $\eta_{0}$ is the turbine efficiency with all aeration systems turned off and $\eta_{a}$ is the turbine efficiency with one or more aeration systems turned on. Both $\eta_{0}$ and $\eta_{\mathrm{a}}$ are found using procedures of PTC-18 and IEC 41. Airflow and aeration outlet pressure are needed to verify hydraulic characteristics of individual aeration options, if desired. The environmental performance of an aerating turbine is measured by the dissolved oxygen uptake and level of total dissolved gas in the tailrace. Depending on site-specific conditions, other water quality parameters also may be required. Airflow is needed to verify gas transfer characteristics of individual aeration options, if desired. Because air entrainment can affect other mechanical aspects of turbine operation, measurements for cavitation and vibration should also be a part of aeration testing.

It is emphasized that test codes PTC-18 and IEC 41 provide detailed guidelines for both absolute performance testing and index testing. Because changes in performance rather than absolute performance are of primary interest, index testing is often adequate for many aeration performance tests.

In general, compared to testing of conventional units, much less knowledge and experience currently exist for testing aerating turbines. Changes in the concentration of dissolved oxygen of only a few tenths of a $\mathrm{mg} / \mathrm{L}$ are significant from the standpoint of cost and meeting environmental commitments. However, measuring DO to this level of accuracy is difficult for several reasons. First, the spatial distribution of DO at the inlet and exit of the turbine can be highly nonuniform, often requiring a strategic deployment of multiple sensors. Secondly, DO sensors can drift significantly during the course of a test, requiring careful pre, post, and perhaps intermediate calibration experiments. Thirdly, DO levels in the tailrace are highly dependent on the distance downstream from the draft tube exit, requiring additional analyses to account for the effects of surface aeration and perhaps biological activity. TVA has gained substantial knowledge in addressing these issues. However, more study and experience are necessary to gain a better 
understanding of the achievable accuracy for DO, TDG, and other water quality measurements in testing aerating turbines.

Part of the difficulties in measuring dissolved oxygen could be overcome by improvements in sensor technology. Nearly all DO probes currently used for turbine testing rely on oxygen permeable membrane electrodes with verification by the Winkler method (see APHA, 1990). Despite many improvements, this forty-year-old technology remains troublesome. Common deficiencies include:

- The accuracy can be low-While the specified accuracy of most DO probes is 0.2 $\mathrm{mg} / \mathrm{L}$, field experience has shown that measurements at times are good only to 0.5 $\mathrm{mg} / \mathrm{L}$.

- The sensors drift out of calibration--Even under clean water conditions, sensors can drift out of calibration within a day.

- The sensors foul easily-Microscopic organisms, algae, and silt collect on the sensor membranes, causing inaccurate, readings.

With this type of DO sensor, it often is difficult to obtain good data, even in closely monitored performance tests. A greater impact perhaps occurs in the routine DO measurements used to establish operating conditions for hydropower oxygenation systems. The less-stringent $D O$ probe maintenance requirements that typically accompany these measurements can easily result in data of poor quality. In many cases this leads to overuse of oxygenation equipment, thereby creating needless costs for operation and maintenance. Along with the development of advanced technology for turbine aeration, work also is needed for new technology and/or methods to measure and obtain accurate DO data.

\subsubsection{Test Code Recommendations}

A preliminary version for an aerating turbine test code is presented in Appendix 10.6. This document describes guidelines, procedures, measurements and instrumentation, and calculations required for an aerating turbine test. The purpose of the document is to provide guidelines for both performance and acceptance testing that will eventually lead to a comprehensive test code. This code is generally modeled after the American Society of Mechanical Engineers (ASME) Performance Test Code (PTC) series, although it is in no way sponsored or endorsed by ASME at this time. 


\subsubsection{OPERATION OF AERATING TURBINES}

The operation of aerating turbines requires an understanding of basic requirements for water quality, monitoring and control of dissolved oxygen and aeration systems, and biological impact. The following includes brief discussions of each of these items.

\subsubsection{Water Quality Requirements}

Dissolved oxygen is usually the most critical water quality factor affecting survival and growth of fish and other aquatic organisms. In addition to damaging aquatic wildlife, low DO can contribute to problems related to the dissolution of trace metals, release of nutrients, formation of hydrogen sulfide, depression of $\mathrm{pH}$, and low assimilative capacity. Other water quality parameters affecting aquatic activity which can be influenced by turbine operation include minimum flow, temperature, and total dissolved gas.

Many studies have been performed to investigate the impact of DO on fish mortality, growth rates, and survival. The results of these studies, which are summarized by EPRI (1990) and EPA (1986), provide the basis for establishing guidelines for DO in reservoirs, rivers, and streams. In general, guidelines include the effect of dissolved oxygen at five different levels of impaiment for aquatic wildlife - no production impairment, slight production impairment, moderate production impairment, severe production impairment, and a limit to avoid acute mortality. These levels further have been determined for two life stages of fish - "early life stages" and "other life stages". The DO levels also depend on the type of aquatic wildlife in three broad categories - salmonid/cold water species (trout, salmon, whitefish), nonsalmonid/warm water species (bass, bluegill, walleye), and invertebrates. The guidelines are presented in Table 5.5-5 through Table 5.5-7. For most projects, the low DO season typically occurs during "other life stages" where the guidelines for no production impairment varies between 6 and $8 \mathrm{mg} / \mathrm{L}$. Most states have adopted minimum levels, however, that are aligned with the requirements for slight production impairment -5 and $6 \mathrm{mg} / \mathrm{L}$, respectively, for non-salmonid and salmonid waters.

Note that these DO levels should be considered subjective because they are based on short-term laboratory tests that do not include combined water quality effects as found in the natural environment. More field experience and testing is required to obtain a better understanding of conditions that are wellsuited for aquatic life and achievable with turbine aeration technology.

\begin{tabular}{|l|c|}
\hline \multicolumn{2}{|c|}{$\begin{array}{c}\text { Salmonid Waters } \\
\text { (trout, salmon, whitefish) }\end{array}$} \\
\hline Life Stage \& Impairment Level & $\begin{array}{c}\text { DO Level } \\
\text { (mg/L) }\end{array}$ \\
\hline No production impairment & 11 \\
\hline Slight production impairment & 9 \\
\hline Moderate production impairment & 8 \\
\hline Severe production impairment & 7 \\
\hline Limit to avoid acute mortality & 6 \\
\hline No production impairment & 8 \\
\hline Slight production impairment & 6 \\
\hline Moderate production impairment & 5 \\
\hline Severe production impairment & 4 \\
\hline Limit to avoid acute mortality & 3 \\
\hline
\end{tabular}

Table 5.5-5 DO Guidelines for Saimonid Waters (EPA, 1986) 


\begin{tabular}{|c|c|}
\hline \multicolumn{2}{|l|}{$\begin{array}{l}\text { Non-Salmonid Waters } \\
\text { (bass, bluegill, walleye) }\end{array}$} \\
\hline Lif́e Stage \& Impairment Level & $\begin{array}{l}\text { DO Level } \\
\text { (mg/L) }\end{array}$ \\
\hline W Earfoliféstages? & 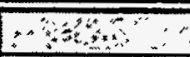 \\
\hline No production impairment & 6.5 \\
\hline Slight production impairment & 5.5 \\
\hline Moderate production impairment & 5 \\
\hline Severe production impairment & 4.5 \\
\hline Limit to avoid acute mor:ality & 4 \\
\hline 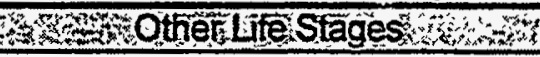 & 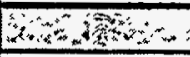 \\
\hline No production impairment & 6 \\
\hline Slight production impairment & 5 \\
\hline Moderate production impairment & 4 \\
\hline Severe production impairment & 3.5 \\
\hline Limit to avoid acute mortality & 3 \\
\hline
\end{tabular}

Table 5.5-6 DO Guidelines for Non-Salmonid Waters (EPA, 1986)

\begin{tabular}{|l|c|}
\hline \multicolumn{2}{|c|}{ Invertebrates } \\
\hline No production impairment Level & $\begin{array}{c}\text { DO Level } \\
\text { (mg/l) }\end{array}$ \\
\hline Some production impairment & 8 \\
\hline Acute mortality limit & 5 \\
\hline
\end{tabular}

Table 5.5-7 DO Guidelines for Invertebrates (EPA, 1986)

\subsubsection{Monitoring and Control}

To effectively operate air entrainment systems in an aerating turbine, monitoring is required. The primary parameter to be measured is the dissolved oxygen level in the turbine discharge. Effective control of the turbine will require monitoring of the DO uptake and efficiency (i.e., environmental and hydraulic performance). Depending on site-specific conditions, measurements also may be needed for discharge, temperature, total dissolved gas, or other water quality parameters.

For any parameters, the detailed monitoring arrangements will depend on several factors, including the frequency and magnitude of variations, available types of instrumentation, costs and O\&M requirements for instrumentation, project location, and operating patterns for the turbine (e.g., base load, peaking, load regulation). For projects where the DO varies rapidly, continuous monitoring may be desired, while for those where DO varies gradually, weekly grab samples may be adequate. The placement and number of permanent sensors or location of grab samples ultimately depends on site-specific characteristics. Considerations can include placing DO sensors at a distance downstream of the plant to include tailrace aeration, placing sensors away from sluggish eddy zones, and placing sensors so they can be easily accessed for reading and maintenance. 
Aerating turbines can be equipped with a variety of airflow alternatives (recall Figure 5.5-6), each possessing distinct operating characteristics with respect to DO uptake (i.e., environmental performance), aeration-induced efficiency loss (i.e., hydraulic performance), and O\&M cost. For aerating turbines, O\&M costs will include primarily that for efficiency loss. If the turbine is equipped with a forced injection system, the cost to operate air compressors or blowers also will be incurred. Other costs may stem from increased wear due to cavitation or vibration, if caused by an aeration alternative. However, based on TVA experience, aeration tends to reduce, not exacerbate, cavitation and vibration.

In the context of this report, control refers to decisions as to when to operate the turbine aeration alternatives, and if multiple alternatives are available, which should be operated. Other issues related to the specific equipment used to open and close aeration alternatives, including automatic controls, are not addressed herein.

Operation of turbine aeration alternatives should commence when the tailwater DO falls and approaches the target minimum level established for the project. Operating the turbine in the most cost-effective manner will involve determining the best alternative, or combination of alternatives, to meet the DO and power requirements. Other operating requirements may include maintaining minimum flows, temperature, and total dissolved gas. Because the environmental and hydraulic performance of a given alternative varies with the head and power, the options used to meet the desired DO can be strategically chosen to minimize the aeration-induced efficiency loss and other costs. As an example, consider the 1996 DO data for the new units at TVA's Norris Dam, shown in Figure 5.5-12. Turbine aeration was initiated in July when the scrollcase DO began to decrease. Throughout the low DO season, a mix of aeration options was used, based on the head, power output, and required DO uptake, to limit the turbine efficiency loss. Aeration was discontinued in November following reservoir turnover. On the average, the DO downstream of the project was maintained near the $6.0 \mathrm{mg} / \mathrm{L}$ target (except for a period when aeration was disrupted for an extreme series of performance tests on the new units). During the same period, the average aeration-induced turbine efficiency loss was about 1.9 percent.

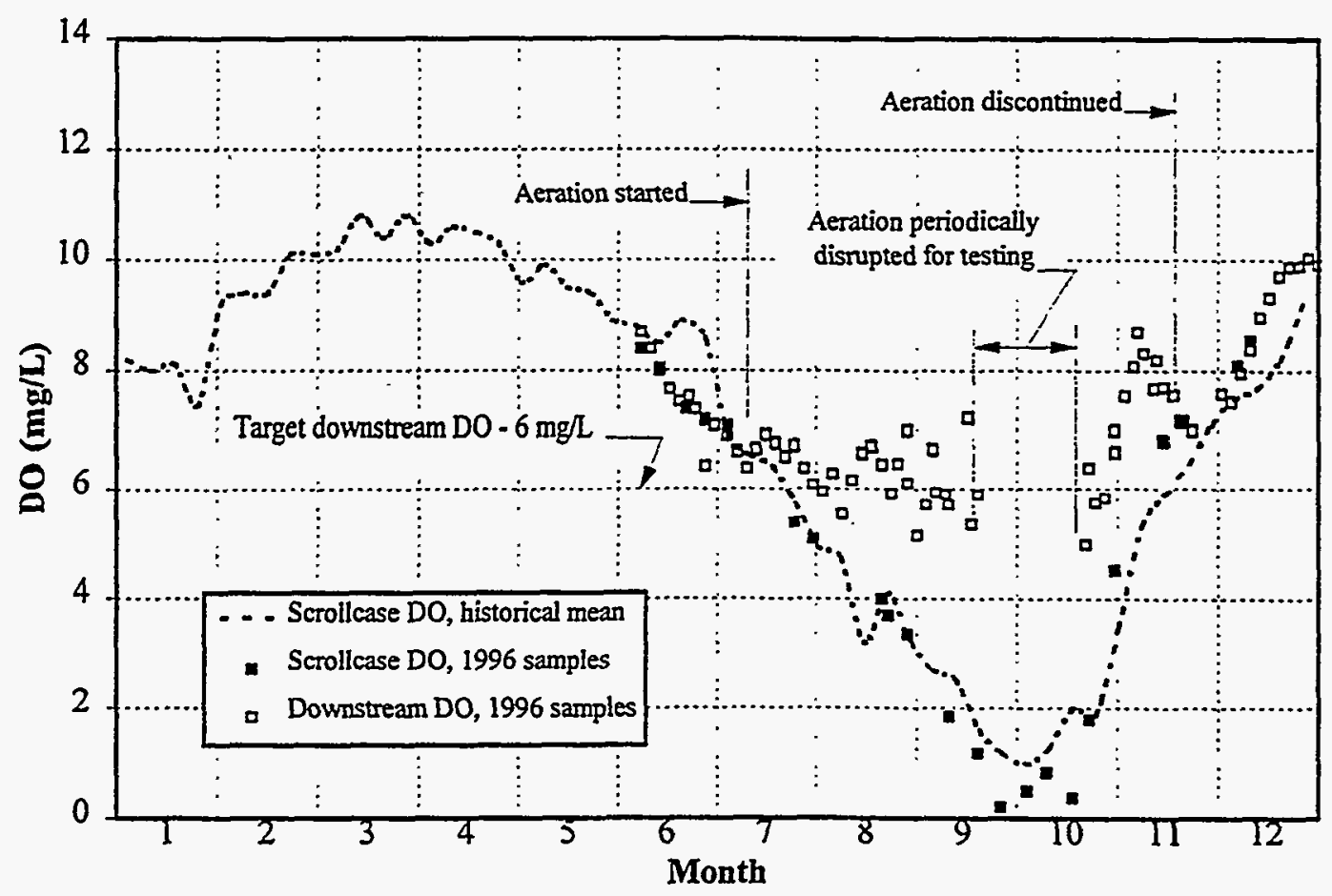

Figure 5.5-12 Dissolved Oxygen Improvement for Norris Dam, 1996. 



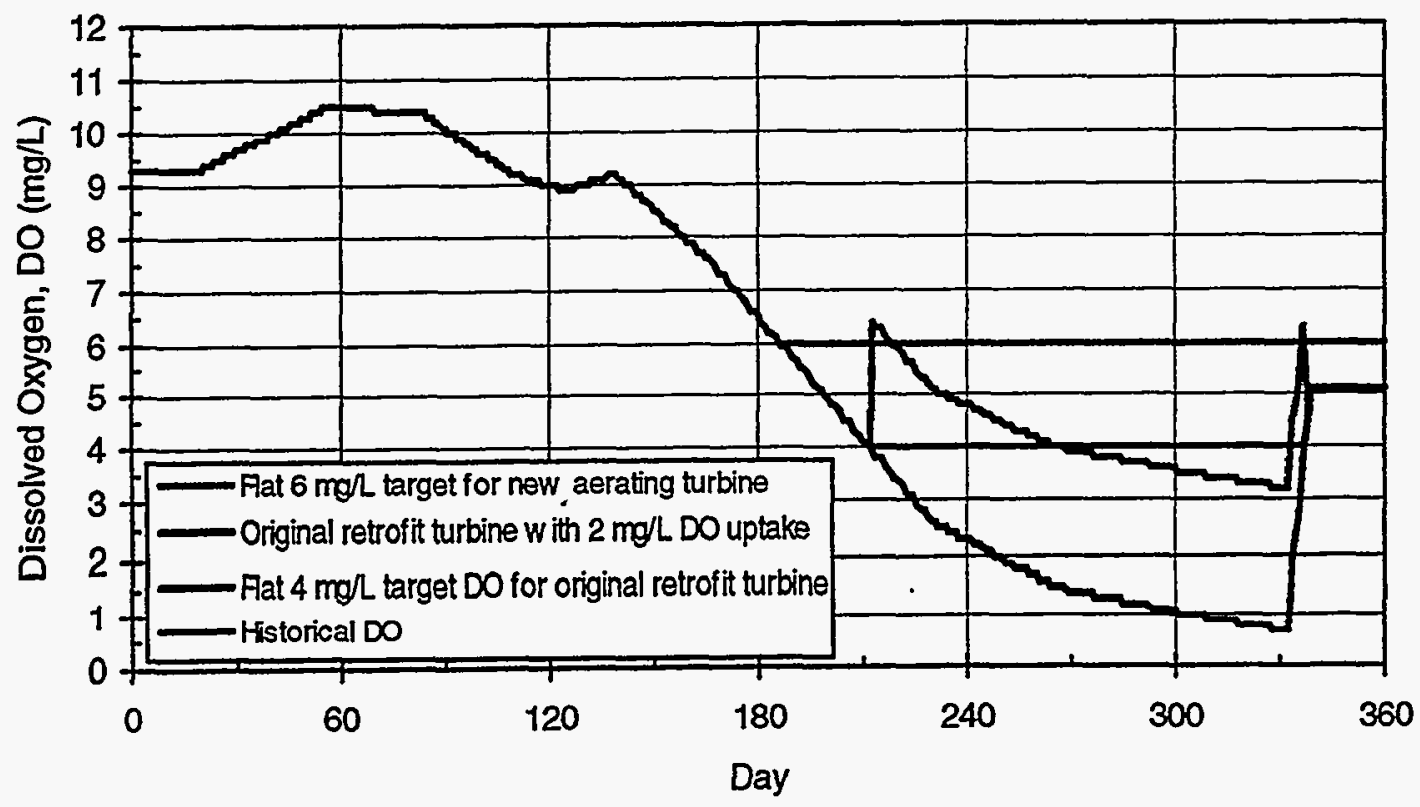

Plot (a) Assumed Annual Variation of Tailwater Dissolved Oxygen

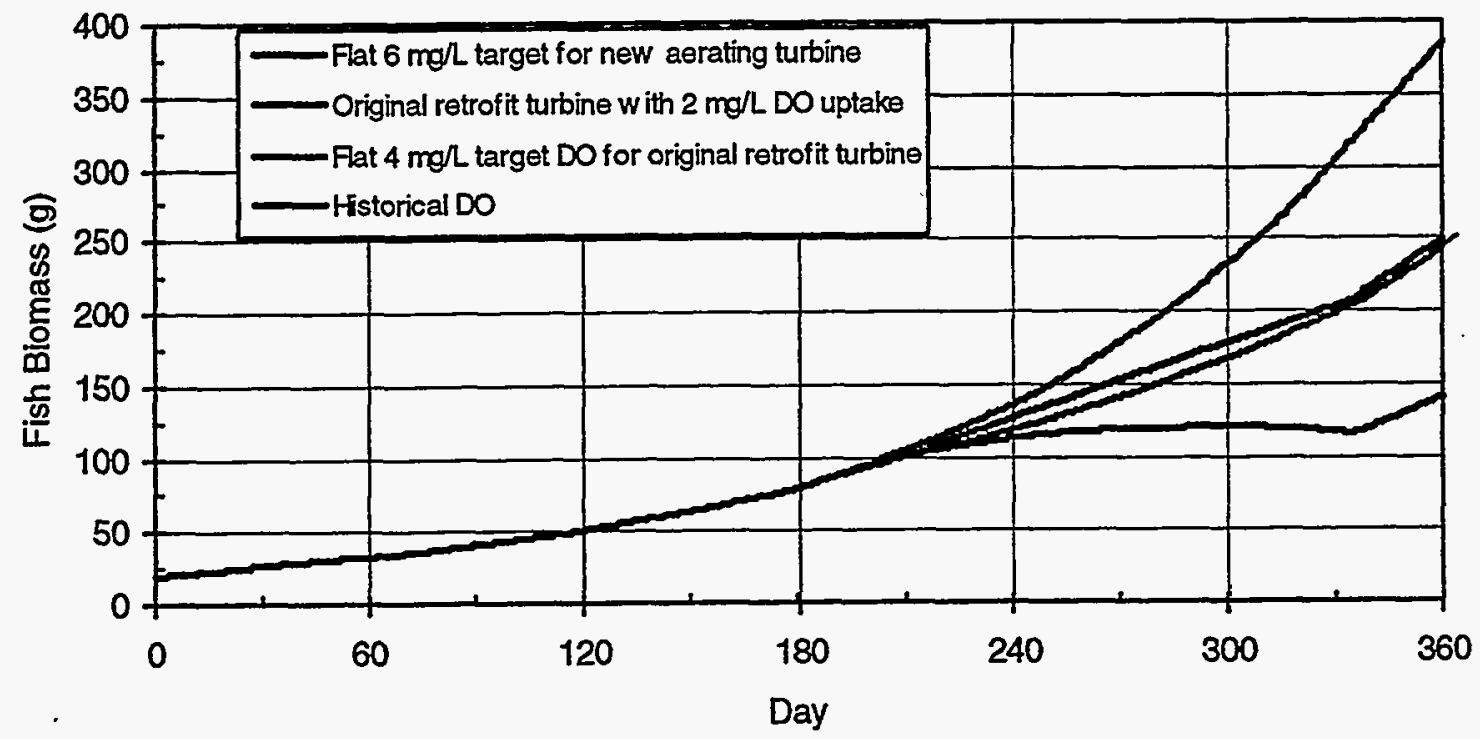

Plot (b) Computed Biomass for Rainbow Trout

Figure 5.5-13. Bioenergetics Model Simulation for Tailwater of Norris Dam 


\subsubsection{SUMMARY AND CONCLUSIONS}

For a given hydropower facility, the amount of dissolved oxygen in the turbine discharges will vary depending on a variety of factors. Included are the design, environmental, watershed, and operational characteristics of the project. The likelihood of occurrence of low dissolved oxygen has been evaluated in several studies based on project geographic location, season, and size of turbines. Data collected in the tailwater at numerous sites confirm that dissolved oxygen enhancements are needed at many hydropower facilities.

Based on experience of the Tennessee Valley Authority, over seventy-five percent of the required DO enhancements in the United States could be achieved using turbine aeration. The greatest opportunities occur in situations involving new units (i.e., new construction or upgrades). In these cases, objectives for DO enhancement can be included as an integral part of the turbine design. Within the physical limits of most installations, the shape and orientation of the turbine components can often be selected to provide aeration. Based on knowledge obtained at TVA's Norris Dam, a wide range of design factors and, consequently, air supply alternatives can usually be found. The challenge in designing advanced hydroturbines is to determine the number and type of alternatives providing the most cost effective dissolved oxygen uptake. Since turbine and water quality characteristics vary from project to project, the optimal aeration arrangement for a given installation is site specific.

In considering aeration technologies for advanced hydroturbines, attention also must be given to existing units. This is because for most projects it is not economically feasible to install new turbines for the sole purpose of providing aeration. Although the number of design options are fewer, innovative retrofit arrangements usually can be used to provide turbine aeration in existing projects. The most common include a combination of hub baffles and bypass conduits.

The analysis of aerating hydroturbines focuses on the prediction of environmental and hydraulic performance. The first is measured by the dissolved oxygen uptake, the second is measured by the aeration-induced turbine efficiency loss. In general, procedures to perform these evaluations fall far behind the level of accuracy needed to obtain reliable aerating turbine designs. An extensive amount of study is needed to improve predictions. These should consider several factors, including additional site and turbine operating parameters, tailrace oxygen transfer, measurement uncertainty (primarily DO), and state-of-the-art CFD evaluation techniques.

An obvious need currently exists for test procedures for aerating turbines. Owners have begun to issue specifications containing requirements for environmental and hydraulic performance. Verification of this performance, as well as compliance with dissolved oxygen requirements imposed by regulatory agencies, will rely on well defined test procedures. The major test codes currently available, PTC-18 and IEC 41, address only the performance of conventional, non-aerating units. To facilitate development of procedures for aerating units, a preliminary test code is presented in this study. Until industry-accepted procedures emerge, specifications for aerating turbines should include requirements for DO uptake, aeration-induced efficiency loss, and statements of qualifications for providing this technology.

Dissolved oxygen is perhaps the most critical water quality parameter affecting the survival and growth of fish and other aquatic organisms. Higher levels of DO will promote fish growth in all life stages. Over a period of several years, the use of turbine aeration will create an aquatic community dependent on higher DO. As a result, it becomes increasingly important to provide aeration as the diversity and size of the aquatic habitat develops. To avoid fish kills or other biological damage, close attention must be given to the measured tailwater DO and reliable operation of aeration alternatives. Optimal operation will be achieved 
Development Of Environmentally Advanced Hydropower Turbine System Design Concepts

Section 5.0

by the aeration alternative, or combination of alternatives, that meets the required DO uptake with minimum impact on power production. 


\subsubsection{REFERENCES}

Almquist, C.W., P.N. Hopping, and P.A. March, "Energy Losses Due to Air Admission in Hydroturbines," Proceedings 1991 National Conference on Hydraulic Engineering, ASCE, 1991.

APHA, Standard Methods for the Examination of Water and Wastewater, American Public Health Association, $17^{\text {th }}$ Edition, Section 4500-0, Oxygen (Dissolved), 1990.

ASME, Hydraulic Turbines, American Society of Mechanical Engineers, Performance Test Codes, PTC18, 1992.

Azbel, D., Two-Phase Flows in Chemical Engineering, Chapter 7, Cambridge University Press: Cambridge, England, 1981.

Bohac, C.E., and R.J. Ruane, "Solving the Dissolved Oxygen Problem," Hydro Review, Vol. 9, No. 1 , 1990.

Bohac, C. E., J.W. Boyd, E.D. Harshbarger, and A.R. Lewis, "Techniques for Reaeration of Hydropower Releases," Technical Report E-83-5, U.S. Army Corps of Engineers, Waterways Experiment Station, 1983.

Buck, C.L., D.E. Miller, and A.R. Sheppard, "Prediction of Oxygen Uptake Capabilities in Hydraulic Turbines Utilizing Draft Tube Aeration Systems," Research Paper, Alabama Power Company, Environmental and Research Services, 1980.

Carter J.C., Jr., "Recent Experience With Turbine Venting at TVA," Proceedings, Waterpower '95, ASCE, 199 .

Cybular, J.M., T.A. Brice, and T.T. Do, "Executive Summary of the Model Test Report for Norris Dam Aeration Vertical Francis Turrbine Units 1 and 2," Report No. 2677-0029, Voith Hydro, Inc. and Tennessee Valley Authority, 1992.

EPA, Ambient Water Quality for Dissolved Oxygen, U.S. Environmental Protection Agency, Office of Regulations and Standards, 440/5-86-003, 1986.

EPA, Quality Criteria for Water - 1986, U.S. Environmental Protection Agency, Office of Regulations and Standards, EPA 440/5-86-001,1986.

EPRI, Assessment and Guide for Meeting Dissolved Oxygen Water Quality Standards for Hydroelectric Plant Discharges, Electric Power Research Institute, Final Report, Research Project 2694-8, 1990.

Falvey, H.T., Air-Water Flow in Hydraulic Structures, Engineering Monograph No. 41, U. S. Department of Interior, Bureau of Reclamation: Denver, Colorado, 1980.

Greenplate, B.S., and J.M. Cybularz, "Hydro Turbine Aeration," Proceedings, Waterpower '93, ASCE, 1993.

Gulliver, J.S., J.R. Thene, and A.J. Rindels, "Indexing Gas Transfer in Self-Aerated Flows," Journal of Environmental Engineering, ASCE, Vol. 116, No. HY3, 1990.

Harshbarger, E.D., "Streamlined Hub Baffles for Aeration at Norris Dam," Report No. WR28-1-2-110, Tennessee Valley Authority, Engineering Laboratory, 1984.

Hinze, J.O., "Fundamentais of the Hydrodynamic Mechanism of Splitting in Dispersion Processes," Joumal of the American Institute of Chemical Engineers, pp 289-295, Sep. 1955. 
Hopping, P.N., P.A. March, T.A. Brice, and J.M. Cybularz, "Plans for Testing and Evaluating the New Auto-Venting Turbines at TVA's Norris Hydro Project," Proceedings, North American Water and Environment Congress, ASCE, 1996.

IEC, "Field Acceptance Tests to Determine the. Hydraulic Performance of Hydraulic Turbines, Storage Pumps, and Pump-Turbines, "International Electrotechnical Commission, IEC 41, 1991

Jun, K.S. and S.C. Jain., "Oxygen Transfer in Bubbly Turbulent Shear Flow," Journal of Hydraulic Engineering, ASCE, Vol. 119, No. HY1, 1993.

Levich, V.G., Physiochemical Hydrodynamics, Prentice-Hall: Englewood Cliffs, New Jersey, 1962.

Lueders, B.C., "Turbine Venting for Stream Reaeration," Presentation to paper company officials, Wisconsin Rapids, Wisconsin, 1956.

March, P.A., T.A. Brice, M.H. Mobley, and J.M. Cybularz, "Turbines for Solving the DO Dilemma," Hydro Review, Vol. 11, No. 1, 1992.

Miller, D.E., and A.R. Sheppard, "Current Status of Turbine Aeration Activities at Alabama Power Co.," Proceedings, Waterpower '83, ASCE, 1983.

Mobley, M.H. and T.A. Brice, "Experimental Difficulties Encountered in Testing AirMater Mixtures," ASCE National Conference on Hydraulic Engineering and International Forum on Ground Water, Nashville, TN, August 1991.

Mosonyi, E.L., Low-Head Power Plants, Akademiai Kiado, Budapest, 1987.

Schroeder, E.D., Water and Wastewater Treatment, Chapter 4, McGraw-Hill: New York, 1977.

Shiao, M., G.E. Hauser, B.L. Yeager, and T.A. McDonough, "Development and Testing of a Fish Bioenergetics Model for Tailwaters," Report No. WM-94002, Tennessee Valley Authority, Engineering Services and Water Management, 1993.

Tennekes, H., and J.L. Lumley, A First Course in Turbulence, MIT Press, Cambridge, Massachusetts, 1972.

Thompson, E.J. and J.S. Gulliver, "Oxygen Transfer Similitude for a Vented Hydroturbine," Journal of Hydraulic Engineering, ASCE, in press, 1997.

Ventikos, Y., F. Sotiropoulos, and V.C. Patel, "Modelling Complex Draft-Tube Flows Using Near-Wall Turbulence Closures," Proceedings, XVIII IAHR Symposium on Hydraulic Machinery and Cavitation, Kluwer Press, Netherlands, pp. 140-149, 1996.

Wagner, H., "Experiments with Artificial River Water Aeration," Voith Forschung and Konstrucktion, Heft 4, 1958.

Wiley, A.J., B.F. Lueck, R.H. Scott, and T.F. Wisniewski, "Commercial Scale Stream Aeration," Joumal of the Water Pollution Control Federation, Vol. 34, 1962.

Wilhelms, S.C., M.L. Schneider, and S.E. Howington, "Improvement of Hydropower Release Dissolved Oxygen with Turbine Venting," Technical Report E-87-3, U.S. Army Corps of Engineers, Waterways Experiment Station, 1987.

Wisniewski, T. F., "Improvement of the Quality of Reservoir Discharges Through Turbine or Tailrace Aeration," Proceedings of the Symposium on Streamflow Regulation for Quality Control, U.S. Public Health Service, Cincinnati, Ohio, 1965. 


\subsection{TASK 4 REPORT -- PRESENTATION OF DESIGN CONCEPTS}




\subsection{TASK 4 REPORT - PRESENTATION OF DESIGN CONCEPTS}

\subsection{INTRODUCTION}

Design practices of the past have not typically included specific fish friendly considerations, primarily as a consequence of economics. However this need not be the case, and when the need is present for design changes to provide for improved conditions for fish passage, alternative designs are possible. This section presents advanced design concepts that have potential for improving fish passage survival and environmental compatibility for axial flow and Francis type units based on discussions previously presented in Sections 4 and 5 . They include mechanical design concepts, operational concepts, lubrication schemes, electrical concepts and control concepts. A description of turbine types is located in appendix 10.2 .

While the thrust of this work has been to address the existing $92000 \mathrm{MW}$ of installed turbine capacity, many of these advanced design concepts are as applicable to new units as they are for the rehabilitation of existing units. The differences between rehabilitation and new unit design considerations will be discussed in each section as applicable. More detailed analyses are required to determine the merit and cost tradeoffs of each concept. The fish friendly concepts deal primarily with direct injury to fish as they pass through the unit or with water quality. Only in a secondary manner do they address the potential problem of disorientation and associated predation. Due to the fact that the ratio between fish size and turbine size is significant for fish passage survival, there is some turbine size below which the best solution for fish passage survival may be to keep fish out of the unit.

Due to the fact that every project site has its own unique features, each site has a customized-turbine design. Because of this, this deliverable is provided as a series of generalized design concept elements which will need to be assembled and customized to each specific turbine site. Based on the studies of Task 1 and the recommendations of the project review board, the three design concepts chosen for presentation are:

- An advanced environmentally friendly Kaplan turbine featuring a high efficiency level, cavitation free operation and the possibility for reduced backroll; a gapless design for wicket gates and for the hub and discharge ring with the blades; a hub filled with an environmentally compatible fluid; greaseless bushings for the wicket gates; an upgraded smooth surface for stay vanes, wicket gates and draft tube cone; an adjustable speed generator; and an advanced control system for speed adjustment, cam optimization and optimized energy generation with considerations for improved fish passage survival.

- An advanced environmentally friendly Francis turbine featuring a high efficiency level, cavitation free operation to powers beyond previous generations of turbines and the possibility for reduced backroll; a reduced number of blades; appropriate clearance between wicket gates and the runner blade entrance edge; greaseless wicket gate bushings; a gapless design for the wicket gates; an upgraded smooth surface for stay vanes, wicket gates and draft tube cone; an adjustable speed generator; and an advanced control system for speed adjustment and optimized energy generation with considerations for improved fish passage survival.

- An advanced environmentally friendly aerating Francis turbine with the above features and with design features for increasing the quantities of dissolved oxygen in the water discharging from the turbine. This Section will appear in a supplement to this report to be issued at a later date. 


\subsection{ENVIRONMENTALLY ADVANCED KAPLAN DESIGN FOR IMPROVED FISH SURVIVABILITY}

\subsubsection{PRIMARY ISSUES}

\subsubsection{Runner Gaps}

A Kaplan runner has three to seven adjustable tilt blades attached to a central hub. The blade and hub assembly (runner) rotates inside a stationary discharge ring. Adjustable blade tilt allows the machine to maintain a relatively high efficiency over a wide range of operation. The ratio of hub diameter to runner diameter is a compromise of hydraulic and mechanical concerns. Hydraulically it is preferable for this ratio to be small. This creates lower velocities through the runner and improves overall performance. Mechanically it is preferable for this ratio to be large in order to accommodate the blade tilt adjusting mechanism.

The conventional hub and discharge ring are combinations of spherical, cylindrical and conical sections in the areas where they are in close proximity to the blades. This combination of surfaces is a compromise between hydraulic, mechanical and economic concerns. The advantages of cylindrical and conical sections on the hub relate to lower cost of manufacture and more space in which to house the blade tilt operating mechanism. Conventional Kaplans use cylindrical sections on the upper half of the discharge ring for lower costs and ease of assembly and disassembly in the field. In the gapless design, the hub and discharge ring geometry is spherical in the region swept by the blades requiring a more complex blade actuation mechanism and a removable upper portion of the discharge ring. Figure 6.2.1-1 shows a Kaplan blade at minimum and maximum tilts. Figure 6.2.1-2 shows the conventional design gaps created by cylindrical and conical sections on the hub and periphery. See Section 4.3.2.2 for descriptions of clearances and gaps.

Certain features discussed in this material relating to gapless Kaplan turbine designs are based on technology developed by Voith outside the scope of this DOE program and are the subject of one or more patent applications.

\section{Rehabilitation Design}

Figure 6.2.1-3 shows a gapless Kaplan runner design with spherical surfaces on the hub, blade, and discharge ring wherever the surfaces are in close proximity to each other. The gapless design will result in increased efficiency, improved cavitation, minimized leakage vortices and eliminated mechanical gaps through which fish could pass. Associated with the reduced mortality mechanisms and improved performance will be an increase in manufacturing cost and a more complicated assembly and disassembly of the unit in the field. Aspects of these design features have already been incorporated into the upgraded designs for Rocky Reach, Bonneville and Wanapum projects.

\section{New Unit Design}

A new unit design incorporates the same contours as the rehabilitation design. Spherical discharge ring shapes will be easier to achieve in a design of a new unit.

\subsubsection{Wicket Gate Overhang}

In a conventional design, the diameter of the wicket gate shaft location is often minimized in order to reduce the overall size and cost of the machine. Reducing the gate pin circle reduces the size of the gate operating mechanism, stay ring, head cover, bottom ring, spiral case, and possibly the power house. The runner diameter is maximized to improve hydraulic performance. The combination of minimum gate pin 
circle and maximum runner diameter can lead to wicket gates which overhang the bottom ring at higher gate openings. The resulting leakage flow through the overhung gap disrupts smooth flow and induces strong vortices and additional energy losses, i.e. avoidable losses.

\section{Rehabilitation Design}

The overhang can be reduced or eliminated by changing the shape of the discharge ring as shown in Figure 6.2.1-4 and/or moving the trailing edge of the wicket gate to a larger diameter. Reducing this overhang will increase efficiency and reduce avoidable losses.

\section{New Unit Design}

A new unit design will incorporate the same contours as the rehabilitation design. Spherical discharge ring shapes will be easier to achieve in the design of a new unit.

\subsubsection{Optimized Hydraulic Design}

An optimized hydraulic Kaplan design contains the design elements mentioned above: no gaps between the blades and the hub or periphery, and no wicket gate overhang. The design of rehabilitated, upgraded or new turbine components is optimized by cutting edge flow analysis (CFD) tools at all operating conditions to maximize efficiency, avoid cavitation and provide for maximum flow smoothness and minimized fluid mechanisms for mctality. Through use of the CFD tools, even backroll associaied with draft tube exit velocity distributions can be addressed. New unit designs can benefit to a greater extent from the cutting edge technology as there is more flexibility in developing advanced geometrical shapes for the turbine components. Design changes for upgrade or rehabilitation are limited by, existing structures, the difficulty in alterations to concrete structures, and in many cases by component strength issues.

The use of cutting edge technologies has provided improved efficiency and cavitation performance for recent and "in progress" upgrades at Rocky Reach, Bonneville, Dardanelle, and Wanapum.

\subsubsection{Lubrication}

In a conventional Kaplan design the blade operating linkage mechanism inside the hub is submerged in lubrication oil. The oil can be either normal oil or one of the newer special biodegradable oils. Seals are designed to prevent oil leakage from the hub to the water and to prevent water leakage into the hub. Despite the seals, there is the potential for oil leaking into the water. The vast majority of existing units also use grease lubricated wicket gate bushings which have the potential of grease leaking into the water.

Certain concepts developed in connection with the use of an environmentally friendly medium to fill the hub were developed by Voith outside the scope or this DOE program and are the subject of a patent application.

\section{Rehabilitation Design}

Environmentally friendly designs will use an environmentally friendly medium inside the hub. The medium could be an biodegradable oil or, for example, water. The use of water would require the use of corrosion resistant materials and coatings that may be difficult to apply in an existing hub and use oil free bushings in place of the normal oil lubricated bushings for the blade adjustment mechanism. For the wicket gate mechanisms, the use of greaseless self-lubricated wicket gate bushings is foreseen. There are a variety of these bushings on the market today where the lubricant is an integral part of the bushing. 


\section{New Unit Design}

The design concept will be the same as for a rehabilitation design but implementation will be simpler.

\subsubsection{Surface Roughness}

Roughness refers to turbine component surfaces. For older turbines, surface smoothness may have deteriorated over a period of time. Rough surfaces and surface roughness hot spots associated with cavitation damage or rough structural welds in the water passage (there may be weld joints in an aswelded condition in spiral cases, draft tubes, and some stay rings) can cause damage to the fish as it scrapes along or is carried against a surface as a result of the turbulent flow field within the turbine. As more biological data becomes available, it may be possible to evaluate fish injury for different values of roughness. The water velocity in some of these parts is relatively low. Therefore, the cost to "smooth" these surfaces and maintain them may not be justified from a performance standpoint.

\section{Rehabilitation Design}

Providing for a surface upgrade for the stay vane, wicket gate, and upper draft tube cone, as a minimum, may decrease descaling associated with scraping. Figure 6.2.1-5 shows a reduction in weld roughness. The surface upgrade can be accomplished by a combination of surface restoration, smoothing and use of special friction reducing coatings. Even compliant coatings may provide value on components where fish may impact the surface with high energy. Some older designs used rivets to join steel plates in some of the larger water passages such as in the spiral case and draft tube. For structural reasons these rivets can not be reduced in size.

\section{New Unit Design}

Selection of initial base material will have an effect on the ease with which surface smoothness can be maintained.

\subsubsection{Fixed vs Adjustable Rotational Speed (RPM)}

In a conventional design all operation is at a fixed rpm because generators have a fixed number of poles and must output a fixed frequency. Running at a fixed rpm restricts the machine to being at peak efficiency at only one combination of head and discharge. As head or discharge change, the point of operation moves away from the peak as shown in Figure 6.2.1-6 The plant operator has control of the discharge by controlling the gate opening. The plant operator has no direct control over the head. As head changes, the unit must move away from the point of optimum performance. This will cause a drop in efficiency and move the operating point closer to cavitation and/or pressure pulsation operation limits. Moving to different locations on the operating hill curve will also have an effect on fish friendliness as discussed in Section 4. The disadvantages of fixed rpm increase as the head range increases.

\section{Rehabilitation Design}

Installation of electrical conversion equipment enables the turbine to operate with adjustable speeds. To take full advantage of this equipment, a new runner design should be part of this upgrade. Adjustable rpm compensates for head variations. The combination of adjustable rpm and the conventional adjustable gate opening allows the machine to stay near the optimum operating point as shown in Figure 6.2.1-7. The definition of optimum is derived by considering:

- $\quad$ Strike probability

- $\quad$ Size of shear zones 


$\begin{array}{ll}\text { - } & \text { Efficiency } \\ \text { - } & \text { Cavitation } \\ \text { Pressure pulsations }\end{array}$

There is an inefficiency associated with the electrical conversion equipment. This will reduce the overall plant efficiency but has no impact on the hydraulic efficiency of the turbine. This conversion equipment is becoming more efficient and less expensive as research develops more cost effective solutions and a higher sales volume leads to lower costs. The conversion equipment is relatively large and must be housed indoors.

\section{New Unit Design}

The advantages of adjustable speed for a new unit is the same as for a rehabilitated unit. In addition, several of the hydraulic components would be designed to take full advantage of adjustable speed.

\subsubsection{Advanced Control System}

Utilizing advanced sensors and digital technology, an advanced control system can provide significant advantages in turbine operation to improve fish survival. Șeveral features are discusses below.

- Adjustable speed control in conjunction with an adjustable speed generator can adjust the operation of the turbine to provide the maximum fish survival at the discharge of operation independent of the head at the power plant. At all heads of operation, the turbine characteristics can be those of the most fish friendly point of operation at the required discharge.

- It is a fact that most Kaplan turbines are not operated at the optimum cam position because of the difficulty in determining the optimum position and because of the dependence of the optimum position of a wide number of variables. Automated cam optimization can be incorporated into the turbine governor to assure that the turbine blade and wicket gates are in the positions to provide $\cdot e$ maximum efficiency at a given head and discharge point of operation. Operation at the on cam blade and gate positions minimizes fluid injury mechanisms associated with off cam operation within the turbine. Certain features discussed in this material relating to Kaplan cam optimization are based on technology developed by Voith outside the scope of this DOE program and are the subject of pending patent applications.

- Kaplan turbines often operate with significant trash on the trash racks. This results in disturbed flow entering the intake and can move fish from the upper intake to the lower intake exposing them to greater injury associated with blade tip strike. Use of an automated system to announce that trash racks need cleaning can minimize this problem. Certain features discussed in this material relating to trash rack cleaning are based on technology developed outside the scope of this DOE program and are the subject of one or more patent applications.

- For multiunit plants, the units are often not operated based on optimized plant efficiency for the given output, but rather based on other criteria. An automated multiunit optimization system can aid the operator in determining how to operate the plant to optimize the plant efficiency for the required output. While this will provide better conditions for fish passage, it is still not the best that can be done. When fish are present in the unit, a system to operate the unit at optimum plant fish passage survival discharge would provide conditions within the turbine having lower mechanical and fluid mechanisms for injury. Such advanced sensing and control system is based on technology developed by Voith outside the scope of this DOE program and is the subject of pending patent applications. 

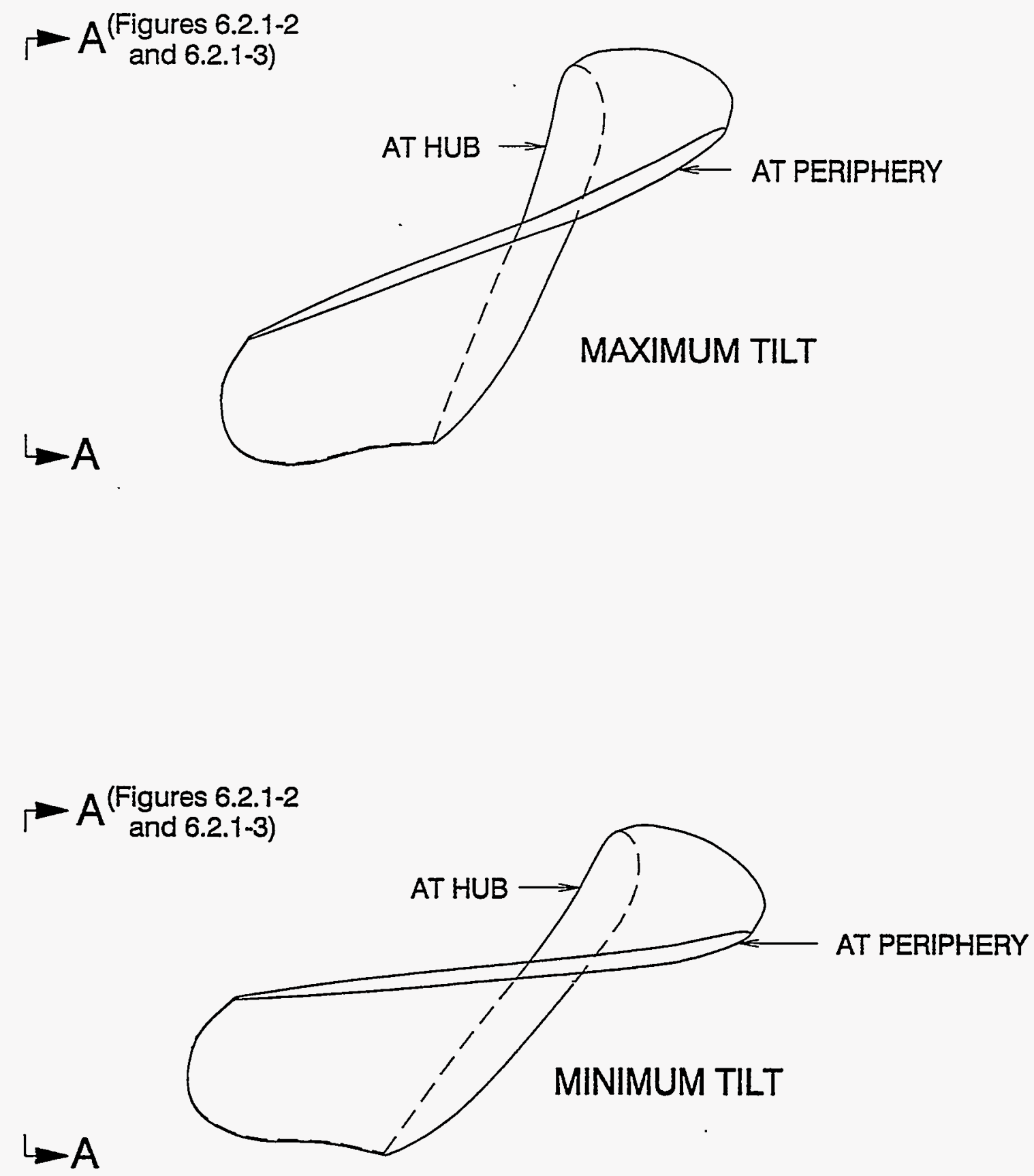

END VIEW OF BLADE WITHOUT HUB

Figure 6.2.1-1 Explanation of Blade Tilt 

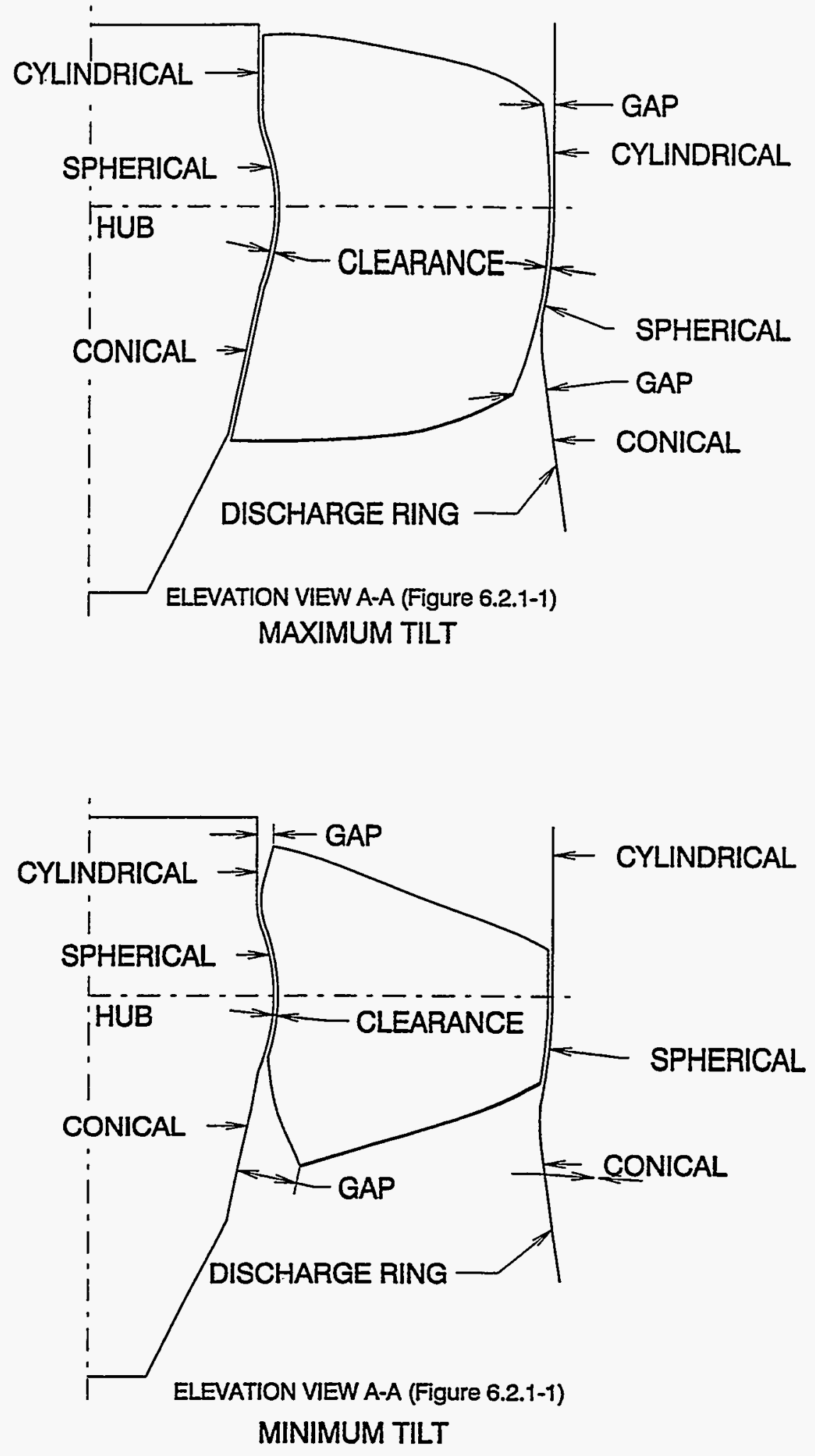

Figure 6.2.1-2 Typical Runner with Combination of Cylindrical,

Spherical, and Conical Hub and Discharge Ring Profiles 

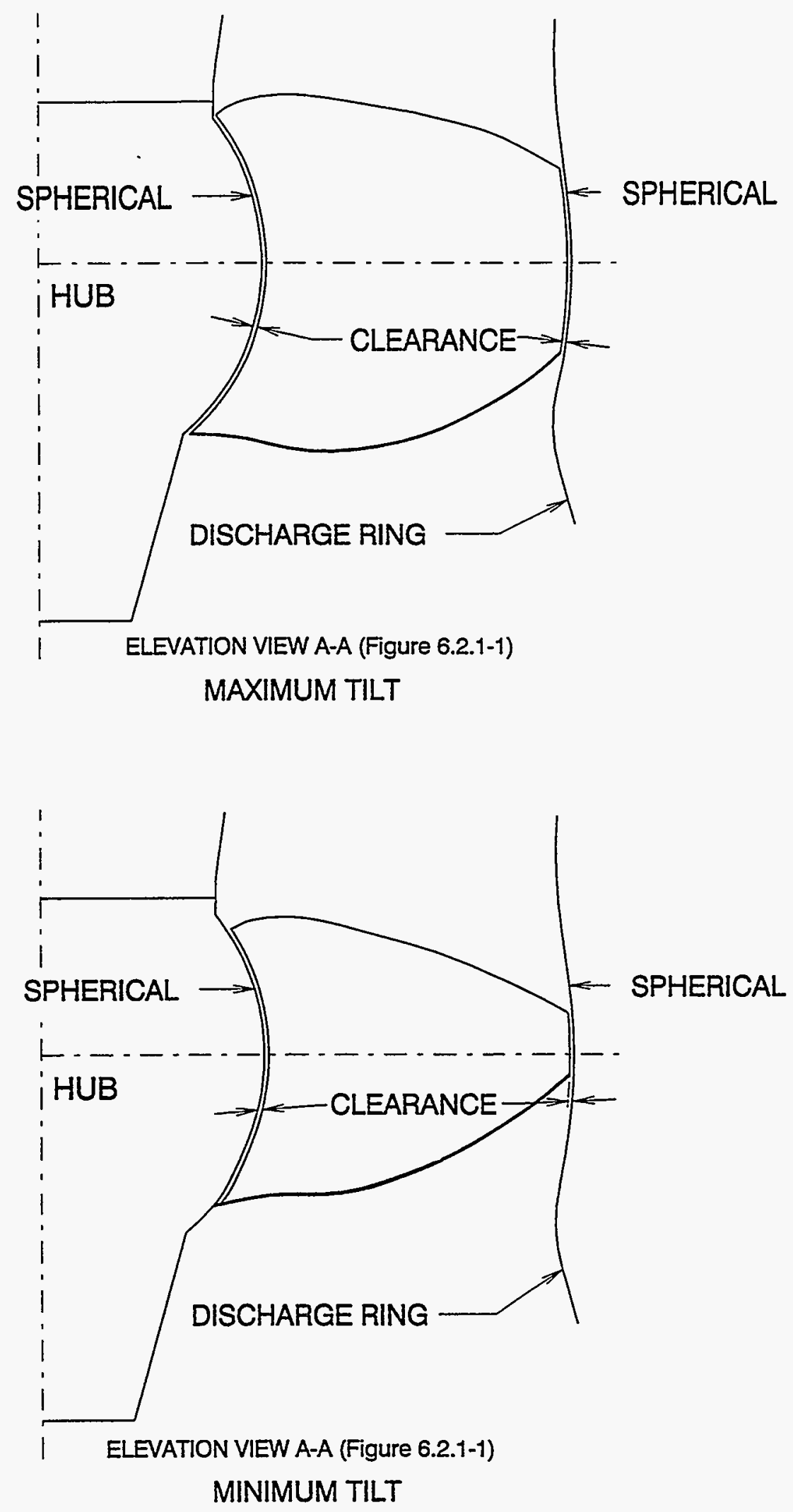

Figure 6.2.1-3 Typical Runner with Spherical Hub and Discharge Ring Profiles 


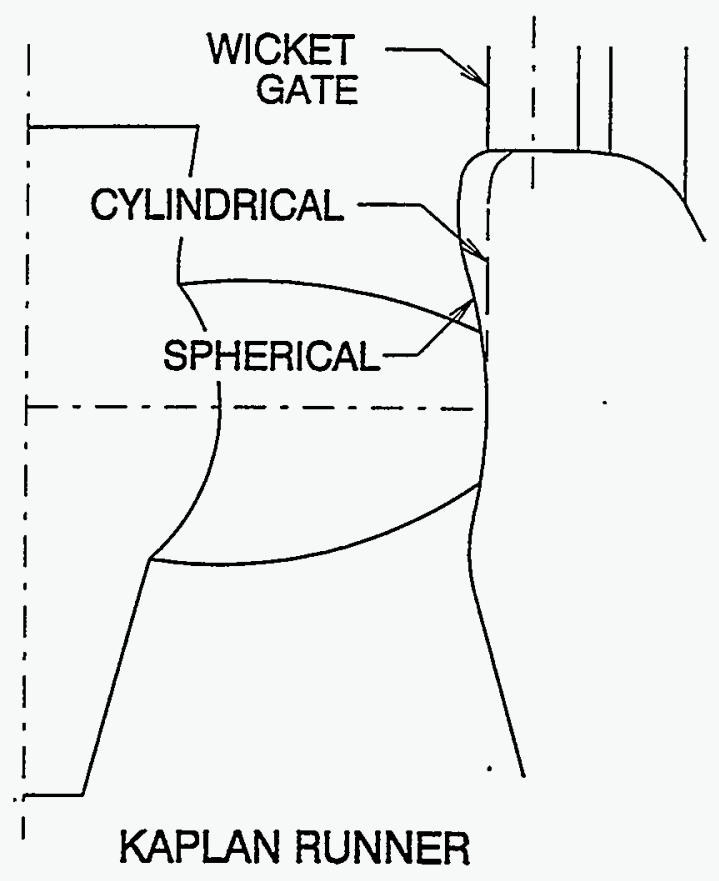

Figure 6.2.1-4 Elimination of Wicket Gate Overhang

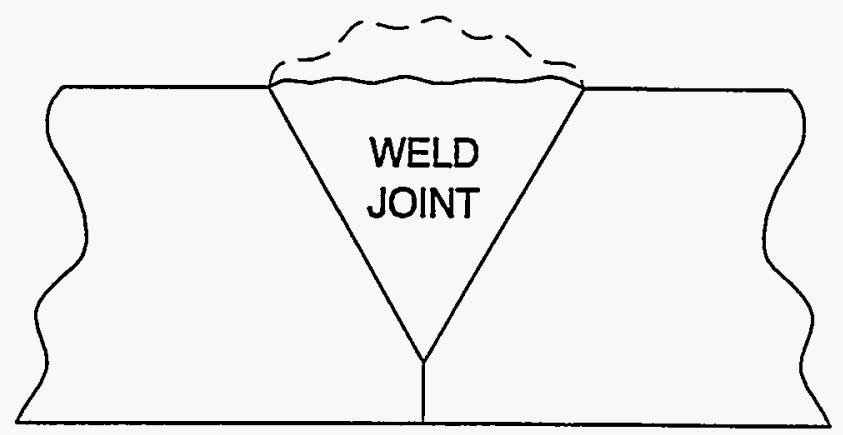

- - - - CONVENTIONAL DESIGN

FISH FRIENDLY DESIGN

Figure 6.2.1-5 Reduction of Weld Joint Roughness 


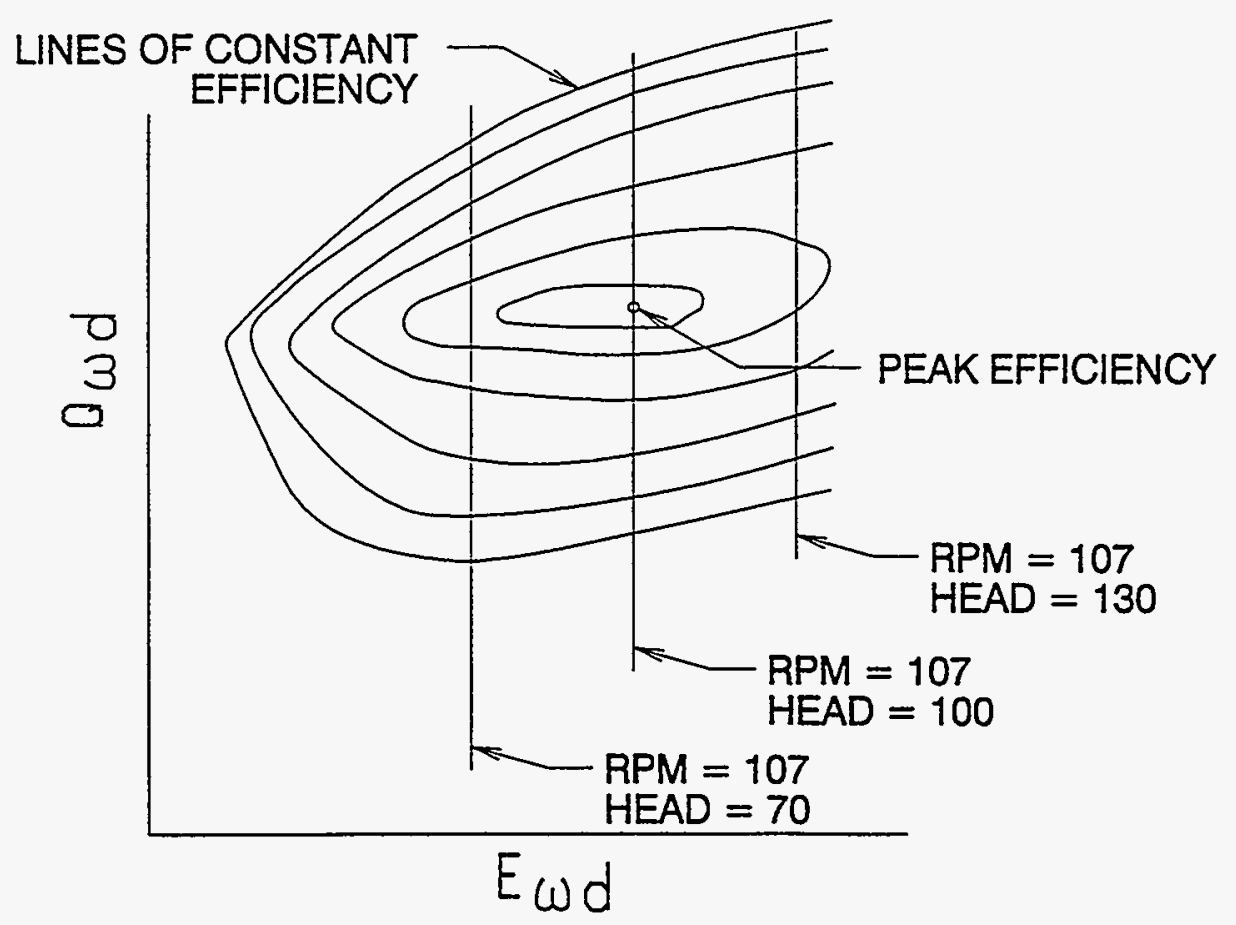

Figure 6.2.1-6 Operation Range with Constant RPM

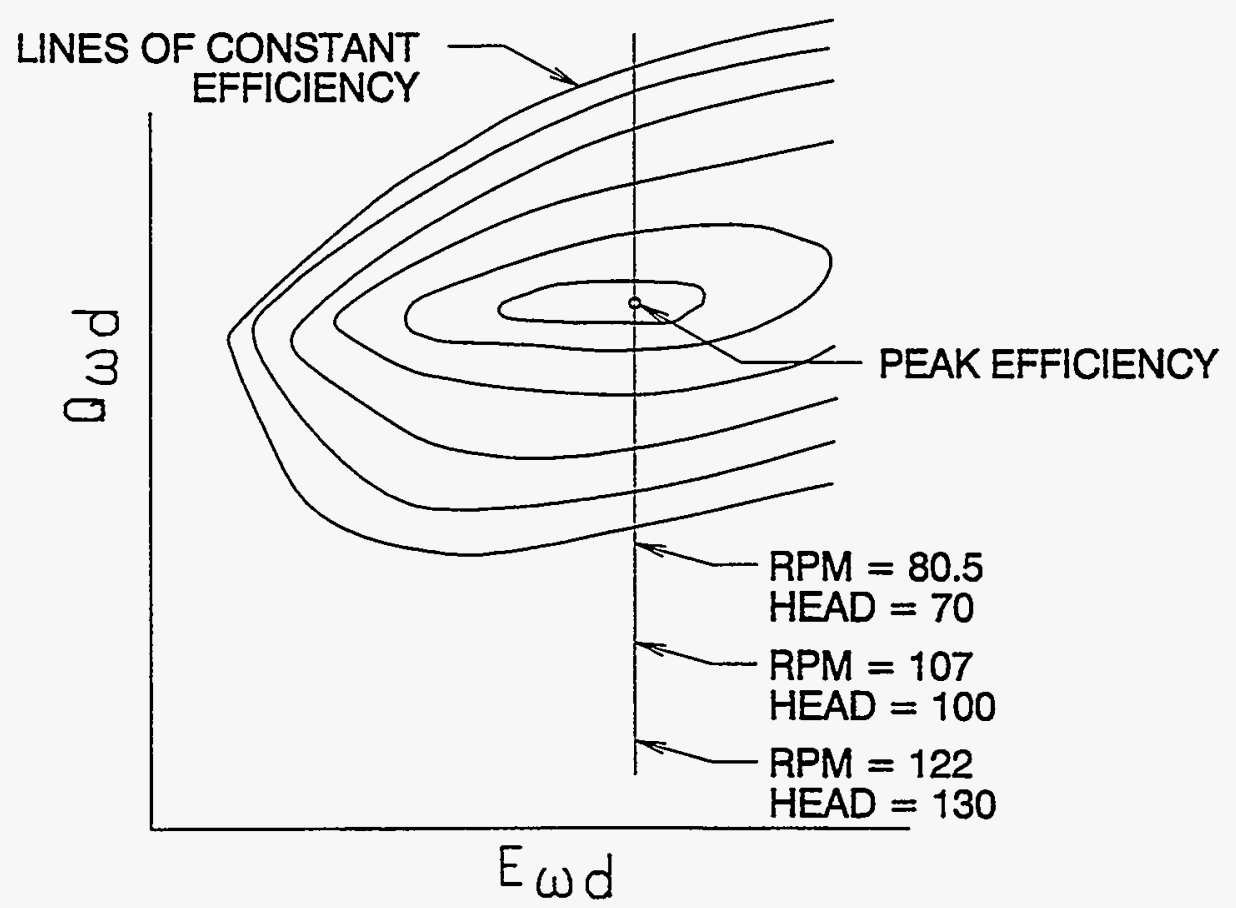

Figure 6.2.1-7 Operation Range with Adjustable RPM 


\subsubsection{SECONDARYISSUES}

\subsubsection{Interaction Of Wicket Gates and Stay Vanes}

Wicket gate overhang covered in Section 6.2.1.2 is one factor discussed in this section. The other factors are the number of wicket gates and the relative position of wicket gates to stay vanes. Each of these factors may have an interaction with one or more of the others.

In a conventional design the number of wicket gates and stay vanes typically varies from 16 to 32 . Some existing designs use one stay vane for each two wicket gates. The wicket gates serve two purposes: 1) They shut off the flow when the unit is idle, and 2) They control the flow to the unit to achieve different levels of output. The shape of the wicket gate has a significant influence on efficiency. The stay vane is a very important structural member linking the top and bottom portions of the unit. The shape of the stay vane also has a significant influence on efficiency. The relative position of the stay vanes and wicket gates was often determined principally by mechanical considerations. Fluid analysis tools of the past were non existent or inadequate to address the effect of design shapes and relative position of the gates and stay vanes on efficiency. In some of the these designs the wicket gates and stay vanes were not aligned to minimize the potential for mechanical strike such as the wicket gate being located in the "shadow" of a stay vane as shown in Figure 6.2.2-1. CFD tools can help optimize the fluid induced disturbances and minimize mechanical strike for a selected range of gate openings.

\section{Rehabilitation Design}

Wicket Gate Overhang: As mentioned in section 6.2.1.2. Reducing this overhang will increase efficiency and reduce fluid and mechanical mechanisms for fish injury. The overhang can be reduced or eliminated by changing the shape of the discharge ring as shown in Figure 6.2.1-4 and/or moving the trailing edge of the wicket gate to a larger diameter. The trailing edge of the wicket gate can be moved to a larger diameter by moving the gate pin circle to a larger diameter and/or by shortening the wicket gate. Since the gates have to touch each other in the closed position, a shorter gate may require a larger number of gates. The above mentioned modification to the discharge ring will complicate the removal of the runner. An additional, less important, advantage of a larger gate pin circle is the lower velocities through the stay vanes and wicket gates which result from having these parts at a larger diameter and therefore at a larger flow through area.

Relative Position of Wicket Gates and Stay Vanes: Rotating the wicket gate pin circle can allow a wicket gate (at least at one gate opening) to be the "shadow" of a stay vane, thus reducing strike probability (Figure 6.2.2-1). The rotation must be evaluated by CFD methods to determine the effectiveness. Making this modification on an existing unit will require changes to the gate operating and servomotor system. Since this could be accomplished by rebolting components, the shift may be limited to the existing bolt spacing in the head cover and bottom ring.

Number of Wicket Gates: In general, lowering the number of wicket gates will decrease strike probability if it could be done without producing a gate overhang gap. However, it must be recognized that, for a rehabilitation, a larger number of wicket gates may allow a better alignment of wicket gates behind existing stay vanes and may be needed to eliminate gate overhang gaps. When more of the wicket gates are in the "shadow" of a stay vane the strike probability can be lower. For new units the number of wicket gates should equal one or two times the number of stay vanes with proper relative position. If the number of wicket gates and stay vanes are equal and uniformly spaced, each gate can be in the shadow of a stay vane. If the number of stay vanes can be one half the number of wicket gates, (for lower head units) every other gate can be in the shadow of a stay vane. 
Achieving these changes in an existing plant will require careful review of the mechanical and civil structure.

\section{New Unit Design}

Accommodating the above mentioned geometries will be more easily done in a new unit design since civil, mechanical and hydraulic requirements can be coordinated at the initial design stage. Unconventional design shapes may be investigated using cutting edge CFD tools to minimize strike.

\subsubsection{Rotational Speed (RPM)}

The selection of rotational speed deals primarily with new units. The ongoing trend in the industry is to use higher fixed rpm units for a given site condition and output requirement. The size and cost of the turbine and generator decrease as the rpm increase. Since the smaller unit must produce the same output, the discharge must be the same as it would be for a larger unit. Therefore, the smaller unit would have higher water velocities. For the smaller unit with the same sized fish, the probability of strike will be higher. The energy concentrated in the fluid injury mechanisms will be higher. Therefore the trend to higher speeds for a given head turbine is going in the wrong direction for improved survivability.

\section{New Unit Design}

Use of a lower rpm machine for the design conditions will reduce the water velocities and increase the size of the water passages for a given site condition and output requirement. The lower rpm machine will have more margin against cavitation for a given submergence. If there is sufficient margin against cavitation, the lower rpm machine can be installed at a higher elevation. This will decrease installation costs. Larger units will, of course, have higher hardware costs and may require a larger power house.

\subsubsection{Draft Tube Piers}

The number and size of draft tube piers are determined by the civil design of the power house. Typical designs have from 0 to 2 vertical piers. A few designs also have horizontal piers. The velocities at the inlet to the pier are relatively low but the flow pattern can be complex at off-design conditions - especially for fixed blade axial flow machines.

\section{Rehabilitation Design}

For structural reasons elimination of piers in an existing powerhouse would not be practical. The shape of the pier nose should be reviewed using cutting edge CFD analysis tools for possible improvements.

\section{New Unit Design}

Eliminating the pier(s) removes a strike source. This would have to be incorporated into the initial powerhouse design and may be impractical for larger draft tubes. Changing the draft tube cross-sectional area will influence the structural requirements. Increasing the height while decreasing the width may allow a pier(s) to be eliminated. See Figure 6.2.2-2 for examples. If the pier(s) cannot be removed, the shape of the pier nose should be reviewed for possible improvements.

\subsubsection{Runner Cones}

In a conventional design axial flow hubs are typically extended beyond the outlet edge of the blades with a conical extension (Figure 10.2-7). 


\section{Rehabilitation Design}

Further investigation is required to determine if the shape and length of these extensions influence the flow patterns in a manner that affects fish friendliness.

New Unit Design

Same as rehabilitation design.

\subsubsection{Inlet Valves}

Higher head axial flow machines sometimes have a penstock and inlet pipe instead of the more conventional rectangular inlet section. For these units there is a valve near the inlet to the spiral case. These valves have a disk that remains in the water passage when it is in its full-open position. This obstruction in the water passage causes some loss of efficiency and creates some strike probability.

\section{Rehabilitation Design}

Option 1: Use a spherical valve that will have no obstruction in the water passage. This is an expensive solution, but it is the best valve for fish friendliness and efficiency. A spherical valve housing is relatively large. Retrofitting will require a detailed review of the plant layout.

Option 2: Install trunnion fairings and blend any sharp comers that have an obstruction in the water passage. This is a relatively inexpensive solution. These modifications will reduce the head loss and increase the efficiency of the valve.

\section{New Unit Design}

Use of a spherical valve or a ring gate will eliminate the obstruction from the water passageway.

\subsubsection{Sharp Corners}

In a conventional design some of the corners at inlet edges are manufactured with sharp corners. The cost to round these corners is not justified from a performance standpoint.

\section{Rehabilitation Design}

Rounding of these corners may decrease injury when strike does occur. See Figure 6.2.2-3

New Unit Design

Same as rehabilitation design.

\subsubsection{Gate Slots}

Sliding gates are used as closure devices in the draft tube and/or inlet sections of turbines. They ride in slots that are located on the perimeter of the sections. When the units are operating, these gates are always fully opened which exposes the gate slots to the flow. These slots typically have relatively sharp corners and can cause vortices.

\section{Rehabilitation Design}

Filling these slots with a removable filler strip will minimize the possibility of a strike. The time needed to install and remove these fillers must be weighed against the frequency of use. See Figure 6.2.2-4. 
Development Of Environmentally Advanced Hydropower Turbine System Design Concepts

Section 6.0

\section{New Unit Design}

In addition to slot filling, rounding the corners of these slots could decrease the probability of injury if a strike occurs. 


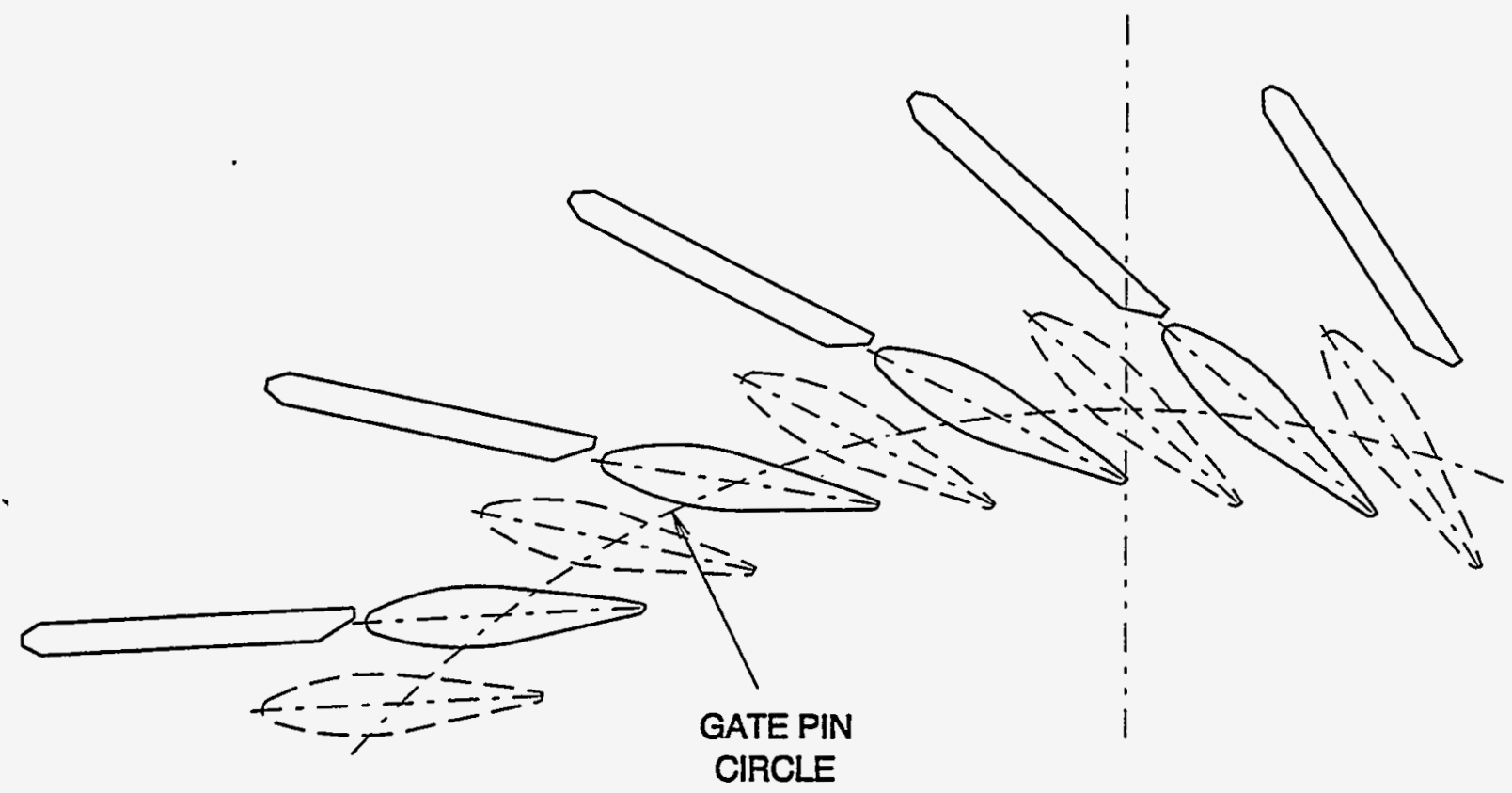

\section{$-\cdots--$ CONVENTIONAL DESIGN \\ FISH FRIENDLY DESIGN}

Figure 6.2.2-1 Wicket Gate / Stay Vane Relative Position 

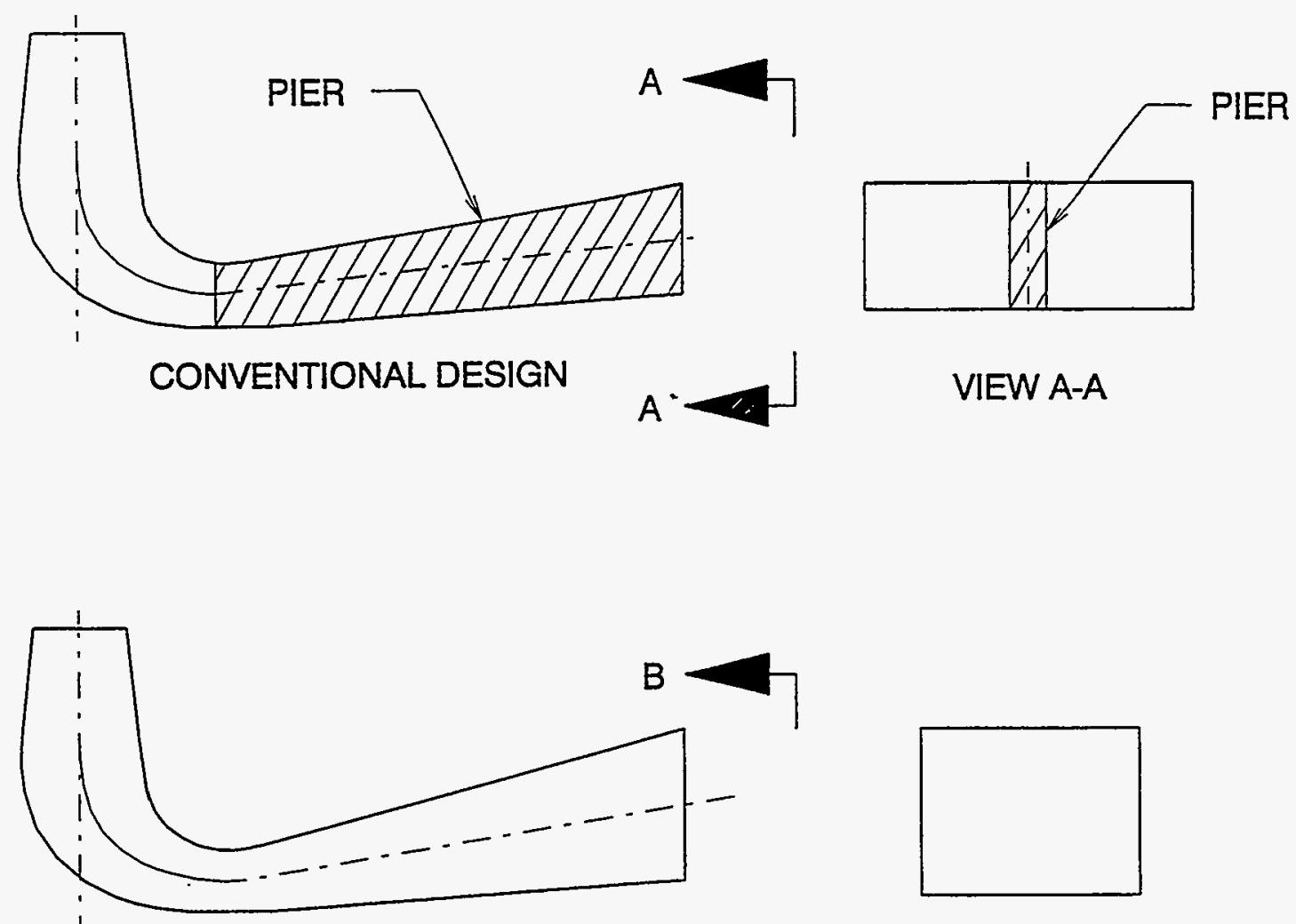

FISH FRIENDLY DESIGN
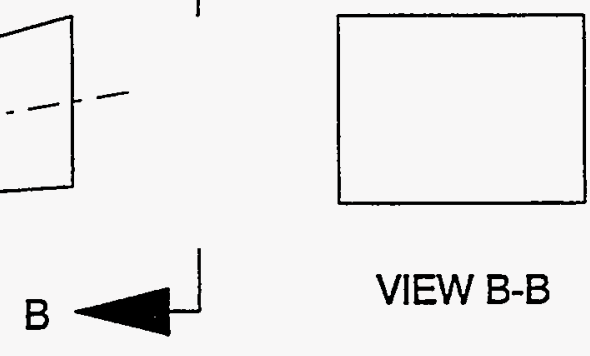

VIEW B-B
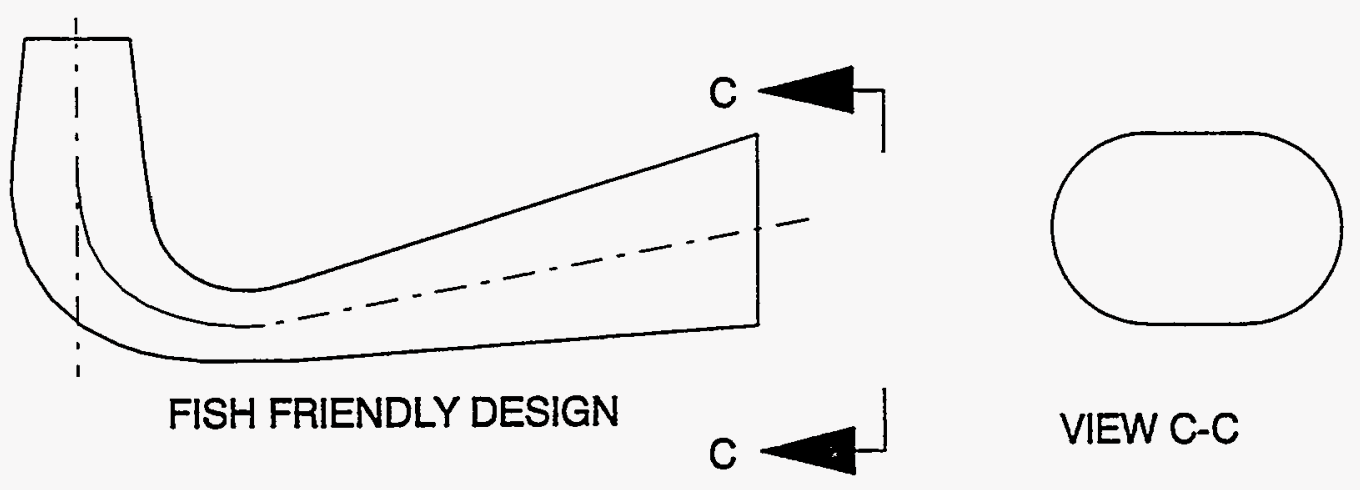

NOTE: OUTLET AREA IS SAME ON ALL VIEWS

Figure 6.2.2-2 Elimination of Draft Tube Piers 


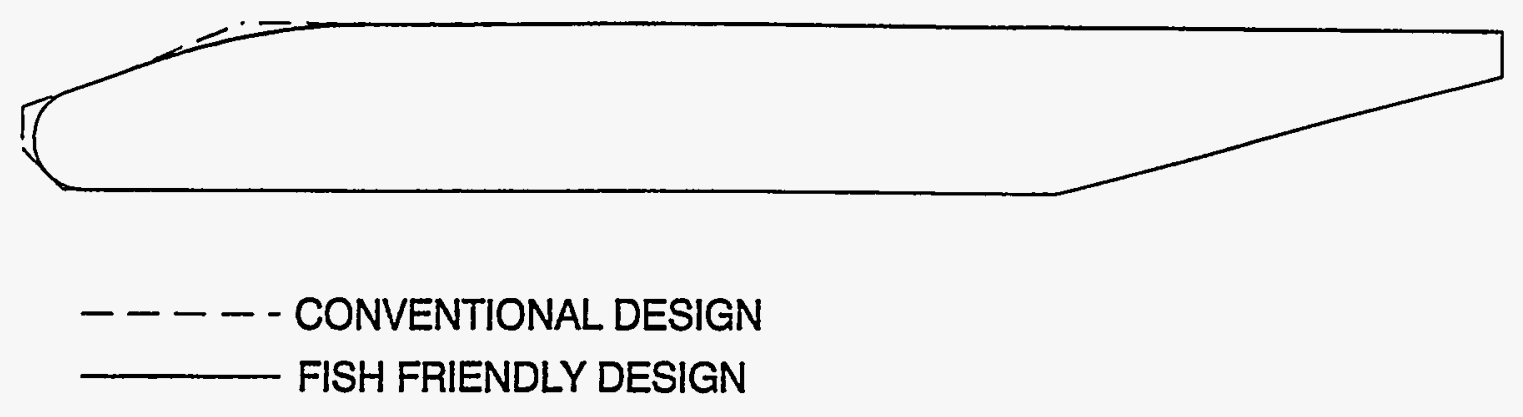

Figure 6.2.2-3 Elimination of Sharp Corners

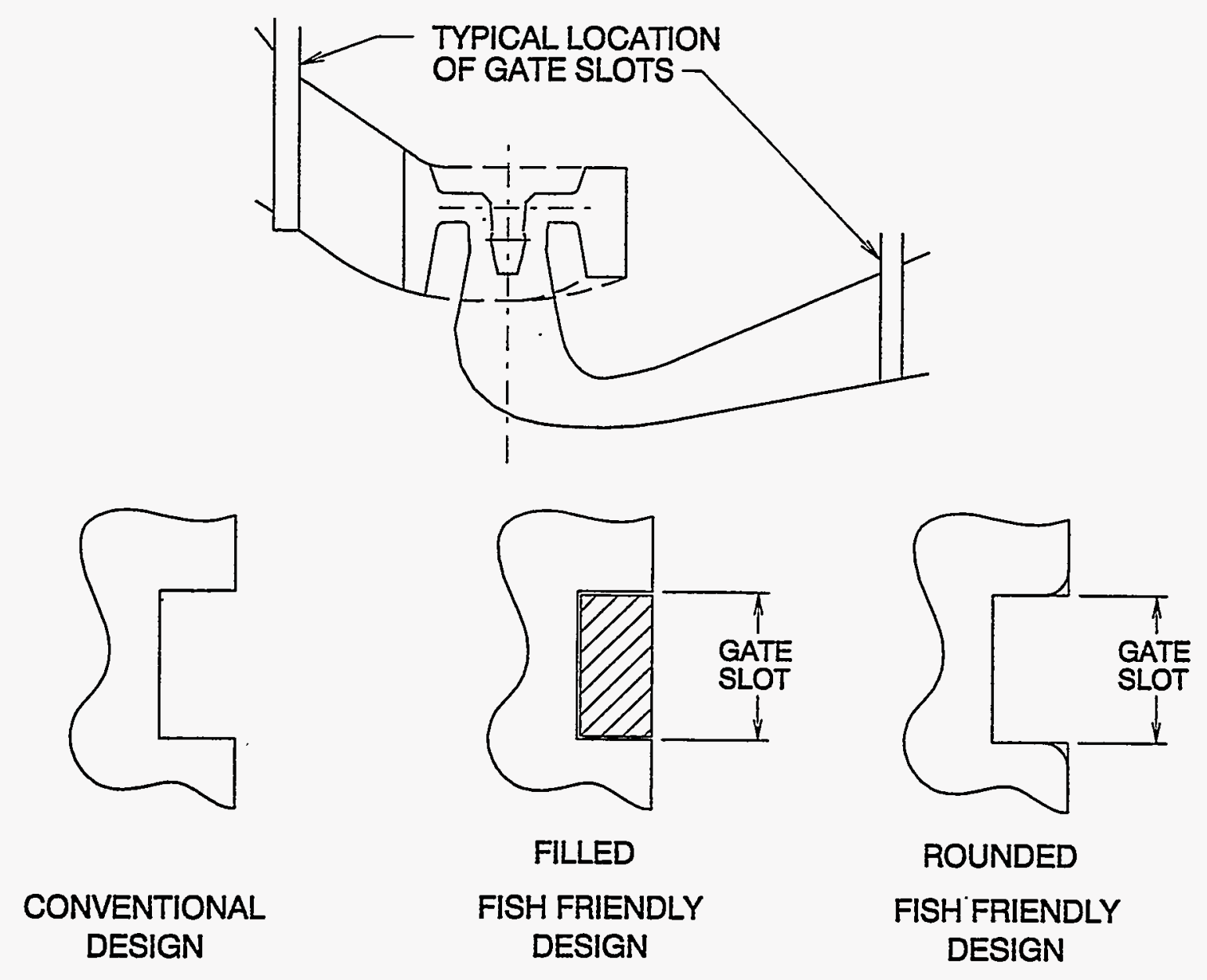

Figure 6.2.2-4 Treatment of Gate Slots 


\subsection{ENVIRONMENTALLY ADVANCED FRANCIS DESIGN FOR IMPROVED FISH SURVIVABILITY}

\subsubsection{PRIMARY ISSUES}

\subsubsection{Number of Runner Blades}

A Francis runner has multiple fixed position blades attached to a central hub (crown) and an outer shroud (band). The runner rotates inside a stationary headcover and bottom ring. The shape of the runner for a low head site is much different from one for a high head site. See Figures 10.2-9 and 10.2-10. Traditional designs have runners with the number of blades varying from 13 to 30 .

\section{Rehabilitation Design}

In comparison to a conventional design, a more fish friendly Francis runner design would have a lower number of blades which would decrease probability of strike and increase the space between adjacent blades minimizing the probability for abrasion. Lowering the number of blades while maintaining the same design power rating will usually result in longer (from top to bottom) blades in order to maintain capacity and minimize cavitation. See Figure 6.3.1-1. To implement a lower number of blades design for a turbine rehabilitation or upgrade will require some mechanical and civil changes to the bottom ring and draft tube cone. Advanced CDF flow analysis tools and FEM structural analysis tools are suitable for comparing alternative designs. Section 4.3.5 discusses the results of a series of design studies to evaluate the tradeoffs in lowering the number of blades for a typical Francis turbine project where an upgrade has take place. As can be seen from that section, the effect of the number of blades on strike probability is especially significant for smaller runners

\section{New Unit Design}

An environmentally enhanced runner design for new turbines would have similar characteristics as that for the rehabilitation design but the implementation may be less complicated because the longer blades could be more easily accommodated by the initial design of the mechanical and civil structure. Because of the effect of the rotational speed selection on the runner size and corresponding strike probability, a different set of geometries for the runner may result. See Section 6.3.2.1.

\subsubsection{Inlet Edge Thickness}

The effect of the inlet edge thickness on injury mechanism is two fold. The first is on the fluid injury mecnanisms discussed in Section 4.3.3. The angle of the water with respect to the runner blade varies with the operating head and discharge. When the unit must operate over a wide range of heads there will be a wide variation of water inflow angle of attack to the blade. This range of inflow angles creates an unfavorable flow field with large shear zones at the blade entrance edge and can give rise to large efficiency losses at operating points at the extremes of the operating head range. If there is too much mismatch between the water angle and the blade angle (too high an attack angle) cavitation can originate at the inlet edge. For many Francis sites the head range is relatively small with (Hmax-Hmin)/Hoptimum < 0.1 . Runners at these sites are acceptable with standard inlet edge thickness. For the sites that have large head ranges, (Hmax-Hmin)/Hoptimum $>0.4$, a thicker inlet edge is clearly beneficial in minimizing the fluid injury mechanisms at heads of operation near the extremes of the head range. The second effect relates to mechanical mechanisms of injury. While not validated with CFD tools it is believed that a thicker entrance edge than that normally required for classical design reasons will help carry small fish around the entrance edge, thus minimizing the probability of strike. 


\section{Rehabilitation Design}

In developing a design for rehabilitation of upgrade of an existing runner, using a thicker blade entrance edge than that required by conventional design reasons will result in a runner design having somewhat flatter efficiency characteristics as a function of head. The improved efficiency and reduced susceptibility for entrance edge cavitation at heads at the extremes of the head range will result in less intense fluid related injury mechanisms. As a result of the thicker edge, the enhanced tendency of the flow to carry fish around the entrance edge rather than against it will lower the probability of strike. Runner costs will increase as a result of using a thicker blade design.

\section{New Unit Design \\ Same as rehabilitation design.}

\subsubsection{Interaction Of Runner Blades, Wicket Gates, And Stay Vanes}

In a conventional design the gate pin circle is minimized in order to reduce the overall size of the machine. Reducing the gate pin circle reduces the size of the gate operating mechanism, stay ring, head cover, bottom ring, spiral case, and possibly the power house. The runner diameter is often maximized to improve hydraulic performance. The combination of minimum gate pin circle and maximum runner diameter leads to wicket gates which overhang the bottom ring. The resulting leakage flow through the overhung gap disrupts smooth flow and induces additional energy losses, i.e. avoidable losses. Wicket gates with small gate pin circle can also result in a situation where the discharge of the wicket gates can be near the Francis runner blades when operating near full gate opening. This close proximity of the wicket gates to Francis runner blades can result in the chopping of fish between the stationary wicket gate and rotating Francis runner blades if this distance is comparable to fish length.

In conventional designs, the number of wicket gates and stay vanes typically varies from 16 to 32 . Some designs use one stay vane for each two wicket gates. The wicket gates serve two purposes: 1) They shut off the flow when the unit is idle, and 2) They control the flow to the unit to achieve different levels of output. The shape of the wicket gate has a significant influence on efficiency. The stay vane is a very important structural member linking the top and bottom portions of the unit. The shape of the stay vane also has a significant influence on efficiency. The relative position of the stay vanes and wicket gates was often determined principally by mechanical considerations. Fluid analysis tools of the past were non existent or inadequate to address the effect of design shapes and the relative position of the gates and stay vanes on efficiency. In some of the these designs the wicket gates and stay vanes were not aligned to minimize the potential for mechanical strike such as the wicket gate being located in the "shadow" of a stay vane as shown in Figure 6.2.2-1. CFD tools can help optimize the fluid induced disturbances and minimize mechanical strike for a selected range of gate openings.

\section{Rehabilitation Design}

Wicket Gate Overhang: As mentioned above, reducing this overhang will increase efficiency and reduce fluid and mechanical mechanisms for fish injury. The overhang can be reduced or eliminated by changing the shape of the discharge ring as shown in Figure 6.3.1-2 and/or moving the trailing edge of the wicket gate to a larger diameter. The trailing edge of the wicket gate can be moved to a larger diameter by moving the gate pin circle to a larger diameter and/or by shortening the wicket gate. Since the gates have to touch each other in the closed position, a shorter gate may require a larger number of gates. The above mentioned modification to the discharge ring will complicate the removal of the runner. An additional, less important, advantage of a larger gate pin circle is the lower velocities through the stay vanes and wicket gates which result from having these parts at a larger diameter and therefore at a larger flow through area. 
Space between Francis Runner and Wicket Gates: Moving the gate pin circle to a larger diameter will increase the space between the outlet edge of the wicket gates and the rotating runner. For smaller turbines, this should reduce the probability of a fish being trapped and chopped by the action of the runner blade passing by the wicket gates. An additional, less important, advantage in doing this will be the lower velocities through the stay vanes and wicket gates resulting from having these parts at a large diameter and therefore a larger flow through area. See Figure 6.3.1-3. Alternatively, a runner design with an unconventional blade shape may be explored to increase the space between the gate trailing edge and the blade entrance edge.

Relative Position of Wicket Gates and Stay Vanes: While an issue of secondary effect, shifting the gate pin circle can allow a wicket gate (at least at one gate opening) to be the "shadow" of a stay vane, thus reducing strike probability. See Figure 6.2.2-1. Making this modification on an existing unit will require changes to the gate operating and servomotor system. Since this could be accomplished by rebolting components, the shift may be limited to the existing bolt spacing in the head cover and bottom ring.

Achieving these changes in an existing plant will require careful review of the mechanical and civil structure.

\section{New Unit Design}

Accommodating the above mentioned geometries will be more easily done in a new unit design since civil, mechanical and hydraulic requirements can be coordinated at the initial design stage. In addition to the above, the number of wicket gates should be evaluated for reducing mechanical injury effects.

Number of Wicket Gates: In general, lowering the number of wicket gates will decrease strike probability. The number of wicket gates should equal one or two times the number of stay vanes with proper relative position. If the number of wicket gates and stay vanes are equal, each gate can be in the shadow of a stay vane. If the number of stay vanes can be one half the number of wicket gates, (for lower head units) every other gate can be in the shadow of a stay vane.

\subsubsection{Optimized Hydraulic Design}

An optimized Francis design contains the design elements mentioned above. The runner consists of fewer blades than a conventional design, with greater blade thickness at the entrance edges. Fewer blades will reduce the leading edge strike probability and the thicker (and carefully profiled) blade entrance edge shapes will reduce shear zones when the turbine is operated away from the best efficiency condition. Stay vanes and wicket gate shapes can be optimized to minimize fluid and mechanical mechanisms for injury. The design of rehabilitated, upgraded or new turbine components is optimized by cutting edge flow analysis (CFD) tools at all operating conditions to maximize efficiency, avoid cavitation and provide for maximum flow smoothness and minimized fluid mechanisms for mortality. Through use of the CFD tools, even backroll associated with draft tube exit velocity distributions can be addresses. New unit designs can benefit to a greater extent from the cutting edge technology as there is more flexibility in developing advanced geometrical shapes for the turbine components. Design changes for upgrade or rehabilitation are limited by, existing structures, the difficulty in alterations to concrete structures, and in many cases by component strength issues.

The use of cutting edge technologies has provided improved efficiency and cavitation performance for recent and "in progress" upgrades. Some recently redesigned Francis turbine runners incorporating 11 blades are operating at Flatrock and West Buxton plants and are being manufactured or installed for Sartell, McDougal, Watertown, Rock Island Arsenal and Nottely plants. 


\subsubsection{Lubrication}

The vast majority of units use grease lubricated wicket gate bushings which have the potential of grease leaking into the water.

\section{Rehabilitation Design}

An environmentally advanced Francis turbine would use greaseless self-lubricated wicket gate bushings. There are a variety of these bushings on the market today where the lubricant is an integral part of the bushing.

\section{New Unit Design}

The goals will be the same as a rehabilitation design but implementation will be simpler.

\subsubsection{Surface Roughness}

Roughness refers to turbine component surfaces. For older turbines, surface smoothness may have deteriorated over a period of time. Rough surfaces and surface roughness hot spots associated with cavitation damage or rough structural welds in the water passage (there may be weld joints in an aswelded condition in spiral cases, draft tubes, and some stay rings) can cause damage to the fish as it scrapes along or is carried against a surface as a result of the turbulent flow field within the turbine. As mrre biological data becomes available, it may be possible to evaluate fish injury for different values of roughness. The water velocity in some of these parts is relatively low. Therefore, the cost to "smooth" these surfaces and maintain them may not be justified from a performance standpoint.

\section{Rehabilitation Design}

Providing for a surface upgrade for the stay vane, wicket gate, and upper draft tube cone, as a minimum, may decrease descaling associated with scraping. Figure 6.2.1-5 shows a reduction in weld roughness. The surface upgrade can be accomplished by a combination of surface restoration, smoothing and use of special friction reducing coatings. Even compliant coatings may provide value on components where fish may impact the surface with high energy. Some older designs used rivets to join steel plates in some of the larger water passages such as in the spiral case and draft tube. For structural reasons these rivets can not be reduced in size.

\section{New Unit Design}

Selection of initial base material will have an effect on the ease with which surface smoothness can be maintained.

\subsubsection{Fixed vs Adjustable Rotational Speed (RPM)}

In a conventional design all operation is at a fixed rpm because generators have a fixed number of poles and must output a fixed frequency. Running at a fixed rpm restricts the machine to being at peak efficiency at only one combination of head and discharge. As head or discharge change, the point of operation moves away from the peak as shown in Figure 6.2.1-6. The plant operator has control of the discharge by controlling the gate opening. The plant operator has no direct control over the head. As head changes, the unit must move away from the point of optimum performance. This will cause a drop in efficiency and move the operating point closer to cavitation and/or pressure pulsation operation limits. Moving to different locations on the operating hill curve will also have an effect on fish friendliness as discussed in Section 4. The disadvantages of fixed rpm increase as the head range increases. 


\section{Rehabilitation Design}

Installation of electrical conversion equipment enables the turbine to operate with adjustable speeds. To take full advantage of this equipment, a new runner design should be part of this upgrade. Adjustable rpm compensates for head variations. The combination of adjustable rpm and the conventional adjustable gate opening allows the machine to stay near the optimum operating point as shown in Figure 6.2.1-7. The definition of optimum is derived by considering:

$\begin{array}{ll}\text { - } & \text { Strike probability } \\ \text { - } & \text { Size of shear zones } \\ \text { - } & \text { Caviciency } \\ \text { - } & \text { Pressure pulsations }\end{array}$

There is an inefficiency associated with the electrical conversion equipment. This will reduce the overall plant efficiency but has no impact on the hydraulic efficiency of the turbine. This conversion equipment is becoming more efficient and less expensive as research develops more cost effective solutions and a higher sales volume leads to lower costs. The conversion equipment is relatively large and must be housed indoors.

\section{New Unit Design}

The advantages of adjustable speed for a new unit is the same as for a rehabilitated unit. In addition, several of the hydraulic components would be designed to take full advantage of adjustable speed.

\subsubsection{Advanced Control System}

Utilizing advanced sensors and digital technology, an advanced control system can provide significant advantages in turbine operation to improve fish survival. Several features are discusses below.

- Adjustable speed control in conjunction with an adjustable speed generator can adjust the operation of the turbine to provide the maximum fish survival at the discharge of operation independent of the head at the power plant. At all heads of operation, the turbine characteristics can be those of the most fish friendly point of operation at the required discharge.

- Francis turbines often operate with significant trash on the trash racks. This results in disturbed flow entering the intake and can move fish from the upper intake to the lower intake exposing them to greater injury associated with blade tip strike. Use of an automated system to announce when trash racks need cleaned can minimize this problem. Certain features discussed in this material relating to trash rack cleaning are based on technology developed outside the scope of this DOE program and are the subject of one or more patent applications.

- For multiunit plants, the units are often not operated based on optimized plant efficiency for the given output, but rather based on other criteria. An automated multiunit optimization system can aid the operator in determining how to operate the plant to optimize the plant efficiency for the required output. While this will provide better conditions for fish passage, it is still not the best that can be done. When fish are present in the unit, a system to operate the unit at optimum plant fish passage survival discharge would provide conditions within the turbine having lower mechanical and fluid mechanisms for injury. Such an advanced sensing and control system is based on technology developed by Voith outside the scope of this DOE program and is the subject of pending patent applications. 


\subsubsection{Pressure Change}

Fish mortality due to sudden reductions of pressure is of primary importance at sites with operating heads above approximately $35 \mathrm{~m}$ (120 ft). Section 4.3 .4 addresses the mechanisms of these pressure changes.

\section{Rehabilitation Design}

Since the design concepts described in this section involve the civil structure of the dam and / or penstock system, they are primarily of interest for new sites and will be impractical to implemen: at most existing plants.

\section{New Unit Design}

Figure 6.3.1-4 shows plant layout possibilities for plants with short penstocks. Option (a) shows a dam with a penstock entrance at a relatively low elevation. This inlet will draw fish which have become acclimated to high pressures. They will then be transported quickly to the low pressure of the tailrace, with the possibility of decompression trauma. Option (b) is more fish friendly because it will draw fish which are acclimated to low pressures and transport them quickly through the high pressure region at the turbine iniet and back to the low pressure in the tailrace. Design concepts like that of Figure 6.3.1-4b are preferred to minimize decompression trauma.

Figure 6.3.1-5 shows plant layout possibilities for plants with long penstocks. Option (a) shows a penstock which draws fish at low to moderate pressure and then exposes them to a high pressure and retains them at this high pressure for a period long enough for acclimation and then transports them quickly to the low pressure of the tailrace, with the possibility of decompression trauma. Option (b) is more fish friendly because it allows the fish to remain at low pressures and transports them quickly through the high pressure region and back to the low pressure in the tailrace. Design concepts like that of Figure 6.3.1-5b are preferred to minimize decompression trauma.

Obviously, civil constraints may dictate some compromise between the (a) and (b) solutions. If a long penstock of type (a) can not be avoided, a smaller diameter penstock could be considered. Smaller penstock diameters will increase water velocity and reduce both the transport time and the time for acclimation to high pressures. Smaller penstocks will reduce installation cost but also plant efficiency as a consequence of higher head losses. 


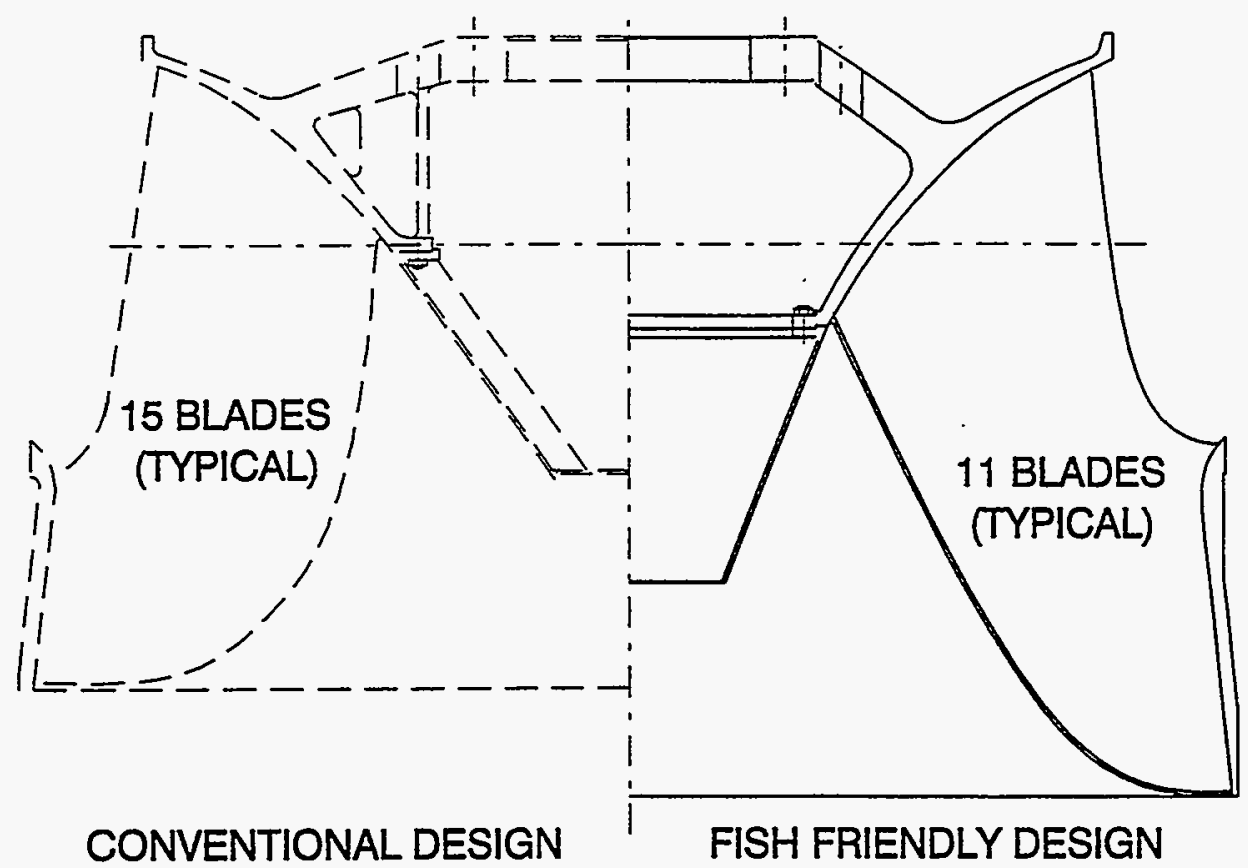

Figure 6.3.1-1 Reduction of Number of Francis Runner Blades

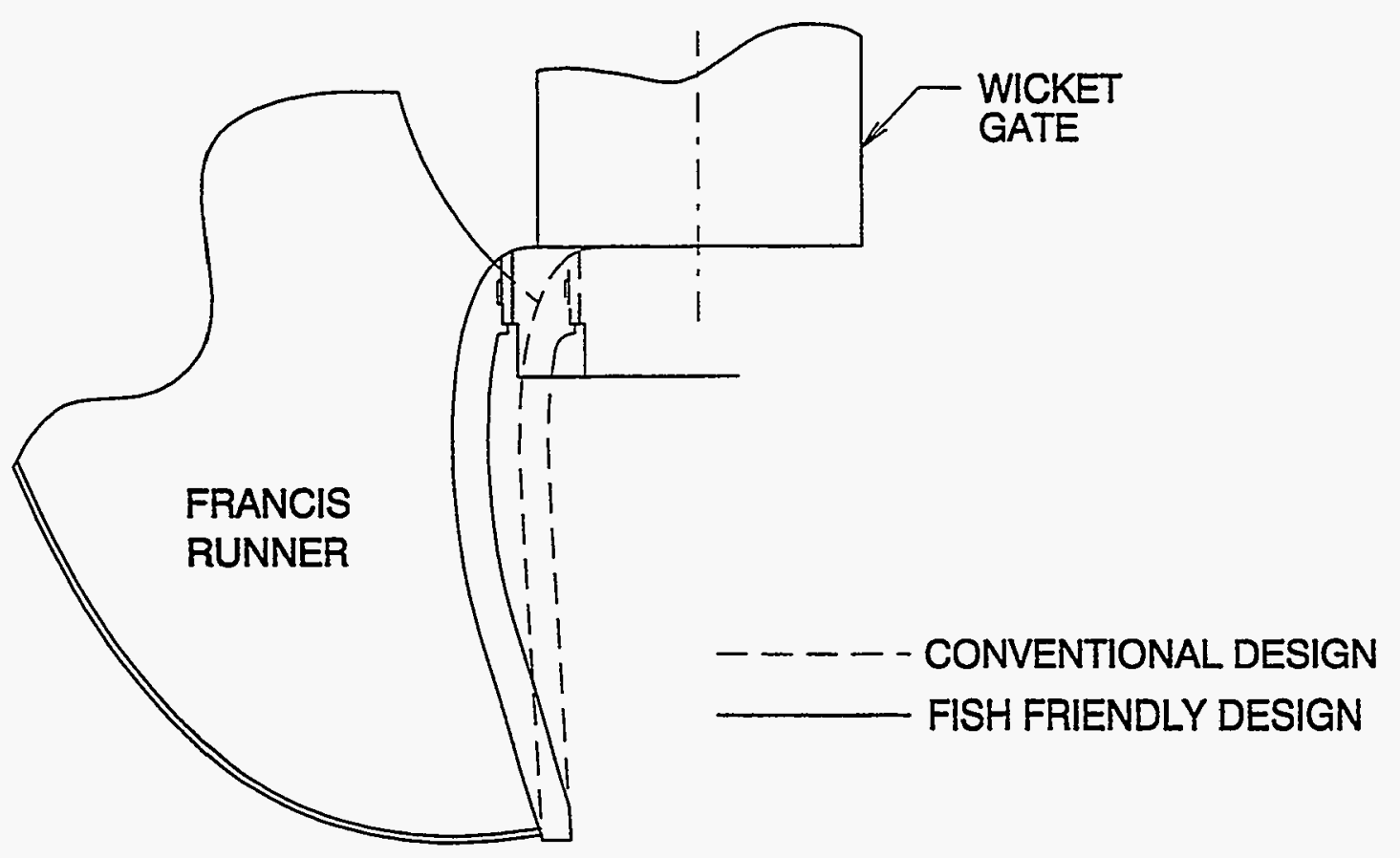

Figure 6.3.1-2 Elimination of Wicket Gate Overhang 


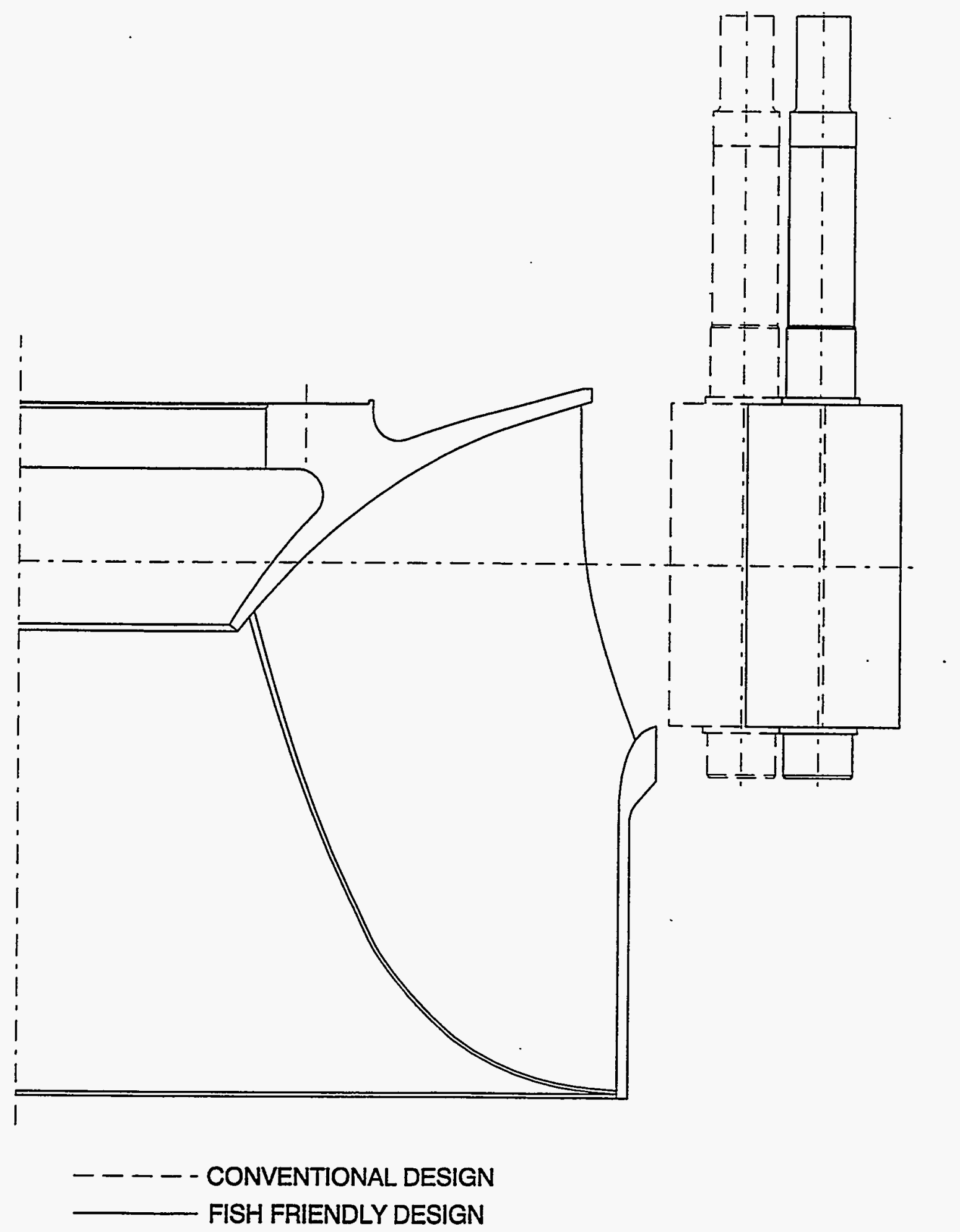

Figure 6.3.1-3 Increased Space Between Wicket Gates and Runner 


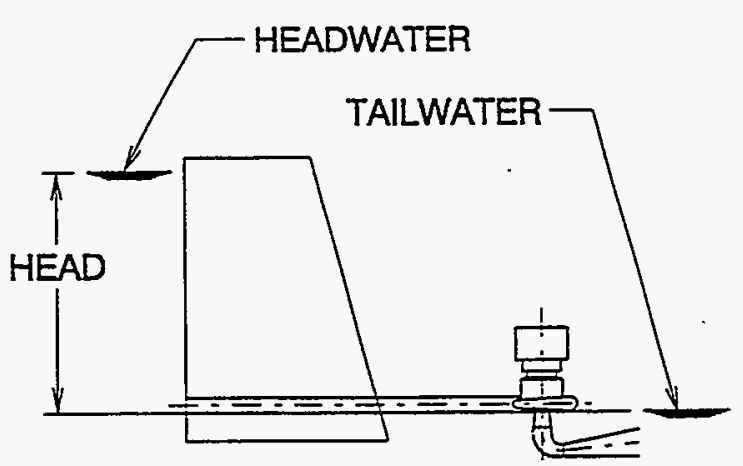

(a)

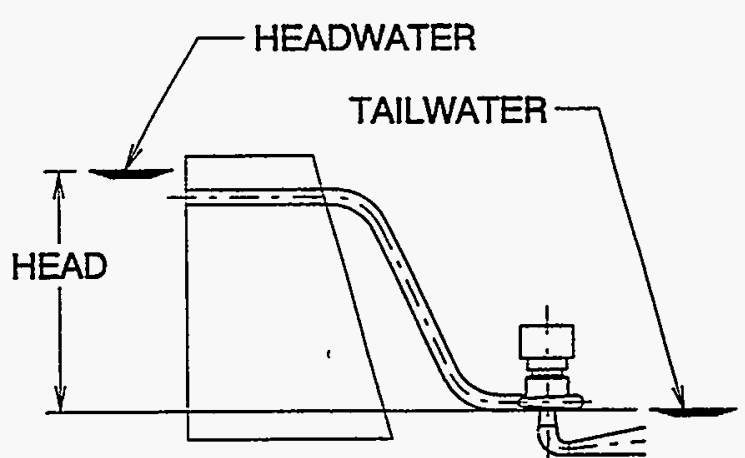

(b)

Figure 6.3.1-4 Pressure Change in Short Penstocks

(a) Will draw fish acclimated to high pressure and transport quickly to low pressure

(b) Will draw fish acclimated to low pressure and transport quickly through high pressure and back to low pressure

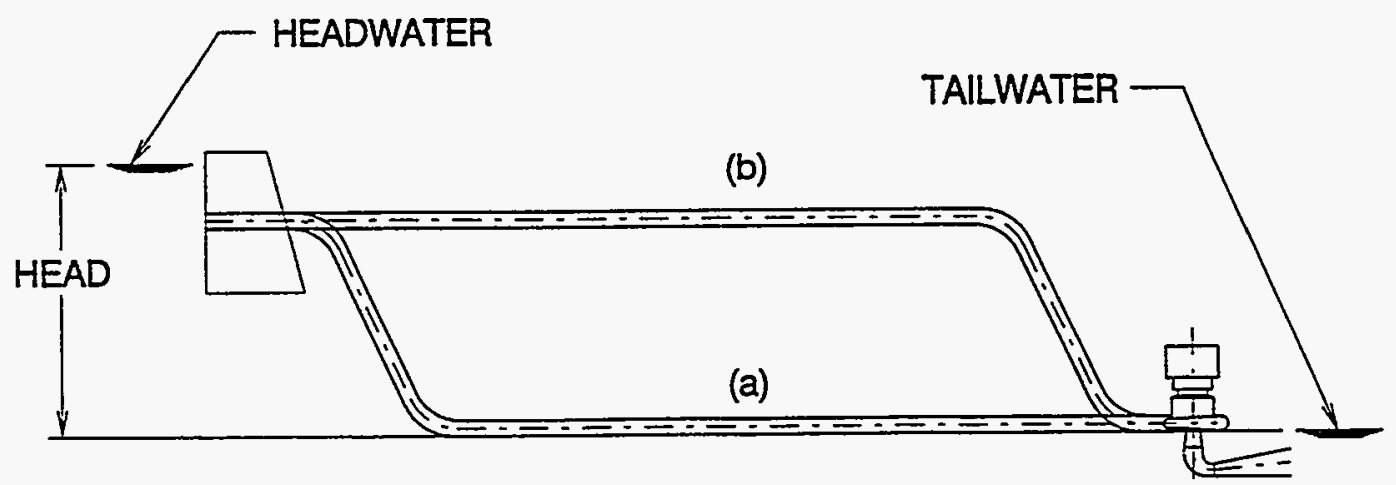

Figure 6.3.1-5 Pressure Change in Long Penstocks

(a) Will retain fish at high pressure long enough for acclimation and then transport quickly to low pressure

(b) Will retain fish at low pressure and transport quickly through high press.ure and back to low pressure 


\subsubsection{SECONDARY ISSUES}

\subsubsection{Rotational Speed (RPM)}

The selection of rotational speed deals primarily with new units. The ongoing trend in the industry is to use higher fixed rpm units for a given site condition and output requirement. The size and cost of the turbine and generator decrease as the rpm increase. Since the smaller unit must produce the same output, the discharge must be the same as it would be for a larger unit. Therefore, the smaller unit would have higher water velocities. For the smaller unit with the same sized fish, the probability of strike will be higher. The energy concentrated in the fluid injury mechanisms will be higher. Therefore the trend to higher speeds for a given head turbine is going in the wrong direction for improved survivability.

\section{New Unit Design}

Use of a lower rpm machine for the design conditions will reduce the water velocities and increase the size of the water passages for a given site condition and output requirement. The lower rpm machine will have more margin against cavitation for a given submergence. If there is sufficient margin against cavitation, the lower rpm machine can be installed at a higher elevation. This will decrease installation costs. Larger units will, of course, have higher hardware costs and may require a larger power house.

\subsubsection{Draft Tube Piers}

The number and size of draft tube piers are determined by the civil design of the power house. Typical designs have from 0 to 2 vertical piers. A few designs also have horizontal piers. The velocities at the inlet to the pier are relatively low but the flow pattern can be complex at off-design conditions - especially for Francis machines.

\section{Rehabilitation Design}

For structural reasons elimination of piers in an existing powerhouse would not be practical. The shape of the pier nose should be reviewed using cutting edge CFD analysis tools for possible improvements.

\section{New Unit Design}

Eliminating the pier(s) removes a strike source. This would have to be incorporated into the initial powerhouse design and may be impractical for larger draft tubes. Changing the draft tube cross-sectional area will influence the structural requirements. Increasing the height while decreasing the width may allow a pier(s) to be eliminated. See Figure 6.2.2-2 for examples. If the pier(s) cannot be removed, the shape of the pier nose should be reviewed for possible improvements.

\subsubsection{Runner Cones}

In a conventional designs, Francis runner crowns are typically extended beyond the outlet edge of the blades with a conical extension (Figure 10.2-8).

\section{Rehabilitation Design}

Further investigation is required to determine if the shape and length of these extensions influence the flow patterns in a manner that affects fish friendliness.

\section{New Unit Design}

Same as rehabilitation design. 


\subsubsection{Inlet Valves}

In a conventional design of a unit having a penstock or inlet pipe, there is usually a valve near the inlet to the spiral case. For low to medium head units these valves have a disk that remains in the water passage when it is in its full-open position. This obstruction in the water passage causes some loss of efficiency and creates some strike probability. High head units tend to use spherical valves that have no obstruction in the water passage when opened.

\section{Rehabilitation Design}

Option 1: Use a spherical valve that will have no obstruction in the water passage. This is an expensive solution, but it is the best valve for fish friendliness and efficiency. A spherical valve housing is relatively large. Retrofitting will require a detailed review of the plant layout.

Option 2: For butterfly valves, install trunnion fairings and blend any sharp corners that have an obstruction in the water passage. This is a relatively inexpensive solution. These modifications will reduce the head loss and increase the efficiency of the valve.

\section{New Unit Design}

Use of a spherical valve or a ring gate will eliminate the obstruction from the water passageway.

\subsubsection{Sharp Corners}

In a conventional design some of the corners at inlet edges are manufactured with sharp corners. The cost to round these comers is not justified from a performance standpoint.

\section{Rehabilitation Design}

Rounding of these corners may decrease injury when strike does occur. See Figure 6.2.2-3

\section{New Unit Design}

Same as rehabilitation design.

\subsubsection{Gate Slots}

Sliding gates are used as closure devices in the draft tube and/or inlet sections of turbines. They ride in slots that are located on the perimeter of the sections. When the units are operating, these gates are always fully opened which exposes the gate slots to the flow. These slots typically have relatively sharp comers and can cause vortices.

\section{Rehabilitation Design}

Filling these slots with a removable filler strip will minimize the possibility of a strike. The time needed to install and remove these fillers must be weighed against the frequency of use. See Figure 6.2.2-4.

\section{New Unit Design}

In addition to slot filling, rounding the corners of these slots could decrease the probability of injury if a strike occurs. 


\subsection{AERATING FRANCIS DESIGN FOR INCREASING DISSOLVED OXYGEN CONTENT}

This section will be delivered at a later date as a supplement to this report in conjunction with the delivery of a report on the use of advanced CFD and a "virtual fish" to evaluate the four conditions tested experimentally by fish injection at Wanapum dam (described in Section 4.4.6). 


\subsection{SUMMARY AND CONCLUSIONS}

This study was conducted to define three families of environmentally advanced hydro turbine design concepts to improve hydropower's impact on the environment and to improve the understanding of the technical and environmental issues that especially effect fish survival. The study conclusively demonstrates that enhanced environmental designs can improve fish survival during turbine passage. In addition, enhanced design concepts can improve operating efficiency, reduce operations and maintenance expenses, and improve water quality. Based on the results of the studies conducted, the team members feel that the environmentally friendly design features presented can be incorporated into existing and new designs in a cost effective manner. Several rehabilitation projects currently underway already include some of the design concepts presented providing evidence of market acceptance.

To improve the environmental compatibility of hydro projects, existing hydropower turbine designs can be upgraded using some of the design concepts presented. Each piant is unique and the presented design concepts will need to be adapted to the plant requirements and the project constraints. In addition to design improvements, plant operation can be coordinated with the presence of fish to result in fish passage survival improvements. Many of the design concepts can be implemented with a minimal impact on cost when combined with an upgrade initiated to address mechanical problems or to take advantage of efficiency and/or capacity gains arising from improved turbine design technology. Other of the design concepts can be implemented providing further improvements, but with a higher marginal cost. For new turbines, many of the design concepts can be integrated into the design with a minor cost impact.

The implementation of the presented design concepts will have a positive impact on the environment. Each of the concepts will have an incrementally different contribution to the improvements. Estimation of the incremental cost of an improvement can be made. This will be done and be included in the supplemental report which will be issued at a later date. Estimation of the incremental environmental improvement is more difficult to do and despite progress made during this study is subjective. However an attempt to quantify the improvement will be included in the supplemental report also.

- Project specific designs may be developed incorporating elements of the three families of design concepts presented. However, more than three families of design concepts are needed to address all of the relevant issues. Design concepts to address minimum stream flows, for example, were not addressed. 


\subsection{OVERALL CONCLUSIONS}




\subsection{OVERALL CONCLUSIONS}

This study was conducted to define three families of environmentally advanced hydro turbine design concepts to improve hydropower's impact on the environment and to improve the understanding of the technical and environmental issues involved, in particular, on fish survival. The study conclusively demonstrates that enhanced environmental designs can improve fish survival during turbine passage. In addition, enhanced design concepts can improve operating efficiency, reduce operations and maintenance expenses, and improve water quality. Based on the results of the studies conducted, the team members feel that environmentally friendly design features presented can be incorporated into new and existing designs in a cost effective manner. Several rehabilitation projects currently underway already include some of the design concepts presented providing evidence of market acceptance.

Specific results and conclusions are:

- Project specific designs may be developed incorporating elements of the families of design concepts presented which will improve the environmental compatibility of hydropower installations. Concept family one addresses Kaplan turbines for improved fish passage survival. Concept family two addresses Francis turbines. This family of concepts is applicable to many low-head Francis units which are important for fish passage at older projects in the eastern and upper mid west states. Concept family three addresses Francis turbines for improving levels of dissolved oxygen in their discharge. However, more than three families of design concepts are needed to address all of the relevant issues. Design concepts to address minimum stream flows, for example, were not addressed.

- Turbine operation has a significant effect on fish survival during turbine passage. Field test results and CFD analyses were used to characterize the effects of turbine operation. When fish are present, limitation of turbine operation to the range of discharges providing the best survival will improve fish passage survival compared to conventional operation which does not recognize the effect.

- Improvements in the level of understanding of the physics governing fish damage due to leading edge strike were achieved. Revised equations to estimate strike mortality were presented. The concept of blade effective zone (BEZ) was developed to expand the concept of the interaction of fish with the blade and its near by fluid characteristics induced by the blade presence.

- The utility of advanced turbulence models in computational fluid dynamics (CFD) investigations of fish passage issues is demonstrated. More accurate prediction of flow characteristics results.

- Controlled field test experiments and CFD calculations demonstrate that different zones of the turbine have significantly different effects on fish during passage. Zonal geometry and its associated flow conditions are important. In planning tests to evaluate fish passage, zonal effect determination must be considered to adequately develop a survival estimate for the turbine.

- In the absence of cavitation, pressure effects on fish during turbine passage are not significant. Effects related to the state of pressure acclimation are significant. These effects relate more to project planning than to turbine design or operation.

- Incorporating capabilities for aeration in the turbine design can alleviate water quality problems stemming from low dissolved oxygen in hydropower releases. Depending on design conditions, aerating turbines can increase the level of dissolved oxygen by over $5 \mathrm{mg} / \mathrm{L}$. 
Furthermore a review of existing test results and testing procedures pointed out that:

- Only a few tests conducted under controlled conditions have provided some understanding of mechanisms of fish injury and mortality and are deemed useful from the standpoint of turbine design modifications. Data from these tests show that fish survival and injury types differ depending on entrainment depths, point of turbine operation, intake configuration (e.g., whether fish guidance screens are present), and site-specific characteristics. However, these test results have also demonstrated large knowledge voids with respect to the actual path of entrained fish in passage through turbines, flow patterns within turbines, etc. Integration of information on these parameters can lead to further refinement of turbine designs.

- Risks of injury and mortality due to mechanical causes, fluid mechanisms (shear-turbulence and cavitation) and pressure changes are not the same at all sites nor at all operating conditions at the same site. At low head dams, mechanically related injuries and mortality predominate while at high head dams, whether equipped with hydro turbines or not, pressure changes can inflict a high level of injury (rupture of air bladder and other internal organs, decompression trauma, etc.) and mortality

- Specific biological criteria for turbine redesign are difficult to develop from the existing database due to lack of replication in experimental data and variability in tests between similar type turbines at a site.

- Most studies have been conducted with small fish (<200 mm (<7.9 in.)), particularly anadromous fishes. Because few survival data exist on large sized fish, either resident or migratory, considerations for turbine design modifications for these fish cannot be fully concluded.

- Recent experimental data and reanalysis of historical data do not support certain historical hypotheses. Instead, they show that (1) survival is not necessarily maximized at peak turbine operating efficiency, (2) survival is not necessarily higher for fish entrained near the hub, and (3) survival is not necessarily lower for unguided fish at turbines equipped with fish guidance screens. The report demonstrates that complex interacting mechanisms are in effect within the turbine and the fish passage survival depends of the turbine geometry, its operation and on the fish and its location in the water column.

- None of the passage routes is $100 \%$ safe for fish. Survival through alternative passage routes (e.g., sluices, spillway, etc.) at some sites is comparable to that in passage through turbines. Pressure related and impact injuries can occur in passage through these routes depending upon the physical configuration, head, turbulence, characteristics of plunge pool, etc.

- The effectiveness of turbine designs should be evaluated against "best of class" benchmarks. This would help in setting realistic, achievable goals in fish survival improvement for each turbine type. Effects of turbine modifications on fish survival can be evaluated using tests and "comparative" benchmarking.

An objective of the work was to improve the understanding of the technical and environmental issues involved in improving fish passage survival and to point out needs for additional research. While improvements were made, insights developed led to the following conclusions which indicate areas needing additional investigation: 
- Fish paths within intakes and turbines are not well understood. The effects of both the dynamics of three dimensional bodies as well as fish volitional movement (FVM) will need to be investigated fully to provide additional improvements in fish survival.

- Additional testing is required to develop accurate indices of forces, pressure differentials, or other deterministic quantities that can be related to fish damage mechanisms in more detail.

- Calculation of flow fields can be performed. However a means of calculating the resulting loads on the fish and the effect of the loads on fish survival is needed to advance the state of the art. 


\subsection{RECOMMENDATIONS FOR FUTURE TESTING AND INVESTIGATION}




\subsection{RECOMMENDATIONS FOR FUTURE TESTING AND INVESTIGATION}

This work has shown that there are attractive design concepts for improving fish passage survival. The attractiveness has been perceived based on theories derived from a combination of analytic studies (CFD) and knowledge of fluid flow fields and from correlation of the theories with site survival studies. Testing coupled with more research is required to sharpen the theories. The characteristics of fluid and mechanical mechanisms which injured fish need to be quantified. The Advanced Hydro Turbine Program can benefit significantly from additional research and tests that will fill the knowledge voids in the existing data and improve the probability of success for developing further improvements to the presented design and operational concepts and incorporating them into project designs for more fish friendly turbines and hydro plant systems and operating those plants more successfully. Some of these types of experiments are identified below.

- Design and conduct tests to determine the effect of fluid and mechanical mechanisms which may injure fish. In the field, this should include the release of fish into multiple locations (zones) determined to have significant mechanical or fluid mechanisms to cause injury which warrant evaluation. CFD analysis tools and scale model testing should be used to identify the zones within the turbine where the mechanical or fluid mechanisms are significant and quantify the intensity of the mechanism. Areas that are benign and others which are not should be identified. Temporary modifications to turbine component geometry could be made to accommodate testing to separate multiple effects taking place within a zone. As an example, the higher mortality observed at Wanapum dam for fish that were presumed to enter the runner near the hub is presumed to be related to hub gaps, and the hub surface geometry. Wanapum has a three-dimensional localized contour on the hub downstream of the spherical portion of the hub to minimize the gap between the blade inner edge and the hub. These contours are an obstruction to the flow when the blades are not near minimum blade position. Repeating the tests at a blade position with the gaps temporarily closed would provide the insight to the effect related to the gaps alone.

- Design and conduct tests to quantify the effects of fluid shear to obtain sufficient data for 3-D "virtual fish" CFD correlation.

- Test multiple turbine operating points in all field experiments.

- Include a wider range of fish size and species (of interest) in the tests than in the past. Data on larger sized fish (e.g., post-spawned migratory fish, upstream migrant fall backs) are scant. Inclusion of strong and weak swimmers in tests will provide comparative data.

- Conduct a test where fish are injected at a location to enter the runner in the blade periphery zone. Note that most plants have some wicket gate overhang when the blades are at maximum blade position. It may be difficult to separate the effect of blade periphery gap and wicket gate overhang.

- Design and conduct field and laboratory tests subjecting fish to turbine like cavitation mechanisms. Zonal field testing is appropriate, but the zone of cavitation related fluid mechanisms lies in the vicinity of the blace surface and rotates with the blades. In the majority of the space between blades there may not be any cavitation. Therefore zonal testing will not be able to identify which fish get into the cavitation zone and which pass in the non cavitating zone. A laboratory experiment would need to be carefully designed to simulate 
the characteristics of cavitation and the related fluid effects (bubble sizes compared to fish size, velocity gradients etc.) present in turbines.

- The strike equations predict an increased tendency for strike as the turbine head is decreased. Tests could be designed and conducted to verify this effect.

- Testing designed to clarify a number of unknown factors relating to fish behavior would add to the knowledge base. It would be valuable to know if fish actively swim inside the turbine, and if so, where and why and if in their passage through the higher velocity part of the turbine (through wicket gates and runner blades) they maintain an orientation to the local flow field. How fish respond to changes in the local pressure field is another point for further clarification. Tests to delineate the actual flow path entrained fish traverse in passage from the point of entry into the turbine to the exit point would be instructive. This information will validate or invalidate the assumption that a fish is moving involuntarily with the flow and not "behaving". Release of dead fish (see if injury types are the same) along with the alive fish (same size and species) at the same location may shed some light on this if technology does not exist to track fish passage by unobtrusive means. This would give insight into behavior.

- Controlled tests for turbines equipped with fish guidance screens or bypass structures, and for turbines without guidance screens or bypass are needed to understand the effect of the bypass structure and fish screens on fish redistribution from the intake to the turbine runner.

- Through testing, evaluate synergistic effects of gas supersaturation and turbine passage (mostly a Pacific Northwest concern).

- Conduct field tests to quantify spatial distribution and orientation of fish in the water column prior to entry into the turbine intakes.

- Additional testing of the pressure reduction effect is desired to understand the $100 \%$ variation in mortality that has occurred in different investigations.

- Evaluate civil engineering design modifications of plant intakes and draft tubes for pressure and boil effects. This could be done by numerical investigation and be complimented by laborstory tests and field testing. 


\subsection{SUPPLEMENTAL REPORT}




\subsection{SUPPLEMENTAL REPORT}

This section is reserved for a supplemental report covering the Task 4 family of design concepts relating to aerating Francis design for increasing oxygen content (Section 6.4) and a report on the use of advanced CFD and a "virtual fish" to evaluate the four conditions tested experimentally by fish injection at Wanapum Dam (described in Section 4.4.6). 


\subsection{APPENDICES}


Development Of Environmentally Advanced Hydropower Turbine System Design Concepts

Section 10.1

APPENDIX 10.1

COMPILATION OF SURVIVAL DATA 
Table 10.1-1

Comparison of physical and hydraulic characteristics of low-head hydroelectric dams equipped with propeller/Kaplan type turbines at : which turbine passage survival was estimated.

\begin{tabular}{|c|c|c|c|c|c|c|}
\hline Station & $\begin{array}{l}\text { Designed } \\
\text { Turbine } \\
\text { Discharge } \\
\text { (cms) } \\
\end{array}$ & $\begin{array}{l}\text { Number } \\
\text { of } \\
\text { Blades }\end{array}$ & $\begin{array}{l}\text { Runner Speed } \\
\text { (rpm) }\end{array}$ & $\begin{array}{l}\text { Head } \\
\text { (m) }\end{array}$ & $\begin{array}{l}\text { Runner } \\
\text { Diameter (m) }\end{array}$ & $\begin{array}{l}\text { Peripheral } \\
\text { Velocity }(\mathrm{m} / \mathrm{s})\end{array}$ \\
\hline Annapolis, NS & 404.6 & - & 50.0 & 6.7 & 6.78 & 17.7 \\
\hline Big Cliff, OR & 71.1 & 6 & 163.6 & 27.7 & 3.76 & 32.2 \\
\hline Bonneville, OR-WA & 498.4 & 5 & 69.2 & 18.3 & 8.38 & 30.4 \\
\hline Chalk Hill, MI-WI & 37.7 & 4 & 150.0 & 8.8 & 2.59 & 20.3 \\
\hline Conowingo, MD & 283.2 & 6 & 120.0 & 27.4 & 5.72 & 35.9 \\
\hline Craggy Dam, NC & 17.0 & 4 & 229.0 & 6.4 & 1.75 & 21.0 \\
\hline Crescent, NY & 43.0 & 5 & 144.0 & 8.2 & 2.74 & 20.7 \\
\hline Feeder Dam, NY & 29.5 & 6 & 120.0 & 4.7 & 2.92 & 18.3 \\
\hline Foster Dam, OR & 22.7 & 6 & 257.0 & 33.5 & 2.54 & 34.2 \\
\hline Fourth Lake, NS & 15.0 & 6 & 360.0 & 22.9 & - & NA \\
\hline Greenup Dam, OH (Vanceburg) & 336.7 & 5 & - & 9.1 & 7.19 & NA \\
\hline Hadley Falls, MA & 118.9 & 5 & 128.0 & 15.8 & 4.32 & 28.9 \\
\hline Herrings, NY & 34.0 & 4 & 138.0 & 5.8 & 2.87 & 20.7 \\
\hline Kleber Dam, MI & 5.7 & - & 450.0 & 13.4 & - & NA \\
\hline la centrale Beauhamois, Quebec & 262.7 & 6 & 94.7 & 24.1 & 6.32 & 31.3 \\
\hline Lawrence, MA (Essex) & 124.6 & 3 & 128.6 & 8.8 & 4.00 & 26.9 \\
\hline Little Goose, WA & 509.8 & 6 & 90.0 & 28.3 & 7.92 & 37.3 \\
\hline Lowell, MA & 127.4 & 5 & 120.0 & 11.9 & 3.86 & 24.2 \\
\hline Lower Granite, WA & 538.1 & 6 & 90.0 & 29.9 & 7.92 & 37.3 \\
\hline Lower Monumental, WA & 509.8 & 6 & 90.0 & 28.7 & 7.92 & 37.3 \\
\hline Marshall, NC & 35.4 & 4 & 212.0 & 9.4 & 3.78 & 42.0 \\
\hline McNary, WA & 348.3 & 6 & 87.5 & 24.4 & 7.11 & 32.6 \\
\hline Morrow, MI & 6.7 & - & 175.0 & 3.7 & 1.37 & 12.6 \\
\hline Racine, WI & 226.6 & 4 & 62.1 & 6.7 & 7.71 & 25.1 \\
\hline Raymonoville, NY & 46.4 & 6 & 120.0 & 6.4 & 3.33 & 20.9 \\
\hline Rock Island, WA (Powerhouse 1) & 498.4 & 6 & 100.0 & 13.7 & 7.01 & 36.7 \\
\hline Rock Island, WA (Powerhouse 2) & 509.8 & 4 & 85.7 & 12.2 & 7.01 & 31.4 \\
\hline Rocky Reach, WA (Unit 3) & 453.1 & 6 & 90.0 & 28.0 & 7.11 & 33.5 \\
\hline Rocky Reach, WA (Unit 5) & 453.1 & 6 & 90.0 & 28.0 & 7.11 & 33.5 \\
\hline Rocky Reach, WA (Unit 6) & 453.1 & 6 & 90.0 & 28.0 & 7.11 & 33.5 \\
\hline Rocky Reach, WA (Unit 8) & 594.7 & 5 & 85.7 & 26.4 & 7.90 & 35.4 \\
\hline Safe Harbor, PA (Unit 7) & 235.1 & 5 & 109.0 & 16.8 & 5.64 & 32.2 \\
\hline Safe Harbor, PA (Unit 8) & 260.5 & 7 & 75.0 & 16.8 & 6.15 & 24.1 \\
\hline T.W. Sullivan, OR & 11.0 & 6 & 240.0 & 12.8 & 1.78 & 22.3 \\
\hline Thomapple, WI & 19.8 & 6 & 120.0 & 4.9 & 1.09 & 6.9 \\
\hline Townsend Dam, PA & 42.5 & 3 & 152.0 & 4.9 & 2.87 & 22.8 \\
\hline Tusket, NS & - & - & 225.0 & 8.2 & - & NA \\
\hline Twin Branch, IN & 11.6 & 4 & 241.0 & 6.5 & - & NA \\
\hline Walterville, OR & 70.8 & 5 & - & 16.8 & 3.07 & NA \\
\hline Wanapum, WA & 481.5 & 5 & 85.7 & 24.4 & 7.24 & 32.5 \\
\hline Wells, WA & 566.4 & 6 & 85.7 & 19.8 & 7.43 & 33.3 \\
\hline West Enfield, ME & 150.1 & 3 & 89.0 & 6.4 & 4.88 & 22.7 \\
\hline Wilder, VT-NH & 127.4 & 5 & 112.5 & 15.5 & 4.57 & 26.9 \\
\hline Range & $5.7-595$ & $3-7$ & $50-450$ & $3.7-33.5$ & $1.09-8.38$ & $6.9-42$ \\
\hline
\end{tabular}


Physlcal and hydraulle characterlslics of all hydroolectrlc dams equipped with Kaplan type turblnes for which survival dale are avallable.

\begin{tabular}{|c|c|c|c|c|c|c|c|c|c|c|c|c|c|c|c|}
\hline ctatlon & Samnlina Melhod & Snocleg Tested & $\begin{array}{l}\text { Tost } \\
\text { Samplo }\end{array}$ & $\begin{array}{l}\text { Control } \\
\text { Samplo } \\
\text { Sizo }\end{array}$ & $\begin{array}{l}\text { Avg. Flsh } \\
\text { Longth } \\
\text { (mm) }\end{array}$ & $\begin{array}{l}\text { Turblne } \\
\text { Discharge } \\
\text { (cms) }\end{array}$ & $\begin{array}{l}\text { No. } \\
\text { of } \\
\text { Blados }\end{array}$ & $\begin{array}{l}\text { Funner } \\
\text { Spoed } \\
\text { (rom) }\end{array}$ & $\begin{array}{l}\text { Hoad } \\
\text { (m) }\end{array}$ & $\begin{array}{l}\text { Runnor } \\
\text { Dla. } \\
\text { (m) }\end{array}$ & $\begin{array}{l}\text { Control } \\
\text { Survival } \\
\text { (\%) }\end{array}$ & $\bar{T}$ & $\begin{array}{l}\text { icent } \\
\text { Caplure } \\
\text { Control }\end{array}$ & $\begin{array}{l}\% \\
\text { Survival }\end{array}$ & Source \\
\hline Annapolis, NS & Radio telemetry & Amorican shad & 20 & 29 & $\cdot$ & 404.6 & $\cdot$ & 50 & 6.7 & 6.78 & NA & NA & NA & 53.7 & Hogan (1986) \\
\hline $\begin{array}{l}\text { Big Clill, OR (1964) } \\
\text { Big Clill, OR (1964) } \\
\text { Big Clill, OR (1964) } \\
\text { Blg Clill, OR (1966) } \\
\text { Big Clll, OR (1966) } \\
\text { Blg Clil, OR (1966) } \\
\text { Big Clill, OR (1987) }\end{array}$ & $\begin{array}{l}\text { Full discharge netling } \\
\text { Full discharge netling } \\
\text { Futl discharge netling } \\
\text { Full discharge netling } \\
\text { Full discharge netling } \\
\text { Full discharge netting } \\
\text { Full discharge netting }\end{array}$ & $\begin{array}{l}\text { Chinook Salmon } \\
\text { Chlnook Salmon } \\
\text { Chinook Salmon } \\
\text { Chinook Salmon } \\
\text { Chinook Salmon } \\
\text { Chinook Salmon } \\
\text { Sleelhead }\end{array}$ & $\begin{array}{l}3,500 \\
2,750 \\
3,500 \\
2,750 \\
3,750 \\
2,500 \\
-\end{array}$ & $\begin{array}{l}3,500 \\
2,750 \\
3,500 \\
2,750 \\
3,750 \\
2,500\end{array}$ & $\begin{array}{l}100 \\
100 \\
100 \\
100 \\
100 \\
100 \\
152\end{array}$ & $\begin{array}{l}52.5 \\
71.1 \\
71.1 \\
52.5 \\
71.1 \\
71.1 \\
71.1\end{array}$ & $\begin{array}{l}6 \\
6 \\
6 \\
6 \\
6 \\
6 \\
6\end{array}$ & $\begin{array}{l}163.6 \\
163.6 \\
163.6 \\
163.6 \\
163.6 \\
163.6 \\
163.6\end{array}$ & $\begin{array}{l}27.7 \\
24.7 \\
21.6 \\
27.7 \\
24.7 \\
21.6 \\
21.6\end{array}$ & $\begin{array}{l}3.76 \\
3.76 \\
3.76 \\
3.78 \\
3.78 \\
3.76 \\
3.76\end{array}$ & $\begin{array}{l}\text { NA } \\
\text { NA } \\
\text { NA } \\
\text { NA } \\
\text { NA } \\
\text { NA } \\
\text { NA }\end{array}$ & $\begin{array}{l}98.1 \\
98.1 \\
98.1 \\
93.2 \\
93.2 \\
93.2 \\
-\end{array}$ & $\begin{array}{l}97.0 \\
97.0 \\
97.0 \\
98.9 \\
98.9 \\
98.9\end{array}$ & $\begin{array}{l}91.1 \\
94.5 \\
89.7 \\
92.2 \\
89.8 \\
90.6 \\
90.4\end{array}$ & $\begin{array}{l}\text { Oligher \& Donaldson (1966) } \\
\text { Oligher \& Donaldson (1966) } \\
\text { Olighor \& Donaldson (1966) } \\
\text { Oligher \& Donaldson (1966) } \\
\text { Oligher \& Donaldson (1966) } \\
\text { Oligher \& Donaldson (1966) } \\
\text { Oligher \& Donaldson (1966) }\end{array}$ \\
\hline Bonnoville, OAWA & Brand, CWr, Selne & Chinook salmon & 850,408 & 435.089 & 91 & 498.4 & 5 & 69.2 & 18.3 & 8.38 & NA & $<1.0$ & $<1.0$ & 97.5 & EPRI (1992) \\
\hline $\begin{array}{l}\text { Chalk Hill, MI-WI } \\
\text { Chalk HIII, MI-WI } \\
\text { Chalk Hill, MI-WI } \\
\text { Chalk Hill, MI-WI }\end{array}$ & $\begin{array}{l}\text { HI.Z Turb'N Tag } \\
\text { HI-Z Turb'N Tag } \\
\text { HI-Z Turb'N Tag } \\
\text { HI-Z Turb'N Tag }\end{array}$ & $\begin{array}{l}\text { Bluegill } \\
\text { Bluegill } \\
\text { W. Sucker/R. Trout } \\
\text { W. Sucker/R. Trout }\end{array}$ & $\begin{array}{l}60 \\
50 \\
77 \\
38\end{array}$ & $\begin{array}{l}43 \\
67 \\
70 \\
45\end{array}$ & $\begin{array}{l}103 \\
153 \\
119 \\
261\end{array}$ & $\begin{array}{l}37.7 \\
37.7 \\
37.7 \\
37.7\end{array}$ & $\begin{array}{l}4 \\
4 \\
4 \\
4\end{array}$ & $\begin{array}{l}150 \\
150 \\
150 \\
150\end{array}$ & $\begin{array}{l}8.8 \\
8.8 \\
8.8 \\
8.8\end{array}$ & $\begin{array}{l}2.59 \\
2.59 \\
2.59 \\
2.59\end{array}$ & $\begin{array}{l}95.3 \\
95.5 \\
94.3 \\
100.0\end{array}$ & $\begin{array}{l}86.7 \\
94.0 \\
80.5 \\
97.4\end{array}$ & $\begin{array}{l}97.7 \\
97.0 \\
94.3 \\
100.0\end{array}$ & $\begin{array}{l}97.0 \\
98.0 \\
91.0 \\
97.0\end{array}$ & $\begin{array}{l}\text { RMC (1994) } \\
\text { RMC (1994) } \\
\text { RMC (1994) } \\
\text { AMC (1994) }\end{array}$ \\
\hline Conowingo. MD & HI-Z Turb'N Tag & American Shad & 108 & 108 & 125 & 228.6 & 6 & 120 & 27.4 & 5.72 & 91.7 & 88.0 & 97.6 & 94.9 & RMC (1994) \\
\hline $\begin{array}{l}\text { Craggy Dam, NC } \\
\text { Craggy Dam, NC } \\
\text { Craggy Dam, NC } \\
\text { Craggy Dam, NC } \\
\text { Craggy Dam, NC } \\
\text { Craggy Dam, NC }\end{array}$ & $\begin{array}{l}\text { HI-Z Turb'N Tag } \\
\text { HIl-Z Turb'N Tag } \\
\text { HI-Z Turb'N Tag } \\
\text { HI-Z Tusb'N Tag } \\
\text { HI-Z Turb'N Tag } \\
\text { HI-Z Tuib'N Tag }\end{array}$ & $\begin{array}{l}\text { Channel Callish } \\
\text { Channel Callish } \\
\text { Channel Callish } \\
\text { Bluegill } \\
\text { Channol Catilsh } \\
\text { Bluegill }\end{array}$ & $\begin{array}{l}43 \\
63 \\
39 \\
33 \\
32 \\
72\end{array}$ & $\begin{array}{l}28 \\
28 \\
22 \\
40 \\
22 \\
54\end{array}$ & $\begin{array}{l}180 \\
180 \\
277 \\
100 \\
277 \\
155\end{array}$ & $\begin{array}{l}17.0 \\
5.7 \\
5.7 \\
5.7 \\
17.0 \\
5.7\end{array}$ & $\begin{array}{l}4 \\
4 \\
4 \\
4 \\
4 \\
4\end{array}$ & $\begin{array}{l}229 \\
229 \\
229 \\
229 \\
229 \\
229\end{array}$ & $\begin{array}{l}6.4 \\
6.4 \\
6.4 \\
6.4 \\
6.4 \\
6.4\end{array}$ & $\begin{array}{l}1.75 \\
1.75 \\
1.75 \\
1.75 \\
1.75 \\
1.75\end{array}$ & $\begin{array}{l}100.0 \\
100.0 \\
100.0 \\
90.0 \\
100.0 \\
96.0\end{array}$ & $\begin{array}{l}93.0 \\
90.0 \\
90.0 \\
85.0 \\
88.0 \\
90.0\end{array}$ & $\begin{array}{l}100.0 \\
100.0 \\
100.0 \\
90.0 \\
100.0 \\
96.0\end{array}$ & $\begin{array}{l}93.0 \\
90.0 \\
81.0 \\
96.0 \\
93.0 \\
86.0\end{array}$ & $\begin{array}{l}\text { Malhur et al. (1993) } \\
\text { Mathur et al. (1993) } \\
\text { Malhur et al. (1993) } \\
\text { Mathur et al. (1993) } \\
\text { Mathur et al. (1993) } \\
\text { Malhur et al. (1993) }\end{array}$ \\
\hline Croscent, NY & HI.Z Turb'N Tag & Blueback Hering & 125 & 125 & 91 & 43.0 & $\mathbf{5}$ & 144 & 8.2 & 2.74 & 90.0 & 84.0 & 86.0 & 96.0 & Malthur et al. (1996) \\
\hline Essex, MA (bulb (urblne) & Radlo telemetry & Allantic Salmon & 50 & 0 & 208 & 124.6 & 3 & 128.6 & 8.8 & 4.00 & NA & 50.0 & NA & 98.0 & Knight (1982) \\
\hline $\begin{array}{l}\text { Foster, OR (lests combined) } \\
\text { Foster, OR (lests comblned) } \\
\text { Foster, OR (lests comblned) }\end{array}$ & $\begin{array}{l}\text { Full discharge nelling } \\
\text { Full discharge nelling } \\
\text { Full discharge nelling }\end{array}$ & $\begin{array}{l}\text { Chinook Salmon } \\
\text { Chinook Salmon } \\
\text { Clinnook Salmon }\end{array}$ & : & $\dot{-}$ & $\begin{array}{l}120 \\
120 \\
120\end{array}$ & $\begin{array}{l}22.7 \\
22.7 \\
22.7\end{array}$ & $\begin{array}{l}6 \\
6 \\
6\end{array}$ & $\begin{array}{l}257 \\
257 \\
257\end{array}$ & $\begin{array}{l}30.8 \\
33.5 \\
33.5\end{array}$ & $\begin{array}{l}2.54 \\
2.54 \\
2.54\end{array}$ & $\begin{array}{l}\text { NA } \\
\text { NA } \\
\text { NA }\end{array}$ & $\begin{array}{l}\text { NA } \\
\text { NA } \\
\text { NA }\end{array}$ & $\begin{array}{l}\text { NA } \\
\text { NA } \\
\text { NA }\end{array}$ & $\begin{array}{l}82.1 \\
93.9 \\
88.8\end{array}$ & $\begin{array}{l}\text { Bell (1981) } \\
\text { Bell (1981) } \\
\text { Bell (1981) }\end{array}$ \\
\hline $\begin{array}{l}\text { Foeder Dam, NY } \\
\text { Foeder Dam, NY } \\
\text { Feeder Dam, NY } \\
\text { Fesder Dam, NY } \\
\text { Feedor Dam, NY } \\
\text { Feeder Dam, NY } \\
\text { Feoder Dam, NY }\end{array}$ & $\begin{array}{l}\text { Full discharge nelling } \\
\text { Full discharge nelling } \\
\text { Full discharge nelling } \\
\text { Full discharge nelling } \\
\text { Full discharge nelling } \\
\text { Full discharge netling } \\
\text { Full discharge netling }\end{array}$ & $\begin{array}{l}\text { Bluegill } \\
\text { Bluegill } \\
\text { Largemouth bass } \\
\text { Largemouth bass } \\
\text { Largemouth bass } \\
\text { Brown trout } \\
\text { Golden shiner }\end{array}$ & : & : & $\begin{array}{l}91.6 \\
128.6 \\
87.7 \\
190 \\
292.1 \\
205.5 \\
88\end{array}$ & $\begin{array}{l}29.5 \\
29.5 \\
29.5 \\
29.5 \\
29.5 \\
29.5 \\
29.5\end{array}$ & $\begin{array}{l}6 \\
6 \\
6 \\
6 \\
6 \\
6 \\
6\end{array}$ & $\begin{array}{l}120 \\
120 \\
120 \\
120 \\
120 \\
120 \\
120\end{array}$ & $\begin{array}{l}4.7 \\
5.2 \\
5.5 \\
5.8 \\
6.1 \\
6.4 \\
6.7\end{array}$ & $\begin{array}{l}2.92 \\
2.92 \\
2.92 \\
2.92 \\
2.92 \\
2.92 \\
2.92\end{array}$ & $\begin{array}{l}100.0 \\
97.7 \\
90.1 \\
96.3 \\
99.2 \\
93.1 \\
95.0\end{array}$ & $\begin{array}{l}- \\
\vdots \\
- \\
- \\
80.5 \\
92.8\end{array}$ & $\begin{array}{l}- \\
\vdots \\
\vdots \\
\dot{93.1} \\
95.8\end{array}$ & \begin{tabular}{l|}
97.3 \\
02.3 \\
98.0 \\
90.0 \\
86.8 \\
86.4 \\
96.8
\end{tabular} & $\begin{array}{l}\text { Acres (1995) } \\
\text { Acros (1995) } \\
\text { Acres (1995) } \\
\text { Acres (1995) } \\
\text { Acres (1995) } \\
\text { Acres (1995) } \\
\text { Acres (1995) }\end{array}$ \\
\hline $\begin{array}{l}\text { Fourth Lake, NS } \\
\text { Fourth Lake, NS } \\
\text { Fourth Lake, NS }\end{array}$ & $\begin{array}{l}\text { Full dschrg/dye or brand } \\
\text { Full dschrg/dye or brand } \\
\text { Full dschrg/dye or brand }\end{array}$ & $\begin{array}{l}\text { Allantic Salmon } \\
\text { Brook trout } \\
\text { Alowilo }\end{array}$ & $\begin{array}{l}503 \\
1,908 \\
675\end{array}$ & $\begin{array}{l}494 \\
N A \\
627\end{array}$ & $\begin{array}{l}163 \\
105.5 \\
96\end{array}$ & $\begin{array}{l}15.0 \\
15.0 \\
15.0\end{array}$ & $\begin{array}{l}6 \\
6 \\
6\end{array}$ & $\begin{array}{l}360 \\
360 \\
360\end{array}$ & $\begin{array}{l}22.9 \\
22.9 \\
22.9\end{array}$ & $\dot{-}$ & $\begin{array}{l}99.4 \\
96.5 \\
83.1\end{array}$ & $\begin{array}{l}74.4 \\
24.5 \\
70.8\end{array}$ & $\begin{array}{l}74.3 \\
- \\
83.1\end{array}$ & $\begin{array}{l}83.7 \\
87.1 \\
89.0\end{array}$ & $\begin{array}{l}\text { Ruggles el al. (1990) } \\
\text { Ruggles el al. (1990) } \\
\text { Ruggles el al. (1990) }\end{array}$ \\
\hline
\end{tabular}


Tabla 10.1-2

Physical and hydraulle characleristlcs of all hydroelectric dams equipped with Kaplan type turbines for which survival data are avaliable.

\begin{tabular}{|c|c|c|c|c|c|c|c|c|c|c|c|c|c|c|c|}
\hline \multirow[b]{2}{*}{ Station } & \multirow[b]{2}{*}{ Sampling Molhod } & \multirow[b]{2}{*}{ Specles Tested } & \multirow{2}{*}{$\begin{array}{l}\text { Test } \\
\text { Sample } \\
\text { Slzo } \\
\end{array}$} & \multirow{2}{*}{$\begin{array}{l}\text { Control } \\
\text { Samplo } \\
\text { Size } \\
\end{array}$} & \multirow{2}{*}{$\begin{array}{l}\text { Avg. Fish } \\
\text { Length } \\
\text { (mm) }\end{array}$} & \multirow{2}{*}{$\begin{array}{l}\text { Turbine } \\
\text { Dlscharge } \\
\text { (cms) }\end{array}$} & \multirow{2}{*}{$\begin{array}{l}\text { No. } \\
\text { of } \\
\text { Blades }\end{array}$} & \multirow{2}{*}{$\begin{array}{l}\text { Runner } \\
\text { Speed } \\
\text { (rpm) }\end{array}$} & \multirow{2}{*}{$\begin{array}{l}\text { Head } \\
\text { (m) }\end{array}$} & \multirow{2}{*}{$\begin{array}{l}\text { Runner } \\
\text { Dla. } \\
\text { (m) }\end{array}$} & \multirow{2}{*}{$\begin{array}{l}\text { Control } \\
\text { Survival } \\
(\%)\end{array}$} & \multicolumn{2}{|c|}{$\begin{array}{c}\text { Porcent } \\
\text { Recapture }\end{array}$} & \multirow{2}{*}{$\begin{array}{l}\% \\
\text { Survival } \\
1 \text { hr }\end{array}$} & \multirow[b]{2}{*}{ Sourco } \\
\hline & & & & & & & & & & & & Test & Control & & \\
\hline Greenup Dam, OH (Vanceburg) & Radio telemelry & Sauger & 48 & NA & 231 & 336.1 & 5 & 90 & 9.1 & 6.10 & NA & 85.4 & NA & 85.4 & Olson (1990) \\
\hline $\begin{array}{l}\text { Hadley Falls, MA } \\
\text { Hadley Falls, MA } \\
\text { Hadley Falls, MA } \\
\text { Hadley Falls, MA }\end{array}$ & $\begin{array}{l}\text { Radio tolemalry } \\
\text { HI.Z Turb'N Tag } \\
\text { Radio telemetry } \\
\text { HI-Z Turb'N Tag }\end{array}$ & $\begin{array}{l}\text { Amarican Shad } \\
\text { American Shad } \\
\text { Allanic Salmon } \\
\text { American Shad }\end{array}$ & $\begin{array}{l}36 \\
100 \\
108 \\
100\end{array}$ & $\begin{array}{l}69 \\
.100 \\
89 \\
100\end{array}$ & $\begin{array}{l}560 \\
82 \\
285 \\
82\end{array}$ & $\begin{array}{l}118.9 \\
118.9 \\
118.9 \\
43.9\end{array}$ & $\begin{array}{l}5 \\
5 \\
5 \\
5\end{array}$ & $\begin{array}{l}128 \\
128 \\
128 \\
128\end{array}$ & $\begin{array}{l}15.8 \\
15.8 \\
15.8 \\
15.8\end{array}$ & $\begin{array}{l}4.32 \\
4.32 \\
4.32 \\
4.32\end{array}$ & $\begin{array}{l}98.6 \\
75.0 \\
92.5 \\
77.0\end{array}$ & $\begin{array}{l}76.0 \\
100.0 \\
81.0\end{array}$ & $\begin{array}{l}76.0 \\
100.0 \\
78.0\end{array}$ & $\begin{array}{l}78.2 \\
97.3 \\
93.7 \\
100.0\end{array}$ & $\begin{array}{l}\text { Bell and Kynard (1988) } \\
\text { Malhur ot al. (1994) } \\
\text { Kynard ef al. (1982) } \\
\text { Malhur el al. (1994) }\end{array}$ \\
\hline $\begin{array}{l}\text { Herrings, NY } \\
\text { Herrings, NY } \\
\text { Herrings, NY } \\
\text { Herrings, NY } \\
\text { Herrings, NY } \\
\text { Herrings, NY } \\
\text { Herrings, NY } \\
\text { Herrings, NY } \\
\text { Horrings, NY } \\
\text { Herrings, NY } \\
\text { Herrings, NY } \\
\text { Herrings, NY } \\
\text { Herrings, NY } \\
\text { Herrings, NY } \\
\text { Herrings, NY } \\
\text { Herrings, NY } \\
\text { Herrings, NY } \\
\text { Herrings, NY } \\
\text { Herrings, NY } \\
\text { Heurings, NY }\end{array}$ & 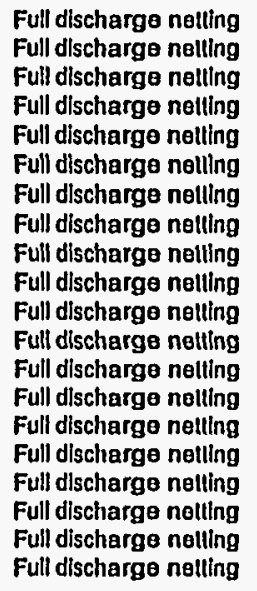 & $\begin{array}{l}\text { Centrarchld } \\
\text { Centrarchid } \\
\text { Contrarchid } \\
\text { Porcld } \\
\text { Salmonlds } \\
\text { Salmonlds } \\
\text { Salmonlds } \\
\text { Centrarchld } \\
\text { Cenirarchld } \\
\text { Centrarchid } \\
\text { Percld } \\
\text { Porcld } \\
\text { Porcld } \\
\text { Salmonlds } \\
\text { Salmonids } \\
\text { Salmonlds } \\
\text { Solt ray } \\
\text { Soll ray } \\
\text { Solt ray } \\
\text { Clupelds }\end{array}$ & $\begin{array}{l}74 \\
77 \\
80 \\
46 \\
31 \\
74 \\
82 \\
90 \\
80 \\
90 \\
185 \\
179 \\
138 \\
91 \\
95 \\
111 \\
188 \\
201 \\
175 \\
198\end{array}$ & $\begin{array}{l}65 \\
63 \\
65 \\
51 \\
57 \\
63 \\
72 \\
65 \\
69 \\
77 \\
78 \\
139 \\
137 \\
74 \\
72 \\
77 \\
144 \\
159 \\
125 \\
166\end{array}$ & $\begin{array}{l}100 \\
175 \\
250 \\
100 \\
100 \\
175 \\
250 \\
100 \\
175 \\
250 \\
100 \\
175 \\
250 \\
100 \\
175 \\
250 \\
100 \\
175 \\
250 \\
100\end{array}$ & $\begin{array}{l}34.0 \\
34.0 \\
34.0 \\
34.0 \\
34.0 \\
34.0 \\
34.0 \\
34.0 \\
34.0 \\
34.0 \\
34.0 \\
34.0 \\
34.0 \\
34.0 \\
34.0 \\
34.0 \\
34.0 \\
34.0 \\
34.0 \\
34.0 \\
34.0\end{array}$ & $\begin{array}{l}4 \\
4 \\
4 \\
4 \\
4 \\
4 \\
4 \\
4 \\
4 \\
4 \\
4 \\
4 \\
4 \\
4 \\
4 \\
4 \\
4 \\
4 \\
4 \\
4\end{array}$ & $\begin{array}{l}138 \\
138 \\
138 \\
138 \\
138 \\
138 \\
138 \\
138 \\
138 \\
138 \\
138 \\
138 \\
138 \\
138 \\
138 \\
138 \\
138 \\
138 \\
138 \\
138 \\
138\end{array}$ & $\begin{array}{l}5.8 \\
5.8 \\
5.8 \\
5.8 \\
5.8 \\
5.8 \\
5.8 \\
5.8 \\
5.8 \\
5.8 \\
5.8 \\
5.8 \\
5.8 \\
5.8 \\
5.8 \\
5.8 \\
5.8 \\
5.8 \\
5.8 \\
5.8\end{array}$ & $\begin{array}{l}2.87 \\
2.87 \\
2.87 \\
2.87 \\
2.87 \\
2.87 \\
2.87 \\
2.87 \\
2.87 \\
2.87 \\
2.87 \\
2.87 \\
2.87 \\
2.87 \\
2.87 \\
2.87 \\
2.87 \\
2.87 \\
2.87 \\
2.87\end{array}$ & $\begin{array}{l}88.3 \\
100.0 \\
100.0 \\
99.1 \\
100.0 \\
100.0 \\
6 \\
98.2 \\
100.0 \\
100.0 \\
100.0 \\
100.0 \\
100.0 \\
100.0 \\
100.0 \\
100.0 \\
100.0 \\
100.0 \\
100.0 \\
100.0\end{array}$ & \begin{tabular}{|l|}
74.3 \\
96.0 \\
91.3 \\
84.8 \\
32.3 \\
32.4 \\
32.4 \\
96.2 \\
96.7 \\
92.2 \\
88.9 \\
83.8 \\
91.1 \\
84.8 \\
24.2 \\
78.9 \\
64.0 \\
63.3 \\
74.1 \\
95.4 \\
90.3
\end{tabular} & $\begin{array}{l}90.8 \\
100.0 \\
70.8 \\
88.2 \\
22.8 \\
1.6 \\
0.0 \\
95.4 \\
97.1 \\
97.4 \\
84.6 \\
94.2 \\
94.2 \\
18.9 \\
73.6 \\
72.7 \\
85.4 \\
94.7 \\
99.2 \\
90.4\end{array}$ & $\begin{array}{l}98.3 \\
97.3 \\
93.2 \\
91.1 \\
90.0 \\
87.5 \\
96.2 \\
95.0 \\
96.4 \\
92.5 \\
94.9 \\
98.2 \\
96.2 \\
95.5 \\
98.7 \\
98.6 \\
97.5 \\
91.7 \\
85.1 \\
92.8\end{array}$ & $\begin{array}{l}\text { KA (1996) } \\
\text { KA (1996) } \\
\text { KA (1996) } \\
\text { KA (1996) } \\
\text { KA (1996) } \\
\text { KA (1996) } \\
\text { KA (1996) } \\
\text { KA (1996) } \\
\text { KA (1996) } \\
\text { KA (1996) } \\
\text { KA (1996) } \\
\text { KA (1996) } \\
\text { KA (1996) } \\
\text { KA (1996) } \\
\text { KA (1996) } \\
\text { KA (1996) } \\
\text { KA (1996) } \\
\text { KA (1996) } \\
\text { KA (1996) } \\
\text { KA (1996) }\end{array}$ \\
\hline Kleber Dam, MI & Full discharge nibling & Mixed resident lish & - & - & Adulls & 5.7 & - & 450 & 13.4 & - & - & - & - & 59.0 & EPRI (1992) \\
\hline $\begin{array}{l}\text { la centralo do Beauharnois, } \\
\text { Quebec, Canada }\end{array}$ & Fioal lag & American eol & 122 & - & 881 & 262.7 & $\boldsymbol{\theta}$ & 94.7 & 24.1 & 6.32 & NA & 95.9 & - & 76.1 & Desrochers (1895) \\
\hline Litilo Gooso, WA & PIT log & Chinook salmon & - & - & - & 509.8 & $\theta$ & 90 & 28.3 & 7.02 & $\cdot$ & $\cdot$ & - & 92.0 & Mulr ol al. (1995) \\
\hline Lowoll, MA & Radlo telemetry & Allantic Salmon & 50 & 0 & 265 & 127.4 & 5 & 120 & 11.9 & 3.86 & NA & 100.0 & NA & 88.5 & Nelson et al. (1989) \\
\hline $\begin{array}{l}\text { Lower Granile, WA } \\
\text { Lower Granlte, WA } \\
\text { Lower Granite, WA } \\
\text { Lower Granite. WA } \\
\text { Lower Granile, WA } \\
\text { Lower Granlte, WA } \\
\text { Lower Granile, WA } \\
\text { Lower Granilo, WA }\end{array}$ & $\begin{array}{l}\text { Hl.Z Turb'N Tag } \\
\text { H.-Z Turb'N Tag } \\
\text { PIT lagging } \\
\text { HI.ZZ Turb'N Tag } \\
\text { H1.Z Tuib'N Tag } \\
\text { HI.Z Turb'N Tag } \\
\text { Hl.Z Turb'N Tag } \\
\text { HI.Z Turb'N Tag }\end{array}$ & $\begin{array}{l}\text { Chinook Salmon } \\
\text { Chinook Salmon } \\
\text { Chinook Salmon } \\
\text { Chinook Salmon } \\
\text { Chinook Salmon } \\
\text { Chinook Salmon } \\
\text { Chinook Salmon } \\
\text { Chlnook Salmon }\end{array}$ & $\begin{array}{l}820 \\
320 \\
3,200 \\
320 \\
250 \\
300 \\
250 \\
320\end{array}$ & $\begin{array}{l}821 \\
320 \\
1,600 \\
320 \\
250 \\
300 \\
250 \\
320\end{array}$ & $\begin{array}{l}134 \\
151 \\
151 \\
150 \\
148 \\
148 \\
151 \\
150\end{array}$ & $\begin{array}{l}594.7 \\
509.8 \\
509.8 \\
509.8 \\
382.3 \\
538.1 \\
509.8 \\
509.8\end{array}$ & $\begin{array}{l}6 \\
6 \\
6 \\
6 \\
6 \\
6 \\
6 \\
6 \\
6 \\
6\end{array}$ & $\begin{array}{l}90 \\
80 \\
90 \\
90 \\
90 \\
90 \\
80 \\
80\end{array}$ & $\begin{array}{l}29.9 \\
29.9 \\
29.9 \\
29.9 \\
29.9 \\
29.9 \\
29.9 \\
29.9\end{array}$ & $\begin{array}{l}7.92 \\
7.92 \\
7.92 \\
7.92 \\
7.92 \\
7.92 \\
7.92 \\
7.92\end{array}$ & $\begin{array}{l}97.8 \\
98.4 \\
N A \\
98.4 \\
98.4 \\
99.3 \\
99.6 \\
98.1\end{array}$ & $\begin{array}{l}94.5 \\
96.8 \\
- \\
96.6 \\
96.4 \\
96.7 \\
98.1 \\
98.2\end{array}$ & $\begin{array}{l}98.8 \\
98.7 \\
- \\
98.7 \\
99.6 \\
99.3 \\
98.1 \\
98.1\end{array}$ & $\begin{array}{l}94.6 \\
94.9 \\
92.7 \\
95.3 \\
97.2 \\
94.6 \\
97.5 \\
97.5\end{array}$ & $\begin{array}{l}\text { RMC ol al. (1994) } \\
\text { Normandeau el al. (1995) } \\
\text { Muir et al. (1M75) } \\
\text { Normandeau ot al. (1995) } \\
\text { Normandeau ol al. (1995) } \\
\text { Normandeau ol al. (1995) } \\
\text { Normandeau ot al. (1995) } \\
\text { Normandeau el al. (1995) }\end{array}$ \\
\hline
\end{tabular}


Tablo 10.1-2

Physlcal and hydraullc characteristics of all hydroslectric dams equipped wilh Kaplan typo turblnes for whlch survival data aro avallablo.

\begin{tabular}{|c|c|c|c|c|c|c|c|c|c|c|c|c|c|c|c|}
\hline \multirow[b]{2}{*}{ Station } & \multirow[b]{2}{*}{ Sampllng Mothod } & \multirow[b]{2}{*}{ Speclos Tested } & \multirow{2}{*}{$\begin{array}{l}\text { Tosi } \\
\text { Samplo } \\
\text { Slzo }\end{array}$} & \multirow{2}{*}{$\begin{array}{l}\text { Control } \\
\text { Sample } \\
\text { Slzo } \\
\end{array}$} & \multirow{2}{*}{$\begin{array}{l}\text { Avg. Fish } \\
\text { Length } \\
\text { (mm) }\end{array}$} & \multirow{2}{*}{$\begin{array}{l}\text { Turblno } \\
\text { Dlschargo } \\
\text { (cms) }\end{array}$} & \multirow{2}{*}{$\begin{array}{l}\text { No. } \\
\text { of } \\
\text { Blades }\end{array}$} & \multirow{2}{*}{$\begin{array}{l}\text { Gunner } \\
\text { Speed } \\
\text { (rpm) }\end{array}$} & \multirow{2}{*}{$\begin{array}{l}\text { Hoad } \\
\text { (m) }\end{array}$} & \multirow{2}{*}{$\begin{array}{l}\text { Runnor } \\
\text { Dla. } \\
\text { (m) }\end{array}$} & \multirow{2}{*}{$\begin{array}{l}\text { Control } \\
\text { Survival } \\
(\%)\end{array}$} & \multicolumn{2}{|c|}{$\begin{array}{c}\text { Porcont } \\
\text { Pecaplure }\end{array}$} & \multirow{2}{*}{$\begin{array}{l}\% \\
\text { Survival } \\
1 \text { hr }\end{array}$} & \multirow[b]{2}{*}{ Source } \\
\hline & & & & & & & & & & & & Test & Control & & \\
\hline Lower Monumental, WA & PIT lag & Chlnook Salmon & - & - & - & 609.8 & 6 & 80 & 28.7 & 7.92 & - & $\cdot$ & $\cdot$ & 86.5 & Muir ef al. (1995) \\
\hline Marshall, NC & Partial nolling & Resldent spp. & 2,544 & 2,544 & - & 35.4 & 4 & 212 & 8.6 & 3.79 & - & - & 39.0 & 82.3 & EPPI (1992) \\
\hline McNary, WA & Brand/partlal nolting & Chinook salmon & 120,000 & 120,000 & 52 & 348.3 & 6 & 82.5 & 24.4 & 7.11 & $\cdot$ & $<5.0$ & $<5.0$ & 89.0 & Schoeneman el al. (1961) \\
\hline $\begin{array}{l}\text { Morrow, MI } \\
\text { Morrow, MI } \\
\text { Morrow, MI } \\
\text { Morrow, MI } \\
\text { Morrow, MI } \\
\text { Morrow, MI } \\
\text { Morrow, MI } \\
\text { Morrow, MI } \\
\text { Morrow, MI }\end{array}$ & $\begin{array}{l}\text { Full discharge nelling } \\
\text { Full discharge nelling } \\
\text { Full discharge nelling } \\
\text { Full discharge nelling } \\
\text { Full discharge neitling } \\
\text { Full discharge nelling } \\
\text { Futl discharge netling } \\
\text { Full discharge netling } \\
\text { Full dlscharge netling }\end{array}$ & $\begin{array}{l}\text { Brown Bullhead } \\
\text { Pumpkinsed } \\
\text { Black Crappio } \\
\text { Whlle Sucker } \\
\text { Yollow Perch } \\
\text { Redhorse } \\
\text { Largemoulh Bass } \\
\text { Northem Plke } \\
\text { Yollow Bullhoad }\end{array}$ & $\begin{array}{l}117 \\
88 \\
90 \\
64 \\
39 \\
31 \\
24 \\
21 \\
39\end{array}$ & $\begin{array}{l}39 \\
22 \\
33 \\
29 \\
5 \\
10 \\
5 \\
1 \\
5\end{array}$ & $\begin{array}{l}\text { Adull } \\
\text { Adulliyoy } \\
\text { AdulliYoY } \\
\text { AdulliYoY } \\
\text { Adult } \\
\text { Adull } \\
\text { Adull } \\
\text { Adult } \\
\text { Adult }\end{array}$ & $\begin{array}{l}6.7 \\
6.7 \\
6.7 \\
6.7 \\
6.7 \\
6.7 \\
6.7 \\
6.7 \\
6.7\end{array}$ & $:$ & $\begin{array}{l}175 \\
175 \\
175 \\
175 \\
175 \\
175 \\
175 \\
175 \\
175\end{array}$ & $\begin{array}{l}3.7 \\
3.7 \\
3.7 \\
3.7 \\
3.7 \\
3.7 \\
3.7 \\
3.7 \\
3.7\end{array}$ & $\begin{array}{l}1.37 \\
1.37 \\
1.37 \\
1.37 \\
. .37 \\
1.37 \\
1.37 \\
1.37 \\
1.37\end{array}$ & $\begin{array}{l}100.0 \\
100.0 \\
93.0 \\
100.0 \\
100.0 \\
100.0 \\
100.0 \\
0.0 \\
100.0\end{array}$ & $\begin{array}{l}75.2 \\
86.4 \\
67.8 \\
79.7 \\
82.1 \\
87.1 \\
87.5 \\
95.2 \\
82.1\end{array}$ & $\begin{array}{l}84.6 \\
100.0 \\
90.9 \\
100.0 \\
100.0 \\
100.0 \\
100.0 \\
100.0 \\
100.0\end{array}$ & $\begin{array}{l}97.0 \\
90.0 \\
74.0 \\
67.0 \\
78.0 \\
71.0 \\
81.0 \\
45.0 \\
92.0\end{array}$ & $\begin{array}{l}\text { EPRI (1992) } \\
\text { EPPI (1992) } \\
\text { EPPI (1992) } \\
\text { EPRI (1992) } \\
\text { EPPI (1992) } \\
\text { EPRI (1992) } \\
\text { EPRI (1992) } \\
\text { EPRI (1992) } \\
\text { EPRI (1902) }\end{array}$ \\
\hline $\begin{array}{l}\text { Racine, WI } \\
\text { Racine, WI } \\
\text { Racine, WI }\end{array}$ & $\begin{array}{l}\text { Partial nelling } \\
\text { Partial netling } \\
\text { Partial nelling }\end{array}$ & $\begin{array}{l}\text { Gizzard shad } \\
\text { Drum } \\
\text { Game species }\end{array}$ & $\dot{-}$ & : & : & $\begin{array}{l}226.6 \\
226.6 \\
226.6\end{array}$ & $\begin{array}{l}4 \\
4 \\
4\end{array}$ & $\begin{array}{l}62.1 \\
62.1 \\
62.1\end{array}$ & $\begin{array}{l}6.7 \\
6.7 \\
6.7\end{array}$ & $\begin{array}{l}7.71 \\
7.71 \\
7.71\end{array}$ & $\begin{array}{l}\text { NA } \\
\text { NA } \\
\text { NA }\end{array}$ & $\dot{-}$ & $\vdots$ & $\begin{array}{l}93.5^{\circ} \\
94.0^{\circ} \\
94.0^{\circ}\end{array}$ & $\begin{array}{l}\text { EPRI (1992) } \\
\text { EPRI (1992) } \\
\text { EPRI (1992) }\end{array}$ \\
\hline $\begin{array}{l}\text { Rock Island, WA (bulb lurbine) } \\
\text { Rock Island, WA (bulb lurbine) } \\
\text { Rock Island, WA (bulb lurbine) } \\
\text { Rock Island, WA (PH 1, Unil 4) } \\
\text { Rock Island, WA (PH 1, Unil 5) }\end{array}$ & $\begin{array}{l}\text { Brand/partlal nelling } \\
\text { Brand/parlial nelling } \\
\text { HI.Z Turb'N Tag } \\
\text { HI.Z Turb'N Tag } \\
\text { HI.Z Turb'N Tag }\end{array}$ & $\begin{array}{l}\text { Coho salmon } \\
\text { Stealhead } \\
\text { Chinook Salmon } \\
\text { Chinook Salmon } \\
\text { Chinook Salmon }\end{array}$ & $\begin{array}{l}203,330 \\
58,571 \\
280 \\
280 \\
280\end{array}$ & $\begin{array}{l}203,843 \\
57,864 \\
140 \\
140 \\
140\end{array}$ & $\begin{array}{l}115 \\
166 \\
162 \\
162 \\
162\end{array}$ & $\begin{array}{l}509.8 \\
509.8 \\
4984.4 \\
481.5 \\
481.5\end{array}$ & $\begin{array}{l}4 \\
4 \\
4 \\
6 \\
6\end{array}$ & $\begin{array}{l}85.7 \\
85.7 \\
85.7 \\
100 \\
100\end{array}$ & $\begin{array}{l}12.2 \\
12.2 \\
12.2 \\
13.7 \\
13.7\end{array}$ & $\begin{array}{l}7.01 \\
7.01 \\
7.01 \\
5.74 \\
5.74\end{array}$ & $\begin{array}{l}\text { NA } \\
\text { NA } \\
100.0 \\
100.0 \\
100.0\end{array}$ & $\begin{array}{l}18.4 \\
17.9 \\
100.0 \\
100.0 \\
100.0\end{array}$ & $\begin{array}{l}19.5 \\
18.5 \\
100.0 \\
100.0 \\
100.0\end{array}$ & $\begin{array}{l}93.0 \\
96.9 \\
96.1 \\
95.0 \\
96.1\end{array}$ & $\begin{array}{l}\text { Olson \& Kaczynskl (1980) } \\
\text { Olson \& Kaczynski (1980) } \\
\text { Normandeau \& Skalski (1997) } \\
\text { Normandeau \& Skalski (1997) } \\
\text { Normandeau \& Skalski (1997) }\end{array}$ \\
\hline 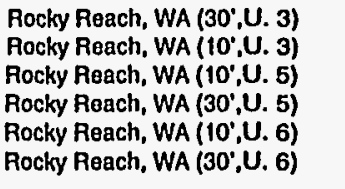 & $\begin{array}{l}\text { Hl-Z Turb'N Tag } \\
\text { Hl-Z Tuib'N Tag } \\
\text { Hl-Z Turb'N Tag } \\
\text { Hl-Z Turb'N Tag } \\
\text { HI-Z Turb'N Tag } \\
\text { HI-Z Tuib'N Tag }\end{array}$ & $\begin{array}{l}\text { Chinook Salmon } \\
\text { Chinook Salmon } \\
\text { Chinook Salmon } \\
\text { Chlnook Salmon } \\
\text { Chinook Salmon } \\
\text { Chinook Salmon }\end{array}$ & $\begin{array}{l}250 \\
350 \\
235 \\
241 \\
420 \\
235\end{array}$ & $\begin{array}{l}250 \\
350 \\
300 \\
220 \\
300 \\
220\end{array}$ & $\begin{array}{l}161 \\
161 \\
184 \\
184 \\
184 \\
184\end{array}$ & $\begin{array}{l}453.1 \\
453.1 \\
339.5 \\
396.5 \\
396.5 \\
398.5\end{array}$ & $\begin{array}{l}6 \\
6 \\
6 \\
6 \\
6 \\
6\end{array}$ & $\begin{array}{l}90 \\
90 \\
90 \\
90 \\
90 \\
90\end{array}$ & $\begin{array}{l}28.0 \\
28.0 \\
28.0 \\
28.0 \\
28.0 \\
28.0\end{array}$ & $\begin{array}{l}7.11 \\
7.11 \\
7.11 \\
7.11 \\
7.11 \\
7.11\end{array}$ & $\begin{array}{l}\mathbf{9 8 . 9} \\
\mathbf{9 8 . 9} \\
\mathbf{9 9 . 0} \\
\mathbf{9 7 . 3} \\
\mathbf{9 9 . 0} \\
\mathbf{9 7 . 3}\end{array}$ & $\begin{array}{l}96.4 \\
95.0 \\
98.3 \\
98.3 \\
96.3 \\
97.6 \\
97.1\end{array}$ & $\begin{array}{l}98.8 \\
96.0 \\
99.0 \\
97.7 \\
99.0 \\
97.7\end{array}$ & $\begin{array}{l}94.7 \\
93.9 \\
97.3 \\
94.4 \\
94.2 \\
95.8\end{array}$ & $\begin{array}{l}\text { Mathur et al. (1996) } \\
\text { Mathur et al. (1996) } \\
\text { Normandeau \& Skalskl (1996) } \\
\text { Normandeau \& Skalski (1996) } \\
\text { Normandeau \& Skalski (1996) } \\
\text { Normandeau \& Skalski (1996) }\end{array}$ \\
\hline Sale Harbor, PA (Unlt 7) & HI-Z Turb'N Tag & American Shad & 100 & 100 & 118 & 235.1 & 5 & 109 & 16.8 & 5.64 & 99.0 & 99.0 & 99.0 & 98.0 & Heisey el al. (1992) \\
\hline $\begin{array}{l}\text { Thomapple, WI } \\
\text { Thomapple, WI } \\
\text { Thomapple, WI } \\
\text { Thomapple, WI } \\
\text { Thomapple, WI } \\
\text { Thornapple, WI }\end{array}$ & $\begin{array}{l}\text { Full discharge nelling } \\
\text { Full discharge nelling } \\
\text { Full discharge nelling } \\
\text { Full discharge nelling } \\
\text { Full discharge nelling } \\
\text { Full discharge nelling }\end{array}$ & $\begin{array}{l}\text { Indigenous spp. } \\
\text { Bullheads/Callish } \\
\text { Suckers/Redhorse } \\
\text { Panlish/Y. Perch } \\
\text { N. Pike/Muskilunge } \\
\text { Burbot }\end{array}$ & $\begin{array}{l}3,378 \\
\vdots \\
\vdots \\
-\end{array}$ & $\begin{array}{l}: \\
: \\
: \\
:\end{array}$ & : & $\begin{array}{l}19.8 \\
: \\
- \\
- \\
-\end{array}$ & $\begin{array}{l}6 \\
6 \\
6 \\
6 \\
6 \\
6\end{array}$ & $\begin{array}{l}120 \\
120 \\
120 \\
120 \\
120 \\
120\end{array}$ & $\begin{array}{l}4.6 \\
: \\
: \\
: \\
:\end{array}$ & $\begin{array}{l}2.79 \\
2.79 \\
2.79 \\
2.79 \\
2.79 \\
2.79\end{array}$ & $\begin{array}{l}: \\
: \\
:\end{array}$ & : & $\dot{:}$ & $\begin{array}{l}95.3 \\
91.9 \\
93.4 \\
93.5 \\
94.1 \\
96.9\end{array}$ & $\begin{array}{l}\text { EPRI (1992) } \\
\text { EPRI (1992) } \\
\text { EPRI (1992) } \\
\text { EPRI (1992) } \\
\text { EPRI (1992) } \\
\text { EPRI (1992) }\end{array}$ \\
\hline
\end{tabular}


Table 10.1-2

Physleal and hydraulle characterlstics of all hydroelectric dams oquipped wlth Kaplan type turblnes for whlch survival data are avallable.

\begin{tabular}{|c|c|c|c|c|c|c|c|c|c|c|c|c|c|c|c|}
\hline \multirow{2}{*}{ Slation } & \multirow{2}{*}{ Sampling Melhod } & \multirow{2}{*}{ Spacles Tested } & \multirow{2}{*}{$\begin{array}{l}\text { Test } \\
\text { Samplo } \\
\text { Slze } \\
\end{array}$} & \multirow{2}{*}{$\begin{array}{l}\text { Gontral } \\
\text { Somplo } \\
\text { Size } \\
\end{array}$} & \multirow{2}{*}{$\begin{array}{l}\text { Avg. Fish } \\
\text { Longlh } \\
\text { (mm) }\end{array}$} & \multirow{2}{*}{$\begin{array}{l}\text { Turblne } \\
\text { Discharge } \\
\text { (cms) } \\
\end{array}$} & \multirow{2}{*}{$\begin{array}{l}\text { No. } \\
\text { of } \\
\text { Blados } \\
\end{array}$} & \multirow{2}{*}{$\begin{array}{l}\text { Runner } \\
\text { Speed } \\
\text { (rpm) }\end{array}$} & \multirow{2}{*}{$\begin{array}{l}\text { Head } \\
\text { (m) }\end{array}$} & \multirow{2}{*}{$\begin{array}{l}\text { Aunner } \\
\text { Dla. } \\
\text { (m) }\end{array}$} & \multirow{2}{*}{$\begin{array}{l}\text { Control } \\
\text { Survlval } \\
\text { (\%) }\end{array}$} & \multicolumn{2}{|c|}{$\begin{array}{c}\text { Percent } \\
\text { Recapture }\end{array}$} & \multirow{2}{*}{$\begin{array}{l}\% \\
\text { Survival } \\
1 \mathrm{hr} \\
\end{array}$} & \multirow[b]{2}{*}{ Source } \\
\hline & & & & & & & & & & & & Test & & & \\
\hline Thomapple, WI & Full dischargo nelling & Mnnw/Dace/Drt & $\cdot$ & $\cdot$ & - & $=$ & 6 & 120 & - & 2.79 & - & - & $\cdot$ & 97.1 & EPRI (1992) \\
\hline Thomapplo, WI & Fuli dischargo netling & Sm/Lgmlh Bass & - & - & - & - & 6 & 120 & - & 2.79 & - & - & - & 97,4 & EPRI (1992) \\
\hline Thomapple, WI & Full discharge nolling & Walleye & - & - & - & - & 6 & 120 & - & 2.79 & - & - & - & 97.6 & EPRI (1992) \\
\hline Townsend Dam, PA & HI-Z Turb'N Tag & Largemouth Bass & 31 & NA & 217 & 42.5 & 3 & 152 & 4.9 & 2.87 & NA & 96.8 & NA & 96.8 & RMC (1994) \\
\hline Townsen̨d Dam, PA & Hl-Z Turb'N Tag & Rainbow Trout & 54 & 52 & 139 & 22.7 & 3 & 152 & 4.9 & 2.87 & 100.0 & 96.3 & 100.0 & 94.4 & RMC (1994) \\
\hline Townsend Dam, PA & Hl.Z Turb'N Tag & Rainbow Troul & 52 & 51 & 344 & 22.7 & 3 & 152 & 4.9 & 2.87 & 100.0 & 92.3 & 94.1 & 86.5 & RMC (1994) \\
\hline Townsend Dam, PA & HH.Z Turb'N Tag & Largemoulh Bass & 51 & 50 & 102 & 22.7 & 3 & 152 & 4.9 & 2.87 & 98.0 & 98.0 & $\mathbf{9 8 . 0}$ & 100.0 & PMC (1994) \\
\hline Townsend Dam, PA & HI-Z Turb'N Tag & Largemouth Bass & 50 & 50 & 217 & 22.7 & 3 & 152 & 4.9 & 2.87 & 100.0 & 100.0 & 100.0 & 86.0 & RMC (1994) \\
\hline Townsend Dam. PA & HI-Z Turb'N Tag & Rainbow Trout & 21 & NA & 139 & 42.5 & 3 & 152 & 4.9 & 2.87 & NA & 100.0 & NA & 100.0 & PMC (1994) \\
\hline Tuskel, NS & Drall lube nel & Allantic salmon & - & - & - & - & - & 225 & 8.2 & - & - & - & - & 84.5 & Puggles of al. (1990) \\
\hline Twin Branch, IN & Full discharge nelling & Stoolhoad Trout & 300 & 300 & 186 & 11.6 & 4 & 241 & 6.5 & NA & - & 65.0 & 79.7 & 93.2 & RMC (1994) \\
\hline Twin Branch, IN & Full discharge nelling & Chinook Salmon & 600 & 450 & 121 & 11.6 & 4 & 241 & 6.5 & NA & - & 97.5 & 99.3 & 99.3 & FMC (1994) \\
\hline Twin Branch, IN & Full discharge nelting & Bluegill & 300 & 300 & 126 & 11.6 & 4 & 241 & 6.5 & NA & - & 73.0 & 57.7 & 94.7 & RMC (1994) \\
\hline T.W. Sullivan, OA (Unil 7) & Full discharge nelling & Steolhead & 1,800 & 600 & 128 & 11.0 & 6 & 240 & 12.8 & 1.78 & 92.8 & 6.6 & 44.6 & 92.3 & Massen (1967) \\
\hline T.W. Sullivan, OA (Unil 7) & Full dlscharge nelling & Chinook salmon & 1,800 & 500 & 112 & 11.0 & 6 & 240 & 12.8 & 1.78 & 97.3 & 23.6 & 89.6 & 88.2 & Massen (1967) \\
\hline T.W. Sulllvan, OR (Unil O) & Full discharge nelling & Steolhead & 1,800 & 500 & 128 & 7.4 & 6 & 240 & 12.8 & 1.78 & 99.0 & 43.2 & 97.0 & 90.1 & Massen (1967) \\
\hline T.W. Sullivan, OR (Unil 8) & Full dischargo nalling & Chinook salmon & 1,800 & 500 & 112 & 7.4 & 6 & 240 & 12.8 & 1.78 & 98.4 & 61.1 & 100.0 & 89.5 & Masson (1967) \\
\hline Wallerville, OR(61\% wckl) & Brand, full dschrg nolling & Ralnbow Trout & 991 & 631 & fingerting & 56.9 & $\cdot$ & $\cdot$ & 16.8 & 3.05 & - & 63.0 & 94.9 & 97.5 & Eicher Associatos (1987) \\
\hline Waltorville, OR(77\% wckl) & Brand, full dschrg nolling & Rainbow Troul & 991 & 631 & fingerling & 56.8 & - & - & 16.8 & 3.05 & - & 36.4 & 68.3 & 92.5 & Eicher Associales (1987) \\
\hline Waltorville, OR & Brand,dwnstr bypass Irap & Chinook Salmon & 30,000 & 30,000 & 135 & 56.6 & - & : & 16.8 & 3.05 & - & - & - & 87.0 & Elcher Associates (1987) \\
\hline Wanapum, WA (10It, Unit 9) & HI-Z Turb'N Tag & Coho Salmon & 158 & 160 & 154 & 254.9 & 5 & 85.7 & 22.9 & 7.24 & 88.8 & 92.4 & 98.8 & 89.7 & Normandeau et al. (1996) \\
\hline Wanapum, WA (1011, Unil 9) & HI-Z Turb'N Tag & Coho Saimon & 160 & 160 & 154 & 311.5 & 5 & 85.7 & 22.9 & 7.24 & 96.9 & 93.1 & 96.9 & 92.4 & Nomandeau el al. (1996) \\
\hline Wanapum, WA (10lt, Unlt 0) & HI-Z Turb'N Tag & Colio Salmon & 160 & 160 & 154 & 424.8 & 5 & 85.7 & 22.9 & 7.24 & 97.5 & 93.8 & 97.5 & 94.8 & Normandeau el al. (1996) \\
\hline Wanapum, WA (toll, Unil 9) & HH.Z Tub'N Tag & Colio Salman & 160 & 160 & 154 & 481.5 & 5 & 85.7 & 22.9 & 7.24 & 09.4 & 88.2 & 09.4 & 88.5 & Nomandeau of al. (1096) \\
\hline Wanapum, WA (30ll, Unil 9) & HI.Z Turb'N Tag & Coho Salmon & 160 & 160 & 154 & 254.9 & 5 & 85.7 & 22.9 & 7.24 & 98.8 & 95.7 & 98.8 & 94.9 & Normandeau of al. (1996) \\
\hline Wanapum, WA (30ll, Unil 9) & HI-Z Turb'N Tag & Coho Salmon & 160 & 160 & 154 & 311.5 & 5 & 85.7 & 22.9 & 7.24 & 86.9 & 95.6 & 96.9 & 96.8 & Normandeau el al. (1996) \\
\hline Wanapum, WA (30ll, Unil 9) & HI-Z Turb'N Tag & Coho Salmon & 160 & 160 & 154 & 424.8 & 5 & 85.7 & 22.9 & 7.24 & 97.4 & 98.1 & 97.4 & 100.0 & Normandeau of al. (1996) \\
\hline Wanapum, WA (30It, Unil 9) & HI-2 Turb'N Tag & Coho Salmon & 160 & 160 & 154 & 481.5 & 5 & 85.7 & 22.9 & 7.24 & 97.4 & 96.2 & 89.4 & 98.8 & Normandoau of al. (1996) \\
\hline Wells, WA(Unit 1) & Brand, Partlal nolling & Sloolhead & - & - & smolls & 568.4 & 6 & 85.7 & 19.8 & 7.43 & NA & - & - & 84.0 & Parametrix (1986) \\
\hline Wost Enliald, ME & Radlo tolemetry & Allantlc Salmon & 148 & NA & 212 & 150.1 & 3 & 89 & 6.4 & 4.88 & NA & 100.0 & NA & 98.0 & Shopard (1988) \\
\hline Wilder, VT-NH & HI-Z Turb'N Tag & Allantlo Salmon & 125 & 125 & 191 & 127.4 & 5 & 112.5 & 15.5 & 4.57 & 100.0 & 89.2 & 100.0 & 98.0 & RMC (1994) \\
\hline
\end{tabular}

$N A=$ Not Avallable, Not Ap
$N E=$ Nalurally Entralned

- Agency agreed upon estimalos

-. Release numbers unavallable al present but the sludy appears valld and meets the screening criteria. When release numbers become avallable they will be included 


\section{Table 10.1-3}

Physical and hydraulle charactorlsllcs of all hydroelectric dams equipped with propellor type turbines for which survival data are avallable.

\begin{tabular}{|c|c|c|c|c|c|c|c|c|c|c|c|c|c|c|c|}
\hline & & & $\begin{array}{l}\text { Test } \\
\text { Samplo }\end{array}$ & $\begin{array}{l}\text { Control } \\
\text { Samplo }\end{array}$ & $\begin{array}{l}\text { Avg. Fish } \\
\text { Length }\end{array}$ & $\begin{array}{l}\text { Turblne } \\
\text { Dlscharge }\end{array}$ & $\begin{array}{l}\text { No. } \\
\text { of }\end{array}$ & $\begin{array}{l}\text { Funner } \\
\text { Speed }\end{array}$ & Head & $\begin{array}{l}\text { Runner } \\
\text { Dla. }\end{array}$ & $\begin{array}{l}\text { Control } \\
\text { Survival }\end{array}$ & & $\begin{array}{l}\text { icont } \\
\text { aplure }\end{array}$ & $\begin{array}{l}\text { Est. } \\
\text { Porcent }\end{array}$ & \\
\hline Station & Sampling Mothod & Specles Tosted & & & & & & & (m) & & & Test & Conlrol & Survival & Source \\
\hline Hadley Falls, MA & Hl-Z Turb'N Tag & American Shad & 120 & 120 & 82 & 118.8 & 5 & 150 & 15.8 & 4.32 & 83.3 & 74.2 & 83.3 & 89.1 & RMC (1992) \\
\hline Rocky Reach, WA $(10$, U. 8) & Hl.Z Turb'N Tag & Chlnook Salmon & 265 & 265 & 114 & 566.4 & 5 & 85.7 & 26.4 & 7.80 & 88.7 & 85.7 & 88.7 & 96.9 & RMC \& Skalski (1994) \\
\hline $\begin{array}{l}\text { Sale Harbor, PA (Unit 8) } \\
\text { Sale Harbor, PA (Unit 8) }\end{array}$ & $\begin{array}{l}\text { H1.Z Turb'N Tag } \\
\text { HI-Z Turb'N Tag }\end{array}$ & $\begin{array}{l}\text { American Shad } \\
\text { American Shad }\end{array}$ & $\begin{array}{l}100 \\
100\end{array}$ & $\begin{array}{l}100 \\
100\end{array}$ & $\begin{array}{l}118 \\
118\end{array}$ & $\begin{array}{l}260.5 \\
260.5\end{array}$ & $\begin{array}{l}7 \\
7\end{array}$ & $\begin{array}{l}75 \\
75\end{array}$ & $\begin{array}{l}16.8 \\
16.8\end{array}$ & $\begin{array}{l}6.15 \\
6.15\end{array}$ & $\begin{array}{l}92.0 \\
98.0\end{array}$ & $\begin{array}{l}92.0 \\
96.0\end{array}$ & $\begin{array}{l}92.0 \\
98.0\end{array}$ & $\begin{array}{l}97.8 \\
98.9\end{array}$ & $\begin{array}{l}\text { Heisey et al. (1992) } \\
\text { Heisey et al. (1992) }\end{array}$ \\
\hline
\end{tabular}


Table 10.1-4

Comparison of physical and hydraulic characteristics of hydroelectric dams equipped with Francis type turbines.

\begin{tabular}{|c|c|c|c|c|c|c|}
\hline Station & $\begin{array}{l}\text { Designed } \\
\text { Turbine } \\
\text { Flow (cms) }\end{array}$ & $\begin{array}{l}\text { Number } \\
\text { of } \\
\text { Buckets }\end{array}$ & $\begin{array}{l}\text { Runner } \\
\text { Speed } \\
\text { (rpm) }\end{array}$ & $\begin{array}{l}\text { Head } \\
(m)\end{array}$ & $\begin{array}{l}\text { Runner } \\
\text { Diameter } \\
\text { (m) }\end{array}$ & $\begin{array}{l}\text { Peripheral } \\
\text { Velocity } \\
\text { (m/s) }\end{array}$ \\
\hline Alcona, MI & 17.4 & 16 & 90 & 13.1 & 2.54 & 12.0 \\
\hline Alcona, MI & 47.0 & 16 & 90 & 13.1 & 2.54 & 12.0 \\
\hline Baker, WA & - & - & 300 & 76.2 & 1.52 & 23.9 \\
\hline Bond Falls, MI & 12.7 & 16 & 300 & 64.0 & 1.84 & 28.9 \\
\hline Buchanan, MI & 2.8 & - & - & - & - & NA \\
\hline Caldron Falls, WI (Unit 1) & 18.4 & 15 & 226 & 24.4 & 1.83 & 21.6 \\
\hline Centralia, WI (Unit 1) & 14.4 & 15 & - & 6.1 & $\cdot$ & $\mathrm{NA}$ \\
\hline Centralia, WI (Unit 2) & 14.4 & 15 & 90 & 6.1 & 0.71 & 3.3 \\
\hline Colton, NY & 14.1 & 19 & 360 & 80.8 & 1.50 & 28.2 \\
\hline Crown Zellerback, OR & 11.5 & - & $2 \pi$ & 11.9 & - & NA \\
\hline Cushman Plant 2, WA (1960) & 22.7 & 17 & 300 & 137.2 & 2.11 & 33.1 \\
\hline Cushman Plant 2, WA & 22.7 & 17 & 300 & 137.2 & 2.11 & 33.1 \\
\hline E. J. West, NY & 76.5 & 15 & 113 & 19.2 & 3.33 & 19.7 \\
\hline Elwha, WA & 14.2 & - & 300 & 31.7 & 1.49 & 23.4 \\
\hline Faraday,OR & - & - & 360 & 36.6 & 1.01 & 19.0 \\
\hline Finch Pruyn, NY (Unit 4) & 20.1 & 15 & 225 & 14.0 & 1.04 & 12.3 \\
\hline Finch Pruyn, NY (Unit 5) & 23.7 & 15 & 225 & 14.0 & 1.04 & 12.3 \\
\hline Five Channels, MI & 19.1 & 16 & 150 & 11.0 & 1.40 & 11.0 \\
\hline Five Channels, MI & 33.1 & 16 & 150 & 11.0 & 1.40 & 11.0 \\
\hline Glines, WA & 44.7 & - & 225 & 59.1 & 2.35 & 27.6 \\
\hline Grand Rapids, WI (U 1,2,4 comb) & 18.3 & 15 & 90 & 8.5 & 1.47 & 6.9 \\
\hline Grand Rapids, WI (Unit 2) & 18.3 & 15 & 150 & 8.5 & 1.47 & 11.6 \\
\hline Grand Rapids, WI (Unit 4) & 26.2 & 6 & 180 & 8.5 & 1.83 & 17.2 \\
\hline Hardy, MI (Unit 2) & 14.4 & 16 & 163.6 & 30.5 & 2.13 & 18.2 \\
\hline High Falls, WI (Unit 5) & 7.8 & 12 & 358 & 25.3 & 0.99 & 18.6 \\
\hline Highley, NY & 19.1 & 13 & 257 & 14.0 & 1.22 & 16.4 \\
\hline Hoist, MI & 8.5 & 19 & 360 & 43.3 & 1.83 & 34.5 \\
\hline Holtwood, PA & 99.1 & 16 & 95 & 16.8 & 4.17 & 20.7 \\
\hline Holtwood, PA (U3/double runner) & 99.1 & 17 & 102.8 & 18.9 & 2.84 & 15.3 \\
\hline Holtwood, PA(U10/single runner) & 99.1 & 16 & 94.7 & 18.9 & 3.80 & 18.8 \\
\hline Leạburg, OR & 31.2 & - & 225 & 27.1 & 2.29 & 26.9 \\
\hline Lequillo, NS & 9.9 & 13 & 519 & 118.0 & 1.37 & 37.3 \\
\hline Luray, VA & 10.5 & 12 & 164 & 5.5 & 1.59 & 13.7 \\
\hline Maclure, MI & 4.4 & - & 600 & 129.2 & - & NA \\
\hline Minetto, NY & 42.5 & 16 & 72 & 5.2 & 3.53 & 13.3 \\
\hline North Fork, OR & 70.8 & - & 139 & 41.5 & 2.96 & 21.5 \\
\hline Peshtigo, WI (Unit 4) & 13.0 & 15 & 100 & 4.0 & 2.03 & 10.6 \\
\hline Potato Rapids, WI (Unit 1) & 14.2 & 15 & 123 & 5.2 & 2.13 & 13.7 \\
\hline Potato Rapids, WI (Unit 2) & 12.5 & 15 & 135 & 5.2 & 2.03 & 14.4 \\
\hline Pricket, MI & 9.2 & 15 & 257 & 16.5 & 1.36 & 18.3 \\
\hline Publishers, OR & 7.9 & - & 300 & 12.8 & 0.91 & 14.4 \\
\hline Puntledge, BC & - & - & 277 & 103.6 & 2.16 & 31.4 \\
\hline Rogers, MI (units 1 \& 2) & 10.8 & 15 & 150 & 11.9 & 1.52 & 12.0 \\
\hline Ruskin, BC & 113.3 & - & 120 & 39.6 & 3.78 & 23.8 \\
\hline Sandstone Rapids,WI & 18.4 & 15 & 150 & 12.8 & 2.21 & 17.3 \\
\hline Schaghticoke, NY (Unit 4) & 11.6 & 17 & 300 & 46.6 & 2.03 & $3+.9$ \\
\hline Seton Creek, BC & 127.4 & - & 120 & 45.7 & 2.90 & 18.2 \\
\hline Shasta, CA & 90.6 & 15 & 138.5 & 115.8 & 4.67 & 33.9 \\
\hline Shasta, CA & 90.6 & 15 & 138.5 & - & 4.67 & 33.9 \\
\hline Stevens Creek, SC & 28.3 & 14 & 75 & 8.5 & 3.43 & 13.5 \\
\hline T. W. Sullivan, OR & 11.8 & - & 240 & 12.8 & 1.88 & 23.6 \\
\hline Vernon, VTNH & 51.9 & 15 & 74 & 10.4 & 3.96 & 15.3 \\
\hline White Rapids, WI & 43.6 & 14 & 100 & 8.8 & 3.40 & 17.8 \\
\hline Youghiogheny, PA & 21.2 & - & - & 36.6 & - & NA \\
\hline
\end{tabular}


Tablo 10.1-5

Physlcal and hydraulle charactoristles of all hydrooloctric dams oquippod with Francls typo turbines for which survival data are avallable.

\begin{tabular}{|c|c|c|c|c|c|c|c|c|c|c|c|c|c|c|}
\hline \multirow[b]{2}{*}{ Statlon } & \multirow{2}{*}{$\begin{array}{l}\text { Sampllng } \\
\text { Mothod }\end{array}$} & \multirow[b]{2}{*}{ Specles Tested } & \multirow{2}{*}{$\begin{array}{l}\text { rost } \\
\text { samplo } \\
\text { size }\end{array}$} & \multirow{2}{*}{$\begin{array}{l}\text { Control } \\
\text { samplo } \\
\text { slzo } \\
\end{array}$} & \multirow{2}{*}{$\begin{array}{l}\text { Avg. Flsh } \\
\text { Longth } \\
\text { (mm) }\end{array}$} & \multirow{2}{*}{$\begin{array}{l}\text { Turblno } \\
\text { Dischargo } \\
\text { (cms) }\end{array}$} & \multirow{2}{*}{$\begin{array}{l}\text { No. } \\
\text { of } \\
\text { Buckets }\end{array}$} & \multirow{2}{*}{$\begin{array}{l}\text { Runner } \\
\text { Speed } \\
\text { (rpm) }\end{array}$} & \multirow{2}{*}{$\begin{array}{l}\text { Head } \\
\text { (m) }\end{array}$} & \multirow{2}{*}{$\begin{array}{l}\text { Runnor } \\
\text { Dla. } \\
\text { (m) } \\
\end{array}$} & \multicolumn{2}{|c|}{$\begin{array}{c}\text { Porcent } \\
\text { Pecapturo } \\
\end{array}$} & \multirow{2}{*}{$\begin{array}{l}\text { \% } \\
\text { Survival } \\
1 \mathrm{hr} \\
\end{array}$} & \multirow[b]{2}{*}{ Sourco } \\
\hline & & & & & & & & & & & Test & Contro! & & \\
\hline Alcona, MI & Full dschrg nelling & Bluegill & 97 & - & 118 & 47.0 & 16 & 90 & 13.1 & 2.54 & 97.0 & - & 80.2 & LMS (1991) \\
\hline Alcona, MI & Full dschrg nelling & Bluegill & 102 & - & 170 & 47.0 & 16 & 90 & 13.1 & 2.54 & 86.0 & - & 84.1 & LMS (1991) \\
\hline Alcona, MI & Full dschrg nolling & Gold./Common Shiner & 51 & - & 114 & 47.1 & 16 & 90 & 13.1 & 2.54 & 86.0 & - & 80.9 & LMS (1991) \\
\hline Alcona, MI & Full dschrg nelling & Gold./Common Shiner & 58 & - & 154 & 47.1 & 16 & 90 & 13.1 & 2.54 & 80.0 & - & 84.7 & LMS (1991) \\
\hline Alcona, MI & Full dschrg nolling & Grass Pickerel & 30 & - & 235 & 47.1 & 16 & 90 & 13.1 & 2.54 & 100.0 & - & 86.7 & $\operatorname{LMS}(1991)$ \\
\hline Alcona, MI & Full dschrg nelling & Northern Pike & 44 & - & 352 & 47.2 & 16 & 90 & 13.1 & 2.54 & 98.0 & - & 51.2 & LMS (1991) \\
\hline Alcona, MI & Full dschrg nelling & Ralnbow Troul & 40 & - & 108 & 47.2 & 16 & 90 & 13.1 & 2.54 & 70.0 & - & 100 & LMS (1991) \\
\hline Alcona, MI & Full dschrg nelling & Falnbow Trout & 40 & - & 317 & 47.2 & 16 & 90 & 13.1 & 2.54 & 70.0 & - & 89.4 & LMS (1991) \\
\hline Alcona, MI & Full dschrg nelling & Spottail Shiner & 40 & - & 116 & 47.2 & 16 & 90 & 13.1 & 2.54 & 88.0 & - & 59.5 & LMS (1991) \\
\hline Alcona, MI & Full dschrg nelling & Walleye & 47 & - & 162 & 47.3 & 16 & 90 & 13.1 & 2.54 & 100.0 & - & 16.4 & LMS (1991) \\
\hline Alcona, MI & Full dschrg netling & Walleye & 45 & - & 385 & 47.3 & 16 & 90 & 13.1 & 2.54 & 100.0 & - & 38.7 & LMS (1991) \\
\hline Alcona, MI & Full dschrg nelling & Whlle Sucker & 60 & - & 180 & 47.3 & 16 & 80 & 13.1 & 2.54 & 100.0 & - & 94.4 & LMS (1991) \\
\hline Alcona, MI & Full dschrg nelling & Whille Sucker & 54 & - & 290 & 47.4 & 16 & 90 & 13.1 & 2.54 & 100.0 & - & 90.4 & LMS (1991) \\
\hline Alcona, MI & Full dschrg nelling & Yollow Perch & 55 & - & 107 & 47.4 & 16 & 90 & 13.1 & 2.54 & 100.0 & - & 65.1 & LMS (1991) \\
\hline Alcona, MI & Full dschrg nelling & Yellow Perch & 45 & $\cdot$ & 186 & 47.4 & 16 & 90 & 13.1 & 2.54 & 89.0 & - & 55.1 & LMS (1991) \\
\hline Baker, WA & Fyke nel & Sockeye salmon & - & - & - & 15.6 & 19 & 300 & 76.2 & 1.52 & - & - & 64.0 & Elcher Associates (1987) \\
\hline Baker, WA & Fyke nel & Colio salmon & - & $\cdot$ & - & 15.6 & 19 & 300 & 76.2 & 1.52 & - & $\cdot$ & 72.0 & Eichor Assoclales (1987) \\
\hline Buchanan, MI & Full dschrg nelling & Chinook salmon & 600 & 400 & 420 & 2.8 & - & - & - & - & 79.7 & 98.3 & 79.6 & RMC (1992) \\
\hline Buchanan, MI & Full dschrg nelling & Sleelhead troul & 600 & 400 & 420 & 6.2 & - & - & - & $\cdot$ & 75.3 & 07.8 & 79.4 & RMC (1992) \\
\hline Bond Falls, MI & Full dschrg netting & Rainbow Trout & 350 & 225 & 210 & 12.7 & - & 300 & 64.0 & - & 82.0 & 97.8 & 83.8 & RMC (1996) \\
\hline Bond Falls, MI & Full dschrg nelling & Yellow Perch & 360 & 225 & 102 & 12.7 & - & 300 & 64.0 & - & 82.5 & 98.7 & 79.5 & RMC (1996) \\
\hline Bond Falls, MI & Full dschrg nelling & Golden Shiner & 405 & 225 & 70 & 12.7 & - & 300 & 64.0 & - & 70.4 & 93.3 & 77.8 & AMC (1996) \\
\hline Bond Falls, MI & Full dschrg nelling & Bluegill & 660 & 450 & 115 & 12.7 & - & 300 & 64.0 & $\cdot$ & 82.1 & 97.3 & 81.7 & RMC (1996) \\
\hline Caldton Falls, WI (Unit 1) & Full dschrg nelling & Centrarchilorms & 144 & 94 & 76 & 18.4 & 15 & 226 & 24.4 & 1.83 & 99.3 & 07.2 & 100.0 & Harza (1995) \\
\hline Caldron Falls, WI (Unlt 1) & Full dschrg netting & Centrarchilorms & 141 & 90 & 127 & 18.4 & 15 & 226 & 24.4 & 1.83 & 87.2 & 92.2 & 98.2 & Harza (1995) \\
\hline Caldron Falls, WI ( Unit 1) & Full dschrg nelling & Centrarchilorms & 76 & 35 & 178 & 18.4 & 15 & 226 & 24.4 & 1.83 & 100.0 & 100.0 & 86.8 & Harza (1995) \\
\hline Caldron Falls, WI ( Unit 1) & Full dschrg netling & Fusiforms & 145 & 86 & 76 & 18.4 & 15 & 226 & 24.4 & 1.83 & 86.9 & 95.3 & 80.3 & Harza (1995) \\
\hline Caldron Falls, WI (Unit i) & Full dschrg netling & Fusiforms & 139 & 92 & 127 & 18.4 & 15 & 226 & 24.4 & 1.83 & 95.7 & 91.3 & 84.8 & Harza (1995) \\
\hline Caldron Falls, WI ( Unit i) & Full dschrg netling & Fusilorms & 125 & 58 & 178 & 18.4 & 15 & 226 & 24.4 & 1.83 & 95.2 & 100.0 & 70.3 & Harza (1995) \\
\hline Caldron Falls, wi (Unil i) & Full dschrg nelling & Fusiforms & 136 & 63 & 229 & 18.4 & 15 & 226 & 24.4 & 1.83 & 100.0 & 98.4 & 64.3 & Harza (1995) \\
\hline Caldion Falls, WI (Unit 1) & Full dschrg nettling & Fusllorms & 146 & 94 & 292 & 18.4 & 15 & 226 & 24.4 & 1.83 & 97.9 & 85.0 & 59.5 & Harza (1995) \\
\hline Caldron Falls, WI (Unit 1) & Full dschrg nelling & Fuslforms & 153 & 76 & $>292$ & 18.4 & 15 & 226 & 24.4 & 1.83 & 95.4 & 81.6 & 35.5 & Harza (1995) \\
\hline Centralia, WI (Unit 2) & Full dschrg nolling & Whilte Sucker & - & - & 125 & 14.4 & 15 & 90 & 6.1 & 0.71 & - & - & 97.9 & Harza (1995) \\
\hline Cenlralia, WI (Unll t) & Full dschrg nolling & Bluegill & - & - & 125 & 14.4 & 15 & 90 & 6.1 & 0.71 & - & - & 98.2 & Harza (1995) \\
\hline Contralla, WI (Unit 1) & Full dschrg natting & Bluegill & - & - & 175 & 14.4 & 15 & 90 & 6.1 & 0.71 & - & - & 86.8 & Harza (1995) \\
\hline Centralla, WI & Full dschrg netling & resident & $\cdot$ & $\cdot$ & $<100$ & variable & 15 & 90 & 4.7 & 0.71 & $\cdot$ & $\cdot$ & 64.0 & BVMCA, (1991) \\
\hline Collon, NY & Full dschrg nelting & Centrarchld & - & - & $<100$ & 14.1 & 19 & 360 & 80.8 & 1.50 & - & - & 3.0 & KA (1996) \\
\hline Collon, NY & Full dschrg nalting & Centrarchid & - & - & 175 & 14.1 & 19 & 360 & 80.8 & 1.50 & - & - & 1.0 & KA (1996) \\
\hline Collon. NY & Full dschrg nolling & Centrarchid & - & - & $>250$ & 14.1 & 19 & 360 & 80.8 & 1.50 & - & - & 0.0 & $K A(1996)$ \\
\hline Collon, NY & Full dschrg notting & Percid & - & - & $<100$ & 14.1 & 19 & 360 & 80.8 & 1.50 & - & - & 65.0 & KA (1996) \\
\hline
\end{tabular}




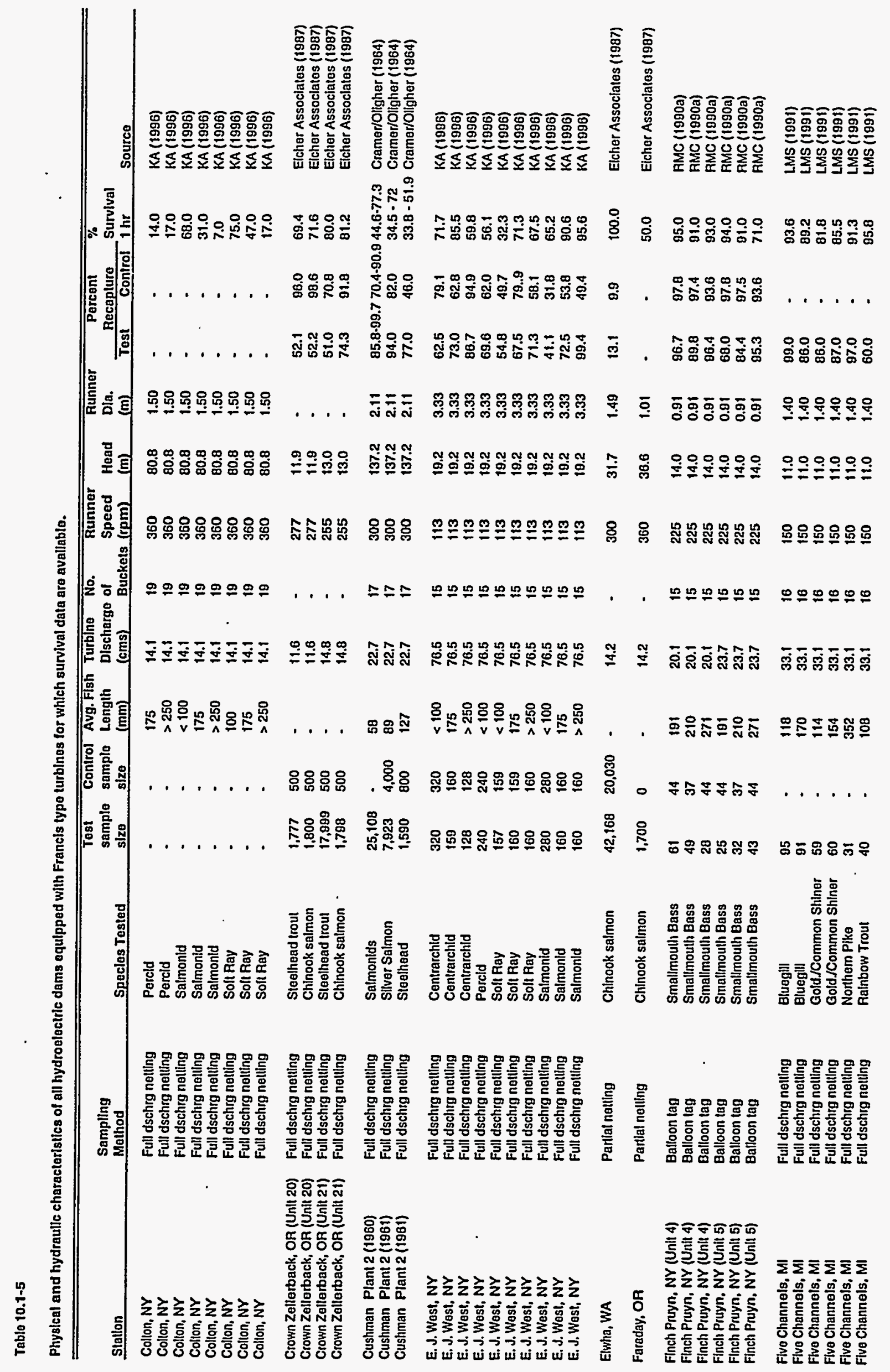


Physlcal and hydraulic characteristics of all hydroclectric dams oquipped with Francls typo turbines for which survival data are avallablo.

\begin{tabular}{|c|c|c|c|c|c|c|c|c|c|c|c|c|c|c|}
\hline \multirow[b]{2}{*}{ Station } & \multirow{2}{*}{$\begin{array}{l}\text { Sampling } \\
\text { Mothod }\end{array}$} & \multirow[b]{2}{*}{ Specios Tosled } & \multirow{2}{*}{$\begin{array}{l}\text { Tost } \\
\text { samplo } \\
\text { sizo } \\
\end{array}$} & \multirow{2}{*}{$\begin{array}{l}\text { Control } \\
\text { samplo } \\
\text { size } \\
\end{array}$} & \multirow{2}{*}{$\begin{array}{l}\text { Avg. Flsh } \\
\text { Lenglh } \\
\text { (mm) }\end{array}$} & \multirow{2}{*}{$\begin{array}{l}\text { Turbine } \\
\text { Dlschargo } \\
\text { (cms) }\end{array}$} & \multirow{2}{*}{$\begin{array}{l}\text { No. } \\
\text { of } \\
\text { Buckets }\end{array}$} & \multirow{2}{*}{$\begin{array}{l}\text { Runnar } \\
\text { Spood } \\
\text { (rpm) }\end{array}$} & \multirow{2}{*}{$\begin{array}{l}\text { Hoad } \\
\text { (m) }\end{array}$} & \multirow{2}{*}{$\begin{array}{l}\text { Runnor } \\
\text { Dia. } \\
\text { (m) }\end{array}$} & \multicolumn{2}{|c|}{$\begin{array}{c}\text { Porcent } \\
\text { Pocaplure }\end{array}$} & \multirow{2}{*}{$\begin{array}{l}\% \\
\text { Survival } \\
1 \mathrm{hr} \\
\end{array}$} & \multirow{2}{*}{ Source } \\
\hline & & & & & & & & & & & Test & Control & & \\
\hline Flve Channols, MI & Full dschrg netling & Rainbow Troul & 46 & - & 317 & 33.1 & 16 & 150 & 11.0 & 1.40 & 20.0 & - & 70.0 & LMS (1991) \\
\hline Five Channels, MI & Full dschrg natling & Spollall Shiner & 30 & - & 116 & 33.1 & 16 & 150 & 11.0 & 1.40 & 37.0 & - & 36.4 & LMS (1991) \\
\hline Flve Channels, MI & Full dschrg netling & Walleyo & 55 & - & 182 & 33.1 & 16 & 150 & 11.0 & 1.40 & 100.0 & - & 71.2 & LMS (1991) \\
\hline Fivo Channels, MI & Full dschrg nolling & Walleyo & 60 & - & 385 & 33.1 & 16 & 150 & 11.0 & 1.40 & 100.0 & - & 76.7 & L.MS (1991) \\
\hline Five Channels, MI & Full dschrg nelling & While Sucker & 56 & - & 180 & 33.1 & 16 & 150 & 11.0 & 1.40 & 86.0 & - & 88.6 & LMS (1991) \\
\hline Fivo Channels, MI & Full dschrg nelling & White Sucker & 60 & - & 290 & 33.1 & 16 & 150 & 11.0 & 1.40 & 82.0 & - & 71.4 & LMS (1991) \\
\hline Flve Channels, MI & Full dschrg nelling & Yellow Perch & 25 & - & 107 & 33.1 & 16 & 150 & 11.0 & 1.40 & 88.0 & - & 72.7 & LMS (1991) \\
\hline Fivo Channeis, MI & Full dschrg netling & Yellow Perch & 30 & $\cdot$ & 186 & 33.1 & 16 & 150 & 11.0 & 1.40 & 93.0 & $\cdot$ & 77.1 & LMS (1991) \\
\hline Glines, WA & Partlal nelling & Silver salmon & 31,256 & 23,442 & $\cdot$ & 42.5 & $\cdot$ & 225 & 59.1 & 2.35 & 5.0 & 49.3 & 69.6 & Elchier Associates (1987) \\
\hline Grand Raplds, WI (U 1,2,4 comb) & Full dschrg nelling & Bluegll! & - & - & 78 & 18.3 & 15 & 90 & 8.5 & 1.47 & - & - & 96.7 & NAI (1994) \\
\hline Grand Raplds, WI (U 1,2,4 comb) & Full dschrg netting & Bluegill & - & - & 127 & 18.3 & 15 & 90 & 8.5 & 1.47 & - & - & 100.0 & NAl (1994) \\
\hline Grand Raplds, Wi (U 1,2,4 comb) & Full dschrg nelling & Bluegill & - & - & 178 & 18.3 & 15 & 90 & 8.5 & 1.47 & - & - & 94.9 & NAI (1994) \\
\hline Grand Raplds, WI (U 1,2,4 comb) & Full dschirg nelling & While Sucker & - & - & 76 & 18.3 & 15 & 90 & 8.5 & 1.47 & - & - & 100.0 & NAI (1994) \\
\hline Grand Rapids, WI (U 1,2,4 comb) & Full dschrg nolling & While Sucker & - & - & 127 & 18.3 & 15 & 90 & 8.5 & 1.47 & - & - & 100.0 & NAI (1994) \\
\hline Grand Raplds, WI (U 1,2,4 comb) & Full dschrg nolling & While Sucker & - & - & 178 & 18.3 & 15 & 90 & 8.5 & 1.47 & - & - & 94.9 & NAI (1994) \\
\hline Grand Raplds, WI (U 1,2,4 comb) & Full dschrg netlling & Whille Sucker & - & - & 229 & 18.3 & 15 & 90 & 8.5 & 1.47 & - & - & 83.7 & NAI (1994) \\
\hline Grand Raplds, WI (U 1,2,4 comb) & Full dschrg nelling & White Sucker & - & - & 292 & 18.3 & 15 & 90 & 8.5 & 1.47 & - & - & 90.4 & $\operatorname{NAI}(1994)$ \\
\hline Grand Raplds, WI (U 1,2,4 comb) & Full dschrg netling & White Sucker & $\cdot$ & $\cdot$ & $>292$ & 18.3 & 15 & 90 & 8.5 & 1.47 & $\cdot$ & $\cdot$ & 80.5 & NAI (1994) \\
\hline Hardy, MI (Unil 2) & Full dschrg nelling & Bluegill & 63 & - & 118 & 14.4 & 16 & 163.6 & 30.5 & 2.13 & 56.0 & - & 89.5 & LMS (1991) \\
\hline Hardy, MI (Unil 2) & Full dschrg netling & Bluegill & 30 & - & 170 & 14.4 & 16 & 163.6 & 30.5 & 2.13 & 80.0 & - & 91.5 & LMS (1991) \\
\hline Hardy, MI (Unil 2) & Full dschrg nelling & Gold./Common Shiner & 30 & - & 114 & 14.4 & 16 & 163.6 & 30.5 & 2.13 & 82.0 & - & 85.5 & LMS (1991) \\
\hline Hardy, MI (Unil 2) & Full dschrg nelling & Gold./Common Shiner & 59 & - & 154 & 14.4 & 16 & 163.6 & 30.5 & 2.13 & 81.0 & - & 88.7 & LMS (1991) \\
\hline Hardy, MI (Unil 2) & Full dschirg nolling & Largomoulh Bass & 60 & - & 118 & 14,4 & 16 & 183.6 & 30.5 & 2.13 & 65.0 & - & 76.2 & LMS (199t) \\
\hline Hardy, MI (Unil 2) & Full dschrg nolling & Northern Pike & 58 & - & 352 & 14.4 & 16 & 163.6 & 30.5 & 2.13 & 86.0 & - & 76.0 & LMS (1901) \\
\hline Hardy, MI (Unll 2) & Full dschrg nelting & Rainbow Trout & 59 & - & 108 & 14.4 & 16 & 163.6 & 30.5 & 2.13 & 44.0 & - & 71.4 & LMS (1991) \\
\hline Hardy, MI (Unil 2) & Full dschig nolling & Rainbow Troul & 60 & - & 317 & 14.4 & 16 & 163.6 & 30.5 & 2.13 & 60.0 & - & 68.6 & LMS (1991) \\
\hline Hardy, MI (Unil 2) & Full dschrg nalting & Walleye & 60 & - & 385 & 14.4 & 16 & 163.6 & 30.5 & 2.13 & 95.0 & - & 77.3 & LMS (1991) \\
\hline Hardy, MI (Unil 2) & Full dschrg nelling & Whllo Sucker & 59 & - & 180 & 14.4 & 16 & 163.6 & 30.5 & 2.13 & 65.0 & - & 76.9 & LMS (1991) \\
\hline Hardy, MI (Unit 2) & Full dschrg nelting & Whille Sucker & 60 & - & 290 & 14.4 & 16 & 163.6 & 30.5 & 2.13 & 76.0 & - & 64.5 & LMS (1991) \\
\hline Hardy, MI (Unit 2) & Full dschrg nelling & Yellow Perch & 60 & - & 107 & 14.4 & 16 & 163.6 & 30.5 & 2.13 & 63.0 & - & 83.1 & LMS (1991) \\
\hline Hardy, MI (Unit 2) & Full dschrg nelling & Yellow Perch & $\cdot$ & $\cdot$ & 188 & 14.4 & 16 & 163.6 & 30.5 & 2.13 & 82.0 & - & 95.5 & LMS (1991) \\
\hline Hlgh Falls (Unht 5) & Full dschrg nelling & Centrarchilorms & 154 & 88 & 76 & 7.8 & 12 & 358 & 25.3 & 0.99 & 90.9 & 84.1 & 85.5 & Harza (1995) \\
\hline High Falls (Unlt 5) & Full dschrg nelling & Centrarchilorms & 90 & 48 & 127 & 7.8 & 12 & 358 & 25.3 & 0.99 & 90.0 & 81.3 & 78.1 & Harza (1995) \\
\hline High Falls (Unil 5) & Full dschrg nelling & Centrarchiforms & 111 & 70 & 178 & 7.8 & 12 & 358 & 25.3 & 0.89 & 80.9 & 84.0 & 58.9 & Harza (1995) \\
\hline High Falls (Unit 5) & Full dschrg nelling & Fusilorms & 146 & 95 & 76 & 7.8 & 12 & 358 & 25.3 & 0.99 & 80.1 & 82.1 & 87.8 & Harza (1995) \\
\hline High Falls (Unit 5) & Full dschrg nelling & Fusilorms & 81 & 49 & 127 & 7.8 & 12 & 358 & 25.3 & 0.99 & - & - & 67.9 & Harza (1995) \\
\hline Hlgh Falls (Unil 5) & Full dschrg nelling & Fusilorms & 184 & 79 & 178 & 7.8 & 12 & 358 & 25.3 & 0.99 & - & - & 48.4 & Harza (1995) \\
\hline High Falls (Unit 5) & Full dschrg nelling & Fusilorms & 86 & 66 & 229 & 7.8 & 12 & 358 & 25.3 & 0.89 & - & - & 46.2 & Harza (1995) \\
\hline High Falls (Unit 5) & Full dschrg neiting & Fusiloms & 160 & 58 & 292 & 7.8 & 12 & 358 & 25.3 & 0.89 & - & - & 20.1 & Harza (1995) \\
\hline High Falls (Unit 5) & Full dschrg netling & Fusllorms & 71 & 41 & $>292$ & 7.8 & 12 & 358 & 25.3 & 0.99 & - & - & 2.7 & Harza (1995) \\
\hline Highley, NY & Full dschrg nelling & Centrarchid & - & $\cdot$ & $<100$ & 19.1 & 13 & 257 & 14.0 & 1.22 & - & - & 81.0 & KA (1996) \\
\hline
\end{tabular}


Table 10.1-5

Physical and hydraulle characterlstics ol all hydroelectric dams equipped with Francis typo turbines for which survival data are avallable.

\begin{tabular}{|c|c|c|c|c|c|c|c|c|c|c|c|c|c|c|}
\hline \multirow{2}{*}{ Slallon } & \multirow{2}{*}{$\begin{array}{l}\text { Sampilng } \\
\text { Melhod }\end{array}$} & \multirow{2}{*}{ Specios Tosted } & \multirow{2}{*}{$\begin{array}{l}\text { Test } \\
\text { sample } \\
\text { slze } \\
\end{array}$} & \multirow{2}{*}{$\begin{array}{l}\text { Control } \\
\text { sample } \\
\text { size } \\
\end{array}$} & \multirow{2}{*}{$\begin{array}{l}\text { Avg. Flsh } \\
\text { Longth } \\
\text { (mm) }\end{array}$} & \multirow{2}{*}{$\begin{array}{l}\text { Turbino } \\
\text { Dischargo } \\
\text { (cms) }\end{array}$} & \multirow{2}{*}{$\begin{array}{l}\text { No. } \\
\text { of } \\
\text { Buckets } \\
\end{array}$} & \multirow{2}{*}{$\begin{array}{l}\text { Runner } \\
\text { Speed } \\
\text { (cpm) }\end{array}$} & \multirow{2}{*}{$\begin{array}{l}\text { Head } \\
\text { (m) }\end{array}$} & \multirow{2}{*}{$\begin{array}{l}\text { Runner } \\
\text { Dla. } \\
\text { (m) }\end{array}$} & \multicolumn{2}{|c|}{$\begin{array}{c}\text { Porcent } \\
\text { Recapture }\end{array}$} & \multirow{2}{*}{$\begin{array}{l}\% \\
\text { Survival } \\
1 \text { lir }\end{array}$} & \multirow{2}{*}{ Source } \\
\hline & & & & & & & & & & & Tost & Control & & \\
\hline Highley, NY & Full dschrg nelting & Cenitrarchld & - & - & 175 & 19.1 & 13 & 257 & 14.0 & 1.22 & - & - & 14.0 & KA (1996) \\
\hline Hlghley, NY & Full dschrg nelting & Centrarchid & - & - & $>250$ & 19.1 & 13 & 257 & 14.0 & 1.22 & - & - & 17.0 & KA (1996) \\
\hline Hlghley, NY & Full dschrg nelling & Percld & - & - & $<100$ & 19.1 & 13 & 257 & 14.0 & 1.22 & - & - & 59.0 & KA (1996) \\
\hline Highley, NY & Full dschrg notting & Percld & - & - & $>250$ & 19.1 & 13 & 257 & 14.0 & 1.22 & - & - & 40.0 & KA (1996) \\
\hline Highley, NY & Full dschrg nelling & Salmonld & - & - & $<100$ & 19.1 & 13 & 257 & 14.0 & 1.22 & - & - & 70.0 & KA (1996) \\
\hline Highley, NY & Full dschrg nelling & Salmonid & - & - & 175 & 19.1 & 13 & 257 & 14.0 & 1.22 & - & - & 44.0 & KA (1996) \\
\hline Highley, NY & Full dschrg nelting & Salmonid & - & - & $>250$ & 19.1 & 13 & 257 & 14.0 & 1.22 & - & - & 61.0 & KA (1996) \\
\hline Hlghley, NY & Full dschrg nelling & Soll Ray & - & - & $<100$ & 19.1 & 13 & 257 & 14.0 & 1.22 & - & - & 60.0 & KA (1996) \\
\hline Highloy, NY & Full dschrg nelling & Solt Ray & - & - & 175 & 19.1 & 13 & 257 & 14.0 & 1.22 & - & - & 72.0 & KA (1996) \\
\hline Highley, NY & Full dschrg nolling & Solt Ray & $\cdot$ & - & $>250$ & 19.1 & 13 & 257 & 14.0 & 1.22 & $\cdot$ & $\cdot$ & 40.0 & KA (1996) \\
\hline Holst, MI & Full dschrg nelling & Brown Trout & 150 & 150 & 85 & 8.5 & - & 360 & 43.3 & - & 56.0 & 99.3 & 45.1 & RMC (1993c) \\
\hline Holst, MI & Full dschrg netting & Brook Trout & 150 & 150 . & 135 & 8.5 & - & 360 & 43.3 & - & 73.3 & 1.0 & 43.0 & AMC (1993c) \\
\hline Holst, MI & Full dschrg nolling & Brown Trout & 150 & $150^{\circ}$ & 220 & 8.5 & - & 360 & 43.3 & - & 80.7 & 1.0 & 22.8 & RMC (1993c) \\
\hline Holst, MI & Full dschrg nelling & Bluegill & 150 & 150 & 65 & 8.5 & $\cdot$ & 360 & 43.3 & - & 44.0 & 98.7 & 19.7 & RMC (1993C) \\
\hline Holst, MI & Full dschrg nelling & Bluegill & 150 & 150 & 115 & 8.5 & $\cdot$ & 360 & 43.3 & - & 65.3 & 1.0 & 75.0 & RMC (1993C) \\
\hline Holwood, PA(U10/single runner) & Balloon tag & Amorican Shad & 100 & 100 & 125 & 89.1 & 16 & 84.7 & 18.9 & 3.80 & 81.0 & 90.0 & 89.4 & RMC (1992d) \\
\hline Hollwood, PA (U3/double nunner) & Balloon tag & American Shad & 100 & 80 & 125 & 89.1 & 17 & 102.8 & 18.9 & 2.84 & 78.0 & 93.8 & 83.5 & RMC (1992d) \\
\hline la centrale Boaurhamois, OE & Float lag & Amarican ool & 100 & $\cdot$ & 888 & 198.2 & 13 & 75 & 24.1 & 5.38 & 97.1 & $\cdot$ & 84.2 & Desrochers (1995) \\
\hline Leaburg, OR & Full dschrg nelling & Rainbow Iroul & 1,248 & 624 & $\cdot$ & 31.2 & - & 225 & 27.1 & 2.29 & 67.0 & 86.2 & 95.2 & Eicher Associales (1987) \\
\hline Lequille, NS & Full dschrg nelting & Atlanilic salmon & $\cdot$ & $\cdot$ & - & 8.9 & 13 & 519 & 118.0 & 1.37 & - & - & 52.0 & Elcher Associates (1987) \\
\hline Luray, VA & Full dschrg nelting & American Eol & 393 & $\cdot$ & 853 & 10.5 & 12 & 164 & 4.9 & 1.59 & - & - & 99.0 & RMC (1995) \\
\hline McClure, MI & Full dschrg nelling & Resldent spp. & NA & NA & $\cdot$ & 4.4 & - & 600 & 128.2 & - & - & NA & - & RMC (1993b) \\
\hline Minetto, NY & Full dschrg nelting & Centrarchid & 164 & 104 & $<100$ & 42.5 & 16 & 72 & 5.2 & 3.53 & 64.0 & 86.5 & 62.0 & $K A(1896)$ \\
\hline Minello, NY & Full dschrg nelling & Contrarchid & 236 & 110 & 175 & 42.6 & 16 & 72 & 5.2 & 3.53 & 90.7 & 91.3 & 83.0 & KA (1996) \\
\hline Minelto, NY & Full dschig netting & Contrarchld & 165 & 120 & $>250$ & 42.5 & 16 & 72 & 5.2 & 3.53 & 85.5 & 91.7 & 84.0 & $K A(1896)$ \\
\hline Minallo, NY & Full dschrg netting & Porcid & 133 & 117 & $<100$ & 42.5 & 16 & 72 & 5.2 & 3.53 & 44.4 & 47.0 & 80.0 & $K A(1996)$ \\
\hline Minalto, NY & Full dschrg nattling & Percid & 243 & 142 & 175 & 42.5 & 16 & 72 & 5.2 & 3.53 & 68.7 & 85.2 & 86.0 & KA (1996) \\
\hline MInolto, NY & Full dschrg nelling & Soll Ray & 348 & 220 & $<100$ & 42.5 & 16 & 72 & 5.2 & 3.53 & 48.7 & 42.3 & 82.0 & $K A(1996)$ \\
\hline Minetto, NY & Full dschrg nelling & Soll Ray & 214 & 133 & 175 & 42.5 & 16 & 72 & 5.2 & 3.53 & 72.8 & 98.5 & 94.0 & KA (1996) \\
\hline Minetto, NY & Full dschrg netling & Soft Ray & 177 & 160 & $>250$ & 42.5 & 16 & 72 & 5.2 & 3.53 & 84.4 & 80.0 & 84.0 & KA (1996) \\
\hline Minollo, NY & Full dschirg notting & Salmonids & 237 & 160 & $<100$ & 42.5 & 16 & 72 & 5.2 & 3.53 & 62.5 & 83.3 & 02.0 & KA (1996) \\
\hline Minello, NY & Full dschrg nelting & Salmonlds & 184 & 107 & 175 & 42.5 & 16 & 72 & 5.2 & 3.53 & 81.5 & 84.1 & 91.0 & KA (1996) \\
\hline Minolto, NY & Full dschrg netling & Salmonids & 178 & 159 & $>250$ & 42.5 & 16 & 72 & 5.2 & 3.53 & 78.1 & 67.9 & 92.0 & KA(1998) \\
\hline Minallo, NY & Full dschrg nelling & Amorican Eel & 107 & 92 & 625 & 42.5 & 16 & 72 & 5.2 & 3.53 & 43.9 & 68.3 & 94.0 & KA (1986) \\
\hline Minello, NY & Full dschrg notling & Alowile & 189 & 140 & $<100$ & $\cdot$ & - & 1. & $\cdot$ & $\cdot$ & 74.1 & 90.0 & 80.0 & KA (1998) \\
\hline North Fork, OR & Partlal netling & Coho salmon & 4,076 & 5,158 & - & 70.8 & - & 139 & 41.5 & 2.95 & 18.2 & 23.1 & 74.0 & Elcher Assoclates (1987) \\
\hline
\end{tabular}


Table 10.1-5

Physlcal and hydraulic characteristles of all hydroalectric dams equippod with Francis typo lurblnes for which survival data aro avallable.

\begin{tabular}{|c|c|c|c|c|c|c|c|c|c|c|c|c|c|c|}
\hline \multirow[b]{2}{*}{ Stalion } & \multirow{2}{*}{$\begin{array}{l}\text { Sampiling } \\
\text { Molhod }\end{array}$} & \multirow{2}{*}{ Specles Tested } & \multirow{2}{*}{$\begin{array}{l}\text { Test } \\
\text { gamplo } \\
\text { size } \\
\end{array}$} & \multirow{2}{*}{$\begin{array}{l}\text { Control } \\
\text { samplo } \\
\text { size } \\
\end{array}$} & \multirow{2}{*}{$\begin{array}{l}\text { Avg. Fish } \\
\text { Longth } \\
\text { (mm) }\end{array}$} & \multirow{2}{*}{$\begin{array}{l}\text { Turblino } \\
\text { Dlschargo } \\
\text { (cms) }\end{array}$} & \multirow{2}{*}{$\begin{array}{l}\text { No. } \\
\text { of } \\
\text { Buckats }\end{array}$} & \multirow{2}{*}{$\begin{array}{l}\text { Runnor } \\
\text { Spood } \\
\text { (rpm) }\end{array}$} & \multirow{2}{*}{$\begin{array}{l}\text { Hoad } \\
\text { (m) }\end{array}$} & \multirow{2}{*}{$\begin{array}{l}\text { Rilinnor } \\
\text { Dla. } \\
\text { (m) }\end{array}$} & \multicolumn{2}{|c|}{$\begin{array}{c}\text { Percont } \\
\text { Pocapluro }\end{array}$} & \multirow{2}{*}{$\begin{array}{l}\% \\
\text { Survival } \\
1 \mathrm{hr} \\
\end{array}$} & \multirow[b]{2}{*}{ Source } \\
\hline & & & & & & & & & & & Tost & Control & & \\
\hline Peshllgo, WI (Unll 4) & Full dschrg netling & Centrarchillorms & 146 & 84 & 78 & 13.0 & 15 & 100 & 4.0 & 2.03 & 88.4 & 91.7 & 100.0 & Harza (1995) \\
\hline Peshllgo, WI (Unil 4) & Full dschrg nelling & Centrarchilorms & 140 & 77 & 127 & 13.0 & 15 & 100 & 4.0 & 2.03 & 79.3 & 79.2 & 98.9 & Harza (1995) \\
\hline Peshllgo. WI (Unll 4) & Full dschrg nelling & Centrarchilorms & 121 & 75 & 178 & 13.0 & 15 & 100 & 4.0 & 2.03 & 71.9 & 69.3 & 100.0 & Harza (1995) \\
\hline Peshligo, WI (Unil A) & Full dschrg netling & Fusilorms & $15 B$ & 103 & 76 & 13.0 & 15 & 100 & 4.0 & 2.03 & 85.4 & 97.1 & 84.0 & Harza (1995) \\
\hline Peshtlgo, WI (Unil 4) & Full dschrg nelling & Fusilorms & 141 & 90 & 127 & 13.0 & 15 & 100 & 4.0 & 2.03 & 86.5 & 95.6 & 93.7 & Harza (1995) \\
\hline Peshtlgo, WI (Unil 4) & Full dschrg nolling & Fusiloms & 166 & 109 & 178 & 13.0 & 15 & 100 & 4.0 & 2.03 & 92.2 & 93.6 & 96.6 & Harza (1995) \\
\hline Peshitgo, wi (Unil 4) & Full dschrg nelling & Fusilorms & 158 & 93 & 229 & 13.0 & 15 & 100 & 4.0 & 2.03 & 94.9 & 91,4 & 95.4 & Harza (1995) \\
\hline Peshtigo, WI (Unil 4) & Full dschrg netling & Fusiloms & 166 & 105 & 292 & 13.0 & 15 & 100 & 4.0 & 2.03 & 85.5 & 84.8 & 85.5 & Harza (1995) \\
\hline Peshtigo, WI (Unit 4) & Full dschrg nelting & Fusilorms & 128 & 79 & $>292$ & 13.0 & 15 & 100 & 4.0 & 2.03 & 83.6 & 79.7 & 82.8 & Harza (1995) \\
\hline Potato Rapids, WI (Unil 1) & Full dschrg nelting & Centrarchilorms & 134 & 94 & 76 & 14.2 & 15 & 123 & 5.2 & 2.13 & 94.0 & 93.6 & 100.0 & Harza (1995) \\
\hline Potato Raplds, WI (Unit 1) & Full dschrg nelling & Centrarchilorms & 154 & 93 & 127 & 14.2 & 15 & 123 & 5.2 & 2.13 & 75.3 & 96.8 & 84.7 & Harza (1995) \\
\hline Potalo Raplds, WI (Uniti) & Full dschrg netting & Centrarchiforms & 111 & 70 & 178 & 14.2 & 15 & 123 & 5.2 & 2.13 & 49.5 & 98.6 & 83.0 & Harza (1995) \\
\hline Potalo Raplds, wI (Unit 1) & Full dschrg nelting & Fusitorms & 168 & 104 & 76 & 14.2 & 15 & 123 & 5.2 & 2.13 & 87.5 & 92.3 & 89.2 & Harza (1905) \\
\hline Polato Raplds, wi (Unil 1) & Full dschirg nolling & Fusilorms & 104 & 69 & 127 & 14.2 & 15 & 123 & 3.2 & 2.13 & 93.3 & 98.6 & 76.5 & Harza (1995) \\
\hline Polato Raplds, wi (Unili i) & Full dschrg nelling & Fusilorms & 150 & 91 & 178 & 14.2 & 15 & 123 & 5.2 & 2.13 & $\mathbf{9 8 . 0}$ & 93.4 & 68.4 & Harza (1995) \\
\hline Potalo Rapids, wi (Unli i) & Full dschrg nolling & Fusilorms & 160 & 96 & 229 & 14.2 & 15 & 123 & 5.2 & 2.13 & 75.6 & 98.9 & 61.1 & Harza (1995) \\
\hline Potalo Raplds, wi (Unit 1) & Full dschrg nelling & Fusiforms & 136 & 83 & 292 & 14.2 & 15 & 123 & 5.2 & 2.13 & $\mathbf{8 9 . 0}$ & 100.0 & 53.3 & Harza (1995) \\
\hline Potato Rapids, WI (Unit 1) & Full dschrg nelling & Fusilorms & 145 & 112 & $>292$ & 14.2 & 15 & 123 & 5.2 & 2.13 & 89.7 & 94.6 & 34.5 & Harza (1995) \\
\hline Potato Rapids, wi (Unil 2) & Full dschrg nelling & Centrarchiforms & 168 & 105 & 76 & 14.2 & 15 & 123 & 5.2 & 2.13 & 89.2 & 97.1 & 93.4 & Harza (1995) \\
\hline Polato Raplds, WI (Unit 2) & Full dschrg nelting & Centrarchilorms & 137 & 104 & 127 & 12.5 & 15 & 135 & 5.2 & 2.03 & 74.5 & 98.1 & 83.7 & Harza (1995) \\
\hline Potato Raplds, WI (Unit 2) & Full dschrg nelting & Centrarchilorms & 58 & 28 & 178 & 12.5 & 15 & 135 & 5.2 & 2.03 & 100.0 & 96.4 & 91.4 & Haza (1995) \\
\hline Polato Rapids, wi (Unit 2) & Full dschrg nolling & Fusiforms & 179 & 123 & 76 & 12.5 & 15 & 135 & 5.2 & 2.03 & 74.3 & 67.5 & 84.5 & Harza (1995) \\
\hline Polalo Raplds, WI (Unit 2) & Full dschrg nelting & Fusiloms & 134 & 93 & 127 & 12.5 & 15 & 135 & 5.2 & 2.03 & 90.3 & 100.0 & 61.7 & Harza (1995) \\
\hline Potalo Raplds, wi (Unit 2) & Full dschrg nolling & Fusiforms & 138 & 92 & 178 & 12.5 & 15 & 135 & 5.2 & 2.03 & 97.8 & 98.8 & 75.1 & Harza (1995) \\
\hline Potalo Rapids, wi (Unit 2) & Full dschrg nelling & Fusiforms & 158 & 98 & 229 & 12.5 & 15 & 135 & 5.2 & 2.03 & 91.8 & 99.0 & 61.0 & Harza (1995) \\
\hline Potalo Rapids, wI (Unil 2) & Full dschrg nolling & Fusiforms & 156 & 91 & 292 & 12.5 & 15 & 135 & 5.2 & 2.03 & 89.7 & 97.8 & 57.8 & Harza (1995) \\
\hline Polato Rapids, WI (Unil 2) & Full dschrg nelling & Fusilorms & 149 & 85 & $>292$ & 12.5 & 15 & 135 & 5.2 & 2.03 & 92.3 & 94.1 & 48.2 & Harza (1995) \\
\hline Pricket, MI & Full dschrg netling & Bluegill & 256 & 150 & 52 & 9.2 & 15 & 257 & 16.5 & 1.36 & 57.0 & 62.7 & 97.7 & RMC (1991c) \\
\hline Pricket, MI & Full dschrg nolling & Golden Shiner & 182 & 120 & $<100$ & 9.2 & 15 & 257 & 16.5 & 1.36 & 93.3 & 70.0 & 93.9 & RMC (1991c) \\
\hline Prickel, MI & Full dschrg nelting & Bluegill & 131 & 90 & 102 & 9.2 & 15 & 257 & 16.5 & 1.36 & 80.9 & 80.0 & 92.5 & RMC (1991c) \\
\hline Prlckel, MI & Full dschrg nelting & Bluegill & 21 & 21 & $>127$ & 9.2 & 15 & 257 & 16.5 & 1.36 & 100.0 & 80.5 & 85.7 & RMC (1991c) \\
\hline Prickel, MI & Full dschrg netling & Mixed resldenl & - & - & - & 9.2 & 15 & 257 & 16.5 & 1.36 & & & 97.8 & RMC (1991c) \\
\hline Prickel, MI & Full dschrg nelling & White Sucker & 201 & 119 & 165 & 9.2 & 15 & 257 & $\mathbf{1 6 . 5}$ & 1.36 & 81.6 & 80.7 & 70.8 & AMC (1991C) \\
\hline Prickal, MI & Full dschrg netting & White Sucker & 15 & 10 & $>254$ & 9.2 & 15 & 257 & 16.5 & 1.36 & 93.3 & 70.0 & 35.7 & AMC (1991c) \\
\hline Publlshers, OR (1960) & Full dschrg nelling & Steelhead trout & 1,768 & 500 & - & 7.8 & - & 255 & 12.2 & - & 36.2 & 58.0 & 87.9 & Eicher Associates (1987) \\
\hline Publishers, OR (1960) & Full dschrg nelling & Chinook salmon & 1,798 & 503 & - & 7.8 & - & 255 & 12.2 & - & 51.2 & 100.0 & 87.4 & Elcher Associates (1987) \\
\hline Publishers, OR (1961) & Full dschrg nolling & Sleolliead Irout & 1,800 & 500 & - & 7.8 & - & 255 & 12.2 & - & 24.9 & 36.0 & 84.5 & Elcher Associates (1987) \\
\hline Publishers, OR (1961) & Full dschurg netling & Chinook salmon & 1,800 & 500 & - & 7.8 & - & 255 & 12.2 & - & 43.5 & 69.6 & 87.1 & Eicher Associates (1987) \\
\hline Punlledge, BC & Floaling net & Steelhead trout & 1.500 & - & 124 & - & - & 277 & 103.6 & 2.16 & 3.5 & - & 58.1 & Elcher Associales (1987) \\
\hline Puntledge, BC & Floating not & Kamploops & 1,500 & - & 69 & - & - & 277 & 103.6 & 2.16 & 3.4 & - & 72.5 & Eicher Associales (1987) \\
\hline Puntledge, BC & Floatling net & Kamploops & 1,500 & - & 46 & : & - & 277 & 103.6 & 2.16 & 4.9 & - & 71.2 & Eicher Associates (1987) \\
\hline Puntladgo, BC & Floating net & Salmon & 1,500 & - & 36 & $:$ & - & 277 & 103.6 & 2.16 & 2.5 & - & 67.4 & Elcher Associales (1987) \\
\hline
\end{tabular}




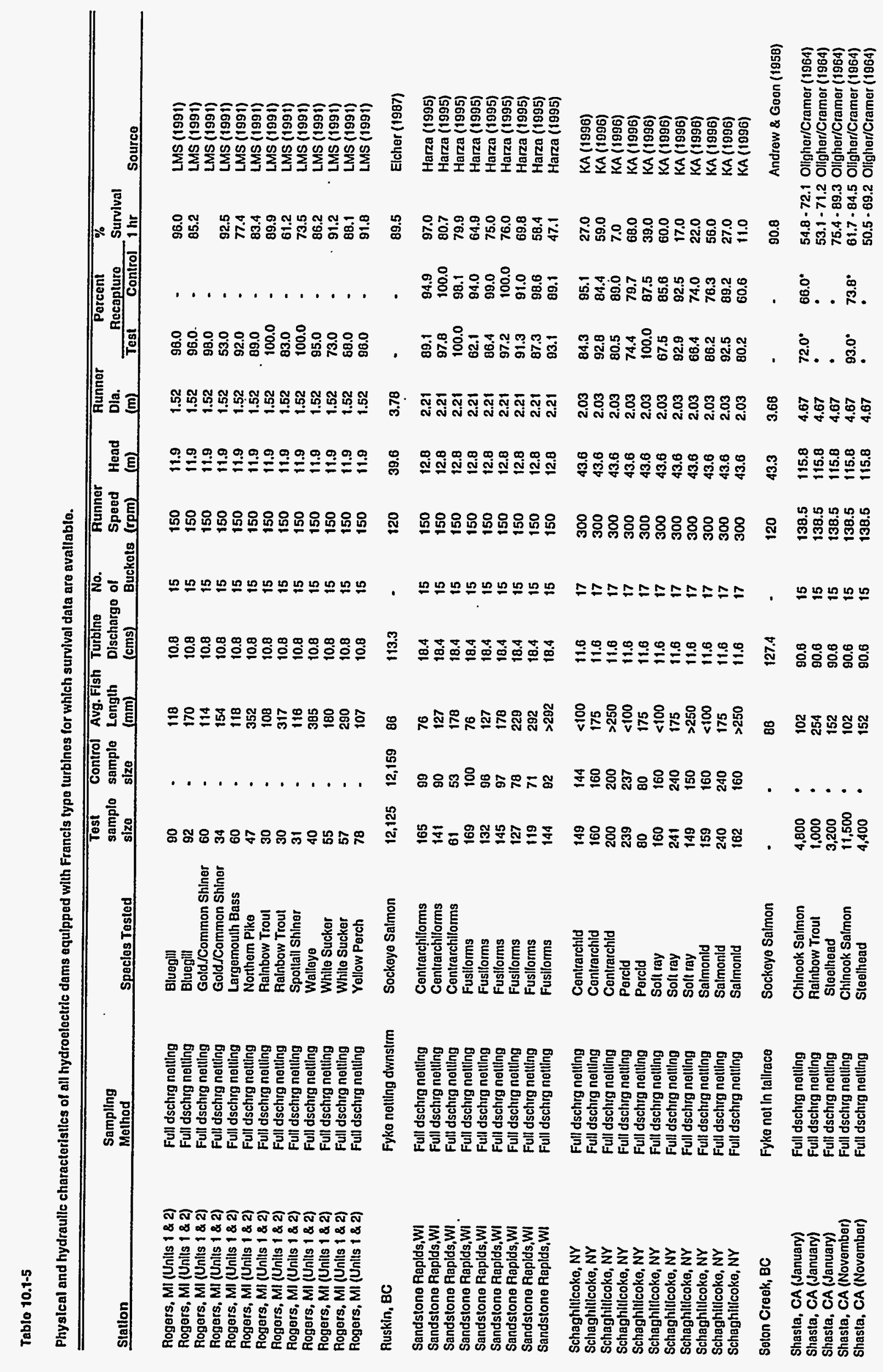


Table 10.1-5

Physical and hydraulle characterlstics of all hydrooloctrle dams equippod with Francls typo turblnes for which survival data are availablo.

\begin{tabular}{|c|c|c|c|c|c|c|c|c|c|c|c|c|c|c|}
\hline \multirow[b]{2}{*}{ Stallon } & \multirow{2}{*}{$\begin{array}{l}\text { Sampling } \\
\text { Melhod }\end{array}$} & \multirow[b]{2}{*}{ Specles Testod } & \multirow{2}{*}{$\begin{array}{l}\text { Test } \\
\text { 8amplo } \\
\text { slze } \\
\end{array}$} & \multirow{2}{*}{$\begin{array}{l}\text { Control } \\
\text { sample } \\
\text { size }\end{array}$} & \multirow{2}{*}{$\begin{array}{l}\text { Avg. Flsh } \\
\text { Longth } \\
\text { (mm) } \\
\end{array}$} & \multirow{2}{*}{$\begin{array}{l}\text { Turblne } \\
\text { Dlscharge } \\
\text { (cms) }\end{array}$} & \multirow{2}{*}{$\begin{array}{l}\text { No. } \\
\text { of } \\
\text { Buckots }\end{array}$} & \multirow{2}{*}{$\begin{array}{l}\text { Runner } \\
\text { Spoad } \\
\text { (rpm) }\end{array}$} & \multirow{2}{*}{$\begin{array}{l}\text { Hoad } \\
\text { (m) }\end{array}$} & \multirow{2}{*}{$\begin{array}{l}\text { Runnor } \\
\text { Dla. } \\
\text { (m) }\end{array}$} & \multicolumn{2}{|c|}{$\begin{array}{l}\text { Percont } \\
\text { Recapture }\end{array}$} & \multirow{2}{*}{$\begin{array}{l}\% \\
\text { Survival } \\
1 \mathrm{hr}\end{array}$} & \multirow[b]{2}{*}{ Source } \\
\hline & & & & & & & & & & & Tost & Control & & \\
\hline Shasta, CA (November) & Full dschrg nelting & Rainbow Trout & 1.025 & - & 254 & 90.8 & 16 & 138.5 & 115.8 & 4.67 & - & - & $39.6 \cdot 90.5$ & Ollgher/Cramer (1964) \\
\hline Stevens Creak, SC & Balloon lag & Bluegill & 110 & 110 & 122 & 28.3 & 14 & 75 & 8.5 & 3.43 & 95.5 & 99.1 & 95.4 & RMC (1994d) \\
\hline Stovens Creak, SC & Balloon lag & Blueback Herring & 131 & 120 & 203 & 28.3 & 14 & 75 & 8.5 & 3.43 & 90.8 & 89.2 & 95.3 & RMC (1994d) \\
\hline Slevens Creek, SC & Balloon lag & Spolted SuckerN̄. Perch & 120 & 120 & 165 & 28.3 & 14 & 75 & 8.5 & 3.43 & 96.7 & 98.3 & 98.3 & RMC (1994d) \\
\hline T. W. Sullivan, OR & Discharge nelling & Steolhead Iroul & - & . & - & $\cdot$ & - & 242 & 12.5 & - & - & - & 74.1 & Elcher Assoclates (1987) \\
\hline T.W. Sullivan, OR & Discharge netling & Chinook salmon & $\cdot$ & $\cdot$ & $\cdot$ & 7.4 & - & 242 & 12.5 & $\cdot$ & $\cdot$ & $\cdot$ & 85.7 & Eicher Assoclates (1987) \\
\hline Vemon, VT/NH & Balloon tag & American Shad & 153 & 150 & 85 & 51.9 & 15 & 74 & 10.4 & 3.96 & 93.5 & 88.7 & 94.7 & NAI (1996b) \\
\hline While Raplds, WI & Balloon lag & While Sucker & 42 & 38 & 204 & 25.5 & 14 & 100 & 8.8 & 3.40 & 80.5 & 91.7 & 93.0 & AMC (1993) \\
\hline Whito Raplds, WI & Balloon tag & Whilte Sucker & 58 & 64 & 112 & 25.5 & 14 & 100 & 8.8 & 3.40 & 98.6 & 88.4 & 100.0 & RMC (1893) \\
\hline While Raplds, WI & Balloon tag & Bluegill & 56 & 62 & 80 & 25.5 & 14 & 100 & 8.8 & 3.40 & 92.9 & 98.4 & 85.0 & AMC (1993) \\
\hline White Raplds, WI & Balloon lag & Bluegill & 44 & 38 & 155 & 25.5 & 14 & 100 & 8.8 & 3.40 & 03.2 & 97.4 & 100.0 & RMC (1993) \\
\hline Youghlogheny, PA & Full dschrg nelling & Alowilo & Nalurally & entrained & 51 & 21.2 & - & - & 36.6 & - & - & - & 0.1 & RMC (1992a) \\
\hline Youghlogheny, PA & Full dschrg nelling & Walleye & Nalurally & entrained & 378 & 21.2 & - & - & 36.6 & - & - & - & 39.5 & RMC (1992a) \\
\hline Youghlogheny, PA & Full dschrg nelling & Rock bass & Nalurally & entralned & - & 21.2 & - & - & 36.6 & - & - & - & 4 & FMC (1892a) \\
\hline Youghlogheny, PA & Full dschrg nolling & Yollow perch & Nalurally & entrained & - & 21.2 & - & - & 36.6 & - & - & - & 7 & PMC (1992a) \\
\hline Youghlogheny, PA & Full dschrg nottlng & Crapples & Nalurally & entrained & - & 21.2 & - & - & 36.6 & - & - & - & 0.2 & RMC (1992a) \\
\hline Youghiogheny, PA & Full dschrg nelling & White sucker & Naturally & entralned & - & 21.2 & - & - & 36.6 & - & - & - & 9.5 & RMC (1992a) \\
\hline
\end{tabular}

Composite number of fish Introduced and their recapture rates; November lests - $105 t=91.0 \%$ and control $=73.8 \%$, January lests - test $=72 \%$ and conlrol $=66 \%$. 
There are two major families of turbines: reaction and impulse. The axial flow and Francis turbines covered in this report are in the reaction family. Low head sites utilize axial flow type units. There are two categories of axial flow units. Axial flow Kaplan units have adjustable tilt blades as shown in Figures 10.21 and 10.2-2. Axial flow fixed blade or propeller units have blades which are welded to the hub at a fixed tilt as shown in Figure 10.2-3 and 10.2-4. Medium and high head sites utilize Francis type units as shown in Figure 10.2-5 and 10.2-6. These figures illustrate the maior turbine and generator components. Figures 10.2-7 and 10.2-8. show components of runner assemblies for Kaplan and Francis units respectively.

Turbines are typically classified according to a characteristic called specific speed. Specific speed is typically defined as follows:

$$
n_{q}=\frac{N^{*} \sqrt{Q}}{H^{.75}}
$$

$$
\begin{aligned}
& \text { Where: } \quad N=\mathrm{rpm} \\
& Q=\text { Flow (cms) } \\
& H=\operatorname{Head}(\mathrm{m})
\end{aligned}
$$

Figure 10.2-9 shows various turbines as a function of specific speed. Specific speed is the rpm at which a unit would operate under 1 meter of head at a discharge of $1 \mathrm{~m}^{3} / \mathrm{s}$. The numerical value of this number varies with the system of units and the operating point at which it is defined. It is typically defined at the peak efficiency point. It does not vary with the size of the unit. Low specific speed designs are applied to high head sites and high specific speed designs are applied to low head sites. As specific speed increases within the axial flow type the number of blades decreases. As specific speed increases within the Francis type the ratios of runner outlet diameter to inlet diameter and wicket gate height to inlet diameter increase as shown in Figure 10.2-10. 
Kaplan Turbine with Generator

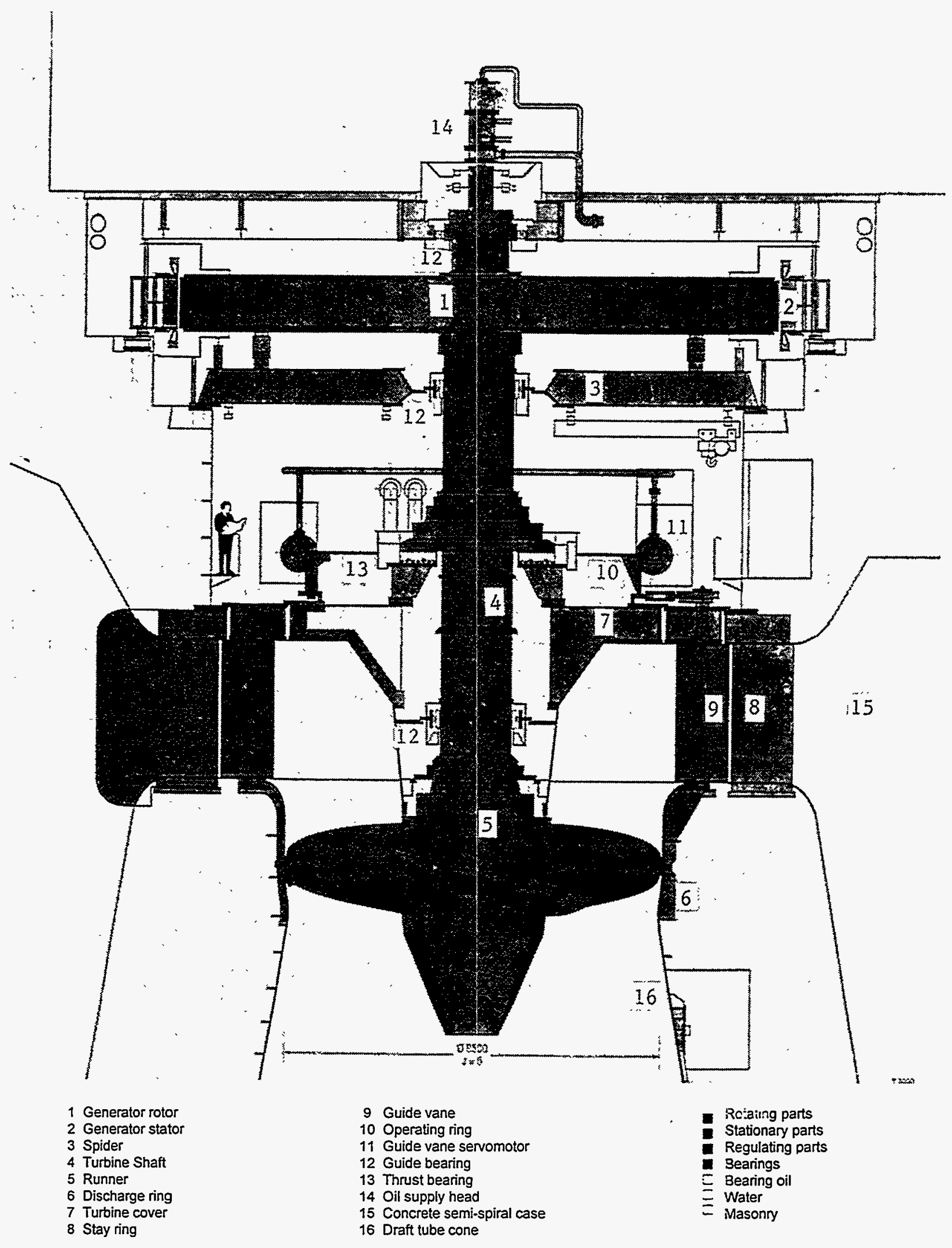

Figure 10.2-1 Axial Flow Kaplan Unit 


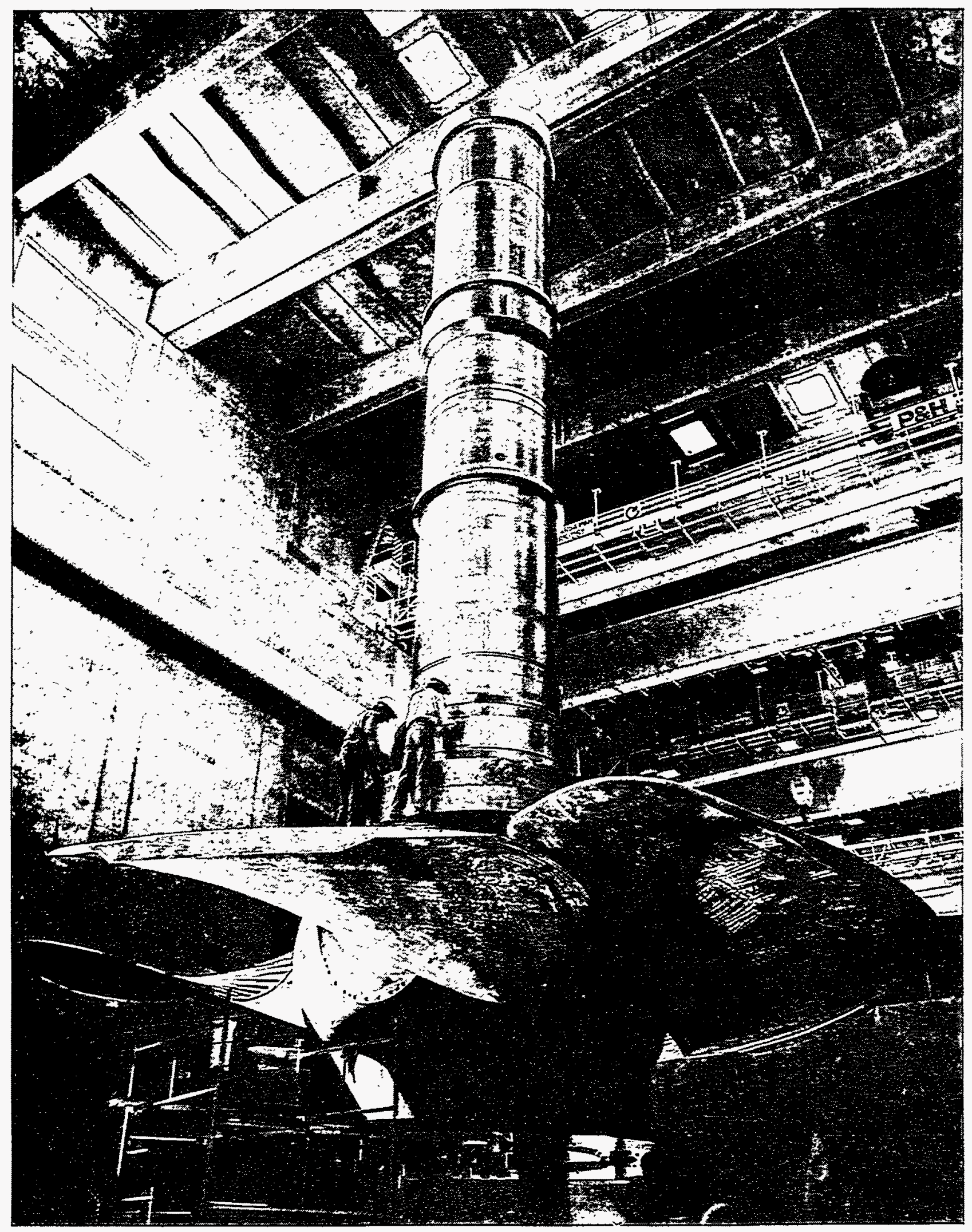

Figure 10.2-2 Axial Flow Kaplan Runner 


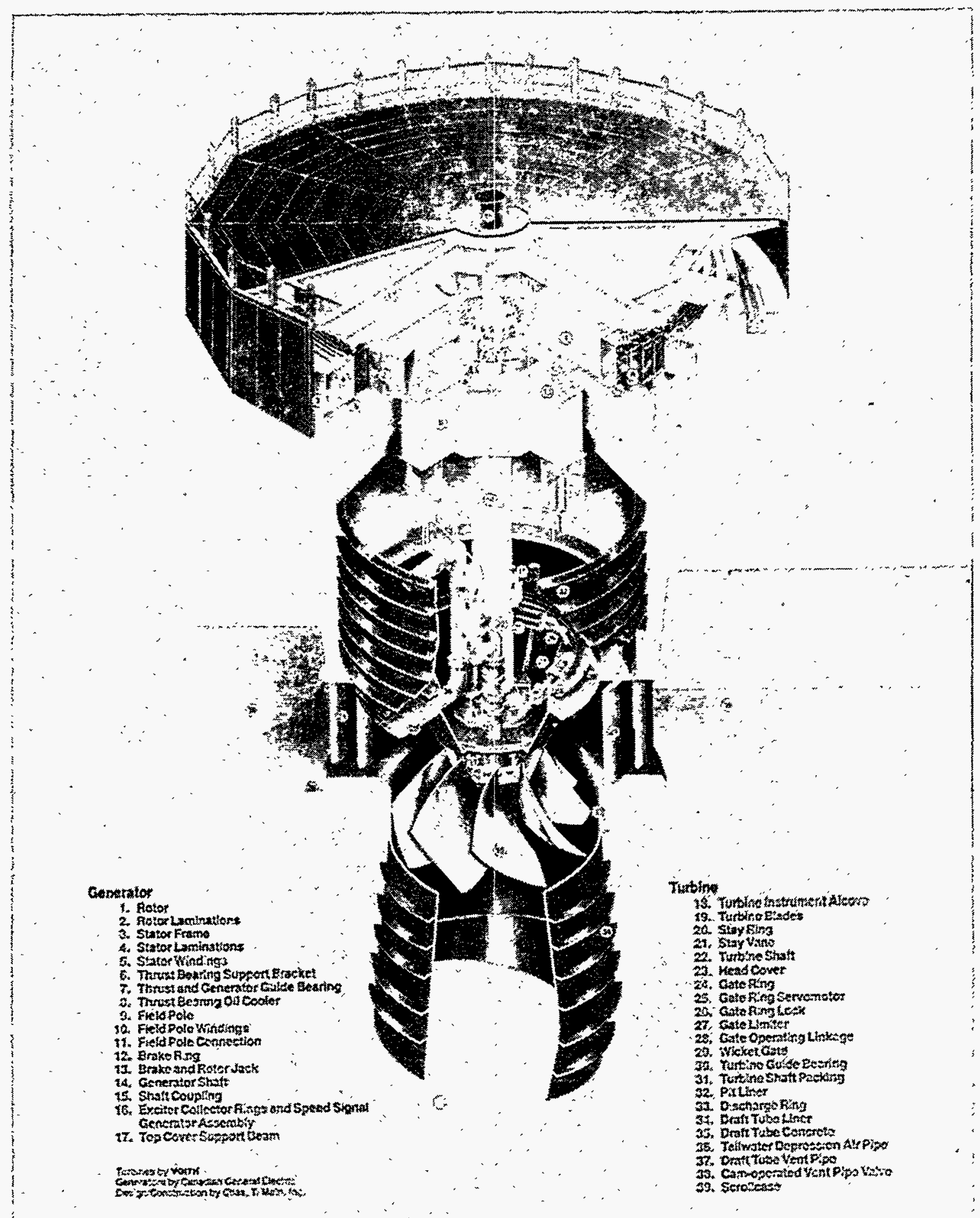

Figure 10.2-3 Fixed Blade Unit 


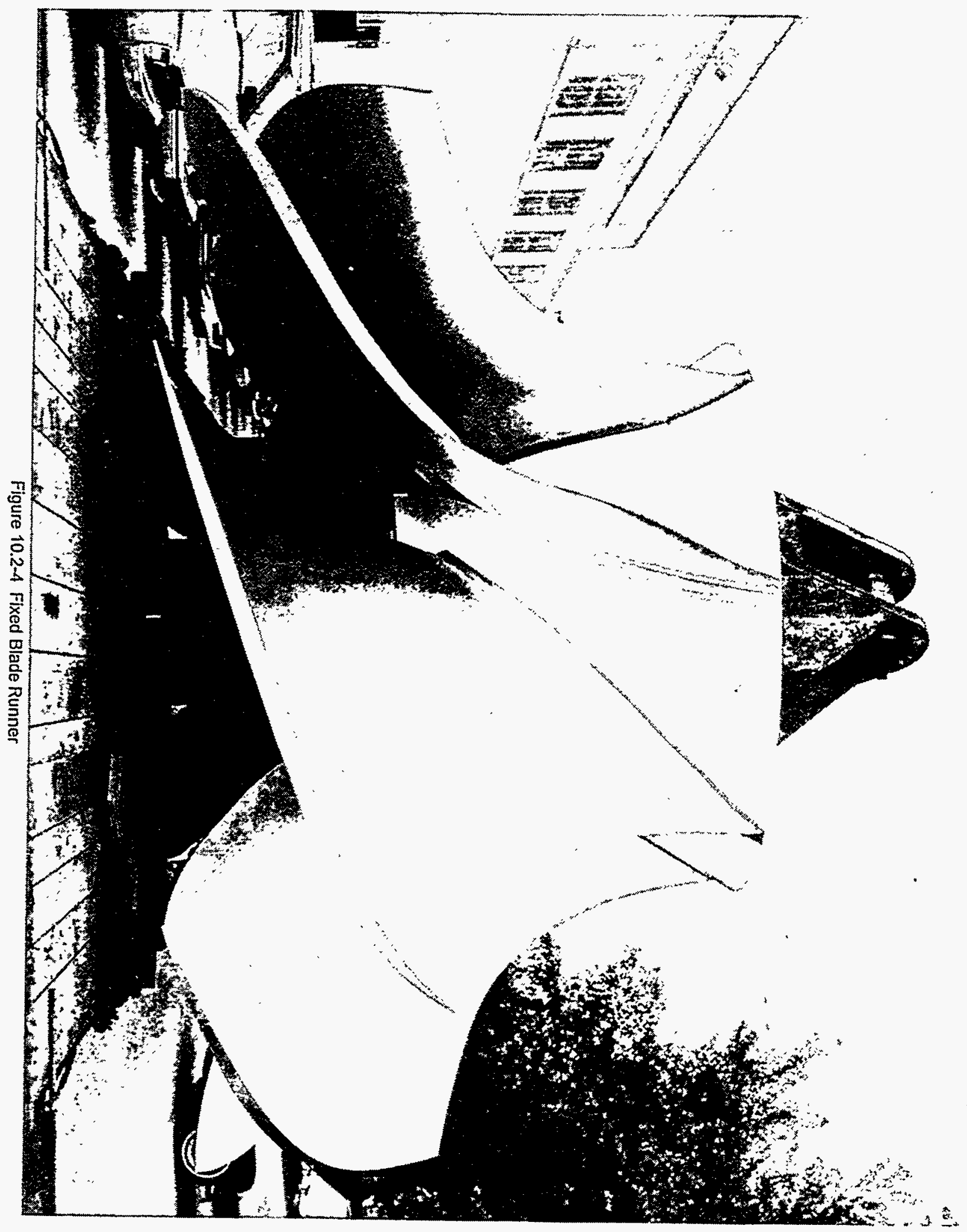




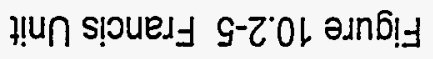

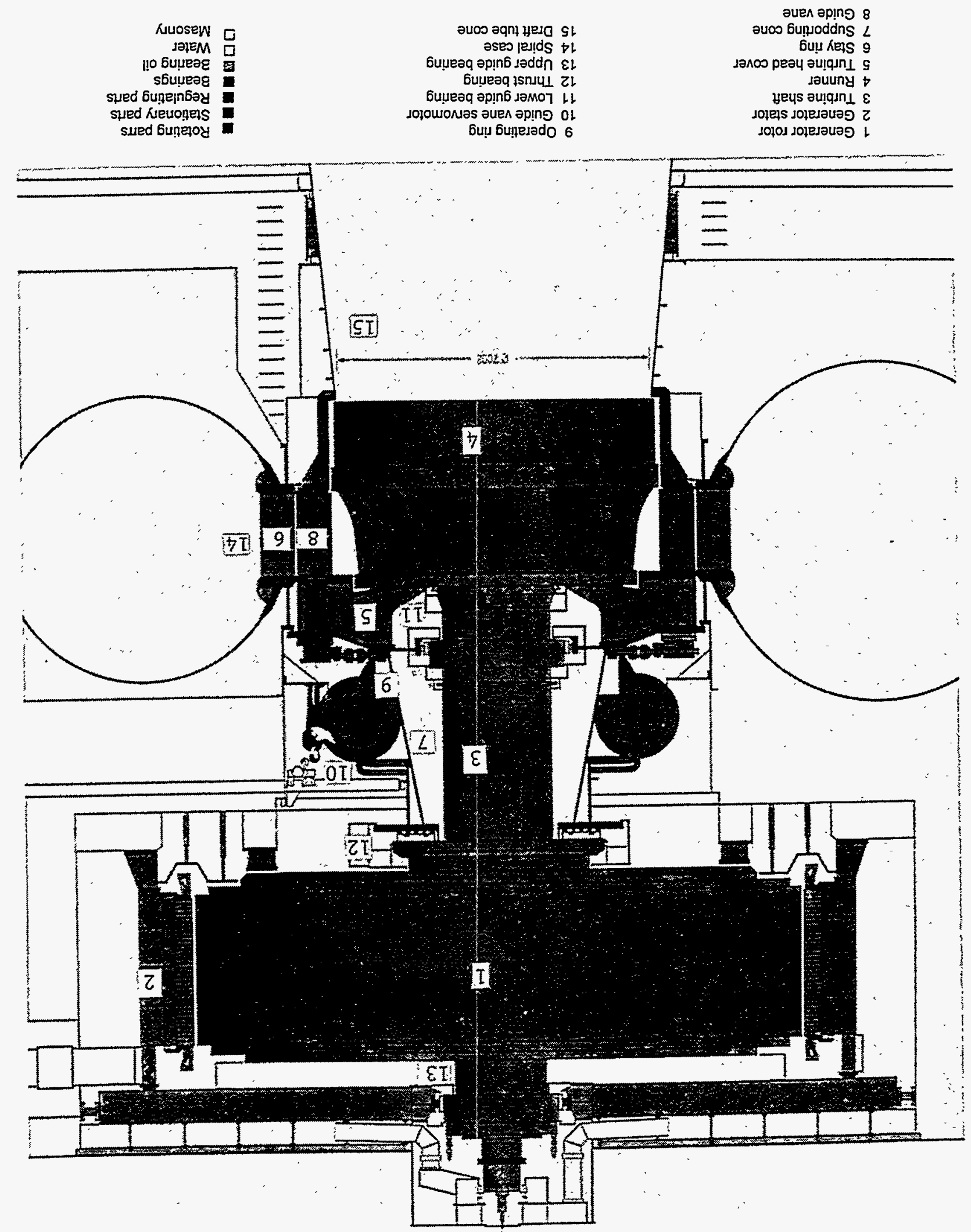


dəuuny s!̣ued $9-Z^{\circ} 0\llcorner$ วגn6!!

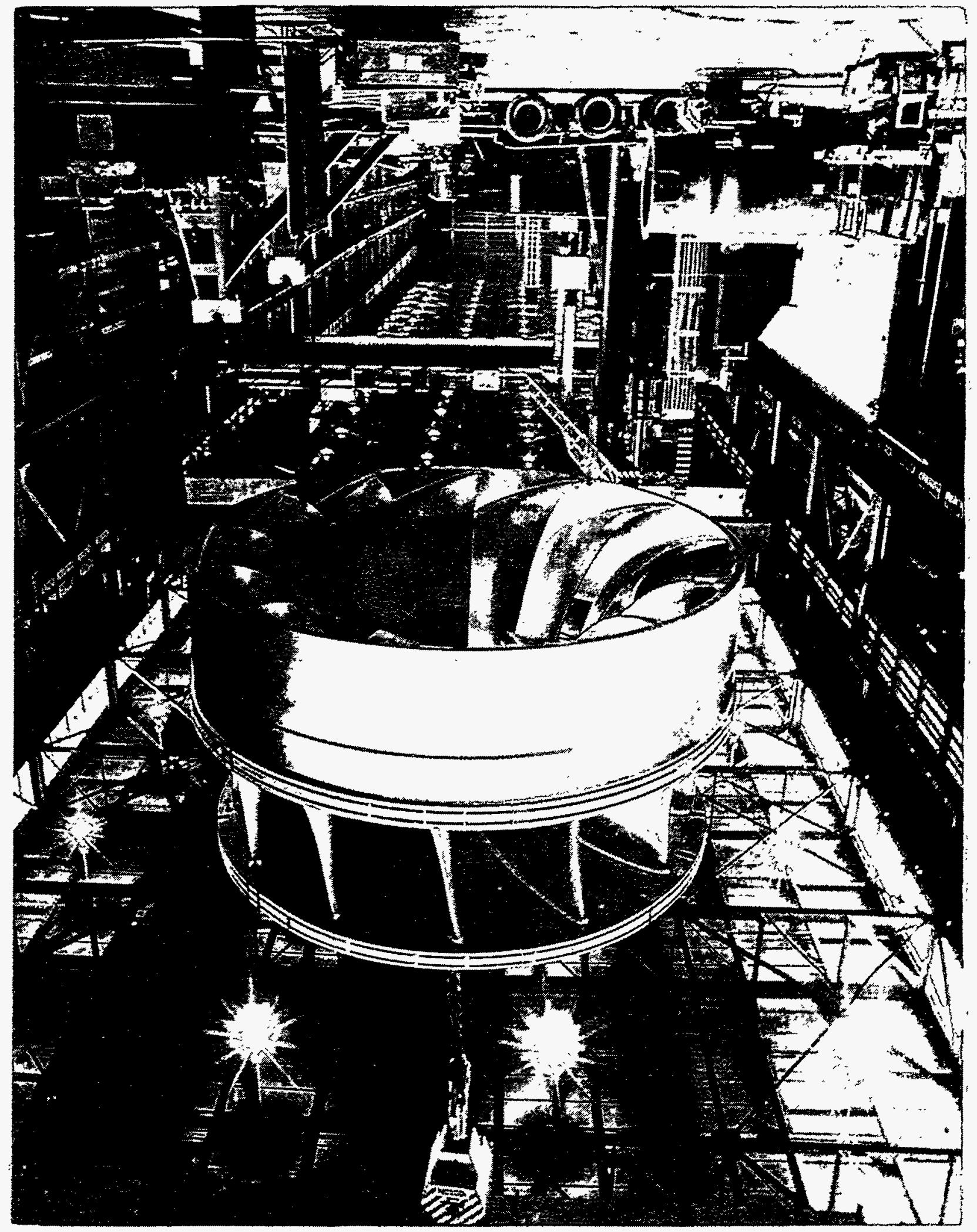




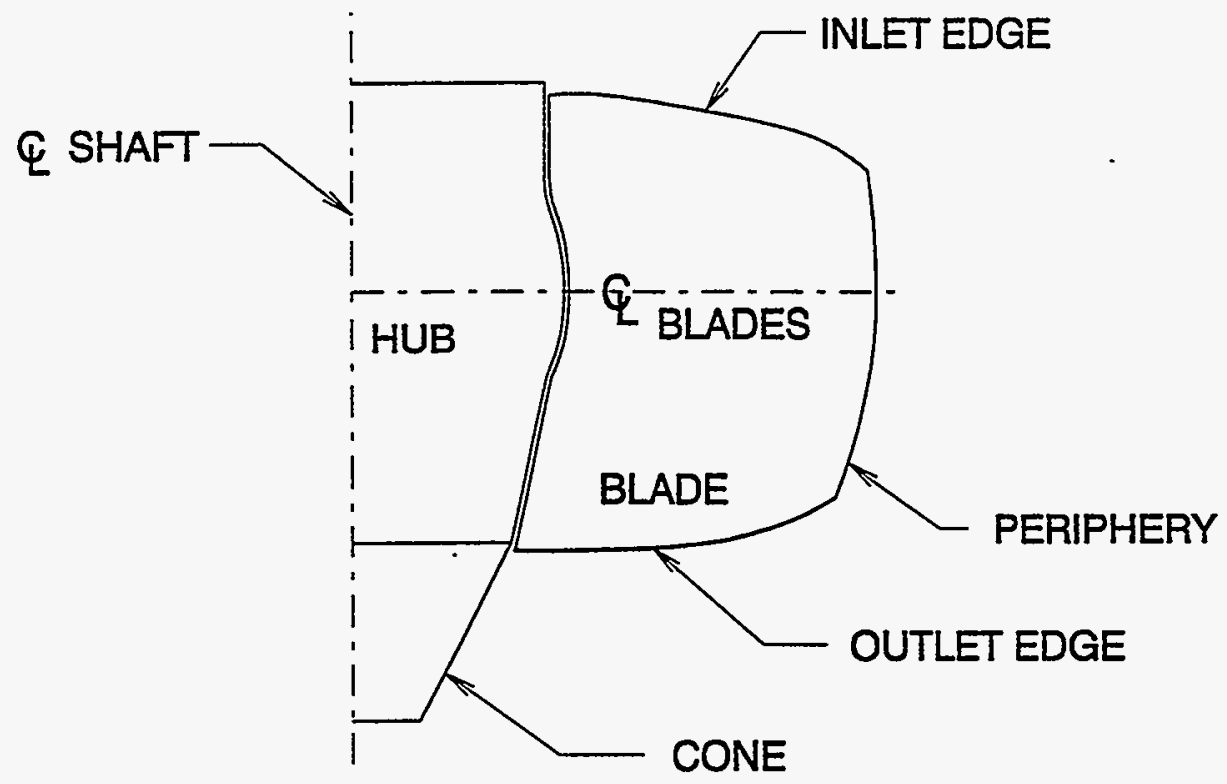

Figure 10.2-7 Major Parts of Kaplan Runner

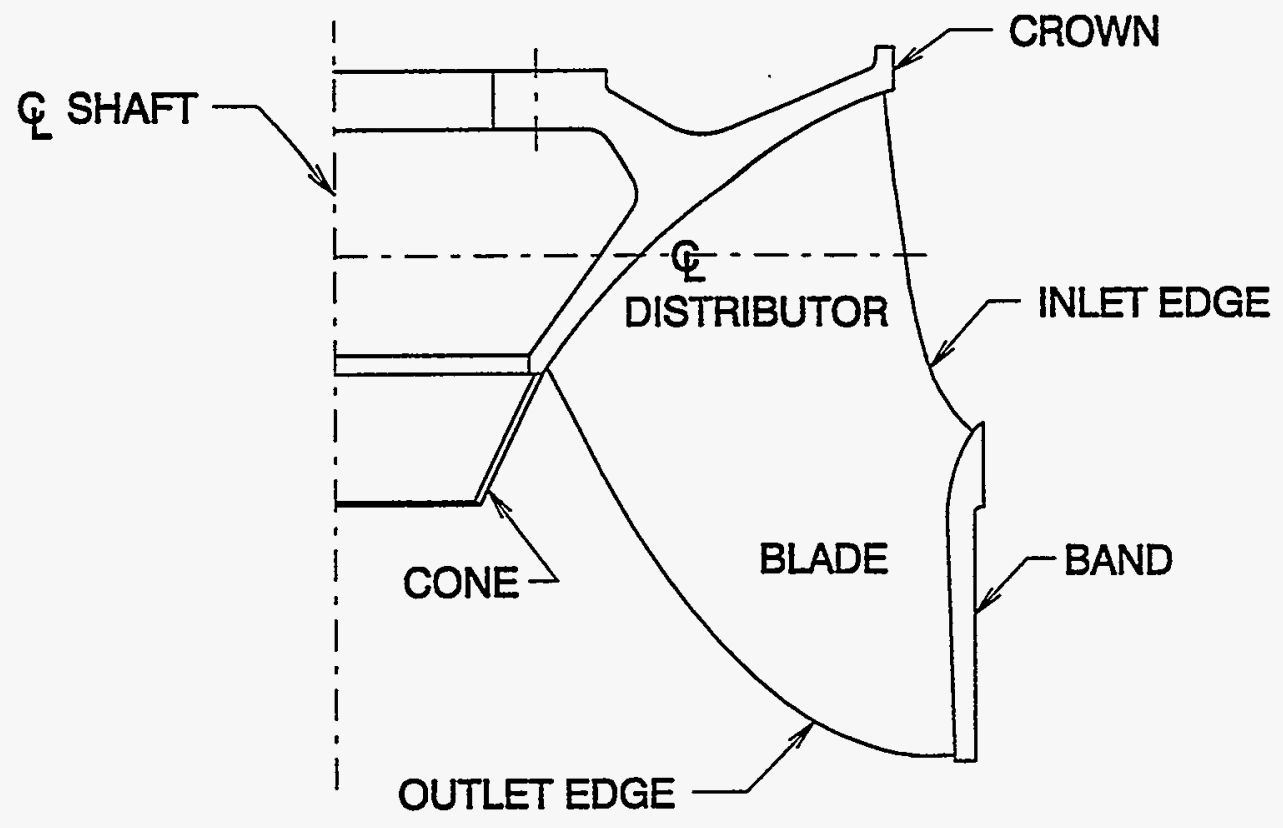

Figure 10.2-8 Major Parts of Francis Runner 


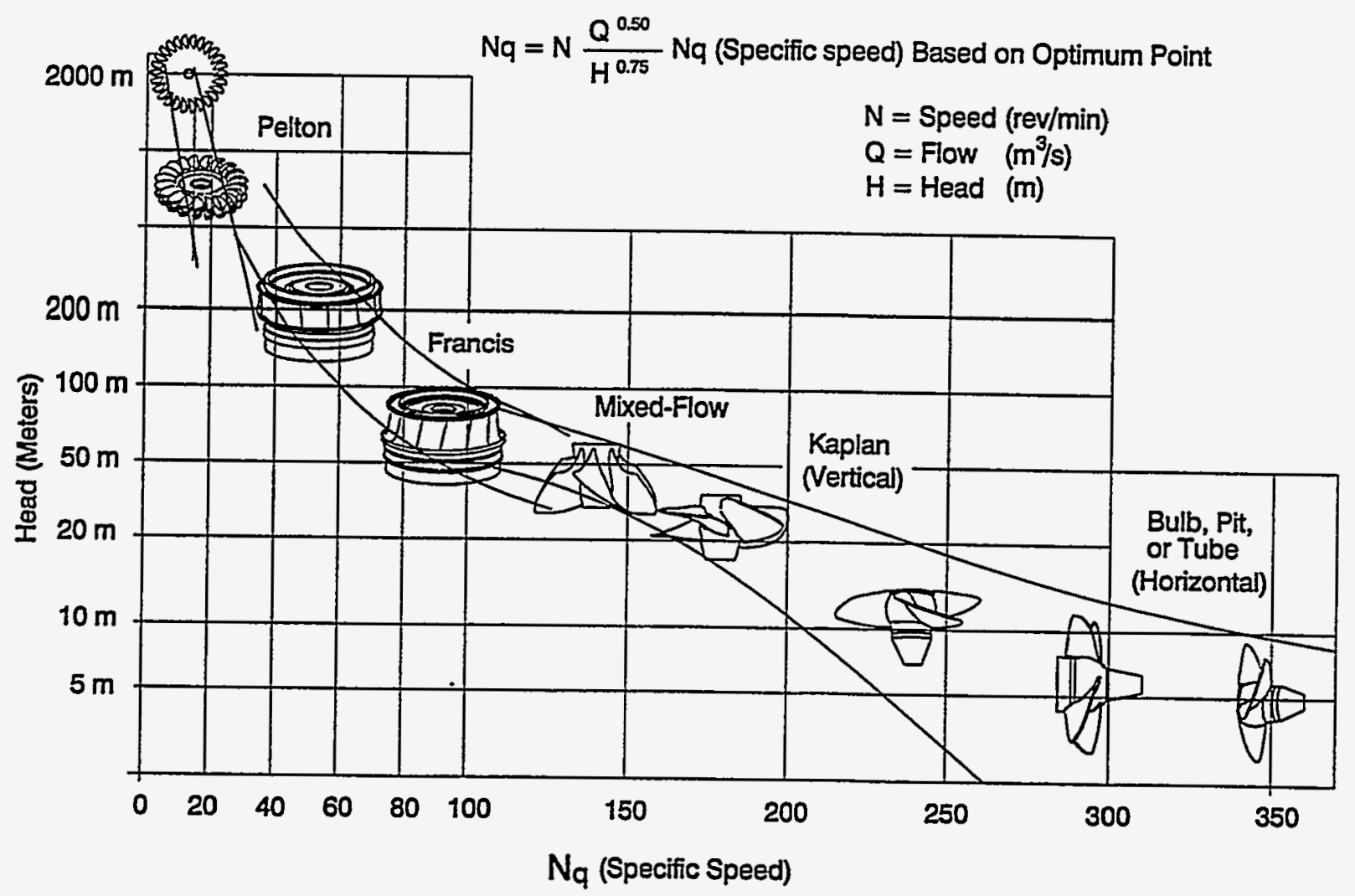

Figure 10.2-9 Turbine Type as a Function of Specific Speed 


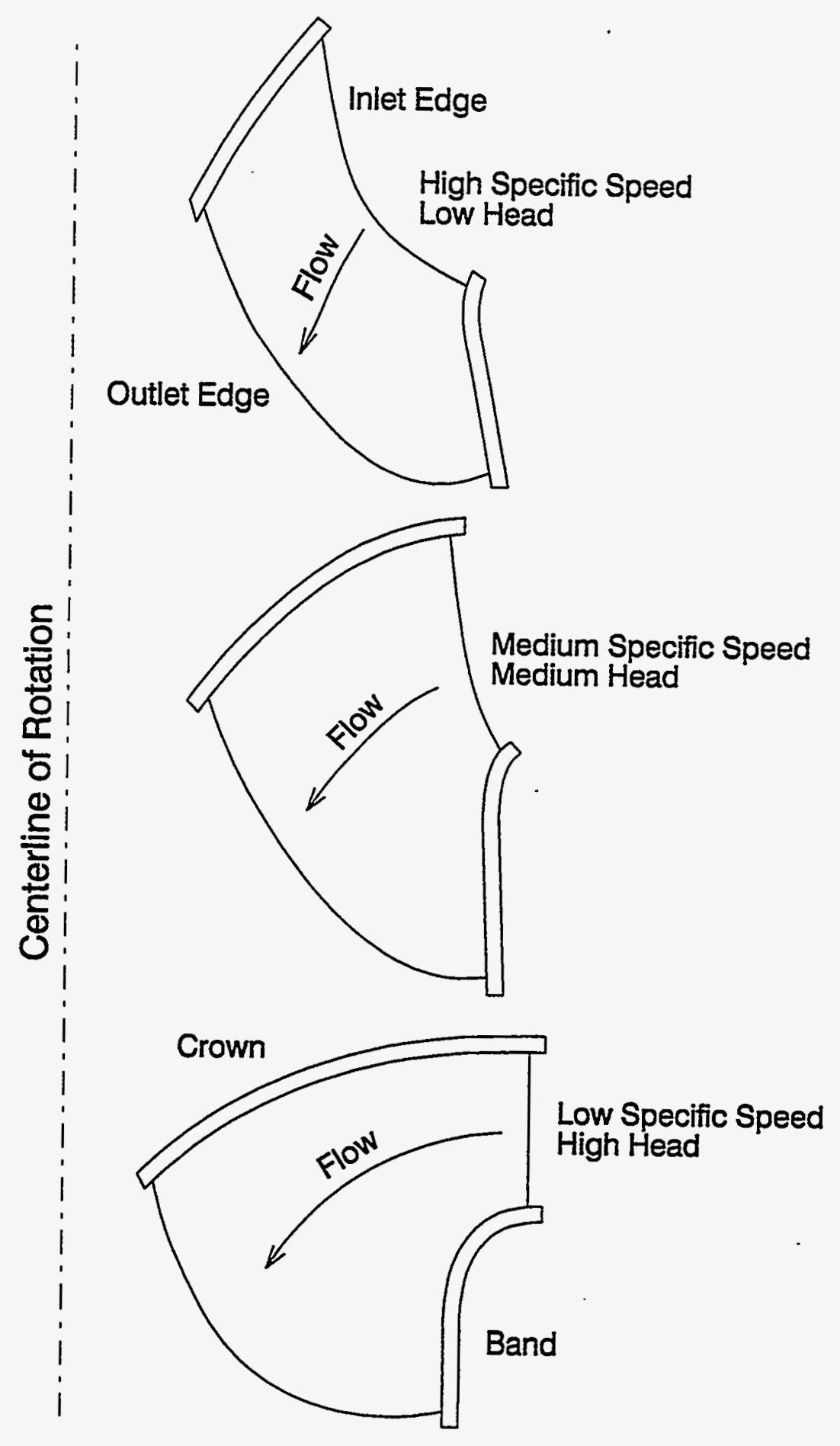

Figure 10.2-10 Variation of Francis Runner Shape with Specific Speed 


\section{APPENDIX 10.3}

\section{DERIVATION OF SHEAR PROBABILITY EQUATION}




\section{DERIVATION OF SHEAR PROBABILITY EQUATION}

The calculation of the probability that a fish will enter a critical shear zone is calculated in a manner very similar to the strike calculation. This calculation method is called the shear probability equation. Rather than considering the blade to be a point, as is done for the strike probability equation, the blade entrance edge has a finite dimension. The time for the passage of successive blades is based on the blade spacing minus the critical shear distance.

$t_{\text {runer }}=\frac{\frac{\pi D}{N}-d}{\frac{\omega D}{2}}$

This time is the same as was used in the leading edge strike equations if the value of $d$ is zero. To use the non-dimensional value of critical shear distance, this equation may be rearranged slightly:

$$
t_{\text {ranner }}=\frac{2 \pi}{N \omega}\left(1-D^{*}\right)
$$

This equation is also identical to the strike equation if the value of $d$ is zero.

The resulting shear probability equations are:

Francis Turbine

$P_{\text {shear }}=\lambda_{\text {shear }} \frac{N \cdot L}{D}\left(\frac{1}{1-D^{*}}\right)\left[\frac{\sin \alpha_{t} \cdot \frac{B}{D_{1}}}{2 Q \omega d}+\frac{\cos \alpha_{t}}{\pi}\right]$

Kaplan and Propeller Turbine

$$
P_{\text {shear }}=\lambda_{\text {shear }} \frac{N \cdot L}{D}\left(\frac{1}{1-D^{*}}\right)\left[\frac{\cos \alpha_{a}}{8 Q_{\omega d}}+\frac{\sin \alpha_{a}}{\pi \frac{r}{R}}\right]
$$

From these equations, it is clear that the non-dimensional shear distance has a linear effect on the shear probability. 
A correlating function, $\lambda_{\text {shear }}$ has been introduced. It's value is unknown, but could be significantly different than the correlating function for leading edge strike. A CFD analysis with a virtual fish might shed light on this question.

Based on the previous evaluation of flow over airfoils, the non-dimensional shear distances have values up to .03 , when the angle of attack becomes very large. As compared to the strike calculation, and ignoring any difference in correlating functions, a non-dimensional shear value of $3 \%$ will increase the strike / shear probability by a factor of $(1 /(1-.03))$ or by 1.03 . This increase in the strike probability will have a small effect when the strike probability is low. For example, if the strike probability is $10 \%$, a factor of 1.03 will increase it to $10.3 \%$. If the strike probability is $90 \%$, a factor of 1.03 will increase it to $92.7 \%$. These effects seem too small to account for any observed fish survival effects.

The shear probability equations may be a useful analysis, but the lack of information regarding the correlating function, and the simplified shear analysis does not give results that support observed fish survival effects. 


\section{APPENDIX 10.4 \\ EVALUATION OF ACCURACY OF FLOW ANGLE CALCULATIONS}

\section{KAPLAN TURBINE}

A CFD analysis of a Kaplan runner was used to evaluate the approximate method used to calculate the flow angle upstream of the runner. Figure 10.4-1 shows that the grid used. Two comparisons were made. Figure 10.4-2 uses a surface at the inlet of the computational model to compare the flow angle calculated by CFD with the approximate analysis. Generally, the angles agree within 4 to 10 degrees. A second surface closer to the runner was also used. This surface has more nearly axial flow than the inlet surface, but has more non-uniformity due to the near influence of the runner blade. Figure 10.4-3 shows the comparison the flow angle calculated by CFD with the approximate analysis. The angles agree within 3 degrees at the periphery, and within 8 to 10 degrees at the midspan.

\section{FRANCIS TURBINE}

A CFD analysis was performed on stay vanes and wicket gates of a Francis turbine. Two gate openings were analyzed. A location downstream of the wicket gates was used as a comparison plane. Figures 10.4-4 and 10.4-5 show a comparison of flow angles determined by the CFD analysis and by the approximate method of Section 4.3. The velocity profiles according to the CFD analysis are shown as well. The velocities and angles vary significantly from crown to band, but the approximate angle calculation is a good average value. 


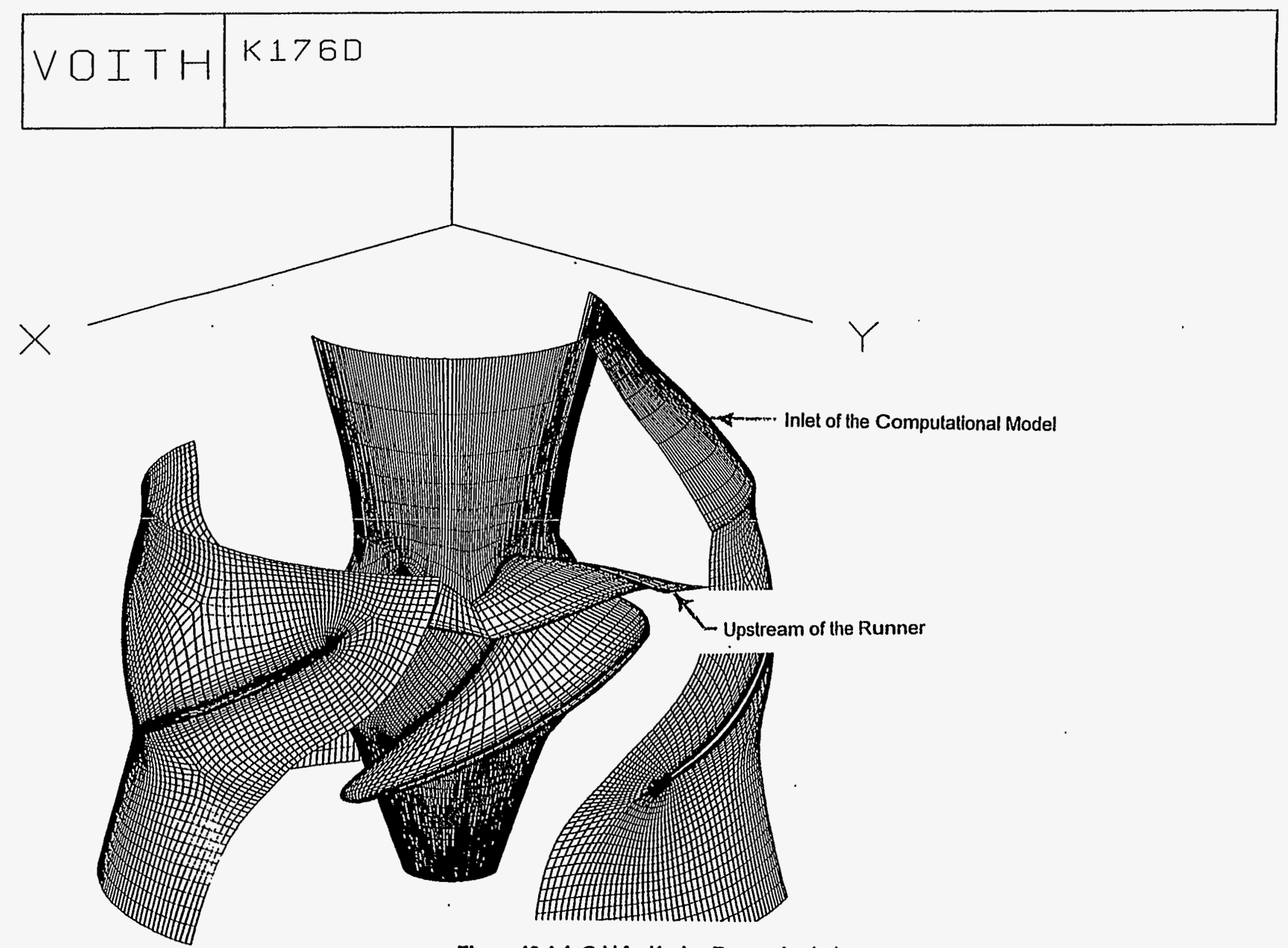

Figure 10.4-1 Grid for Kaplan Runner Analysis 


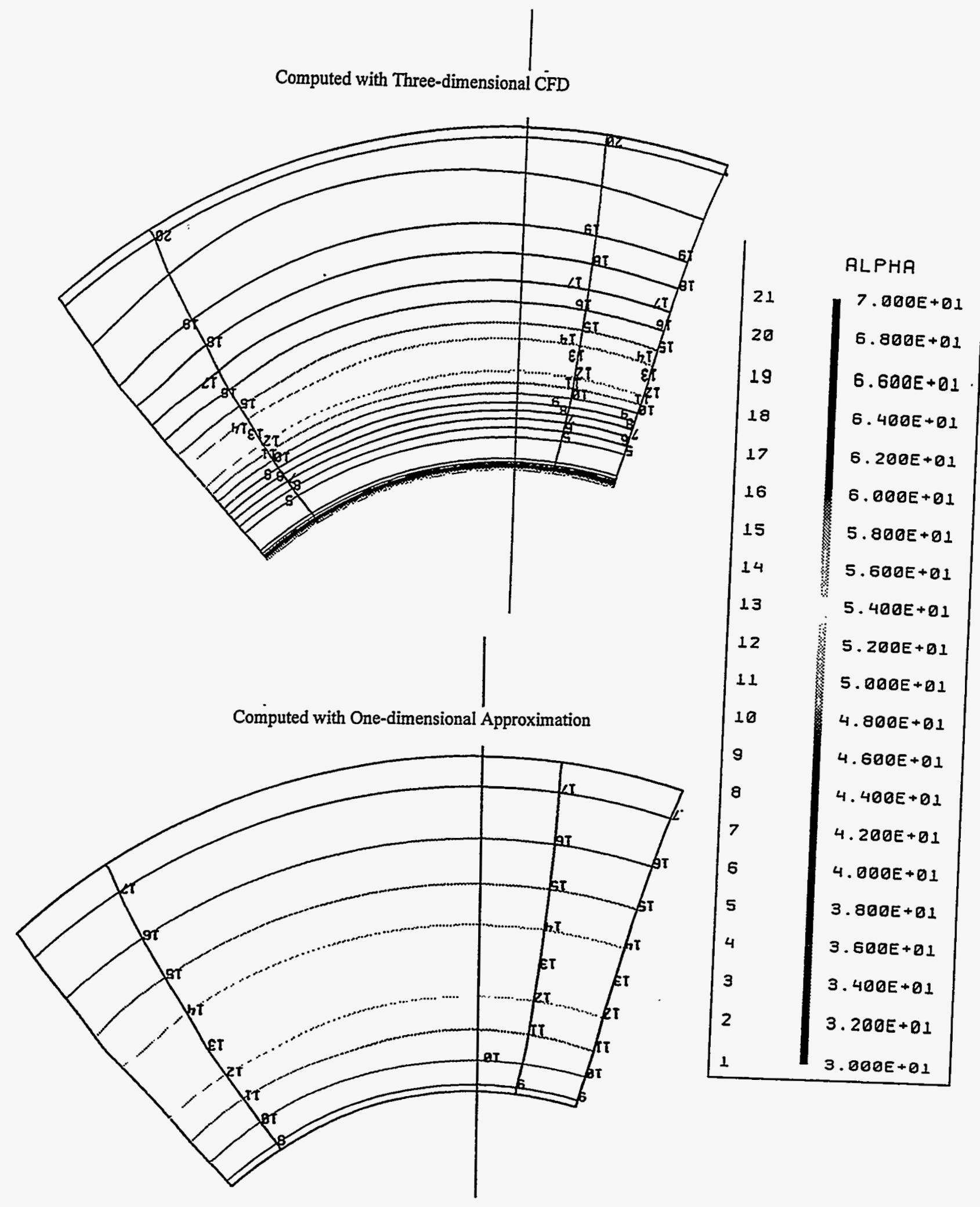

Figure 10.4-2 Comparison of Kaplan Flow Angle at the Inlet of the Computational Model 


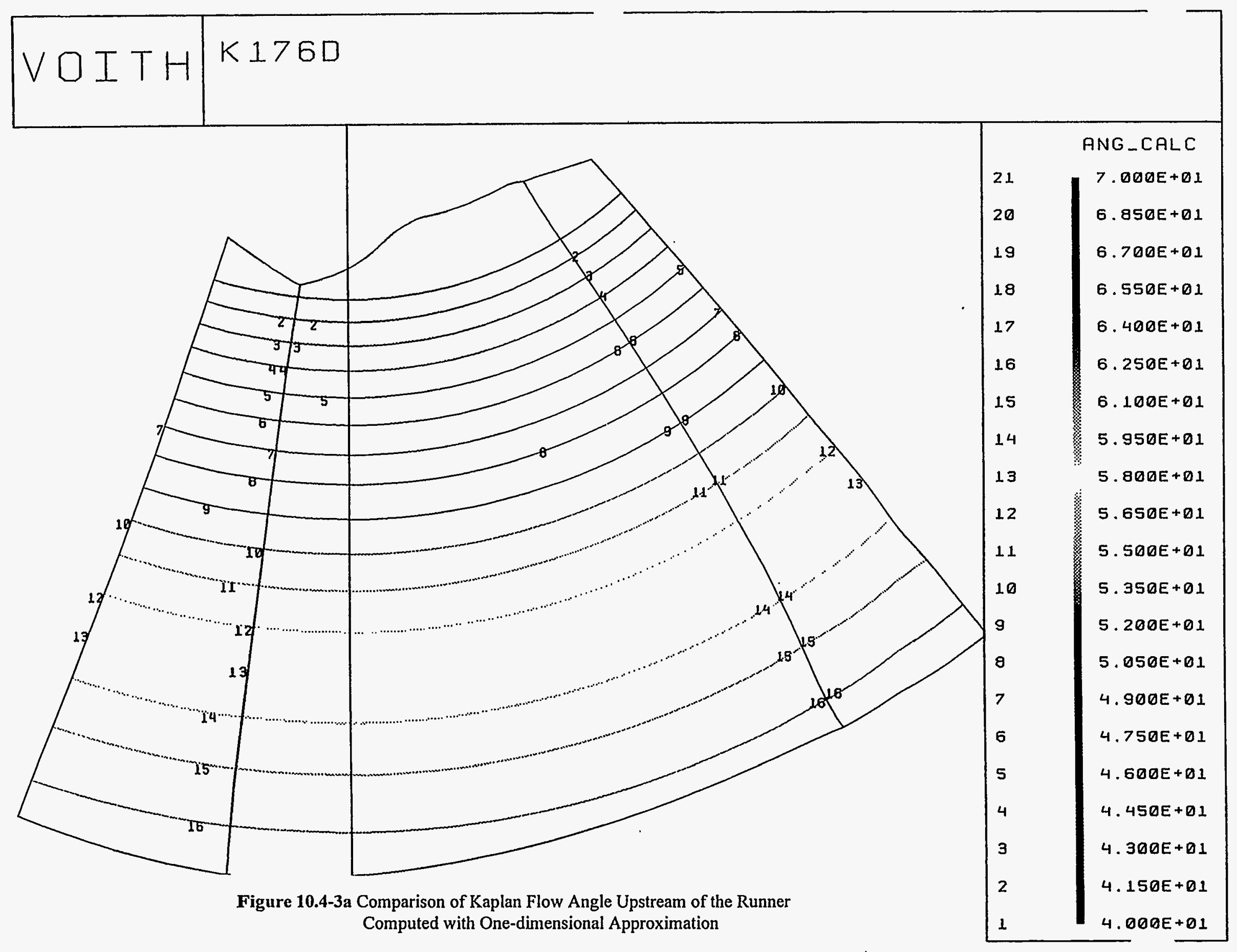




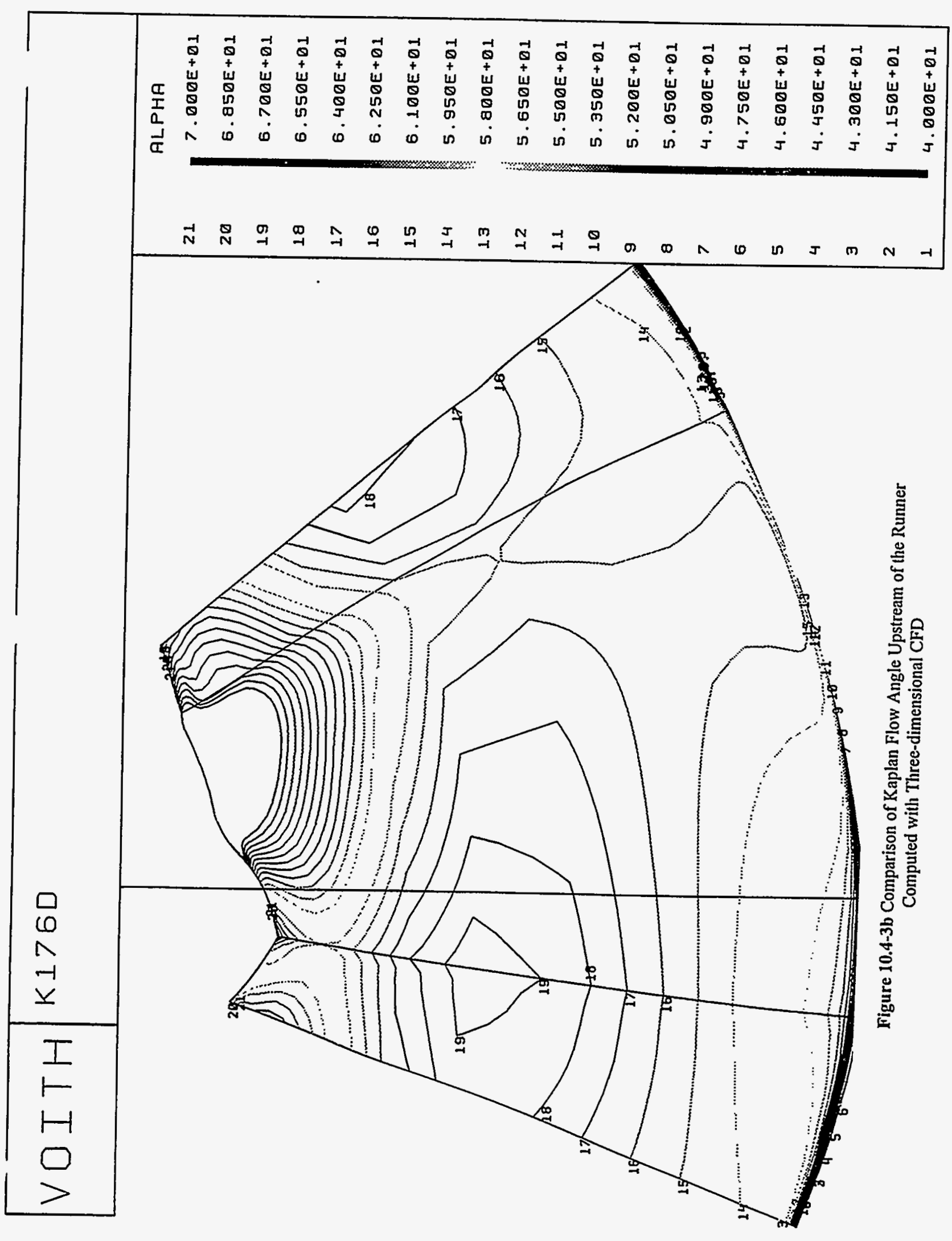


comparison of CFD results to one-dimensional calculation

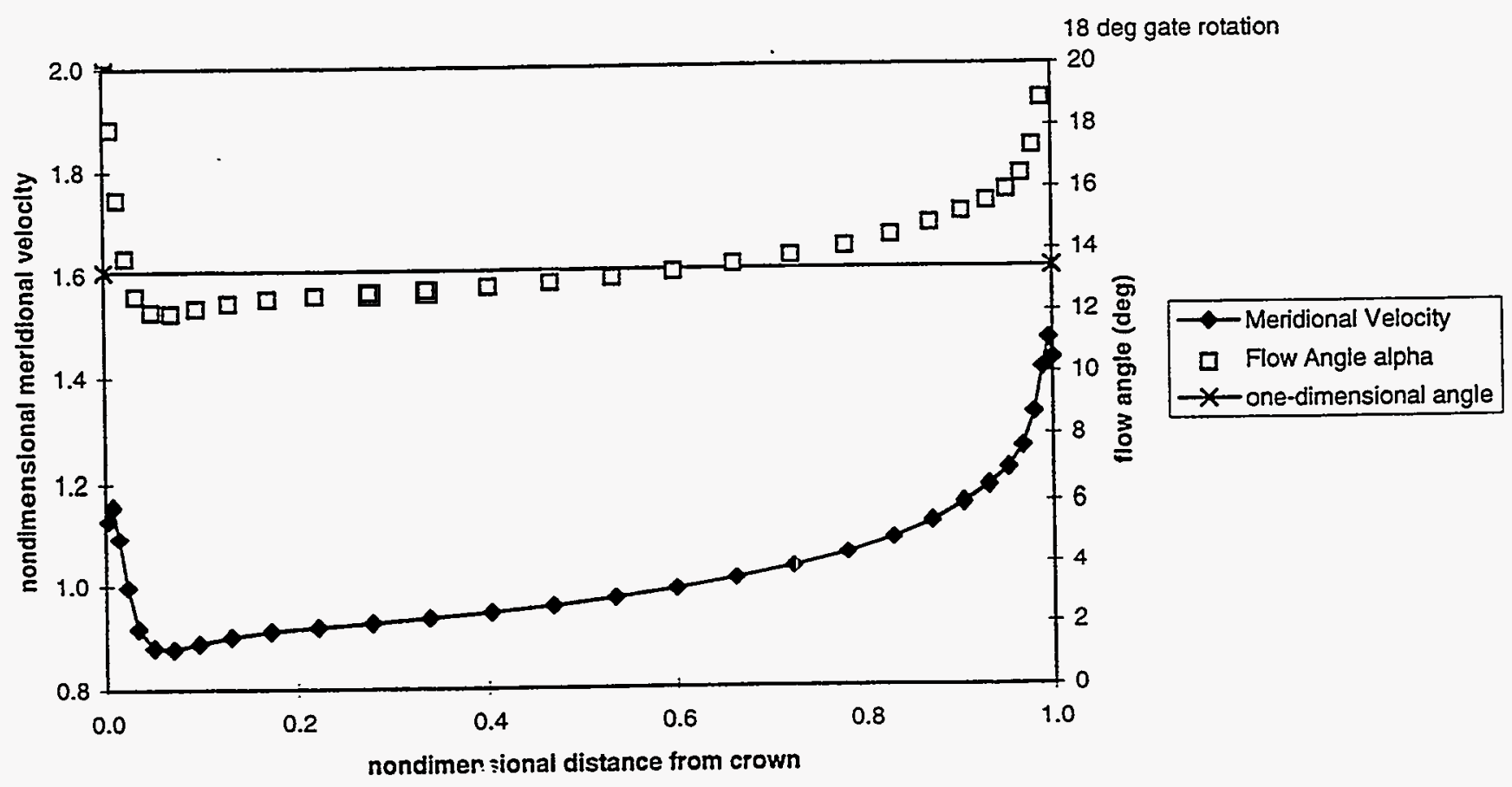

Figure 10.4-4 Comparison of Francis Flow Angle Upstream of the Runner, Smaller Gate Opening

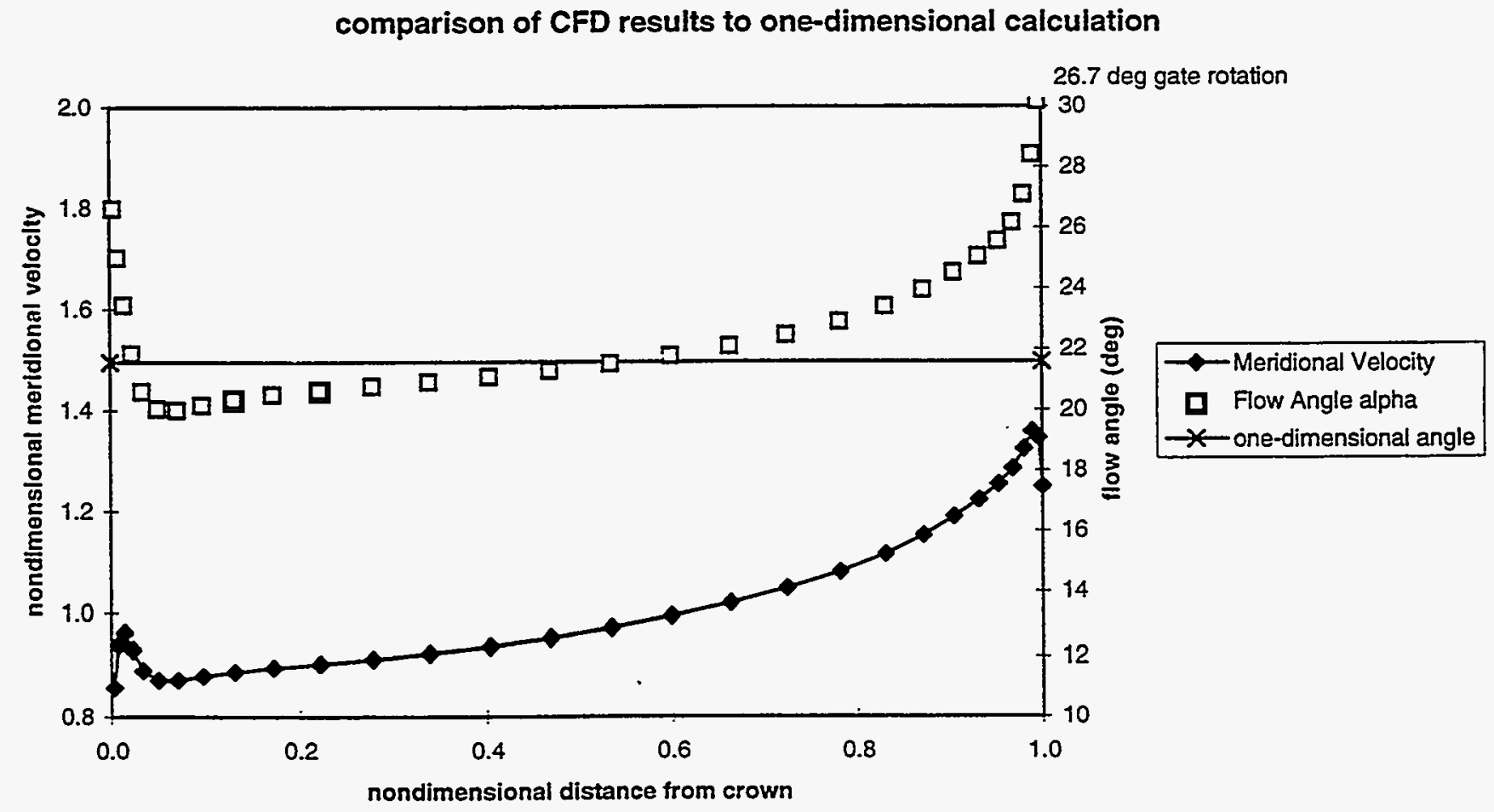

Figure 10.4-5 Comparison of Francis Flow Angle Upstream of the Runner, Larger Gate Opening 


\section{ADVANCED TURBULENCE MODELLING PUBLICATIONS}




\section{APPENDIX 10.6 \\ PERFORMANCE TESTING OF AERATING HYDROTURBINES}

\section{OBJECT AND SCOPE}

The objective of this test code is to present procedures for testing (including acceptance testing) turbines which have been designed to improve the dissolved oxygen content of water in hydropower operations. These include both new turbines with integrated aeration systems and existing turbines containing retrofit aeration systems. The procedures are applicable to testing of the aeration capabilities of all types of turbines, although Francis and fixed-blade propeller turbines form the majority of the experience base. This procedure applies to any size of hydroturbine.

\section{GUIDING PRINCIPLES}

\section{Aeration Acceptance/Guarantee Criteria}

The following parameters may be the basis for guarantees and acceptance criteria for aerating hydroturbines:

- Dissolved oxygen (DO) uptake of specified $\mathrm{mg} / \mathrm{L}$,

- Total dissolved gas (TDG) in tailwater of specified percent,

- Efficiency loss of less than specified percent,

- Max power output loss less than specified hp/kW,

- Thrust increase limitation,

- Shaft runout increase limitation,

- Amount of compressor assist required (SCFM at specified pressure), and

- Aeration-induced cavitation guarantee.

Other parameters may exist based on site-specific conditions. Guarantee/acceptance criteria may be specified at multiple power outputs and water quality conditions.

\section{Unit Efficiency Determination}

Turbine efficiency testing will follow the general procedure as outlined in ASME PTC 18 - Hydraulic Turbines. For new units, aeration guarantee testing will be most effectively accomplished if performed in close coordination with acceptance testing. Absent a companion acceptance test, the general procedures of PTC 18 will be followed, with the following exceptions:

- The determination of unit efficiency will generally be sufficient, and

- Absolute flow measurement will not generally be required.

These exceptions of usual ccde procedures apply only for the determination of efficiency change due to operation of aeration systems.

\section{Uncertainty Analysis}

Pre-test and post-test uncertainty analyses are considered essertial in this test procedure. All parties to the test are urged to consider the effects of potential measurement error on the overall uncertainty of the parameters being evaluated when choices are made concerning:

- Selection of instruments,

- Accuracy requirements,

- Agreement to exceptions from the applicable test codes.

\section{Test Conditions}

Guarantees will generally be made for specified conditions, including nominal values for the following:

- Net head on the unit,

- Power output (at peak efficiency and max gate), 
- Tailwater elevation,

- Water temperature, and

- Inlet DO saturation ratio.

Test Limits

Allowable deviations from nominal values will be specified for the following:

- Head,

- Temperature,

- Tailwater elevation,

- Inlet DO saturation ratio,

- Turbine discharge, and

- Turbine speed.

Specified deviations are deviations from nominal test conditions, and deviations from average conditions during a test. PTC18 will be the starting point for this determination for the head deviations.

\section{TEST PROCEDURES}

A typical test sequence is presented below. In general, at each operating point a test run will be performed with: (1) each aeration system operating alone, and (2) with all desired combinations of aeration systems operating.

The sequence for performing an aeration test typically is as follows:

1. Perform zeroing runs in which all instruments are read with the unit off line and the wicket gates closed. Inspect instruments to ensure that all readings are reasonable. A zeroing run should be performed at the beginning and end of each test day.

2. Set wicket gate to desired position.

3. Set plant reactive power to zero.

4. Open air inlets of desired aeration alternatives.

5. Allow tailwater, power output, discharge, and dissolved oxygen to stabilize.

6. Record the electronic and manual measurements for three minutes.

7. Repeat steps 3 through 6 for each combination of alternatives.

8. Return to step 2 for the next wicket operating point.

Test runs are generally performed over a range of gate settings.

\section{INSTRUMENTS AND METHODS OF MEASUREMENT}

\section{Mechanical Performance Measurement}

\section{Power Output}

Because the determination of small changes in efficiency is especially important in aeration testing, the stability and repeatability of the power measuring equipment is especially important.

- Plant meter

- Watt-transducer

- Rotating standard

- Digital power test set

\section{Discharge}

For determination of the effect on efficiency of aerating devices, index test methods will generally be sufficient. Previous calibration or indexing to model tests or to absolute field tests is necessary.

- Winter-Kennedy taps

- Velocity traverse methods 
- Dye-dilution methods

- Ultrasonic flow meters

- Gibson testing

- Thermodynamic method

Wicket Gate Position

Wicket gate position can be measured with either of the following techniques.

- Scale

- Linear displacement transducer

Inlet Head

The inlet head can be measured with either of the following techniques.

- Inlet pressure taps

- Headwater elevation + friction loss calculation

Tailwater Elevation/Discharge Head

The tailwater elevation can be measured with either of the following techniques.

- Installed stilling well

- Submersible pressure cell

- Ultrasonic ranger

- Draft tube pressure taps

\section{Machine Dynamics/Vibration}

The following measurements can be used to evaluate vibration efiects produced by aeration systems.

- Generator guide bearing acceleration

- Turbine guide bearing acceleration

- Thrust bridge deflection

- Shaft runout at turbine guide bearing

Instrumentation to perform these measurements include:

- Accelerometers with appropriate anti-aliasing filter and sample frequency,

- LVDT,

- Proximity probes

\section{Temperature and Dissolved Oxygen Concentration}

A key difficulty in measuring dissolved oxygen concentration is the potential for non-uniform distribution of DO, both in the turbine intake and in the discharge. Non-uniformity in the DO and temperature distributions in the intake usually are caused by thermal stratification in the reservoir. In the tailwater, non-L.iformity can be expected due to operating conditions that create a non-uniform distribution of air and water in the turbine discharge.

Obtaining a DO profile at the entrance to the scrollcase is essential for accurate testing. The DO should be sampled at multiple points around the circumference of the penstock. The sampling interval will depend on the magnitude rate of variation of DO stratification in the intake. If the magnitude of the DO stratification is consistently lower than the accuracy of the DO sensors, only a few readings will be required. For large levels of DO stratification containing frequent variations, multiple measurements may be required.

Temperature and DO profiles measured in the powerhouse forebay will determine the extent of reservoir stratification and potential magnitude of intake temperature and DO variations. If stratification occurs within the withdrawal zone for the turbine intake, frequent measurement of the temperature and DO profiles at the inlet to the scrollcase may be required. 
In the discharge, sampling should be downstream of the zone where: (1) entrained and undissolved gasses escape through the water surface, and (2) surface aeration from the draft tube boil is complete. To minimize non-homogeneity, DO and temperature measurements should be far enough downstream to ensure good mixing of the turbine discharge, subject to the constraints that no mixing with other flows occurs (e.g., from adjacent units or tributary flow), and that no significant free-stream surface aeration occurs. The location of downstream sampling stations also may be influenced by time constraints. Samples located further downstream will require a longer time for measurements to stabilize, increasing both test duration and cost. If sampling for the discharge is located in a zone with incomplete mixing, multiple stations may be required. These should be strategically located based on the flow distribution of the turbine discharge.

\section{Inlet Temperature and DO Concentration Sampling Locations}

The magnitude of inlet temperature and DO stratification must be verified prior to testing. Possible measurement points include the following:

- Inlet head pressure taps,

- Gibson pressure taps, and

- Reservoir profiles.

Discharge Temperature and DO Concentration Sampling Locations

The location of the discharge temperature and DO measurements is critical for obtaining accurate, repeatable results. Some factors important for determining this location include:

- Location of the boil,

- Number of discharge bays,

- Flow patterns (e.g., avoid recirculation zones and flows from other units or DO sources),

- The magnitude of lateral and vertical mixing, and

- The amount of boil-induced surface aeration.

Temperature and Dissolved Oxygen Concentration Measurement

Various options exist for sampling and measuring temperature and DO concentration. Sampling methods include:

- Grab sample,

- In-situ, and

- Pumped sample.

Factors affecting the selected sampling method include the sampling interval, setup difficulty, and the effect of the sampling method on the sample quality and accuracy. For example, methods to collect pumped and grab samples can add additional air and DO by improper setup or handling. Pumps can alter the temperature and pressure of the sample, which can affect the DO concentration significantly.

The two primary methods to measure DO include:

- Winkler titration, and

- Membrane probe.

Because Winkler titration measurements are relatively labor intensive, these are typically used as calibrations checks for automated membrane probe readings.

Air Flow

The following primary elements are appropriate for air flow measurements.

- Bell-mouth inlet

- Venturi meter

- Orifice Plate 
- Velocity traverse

Pitot tube

Hot-film anemometer

- Calibrated elbow meter

Calibrate in lab, including upstream piping

Calibrate in place

- Calibrated single point velocity measurement

Calibrate in lab, including upstream piping

Calibrate in place

The following instruments also will be required for air flow measurement.

- Differential pressure (for differential producing primary elements)

Electronic DP cell (preferred)

Manometer

Differential pressure gage

- Air temperature at primary element

Thermometer

Thermistor

RTD

Thermocouple

- Air pressure at primary element

- Relative humidity at primary element

\section{Water Temperature}

Since the change is usually small, water temperature can be measured at either the inlet or discharge. Most membrane-type DO probes include instrumentation for simultaneous temperature measurements.

\section{Water Quality Parameters}

Water quality parameters other than DO may be important for various sites. These parameters include:

- Total Dissolved Gas (TDG),

- Salinity,

- MBAS/Surfactants,

- Tannins, and

- Other constituents which may affect the measurement of DO concentration.

\section{Total Dissolved Gas}

Total dissolved gas (TDG) concentration can be determined by measuring total gas pressure in conjunction with barometric pressure. Instruments are commercially available that can perform this measurement automatically or manually.

\section{ANALYSIS}

\section{Averaging of Data}

Computations will be based on averages obtained from the individual readings after outliers have been removed, for each test run.

\section{Mechanical Performance}

The following computations can be used to evaluate the mechanical performance of a turbine. A key parameter resulting from these computations is the change in turbine efficiency produced by operating the aeration systems. For turbines with multiple systems, this parameter will be evaluated as a function of the system in service, and as a function of gate position. Note that some relationships given below will differ 
depending on the instrumentation used for a particular test. For example, computation of the turbine discharge will change if measured by a method other than with a Winter-Kennedy differential pressure.

\section{Gravitational Acceleration}

PTC18-1992 gives for local gravitational acceleration

$$
g=(9.80616 / 0.3048)\left(1-0.0026373 \cos 2 \theta+0.0000059 \cos ^{2} 2 \theta\right)-3.086 \times 10^{-6} z,
$$

where

$$
\begin{aligned}
& g=\text { gravitational acceleration in } \mathrm{ft} / \mathrm{s}^{2} . \\
& \theta=\text { latitude of the unit in degrees, and } \\
& z=\text { altitude of the distributor centeriine in feet. }
\end{aligned}
$$

\section{Water Density}

Water density is a function of water temperature. The computation used herein is that of PTC18-1992, which requires specification of $T_{w}$ in ${ }^{\circ} \mathrm{C}$ and $\rho_{w}$ in $\mathrm{kg} / \mathrm{m}^{3}$, given by

$$
\rho_{w}=b_{0}+b_{1} T_{w}+b_{2} T_{w}^{2}+b_{3} T_{w}^{3}+b_{4} T_{w}^{4}+b_{5} T_{w}^{5}
$$

where

$$
\begin{aligned}
& \rho_{w}=\text { water density in } \mathrm{kg} / \mathrm{m}^{3}, \\
& T_{w}=\text { water temperature in }{ }^{\circ} \mathrm{C}, \\
& b_{0}=999.8394 \\
& b_{1}=0.06862162, \\
& b_{2}=-0.009270732 \\
& b_{3}=1.155160 \times 10^{-4} \\
& b_{4}=-1.626299 \times 10^{-6}, \text { and } \\
& b_{5}=1.211919 \times 10^{-8} .
\end{aligned}
$$

\section{Specific Weight of Water}

The computation used herein for the specific weight of water is that of PTC18-1992, given by

$$
\begin{aligned}
& \rho_{A}(z)=1.225\left(1-\frac{0.0065}{288.16} z\right)^{4.2561}, \text { and } \\
& \gamma_{W}=\frac{g}{g_{c}}\left[\rho_{W}-\rho_{A}(z)\right] \frac{(0.3048)^{3}}{0.45359237},
\end{aligned}
$$

where

$$
\begin{aligned}
& \rho_{A}=\text { air density in } \mathrm{kg} / \mathrm{m}^{3}, \\
& \gamma_{W}=\text { specific weight of water in } \mathrm{lbf} / \mathrm{ft}^{3}, \text { and } \\
& g_{c}=\text { gravitational constant }-32.17405 \mathrm{ft} / \mathrm{s}^{2} .
\end{aligned}
$$

\section{Water Discharge}

Water discharge is indexed to the differential pressure across the Winter-Kennedy taps. The formula for the discharge is

$$
Q_{w}=C_{w K} \sqrt{\Delta H_{w K}} \text {. }
$$

where

$C_{w k}=$ Winter-Kennedy discharge coefficient in cfs/(inch of water), an:d

$\Delta H_{w k}=$ pressure measured across Winter-Kennedy pressure taps in inches of water. 


\section{Turbine Power}

Turbine power output is the sum of generator power output and generator power losses, given by

$$
P_{t}=P_{G}+P_{G L}
$$

where

$P_{G}=$ Generator power in $M W$, and

$P_{G L}=$ Generator power losses in MW.

Generator power losses can be modeled in many cases by quadratic polynomial,

$$
P_{G L}=c_{0}+c_{1} P_{G}+c_{2} P_{G}^{2},
$$

where

$$
\begin{aligned}
& c_{0}=0.66337, \\
& c_{1}=0.00054371, \text { and } \\
& c_{2}=0.000096853 .
\end{aligned}
$$

\section{Net Head}

Net head is the difference between total specific energy at the scrollcase inlet section and total spe-ific energy at the draft tube exit section. The net head computation will ignore the added volume of air flow at the draft tube exit and is given by

$$
H=\left[Z_{S C}+H_{S C}+\frac{1}{2 g}\left(\frac{Q_{W}}{A_{S C}}\right)^{2}\right]-\left[T W_{D T}+\frac{1}{2 g}\left(\frac{Q_{W}}{A_{D T}}\right)^{2}\right]
$$

where

$Z_{S C}=$ elevation of inlet head measurement point in feet,

$H_{S C}=$ inlet head pressure in feet of water,

$A_{S C}=$ Cross section area of penstock at inlet head measurement point,

$T W_{D T}=$ tailwater elevation in feet, and

$A_{D T}=$ draft tube exit area.

\section{Turbine Efficiency}

Turbine efficiency is the ratio of shaft power (turbine output power) to water power, given by

$$
\eta=737562.1 \frac{P_{t}}{\gamma_{W} Q_{W} H}
$$

where

$$
\begin{aligned}
& \eta=\text { turbine efficiency, } \\
& P_{t}=\text { turbine power output in } \mathrm{MW} \text {, and } \\
& \gamma_{W}=\text { specific weight of water in } \mathrm{Ibf} / \mathrm{ft}^{3} .
\end{aligned}
$$

\section{Turbine Efficiency Change (Aeration Hydraulic Performance)}

The effect of each aeration alternative will be evaluated by the change in turbine efficiency at constant gate setting, with and without aeration, given by

$$
\Delta \eta=\eta_{0}-\eta_{a},
$$

where 
$\Delta \eta=$ change in turbine efficiency

$\eta_{0}=$ turbine efficiency with aeration systems off, and

$\eta_{\mathrm{a}}=$ turbine efficiency with aeration systems on.

\section{Analysis of Vibration Data}

Vibration data can be analyzed by various methods. Possible techniques include:

- Peaks on vibration spectrum,

- Shaft runout limits, and

- Thrust bridge deflection (thrust increase/decrease).

\section{Aeration Performance}

The following computations can be used to evaluate the aeration performance of a turbine. Key parameters resulting from these computations include the dissolved oxygen uptake and the oxygen transfer efficiency. Others, such as total dissolved gas, also can be added. These parameters could be evaluated as a function of aeration option and gate position. The functions presented below will change depending on the instruments used for a particular test.

\section{Net Positive Suction Head}

Net positive suction head (NPSH) is the minimum head required for cavitation-free operation at a reference elevation located near the exit of the runner and is given by

$$
N P S H=\left(\frac{144 p_{b a r}}{\gamma_{W}}\right)-\left(Z_{N P S H}-T W_{D T}\right)-\left(\frac{144 p_{v}}{\gamma_{W}}\right) .
$$

where

$N P S H=$ net positive suction head in feet of water,

$\gamma_{W}=$ specific weight of water in $\mathrm{lbf} / \mathrm{ft}^{3}$,

$Z_{\text {NPSH }}=$ reference elevation for net positive suction head in feet,

$Z_{T W}=$ tailwater elevation in feet, and

$p_{v}=$ vapor pressure of water in psi.

\section{Saturation Vapor Pressure Over Liquid Water}

The saturation vapor pressure over liquid water is given by (ASHRAE, 1989)

$$
p_{w s}=\exp \left(\frac{C_{8}}{T_{w b}}+C_{9}+C_{10} T_{w b}+C_{11} T_{w b}^{2}+C_{12} T_{w b}^{3}+C_{13} \ln T_{w b}\right)
$$

where

$$
\begin{aligned}
& \rho_{w s}=\text { saturation vapor pressure over liquid water in psi, } \\
& T_{w b}=\text { wet bulb temperature in }{ }^{\circ} R, \\
& C_{8}=-1.044039708 \times 10^{4}, \\
& C_{9}=-11.2946496, \\
& C_{10}=-2.7022355 \times 10^{-2}, \\
& C_{11}=1.2890360 \times 10^{-5}, \\
& C_{12}=-2.478068 \times 10^{-9}, \text { and } \\
& C_{13}=6.5459673 .
\end{aligned}
$$

Humidity Ratio

The humidity ratio is given by (ASHRAE, 1989)

$$
w_{s}^{*}=0.62198 \frac{p_{w s}}{p_{b a r}-p_{w s}} \text {, and }
$$




$$
w=\frac{\left(1093-0.556 T_{w b}\right) w_{s}^{*}-0.240\left(T_{d b}-T_{w b}\right)}{1093+0.444 T_{c b}-T_{w b}},
$$

where

$$
\begin{aligned}
& w_{s}^{*}=\text { saturation vapor pressure, } \\
& p_{b a r}=\text { barometric pressure in psi, } \\
& W=\text { humidity ratio, } \\
& T_{d b}=\text { dry bulb temperature in }{ }^{\circ} \mathrm{F} \text {, and } \\
& T_{w b}=\text { wet bulb temperature in }{ }^{\circ} \mathrm{F} .
\end{aligned}
$$

\section{Air Density}

Air density is given by (ASHRAE, 1989)

$$
\begin{aligned}
v & =\frac{R_{\mathrm{a}} T_{d b}}{p_{b a r}}(1+1.6078 w), \text { and } \\
\rho_{A} & =\frac{1+w}{v} .
\end{aligned}
$$

where

$$
\begin{aligned}
& v=\text { specific volume of wet air in } \mathrm{ft}^{3} / \mathrm{lbm}, \\
& R_{a}=0.3705 \text { psia- } \mathrm{ft}^{3} /(\mathrm{lbm}-\mathrm{R}), \\
& \rho_{A}=\text { air density in } \mathrm{lbm} / \mathrm{ft}^{3}, \text { and } \\
& T_{c b}=\text { dry bulb temperature in }{ }^{\circ} \mathrm{R} .
\end{aligned}
$$

\section{Air Viscosity}

The dynamic, or absolute, viscosity of air is computed from a quadratic curve fit to air viscosity data published in NBS Circular 564 (1955), given by

$$
\mu_{A}=1.09472 \times 10^{-5}+1.87925 \times 10^{-8} T_{d b}-7.057778 \times 10^{-12} T_{d b}^{2},
$$

where

$$
\begin{aligned}
& \mu_{a}=\text { dynamic viscosity in } \mathrm{lbm} / \mathrm{ft}-\mathrm{s} \text {, and } \\
& T_{\mathrm{db}}=\text { dry bulb temperature in }{ }^{\circ} \mathrm{F} \text {. }
\end{aligned}
$$

\section{Mass Flowrate of Air (Nozzles)}

The computation of the mass flowrates of air through inlet nozzles is based on the procedure presented in ASME MFC-3M-1989. The following computations are given by

$$
\begin{aligned}
& q_{m}=0.09970190 C_{D} Y d_{t}^{2} \sqrt{\rho_{A} \Delta H}, \\
& C_{D}=0.9975-0.00653\left(\frac{10^{6}}{R_{d}}\right)^{a}, \quad a= \begin{cases}0.5, & R_{d}<10^{6} \\
0.2, & R_{d} \geq 10^{6}\end{cases} \\
& R_{d}=\frac{48 q_{m}}{\pi \mu_{A} d_{t}}, \\
& Y=\sqrt{\left(\frac{\kappa \tau^{2 / x}}{\kappa-1}\right)\left(\frac{1}{1-\tau^{2 / x}}\right)\left(\frac{1-\tau^{(x-1) / \kappa}}{1-\tau}\right)},(\kappa=1.4 \text { for air }), \text { and }
\end{aligned}
$$




$$
\tau=\frac{p_{\text {bar }}+\Delta p_{i}}{p_{\text {bar }}}, \Delta p_{i}=0.03606 \Delta H_{i},
$$

where

$$
\begin{aligned}
& q_{m}=\text { mass flowrate of air in } \mathrm{lbm} / \mathrm{s}, \\
& C_{D}=\text { discharge coefficient, } \\
& Y=\text { expansion factor, } \\
& d_{t}=\text { nozzle throat diameter in inches, } \\
& \rho_{\mathrm{a}}=\text { air density in lbm/ti } \\
& \Delta H=\text { differential pressure in inches of water, } \\
& R_{d}=\text { Reynolds number based on nozzle throat diameter, } \\
& \mu_{a}=\text { dynamic viscosity in } \mathrm{lbm} / \mathrm{ft} \cdot \mathrm{s}, \\
& \kappa=\text { specific heat ratio, } \\
& \tau=\text { pressure ratio, } \\
& p_{b a r}=\text { barometric pressure in psi, and } \\
& \Delta p=\text { pressure differential in psi. }
\end{aligned}
$$

\section{Volumetric Air Flowrate of Air}

The mass flowrate of air through a nozzle is converted to volumetric flowrate of dry air at standard temperature $\left(68^{\circ} \mathrm{F}\right)$ and to a pressure equal to the net positive suction head. Based on the ideal gas law, the air flowrate is given by

$$
\begin{aligned}
& Q=\frac{q_{m}}{\rho_{A}} \frac{\left(p_{b a r}-p_{v}\right)}{p_{N P S H}} \frac{527.67}{T_{c b}}, \\
& p_{v}=\frac{p_{b a r} w}{(0.62198+W)}, \text { and } \\
& p_{N P S H}=\frac{\gamma_{W}}{144}(N P S H),
\end{aligned}
$$

where

$Q_{A}=$ volumetric flowrate of dry air at the reference conditions in $\mathrm{ft}^{3} / \mathrm{s}$,

$p_{\mathrm{v}}=$ partial pressure of water vapor in air in psi, and

$T_{c b}=$ dry bulb temperature.

Air Void Ratio

The air void ratio is volumetric ratio of total air flow to total air/water mixture flow, given by

$$
\phi=\frac{Q_{A}}{Q_{W}+Q_{A}} .
$$

\section{Dissolved Oxygen Saturation Concentration}

The dissolved oxygen saturation concentration is computed by (Hua, 1990)

$$
\begin{aligned}
& D O_{\text {sat }, p 0}=14.562-0.41022 T_{w}+0.0079910 T_{W}^{2}-0.000077774 T_{w}^{3}, \text { and } \\
& D O_{\text {sat }}=\left(\frac{p}{p_{0}}\right) D O_{\text {sat }, p 0},
\end{aligned}
$$

where

$D O_{\text {sat,po }}=$ dissolved oxygen saturation concentration at standard atmospheric pressure, 
$T_{W}=$ water temperature in ${ }^{\circ} \mathrm{C}$,

$D O_{\text {sat }}=$ dissolved oxygen saturation concentration at measured atmospheric pressure in $\mathrm{mg} / \mathrm{L}$,

$p=$ atmospheric pressure in psia, and

$p_{0}=$ standard atmospheric pressure (14.696 psia).

\section{Dissolved Oxygen Uptake (Aeration Environmental Performance)}

The dissolved oxygen uptake is the increase in DO concentration between the turbine scrollcase and tailwater, given by

$$
\Delta D O=D O_{T w}-D O_{S C}
$$

where

$D O_{T w}=$ dissolved oxygen concentration of tailwater in $\mathrm{mg} / \mathrm{L}$, and

$D O_{s c}=$ dissolved oxygen concentration of water entering turbine scrollcase in $\mathrm{mg} / \mathrm{L}$.

\section{Oxygen Transfer Efficiency}

Oxygen transfer efficiency is the fraction of the influent dissolved oxygen deficit the turbine is able to replace. This parameter is computed by (Gulliver et al., 1990)

$$
\begin{aligned}
& E=\frac{D O_{T w}-D O_{S C}}{D O_{\text {sat }}-D O_{S C}}, \\
& E_{20}=1-(1-E)^{\prime}, \text { and } \\
& f=1+0.02103\left(T_{w}-20\right)+8.261 \times 10^{-5}\left(T_{w}-20\right)^{2},
\end{aligned}
$$

where

$E=$ oxygen transfer efficiency, and

$E_{20}=$ oxygen transfer efficiency referenced to a water temperature of $20^{\circ} \mathrm{C}$.

\section{Uncertainty Analysis}

Uncertainly calculations will be based on PTC 19-1.

\section{REFERENCES}

ASHRAE, ASHRAE Handbook, Fundamentals, American Society of Heating, Refrigerating, and AirConditioning Engineers, Inc., Atlanta, Georgia, 1989.

ASME, Hydraulic Turbines, American Society of Mechanical Engineers, Performance Test Codes, PTC$18,1992$.

ASME, Measurement Uncertainty, American Society of Mechanical Engineers, Performance Test Codes, PTC-18, 1992.

ASME MFC-3M-1989, Measurement of Fluid Flow in Pipes Using Orifice, Nozzle, and Venturi, ASME, New York, NY, 1990.

Gulliver, J.S., J.R. Thene, and A.J. Rindels, "Indexing Gas Transfer in Self-Aerated Flows," ASCE Journal of Environmental Engineering, pp 503-523, Vol. 116, No. 3, 1990.

Hua, H., "Accurate Method for Calculation of Saturation DO," ASCE Journal of Environmental Engineering, pp 989-990, Vol. 116, No. 5, 1990.

National Bureau of Standards, "Tables of Thermal Properties of Gases," Circular 564, 1955. 
Thompson, E.J., "Oxygen Transfer Similitude for a Vented Hydroturbine," M.S. Thesis, University of Minnesota, Department of Civil and Mineral Engineering, Minneapolis, MN, 1993 (see also Thompson, E.J., and J.S. Gulliver, 1993).

Thompson, E.J., and J.S. Gulliver, "Oxygen Transfer Similitude for the Auto-Venting Turbine," Proceedings, Waterpower'93, ASCE, 1993.

Thompson, E.J., and J.S. Gulliver, "Oxygen Transfer Similitude for a Vented Turbine," ASCE Journal of Hydraulic Engineering, in Press. 